\title{
DEVELOPMENT OF ENHANCED TEST METHODS TO EVALUATE ALKALI- SILICA REACTION IN CONCRETE
}

by

\author{
Noura Sinno \\ M.Eng, University of Toronto, 2014 \\ B.Eng, American University of Beirut, 2013
}

\author{
A dissertation \\ presented to Ryerson University \\ in partial fulfillment of the \\ requirements for the degree of \\ Doctor of Philosophy \\ in the program of \\ Civil Engineering
}

Toronto, Ontario, Canada, 2019

(CNoura Sinno, 2019 


\section{AUTHOR'S DECLARATION}

I hereby declare that I am the sole author of this dissertation. This is a true copy of the dissertation, including any required final revisions, as accepted by my examiners.

I authorize Ryerson University to lend this dissertation to other institutions or individuals for the purpose of scholarly research.

I further authorize Ryerson University to reproduce this dissertation by photocopying or by other means, in total or in part, at the request of other institutions or individuals for the purpose of scholarly research.

I understand that my dissertation may be made electronically available to the public. 


\title{
Development of Enhanced Test Methods to Evaluate Alkali-Silica Reaction in Concrete
}

\author{
Noura Sinno \\ Doctor of Philosophy, 2019 \\ Department of Civil Engineering \\ Ryerson University
}

\section{Abstract}

Many preventive measures showed improved performance of concrete against alkali-silica reaction (ASR) based on the concrete prism test (CPT) described in the Canadian and American Standards, CSA A23.2-14A and ASTM C1293. However, research has shown that preventive measures that limited the 2-year expansion in the concrete prism test produced late expansion after 7-15 years when tested in the field. The objective of this research is to understand the possible reasons for this late expansion under field conditions and to come up with modified approach to determine the level of supplementary cementing materials (SCM) needed to mitigate the long-term expansion. The research mainly focuses on studying two possible reasons to explain the late expansion. The first reason is the rate and ultimate hydration of SCM, where their capacity to bind alkalis under CPT could be higher than those under field conditions. The other reason for the late expansion could be the geometry and size of the CPT samples which might reduce the expansion due to the excessive alkali leaching. Larger samples showed less leaching compared to standard prisms. 100-mm cylinders showed higher expansion than 75-mm standard prisms; however, both sample shapes showed similar expansions for one tested aggregate when used with SCM. In addition, the capacity of SCM to bind alkalis was shown to be higher at $38^{\circ} \mathrm{C}$ compared to the other two tested temperatures investigated in this study: $23^{\circ} \mathrm{C}$ and $60^{\circ} \mathrm{C}$. Samples with $\mathrm{SCM}$ at high replacement levels expanded more at $60^{\circ} \mathrm{C}$ compared to $38^{\circ} \mathrm{C}$. Due to their reduced leaching compared to prisms, testing cylinders at $60^{\circ} \mathrm{C}$ showed accelerated results reducing the testing duration to one year compared to the standard test duration of two years. Moreover, a new way to predict the minimum levels of SCM required to mitigate expansion due to alkali-silica reaction is presented showing better correlation with the field. Finally, a fast and reliable test method is suggested to evaluate the reactivity of mineral fillers by adapting and adopting the current test methods available for ASR testing. 


\section{Acknowledgements}

First, I would like to express my sincere gratitude to my supervisor Dr. Medhat Shehata for all his support and excellent guidance during my $\mathrm{PhD}$ journey. His passion for concrete materials and his dedication to his work motivated me to work harder. I deeply thank him for all the continuous encouragement and for all the advice that he gave me related to my research as well as advice in life. Words fail to describe my appreciation for all the time he spent to help me improve. I cannot express how grateful and honored I am to have had the opportunity to work with him for the past five years. He helped me become the person who I am standing here today. He will always be the person who inspires me and I hope to be a professor like him in the future who he will be proud of.

I would like also to thank all the technical staff who supported me during my PhD: Nidal Jaalouk, Robin Luong, Khaleel Stoney, Domenic Valle and Min Yao. Special thanks to Robin Luong who was not only a technical staff but also a caring friend full of energy and joy. I wish I could stay in my research for many more years to keep asking him for support. Min Yao, who unfortunately passed away during my PhD journey, was a true friend who made the work in the lab a whole different experience. He was a mentor and a friend who trusted me and cared about my success. He was a big loss for everyone.

I would like to express my appreciation to Dr. Shehata's team who were there for me from the first day I started working in the lab. Special thanks to Gregory Richards who was a great support for me in the lab and helped me a lot especially at the beginning of my lab work.

Lastly, and most importantly I would like to express my deep appreciation to my parents who without them it would not have been possible to become the person who I am standing here today. Without your whole support during my life and all the care that you provided me with, I could have not made it to this level. All what I achieve is not enough to compensate for all the effort and the tough years that you spent to make us happy, my siblings and me. I hope that I made you proud. I have made you wait for many years but now you can call me Dr. Sinno. My siblings, Noha, Mohamed and Maher, you were the greatest support for me in Canada. I know the transition to Canada was not easy but you were here to help me get through it. A deep thank you for supporting 
me and understanding me during my whole $\mathrm{PhD}$ journey. Finally, I really thank my whole family who believed in me.

Thank you God for giving me all the strength and patience to be able to finish my $\mathrm{PhD}$ and without you it would not have been possible to achieve everything I made until today. 


\section{To my parents}

\section{Marwan \& Khadija}




\section{Table of Contents}

Author's Declaration $\quad$ ii

$\begin{array}{ll}\text { Abstract } & \text { iii }\end{array}$

Acknowledgements $\quad$ iv

List of Figures $\quad$ xi

$\begin{array}{ll}\text { List of Tables } & \text { xxi }\end{array}$

$\begin{array}{ll}\text { List of Appendices } & \text { xxii }\end{array}$

$\begin{array}{ll}\text { List of Notations } & \text { xxiii }\end{array}$

$\begin{array}{lr}\text { 1. Introduction } & 1\end{array}$

2. Literature Review 6

2.1. Chemistry of the Alkali-Silica Reaction in Concrete 6

2.1.1. Sources of Alkalis $\quad 8$

2.1.2. Sources of Reactive Silica in the Aggregate 9

2.1.3. Presence of Sufficient Moisture 10

2.1.4. ASR Mechanism 11

2.1.5. Other Factors Affecting ASR 11

2.2. Test methods $\quad 20$

2.2.1. Accelerated Mortar Bar Test 20

2.2.2. Modified Accelerated Mortar Bar Test 21

2.2.3. Concrete Prism Test 21

2.2.4. Accelerated Concrete Prism Test 23

2.2.5. Modified Concrete Prism Test 25

2.2.6. Accelerated Concrete Cylinder Test (ACCT) 26

2.2.7. Field Exposure versus Laboratory Conditions 26

2.3. Preventive Measures 27

2.3.1. Effect of SCM Composition on ASR 28

2.3.2. SCM Degree of Hydration $\quad 34$ 
2.3.3. Degree of Pozzolanic Reaction 34

2.3.4. Effect of Temperature on Hydration of Cementing Materials 37

2.4. Residual Expansion of Structures Affected by ASR 39

2.4.1. Predicting Remaining Life of Concrete Structures Under Field Exposure 39

2.4.2. Case Study: Residual Expansion of a Bridge Affected by ASR in Ontario 43

2.4.3. Expansion of Concrete Containing RCA with Different Deterioration Levels 45

2.5. Potential Alkali-Silica Reactivity of Mineral Fillers in Concrete 46

2.5.1. Mineral Fillers Effect on Concrete 46

2.5.2. ASR Testing of Mineral Fillers $\quad 47$

3. Experimental Program 49

3.1. Materials 49

3.1.1. Cementing Materials $\quad 49$

3.1.2. Aggregates $\quad 50$

3.1.3. Fillers 53

3.1.4. Chemicals $\quad 54$

3.2. Experimental Details

3.2.1. Concrete Expansion Samples $\quad 55$

3.2.2. Aggregate Testing $\quad 62$

3.2.3. Paste Study $\quad 62$

3.2.4. Bridge Barriers and Cores Testing 65

3.2.5. Testing of Alkali Content of Concrete Chunks Obtained from the Barriers 66

3.2.6. RCA Prisms and Cylinders Expansion Testing 67

$\begin{array}{lll}\text { 3.2.7. } & \text { Mineral Fillers Testing } & 67\end{array}$

$\begin{array}{ll}\text { 4. Results and Analysis } & 71\end{array}$

4.1. Effect of Sample Geometry and Aggregate Type on ASR 71

4.1.1. Expansion of Concrete Samples at $38^{\circ} \mathrm{C} \quad 71$

4.1.2. Alkali Leaching from Concrete Samples 80

4.1.3. Alkali Release from Aggregates 83

4.1.4. Relative Humidity Measurements 91 
4.2. Effect of Temperature on Alkali Leaching, Alkali Release and Pozzolanic Activity of SCM 93

4.2.1. Effect of Temperature on Alkali Leaching from Concrete Samples 93

4.2.2. Effect of Temperature on Alkali Release from Aggregates 95

4.2.3. Effect of Temperature on Pozzolanic Activity of SCM 99

4.3. Expansion at $60^{\circ} \mathrm{C} \quad 114$

4.3.1. Expansion of Concrete Samples at $60^{\circ} \mathrm{C} \quad 114$

4.3.2. Comparison of expansion between $38^{\circ} \mathrm{C}$ and $60^{\circ} \mathrm{C} \quad 117$

4.3.3. Correlation Between Expansion Results at $38^{\circ} \mathrm{C}$ and $60^{\circ} \mathrm{C} \quad 124$

4.3.4. Long-Term Expansion at Room Temperature 130

4.4. Ways to Determine the Alkali Threshold for Different Aggregates 139

4.4.1. Alkali Threshold for Concrete Cast with Sudbury Coarse Aggregate 139

4.4.2. Alkali Threshold for Concrete Cast with Spratt Coarse Aggregate 140

4.4.3. Alkali Threshold for Concrete Cast with Springhill Fine Aggregate 141

4.4.4. Soaking Samples in Alkaline Solutions 142

4.5. Residual Expansion of Structures affected by ASR - Sudbury Bridge Barriers 147

4.5.1. Factors Affecting Residual Expansion in Sudbury Bridge Barriers 147

4.5.2. Expansion of Concrete Containing RCA Produced from Bridge Panels 155

4.5.3. Applicability of Sample Geometry on Recycled Concrete Aggregate 159

4.6. Evaluating the Potential Alkali-Silica Reactivity of Mineral Fillers 161

4.6.1. Effect of Replacement Level on Workability of Mortars 161

4.6.2. Effect of Replacement Method on Workability of Mortars 161

4.6.3. Effect of Replacement Method on Mortars Expansion 163

4.6.4. Reactivity of Mineral Fillers 166

4.6.5. Concrete Prism Test on Mineral Fillers 171

4.6.6. Scanning Electron Microscopy Analysis $\quad 173$

$\begin{array}{lll}\text { 5. Summary and Discussion } & 176\end{array}$

5.1. Understanding the factors affecting expansion of concrete due to ASR 176

5.2. Predicting the minimum level of SCM needed to reduce ASR expansion 178 
5.3. Relationship Between Laboratory and Field Expansions

5.4. SCM Capacity to Reduce Expansion Due to ASR at Different Temperatures

5.5. Develop an accelerated test method to evaluate alkali-silica reaction in concrete

5.6. Predicting Remaining Life of Structures Affected by ASR

5.7. Develop a Test Method to Evaluate Alkali-Silica Reactivity of Mineral Fillers

5.8. Main Contribution of the Thesis

6. Conclusions and Recommendations for Further Study 


\section{List of Figures}

Figure $2.1 \quad$ (a) Wall in Norway showing ASR gel extruding from the cracks (FHWA, 2008) (b) ASR damage on bridge pylon (Sika, 2013)

Figure 2.2 (a) Misalignment of adjacent wall section on a highway bridge due to ASR (FHWA, 2012) (b) Extrusion of joint-sealing material due to excessive expansion from ASR (FHWA, 2012)

Figure 2.3 (a) Map cracking in concrete barriers in Massachusetts (FHWA, 2009) (b) Close-up view of the map cracking (FHWA, 2009)

Figure 2.4

(a) ASR gel observed under microscope (Rajabipour, Maraghechi and Fischer, 2010) (b) Scanning electron microscopy showing a glass particle surrounded by ASR gel (Serpa et al., 2013)

Figure 2.5 Variation of ions concentration in concrete with time (FHWA, 2012)

Figure 2.6 Solubility of different siliceous rocks in alkaline solution (FHWA, 2012)

Figure 2.7 Effect of relative humidity on expansion (Swamy, 1992) 11

Figure 2.8 3-month expansion of mortar bars containing Mexican Opal at $37.8^{\circ} \mathrm{C}$ (Gillott, 1975)

Figure 2.9 Expansion of concrete prisms containing siltstone aggregate (Sibbick and Page, 1992)

Figure 2.10 Expansion of concrete prisms containing silicified limestone aggregate (Sibbick and Page, 1992)

Figure 2.11 Expansion of concrete prisms containing greywacke aggregate (Sibbick and Page, 1992)

Figure 2.12 Expansion of concrete prisms containing Nova Scotia greywacke aggregate (Gillott, 1975)

Figure 2.13 Expansion of concrete prisms containing siliceous limestone aggregate (Lindgård et al., 2012)

Figure 2.14 Effect of PC alkali content on concrete expansion (Shehata and Thomas, 2010) 
Figure 2.15 Schematic diagram of gel swelling behavior (Struble, Diamond and Lafayette, 1981)

Figure 2.16 Expansion results obtained from field blocks and from the AMBT (Ideker et al., 2012)

Figure 2.17 Expansion results obtained from field blocks and from the CPT 22 (Ideker et al., 2012)

Figure 2.18 Expansion comparison of CPT at 52 weeks and ACPT at 13 weeks (Ideker et al., 2008)

Figure 2.19 Effect of SCM replacement level on the 2-year expansion of prisms cast with Spratt (Thomas, 2011)

Figure 2.20 Effect of binder $(\mathrm{PC}+\mathrm{FA})$ chemical compositions on pore solution alkalinity of pastes at 2 years (Shehata, 2001)

Figure 2.21 Effect of binder (PC+FA and/or SF) chemical composition on pore solution alkalinity of pastes at 2 years (Shehata, 2001)

Figure 2.22 Effect of binder (PC+FA and/or SF) chemical composition on pore 32 solution alkalinity of pastes at 2 years (Shehata and Thomas, 2010)

Figure 2.23 Effect of binder (PC + slag and/or SF) chemical composition on 33 pore solution alkalinity of pastes at 2 years (Bleszynski, 2002)

Figure 2.24 Effect of binder chemical composition on pore solution alkalinity of pastes at 2 years (Thomas, 2011)

Figure 2.25 Method used to obtain $\mathrm{Ca}(\mathrm{OH})_{2}$ content using TGA (Marsh and 36 Day, 1988)

Figure 2.26 Modified TGA Analysis to determine $\mathrm{Ca}(\mathrm{OH})_{2}$ content (Kim and 36 Olek, 2012)

Figure 2.27 Expansions of mortar bars soaked in $3 \mathrm{~N}$ sodium salts (Chatterji, 40 Thaulow and Jensen, 1987)

Figure 2.28 Expansion of prisms soaked in $1 \mathrm{M}$ alkali solutions (Bérubé and 41 Frenette, 1994)

Figure 2.29 Mortar bars expansions soaked in $\mathrm{NaCl}$ solutions (Chatterji, 42 Thaulow and Jensen, 1987) 
Figure 2.30 Expansion of prisms soaked in alkaline solutions and water (Bérubé and Frenette, 1994)

Figure 2.31 Signs of deterioration in highway bridge barriers (Piersanti, 2015) 43

Figure 2.32 (a) Low deteriorated barrier at the East-North ramp, (b) High deteriorated barrier at the North-West ramp (Piersanti, 2015)

Figure 2.33 Expansion of low and high deteriorated cores (Piersanti, 2015)

Figure 3.1 Particle size distribution of the carbonate filler 53

Figure $3.2 \quad$ Particle size distribution of the carbonate silica filler 53

Figure 3.3 Fabricated molds for cylinders 55

Figure 3.4 Fabricated molds for cubes $\quad 56$

Figure $3.5 \quad$ (a) Studs for cylinders/prisms, (b) binding barrel to secure the 56 studs/pins, (c) pins for cubes side measurement and (d) pins for cubes center-to-center measurements

Figure $3.6 \quad$ (a) Pails for the prism and cylinder samples (b) containers for cube samples

Figure 3.7 Containers used for testing one cylinder at $60^{\circ} \mathrm{C} \quad 58$

Figure $3.8 \quad$ Measurements of (a) cylinders, (b) cubes sides (c) cubes centerto-center

Figure 3.9 Photos of sensors implemented inside the cores of the (a) prism, (b) cylinder, and (c) cube

Figure 3.10 Soaking of prisms in plastic containers

Figure 3.11 (a) High deteriorated barrier, (b) low deteriorated barrier (Piersanti et al., 2015)

Figure 3.12 Cores (a) measurements and (b) soaking

Figure 4.1 Expansion of concrete containing Sudbury aggregate without $\mathrm{SCM}$ at $38^{\circ} \mathrm{C}$

Figure 4.2 Expansion of concrete containing Spratt aggregate without SCM at $38^{\circ} \mathrm{C}$

Figure 4.3 Expansion of concrete cast with Sudbury aggregate and 15\% FA at $38^{\circ} \mathrm{C}$ 
Figure 4.4 Expansion of concrete cast with Sudbury aggregate and $25 \%$ slag at $38^{\circ} \mathrm{C}$

Figure 4.5 Expansion of concrete cast with Spratt aggregate and 15\% FA at $38^{\circ} \mathrm{C}$

Figure 4.6 Expansion of concrete cast with Spratt aggregate and 20\% FA at 74 $38^{\circ} \mathrm{C}$

Figure 4.7 Expansion of concrete cast with Spratt aggregate and 35\% slag at $38^{\circ} \mathrm{C}$

Figure 4.8 Expansion of concrete cast with Spratt aggregate and 50\% slag at 75 $38^{\circ} \mathrm{C}$

Figure 4.9 Expansion of concrete cast with Spratt aggregate and GUB-8SF at 76 $38^{\circ} \mathrm{C}$

Figure 4.10 Expansion of concrete containing Spratt aggregate with GUB-8SF and $15 \% \mathrm{FA}$ at $38^{\circ} \mathrm{C}$

Figure 4.11 Expansion of concrete containing Spratt aggregate with GUB-8SF 77 and $20 \% \mathrm{FA}$ at $38^{\circ} \mathrm{C}$

Figure 4.12 Expansion of concrete cast with Springhill aggregate and 30\% FA 77 at $38^{\circ} \mathrm{C}$

Figure 4.13 Expansion comparison of control samples with no SCM for 78 different sample shapes

Figure 4.14 Expansion comparison of concrete cast with Sudbury and SCM 78 for different sample shapes

Figure 4.15 Expansion comparison of concrete cast with Spratt and SCM for different sample shapes

Figure 4.16 Expansion of cylinders versus prisms at 1 year for samples without SCM and 2 years for samples with SCM

Figure 4.17 Alkalis leached from Sudbury and Springhill concrete samples at 1.5 years

Figure 4.18 Alkalis leached from Spratt concrete samples at 1.5 years 81

Figure 4.19 (a) Expansion of Sudbury samples without SCM until 18 weeks, 82

(b) expansion taken as \% of the total 1-year expansion 
Figure $4.20 \quad$ (a) Expansion of Spratt samples without SCM until 18 weeks, (b) expansion taken as \% of the total 1-year expansion

Figure 4.21 Alkali release from Sudbury aggregate at $38^{\circ} \mathrm{C}$ in alkaline solution of $0.25 \mathrm{M}$

Figure 4.22 Alkali release from Spratt aggregate at $38^{\circ} \mathrm{C}$ in alkaline solution of $0.25 \mathrm{M}$

Figure 4.23 Alkali release from Springhill aggregate at $38^{\circ} \mathrm{C}$ in alkaline solution of $0.25 \mathrm{M}$

Figure 4.24 Alkali release from Sudbury aggregate at $38^{\circ} \mathrm{C}$ in alkaline solution of $0.70 \mathrm{M}$

Figure 4.25 Alkali release from Spratt aggregate at $38^{\circ} \mathrm{C}$ in alkaline solution of $0.70 \mathrm{M}$

Figure 4.26 Alkali release from Springhill aggregate at $38^{\circ} \mathrm{C}$ in alkaline solution of $0.70 \mathrm{M}$

Figure 4.27 $\quad \mathrm{Na}_{2} \mathrm{O}$ released from Sudbury aggregate to distilled water, $0.25 \mathrm{M}$ and $0.70 \mathrm{M} \mathrm{KOH}$ solutions

Figure 4.28 $\quad \mathrm{K}_{2} \mathrm{O}$ released from Sudbury aggregate to distilled water, $0.25 \mathrm{M}$ and $0.70 \mathrm{M} \mathrm{NaOH}$ solutions

Figure 4.29 $\mathrm{Na}_{2} \mathrm{O}$ released from Spratt aggregate to distilled water, $0.25 \mathrm{M}$ and $0.70 \mathrm{M} \mathrm{KOH}$ solutions

Figure 4.30 $\quad \mathrm{K}_{2} \mathrm{O}$ released from Spratt aggregate to distilled water, 0.25 $\mathrm{M}$ and $0.70 \mathrm{M} \mathrm{NaOH}$ solutions

Figure 4.31 $\quad \mathrm{Na}_{2} \mathrm{O}$ released from Springhill aggregate to distilled water, 0.25 $\mathrm{M}$ and $0.70 \mathrm{M} \mathrm{KOH}$ solutions

Figure 4.32 $\quad \mathrm{K}_{2} \mathrm{O}$ released from Springhill aggregate to distilled water, $0.25 \mathrm{M}$ and $0.70 \mathrm{M} \mathrm{NaOH}$ solutions

Figure 4.33 Relative humidity measurements for Spratt aggregate without 92 SCM

Figure 4.34 Relative humidity measurements for Spratt aggregate with $25 \%$ FA 
Figure 4.35 Alkalis leached from concrete prisms and cylinders tested at $38^{\circ} \mathrm{C}$ and $60^{\circ} \mathrm{C}$ at 1.5 years

Figure 4.36 Alkalis leached from concrete cubes tested at $38^{\circ} \mathrm{C}$ and $60^{\circ} \mathrm{C}$ at 1.5 years

Figure 4.37 Comparison of leaching at $38^{\circ} \mathrm{C}$ and $60^{\circ} \mathrm{C} \quad 95$

Figure 4.38 $\quad \mathrm{K}_{2} \mathrm{O}$ release in $0.25 \mathrm{M} \mathrm{NaOH}$ solution 96

Figure 4.39 $\quad \mathrm{K}_{2} \mathrm{O}$ release in $0.70 \mathrm{M} \mathrm{NaOH}$ solution 96

Figure 4.40 $\quad \mathrm{Na}_{2} \mathrm{O}$ release in $0.25 \mathrm{M} \mathrm{KOH}$ solution 97

Figure 4.41 $\quad \mathrm{Na}_{2} \mathrm{O}$ release in $0.70 \mathrm{M} \mathrm{KOH}$ solution 97

Figure 4.42 Total alkali release from Sudbury aggregate at different 98 temperatures

Figure 4.43 Total alkali release from Spratt aggregate at different temperatures 98

Figure 4.44 Total alkali release from Springhill aggregate at different 99 temperatures

$\begin{array}{lll}\text { Figure 4.45 Non-evaporable water in cement paste } & 100\end{array}$

Figure 4.46 Non-evaporable water in paste with 15\% FA 101

Figure 4.47 Non-evaporable water in paste with 25\% FA 101

$\begin{array}{lll}\text { Figure } 4.48 & \text { Non-evaporable water in paste with 25\% Slag }\end{array}$

Figure 4.49 Non-evaporable water in paste with 35\% Slag 102

Figure 4.50 $\mathrm{Ca}(\mathrm{OH})_{2}$ in paste samples without SCM at different temperatures 103

Figure 4.51 $\mathrm{Ca}(\mathrm{OH})_{2}$ in paste samples with FA at $23^{\circ} \mathrm{C} \quad 104$

Figure 4.52 $\mathrm{Ca}(\mathrm{OH})_{2}$ in paste samples with $\mathrm{FA}$ at $38^{\circ} \mathrm{C} \quad 104$

Figure 4.53 $\mathrm{Ca}(\mathrm{OH})_{2}$ in paste samples with FA at $60^{\circ} \mathrm{C} \quad 105$

Figure 4.54 $\mathrm{Ca}(\mathrm{OH})_{2}$ in paste samples with slag at $23^{\circ} \mathrm{C} \quad 105$

Figure 4.55 $\mathrm{Ca}(\mathrm{OH})_{2}$ in paste samples with slag at $38^{\circ} \mathrm{C} \quad 106$

Figure 4.56 $\mathrm{Ca}(\mathrm{OH})_{2}$ in paste samples with slag at $60^{\circ} \mathrm{C} \quad 106$

$\begin{array}{lll}\text { Figure } 4.57 & \mathrm{Ca}(\mathrm{OH})_{2} \text { consumed by SCM at } 7 \text { days } & 108\end{array}$

$\begin{array}{lll}\text { Figure } 4.58 & \mathrm{Ca}(\mathrm{OH})_{2} \text { consumed by SCM at } 28 \text { days } & 108\end{array}$

Figure 4.59 $\mathrm{Ca}(\mathrm{OH})_{2}$ consumed by SCM at 92 days 109

Figure 4.60 Alkali release from paste with 15\% FA in $0.25 \mathrm{M}$ alkaline solution 110

Figure 4.61 Alkali release from paste with 25\% FA in $0.25 \mathrm{M}$ alkaline solution 
Figure 4.62 Alkali release from paste with $35 \%$ Slag in $0.25 \mathrm{M}$ alkaline solution

Figure 4.63 SEM of paste with $35 \%$ slag at $23^{\circ} \mathrm{C}$ tested at 2 years

Figure $4.64 \quad$ SEM of paste with $35 \%$ slag at $38^{\circ} \mathrm{C}$ tested at 2 years

Figure 4.65 Expansion at $60^{\circ} \mathrm{C}$ of concrete cast without SCM containing (a)

Sudbury and (b) Spratt

Figure 4.66 2-year expansion of concrete cast with Sudbury or Springhill aggregates and different SCM combinations at $60^{\circ} \mathrm{C}$

Figure 4.67 2-year expansion of concrete cast with Spratt and different SCM combinations at $60^{\circ} \mathrm{C}$

Figure 4.68 Expansion of concrete cast with Sudbury aggregate at (a) 6 months and (b) 1 year

Figure 4.69 Expansion of concrete cast with Spratt aggregate at (a) 6 months and (b) 1 year

Figure 4.70 Expansion of cylinders cast with Sudbury aggregates

Figure 4.71 Expansion of cylinders cast with Spratt aggregates

Figure 4.72 Expansion of concrete cast with Sudbury and 15\% FA at (a) 1 year and (b) 2 years

Figure 4.73 Expansion of concrete cast with Sudbury and 25\% slag at (a) 1 year and (b) 2 years

Figure 4.74 Expansion of concrete cast with Spratt and 15\% FA at (a) 1 year and (b) 2 years

Figure 4.75 Expansion of concrete cast with Spratt and 20\% FA at (a) 1 year and (b) 2 years

Figure 4.76 Expansion of concrete cast with Spratt and 35\% Slag at (a) 1 year and (b) 2 years

Figure 4.77 Expansion of concrete cast with Spratt and 50\% Slag at (a) 1 year and (b) 2 years

Figure 4.78 Expansion of concrete cast with Spratt and GUB-8SF at (a) 1 year and (b) 2 years 
Figure 4.79 Expansion of concrete containing Spratt with GUB-8SF and 15\% FA at (a) 1 year and (b) 2 years

Figure 4.80 Expansion of concrete containing Spratt with GUB-8SF and 20\% FA at (a) 1 year and (b) 2 years

Figure 4.81 Expansion of concrete cast with Springhill and 30\% FA at (a) 1 123 year and (b) 2 years

Figure 4.82 Correlation between the 6-month expansion of cylinders at $60^{\circ} \mathrm{C}$ and the expansion of standard prisms at 1 year for control samples and 2 years for samples with

Figure 4.83 Correlation between the 1-year expansion of cylinders at $60^{\circ} \mathrm{C}$ 126

Figure 4.84 Correlation between the 1-year expansion of cylinders at $60^{\circ} \mathrm{C}$ and the 2-year expansion of cylinders at $38^{\circ} \mathrm{C}$ for samples with SCM

Figure $4.85 \quad 6$-month expansion of cylinders at $60^{\circ} \mathrm{C}$ put in different containers 128

Figure 4.86 Expansion comparison of cylinders at $60^{\circ} \mathrm{C}$ at 6 months and 129 prisms/cylinders at $38^{\circ} \mathrm{C}$ at 2 years

Figure 4.87 Expansion comparison of cylinders at $60^{\circ} \mathrm{C}$ at 18 weeks and prisms/cylinders at $38^{\circ} \mathrm{C}$ at 2 years

Figure 4.88 Expansion of Sudbury samples without $\mathrm{SCM}$ at $23^{\circ} \mathrm{C}$ taken from (a) $38^{\circ} \mathrm{C}$ and (b) $60^{\circ} \mathrm{C}$

Figure 4.89 Expansion of Sudbury samples with $15 \% \mathrm{FA}$ at $23^{\circ} \mathrm{C}$ taken from (a) $38^{\circ} \mathrm{C}$ and (b) $60^{\circ} \mathrm{C}$

Figure $4.90 \quad$ Expansion of Sudbury samples with $25 \%$ slag at $23^{\circ} \mathrm{C}$ taken from (a) $38^{\circ} \mathrm{C}$ and (b) $60^{\circ} \mathrm{C}$

Figure 4.91 Expansion of Spratt samples without $\mathrm{SCM}$ at $23^{\circ} \mathrm{C}$ taken from (a) 136 $38^{\circ} \mathrm{C}$ and (b) $60^{\circ} \mathrm{C}$

Figure 4.92 Expansion of Spratt samples with $20 \% \mathrm{FA}$ at $23^{\circ} \mathrm{C}$ taken from (a) $38^{\circ} \mathrm{C}$ and (b) $60^{\circ} \mathrm{C}$

Figure $4.93 \quad$ Expansion of Spratt samples with $35 \%$ Slag at $23^{\circ} \mathrm{C}$ taken from (a) $38^{\circ} \mathrm{C}$ and (b) $60^{\circ} \mathrm{C}$

Figure 4.94 1-year expansion and leaching results of cylinders cast with Sudbury at different PC alkali content 
Figure 4.95 1-year expansion and leaching results of cylinders cast with Spratt at different PC alkali content

Figure 4.96 1-year CPT expansion and leaching results of prisms cast with Springhill fine aggregate at different PC alkali

Figure 4.97 1-year expansion of Spratt prisms in alkaline solutions

Figure 4.98 Expansion of Spratt prisms at different ages

Figure 4.99 Expansion comparison of Spratt samples with different pore solution alkalinity at 1 year and 1.5 years

Figure 4.100 Expansion up to 26 weeks for Spratt prisms soaked in $0.4 \mathrm{M}$ solution

Figure 4.101 Expansion of low and high deteriorated bridge barriers

Figure 4.102 High deteriorated barrier after 3.5 years

Figure 4.103

Low deteriorated barrier after 3.5 years

Figure 4.104

Expansion of cores stored above water at $38^{\circ} \mathrm{C}$

Figure 4.105

Expansion of extracted cores soaked in alkaline solutions

Figure 4.106 12-week expansion of extracted cores soaked in $0.4 \mathrm{M}$ alkaline solution

Figure 4.107 12-week expansion of extracted cores soaked in 0.6 M alkaline solution

Figure 4.108 (a) High deteriorated and (b) low deteriorated cores after soaking in $0.6 \mathrm{M}$ solution

Figure 4.109 Released alkalis from concrete chunks to saturated lime solution

Figure 4.110 Comparison of expansion between the bridge barriers and the extracted cores

Figure 4.111 Expansion of concrete cylinders cast with Sudbury virgin and RCA samples

Figure 4.112 1-year expansion of concrete prisms cast with Sudbury virgin and RCA samples

Figure 4.113 Expansion of prisms cast with Sudbury using the standard mix

Figure 4.114 Expansion of cylinders cast with Sudbury using the standard mix 
Figure 4.116 Expansion of cylinders cast with Sudbury using the bridge mix

Figure 4.117 1-year expansion of prisms and cylinders

Figure 4.119 Flow results of sand 1 with different replacement levels of CF taken from sand finest portion

Figure 4.120 Comparison of flow results between the two different replacement methods

Figure 4.121 Expansion of sand 1 with CSF at different replacement levels taken as percent from finest portion

Figure 4.122 Expansion of sand 1 with CSF at different replacement levels taken as percent from total graded sand

Figure 4.123 Expansion of sand 2 with CSF at different replacement levels taken as percent from finest portion

Figure 4.124 Expansion of CSF at different replacement levels taken as percent from total graded sand 2

Figure 4.125 Expansion of sand 2 with $\mathrm{CF}$ at different replacement levels taken as percent from finest portion

Figure 4.126 Expansion of sand 2 with 20\% SH taken from total graded sand

Figure 4.128 Expansion of sand 2 with SH filler at 14 days level from sand finest portion

Figure 5.1 Effect of binder chemical composition on pore solution alkalinity of pastes at 2 years (Thomas, 2011) 


\section{List of Tables}

Table 2.1 Chemical composition of GU Portland cement (Holcim, 2014) 8

Table 2.2 Expansion limits for identifying potentially alkali-silica reactive aggregates (CSA A23.2-27A, 2014)

Table 2.3 Minimum levels of SCM required to prevent ASR expansion (CSA A23.2-27A, 2014)

Table 2.4 Effect of fly ash composition on $\left(\mathrm{Na}_{2} \mathrm{O}_{\mathrm{e}} \mathrm{XCaO}\right) /\left(\mathrm{SiO}_{2}\right)^{2}$ (Shehata and Thomas, 2010)

Table 3.1 Chemical compositions of cementing materials (\% by mass)

Table 3.2 Particle shape of the coarse reactive aggregates used

Table 3.3 Reactive coarse aggregate properties 52

Table $3.4 \quad$ Fine aggregates properties $\quad 52$

Table 3.5 Chemical composition of carbonate silica filler (\% by mass) 54

Table 3.6 Grading required as specified in ASTM C1260 (2014) 67

Table 3.7 Mix design summary for mineral fillers testing using CPT $\quad 70$

Table 4.1 Sample calculation for $\mathrm{Ca}(\mathrm{OH})_{2}$ consumed by SCM for samples at $38^{\circ} \mathrm{C}$ at 28 days

Table 4.2 Alkalis leached from concrete with SH-C filler at 1 year (\% of total alkalis)

Table 5.1 Correlation between threshold alkali content and binder composition

Table 5.2 Minimum SCM level needed to reduce expansion 180

Table 5.3 Comparison of SCM levels obtained from CPT and threshold calculations

Table 5.4 PC alkali content of Sudbury cylinders after correcting for leaching at 1 year

Table 5.5 PC alkali content of Spratt cylinders after correcting for leaching at 1 year 


\section{List of Appendices}

Appendix A Calculations and results of the total amount of $\mathrm{Na}_{2} \mathrm{O}_{e}$ leached from concrete samples expressed as a percent of the initial alkali content

Appendix B Calculations and results of the total amount of $\mathrm{Na}_{2} \mathrm{O}_{e}$ released from aggregate samples expressed as a percent of the aggregate mass

Appendix C Thermogravimetric analysis of paste samples

Appendix D Calculations and results of the total amount of $\mathrm{Na}_{2} \mathrm{O}_{\mathrm{e}}$ released from paste samples expressed as a percent of the sample mass

Appendix E Calculations and results of the total amount of $\mathrm{Na}_{2} \mathrm{O}_{e}$ released from concrete chunks obtained from bridge barriers expressed as a percent of the cement mass

Appendix F Statistical Analysis of concrete expansion samples using t-test and coefficient of variation

Appendix G Statistical analysis of the data obtained from SEM for paste samples with $35 \%$ slag

Appendix $\mathrm{H} \quad$ Expansion of concrete samples cast at $60^{\circ} \mathrm{C}$

Appendix I Long-term expansion of Spratt samples at $23^{\circ} \mathrm{C}$ 


\section{List of Notations}

The following abbreviations are used throughout the thesis:

$\begin{array}{ll}\text { ASR } & \text { Alkali-Silica Reaction } \\ \text { ASTM } & \text { American Society for Testing and Materials } \\ \text { CPT } & \text { Concrete Prism Test } \\ \text { CSA } & \text { Canadian Standards Association } \\ \text { DDW } & \text { Deionized Distilled Water } \\ \text { FA } & \text { Fly Ash } \\ \text { KOH } & \text { Potassium Hydroxide } \\ \text { LOI } & \text { Loss on Ignition } \\ \text { NaOH } & \text { Sodium Hydroxide } \\ \text { Na } \mathrm{O}_{\mathrm{e}} & \text { Equivalent Sodium Content } \\ \mathrm{NEW} & \text { Non-Evaporable Water } \\ \text { PC } & \text { Portland Cement } \\ \text { RH } & \text { Relative Humidity } \\ \text { RCA } & \text { Recycled Concrete Aggregates } \\ \text { SF } & \text { Silica Fume } \\ \text { SCM } & \text { Supplementary Cementing Materials } \\ \text { SEM } & \text { Scanning Electron Microscope } \\ \text { TGA } & \text { Thermogravimetric Analysis } \\ \end{array}$




\section{Chapter 1}

\section{Introduction}

Since 1940, alkali-silica reaction (ASR) in concrete is being studied in order to find preventive measures to mitigate it. Expansion, cracking and other deleterious signs such as pop-outs are involved in the reaction and need to be avoided in concrete structures. Alkali-silica reaction is a chemical reaction between the alkalis present in the cement - or more precisely in concrete pore solution - and the silica in the reactive aggregate. A gel is formed and swells in presence of moisture. The latter exerts pressure to the surrounding leading to cracks in the concrete (Swamy, 1992).

Many preventive measures showed improved performance of concrete against ASR (Shehata and Thomas, 2000; Thomas et al., 2006). The results are based on the concrete prism test (CPT) described in the Canadian and American Standards, CSA A23.2-14A (2014) and ASTM C1293 (2018). This test is the most reliable laboratory test to predict the levels of supplementary cementing materials (SCM) to counteract ASR. However, researchers found that the field expansion at later ages were much higher than the expansion found in the CPT at two years (Fournier et al., 2008; Ideker et al., 2012). Reasons behind this discrepancy in expansion between the field and the laboratory samples could be excessive alkali leaching from the samples and a possible higher binding capacity of the supplementary cementing materials under laboratory conditions; both factors will be investigated in this study. Another challenge that is facing the concrete prism test is the long testing duration which takes 2 years to evaluate the efficiency of the SCM in preventing expansion due to ASR. Many attempts have been made in order to reduce the testing duration such as increasing the temperature (Ideker et al., 2008; Lindgård et al., 2012). However, at higher temperature, it was found that there is excessive leaching in the samples (Lindgård et al., 2012). There is no unique test that was adopted to reduce the testing duration yet.

Some preventive measures that limited the 2-year expansion in the CPT produced late expansion at 15 years when tested in large blocks under field test. This triggered an interest to carry out this research to identify the reasons for this and to come up with a modified approach or test method 
to determine - with high reliability - the level of SCM required to mitigate long-term expansion under field conditions. The research will mainly focus on studying two possible reasons:

(a) The sample size and geometry of CPT could underestimate the expansion. Smaller samples usually promote more leaching which reduces the expansion at late ages although their cores are usually of higher relative humidity $(\mathrm{RH})$ which sustains the swelling gel.

(b) The rate and ultimate hydration of SCM, and hence their capacity to bind alkalis, under CPT conditions could be higher than those under field conditions.

For structures already affected by ASR, a way to predict the remaining life is always in demand. Understanding the factors affecting remaining life of concrete structures is essential coupled with a test method to predict the residual level of expansion. The study of expansion in concrete containing recycled concrete aggregate samples produced from concrete structures affected by ASR may help understand the level of expansion that can take place during the remaining life of the same structure.

This thesis is concerned with proposing testing methods or approaches for determining and mitigating alkali-silica reactivity in: (a) new structures by reliably evaluating reactivity of aggregates and the required level of preventive measures, (b) existing structures by evaluating remaining life and understand the factors affecting potential expansion, and (c) special concrete that requires the use of mineral fillers by evaluating their reactivity.

In light of these three categories, the main objectives of this thesis along with their methodologies are summarized as follows:

\section{Testing ASR for New Structures:}

\subsection{Investigating the factors which lead to discrepancies between field and lab results}

The effect of sample geometry and aggregate type on leaching and expansion results will be studied (Section 4.1). Cube samples (150x150 mm), cylinders and prisms will be cast and measured for expansion at $38^{\circ} \mathrm{C}$. Three different types of aggregates with different reactivity will 
be tested. Alkali release from the aggregate to the pore solution is investigated to help explaining the expansion results. The outcomes of this task will give insights into the factors leading to the difference in expansion between the CPT and the field.

\subsection{Examining the possibility of testing ASR at $60^{\circ} \mathrm{C}$ instead of $38^{\circ} \mathrm{C}$ to shorten the test duration}

Concrete samples are tested at $60^{\circ} \mathrm{C}$ to understand the effect of temperature on concrete leaching and rate/ultimate expansion (Section 4.3). Alkali leaching from concrete samples (Section 4.2.1) and alkali release from aggregates (Section 4.2.2) will be studied and compared to the results obtained from the samples tested under objective a. 1 at $38^{\circ} \mathrm{C}$. The benefits of testing at $60^{\circ} \mathrm{C}$ for samples of different geometry are evaluated.

\subsection{Evaluating the capacity of SCM to bind alkalis and hence mitigate ASR expansion at different temperatures}

The hydration rate of paste samples containing blends of SCM will be investigated under three different regimes (Section 4.2.3):

(i) Storing samples at $38^{\circ} \mathrm{C}$ and $\mathrm{RH}>95 \%$ simulating the conditions of CPT,

(ii) Storing the samples at room temperature at $23^{\circ} \mathrm{C}$ representing the average temperature for non-massive structural elements such as pavements and bridges,

(iii) Storing samples at $60^{\circ} \mathrm{C}$ which simulates testing at $60^{\circ} \mathrm{C}$.

At different time intervals, the samples under the three different regimes will be tested for:

(i) degree of hydration through determining the chemically bound water (CBW),

(ii) degree of pozzolanic reaction by determining the $\mathrm{Ca}(\mathrm{OH})_{2}$ consumption, and

(iii) the alkali binding capacity through the leaching test as will be described later. 
The outcomes of this task will explain whether or not the standard CPT conditions favor more alkali binding by SCM compared to samples exposed to field conditions. This could be another reason, in addition to the sample geometry explained under objective a.1, to explain the discrepancies observed between the CPT and the field. Testing at $60^{\circ} \mathrm{C}$ will also shed light into the pros and cons of testing concrete samples at $60^{\circ} \mathrm{C}$.

\subsection{Determine more reliable approach to predict the minimum levels of SCM required to mitigate ASR}

By understanding the effect of sample shape on leaching and expansion tested under objective a.1, the minimum alkali level that will lead to an expansion of $0.040 \%$ - limit specified in the CPT could be determined. This is done by testing samples at different alkali content for three different types of aggregates. A way to obtain the threshold alkali content will be proposed (Section 4.4). This threshold will allow to find the minimum levels of SCM required to limit the late expansion as will be discussed in Section 5.2.

\section{Assess the remaining expansion in concrete structures affected by ASR}

The aim of this study is to understand the effect of deterioration level on residual expansion of concrete structures affected by ASR (Section 4.5). Barriers obtained from a demolished bridge in Sudbury, Ontario were investigated in this research. The effect of deterioration level on residual expansion and ways to determine the remaining life are proposed based on testing cores and RCA produced from concrete of different deterioration levels.

\section{Identifying test methods to evaluate the alkali-silica reactivity of mineral fillers by adapting current ASR test methods}

Mineral fillers are being implemented in concrete to attain certain properties like selfconsolidation. Different sources of fillers are available depending on the type of original rock from which the filler is formed. Their potential for alkali-silica reaction in concrete might be a concern. 
No standard test methods exist to evaluate the reactivity of mineral fillers. Hence, finding a fast and reliable test to study the potential alkali-silica reactivity of mineral fillers is needed. This research focuses on adapting and adopting the current accelerated mortar bar test to evaluate reactivity of mineral filler (Section 4.6).

Based on the discussed challenges related to ASR, the research questions that need to be investigated in this study are as follows:

(a) Is it possible to find an enhanced test method to evaluate alkali-silica reactivity and preventive measures to show better correlation with the field expansion compared to current test methods?

(b) Using different sample shapes and geometry, could the testing duration of the concrete be reduced when testing at high temperature; i.e. $60^{\circ} \mathrm{C}$ ? 


\section{Chapter 2}

\section{Literature Review}

This section deals with the literature review of the alkali-silica reaction. It includes the reaction's chemistry, the test methods that are currently present and the effect of supplementary cementing materials (SCM) in preventing ASR. In addition, literature related to residual expansion of structures affected by ASR and the potential reactivity of mineral fillers is presented in this section.

\subsection{Chemistry of the Alkali-Silica Reaction in Concrete}

During the 1920s, concrete structures built in California showed signs of severe cracks although they were built with acceptable construction standards. It was then concluded in 1940, by Stanton, that this was not because of external factors such as frost action or saltwater but due to the constituents of the concrete such as the aggregate and the cement used. Stanton demonstrated the existence of alkali-aggregate reaction (Swamy, 1992). Alkali-silica reaction leads to the formation of an expansive gel product which causes cracking, misalignment of structures and pop-outs. Cracks start forming as irregular polygons leading to what is referred to as map cracking. Figure 2.1 to Figure 2.4 show signs of ASR on different structures.

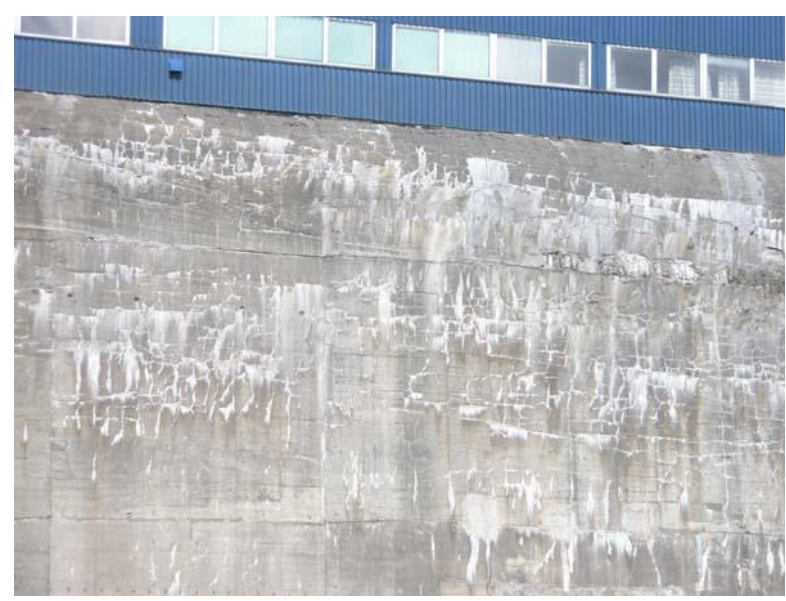

(a)

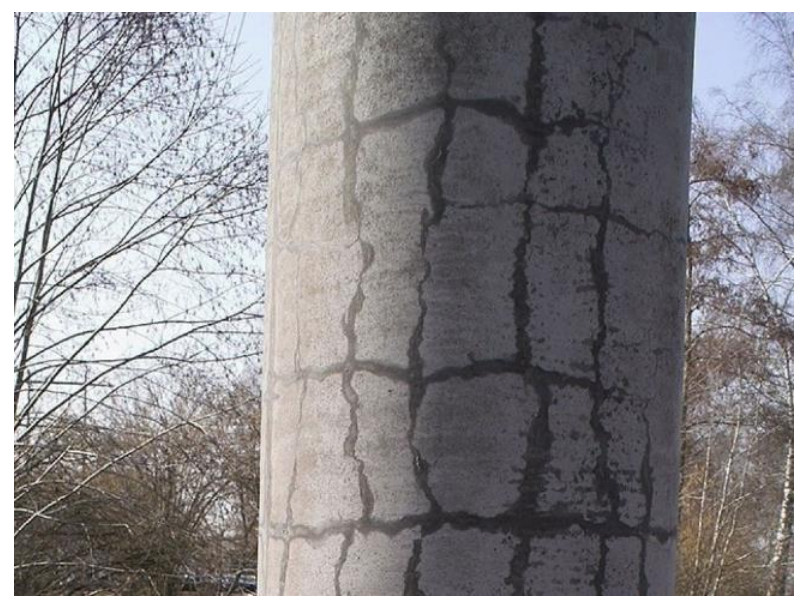

(b)

Figure 2.1: (a) Wall in Norway showing ASR gel extruding from the cracks (FHWA, 2008) (b) ASR damage on bridge pylon (Sika, 2013) 


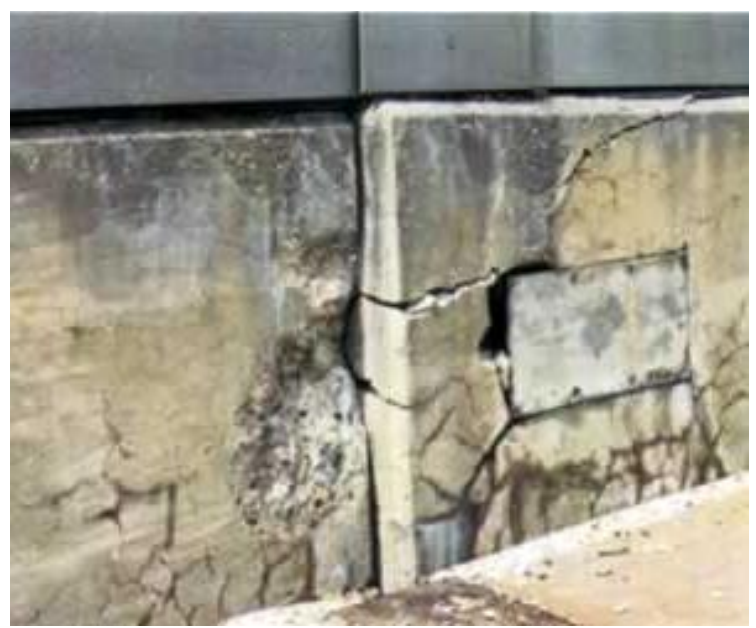

(a)

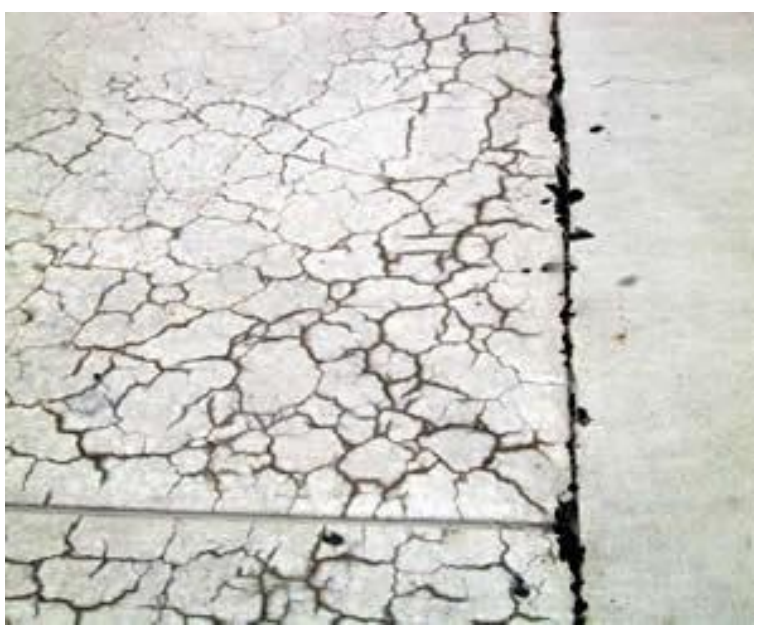

(b)

Figure 2.2: (a) Misalignment of adjacent wall section on a highway bridge due to ASR (FHWA, 2012) (b) Extrusion of joint-sealing material due to excessive expansion from ASR (FHWA, 2012)

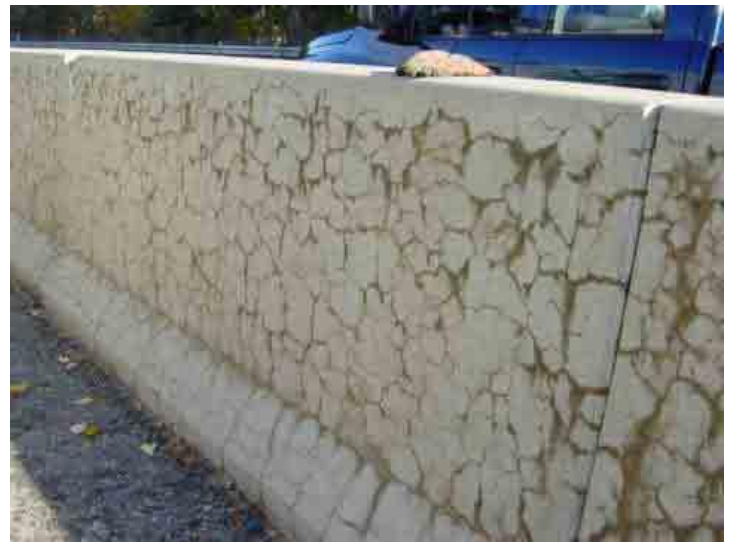

(a)

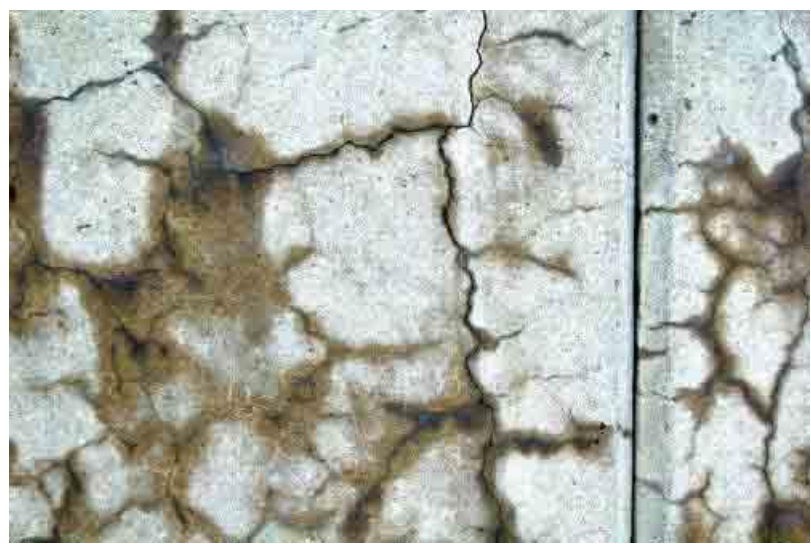

(b)

Figure 2.3: (a) Map cracking in concrete barriers in Massachusetts (FHWA, 2009) (b) Close-up view of the map cracking (FHWA, 2009) 


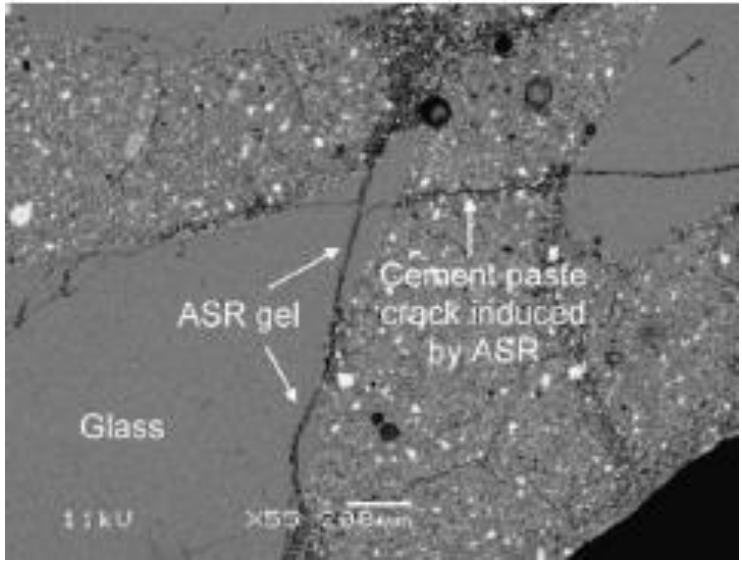

(a)

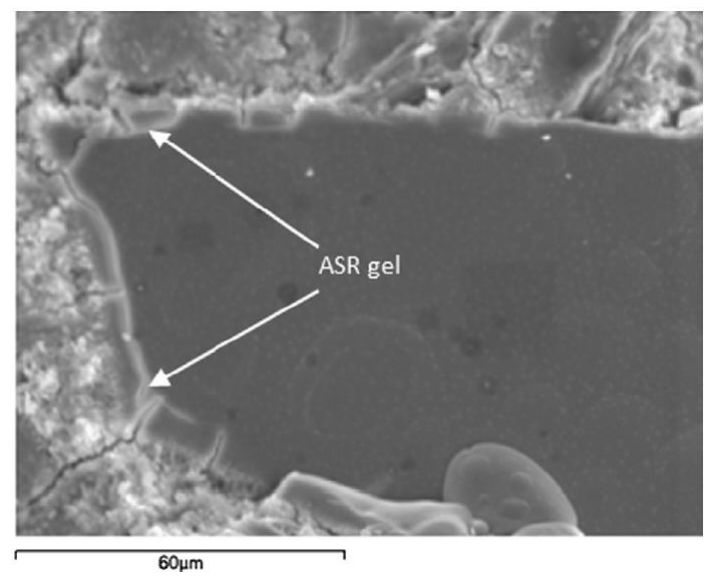

(b)

Figure 2.4: (a) ASR gel observed under microscope (Rajabipour, Maraghechi and Fischer, 2010) (b) Scanning electron microscopy showing a glass particle surrounded by ASR gel (Serpa et al., 2013)

The alkali-silica reaction requires the presence of three major factors to occur:

Presence of alkalis in the pore solution,

Presence of reactive silica in the aggregate,

Sufficient moisture.

\subsubsection{Sources of Alkalis}

Many sources of alkalis can be available in concrete such as aggregates, cement, chemical admixtures as well as external sources. However, the major contributor to the reaction is the Portland cement (PC) which normally has an alkali content in the range of $0.2 \%$ to $1.3 \%$ of $\mathrm{Na}_{2} \mathrm{O}_{\mathrm{e}}$ in North America. The total alkali content is expressed in sodium equivalent as follows:

$$
\mathrm{Na}_{2} \mathrm{O}_{\mathrm{e}}=\mathrm{Na}_{2} \mathrm{O}+0.658 \mathrm{~K}_{2} \mathrm{O}
$$

Table 2.1 shows a type general use (GU) Portland cement used widely in Ontario, Canada. Although the percentage of sodium and potassium in Portland cement is very low compared to other oxides, the alkalis are very soluble and dominant in the concrete pore solution.

Table 2.1: Chemical composition of GU Portland cement (Holcim, 2014)

\begin{tabular}{ccccccccc}
\hline Oxide & $\mathrm{SiO}_{2}$ & $\mathrm{Al}_{2} \mathrm{O}_{3}$ & $\mathrm{Fe}_{2} \mathrm{O}_{3}$ & $\mathrm{CaO}$ & $\mathrm{MgO}$ & $\mathrm{SO}_{3}$ & $\mathrm{Na}_{2} \mathrm{O}_{e}$ & $\mathrm{LOI}$ \\
\hline \hline Mass (\%) & 19.54 & 5.21 & 2.16 & 62.39 & 2.39 & 4.03 & 0.99 & 2.36 \\
\hline
\end{tabular}


Figure 2.5 shows the change in concentration of the different ions in the paste pore solution with time. The concentration of $\mathrm{SO}_{4}{ }^{2-}$ is dropping due to the formation of sulfate phases such as ettringite and calcium mono-sulfoaluminate. To keep the balance with the positively charged ions $\left(\mathrm{Na}^{+}\right.$and $\left.\mathrm{K}^{+}\right)$, the hydroxyl ions get into the solution leading to a pore solution of mostly $\mathrm{Na}^{+}, \mathrm{K}^{+}$ and $\mathrm{OH}^{-}$(FHWA, 2012).

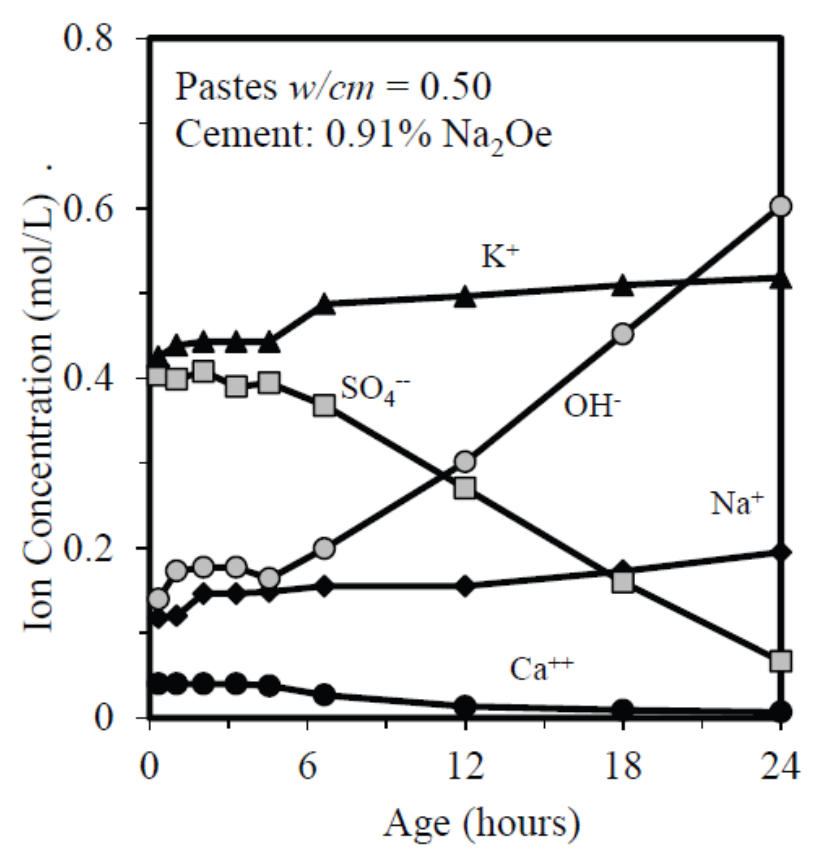

Figure 2.5: Variation of ions concentration in concrete with time (FHWA, 2012)

The recommended threshold content below which the alkali-silica reaction is stopped is $0.6 \%$ $\mathrm{Na}_{2} \mathrm{O}_{\mathrm{e}}$ and the alkali content should be kept below $3 \mathrm{~kg} / \mathrm{m}^{3}$ (Swamy, 1992). However, these recommendations are based on expansion results from concrete prisms tests conducted in the laboratory which have some challenges such as the excessive leaching. These challenges will be explained in details in Section 2.2.3. Adding to this, these thresholds are dependent on other factors such as the reactivity of the aggregates discussed in Section 2.1.5.

\subsubsection{Sources of Reactive Silica in the Aggregate}

A form of reactive silica should be present in the aggregate so that the alkali-silica reaction occurs. The silica, $\mathrm{SiO}_{2}$, is a component of many rocks but not all types of siliceous aggregates can react with alkalis. Depending on their microstructure, some aggregates are unstable at high $\mathrm{pH}$ compared to others having the same chemical composition. An example of highly reactive rock is Opal which has a disordered structure, making it unstable and more soluble at high $\mathrm{pH}$. Opal has the highest 
solubility of $1000 \mathrm{mM} / \mathrm{L}$ compared to that of Quartz (around $25 \mathrm{mM} / \mathrm{L}$ ) when soaked in $1 \mathrm{M} \mathrm{NaOH}$ as shown in Figure 2.6(a). Figure 2.6(b) shows the disordered structure of Opal compared to the stable Quartz explaining the higher silica solubility in the Opal (FHWA, 2012).

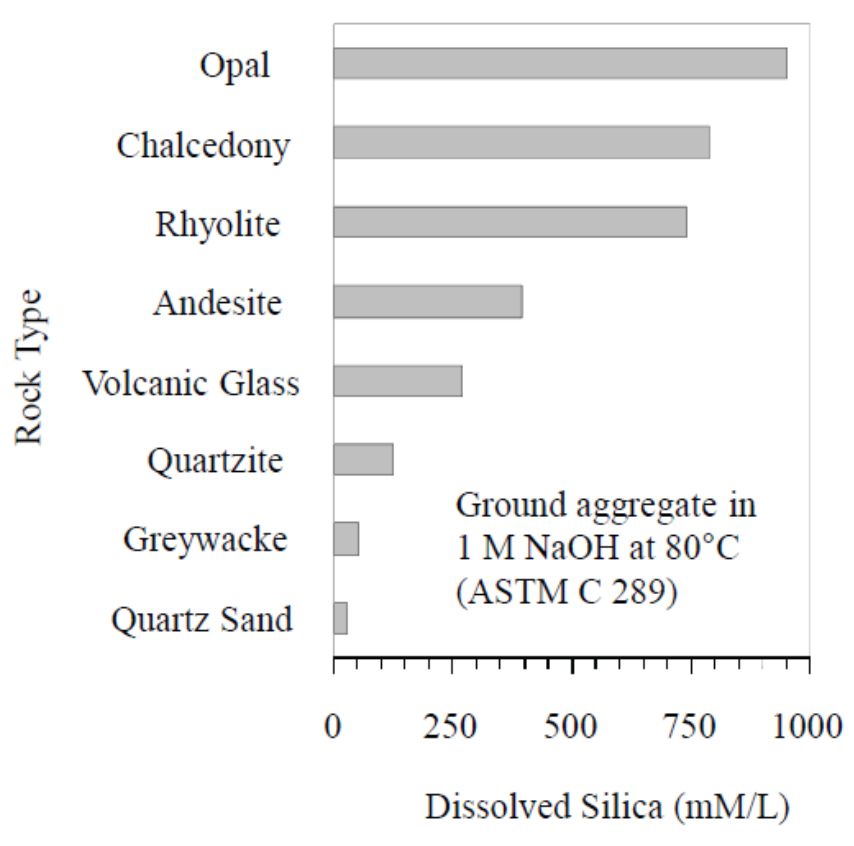

(a) Soluble Silica in Aggregates

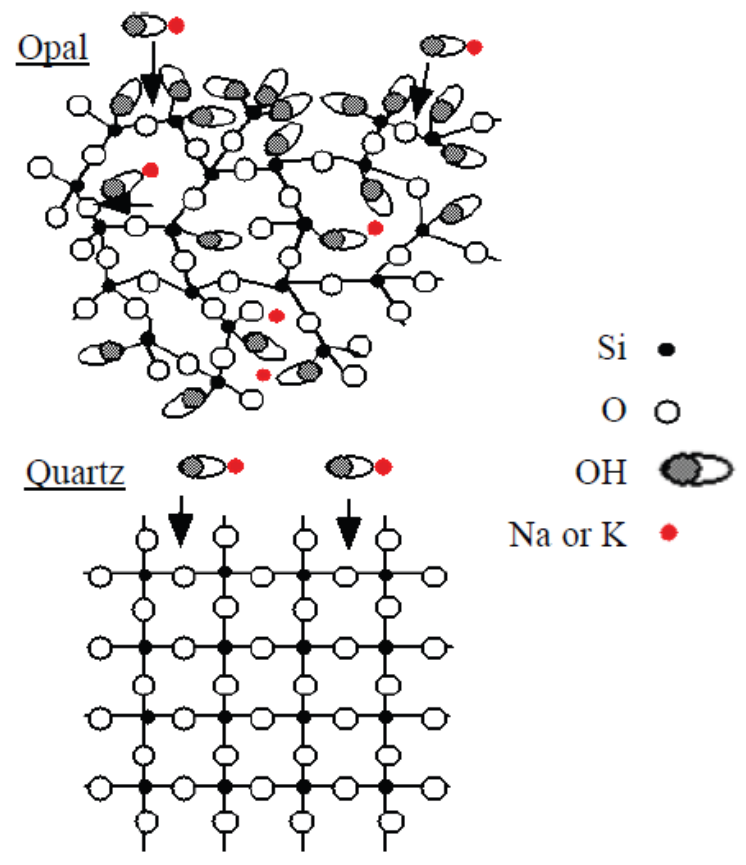

(b) Schematic Showing Crystalline Structure of Opal (top) and Quartz (bottom)

Figure 2.6: Solubility of different siliceous rocks in alkaline solution (FHWA, 2012)

\subsubsection{Presence of Sufficient Moisture}

As many other reactions, water is required for ASR to happen. Other than being a transport for the external alkalis, water is absorbed by the gel formed due to the reaction between alkalis and silica. This gel is a hydrophilic material which swells in presence of water causing pressure to the surrounding and crack formation. Although below $70 \%$ there is minimal expansion but the dramatic change happens at relative humidity $(\mathrm{RH})$ of $80 \%$ and higher as shown in Figure 2.7. 


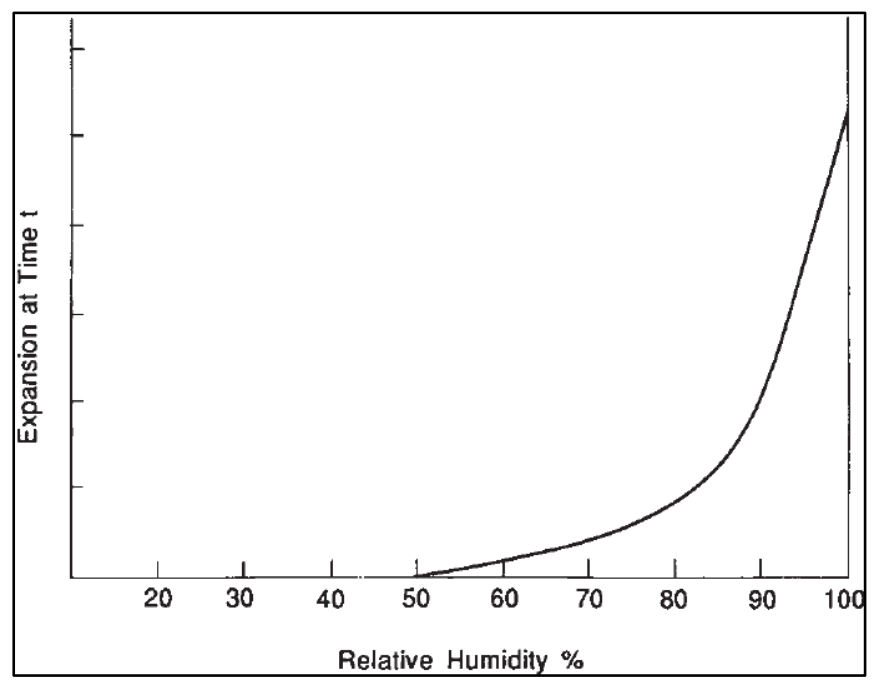

Figure 2.7: Effect of relative humidity on expansion (Swamy, 1992)

\subsubsection{ASR Mechanism}

ASR occurs as a result of the reaction between the siliceous components of the aggregate and the alkalis present in the concrete pore solution. As a result, the alkali-silica gel forms and swells as it absorbs moisture. The swelling pressures, if exceeded the tensile strength of the surrounding, will cause expansion and cracking in concrete. First, the presence of $\mathrm{Na}^{+}$and $\mathrm{K}^{+}$ions will lead to the dissolution of $\mathrm{Ca}(\mathrm{OH})_{2}$ to form $\mathrm{Ca}^{2+}$ and $\mathrm{OH}^{-}$in order to maintain equilibrium (Lindgård et al., 2012). The pore solution alkalinity will increase which will lead to dissolution of the silica from the reactive aggregate. Two main reactions will occur subsequently. In the first stage, the siloxane ( $\mathrm{Si}-\mathrm{O}-\mathrm{Si})$ groups will react in presence of water in the pore solution to form the silanol $(\mathrm{Si}-\mathrm{OH})$ groups. Secondly, at high $\mathrm{pH}$, the $\mathrm{OH}^{-}$ions will attack the silanol to form a negatively charged $\mathrm{Si}$ $\mathrm{O}^{-}$which attracts the positively charged ions present in the pore solution $\left(\mathrm{Na}^{+}, \mathrm{K}^{+}, \mathrm{Ca}^{2+}\right)$. These reactions are summarized as follows:

$$
\begin{aligned}
& \mathrm{Si}-\mathrm{O}-\mathrm{Si}+\mathrm{H}_{2} \mathrm{O} \rightarrow 2 \mathrm{Si}-\mathrm{OH} \\
& \mathrm{Si}-\mathrm{OH}+\mathrm{OH}^{-}+\mathrm{Na}^{+} \longrightarrow \mathrm{Si}-\mathrm{O}-\mathrm{Na}+\mathrm{H}_{2} \mathrm{O}
\end{aligned}
$$

\subsubsection{Other Factors Affecting ASR}

\section{Aggregate Reactivity}

A maximum expansion might occur depending on the type of aggregates and the amount of reactive silica present with some aggregates showing a pessimum effect. At silica levels higher than a specific percent, there is not enough alkalis to increase the expansion. For fast reactive 
aggregates, such as Opal for example, the maximum expansion occurs at low levels of reactive silica, usually below $10 \%$. This is not the case with slowly reactive aggregates which keep expanding with higher content of reactive silica (Lindgård et al., 2012). Gillott (1975) showed a sharp and very clear pessimum in the case of the Opal (Figure 2.8) which might not be the case with less reactive aggregates. However, the pessimum depends on the alkali level as shown in the figure as well as other factors such as particle size.

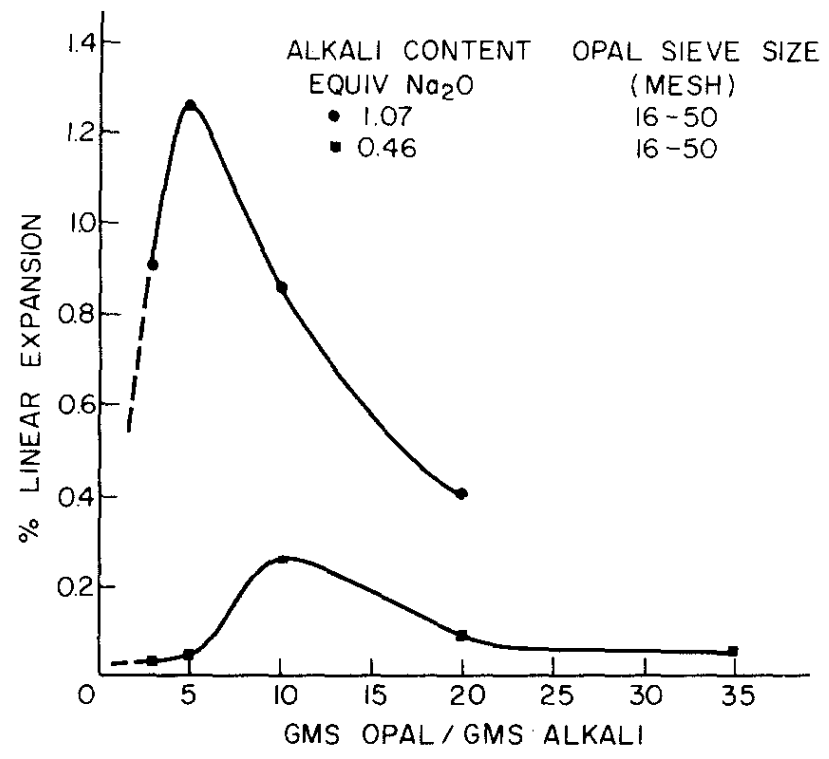

Figure 2.8: 3-month expansion of mortar bars containing Mexican Opal at $37.8^{\circ} \mathrm{C}$ (Gillott, 1975)

Bleszynski and Thomas (1998) showed that when using 100\% reactive flint sand, the expansion is much lower compared to samples containing $35 \%$ of the reactive sand. This is due to the attributed high $\mathrm{SiO}_{2} / \mathrm{Na}_{2} \mathrm{O}_{\mathrm{e}}$ ratio (Bleszynski and Thomas, 1998). When dealing with aggregates showing pessimum effect, it is important to perform mixes with different percentages of reactive components in order to see the pessimum.

\section{$\underline{\text { Alkali Content }}$}

Many studies have been done showing that the expansion is dependent on the cement alkali content. Sibbick and Page (1992) tested three different British aggregates: siltstone, silicified limestone and greywacke aggregates. The expansions of the different aggregates are shown from Figure 2.9 to Figure 2.11. As shown in the figures, expansions higher than the expansion limit of $0.040 \%$ were observed with alkali levels as low as $3.5 \mathrm{~kg} / \mathrm{m}^{3}$ for the siltstone and silicified limestone and $4.5 \mathrm{~kg} / \mathrm{m}^{3}$ for the greywacke aggregate. 


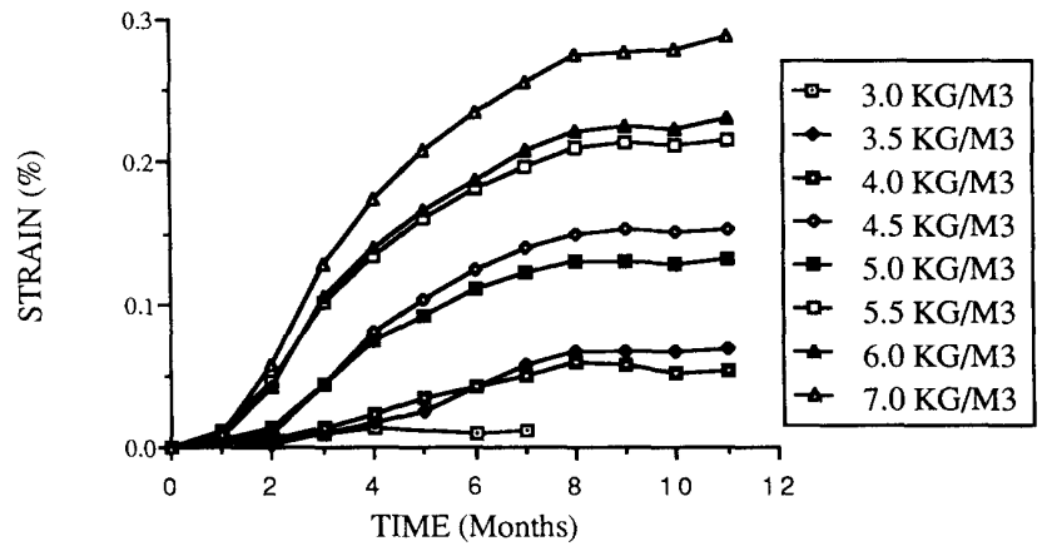

Figure 2.9: Expansion of concrete prisms containing siltstone aggregate (Sibbick and Page, 1992)

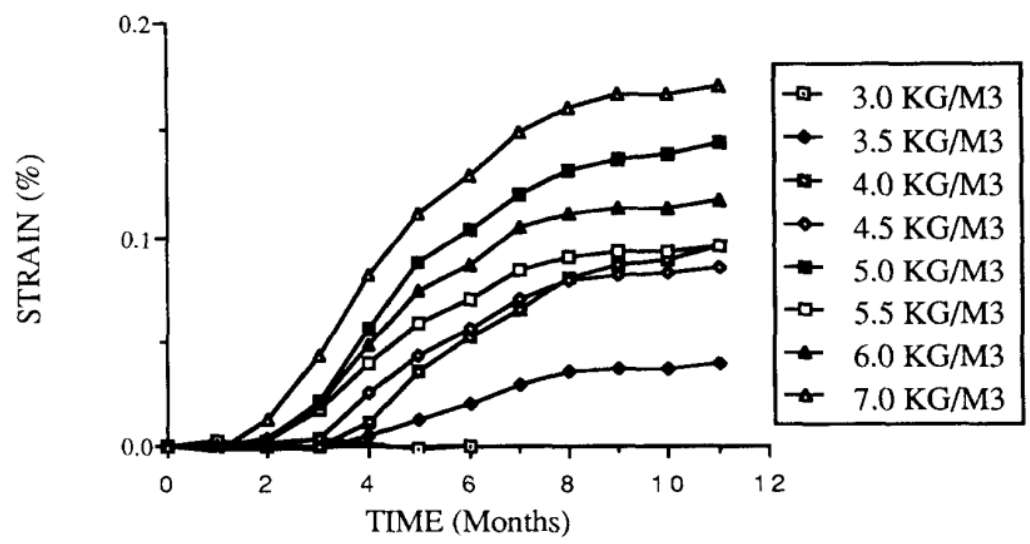

Figure 2.10: Expansion of concrete prisms containing silicified limestone aggregate (Sibbick and Page, 1992)

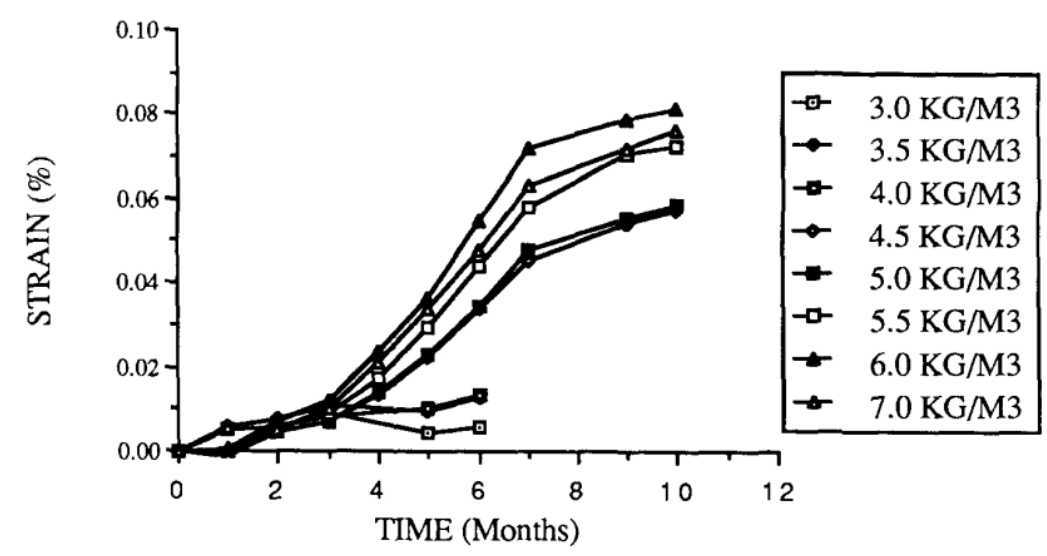

Figure 2.11: Expansion of concrete prisms containing greywacke aggregate (Sibbick and Page, 1992) 
In addition, the rate of expansion changes with the change in PC alkalinity as shown in Figure 2.12 for concrete prisms cast with Nova Scotia greywacke aggregate. The alkali concentration affects the rate and degree of expansion. In North America, the alkali level is restricted to $0.6 \% \mathrm{Na}_{2} \mathrm{O}_{\text {e }}$ (Gillott, 1975). However, damage was found at lower alkalinity in some cases.

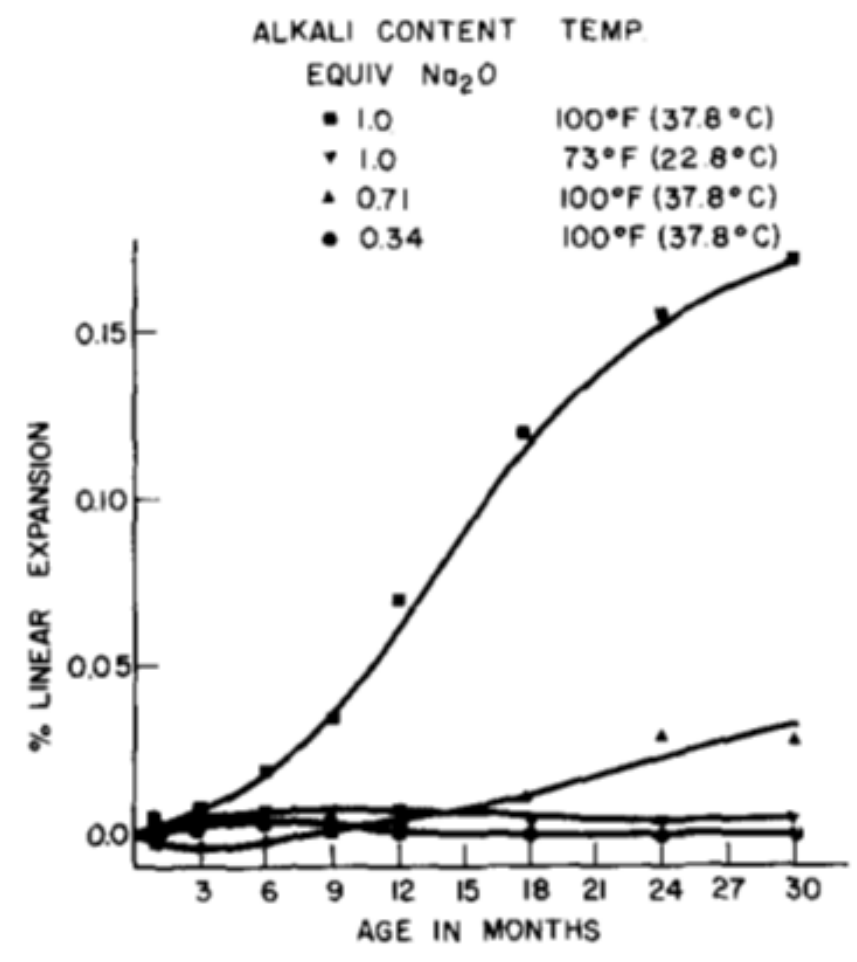

Figure 2.12: Expansion of concrete prisms containing Nova Scotia greywacke aggregate (Gillott, 1975)

Figure 2.13 shows the expansion of concrete prisms as a function of the alkali and the cement content using a siliceous limestone aggregate from Ottawa, Canada. Lindgård et al. (2012) concluded that the expansion is dependent on the alkali content of the concrete. The cement content was found to not affect expansion to the same extent as the PC alkali content (Lindgård et al., 2012). However, Rivard et al. (2007) showed that the expansion level depends greatly on the cement content and not only the pore solution alkalinity. The higher the cement content, the higher the expansion (Rivard et al., 2007). 


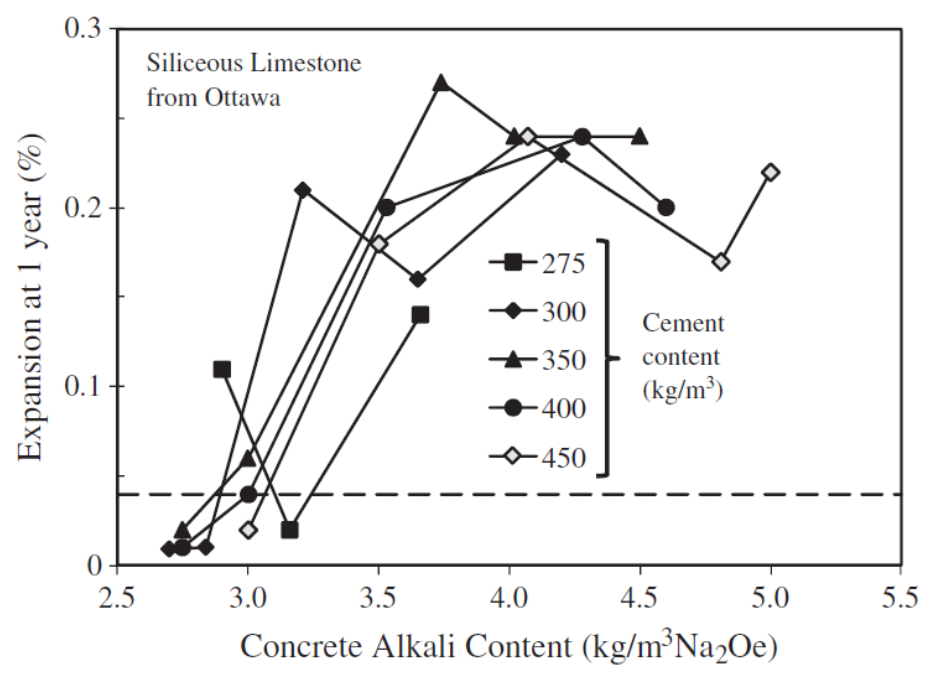

Figure 2.13: Expansion of concrete prisms containing siliceous limestone aggregate (Lindgård et al., 2012)

To understand the effect of the PC alkali content on expansion, Shehata and Thomas (2010) studied three types of aggregates with Jobe sand showing the highest reactivity, followed by Spratt and then Sudbury coarse aggregates. The 1-year CPT expansions of prisms cast with Jobe sand, Spratt and Sudbury aggregates are $0.56 \%, 0.24 \%$ and $0.17 \%$, respectively (Shehata and Thomas, 2010). The maximum levels of PC alkali content that will keep the expansion of concrete prisms below the $0.040 \%$ limit are $0.7 \% \mathrm{Na}_{2} \mathrm{O}_{\text {e }}$ for Jobe and Spratt aggregates and $0.8 \%$ for Sudbury aggregate as shown in Figure 2.14 (Shehata and Thomas, 2010).

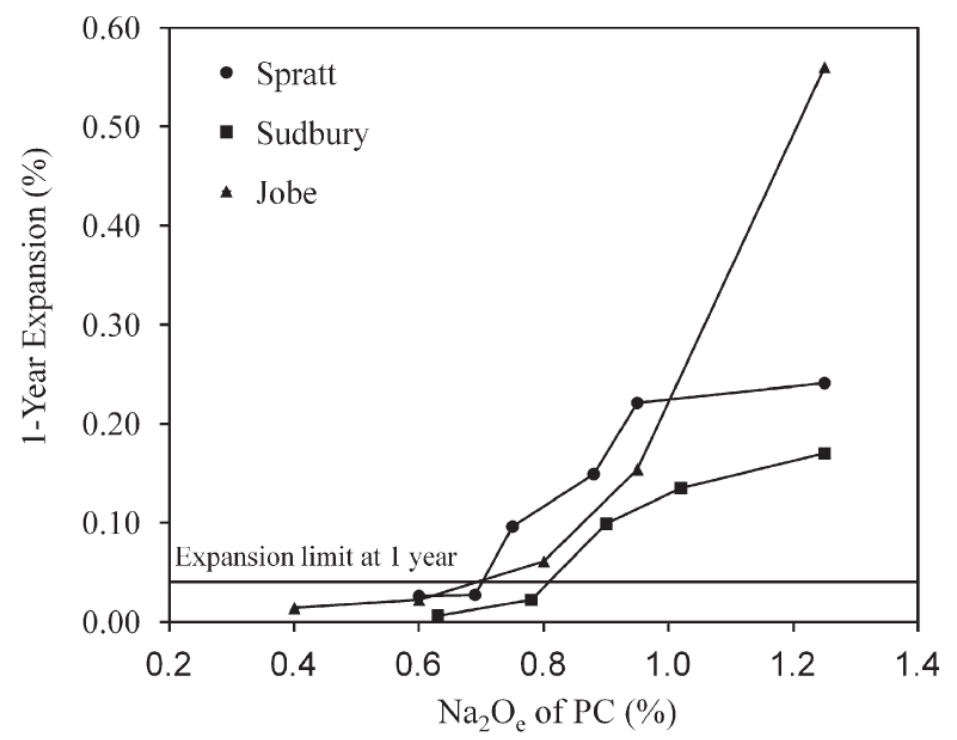

Figure 2.14: Effect of PC alkali content on concrete expansion (Shehata and Thomas, 2010) 


\section{Alkali Release from Aggregates}

Each aggregate type has a different mineralogy affecting its alkali release characteristics. Many factors affect the alkali contribution from the aggregates such as pore solution to aggregate ratio, temperature and $\mathrm{pH}$. Some aggregates contribute significant amounts of alkalis to the pore solution, which should be taken into consideration when building new structures. Bérubé et al. (2002) tested a wide range of aggregates for their alkali release characteristics. The aggregate size tested was 1 to $5 \mathrm{~mm}$ and soaked in $0.7 \mathrm{M} \mathrm{NaOH}$ solution at $38^{\circ} \mathrm{C}$. Bérubé et al. (2002) found that the aggregates contribute from less than 0.1 to $3.4 \mathrm{~kg} / \mathrm{m}^{3} \mathrm{Na}_{2} \mathrm{O}_{\mathrm{e}}$. For instance, in the case of Spratt, a highly reactive aggregate, the alkali release was $0.01 \%\left(0.06 \mathrm{~kg} / \mathrm{m}^{3}\right) \mathrm{Na}_{2} \mathrm{O}_{\mathrm{e}}$. For Sudbury, a moderately reactive aggregate, the alkali release was $0.17 \%$, or $3.08 \mathrm{~kg} / \mathrm{m}^{3} \mathrm{Na}_{2} \mathrm{O}_{\mathrm{e}}$ (Bérubé et al., 2002). In another study, three different types of aggregates were compared: gneiss, a metamorphic type of rock with plagioglase and sericite, granite and a sanidine (potassium feldspar) rock. The gneiss was found to have the highest alkali contribution as compared to the other two rocks ( $\mathrm{Lu} e t$ al., 2006). This might be due to the metamorphic nature of the rock. The alkali release from Springhill coarse aggregate was studied and there was no evidence of released alkalis into pore solution which might be due to the alkali uptake for the formation of ASR gel (Drolet, Duchesne and Fournier, 2017). Moreover, alkali release from aggregates was found to be higher in $0.7 \mathrm{M}$ $\mathrm{NaOH}$ or $\mathrm{KOH}$ solutions compared to saturated lime solutions (Bérubé et al., 2002). However, a study by Yujiang, Min and Mingshu (2008) showed contradicting results with less alkalis released in $0.7 \mathrm{M} \mathrm{NaOH}$ and $\mathrm{KOH}$ solutions compared to saturated $\mathrm{Ca}(\mathrm{OH})_{2}$ solutions.

In addition, with the decrease of the aggregates size, the alkali release is higher with a dramatic increase for particles finer than $1.0 \mathrm{~mm}$, especially with the gneiss rock (Lu et al., 2006). This is due to the fact that this rock contains sericite which would participate in cation exchange reaction in addition to the feldspar that releases alkalis by dissolution. In fact, ASR can occur in structures with even low-alkali cement due to the release of alkalis from the aggregates. Temperature might also have an effect on the alkali release of the aggregates. With increased temperatures, the alkali release was shown to increase exponentially (Lu et al., 2006). This might vary from one type of aggregate to another depending on the metamorphic alterations and mineralogical differences $(\mathrm{Lu}$ et al., 2006). 


\section{$\underline{\text { ASR Gel Composition }}$}

The composition of the gel evolves with time. Initially, the gel is rich in $\mathrm{Na}^{+}$and $\mathrm{K}^{+}$ions. The higher the $\mathrm{Na}_{2} \mathrm{O} / \mathrm{SiO}_{2}$ ratio, the less the viscosity of the gel (Lindgård et al., 2012). Thus, at the beginning, the viscosity of the gel is very low to the level that there is not enough expansive pressure to show cracks. However, this may lead to exudation of ASR gel on the surface of the exposed samples leading to reduced expansion. At later ages, due to the evolution of the reaction, the $\mathrm{Ca}^{2+}$ content increases in the gel which becomes more viscous and expansive compared to the original alkali-rich gel (Bleszynski and Thomas, 1998; Lindgård et al., 2012). In the field, there is limited amount of alkalis provided as compared to the calcium content which is present due to the dissolution of the portlandite. In the laboratory, the gel is more enriched by alkalis due to the addition of $\mathrm{NaOH}$ leading to a Na-rich gel with lower viscosity compared to the field. When adding lime during the mixing phase, higher expansion of concrete prisms compared to samples with no added lime will be obtained (Bleszynski and Thomas, 1998). Many studies have shown that the presence of $\mathrm{Ca}(\mathrm{OH})_{2}$ is needed to show deleterious expansion due to ASR in concrete (Chatterji, 1979; Gaboriaud et al., 2002; Rajabipour et al., 2015). Due to the pozzolanic nature of fly ash, the calcium content will be reduced and thus the ASR gel will be low in calcium and hence remains in a more fluid state without causing any cracks (Bleszynski and Thomas, 1998).

In general, the $\mathrm{Ca}^{2+}$ content depends on the location of the gel formation. The gel rich with $\mathrm{Ca}^{2+}$ is normally at a distance from the aggregate since the alkalis will be replaced by the calcium present in the Portlandite cement (Lindgård et al., 2012). Furthermore, addition of SCM might hinder the ASR expansion in the laboratory tests but not in the field, partly because the viscosity of the gel at high temperatures and at higher relative humidity is lower (Leemann and Merz, 2012). Hence, the expansion in the field might be more severe although slower (Lindgård et al., 2012). However, researches showed that the temperature does not affect the morphology of the gel as compared to others who showed that the gel formed from lab specimens had an amorphous structure while the gel from old concrete structures were partly crystalline (Lindgård et al., 2012).

Soaking samples in $\mathrm{NaOH}$ solution showed more aggressive deterioration and higher expansion compared to KOH solution which showed more crystalline gel (Lu et al., 2006). In addition, the ratio of $\mathrm{Na} / \mathrm{K}$ in the cement seems to have an effect on the expansion of prisms. Leemann and Lothenbach (2008) tested concrete prisms using two different cement with similar $\mathrm{Na}_{2} \mathrm{O}_{\mathrm{e}}$ at $60^{\circ} \mathrm{C}$. 
Samples cast with a cement of $\mathrm{K} / \mathrm{Na}=2.4$ showed higher expansion compared to the samples cast with a cement of higher $\mathrm{K} / \mathrm{Na}$ ratio (3.95). This difference in expansion was attributed to the difference in the ratio of cations (Leemann and Lothenbach, 2008).

\section{Swelling Properties Under Stress}

Gautam et al. (2017) studied the relationship between expansion caused in concrete affected by ASR and its stress state using finite element modeling. The model was applied on restrained and unrestrained cubes subject to multiple stress conditions. A reduction in expansion was observed in the direction of the applied stress and expansion will be transferred from the stressed plane to the unstressed direction. The expansion is ceased in the direction of the highest restraint applied load (Giorla, 2013). In the case of triaxial stress applications, a reduction in expansion forcing the ASR gel to propagate into the increasingly smaller micro-pores in the concrete (Gautam, 2016). The model was validated using experimental data (Gautam et al., 2017).

Struble, Diamond and Lafayette (1981) developed synthetic gels and tested its swelling properties. When applying a certain load below the maximum swell pressure of the gel, the swell will be reduced as the gel absorbs water compared to the swell under no load conditions. When applying a load higher than the maximum swell pressure, the gel will shrink (Struble, Diamond and Lafayette, 1981). The behavior was obtained for gels with a $\mathrm{Na}_{2} \mathrm{O} / \mathrm{SiO}_{2}$ molar mass ratio of 0.27. The expected behavior is shown in Figure 2.15 below.

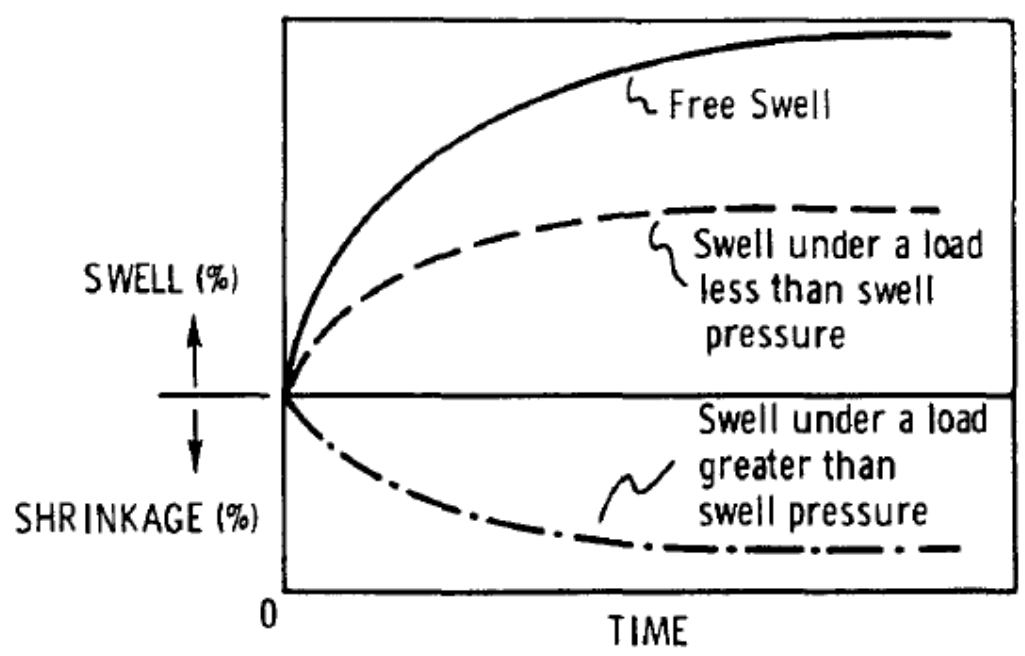

Figure 2.15: Schematic diagram of gel swelling behavior (Struble, Diamond and Lafayette, 1981) 
For $\mathrm{Na}_{2} \mathrm{O} / \mathrm{SiO}_{2}$ equal to 0.34 , when $20 \%$ only from the maximum swell pressure was applied, the gel resulted in progressive shrinkage and liquification. For a load close to the maximum pressure (9.9 MPa), there was an initial shrinkage recovered after 30 hours and a net swell higher than the free swell was obtained. Close behavior was observed for samples with $\mathrm{Na}_{2} \mathrm{O} / \mathrm{SiO}_{2}$ of 0.42 . Those instabilities in the swell behavior can be due to the difference in the non-equilibrium molecular structures of the different gels. The gels used are monomeric and highly polymerized. With age, their structure will change leading to less active gels. The obtained behavior can explain why under sustained load, it is still possible to see expansion in local regions of concrete structures affected by ASR. Another example is the liquification of the gel which will hinder the damage. This is typically what occurs on the external cracks of affected structure. Also, the case of aging could explain the rendering that happens in the gels making them less expansive.

\section{Water to Cement Ratio}

The water to cement ratio (w/c) plays an important role in ASR. By decreasing the w/c ratio, the $\mathrm{OH}^{-}$concentration will increase, as well as the $\mathrm{pH}$ and hence the dissolution of the silica. In addition, the alkali release from the aggregates will increase too (Lindgård et al., 2012). On the other hand, with lower w/c ratio, a denser paste will occur which will hinder the ingress of water and the transport of alkalis (Lindgård et al., 2012). However, hydration will lead to a lower paste volume. This is due to the fact that the volume of the hydration products is smaller than the original reactants used. This is called chemical shrinkage which will lead to empty pores in the concrete. In the hardening phase, the self-desiccation is more apparent with lower w/c ratio, generally lower than 0.40 depending on the cementing materials used. Self-desiccation has an effect on the measurements at early ages, showing some shrinkage in the concrete prisms. Also, it affects the internal RH which controls ASR, particularly if the size of the concrete specimens is larger than $100 \mathrm{~mm}$ and the w/c ratio is lower than 0.4 (Lindgård et al., 2012).

The humidity inside the concrete samples is affected by temperature as well. With an increase in temperature, there will be an increase in local vapor pressure initiating the moisture transport from warmer to cooler areas within the specimens leading to a decrease in RH in local areas within the samples. This can happen when the concrete prisms are taken out one day before for measurements. On the other hand, for small volume samples like concrete prisms, an increase in temperature from $20^{\circ} \mathrm{C}$ to $40^{\circ} \mathrm{C}$ increased the RH by $5 \%$ (Lindgård et al., 2012). 


\subsection{Test methods}

Due to the insufficient data from the field, two standards test methods described in both Canadian and American standards are used to evaluate expansion due to ASR: (1) concrete prism test (CPT) described in CSA A23.2-14A (2014) and ASTM C1293 (2018), and (2) accelerated mortar bar test (AMBT) described in CSA A23.2-25A (2014) and ASTM C1260 (2014). These standard methods are being used as accelerated tests to evaluate the reactivity of aggregates as well as the efficiency of SCM to mitigate expansion. Table 2.2 shows the proposed expansion limits to identify the potential reactivity of alkali-silica aggregates, where the expansion limit is $0.040 \%$ at 1 year for the CPT, and $0.150 \%$ at 14 days for AMBT.

Table 2.2: Expansion limits for identifying potentially alkali-silica reactive aggregates (CSA A23.227A, 2014)

\begin{tabular}{cc}
\hline Concrete Prism Test & Accelerated Mortar Bar Test \\
\hline \hline CSA A23.2-14A & CSA A23.2-25A \\
$\geq 0.040 \%$ at 1 year & $\geq 0.150 \%$ at 14 days \\
\hline
\end{tabular}

The concrete prism test is also described in the French Standards - RILEM AAR-3 (2000) - and the British standards BS 812-123 (1999). The accelerated mortar bar test method is presented in the French standards RILEM AAR-2 (2000).

\subsubsection{Accelerated Mortar Bar Test}

The accelerated mortar bar test consists of soaking the mortar bar samples in $1 \mathrm{M} \mathrm{NaOH}$ solution. The mortar bars are made of aggregates being crushed into the different fine fractions specified in CSA A23.2-25A (2014). This is an easy and fast test which requires the measurements of the samples for only 14 days. However, the test is overly severe as it might identify many aggregates to be reactive despite good performance in the field and in the concrete prism test. The accelerated mortar bar test is very influenced by the test conditions (i.e. temperature and soaking solution) and the size of the samples which is very small making it not very representable. When comparing field performance with the 14-day expansion in Figure 2.16, a good correlation exists between the AMBT and field exposure at 10 years. However, at 15 years, there is a number of samples which passed the AMBT, exceeded the $0.040 \%$ limit in the field (Ideker et al., 2012). 


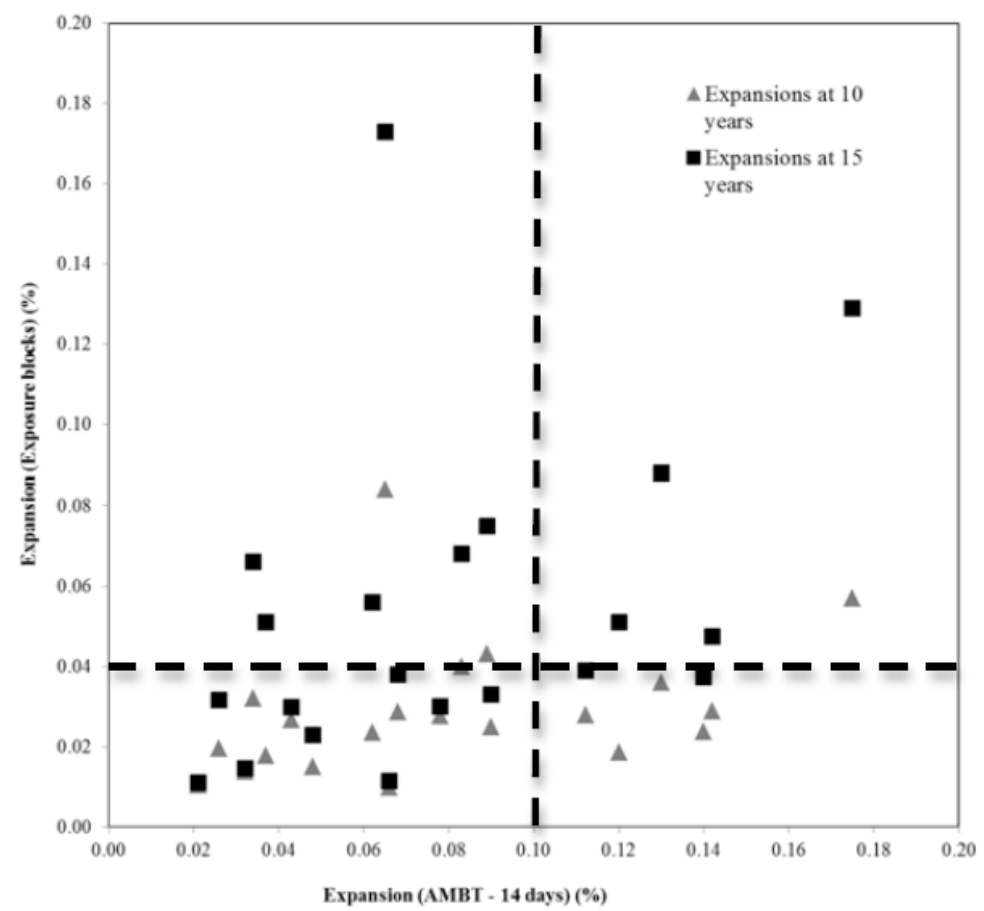

Figure 2.16: Expansion results obtained from field blocks and from the AMBT (Ideker et al., 2012)

\subsubsection{Modified Accelerated Mortar Bar Test}

Shehata and Thomas (2010) tested mortar bar samples using a modified version of the AMBT explained in ASTM C1567 (2004) and ASTM C1260 (2014). They soaked the mortar bars in a solution reflecting the pore solution alkalinity of PC. To predict the alkalinity of the pore solution, they used the following equation developed by Nixon and Page (1987):

$$
\left[\mathrm{OH}^{-}\right](\mathrm{mol} / \mathrm{L})=0.70 \times \mathrm{Na}_{2} \mathrm{O}_{\mathrm{e}} \text { of PC }(\mathrm{wt} . \%)
$$

The test showed close results as for the safe level to prevent ASR in two types of aggregates. However, with the highly reactive Jobe sand the modified test overestimated the expansion results leading to a safe level of $0.35 \% \mathrm{Na}_{2} \mathrm{O}_{\mathrm{e}}$ compared to $0.7 \% \mathrm{Na}_{2} \mathrm{O}_{\mathrm{e}}$ using the CPT described in Section 2.2.3. This could be explained by the fact that this type of aggregates is very sensitive to the alkalis and the soaking solution will provide enough alkalis for the expansion to occur. The concrete prism test is the most reliable laboratory test that is being used to test the reactivity of aggregates.

\subsubsection{Concrete Prism Test}

The concrete prism test requires a mix containing $420 \mathrm{~kg} / \mathrm{m}^{3}$ of cementing materials with a boosted alkali content of $1.25 \% \mathrm{Na}_{2} \mathrm{O}_{\mathrm{e}}$. The prisms are stored in containers above water at $38^{\circ} \mathrm{C}$ and measured for expansion. However, this test requires the boosting of the alkali content by adding 
$\mathrm{NaOH}$ in order to compensate for the alkalis that will be leached during the test. Figure 2.17 shows a comparison of the expansion data from outdoors blocks to CPT results of boosted samples at 10 and 15 years. There is a good correlation between the results at 10 years but not at 15 years. A good number of tests done with CPT satisfied the expansion limit of $0.040 \%$ whereas, in the field it showed much higher expansion indicating that the CPT 2-year expansion limit criterion of $0.040 \%$ is not always indicative of the long-term field performance for some aggregate/SCM combinations (Fournier et al., 2018). The challenge of this test is that the alkalis are being leached from the samples stored above water (Thomas et al., 2006). At later ages, the leaching is being more revealed in the case of smaller samples compared to the blocks which lead to lower expansion results as compared to the site testing. Thus, the excessive alkali leaching from the prisms is one of the main challenges of CPT.

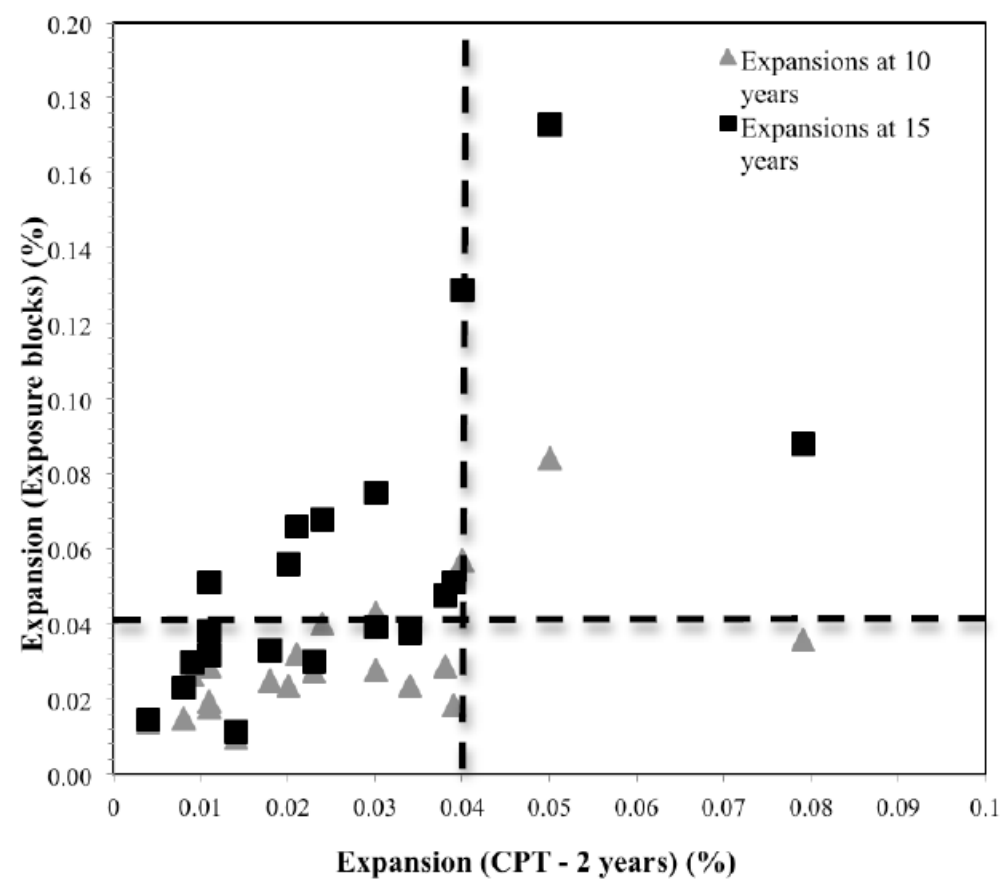

Figure 2.17: Expansion results obtained from field blocks and from the CPT (Ideker et al., 2012)

Many attempts have been made to reduce alkali leaching from concrete samples such as increasing the diameter of the cylindrical samples, increasing the prisms' cross-section or decreasing the airto-concrete ratio in the testing container (Bérubé, Fournier and Côté, 2012; Lindgård et al., 2013; Costa, Mangialardi and Paolini, 2017). The increased expansion observed with the cylinders of higher diameter was attributed partly to the lower air-to-concrete ratio compared to smaller 
diameter samples (Bérubé, Fournier and Côté, 2012). By storing one sample in a bucket, higher leaching will occur leading to lower expansion levelling off faster than with three samples stored in the same bucket (Bérubé, Fournier and Côté, 2012). In addition, Bérubé, Fournier and Côté (2012) attempted to reduce leaching by studying the effect of three different leaching-protective materials for samples without SCM: silane-based sealer application, three sheets of adhesive aluminum foil and plastic sleeve protection. All of the methods reduced leaching except the silanebased sealer method. However, although the leaching was reduced, none of the protective methods was able to increase expansion. In another study by Rivard et al. (2007), a plastic sleeve was used to cover the samples before the 1-year measurement and it was found that the leaching was greatly reduced.

With higher amount of cement, leaching will increase (Rivard et al., 2007). However, the alkali concentration of concrete with $420 \mathrm{~kg} / \mathrm{m}^{3}$ after 102 weeks has reached the same value as the samples with $320 \mathrm{~kg} / \mathrm{m}^{3}$ which was obtained at 82 weeks only (Rivard et al., 2007). Concrete cast with non-reactive aggregates showed a reduction in its pore solution alkalinity which indicates that the alkalinity is reduced not only to the incorporation of the alkalis in the reaction products but also due to leaching.

\subsubsection{Accelerated Concrete Prism Test}

Another challenge of the concrete prism test is the long testing duration. To check the effectiveness of the SCM in mitigating ASR, an expansion below $0.040 \%$ should be obtained at 2 years (CSA A23.2-28A, 2014). Many researchers studied the possibility of shortening the CPT testing duration by increasing the temperature to $60^{\circ} \mathrm{C}$ instead of $38^{\circ} \mathrm{C}$. However, Ideker et al. (2008) found that some non-reactive fine aggregates at $38^{\circ} \mathrm{C}$ have shown expansion in concrete at $60^{\circ} \mathrm{C}$. For instance, when testing two different non-reactive sands with the same aggregate, one classified the aggregate as highly reactive as compared to the other which showed moderate reactivity (Ideker et al., 2008). Another challenge is the excessive leaching obtained at $60^{\circ} \mathrm{C}$ which is expected due to higher diffusion at $60^{\circ} \mathrm{C}$ (Lindgård et al., 2012). The expansion at $60^{\circ} \mathrm{C}$ reached lower ultimate values than the ones at $38^{\circ} \mathrm{C}$ for control samples without any supplementary materials as shown in Figure 2.18. 


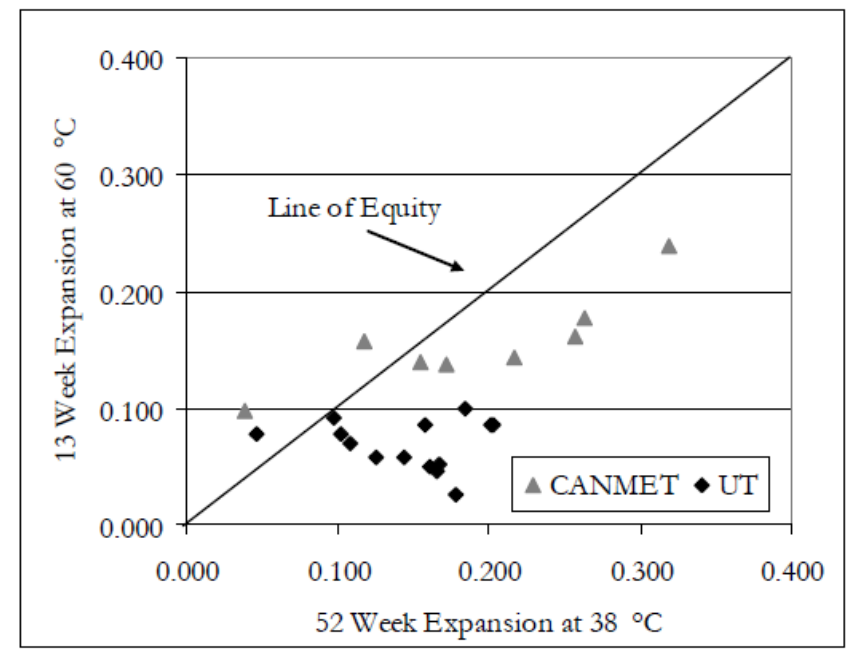

Figure 2.18: Expansion comparison of CPT at 52 weeks and ACPT at 13 weeks (Ideker et al., 2008)

Some explanations proposed that at $38^{\circ} \mathrm{C}$ the expansion is slower and the gel expands more slowly. At lower temperatures, the period at which the gel exerts its maximum pressure is prolonged compared to higher temperatures. Others explained that the gel composition differs from temperature to temperature with its ability to exert higher swelling pressures at lower temperatures (Swamy, 1992). In addition, the expansion was shown to be faster in the short term even if the ultimate expansion is lower. This might be due to the fact that at $60^{\circ} \mathrm{C}$, the $\mathrm{pH}$ for the first few weeks as well as the potassium concentration in the samples were shown to be higher compared to the same samples at $38^{\circ} \mathrm{C}$ (Ideker et al., 2008). The phenomenon is still not clearly understood, thus the need for more research to provide enhanced methods to evaluate ASR with a shorter testing period. The test is not sufficient to draw conclusions related to the reactivity of aggregates as Ideker et al. (2008) found that for the slow or less reactive aggregates, the expansion could be lowered by $50 \%$ at $60^{\circ} \mathrm{C}$ after 13 weeks which might lead to expansions close to the limit of $0.040 \%$. Further investigation of the applicability of this test should be done before reaching any conclusions.

Researches have been made to study the effect of temperature on pore solution of paste samples. Changes in the pore structure of concrete at high temperatures occur. The concentrations of cations such as $\mathrm{Na}^{+}$and $\mathrm{K}^{+}$do not change, however, the concentration of the hydroxyl anions $\mathrm{OH}^{-}$ decreases (Hunger et al., 2012; Fournier et al., 2019). At temperatures higher than $40^{\circ} \mathrm{C}$, the decomposition of calcium sulfoaluminate hydrates happens which leads to an increase in $\mathrm{SO}_{4}{ }^{2-}$ concentration in solution. This is due to the higher solubility of the ettringite at high temperatures. 
In order to maintain equilibrium, the concentration of $\mathrm{OH}^{-}$will drop. In addition, the subsequent reduction in $\mathrm{pH}$ will reduce the rate of silica dissolution from the reactive aggregates (Fournier $e t$ $a l ., 2019)$. Hence, when keeping the concrete specimens more than 1 day at room temperature for curing, less ettringite will be available compared to mono-sulfate and thus less ettringite will be dissolved at elevated temperatures (Lindgård et al., 2012).

Expansion of concrete cast with Spratt aggregate at $60^{\circ} \mathrm{C}$ levelled off after 3 months while that of the moderately reactive aggregate was still in progress. The faster expansion at higher temperature, the alkali-silica gel formation as well as the leaching, and cracking induced at early age, most likely led to a decrease in the $\mathrm{pH}$ of the pore solution to the extent that the expansion leveled off after 3 months. This is not the case at $38^{\circ} \mathrm{C}$ where the expansion takes around 6 months to start leveling off reaching higher expansion than the samples at $60^{\circ} \mathrm{C}$. Proposed limits to test reactivity of aggregates have been suggested in the literature review such as an expansion limit of $0.040 \%$ after 13 weeks for samples at $60^{\circ} \mathrm{C}$ (Touma et al., 2001; Fournier et al., 2019). Some others suggested a $0.04 \%$ after 13 weeks for carbonate and sedimentary aggregates and $0.025 \%$ at 13 weeks for igneous and metamorphic rocks (De Grosbois and Fontaine, 2000). However, the test was only performed on control samples without any supplementary materials. Hence, the need to test samples with SCM to understand better the reactivity of the samples in presence of SCM.

\subsubsection{Modified Concrete Prism Test}

Latifee (2013) suggested a modified CPT which consists of casting 50x50x285 mm prisms and soaking them in alkaline solution at $60^{\circ} \mathrm{C}$. The alkalinity of the solution was obtained based on the equation developed by (HelmuthStark and Diamond, 1993) to predict pore solution alkalinity:

$$
\left[\mathrm{OH}^{-}\right]=0.339 \mathrm{Na}_{2} \mathrm{O} \% /(\mathrm{w} / \mathrm{c})+0.022+/-0.06 \mathrm{~mol} / \mathrm{L}
$$

Linear correlation was obtained between soak solution alkalinity and 28-day expansion at $60^{\circ} \mathrm{C}$. A pore solution alkalinity should be kept below $0.51 \%$ for concrete cast with Spratt aggregate to limit the expansion below $0.040 \%$ (Latifee, 2013).

Some modifications of the standard concrete prism test were suggested by Touma et al. (2001). Prisms stored in $1 \mathrm{~N} \mathrm{NaOH}$ solution at $38^{\circ} \mathrm{C}$ were tested and it was found that expansion can be found in a shorter duration at 26 weeks. However, this procedure overestimated the results of some 
aggregate types and it was severe for other reactive aggregates that were characterized as highly reactive although in the standard CPT were shown to be slowly reactive (Touma et al., 2001).

\subsubsection{Accelerated Concrete Cylinder Test (ACCT)}

Good correlation between 1-month expansions of 7.6x15.2 cm cylinders cast with cement of $0.82 \% \mathrm{Na}_{2} \mathrm{O}_{\mathrm{e}}$ and soaked in its corresponding alkaline solution at $60^{\circ} \mathrm{C}$ and the 1 -year expansion results from CPT was obtained (Liu and Mukhopadhyay, 2015). There is a minimal reduction of alkalinity in the soak solution showing the migration of the ions from the soak solution to the pore solution (Liu and Mukhopadhyay, 2015). After 28 days, the expansion is still gradually increasing where as it should start to decrease showing the effect of ion ingress from the soak solution (Liu and Mukhopadhyay, 2015). However, the effect of preventing leaching from the samples to the soak solution was more pronounced than the effect of the ion migration from the host solution to the inside of the specimens (Liu and Mukhopadhyay, 2015).

\subsubsection{Field Exposure versus Laboratory Conditions}

Testing concrete blocks under environmental conditions is essential to validate the results obtained in controlled laboratory conditions. It captures the fluctuations that happen in the field that might affect expansion. Fournier et al. (2008) found that expansion of concrete blocks could be about 4 to 5 times faster under warmer conditions. Those observations were obtained for control samples without SCM. In addition, the difference in expansion between the two sites, one in Texas and the other in Ottawa, increases with decrease in aggregate reactivity. For instance, with Sudbury, a moderately reactive aggregate, the difference was around $750 \%$ after 3 years while it was only $226 \%$ and $53 \%$ for Spratt, highly reactive coarse and Jobe, highly reactive fine aggregates, respectively (Fournier et al., 2008). Field testing is the most reliable method to measure long-term expansion however, the testing takes much longer than under accelerated laboratory conditions. The concrete prism test is known to be the most reliable lab test to evaluate reactivity of aggregates and effectiveness of SCM. However, at 15 years, some prisms that passed the CPT in the laboratory showed deleterious results in large blocks under field exposure (Ideker et al., 2012; Fournier et al., 2018). Hence, the need of enhanced test methods to correlate better with the field and to better predict the level of SCM needed to reduce expansion in the field. 


\subsection{Preventive Measures}

To prevent ASR, one of the three major components of the reaction should be eliminated:

Avoid the use of reactive aggregates,

$>$ Control the alkali content of the cement,

$>$ Prevent water to reach the concrete.

Other methods used to reduce the ASR expansion are:

Use of supplementary cementing materials,

$>$ Use of lithium-based compounds.

The mostly used method is the addition of SCM in concrete. SCM are pozzolans such as fly ash (FA), silica fume (SF) and ground-granulated blast furnace slag. Their aim is to reduce the alkalis inside the pore solution of the concrete. As shown in Table 2.3, depending on the chemical composition of the pozzolan, a specific replacement level is specified in CSA A23.2-27A (2014) to prevent expansion based on prevention level required. The prevention level depends on the risk level of ASR and the acceptability of ASR as per the standard.

Table 2.3: Minimum levels of SCM required to prevent ASR expansion (CSA A23.2-27A, 2014)

\begin{tabular}{|c|c|c|c|c|c|c|}
\hline \multirow[b]{2}{*}{ Type of SCM } & \multirow{2}{*}{$\begin{array}{l}\text { Total alkali } \\
\text { content of } \\
\text { SCM \% } \mathrm{Na}_{2} \mathrm{O} \\
\text { equivalent* }\end{array}$} & \multirow{2}{*}{$\begin{array}{l}\text { Chemical } \\
\text { composition } \\
\text { requirement } \\
\text { (\% oxides) }\end{array}$} & \multicolumn{4}{|c|}{$\begin{array}{l}\text { Minimum level of SCMs ( } \% \text { by mass of total } \\
\text { cementitious materials) } \dagger\end{array}$} \\
\hline & & & $\begin{array}{l}\text { Prevention } \\
\text { level } \mathrm{W}\end{array}$ & $\begin{array}{l}\text { Prevention } \\
\text { level X }\end{array}$ & $\begin{array}{l}\text { Prevention } \\
\text { level Y }\end{array}$ & $\begin{array}{l}\text { Prevention } \\
\text { level } \mathrm{Z}\end{array}$ \\
\hline \multirow[t]{7}{*}{ Fly ash } & $<3.0$ & $\mathrm{CaO}<8 \%$ & 15 & 20 & 25 & 35 \\
\hline & & $\mathrm{CaO}=8 \%-20 \%$ & 20 & 25 & 30 & 40 \\
\hline & & $\mathrm{CaO}>20 \%$ & $\ddagger$ & $\ddagger$ & $\ddagger$ & $\ddagger$ \\
\hline & $3.0-4.5$ & $\mathrm{CaO}<8 \%$ & 20 & 25 & 30 & 40 \\
\hline & & $\mathrm{CaO}=8 \%-20 \%$ & 25 & 30 & 35 & 45 \\
\hline & & $\mathrm{CaO}>20 \%$ & $\ddagger$ & $\ddagger$ & $\ddagger$ & $\ddagger$ \\
\hline & $>4.5$ & $\ddagger$ & $\ddagger$ & $\ddagger$ & $\ddagger$ & $\ddagger$ \\
\hline $\begin{array}{l}\text { Blast-furnace } \\
\text { slag }\end{array}$ & $<1.0 \ddagger$ & None & 25 & 35 & 50 & 60 \\
\hline Silica fume & $<1.0 \ddagger$ & None & $\begin{array}{l}2.0 \times \\
\text { alkali content }\end{array}$ & $\begin{array}{l}2.5 \times \\
\text { alkali content }\end{array}$ & $\begin{array}{l}3.0 \mathrm{x} \\
\text { alkali content }\end{array}$ & $\doteqdot$ \\
\hline
\end{tabular}


Many theories are being developed to explain the effect of SCM in preventing the expansion due to ASR. Although there is still some disagreement on the nature of the reaction, some of these proposed theories are:

a) The presence of SCM acts like a diluent for the Portland cement. The hydration of the cement will result in the formation of $\mathrm{Ca}(\mathrm{OH})_{2}$. When using a percent replacement of SCM, the amount of Portland cement will be lower, thus the $\mathrm{Ca}(\mathrm{OH})_{2}$ formed will be less than the original amount. Less alkalis will be present in the pore solution for the silica to react with (Swamy, 1992; Lindgård et al., 2012).

b) SCM are fine materials which will lower the permeability of the concrete thus making the migration of the alkalis towards the reactive silica more difficult (Swamy, 1992; Lindgård et al., 2012).

c) The alkali binding capacity of SCM is higher than that of the silica in the aggregate. This means that the silica in the SCM might react faster with the alkalis compared to the aggregate's silica. The hydration products of blended cement systems differ significantly from those of PC systems. The silica present in the pozzolan will react with the calcium hydroxide formed from the hydration of the calcium silicates through the following reaction:

$$
\mathrm{Ca}(\mathrm{OH})_{2}+\mathrm{S}+\mathrm{H} \longrightarrow \mathrm{C}-\mathrm{S}-\mathrm{H}
$$

As a consequence, they have a higher binding power for alkalis compared to siliceous aggregates. The removal of alkalis from the pore solution into cement solids will result in less immediate potential for reaction with aggregates (Swamy, 1992).

\subsubsection{Effect of SCM Composition on ASR}

Different types of SCM affect expansion differently depending on their chemical compositions. SCM that have low calcium to silica ratio tend to be more efficient in controlling the expansion and are required in lower levels of replacement compared to SCM that have high calcium content, as shown in Figure 2.19. Class $\mathrm{C}$ fly ash, with $\mathrm{CaO}>10 \%$, is high in calcium content which explains the high replacement level needed as compared to class F fly ash. Also, the higher the alkali content of the SCM, the higher replacement level needed to minimize the reaction. Figure 2.19 explains the effect of the replacement level on expansion for different types of SCM using Spratt, a highly reactive aggregate. For fly ash class $\mathrm{C}$, a $50 \%$ replacement level was needed to reduce the 
expansion below the acceptable level of $0.040 \%$ as compared to only $20 \%$ for low calcium fly ash. For the silica fume and metakaolin, a very low replacement level of around 10-15\% was sufficient to reduce the expansion significantly due to the high silica content.

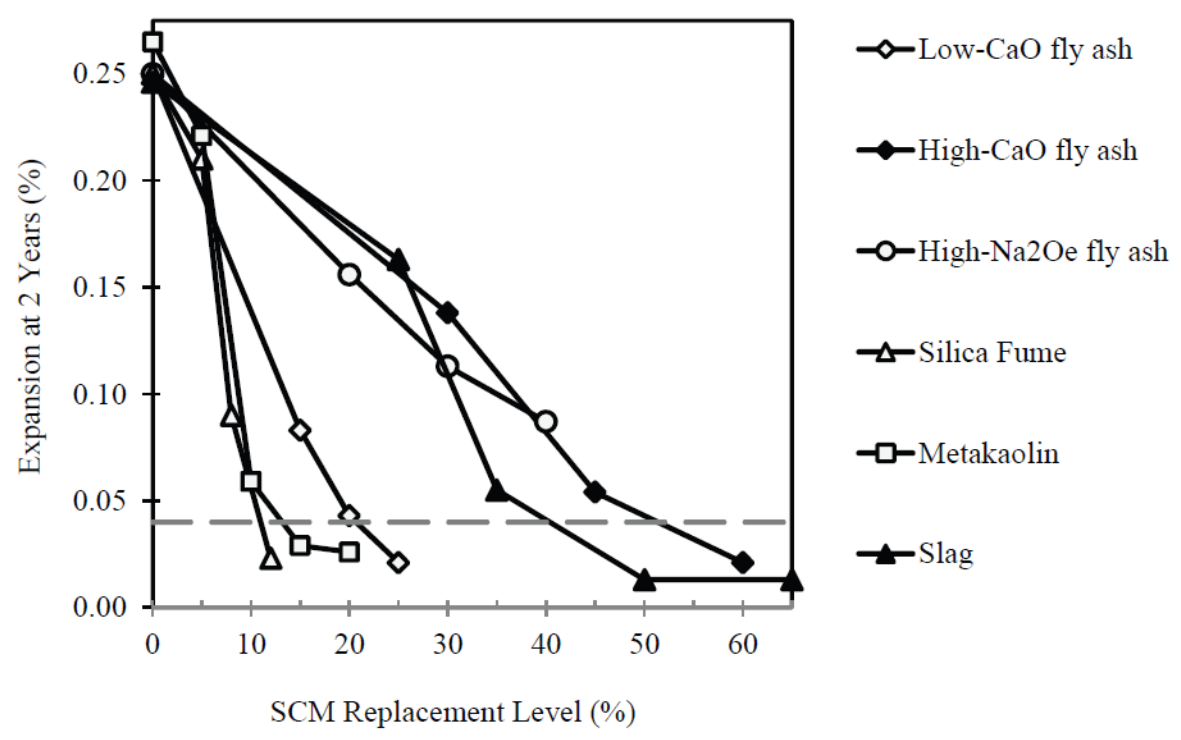

Figure 2.19: Effect of SCM replacement level on the 2-year expansion of prisms cast with Spratt (Thomas, 2011)

This could be explained by the fact that the lower the $\mathrm{Ca} / \mathrm{Si}$ ratio is in the cementing materials, the less the positively charge surface leading to more binding of the alkalis (Shehata and Thomas, 2006). The choice of supplementary materials and their percent replacement is very sensitive and need to be determined carefully. In conclusion, a higher percent replacement is needed with:

$>$ Increase in aggregate reactivity,

$>$ Increase in calcium and alkali content of the SCM,

$>$ Decrease in silica content.

Shehata and Thomas (2006) found that low calcium FA has a higher ability to retain alkalis compared to pastes and samples with SF or high calcium FA when soaked in a solution of 0.25 and $0.4 \mathrm{OH}^{-} \mathrm{mol} / \mathrm{L}$. Ternary blends were found more effective in lowering the pore solution alkalinity of pastes compared to only FA or SF. Using $10 \%$ SF did not show better performance compared to 5\% SF except in the case of ternary blend with high calcium FA (Shehata and Thomas, 2006). In the case of $10 \% \mathrm{SF}$, Thomas (2011) found that the $\mathrm{OH}^{-}$concentration drops rapidly over the first 28 days but then starts to increase slowly with time beyond 3 months. This was not the 
case with ternary blends. This could be due to the fact that when adding SCM other than SF, the presence of alumina in the SCM possibly contributes to the prevention of the release of alkalis back in the pore solution. The presence of alumina forms calcium-aluminosilicate-hydrate (C-A$\mathrm{S}-\mathrm{H}$ ) which increases the alkali binding capacity and hence explains the beneficial effect of the aluminous SCM in reducing the pore solution alkalinity (Thomas, 2011).

Reactive aggregates respond differently to the alkali content of the cement and the use of SCM. Expansion of concrete cast with Spratt, a highly reactive aggregate, increases with higher PC alkali content until a specific alkali level beyond which no significant increase in expansion is observed as was shown in Figure 2.14. The alkali content of high calcium or high alkali fly ashes increases the pore solution alkalinity; however, Spratt is not affected by the increase in pore solution alkalinity. At high levels of alkali content, reduced ion diffusivity or reduction in $\mathrm{Ca}(\mathrm{OH})_{2}$ help explaining the reduction in expansion (Shehata and Thomas, 2010). For Jobe aggregate, the concrete prisms expansion increases with the increase in alkalinity of the cement. Unlike Spratt beyond certain alkali level, pore solution alkalinity has the major effect on expansion of concrete cast with Jobe sand. This is why the high alkali FA showed higher expansion in samples cast with Jobe aggregate compared to control Jobe samples cast without SCM (Shehata and Thomas, 2010). In addition, higher expansion was obtained in samples cast with Jobe and low level of Class C FA compared to the control especially with low alkali cement. It is believed that this is due to the additional water-soluble alkalis added to the system from the fly ash which will be consumed rapidly by the Jobe sand before they were consumed by the hydration products of the cementing materials (Shehata and Thomas, 2010). Gilbert (2007) showed that a ternary blend of 30\% CH FA and $20 \%$ slag was needed to keep the expansion of the Jobe sand below the $0.10 \%$ expansion limit using the AMBT (Gilbert, 2007).

The alkali content of the PC has a secondary effect on the pore solution alkalinity compared to the fly ash composition (Shehata and Thomas, 2010). Shehata and Thomas found a strong correlation between the chemical composition of the cementing materials: $\left(\mathrm{Na}_{2} \mathrm{O}_{\mathrm{e}} \mathrm{XCaO}\right) /\left(\mathrm{SiO}_{2}\right)^{2}$ and the pore solution alkalinity of paste $\left[\mathrm{OH}^{-}\right]$at 90 days. Changing the alkalinity of the cement will not affect the parameter as much as the change in the SCM type as shown in Table 2.4. 
Table 2.4: Effect of fly ash composition on $\left(\mathrm{Na}_{2} \mathrm{O}_{\mathrm{e}} \mathrm{XCaO}\right) /\left(\mathrm{SiO}_{2}\right)^{2}$ (Shehata and Thomas, 2010)

\begin{tabular}{ccc}
\hline \multirow{2}{*}{ Fly ash } & \multicolumn{2}{c}{$\left(\mathrm{Na}_{2} \mathrm{O}_{\mathbf{e}} \times \mathrm{CaO}\right) /\left(\mathrm{SiO}_{2}\right)^{\mathbf{2}}$} \\
\cline { 2 - 3 } & PC of 0.60 wt.\% Na2Oe & PC of 0.94 wt.\% $\mathrm{Na}_{2} \mathrm{O}_{\mathbf{e}}$ \\
\hline \hline FA \# 1 F-LA & 0.06 & 0.07 \\
FA \# 71 CH-LA & 0.09 & 0.11 \\
FA \# 82 CH-HA & 0.16 & 0.18 \\
\hline
\end{tabular}

Many researchers found a correlation between the pore solution alkalinity of pastes and the chemical compositions of the cementing materials. Shehata (2001) studied the chemical composition effect of 18 different $\mathrm{FA}$ types on the $\mathrm{OH}^{-}$concentration of pastes at 2 years as shown in Figure 2.20.

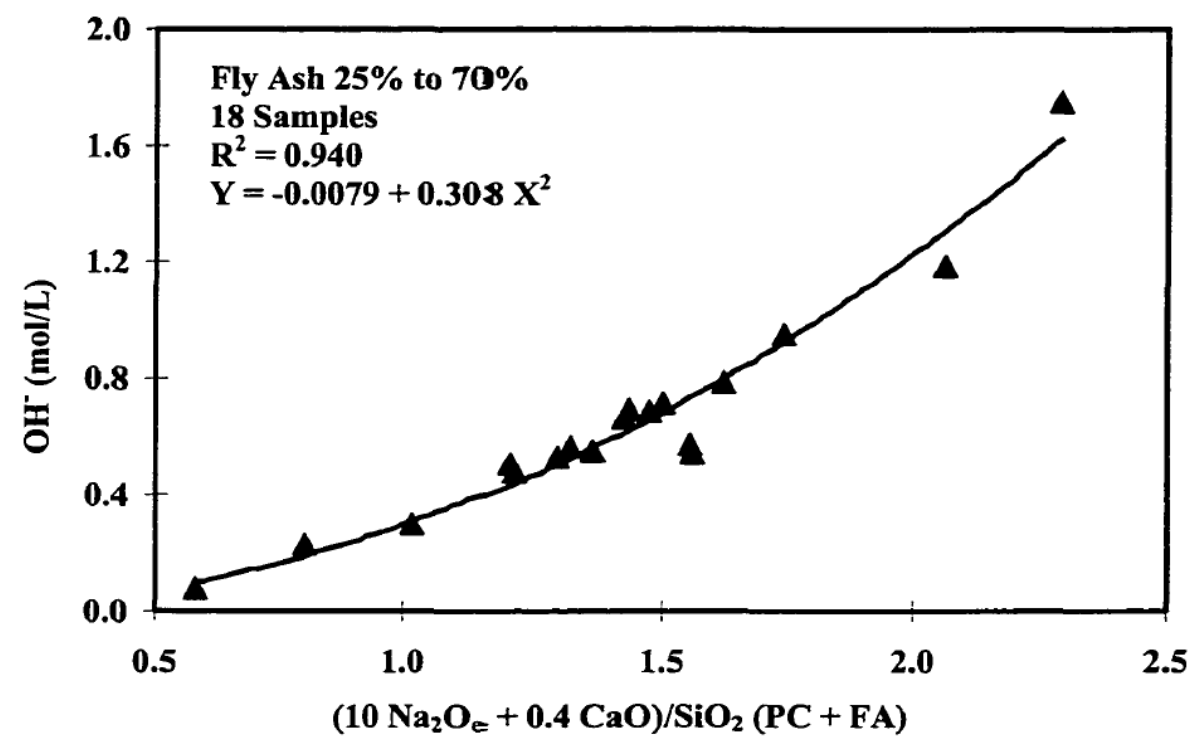

Figure 2.20: Effect of binder (PC+FA) chemical compositions on pore solution alkalinity of pastes at 2 years (Shehata, 2001)

Similar relationship for samples with SF and ternary blends of SF and FA was obtained (Shehata, 2001). Shehata (2001) combined the results from the study of FA, SF and ternary blends (SF+FA) and found good relationship correlating the chemical composition of the SCM and pore solution alkalinity as shown in the following equation:

$$
\left[\mathrm{OH}^{-}\right](\mathrm{mol} / \mathrm{L})=0.046+0.338\left[\left(10 \mathrm{Na}_{2} \mathrm{O}_{\mathrm{e}}+0.34 \mathrm{CaO}\right) / \mathrm{SiO}_{2}\right]^{2}
$$


Figure 2.21 summarizes the obtained relationship between pore solution alkalinity and chemical compositions of SCM (FA and/or SF).

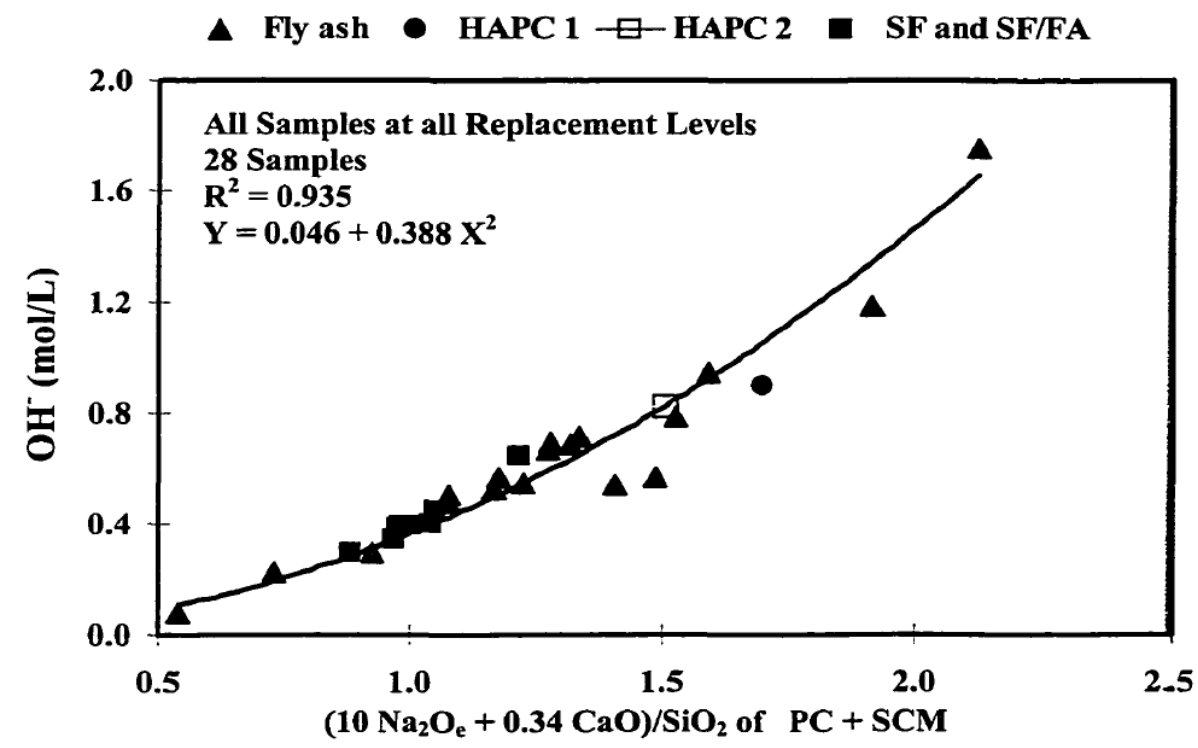

Figure 2.21: Effect of binder (PC+FA and/or SF) chemical composition on pore solution alkalinity of pastes at 2 years (Shehata, 2001)

In another study done by Shehata and Thomas (2010), a linear correlation was obtained between $\left(10 \mathrm{Na}_{2} \mathrm{O}_{\mathrm{e}}+0.34 \mathrm{CaO}\right) / \mathrm{SiO}_{2}$ and pore solution alkalinity at 90 days for FA, SF and ternary blends $(\mathrm{FA}+\mathrm{SF})$ as shown in Figure 2.22.

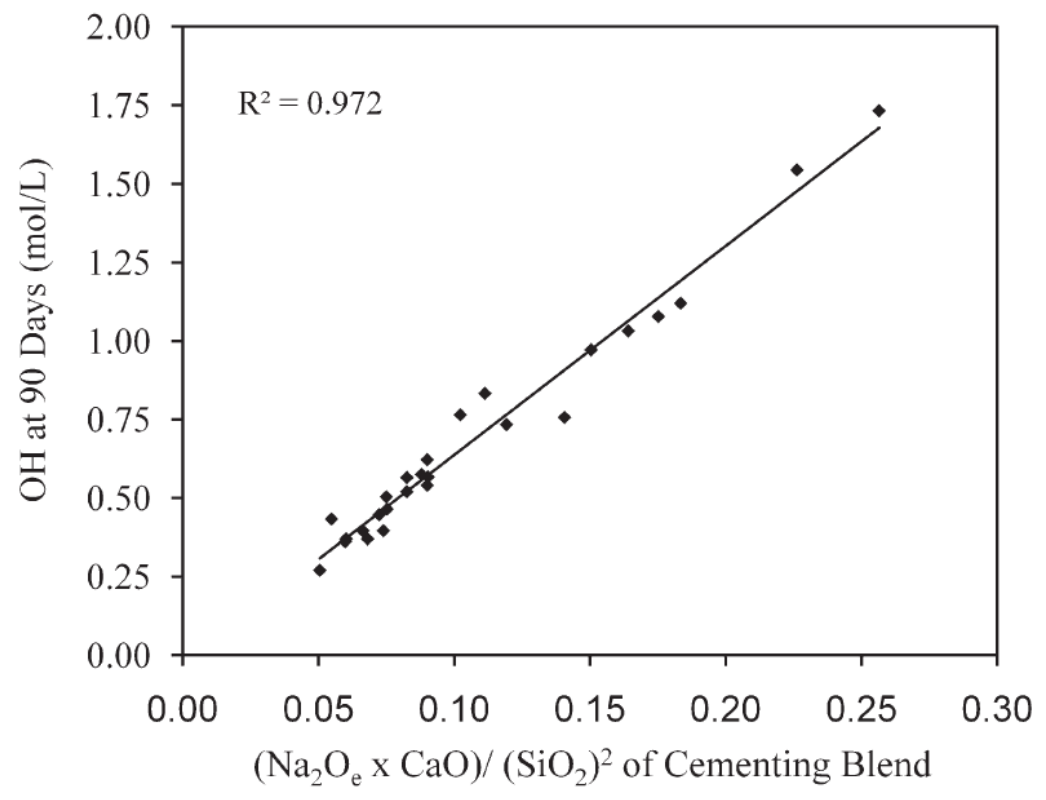

Figure 2.22: Effect of binder (PC+FA and/or SF) chemical composition on pore solution alkalinity of pastes at 2 years (Shehata and Thomas, 2010) 
Similarly, Bleszynski (2002) used the same parameter $\left(10 \mathrm{Na}_{2} \mathrm{O}_{\mathrm{e}}+0.34 \mathrm{CaO}\right) / \mathrm{SiO}_{2}$ and applied it to samples with slag, SF and ternary blends (SF + slag). Bleszynski (2002) found good correlation $(\mathrm{R} 2=0.98)$ as shown in Figure 2.23 using the following equation:

$$
\left[\mathrm{OH}^{-}\right](\mathrm{mM} / \mathrm{L})=754 \times\left(10 \mathrm{Na}_{2} \mathrm{O}_{\mathrm{e}}+0.34 \mathrm{CaO}\right) / \mathrm{SiO}_{2}-407
$$

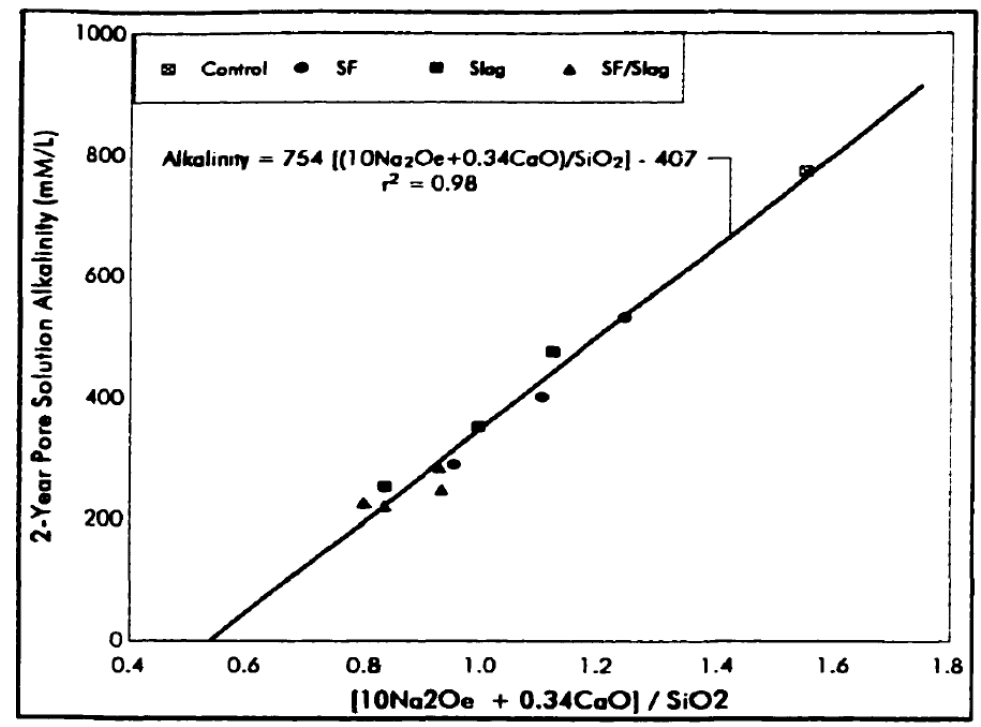

Figure 2.23: Effect of binder (PC + slag and/or SF) chemical composition on pore solution alkalinity of pastes at 2 years (Bleszynski, 2002)

Thomas (2011) came up with a correlation between the $\mathrm{OH}^{-}$of paste samples at 2 years and the chemical composition of cementing materials using all the different SCM obtained from the literature as shown in Figure 2.24.

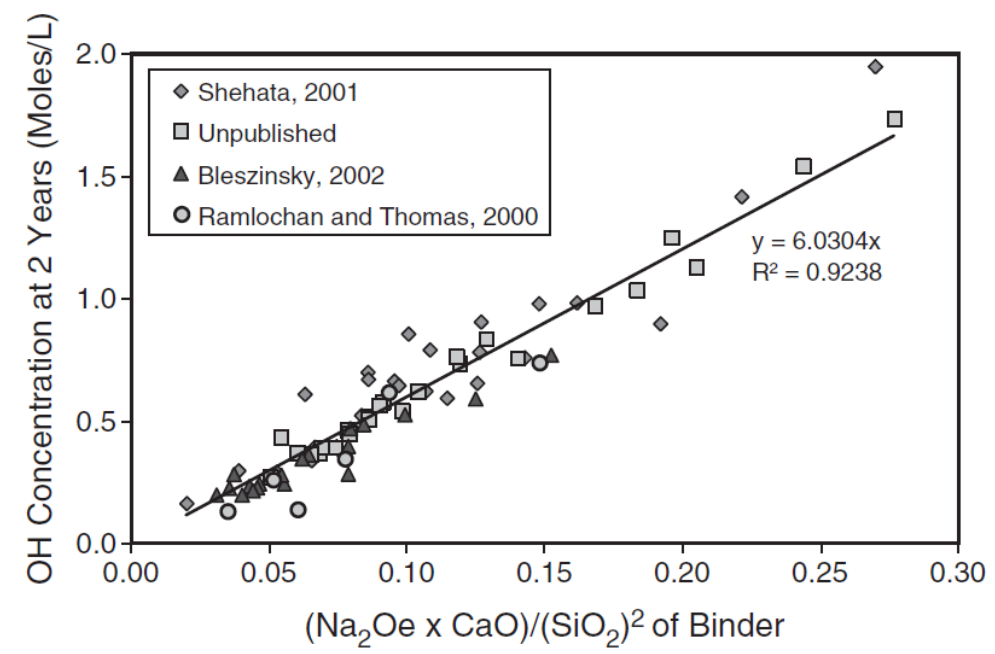

Figure 2.24: Effect of binder chemical composition on pore solution alkalinity of pastes at 2 years (Thomas, 2011) 


\subsubsection{SCM Degree of Hydration}

Pane and Hansen (2005) proposed a way to determine the degree of hydration of blended cement by obtaining the chemically bound water (CBW) value. The degree of hydration at any time is represented by the following equation:

$$
\alpha(t)=\frac{w_{\mathrm{b}}(t)}{w_{\mathrm{b}, \infty}\left(T \approx 0.5^{\circ} \mathrm{C}\right)}
$$

To obtain the ultimate degree of hydration, Pane and Hansen (2005) found that the lower the temperature the higher the ultimate chemically bound water. The ultimate value at each temperature was obtained based on the formula derived from fitting the different points in the curve as shown in the equation below:

$$
\alpha=\alpha_{\infty} \exp \left[-\left(\frac{\tau}{t}\right)^{a}\right]
$$

Where $\alpha$ can be the heat of hydration, the degree of hydration or the chemically bound water and $\alpha_{\infty}$ corresponds to the corresponding ultimate value. $\tau$ and a control the intercept and the curvature of the plot in the logarithmic scale. The ultimate chemically bound water was obtained by extrapolating the curve of chemically bound water vs temperature. The lowest temperature used was $0.5^{\circ} \mathrm{C}$.

With lower water/cement ratio, the heat of hydration is lower. This is because with lower w/c ratio, there is less space for the hydration products to grow hence retarding the hydration process. Also, at higher temperatures, there is more production of heat at the beginning. However, it was found that it does not necessarily lead to higher ultimate heat of hydration. For samples with FA, the heat of hydration was lower than that of the cement paste at $w / c=0.35$. In contrary, slag and silica fume samples seemed to generate higher ultimate heat (Pane and Hansen, 2005).

\subsubsection{Degree of Pozzolanic Reaction}

The degree of SCM pozzolanic reaction can be measured based on the consumption of $\mathrm{Ca}(\mathrm{OH})_{2}$. The calcium silicate hydrates formed due to the pozzolanic reaction do not show any sign of expansion compared to the silica gel formed due to ASR expansion. This could be explained by the fact that the pozzolans are very fine materials which will distribute the C-S-H throughout the cement paste compared to the accumulation of large deposits of alkali-silica gel in discrete locations where the reactive silica aggregates are present around the weak interfacial transition 
zones (Thomas, 2011; FHWA, 2012). However, the binding capacity of the different pozzolans is still not clearly understood at later ages.

Pane and Hansen (2005) plotted the $\mathrm{CH}\left(\mathrm{Ca}(\mathrm{OH})_{2}\right)$ consumption versus $\mathrm{w}_{\mathrm{b}}$ (per $\mathrm{g}$ of $\left.\mathrm{OPC}\right)$ and showed that they follow a unique trend at any temperature. As for the OPC system alone, the data was fitted in a line suggesting that the hydration products formation is proportional to $\mathrm{w}_{\mathrm{b}}$. In order to estimate the degree of pozzolanic reaction, a reference plot of OPC only was needed to compare to the different systems. $\mathrm{CH}$ loss vs $\mathrm{w}_{\mathrm{b}}$ were plotted for the different systems relative to $\mathrm{CH}$ loss vs $\mathrm{w}_{\mathrm{b}}$ plot for OPC and the following equation was suggested to obtain the degree of SCM hydration:

$$
\alpha_{\mathrm{p}}=\frac{\mathrm{CH}_{\text {loss }}^{\mathrm{OPC}}\left(w_{\mathrm{b}}\right)-\mathrm{CH}_{\text {loss }}\left(w_{\mathrm{b}}\right)}{\mathrm{CH}_{\text {loss }}^{\mathrm{OPC}}\left(w_{\mathrm{b}, \infty}\right)-\mathrm{CH}_{\text {loss }}\left(w_{\mathrm{b}, \infty}\right)}
$$

The degree of pozzolanic reaction can be obtained at any time.

$$
\alpha_{\mathrm{p}}(t)=\frac{\Delta \mathrm{CH}_{\text {loss }}\left(w_{\mathrm{b}}(t)\right)}{\Delta \mathrm{CH}_{\text {loss }}\left(w_{\mathrm{b}, \infty}\right)}
$$

Time can be obtained from equation (7) used to get the chemically bound water:

$$
t=\tau\left[\ln \left(\frac{w_{\mathrm{b}, \infty}}{w_{\mathrm{b}}}\right)\right]^{-1 / \alpha}
$$

It was found that the silica fume reacts faster followed by slag and then FA. Many studies have been made to calculate the $\mathrm{Ca}(\mathrm{OH})_{2}$ consumption by SCM. However, there is no agreement on a method to determine the $\mathrm{Ca}(\mathrm{OH})_{2}$ reduction quantitatively. Although thermogravimetric analysis (TGA) is been widely used as a method to determine the $\mathrm{Ca}(\mathrm{OH})_{2}$ content of cementing materials, but the method of interpretation is not similar among researchers. Majors peak changes can be obtained from the weight-loss curve of the TGA as follows: (1) decomposition of $\mathrm{Ca}(\mathrm{OH})_{2}$ near $450^{\circ} \mathrm{C}$, (2) decomposition of calcium carbonate between $700^{\circ} \mathrm{C}$ and $800^{\circ} \mathrm{C}$, if any, and (3) a continuous loss between $105^{\circ} \mathrm{C}$ to $1000^{\circ} \mathrm{C}$ with major weight loss before $500^{\circ} \mathrm{C}$ corresponding to the dehydration of calcium silica hydrates, calcium aluminate hydrates and other minor hydrates (Marsh and Day, 1988). The weight loss before $105^{\circ} \mathrm{C}$ corresponds to the evaporable water (physically bound or free water). Pane and Hansen (2005) showed that chemically bound water started at $140^{\circ} \mathrm{C}$ instead of $105^{\circ} \mathrm{C}$ since distilled water started to boil at $100^{\circ} \mathrm{C}$ and evaporated completely at around $140^{\circ} \mathrm{C}$. To determine the $\mathrm{Ca}(\mathrm{OH})_{2}$ in the samples, Marsh and Day (1988) used the method shown in Figure 2.25. Similar method was used by Shehata (2001). 


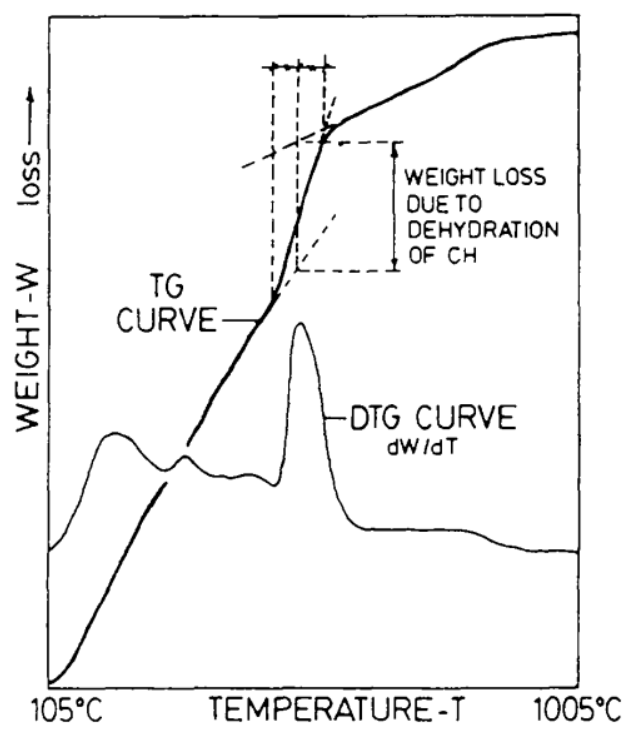

Figure 2.25: Method used to obtain $\mathrm{Ca}(\mathrm{OH})_{2}$ content using TGA (Marsh and Day, 1988)

A modified version was developed by Kim and Olek (2012) to include the carbonation that could occur as shown in Figure 2.26.

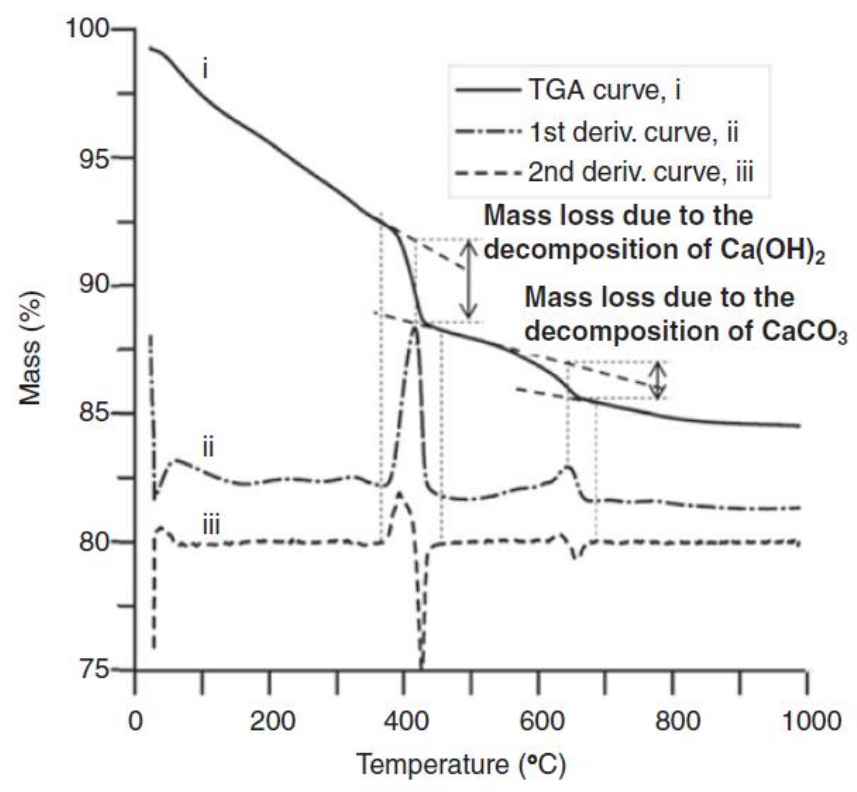

Figure 2.26: Modified TGA Analysis to determine $\mathrm{Ca}(\mathrm{OH})_{2}$ content (Kim and Olek, 2012)

Although Kim and Olek (2012) showed that obtaining the mass loss between fixed temperatures without using the tangential method will be overestimating the results due to the decomposition of other hydrates that are believed to decompose linearly over time, however many researchers used 
the mass loss between two fixed temperatures. Pane and Hansen (2005) used the mass loss between $440^{\circ} \mathrm{C}$ and $520^{\circ} \mathrm{C}$.

The weight loss corrected for chemically bound water was shown to be negligible (Pane and Hansen, 2005). Similarly, the amount of $\mathrm{Ca}(\mathrm{OH})_{2}$ was not corrected for carbonation since it was found that the uncorrected values are more reliable (Pane and Hansen, 2005). The decomposition of the $\mathrm{Ca}(\mathrm{OH})_{2}$ is in a range of $350^{\circ} \mathrm{C}$ and $550^{\circ} \mathrm{C}$ as explained by Kim and Olek (2012). The selection of the start and end point of the $\mathrm{Ca}(\mathrm{OH})_{2}$ is critical since the range could be affected by many factors such as the fineness and mass of the sample. Hence, using a fixed range might not be very accurate method to measure the $\mathrm{Ca}(\mathrm{OH})_{2}$ content (Kim and Olek, 2012). The $\mathrm{CaCO}_{3}$ content was shown to be hard to calculate accurately since structural $\mathrm{OH}^{-}$groups from the calcium silicate hydrates also contribute to the measured mass in the same interval (Gabrovšek, Vuk and Kaučič, 2006). There is no agreement on a method for determination of the $\mathrm{Ca}(\mathrm{OH})_{2}$ content.

\subsubsection{Effect of Temperature on Hydration of Cementing Materials}

In addition to their increased fineness, SCM will react faster at higher temperatures (Lindgård et $a l ., 2012$ ). From the other side, at high temperatures, the pore structure might be altered and the capillary porosity decreases hindering the transport of alkalis to the reaction sites. Hence, the pozzolanic reaction as well as the ASR might not be accelerated at the same rate (Lindgård et al., 2012).

The rate of cement hydration increases with increasing temperature. This is more revealed at early ages. The hydration products are the same at temperatures below $50^{\circ} \mathrm{C}$. At higher temperatures, the paste has higher porosity and coarser pore structure leading to lower strength at later ages. When using fly ash, the $\mathrm{Ca} / \mathrm{Si}$ ratio of the hydration products increases with temperature resulting in a decrease of the alkali sorption capacity (Lindgård et al., 2012). By contrast, more hydration products were formed at temperatures between $40^{\circ} \mathrm{C}$ and $60^{\circ} \mathrm{C}$ compared to $8^{\circ} \mathrm{C}$ and $20^{\circ} \mathrm{C}$ in case of fly ash. Hence, more alkali binding will occur. This opposite trend can indicate that there is an optimum temperature which will give the highest binding capacity of FA. For slag, higher temperatures may lead to higher degree of condensation of the silicate anions in the C-S-H, thus lower $\mathrm{Ca} / \mathrm{Si}$ ratio and higher absorption of alkalis. 
Other studies showed that the higher the curing temperature of the cement paste, the lower its ultimate hydration, the higher its long-term porosity and the denser their hydration products hence decreasing further hydration (Wang et al., 2012). The non-evaporable water content at 720 days was found to be lower at $65^{\circ} \mathrm{C}$ compared to the samples at $20^{\circ} \mathrm{C}$. Wang et al. (2012) explained that this could be due to the formation of dense hydrated phases around the unreacted cement particles, preventing further hydration. At early ages, there will be formation of non-uniform distribution of the hydration products. This was also observed from the $\mathrm{Ca}(\mathrm{OH})_{2}$ consumption where at early ages it was higher at higher temperature. However, at 720 days the $\mathrm{Ca}(\mathrm{OH})_{2}$ at $20^{\circ} \mathrm{C}$ was higher than that at $65^{\circ} \mathrm{C}$ showing that higher temperature promotes early hydration however hinders late hydration. 


\subsection{Residual Expansion of Structures Affected by ASR}

Residual expansion of structures affected by ASR vary from one site to the other depending on the environmental conditions. The surface cracking can underestimate the real expansion attained due to the lower alkali concentration at the surface caused by leaching and carbonation. Wetting and drying cycles for example can contribute to less favorable ASR expansion due to the reduction in humidity during the drying seasons and leaching during the wetting cycles. Freezing and thawing can favor the expansion due to ASR. Saline solutions can reduce the $\mathrm{pH}$ at the surface as for deicing salts they might favor expansion due to ASR (Heisig et al., 2016). All of these conditions could lead to an expansion gradient between the surface of the structures and the cores and to the observed cracks on the concrete skin (Smaoui et al., 2005). Hence, it is important to find reliable ways to predict residual expansion of structures affected by ASR to assess their remaining life.

\subsubsection{Predicting Remaining Life of Concrete Structures Under Field Exposure}

Many studies have been carried out in an attempt to predict the residual expansion of structures affected by ASR by measuring crack width (Leemann and Merz, 2012; Merz and Leemann, 2012; Nomura et al., 2012), thin sections observations (Nomura et al., 2012) and stiffness damage test (Smaoui et al., 2005). Many researchers obtained cores from the field and tested them in the lab. Cores were taken from several structures with different deterioration levels from weakly damaged areas to strongly affected structures and stored in the lab at $38^{\circ} \mathrm{C}$ (Merz and Leemann, 2012). The ultimate expansion of laboratory samples cannot be used to determine the residual expansion in the field due to the alkali leaching occurring during the test (Merz and Leemann, 2012). The expansion rate of cores obtained from more damaged structures was shown to be higher than less deteriorated cores but both showed minimal expansion compared to the field. However, the cores expansion in the lab depends greatly on the extent of the reaction development and the available alkalis in the structures (Merz and Leemann, 2012).

Many attempts have been made to predict the residual expansion in the field. Concrete prisms at $60^{\circ} \mathrm{C}$, reproduced from the same mix used for the field structures, were assumed to be reactive if they show an expansion above $0.02 \%$ at 20 weeks (Leeman and Merz 2012). Another study by Nomura et al. (2012) on cores obtained from structures with different deterioration levels and soaked in $1 \mathrm{M} \mathrm{NaOH}$ solution at $80^{\circ} \mathrm{C}$ was investigated. These cores are expected to show deleterious expansion in the field when an expansion higher than $0.1 \%$ at 21 days is obtained 
(Nomura et al., 2012). The cores expansion showed recession in the case of highly deteriorated structures when tested 10 years after as opposed to less damaged structures which its cores showed almost same expansion after 10 years (Nomura et al., 2012). However, regular inspection of the damaged structures should be done despite the information obtained from the cores. Nomura et al. (2012) attempted to predict residual expansion of structures based on the results from the cores soaked in alkaline solution at $80^{\circ} \mathrm{C}$. When the cores tested showed lower expansion than 10 years earlier, it is predicted that residual expansion recess. When the expansion in the cores remained the same after 10 years, it was expected that the field expansions continue to increase. For cores with an expansion below $0.1 \%$ at 21 days, there is no expansion which was confirmed by the field results however, the thin section observations predicted that the ASR expansion will progress.

Soaking samples in $\mathrm{NaOH}$ was found to produce lower expansion than samples soaked in $\mathrm{NaCl}$ of same normality as shown in Figure 2.27. Chatterji, Thaulow and Jensen (1987) explained that soaking samples in chloride solutions will form Friedel's salt by reacting with the calcium hydroxide. The higher expansion in the $\mathrm{NaCl}$ solution will indicate that the alkali salts will take part directly in the ASR reaction and not only through conversion to hydroxide (Chatterji, Thaulow and Jensen, 1987).

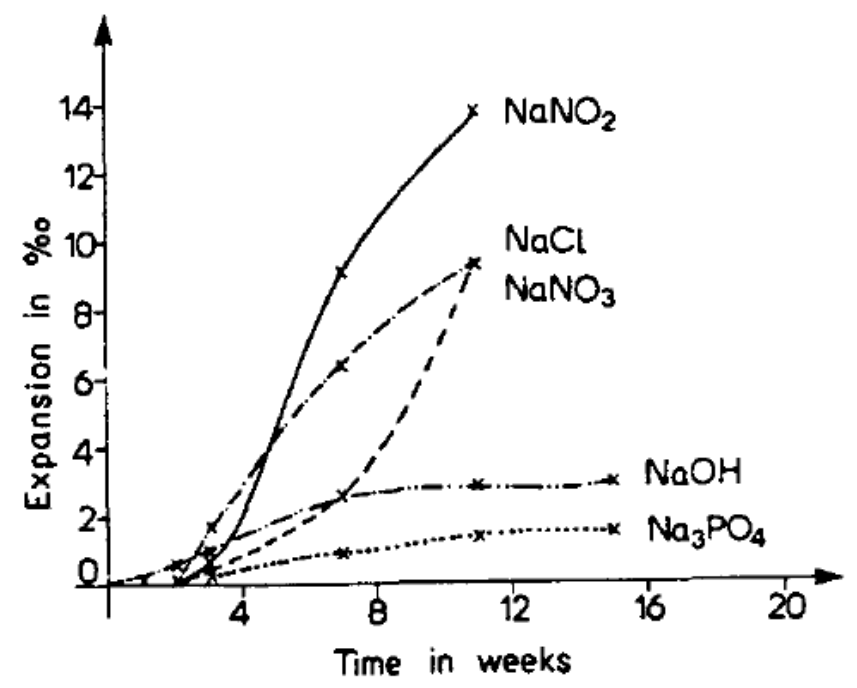

Figure 2.27: Expansions of mortar bars soaked in $3 \mathrm{~N}$ sodium salts (Chatterji, Thaulow and Jensen, 1987)

For the first few months, the samples soaked in $\mathrm{NaOH}$ solutions showed higher expansion as shown in Figure 2.28. This is due to the delay caused due to the replacement of $\mathrm{Cl}^{-}$ions by $\mathrm{OH}^{-}$ from the Portlandite (Bérubé and Frenette, 1994). However, after 6 months, the samples soaked in 
$\mathrm{NaCl}$ solution of same molarity showed higher expansion and even kept expanding at a high rate after 1 year although they have the same amount of alkalis (Bérubé and Frenette, 1994). Bérubé and Frenette (1994) explained that $1 \mathrm{M} \mathrm{NaCl}$ solution could show two expansive mechanisms in the presence of reactive aggregate leading to the formation of the chloroaluminate in addition to the ASR expansive gel. When soaked in salt solution, $\mathrm{NaCl}$ will be converted to $\mathrm{NaOH}$ promoting the alkali-silica reaction in presence of reactive aggregates (Bérubé and Frenette, 1994).

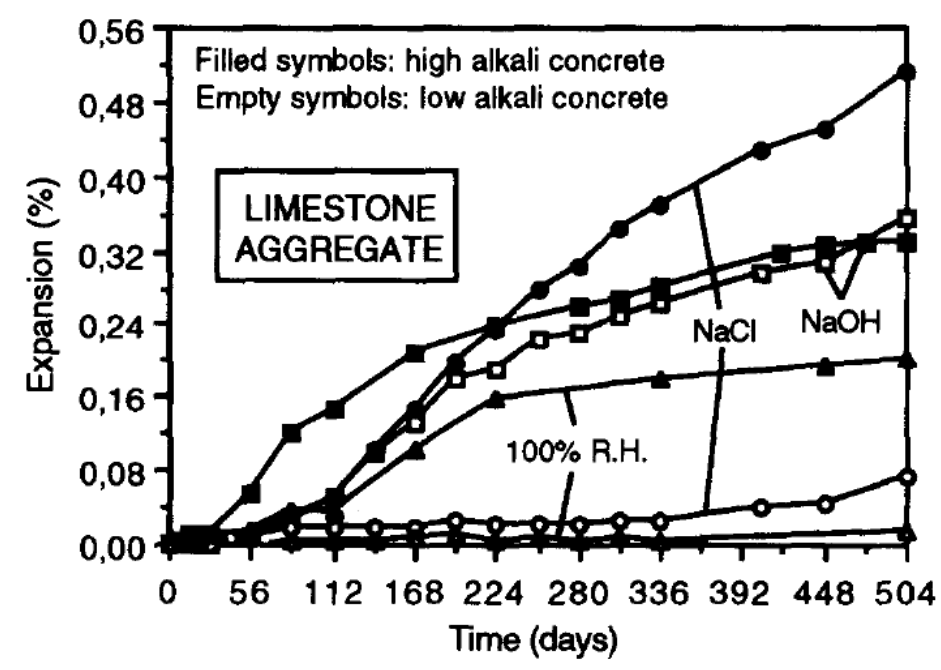

Figure 2.28: Expansion of prisms soaked in $1 \mathrm{M}$ alkali solutions (Bérubé and Frenette, 1994)

In addition, samples cast with low alkali cement and soaked in either $1 \mathrm{M} \mathrm{NaCl}$ or $1 \mathrm{M} \mathrm{NaOH}$ did not show any expansion as shown in Figure 2.28. It is believed that the hydroxide concentration in the concrete pore solution of low alkali cement will take time to build up leading to the assumption that structures with low alkali cement will not show expansion for a long duration even if they were exposed to deicing salt and sea water (Bérubé and Frenette, 1994). On contrary, Heisig et al. (2016) showed that concrete prisms cast with low alkali cement showed expansion when soaked in $20 \% \mathrm{NaCl}$ solution concluding that structures cast with low alkali cement can lead to ASR damage in the field if exposed to $\mathrm{NaCl}$ solutions. They believed that the concentration of $\mathrm{Si}^{2+}$ ions is increased when soaked in $\mathrm{NaCl}$ solutions due to the attraction of the $\mathrm{Na}^{+}$ions and their solvation shells towards the surface of the $\mathrm{Si}^{-} \mathrm{O}^{-}$forming an aqueous $\mathrm{NaHSiO}_{3}{ }^{0}$ complex. This complex might cause formation of alkali-silica gel (Heisig et al., 2016). The presence of $\mathrm{NaCl}$ leads to faster dissolution of the $\mathrm{SiO}_{2}$ in the presence of the $\mathrm{OH}^{-}$ions around it (Heisig et al., 2016). Heisig et al. (2016) showed that the use of low-alkali cement might not prevent ASR if exposed to $\mathrm{NaCl}$ solutions. 
At $0.5 \mathrm{~N} \mathrm{NaCl}$ solutions, very minimal expansion was obtained compared to samples soaked in 1 $\mathrm{N}$ and $2 \mathrm{~N}$ solutions as shown in Figure 2.29 (Chatterji, Thaulow and Jensen, 1987).

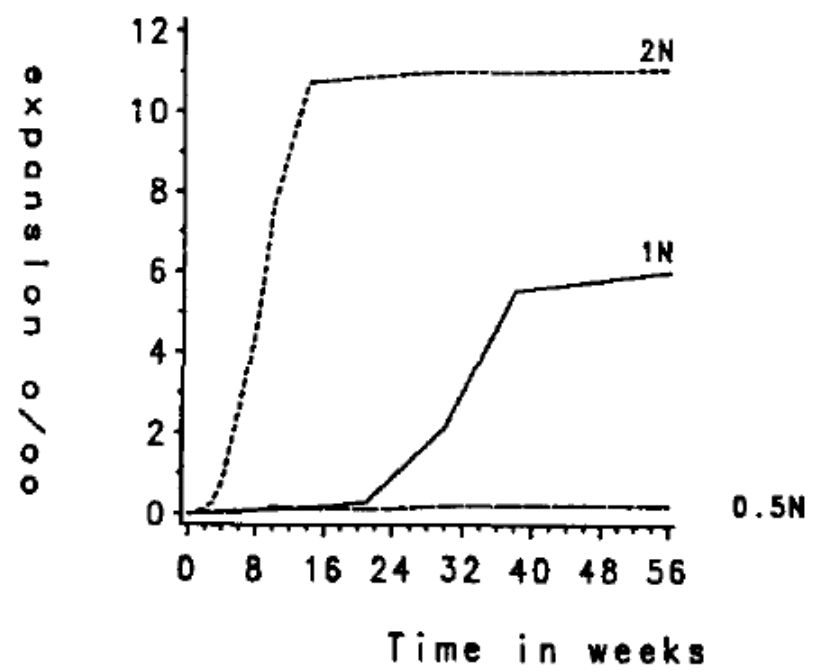

Figure 2.29: Mortar bars expansions soaked in NaCl solutions (Chatterji, Thaulow and Jensen, 1987)

By increasing the concentration of the alkaline solution, the ASR reaction tends to be accelerated confirming diffusion of the alkalis from the soaking solution to the concrete pore solution. This effect is also shown when the samples are soaked in pure water leading to reduced expansion or no expansion at all in the case of prisms with w/c $=0.55$. However, this might not be the case for samples with lower permeability. In such case, the soaking solution might not affect the expansion. Even in water, the expansion could be obtained in case the cement has enough alkali content to sustain the reaction (Bérubé and Frenette, 1994). This was obtained for concrete cast with Spratt, highly reactive aggregate, a cement content of $365 \mathrm{~kg} / \mathrm{m}^{3}$ with $1.15 \% \mathrm{Na}_{2} \mathrm{O}_{\mathrm{e}}$ raised to $5.0 \mathrm{~kg} / \mathrm{m}^{3}$ and $\mathrm{a} w / \mathrm{c}=0.31$ soaked in $1 \mathrm{M} \mathrm{NaOH}, 1 \mathrm{M} \mathrm{KOH}, 1 \mathrm{M} \mathrm{NaCl}$ and in water as shown in Figure 2.30 (Bérubé and Frenette, 1994). 


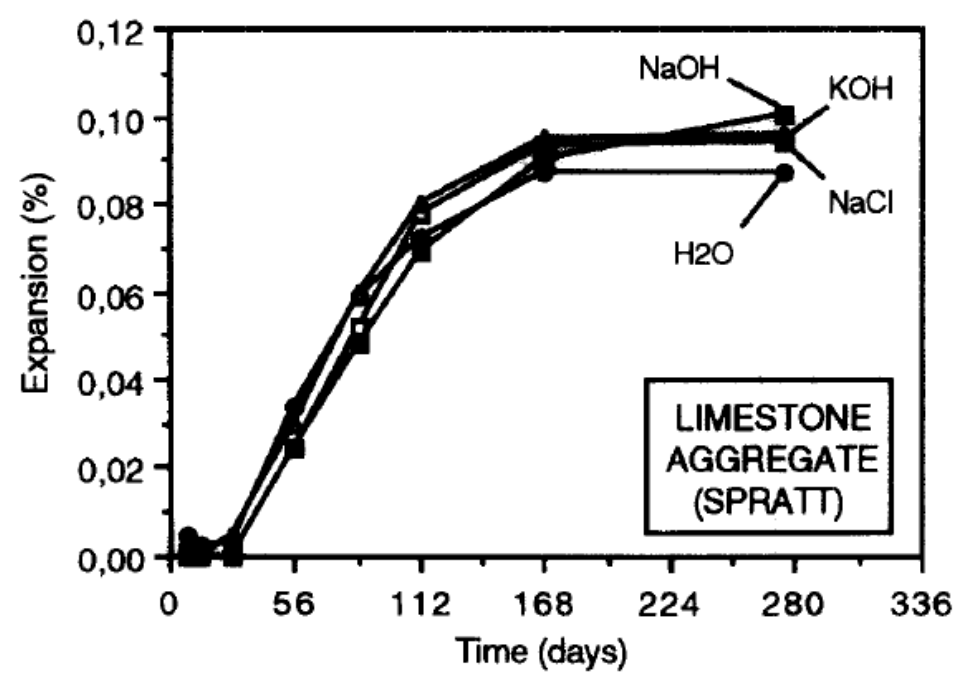

Figure 2.30: Expansion of prisms soaked in alkaline solutions and water (Bérubé and Frenette, 1994)

\subsubsection{Case Study: Residual Expansion of a Bridge Affected by ASR in Ontario}

A bridge in Sudbury, Ontario was cast more than 20 years ago using an aggregate, called Sudbury, which was not known yet to be reactive at that time. A severe deterioration occurred on this bridge and thus the structure was demolished after. Some pictures of the affected bridge are shown in Figure 2.31 below.
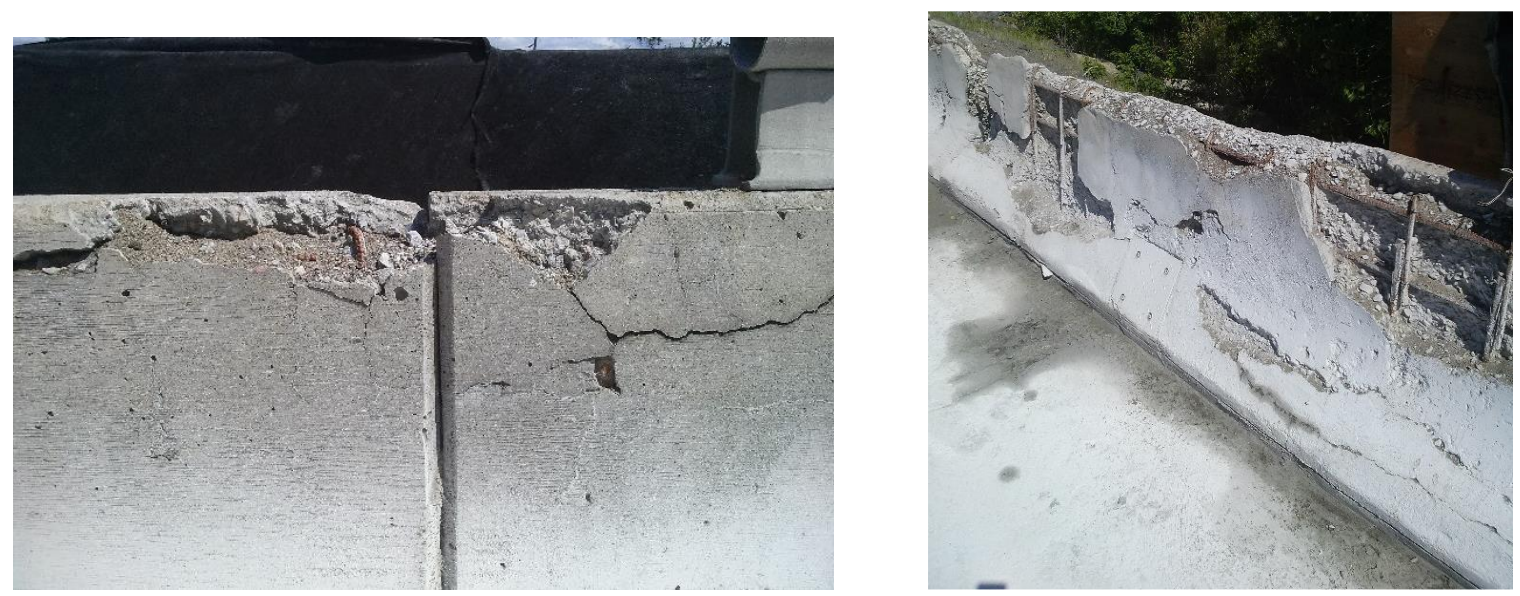

Figure 2.31: Signs of deterioration in highway bridge barriers (Piersanti, 2015)

The observed deteriorations are believed to be the combined effect of alkali-silica reaction as well as freezing and thawing. The level of deterioration of the bridge barriers varied depending on the exposure conditions, i.e. surface facing the sun and exposed to more water will likely show higher level of deterioration. Barriers obtained from the East-North and North-West bridge ramps showed 
different levels of deterioration varying from low to high deterioration. Figure 2.32 shows the two different road barriers.

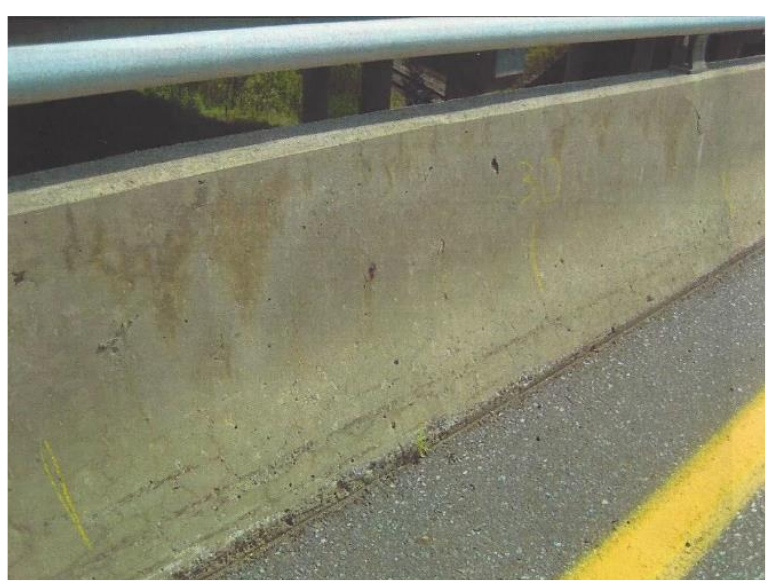

(a)

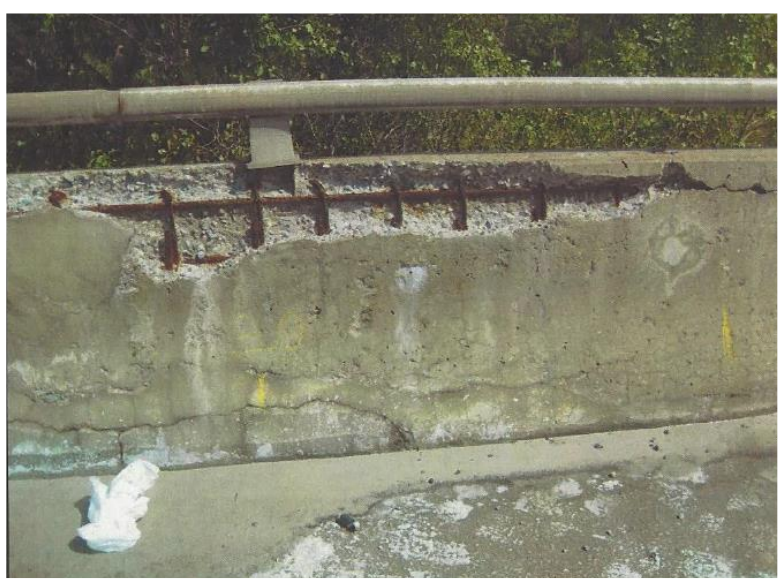

(b)

Figure 2.32: (a) Low deteriorated barrier at the East-North ramp, (b) High deteriorated barrier at the North-West ramp (Piersanti, 2015)

Cores were extracted from these bridge barriers and expansion was monitored over time as shown in Figure 2.33. The expansion of the low deteriorated cores was shown to be higher than the highly deteriorated ones. The reasons for such behavior might be due to the less silica remaining in the highly deteriorated samples to react, or due to the larger cracks, the gel could be diverted, and/or the alkalis could be leached leading to lower expansion (Piersanti, 2015). The residual expansion of the cores under lab conditions at 1 year was higher than the expansion measured in the barriers under field conditions (Piersanti, 2015).

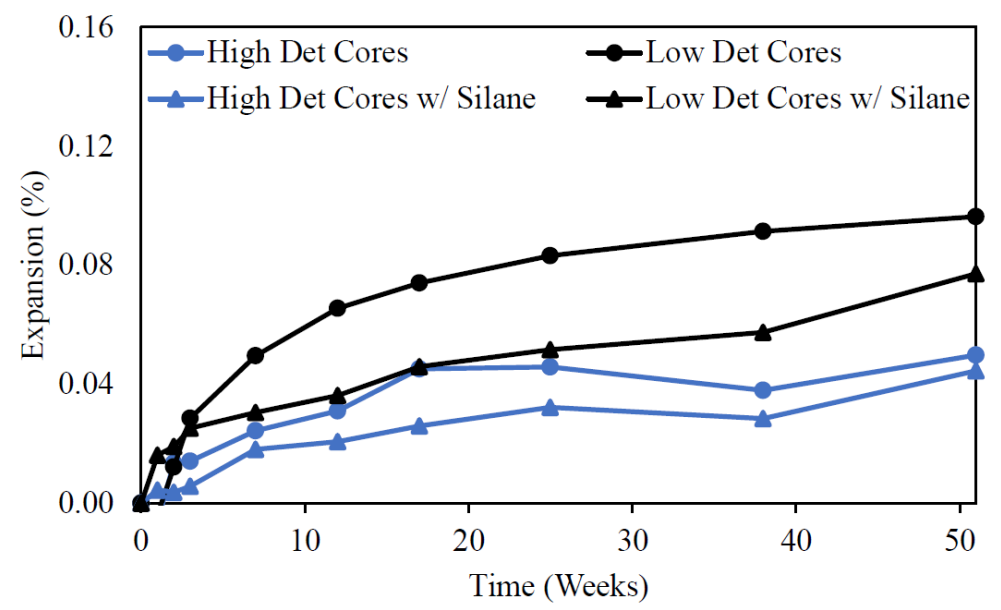

Figure 2.33: Expansion of low and high deteriorated cores (Piersanti, 2015) 


\subsubsection{Expansion of Concrete Containing RCA with Different Deterioration Levels}

Studying the effect of deteriorated level on concrete cast with RCA aggregates is important to help in understanding the remaining life of structures. The expansion of Sudbury RCA samples compared to virgin aggregates was studied by Piersanti et al. (2015). Prisms cast with RCA of high level of deterioration were found to have slightly higher expansions than samples cast with RCA of low level of deterioration. Both showed expansion higher than that of the virgin samples. This was more apparent when using the standard mix (which has higher cement content) compared to the bridge mix (lower cement content in the mix). This suggests that when using RCA, the level of deterioration that has already occurred does not affect the expansion results enormously. The reasons for this could be that when crushing, new faces of the aggregate are being exposed that have not yet reacted, thus causing expansion. Also, the expansion of samples with RCA was higher than that of the virgin Sudbury which could be due to the presence of higher alkalis released from the cement in RCA samples or due to the swelling of existing gel under moisture exposure (Piersanti et al., 2015). Many studies showed that higher level of SCM is required to mitigate expansion in concrete cast with RCA compared to virgin aggregates (Shehata et al., 2010; Piersanti, 2015). 


\subsection{Potential Alkali-Silica Reactivity of Mineral Fillers in Concrete}

Mineral fillers have been implemented more frequently in concrete due to their beneficial impact specially in flowable mixtures such as self-consolidating concrete (SCC). SCC, a type of highperformance concrete, is very flowable making it easy to be placed in formworks with minimal or no vibration (Khayat, 1999). However, it is important to balance between deformability and stability of the mix. To do so, filler materials are added to SCC to preserve its stability and cohesiveness (Uysal, 2012). These fillers are either pozzolanic materials (ex: fly ash, slag etc...) or mineral fillers such as limestone powder. Mineral fillers are being used more in SCC because they are less expensive and are showing good performance. Many different fillers are available depending on their original source. However, some of them might have a potential to cause alkalisilica reaction if implemented without precaution.

\subsubsection{Mineral Fillers Effect on Concrete}

When fillers are added to the mix, the water content is reduced and the concrete will be more dense and with reduced porosity (Uysal, 2012). The amount of viscosity enhancing chemical admixtures needed will be lowered or eliminated due to the addition of fillers instead. Adding mineral fillers is cost effective and enhances the stability of the mix. Furthermore, due to their higher surface area, mineral fillers might increase the degree of cement hydration (Kjellsen and Lagerblad, 1995). Adding mineral fillers to the mix will allow the formation of calcium hydroxide at early ages due to the creation of nucleation sites allowing the development of the hydration products (Pedersen, 2004).

The type of fillers as well as its replacement level can affect the properties of concrete in a different way. Bleeding in concrete will be reduced when filler is added due to their high surface area. The non-pozzolanic mineral fillers reduced bleeding and segregation in SCC more than pozzolanic materials specially at high replacement levels (Elyamany, Abd Elmoaty and Mohamed, 2014). Moreover, the average compressive strength of SCC samples with marble powder was higher by 25\% more than SCC samples with no added fillers (Alyamaç and Ince, 2009). Elyamany, Abd Elmoaty and Mohamed (2014) explained that the non-pozzolanic materials showed close compressive strength to that of pozzolanic fillers. The enhanced performance of fillers is due to the micro-filling capacity which enhances the microstructure of the concrete and the interfacial transition zone (Elyamany, Abd Elmoaty and Mohamed, 2014). 
Many researches are still going in order to study the effect of mineral fillers on durability of concrete. Adding filler by replacing the cement portion or the aggregate is still a debate: some suggested replacing the cement by mineral fillers (Craeye et al., 2010; Turkel and Kandemir, 2010; Murthy et al., 2012), others replaced the aggregate portion (Pedersen, 2004). The method of replacement is still under debate to be able to find the effect of replacement method on concrete properties as well as durability.

\subsubsection{ASR Testing of Mineral Fillers}

Pedersen (2004) studied the potential alkali-silica reacitivity of mineral fillers by replacing a portion of the aggregates by mineral fillers and found that some types of mineral fillers that are potentially reactive can cause expansion in concrete. (Pedersen, 2004). Hence, evaluating the potential alkali-silica reactivity of mineral fillers is important before implementing them. However, there is no standard test for evaluating alkali-silica reactivity of mineral fillers. Different conclusions were obtained when a Norwegian reactive filler was tested using the CPT and AMBT. With the CPT, the filler showed higher expansion than the sample without filler which opposed the results obtained in AMBT for filler with a particle size of 0-125 $\mu \mathrm{m}$ (Pedersen, 2004). It is believed that this could be due to the pozzolanic reactivity of the fillers at different temperatures. The pozzolanic reactivity of the filler used was shown to start at temperatures higher than $38^{\circ} \mathrm{C}$.

Also, the filler's size can affect greatly the expansion. A reactive filler with a particle size of 0$125 \mu \mathrm{m}$ exhibited slightly lower expansion compared to fillers with a size of 0-20 $\mu \mathrm{m}$ when tested using the CPT. This could be because of the faster reaction of smaller particles. However, same reactive fillers when tested using the AMBT showed smaller expansion with smaller size of the filler due to the effect of temperature on pozzolanic activity (Pedersen, 2004). This was not the case with pozzolanic fillers which showed lower expansion with reduced particles size due to the higher pozzolanic activity whether with the CPT or AMBT (Pedersen, 2004).

A filler with $80 \%$ passing $25 \mu \mathrm{m}$ and $20 \%$ between $25 \mu \mathrm{m}$ and $75 \mu \mathrm{m}$ showed lower epxansion than the control at 30\% replacement level. Same filler but with $10 \%$ replacement level showed higher expansion when tested using the CPT at 2 years (Dhir, Dyer and Tang, 2009). Similarly, many other fillers can show pessimum effect as was shown also by Pedersen (2004). Two mechanisms could explain the differences in expansion: (1) the high alkalinity will help in attacking the silica in the fillers which will be occupied by $\mathrm{Na}^{+}, \mathrm{K}^{+}$and $\mathrm{H}^{+}$forming a swelling gel, 
(2) dissolution of silica due to the continuous release of alkalis leading to the loss of the gel and the formation of C-S-H gel by the silica. A simplified model by Dhir, Dyer and Tang (2009) explained that the concrete will be in different phases where the finer fraction will be working into the reduction of ASR and hence the delay of the expansion at earlier ages specially with filler size glass compared to glass used in fine aggregate size. However, with lower level of replacement, the expansion might not be due to the above process however due to the gel formation by the natural aggregate and the release of alkalis. This could lead to the idea that ultimately at higher replacement level, the expansion should reach higher values due to more release of alkalis on the long term (Dhir, Dyer and Tang, 2009). 


\section{Chapter 3}

\section{Experimental Program}

\subsection{Materials}

\subsubsection{Cementing Materials}

General use (GU) Portland cements were used throughout this research with different alkali contents of $0.99 \%, 0.95 \%, 0.92 \%$ and $0.57 \% \mathrm{Na}_{2} \mathrm{O}_{e}$ and named accordingly as GU-0.99, GU-0.95, GU-0.92 and GU-0.57, respectively. In addition, two types of supplementary materials were used: low-calcium fly ash (FA) and slag. A blended Portland cement made of $92 \%$ GU PC and $8 \%$ silica fume (GUB-8SF) was used. The chemical compositions of the different cementing materials used in this research are presented in Table 3.1.

Table 3.1: Chemical compositions of cementing materials ( $\%$ by mass)

\begin{tabular}{cccccccc}
\hline Oxide & GU-0.99 & GU-0.95 & GU-0.92 & GU-0.57 & FA & Slag & GUB-8SF \\
\hline \hline $\mathbf{S i O}_{2}$ & 19.54 & 19.2 & 19.1 & 19.2 & 57.0 & 37.0 & 26.26 \\
$\mathbf{A l}_{2} \mathbf{O}_{3}$ & 5.21 & 5.1 & 5.4 & 4.7 & 23.4 & 8.2 & 4.69 \\
$\mathbf{F e}_{2} \mathbf{O}_{3}$ & 2.16 & 2.6 & 2.7 & 3.04 & 3.5 & 0.5 & 2.15 \\
$\mathbf{C a O}$ & 62.39 & 62.1 & 61.8 & 62.6 & 9.5 & 38.5 & 56.06 \\
$\mathbf{M g O}$ & 2.39 & 2.6 & 2.4 & 3.0 & 1.0 & 10.5 & 2.06 \\
$\mathbf{S O}_{3}$ & 4.03 & 4.0 & 4.0 & 3.34 & 0.1 & 2.7 & 4.08 \\
$\mathbf{N a}_{2} \mathrm{O}$ & 0.24 & 0.21 & - & 0.26 & 2.27 & 0.33 & 0.20 \\
$\mathbf{K}_{2} \mathbf{O}$ & 1.14 & 1.13 & - & 0.47 & 0.66 & 0.52 & 1.13 \\
$\mathbf{N a}_{2} \mathrm{O}_{\mathbf{e}}$ & 0.99 & 0.95 & 0.92 & 0.57 & 2.70 & 0.67 & 0.94 \\
\hline Loss on Ignition & 2.36 & 2.4 & 2.4 & 2.7 & 0.59 & 2.1 & 2.61 \\
\hline Total & 99.46 & 99.31 & 99.08 & 96.61 & 98.02 & 100.35 & 99.24 \\
\hline
\end{tabular}

GU-0.99 was used to cast the concrete expansion samples (prisms, cylinders and cubes) to study the effect of sample geometry on expansion. Prisms soaked in different alkaline solutions were cast with GU-0.95 to study the effect of pore solution alkalinity on expansion of concrete cast with 
Spratt aggregates. Concrete samples at different alkali content stored above water were cast using GU-0.57 and GU-0.92. The study of the mineral fillers was done with GU-0.95. More details about the casting procedure of each of the experiments will be explained in Section 3.2.

\subsubsection{Aggregates}

\section{Coarse aggregate}

Three coarse aggregates of different reactivity were used in this research:

1) Sudbury aggregate, a partially crushed gravel, is slightly metamorphic consisting of greywacke, argillite, quartz-wacke and quartzite obtained from a gravel pit in Sudbury, Ontario (Rogers and MacDonald, 2012). The minerals in this aggregate are composed of sandstone and arkose (32\%), argillite and greywacke (32\%), quartz and quartzite (11\%) and igneous and gneiss (25\%). The 1-year CPT expansion of the concrete prisms cast with Sudbury aggregate is $0.17 \%$.

2) Spratt aggregate is a coarse limestone, slightly siliceous with $9 \% \mathrm{SiO}_{2}$ obtained from a query in Ottawa, Ontario (Shehata and Thomas, 2010; Rogers and MacDonald, 2012). It is composed of siliceous limestone (96\%), slightly shaley limestone (2\%), cherty limestone $(0.5 \%)$ and shaley limestone and shale (1\%). The 1-year CPT expansion of the Spratt aggregate is $0.21 \%$.

3) Springhill aggregate consisting of greywacke obtained from New-Brunswick contains reactive silica. The principal minerals in this aggregate are: Calcite, Muscovite, Chlorite, plagioclase Feldspar and Dolomite (Drolet, Duchesne and Fournier, 2017). The 1-year CPT expansion of concrete prisms cast with Springhill is $0.22 \%$ (Johnson and Shehata, 2016).

The flat and elongated particle test, as per MTO LS-608 (2001), was completed on the three reactive aggregates to analyze the effect of the casting direction on expansion and the results are shown in Table 3.2 and Table 3.3. Springhill aggregate has the highest amount of flat and elongated particles (40.8\%), followed by Spratt (13.2\%) and then Sudbury (10.2\%). Table 3.3 summarizes the physical properties of the three aggregates. 
Table 3.2: Particle shape of the coarse reactive aggregates used

\begin{tabular}{|c|c|c|c|}
\hline Aggregate & Sudbury & Spratt & Springhill \\
\hline Mixed & & & \\
\hline $\begin{array}{l}\text { Passing } 19.5 \mathrm{~mm} \\
\text { sieve and retained } \\
\text { on } 13.2 \mathrm{~mm} \text { sieve }\end{array}$ & & & \\
\hline $\begin{array}{c}\text { Passing } 13.2 \mathrm{~mm} \\
\text { sieve and retained } \\
\text { on } 9.5 \mathrm{~mm} \text { sieve }\end{array}$ & & & \\
\hline $\begin{array}{c}\text { Passing } 9.5 \mathrm{~mm} \\
\text { sieve and Retained } \\
\text { on } 4.75 \mathrm{~mm} \text { sieve }\end{array}$ & & & \\
\hline
\end{tabular}


Table 3.3: Reactive coarse aggregate properties

\begin{tabular}{|c|c|c|c|c|}
\hline \multicolumn{2}{|l|}{ Aggregate } & Sudbury & Spratt & Springhill \\
\hline \multicolumn{2}{|c|}{ Bulk relative density } & 2.552 & 2.691 & 2.723 \\
\hline \multicolumn{2}{|l|}{ Absorption (\%) } & 0.56 & 0.52 & 0.85 \\
\hline \multicolumn{2}{|c|}{$(\mathrm{CSA}$ A23.2-14A $)$} & 0.17 & 0.21 & 0.22 \\
\hline \multirow{4}{*}{$\begin{array}{c}\text { Flat and elongated ( } \% \text { by } \\
\text { mass) for portion } \\
\text { retained on sieve size }\end{array}$} & $13.2 \mathrm{~mm}$ & 5.1 & 9.9 & 39.2 \\
\hline & $9.5 \mathrm{~mm}$ & 4.7 & 17.3 & 38.3 \\
\hline & $4.75 \mathrm{~mm}$ & 20.7 & 12.4 & 44.8 \\
\hline & Average & 10.2 & 13.2 & 40.8 \\
\hline
\end{tabular}

In addition, a concrete clear limestone with maximum nominal size of $19 \mathrm{~mm}$ obtained from Lafarge Dundas aggregate Quarry was used as a non-reactive coarse aggregate. The density and absorption of this non-reactive aggregate are 2.726 and $0.81 \%$, respectively.

\section{Fine aggregate}

Two different non-reactive fine aggregates were used in this study:

1) The first fine aggregate (sand 1) used is a non-reactive (limestone) concrete natural sand obtained from Lafarge Caledon Pit, Ontario.

2) The second fine aggregate (sand 2), derived from Precambrian granites and high-grade metamorphic gneiss, was obtained from a natural sand deposit located in Wakefield, Quebec. This “control sand” gave a 14-day accelerated mortar bar expansion (CSA A23.2$25 \mathrm{~A}$ ) of $0.040 \%$.

The non-reactive fine aggregates properties are shown in Table 3.4.

Table 3.4: Fine aggregates properties

\begin{tabular}{ccc}
\hline Aggregate & Sand 1 & Sand 2 \\
\hline \hline Bulk relative density & 2.538 & 2.659 \\
Absorption (\%) & 1.30 & 0.81 \\
Fineness modulus & 2.635 & 2.427 \\
\hline
\end{tabular}


A reactive fine aggregate, Springhill, was used for mineral fillers testing and for studying the effect of cement alkali content on expansion of concrete prisms cast with this aggregate. Springhill aggregate, obtained from New-Brunswick, has the same mineral properties as the coarse aggregate described above. The density and absorption of the Springhill fine aggregate are 2.562 and $0.33 \%$, respectively.

\subsubsection{Fillers}

The carbonate filler (CF) is a dry ground calcium carbonate with a medium and closely sized particle distribution and excellent shrinkage resistance properties. The carbonate filler contains calcium carbonate (94\%) and magnesium carbonate (2.5\%). The median diameter is $21 \mu \mathrm{m}$ and its particle size distribution is shown in Figure 3.1.

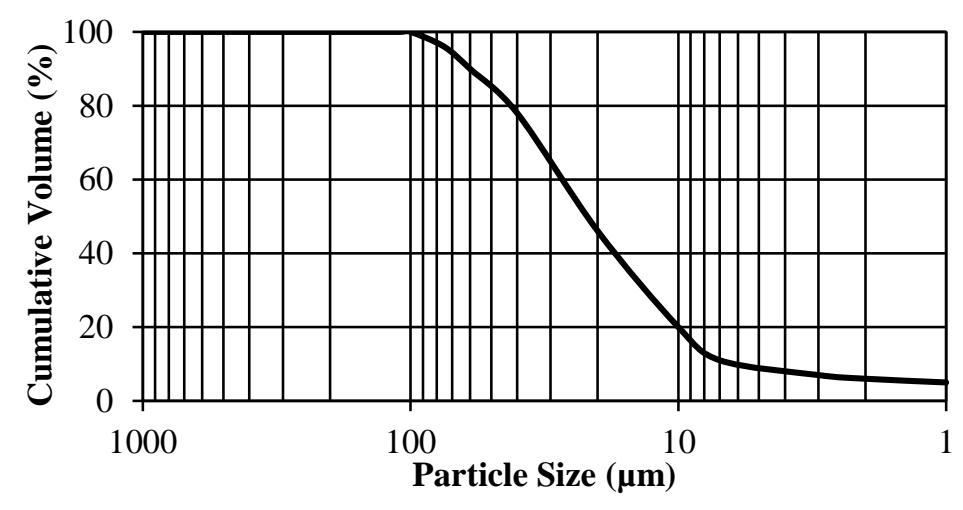

Figure 3.1: Particle size distribution of the carbonate filler

The second mineral filler used, carbonate silica filler (CSF) contains calcium carbonate (66\%), quartz (11\%) and silicate materials (23\%). Its chemical composition is presented in Table 3.5. The median diameter is $40 \mu \mathrm{m}$ and the particle size distribution is provided in Figure 3.2.

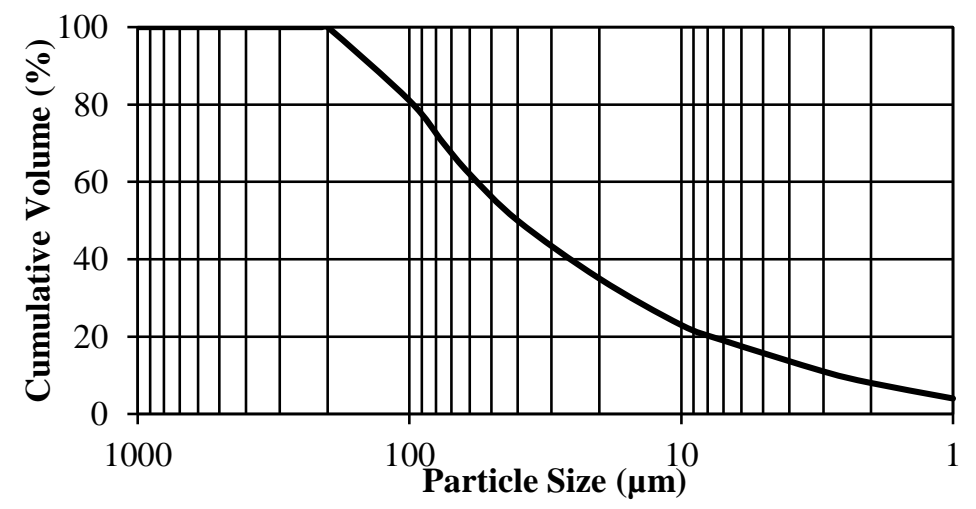

Figure 3.2: Particle size distribution of the carbonate silica filler 
Table 3.5: Chemical composition of carbonate silica filler ( $\%$ by mass)

\begin{tabular}{cc}
\hline Oxide & Carbonate silica filler \\
\hline \hline $\mathrm{SiO}_{2}$ & 27 \\
$\mathrm{Al}_{2} \mathrm{O}_{3}$ & 1 \\
$\mathrm{Fe}_{2} \mathrm{O}_{3}$ & 0.3 \\
$\mathrm{CaO}$ & 42 \\
$\mathrm{MgO}$ & 5 \\
$\mathrm{SO}_{3}$ & - \\
$\mathrm{Na}_{2} \mathrm{O}_{\mathbf{e}}$ & - \\
\hline Loss on Ignition & 29
\end{tabular}

Springhill (SH) is a reactive aggregate (prisms cast with coarse Springhill aggregate have a 1-year CPT expansion of $0.22 \%$ (Johnson and Shehata, 2016)). It is a mix of coarse and fine aggregates which were separated from each other before crushing. Crushing was done on each portion separately in order to obtain the following mineral fillers:

1. Filler obtained from crushing the coarse aggregate until all passed $75 \mu \mathrm{m}$ sieve (SH-C$100 \%$ passing $75 \mu \mathrm{m})$,

2. Filler obtained from crushing the coarse aggregate until $70 \%$ passed $75 \mu \mathrm{m}$ sieve and $30 \%$ passed $150 \mu \mathrm{m}$ sieve and retained on $75 \mu \mathrm{m}$ sieve (SH-C-70\% passing $75 \mu \mathrm{m}$ ),

3. Filler obtained from the fine portion (SH-F) which was crushed until all passed $75 \mu \mathrm{m}$ sieve.

The crushing procedure for the fine and coarse aggregates is explained in Section 3.2.7.

\subsubsection{Chemicals}

Pellets of sodium hydroxide obtained from ALPHACHEM Ltd were added to the mixing water to boost the cement alkali content to $1.25 \%$ when casting concrete expansion samples as per CSA A23.2-14A (2014).

ADVA CAST 575, a polycarboxylate-based high range water reducer (HRWR), was used with mineral fillers to increase workability during casting. A recommended dosage of $460 \mathrm{~mL} / 100 \mathrm{~kg}$ of cementitious materials was used. 


\subsection{Experimental Details}

\subsubsection{Concrete Expansion Samples}

\section{Casting}

Three different sample shapes were studied in this research: standard prisms $(75 \times 75 \times 285 \mathrm{~mm})$, cylinders ( $\varnothing 100 \mathrm{~mm}$ by $285 \mathrm{~mm}$ ) and $150 \mathrm{~mm}$ cubes. Cylindrical and cubical samples were chosen to capture the effect of larger cross section compared to prisms as well as the effect of surface area to volume ratio on expansion due to ASR. The coarse aggregate portion consists of three equal masses of materials size between $19.5 \mathrm{~mm}$ to $13.2 \mathrm{~mm}, 13.2 \mathrm{~mm}$ to $9.5 \mathrm{~mm}$ and $9.5 \mathrm{~mm}$ to 4.75 $\mathrm{mm}$. The coarse to fine aggregate ratio is $60: 40$ by mass and the water to cement ratio used is 0.42 . The cement content is $420 \mathrm{~kg} / \mathrm{m}^{3}$. GU-0.99 is used and its alkalinity is boosted to $1.25 \%$ by weight of cement by adding sodium hydroxide as specified in CSA A23.2-14A (2014). The prism molds used are similar to the ones specified in the standard. For cylinders and cubes, there is no standard test method available hence their molds were fabricated at Ryerson's lab and are shown in Figure 3.3 and Figure 3.4. Figure 3.5 shows the different studs used to allow measurements of the samples.
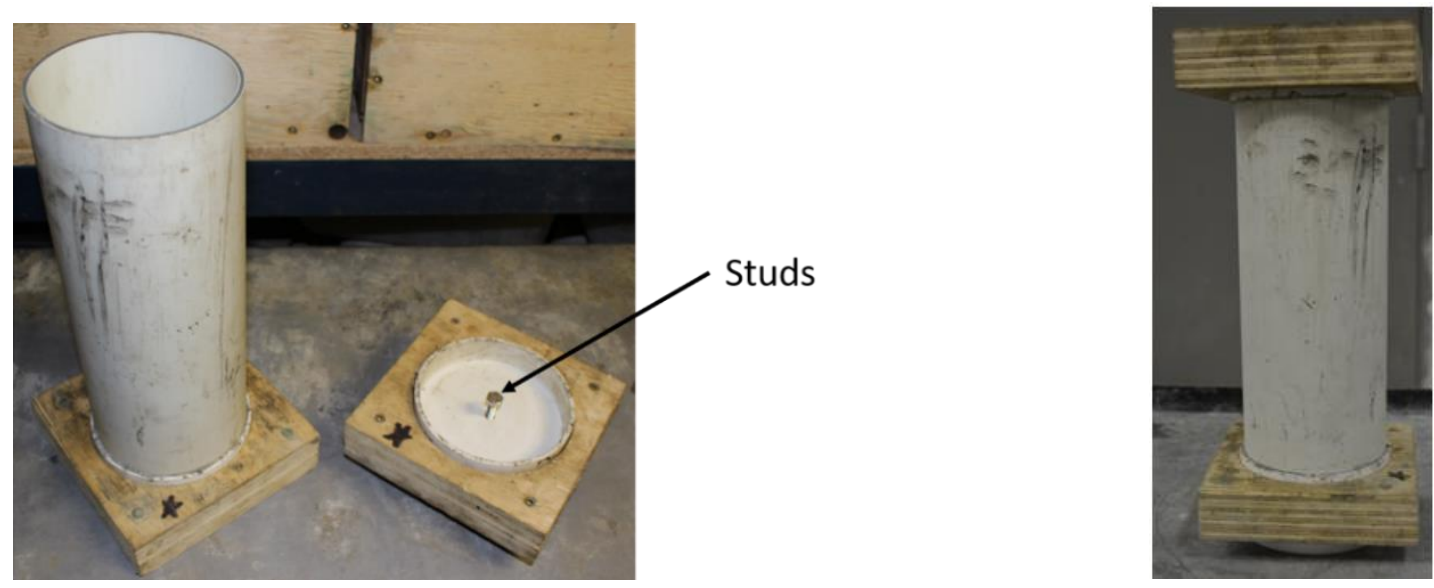

Figure 3.3: Fabricated molds for cylinders 


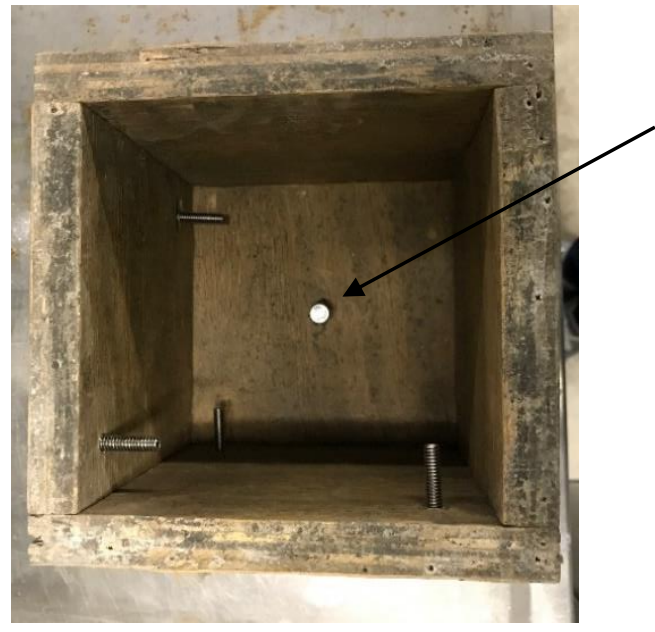

Stud to measure expansion from center-to-centre

Pins to measure expansion from center-to-centre
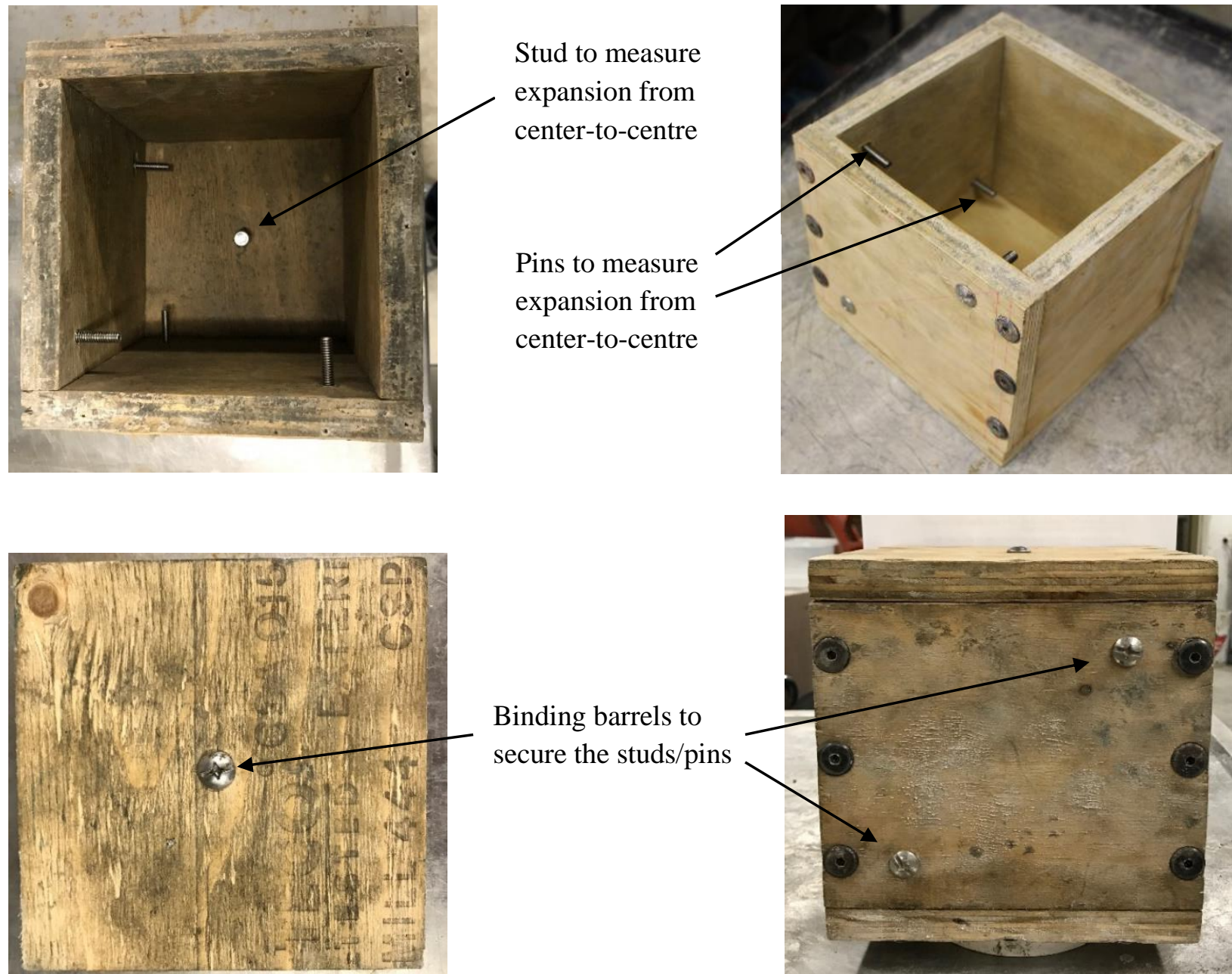

Binding barrels to

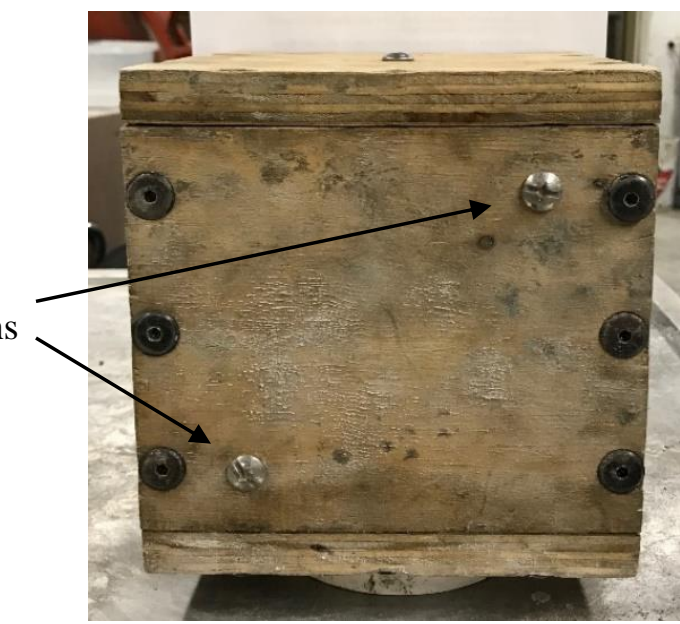

Figure 3.4: Fabricated molds for cubes

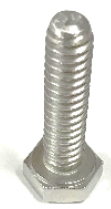

(a)

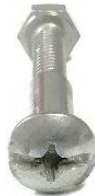

(b)

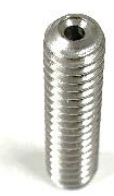

(c)

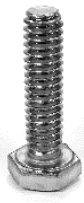

(d)

Figure 3.5: (a) Studs for cylinders/prisms, (b) binding barrel to secure the studs/pins, (c) pins for cubes side measurement and (d) pins for cubes center-to-center measurements

The cubes were cast in three layers and the cylinders in four layers to allow good consolidation. Each layer was tamped 25 times using a standard rod of 10-mm diameter rounded end. The samples were demolded the day after. 


\section{$\underline{\text { Storage }}$}

Containers were prepared by aligning an absorbent cloth on their walls. The clothes were made wet before putting the samples in. The samples were elevated by around $4 \mathrm{~cm}$ above the bottom of the containers and stored above water. The pails for prisms and cylinders fit three samples at a time as for the cubes one sample is stored in each container. The pails used for the prisms/cylinders ( $\varnothing 257$ by $375 \mathrm{~mm}$ ) and the cube containers $(213 \times 191 \times 197 \mathrm{~mm})$ are shown in Figure 3.6.

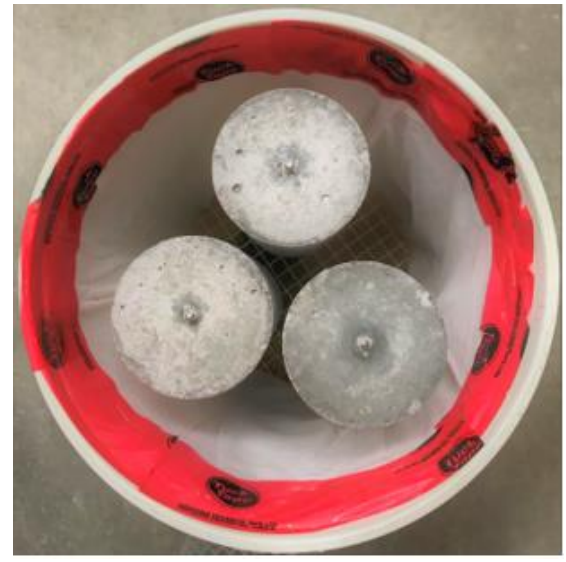

(a)

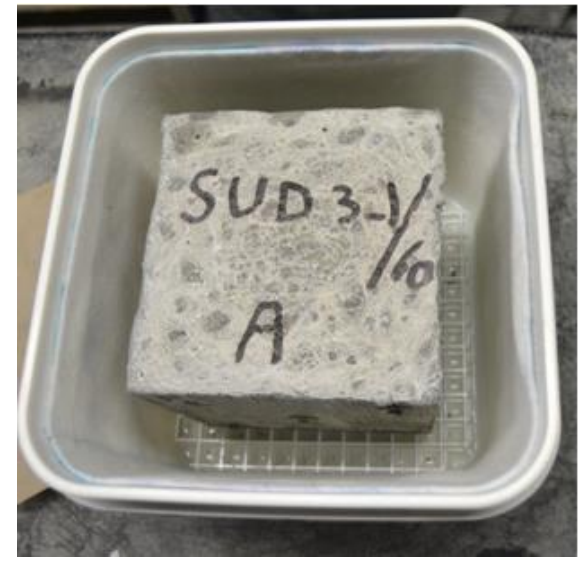

(b)

Figure 3.6: (a) Pails for the prism and cylinder samples (b) containers for cube samples

Each set of samples is composed of three prisms, three cylinders and three cubes. Two sets of the same mix were prepared: one placed in the heat room at $38^{\circ} \mathrm{C}$ and the other set in an oven at $60^{\circ} \mathrm{C}$. The aim of testing at $60^{\circ} \mathrm{C}$ is to understand the effect of temperature on expansion due to ASR and to see whether increasing temperature can accelerate the results. In addition, another method investigated in this research is testing cylinders at $60^{\circ} \mathrm{C}$ using smaller containers to increase the concrete-to-air ratio in an attempt to reduce leaching and thus accelerate the reaction further (Bérubé, Fournier and Côté, 2012). The casting procedure is similar to the one used for the cylinders; however, the only difference is the container size that fits only one cylinder. The containers used have the following dimensions: $\varnothing 150 \mathrm{~mm}$ by $420 \mathrm{~mm}$ length and are shown in Figure 3.7. The concrete-to-air volume ratio is 0.3 for the cylinders stored each in a separate container as compared to 0.2 in the case of three cylinders stored in one pail. 

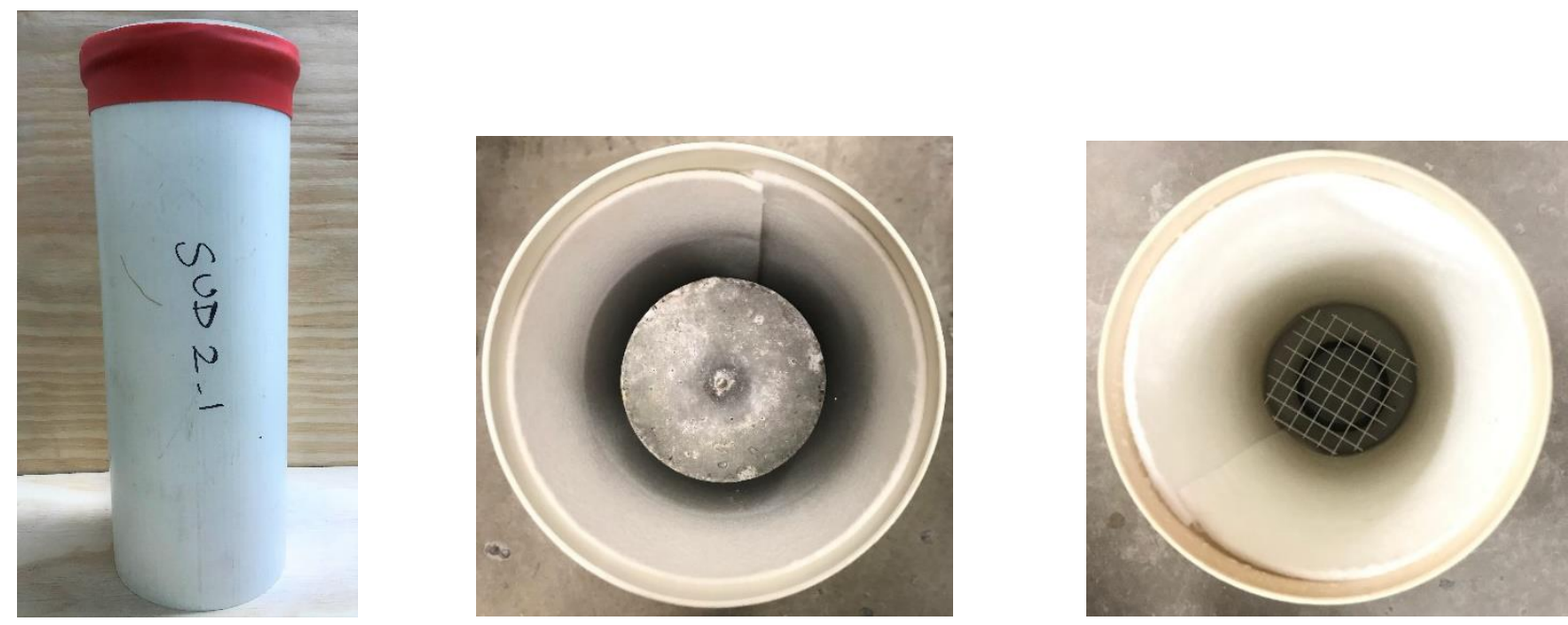

Figure 3.7: Containers used for testing one cylinder at $60^{\circ} \mathrm{C}$

\section{Expansion Measurements}

Before placing the different samples at their assigned temperatures, the zero reading was taken. Measurements were taken at 1, 2, 4, 8, 13, 18, 26, 39, 52 weeks and then once every 3 months until 2 years. At 2 years, samples were taken out and put at $23^{\circ} \mathrm{C}$ to study the effect of pore solution alkalinity and temperature on gel viscosity. The cylinders were measured using the same length comparator used for the prisms. For the cubes, a DEMEC style digital strain gauge was used to measure the change in length on each side. The pins, $150 \mathrm{~mm}$ apart, were put diagonally on two adjacent faces of the cubes and the average expansion of the two sides is reported. In addition, an outside micrometer with a 0.0001 " precision was used to measure the length change longitudinally at the center of the cubes for the samples cast with Spratt aggregate. Studs similar to the ones used for the prisms but without rounding them were installed on the bottom and top wood plates used when casting the cubes. The average expansion of three samples of the same shape at the same temperature is presented. The length comparator and the strain gauges used for the different samples are shown in Figure 3.8. 


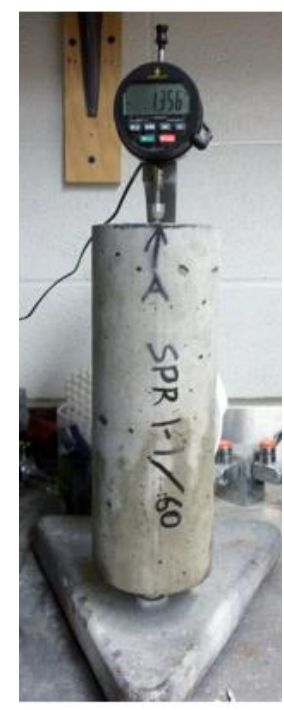

(a)

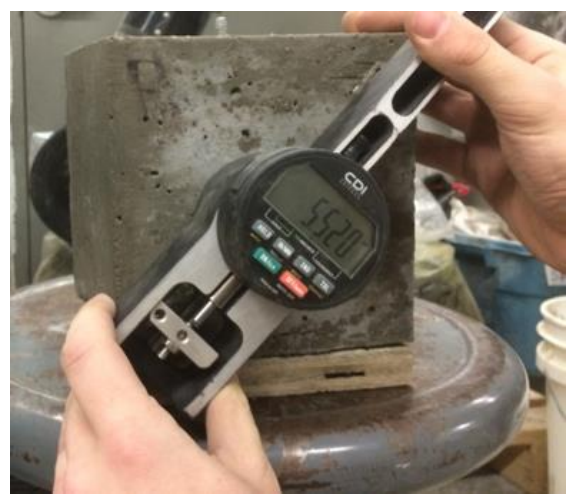

(b)

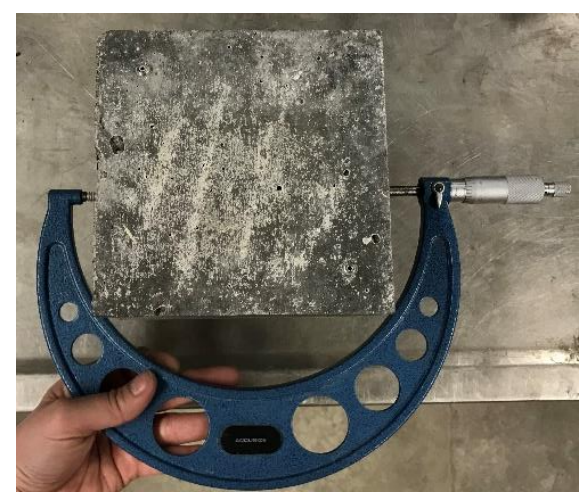

(c)

Figure 3.8: Measurements of (a) cylinders, (b) cubes sides (c) cubes center-to-center

\section{Leaching Measurements}

The amount of alkalis that leached from concrete samples to the water at the bottom of the containers was measured. At 1.5 years, the solution at the bottom of the containers was collected to measure its volume and a $10 \mathrm{~mL}$ sample was taken to test for its $\mathrm{Na}^{+}$and $\mathrm{K}^{+}$concentrations. The concentrations of $\mathrm{Na}^{+}$and $\mathrm{K}^{+}$ions were obtained by ATS 200S/40990 multi-channel flame photometer. The results are then converted to $\mathrm{Na}_{2} \mathrm{O}_{\mathrm{e}}$ and reported as percent of the sample's initial $\mathrm{Na}_{2} \mathrm{O}_{\mathrm{e}}$ content. A sample calculation is provided in Appendix A.

\section{Relative Humidity Measurements}

Relative humidity $(\mathrm{RH})$ was measured in the cores of the samples with all the different shapes using a Rapid RH Easy Readers which monitors temperature and relative humidity. Rapid RH 4.0 EX smart sensors of $40 \mathrm{~mm}$ length were installed in the core of the samples and $10 \mathrm{~mm}$ extensions were added to increase the length of the sensor barrel in the case of the cylinders and cubes. The casting procedure is similar to the one used for the samples cast for expansion measurements. A pre-made hole was prepared in the molds using a piece of foam having similar diameter as the sensor and a length equal half the samples' thickness $(75 \mathrm{~mm}$ and $37.5 \mathrm{~mm}$ for the cubes and prisms, respectively). After 24 hours, the samples were demolded, the piece of foam was removed and the sensors were installed instead. For the cylindrical samples, placing the foam could not have been made before casting since drilling a hole in the cylindrical molds along their diameters was 
not easy. Therefore, the cylinders were cast and then a hole was drilled to the center of the samples using a $19 \mathrm{~mm}$-diameter drill bit. The hole was cleaned and then the sensor was inserted. RH readings were performed daily and then after one month, readings were done once per week. Figure 3.9 shows the sensors inserted in the different samples.

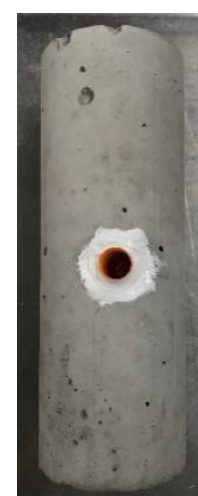

(a)

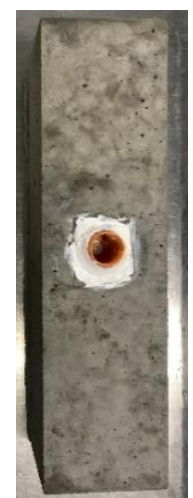

(b)

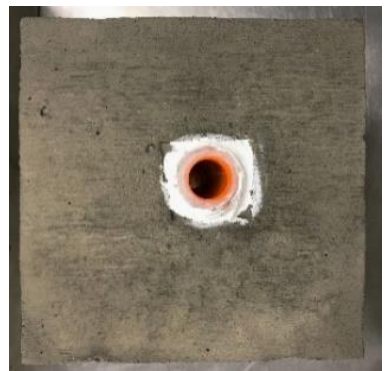

(c)

Figure 3.9: Photos of sensors implemented inside the cores of the (a) prism, (b) cylinder, and (c) cube

\section{Samples with Different Alkali Content}

Samples with different alkali content were cast in order to understand the effect of the cement alkalinity on expansion of concrete cast with aggregate of different reactivity and to obtain the threshold alkali that will trigger expansion. Cylinders were cast for Sudbury and Spratt aggregates and prisms were cast for the Springhill fine aggregate. The $\mathrm{Na}_{2} \mathrm{O}_{\mathrm{e}}$ content used were: $0.57 \%$ (GU0.57 was used), $0.7 \%, 0.8 \%, 0.92 \%$ (GU-0.92 was used), $1.25 \%$. To obtain the required alkalinity of $0.7 \%$ and $0.8 \% \mathrm{Na}_{2} \mathrm{O}_{e}$, both GU-0.57 and GU-0.92 were blended with the right proportions. For the samples cast with $1.25 \% \mathrm{Na}_{2} \mathrm{O}_{e}, \mathrm{GU}-0.92$ was used and the alkalinity was raised using sodium hydroxide pellets. The mixing procedure as well as the storage and measurements are the same as described above. The alkalis leached from the samples to the water at the bottom of the containers were measured at 1 year as described previously in Section 3.2.1.

\section{Soaking of Samples}

Spratt prisms samples cast with GU-0.95 were cast to study the effect of PC alkali content and the soak solution alkalinity on expansion. The prisms were cast as described in CSA A23.2-14A (2014). However, the containers used were different than the ones in the standard to allow soaking of the samples in solution without the need to add a large volume. Containers of 14.2 L capacity 
with the following dimensions: 430 × 340 x $137 \mathrm{~mm}$ were used and shown in Figure 3.10. Three prisms were lined up on a mesh to allow the solution to confine them from all the sides. The prisms were soaked in different alkaline solutions as follows:

- Deionized distilled water (DDW),

- Lime solution saturated with $\mathrm{Ca}(\mathrm{OH})_{2}$,

- $0.4 \mathrm{M} \mathrm{NaOH}$,

- $0.5 \mathrm{M} \mathrm{NaOH}$,

- $0.6 \mathrm{M} \mathrm{NaOH}$,

- $\quad 0.6 \mathrm{M} \mathrm{NaOH}$ and $\mathrm{KOH}$, prepared with $\mathrm{Na}_{2} \mathrm{O} / \mathrm{K}_{2} \mathrm{O}$ ratio $(\mathrm{Na} / \mathrm{K})$ similar to that of $\mathrm{GU}-0.95$,

- $0.7 \mathrm{NaOH}$,

- $0.8 \mathrm{NaOH}$.

In addition, Spratt samples cast with GU-0.57 and soaked in an alkaline solution of $0.4 \mathrm{M}$ mimicking its pore solution as calculated based on equation (2) were prepared. Two soaking solutions of $0.4 \mathrm{M}$ were prepared: (1) $0.4 \mathrm{NaOH}$ and (2) $0.4 \mathrm{NaOH}$ and $\mathrm{KOH}$ prepared with $\mathrm{Na}_{2} \mathrm{O} / \mathrm{K}_{2} \mathrm{O}$ ratio $(\mathrm{Na} / \mathrm{K})$ similar to that of $\mathrm{GU}-0.57$.
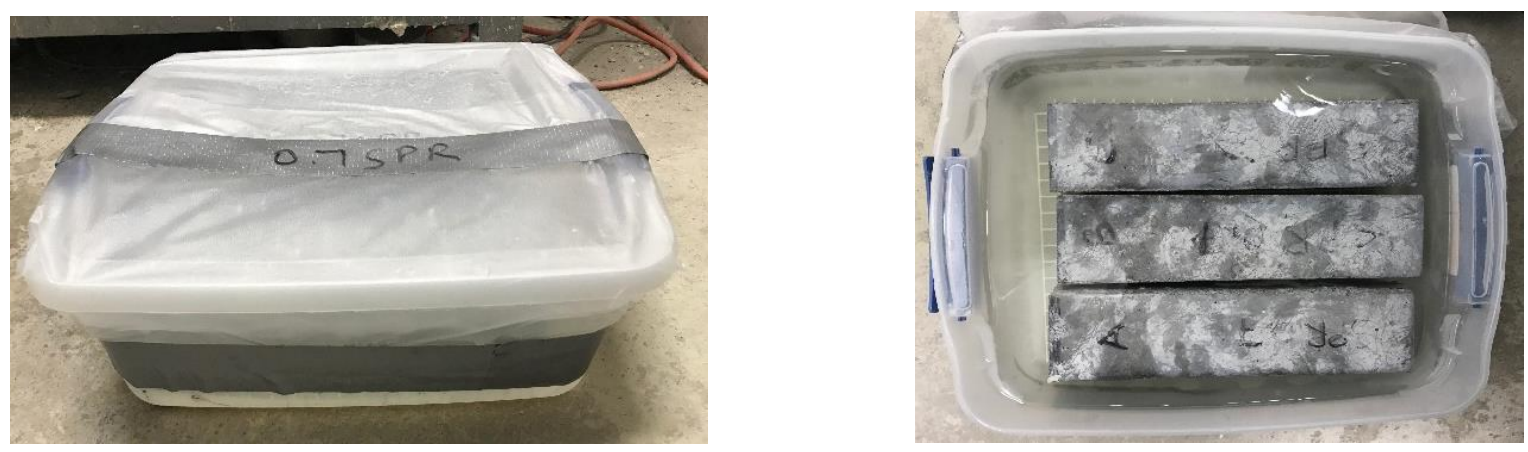

Figure 3.10: Soaking of prisms in plastic containers

Three prisms of the same mix were soaked in the same solution and the average is reported in the study. Measurements were done similar to the CPT but the masses of the containers (including the three prisms and solution) were measured to check for evaporation. At each measurement, distilled water was added to compensate for the evaporation in order to keep the concentration of the solution constant over time. 


\subsubsection{Aggregate Testing}

To study the alkali release from the different aggregates, $100 \mathrm{~g}$ samples consisting of $50 \mathrm{~g}$ passing $4.75 \mathrm{~mm}$ sieve and retained on $2.36 \mathrm{~mm}$ sieve, and $50 \mathrm{~g}$ passing $2.36 \mathrm{~mm}$ sieve and retained on $1.18 \mathrm{~mm}$ sieve were prepared. This size fraction was used because it was found that aggregate size between $1.25 \mathrm{~mm}$ and $5.0 \mathrm{~mm}$ will allow reasonable acceleration for the actual alkali release and will maintain the microstructural characteristics of coarse aggregates compared to finer size aggregates that might overestimate the alkali release (Lu et al., 2006). The dry samples were soaked in solutions of different alkalinities: $0.25 \mathrm{M} \mathrm{NaOH}, 0.25 \mathrm{M} \mathrm{KOH}, 0.70 \mathrm{M} \mathrm{NaOH}$ and 0.70 $\mathrm{M} \mathrm{KOH}$. The concentrations of $\mathrm{Na}^{+}$was measured in $\mathrm{KOH}$ and the concentration of $\mathrm{K}^{+}$was obtained in $\mathrm{NaOH}$ solutions. In addition, aggregate samples were also tested in distilled water to determine the amount of soluble alkalis. The ratio of aggregates to solution used was 1:1 similar to an earlier study by Bérubé et al. (2002). Samples were maintained at $23^{\circ} \mathrm{C}, 38^{\circ} \mathrm{C}$ and $60^{\circ} \mathrm{C}$ with some being agitated to accelerate the release of alkalis at $38^{\circ} \mathrm{C}$. After 4 weeks, $2 \mathrm{~mL}$ samples from the soaking solution were taken for measurements of $\mathrm{Na}^{+}$and $\mathrm{K}^{+}$ions using flame photometry. Three samples from each type of aggregate were prepared and the average was reported as $\mathrm{Na}_{2} \mathrm{O}$ and $\mathrm{K}_{2} \mathrm{O}$ taken as a percent of the aggregate mass. For the samples soaked in distilled water, only one samples from each type of aggregates was tested. A sample calculation is provided in Appendix B. The soaked aggregate samples were then put back at their designated temperatures and measurements were done once every 4 weeks.

\subsubsection{Paste Study}

\section{Sample Preparation}

Cylindrical samples of $50 \mathrm{~mm} \times 100 \mathrm{~mm}$ were cast using a water to cement ratio of 0.42 and different replacement levels of SCM. This study aims at studying the effect of temperature on the pozzolanic activity of SCM.

The samples used to study the effect of temperature are as follows:

- Control samples with $100 \%$ GU-0.99,

- GU-0.99 with $15 \%$ and $25 \%$ FA,

- GU-0.99 with $25 \%$ and $35 \%$ slag.

These samples were tested at three different temperatures: $23^{\circ} \mathrm{C}, 38^{\circ} \mathrm{C}$ and $60^{\circ} \mathrm{C}$. 


\section{Mixing}

A high-shear mixer was used to cast paste samples. First, water is placed in the bowl and then, the cementing materials were added. Three minutes of mixing at low speed was performed and mixing was stopped if needed to remove the materials stuck on the walls of the mixer. After three minutes of mixing, a two-minute rest period was applied and then two minutes of mixing at medium speed was adopted. At the end, another two minutes of rest period was performed followed by one minute of mixing. After the complete 10 minutes, the samples were cast in their corresponding molds and allowed to cure for 24 hours before demolding them.

\section{Storage}

The cylinders are put above water in containers at three different temperatures, $23^{\circ} \mathrm{C}, 38^{\circ} \mathrm{C}$ and $60^{\circ} \mathrm{C}$. Cylinders were tested at 1,3, 7, 28, 96 days after curing. At the age of testing, the sample was crushed into smaller fragments of size between $4.75 \mathrm{~mm}$ and $2.36 \mathrm{~mm}$. after crushing the sample into small fragments, the water was removed from the samples by solvent replacement method where they were soaked in acetone for 7 days. Following this, they were put in desiccators at $38^{\circ} \mathrm{C}$ to allow the evaporation of the acetone. After, they were kept in a $\mathrm{CO}_{2}$ free environment in the desiccator with soda lime and silica gel to prevent further hydration or carbonation from occurring. Two different tests were done on these samples. First, thermogravimetric analysis (TGA) test was done on the different samples to study the degree of pozzolanic reaction of SCM. The second test is to study the release characteristics after hydration of the samples at different temperatures.

\section{Thermogravimetric Analysis}

In this test, the samples were taken out from their desiccator and crushed using a pestle and mortar until they become powder. Thermogravimetric analysis (TGA) was performed using Mettler Toledo TGA/DSC 1 thermogravimetric analyzer where the samples were heated to $1050^{\circ} \mathrm{C}$. The test will generate two different curves: (1) mass loss, and (2) heat flow curves. Two important quantities are obtained from the TGA analysis. First is the chemically bound water (or nonevaporable water) which gives an indication of the degree of hydration of the cementing materials. This is obtained by taking the difference in mass from the mass loss curve and report it as a percent of the ignited mass as follows: 


$$
N E W(\%)=\frac{\text { mass loss } @\left(105^{\circ} \mathrm{C}\right)-\operatorname{mass} \text { loss @ }\left(1050^{\circ} \mathrm{C}\right)}{\operatorname{mass} \operatorname{loss} @\left(1050^{\circ} \mathrm{C}\right)} * 100
$$

The chemically bound water is corrected for the initial loss on ignition (LOI) in the cementing materials. For samples with SCM, to obtain the initial loss on ignition $\left(\mathrm{LOI}_{\mathrm{i}}\right)$ for correction, it is calculated as follows:

$$
\operatorname{LOI}_{i}(\%)=\frac{(100-x) * L O I_{i(P C)}+x * L O I_{i(S C M)}}{100}
$$

Where: $x=$ Replacement level of SCM $(\%)$

$L O I_{i(P C)}=$ Initial loss on ignition of cement $(\%)$

$L O I_{i(S C M)}=$ Initial loss on ignition of SCM $(\%)$

The second important quantity is the decomposition of the calcium hydroxide which occurs in the range of $440^{\circ} \mathrm{C}$ and $550^{\circ} \mathrm{C}$. The $\mathrm{Ca}(\mathrm{OH})_{2}$ gives an indication of the SCM degree of pozzolanic reaction. To obtain the $\mathrm{Ca}(\mathrm{OH})_{2}$ content, the difference in mass between the start and end of the reaction is found. The starting temperature of $\mathrm{Ca}(\mathrm{OH})_{2}$ decomposition corresponds to the maximum point on the energy flow curve in the temperature range of $400^{\circ} \mathrm{C}$ to $500^{\circ} \mathrm{C}$. The end temperature at which the decomposition of $\mathrm{Ca}(\mathrm{OH})_{2}$ is completed is obtained from the first derivative of the mass loss curve where the end temperature corresponds to the maximum in the temperature range of $500^{\circ} \mathrm{C}$ to $600^{\circ} \mathrm{C}$. The difference in mass loss between these two temperatures is the decomposition of the $\mathrm{Ca}(\mathrm{OH})_{2}$. The mass loss is taken as a percent of the ignited mass at $1050^{\circ} \mathrm{C}$. Similarly to NEW, the obtained mass loss corresponding to the decomposition of the $\mathrm{Ca}(\mathrm{OH})_{2}$ is corrected for the initial loss on ignition of the sample. The method of calculation is explained in more details in Appendix C.

\section{Powder Leaching Test}

This test was done to see the alkali release of different samples incorporating SCM. Prior to testing, the samples are crushed and screened to a size of $2.36 \mathrm{~mm}$ to $1.18 \mathrm{~mm}$. The ratio of paste to solution is 1:10. The solutions were prepared at the same $\mathrm{Na}_{2} \mathrm{O}$ to $\mathrm{K}_{2} \mathrm{O}$ ratios as those in the cementing materials $(\mathrm{PC}+\mathrm{SCM})$ of the sample being tested, i.e., for samples with $15 \% \mathrm{FA}$, the total $\mathrm{Na}_{2} \mathrm{O}$ in the blend is equal to $15 \% * \mathrm{Na}_{2} \mathrm{O}(\mathrm{FA})+85 \% * \mathrm{Na}_{2} \mathrm{O}(\mathrm{PC})$, similarly for the $\mathrm{K}_{2} \mathrm{O}$ content. The samples were shaken for a week and they were weighed before and after the shaking to make sure no evaporation occurred. Sodium and potassium ions concentrations were determined by flame photometry and reported as $\%$ of the binder mass. A sample calculation is provided in 
Appendix D. This test will allow the determination of the alkalis released from the sample into the hosting solution.

\section{$\underline{\text { Scanning Electron Microscopy Analysis }}$}

Fragment samples dried in the desiccators were polished using a $0.3 \mu \mathrm{m}$ diamond grade and then carbon coated using Edwards Vacuum Coating System. The samples were then examined by a JEOL JSM-6380 LV scanning electron microscope. The purpose is to study the effect of temperature on the hydration of SCM and their ability to bind alkalis.

\subsubsection{Bridge Barriers and Cores Testing}

Four barriers obtained from a bridge in Sudbury Ontario, were put at an outdoor exposure site in Toronto, Ontario and monitored for expansion as shown in Figure 3.11. Two of them, taken from the north east ramp, suffer high level of deterioration and the other two, from the north west side, showed less signs of deterioration. Each road barrier had holes drilled into it to add studs for measurements. The installation of the studs was explained in more details in Piersanti's thesis (2015). The studs were 20 inches apart from each other and the length change was measured using a Whittemore strain gauge. The data obtained was corrected for thermal expansion depending on the concurrent weather conditions at the day of measurements. The thermal expansion equation is as follows:

$$
\Delta_{L}=\alpha *\left(T_{i}-T_{0}\right) * L
$$

Where: $\Delta_{L}=$ Thermal expansion

$\alpha=$ Coefficient of thermal expansion, $10 * 10^{-6}(\underline{o} C)$

$T_{i}=$ Temperature at the age $i$

$T_{0}=$ Temperature at zero reading

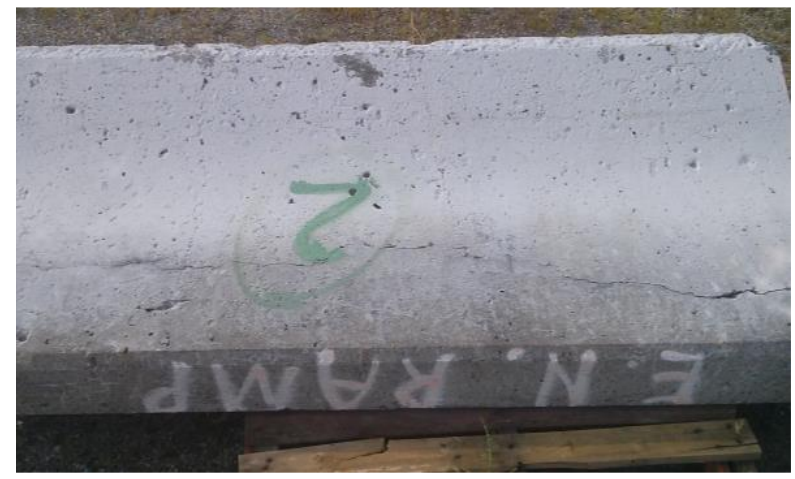

(a)

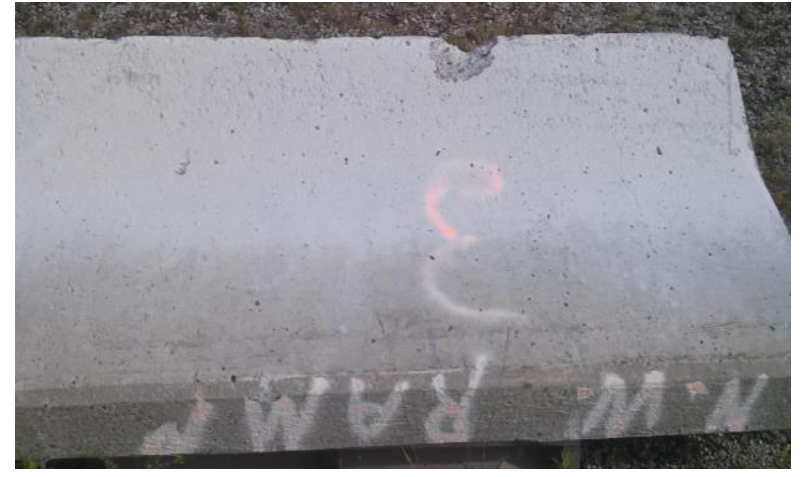

(b)

Figure 3.11: (a) High deteriorated barrier, (b) low deteriorated barrier (Piersanti et al., 2015) 
Four cores were extracted from these bridge barriers, two from the high deteriorated ones and two from the low deteriorated barriers. Holes were drilled to add the studs on the two cross-sectional surfaces as explained in Piersanti's thesis (2015) to allow measurements of the length change along the longitudinal axis. Then, they were stored in containers above water at $38^{\circ} \mathrm{C}$ and monitored for expansion. Measurements were done using an outside micrometer with a 0.0001 " precision as shown in Figure 3.12 (a). At 80 weeks, the cores were taken out and soaked in an alkaline solution of $0.4 \mathrm{M}$, prepared with same $\mathrm{Na}_{2} \mathrm{O} / \mathrm{K}_{2} \mathrm{O}$ ratio $(\mathrm{Na} / \mathrm{K})$ as that of the $\mathrm{PC}$, using cylindrical molds of $\varnothing 150 \mathrm{~mm}$ and $300 \mathrm{~mm}$ length as shown in Figure 3.12 (b). At each measurement, the mass of the sample (core + solution + container) was checked and adjusted for evaporation by adding distilled water to keep the concentration constant. After 12 weeks, the cores were taken out, soaked in 0.6 $\mathrm{M} \mathrm{Na} / \mathrm{K}$ solution and monitored for expansion. Soaking of cores helps in understanding the effect of the solution alkalinity on the residual expansion of low and high deteriorated cores.

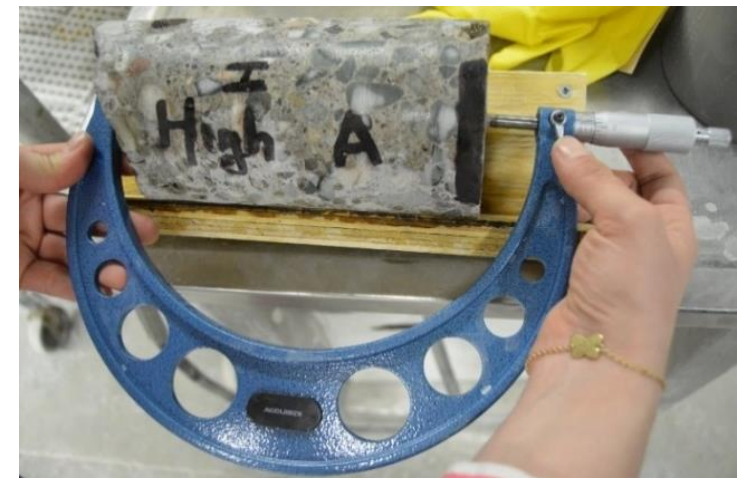

(a)

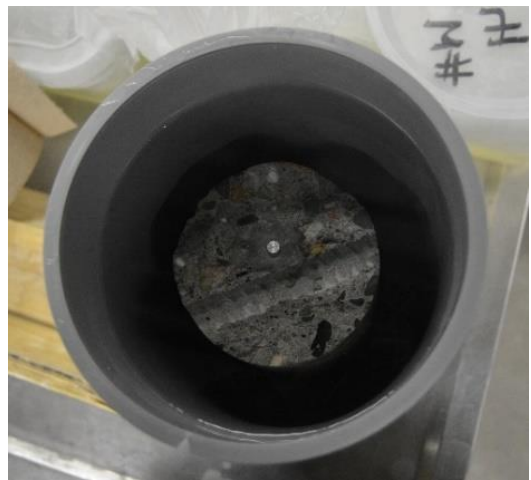

(b)

Figure 3.12: Cores (a) measurements and (b) soaking

\subsubsection{Testing of Alkali Content of Concrete Chunks Obtained from the Barriers}

The aim of testing concrete chunks obtained from the bridge barriers is to measure the remained alkalis, whether inside the stone or cement to understand the role of alkalis on the residual expansion of field barriers and cores. One low deteriorated core and one highly deteriorated were used to obtain the concrete chunks. The cores were crushed to coarse aggregate size using the hammer. Then, the fragments were crushed using the jaw crusher until $100 \mathrm{~g}$ samples constituted of $50 \mathrm{~g}$ passing $4.75 \mathrm{~mm}$ sieve and retained on $2.36 \mathrm{~mm}$ sieve, and $50 \mathrm{~g}$ passing $2.36 \mathrm{~mm}$ sieve and retained on $1.18 \mathrm{~mm}$ sieve were obtained. Three samples from each core were prepared and the average alkali release from the samples was reported. The crushed samples were soaked in 110 $\mathrm{mL}$ saturated $\mathrm{Ca}(\mathrm{OH})_{2}$ solution and were shaken at $38^{\circ} \mathrm{C}$ for 7 days. The concentrations of $\mathrm{Na}^{+}$ 
and $\mathrm{K}^{+}$ions were measured and the released alkalis were reported as percent of the sample total mass. A sample calculation is provided in Appendix E.

\subsubsection{RCA Prisms and Cylinders Expansion Testing}

Standard prisms (75 mm x $75 \mathrm{~mm}$ x $285 \mathrm{~mm}$ ) and cylinders ( $\varnothing 100 \mathrm{~mm}$ x $200 \mathrm{~mm}$ ) were cast using Sudbury RCA aggregates and two different cement contents: (1) standard mix of $420 \mathrm{~kg} / \mathrm{m}^{3}$ as specified in CSA A23.2-14A (2014) and (2) bridge mix - $360 \mathrm{~kg} / \mathrm{m}^{3}$ - which is believed to be the cement content of the bridge from where the barriers were taken. Two types of Sudbury RCA were used, one obtained from the high deteriorated barriers and the other from the barriers with low level of deterioration. The bulk relative density and absorption of the Sudbury RCA are 2.359 and $3.873 \%$, respectively. The casting procedure as well as the fabrication of the molds and addition of studs can be found in Piersanti's thesis (2015). The samples were stored in containers above water as specified in CSA A23.2-14A (2014). Expansion measurements up to 2 years, done using an outside micrometer with a 0.0001 " precision, were taken to study the effect of the sample shape and the alkali content on expansion. It should be noted that the expansions up to 1 year of RCA samples was done by another graduate student at Ryerson University (Piersanti, 2015).

\subsubsection{Mineral Fillers Testing}

\section{Sample Preparation}

\section{$\underline{\text { Sieving of Fine Aggregates }}$}

The gradation of mortar samples is similar to the one specified in the AMBT described in ASTM C1260 (2014). The aggregates follow the gradation shown in Table 3.6 expressed by mass of the total sample $(990 \mathrm{~g})$ required to obtain three samples for each set.

Table 3.6: Grading required as specified in ASTM C1260 (2014)

\begin{tabular}{ccc}
\hline Passing & Retained on & Mass (\%) \\
\hline \hline $4.75 \mathrm{~mm}$ & $2.36 \mathrm{~mm}$ & 10 \\
$2.36 \mathrm{~mm}$ & $1.18 \mathrm{~mm}$ & 25 \\
$1.18 \mathrm{~mm}$ & $600 \mu \mathrm{m}$ & 25 \\
$600 \mu \mathrm{m}$ & $300 \mu \mathrm{m}$ & 25 \\
$300 \mu \mathrm{m}$ & $150 \mu \mathrm{m}$ & 15 \\
\hline
\end{tabular}


Thus, Sand 1 and Sand 2 were sieved until the gradations needed were obtained. Each portion was then washed over its own sieve and dried in the oven.

\section{Crushing of Spratt}

To obtain Spratt aggregates with the gradation listed in Table 3.6, a representative sample of $6 \mathrm{kgs}$ was crushed using the jaw crusher until all the aggregates passed $4.75 \mathrm{~mm}$ sieve. The crushing of $6 \mathrm{kgs}$ was enough to obtain the required gradation. Once, the crushing is done, each portion is washed over its own sieve and dried.

\section{Crushing of Springhill}

Springhill was used as one of the mineral fillers, obtained from reactive aggregate. Springhill aggregate was a mix of fine and coarse aggregates so they were separated to be able to test the reactivity of each. For the coarse portion, they were washed over $4.75 \mathrm{~mm}$ sieve to remove all the finer particles and the fine portion was washed over $75 \mu \mathrm{m}$ to remove all the dust and then they were dried. The coarse aggregate was crushed using the jaw crusher first until all passed sieve 4.75 $\mathrm{mm}$. The sample is then sieved over the fine sieves and each portion is crushed using the pulverizer until all passed $75 \mu \mathrm{m}$ to obtain SH-C filler. For the SH-C-70\% passing $75 \mu \mathrm{m}$, each portion is crushed until $30 \%$ passes sieve $150 \mu \mathrm{m}$ and retained $75 \mu \mathrm{m}$ and $70 \%$ passed $75 \mu \mathrm{m}$ sieve. For the fine Springhill aggregate, it was sieved and larger size aggregates were crushed with the pulverizer until all passed the designated sieve. Then, the same procedure is applied for the subsequent aggregates retained on smaller sizer sieves until all passed $75 \mu \mathrm{m}$ sieve obtaining SH-F filler.

\section{Samples used for the tests}

Two different replacement methods are tested in this research:

1. Replacing the finest portion of the sand by filler: as an example, for a $10 \%$ replacement level, all will be replaced from the portion passing $300 \mu \mathrm{m}$ and retained on $150 \mu \mathrm{m}$ and only $5 \%$ by mass will be left from this sand size. For $20 \%$ replacement level, all the particles passing $300 \mu \mathrm{m}$ and retained on $150 \mu \mathrm{m}$ will be eliminated in addition to $5 \%$ that will be taken out from the portion passing sieve $600 \mu \mathrm{m}$ and retained on $300 \mu \mathrm{m}$ size (Table 3.6). 
2. Replacing the total graded aggregate by filler: for example, for $10 \%$ replacement level, a $10 \%$ of the total aggregate mass $(990 \mathrm{~g})$ will be removed and replaced with filler. The rest $891 \mathrm{~g}$ will be distributed based on the required gradation listed in Table 3.6.

\section{Mixing of Mortars}

The mixing procedure followed is as specified in the standard described in ASTM C305 (2014). The water to cement ratio was 0.47 for all the samples as required in (ASTM C1260, 2014)except for the Spratt control which was 0.5. The water is put first in the mixer and then the cement. They were mixed for 30 seconds at low speed. After, the fine aggregate and the filler used are added to the paste over a 30-second period during mixing. After 30 seconds, the speed of the mixer was changed to medium and the sample was mixed for 30 seconds. This is followed by a 90 seconds of rest period and then 90 seconds of mixing at medium speed.

\section{Flow Test for Mortars}

The workability of mortars was measured as specified in ASTM C1437 (2015). After mixing is completed, a first layer of about $25 \mathrm{~mm}$ thickness was put in the mold on the flow test table and rodded 20 times. A second layer was added until the top of the mold and tamping was performed similar to the first layer. After, the mold was removed and immediately the flow table was dropped for 25 times. The diameter of the sample was taken from four different angles. The flow is the change in the average diameter and is expressed as a percent of the inner diameter of the mold's base.

\section{Accelerated Mortar Bar Test}

The procedure followed is similar to the one described in ASTM C1260 (2014). The mixed samples were placed in $25 \times 25 \times 285 \mathrm{~mm}$ molds and were put in the curing room for one day. The next day, the samples were demolded and put in water at $80^{\circ} \mathrm{C}$ for another 24 hours. Following this, the samples were taken out from water and zero measurements were obtained. They were soaked after in $1 \mathrm{M} \mathrm{NaOH}$ solution and placed in an oven at $80^{\circ} \mathrm{C}$. Subsequent measurements were done at 1, 3, 7 days and then once per week until 56 days. After the testing period is done, the mortar bars were broken and a fragment was taken from the middle of the samples and SEM was carried out to study the reactivity of the mineral fillers. SEM analysis was done for 2 samples cast with sand 2 at 20\% replacement level with carbonate silica filler (CSF) and Springhill filler (SHC-70\% passing $75 \mu \mathrm{m})$. 


\section{Concrete Prism Test}

The coarse aggregate gradation as well as the ratio of fine to coarse used and the cement content were similar to that of the concrete samples used to test the effect of geometry on expansion as explained in Section 3.2.1. The water to cement ratio was increased to 0.45. The total mass of filler used was taken as a percent of the total coarse and fine aggregate in the mix. The filler replaced the fine aggregate portion in the mix. The Springhill fillers obtained from coarse aggregate crushing were tested using the CPT. All the samples were cast with limestone non-reactive aggregate and GU-0.95 and the alkalinity was raised to $1.25 \%$. Leaching of alkalis to the water at the bottom of the containers was also measured at 1 year for the different mixes as explained in Section 3.2.1. Table 3.7 shows a summary of the mixes that were used for the CPT samples.

Table 3.7: Mix design summary for mineral fillers testing using CPT

\begin{tabular}{ccccccc}
\hline Mix \# & $\begin{array}{c}\text { Coarse } \\
\left(\mathbf{k g} / \mathbf{m}^{\mathbf{3}}\right)\end{array}$ & $\begin{array}{c}\text { Fine } \\
\left(\mathbf{k g} / \mathbf{m}^{\mathbf{3}}\right)\end{array}$ & $\begin{array}{c}\text { SH-C } \\
\left(\mathbf{k g} / \mathbf{m}^{\mathbf{3}}\right)\end{array}$ & $\begin{array}{c}\text { Cement } \\
\left(\mathbf{k g} / \mathbf{m}^{\mathbf{3}}\right)\end{array}$ & $\begin{array}{c}\text { Water } \\
\left(\mathbf{k g} / \mathbf{m}^{\mathbf{3}}\right)\end{array}$ & $\begin{array}{c}\text { HRWR } \\
(\mathbf{m L})\end{array}$ \\
\hline \hline Control & 1065 & 710 & 0 & 420 & 189 & 0 \\
$\mathbf{5 \%}$ SH-C-70\% passing $\mathbf{7 5} \boldsymbol{\mu m}$ & 1065 & 621 & 89 & 420 & 189 & 4 \\
$\mathbf{1 0 \%}$ SH-C-70\% passing $\mathbf{7 5} \boldsymbol{\mu m}$ & 1065 & 532 & 178 & 420 & 189 & 20 \\
$\mathbf{2 0 \%}$ SH-C-70\% passing $\mathbf{7 5} \boldsymbol{\mu m}$ & 1065 & 355 & 355 & 420 & 189 & 32 \\
$\mathbf{1 0 \%}$ SH-C-100\% passing $\mathbf{7 5} \boldsymbol{\mu m}$ & 1065 & 532 & 178 & 420 & 189 & 27 \\
\hline
\end{tabular}




\section{Chapter 4}

\section{Results and Analysis}

\subsection{Effect of Sample Geometry and Aggregate Type on ASR}

The aim of this section is to study the effect of sample geometry and aggregate reactivity on alkali leaching and expansion due to ASR. Prisms, cylinders and cubes cast using three types of aggregates with different reactivity: Sudbury, Spratt and Springhill were studied with and without SCM. The non-reactive fine aggregate (sand 1) was used with all the samples investigated in this section.

\subsubsection{Expansion of Concrete Samples at $38^{\circ} \mathrm{C}$}

Expansions of prisms, cylinders and cubes cast with Sudbury and Spratt aggregates without SCM are shown in Figure 4.1 and Figure 4.2. Sudbury and Spratt cylinders had the highest expansion followed by the prisms while the cubes measured side-to-side had an expansion close to that of the prisms. The 1-year CPT expansions of concrete prisms were $0.17 \%$ for Sudbury and $0.21 \%$ for Spratt. Spratt cubes measured center-to-center had same expansion as the cylinders. The "cubes200 " curve represents the average expansion of three $200-\mathrm{mm}$ cubes that were initially cast with Sudbury. However, due to the heavy weight of these samples, only smaller size samples, i.e. 150$\mathrm{mm}$ cubes, were cast with the rest of the samples. 


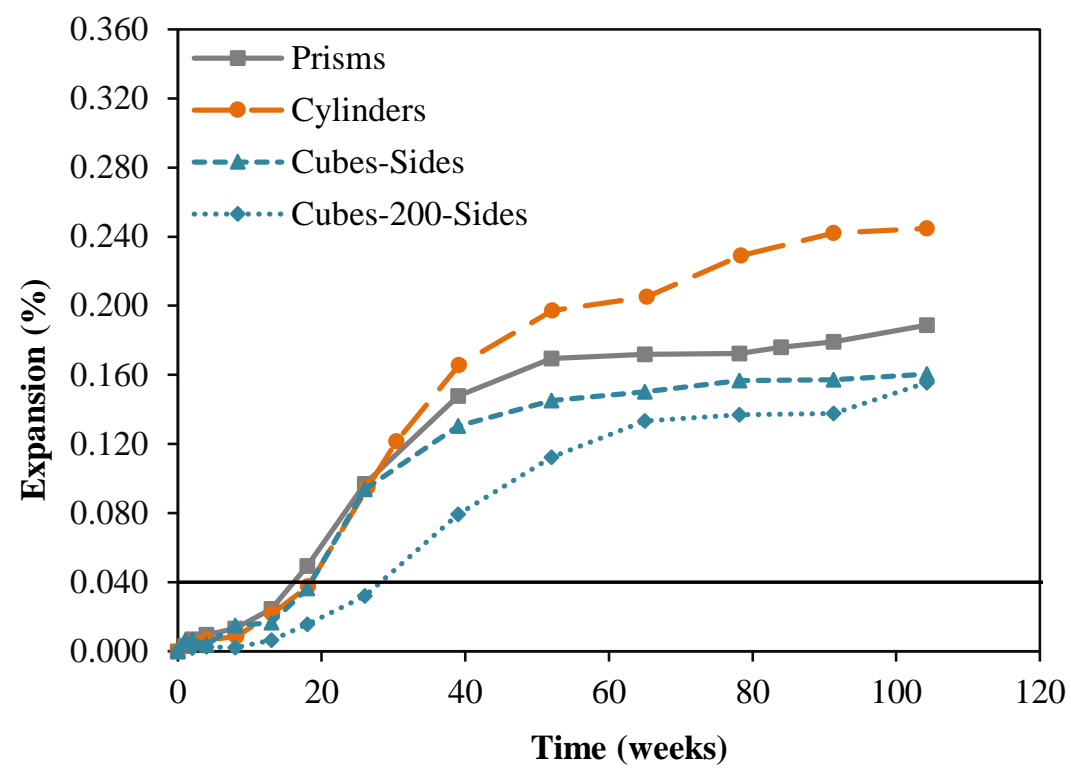

Figure 4.1: Expansion of concrete containing Sudbury aggregate without SCM at $38^{\circ} \mathrm{C}$

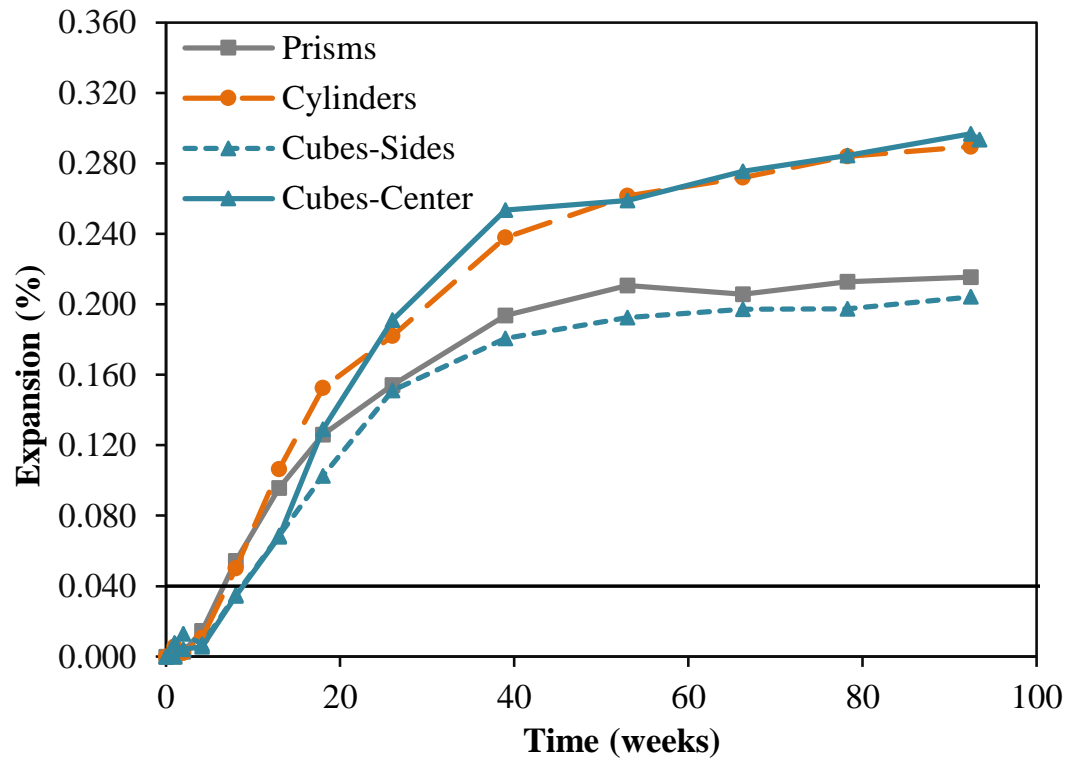

Figure 4.2: Expansion of concrete containing Spratt aggregate without $\mathrm{SCM}$ at $38^{\circ} \mathrm{C}$

Sudbury samples cast with 15\% FA and 25\% slag are shown in Figure 4.3 and Figure 4.4. Cylinders showed higher expansion compared to prisms and cubes. Prisms cast with $25 \%$ slag passed the CPT criterion having 2-year expansion below $0.040 \%$ (0.037\%). However, the cylinders failed to pass the CPT showing a 2-year expansion higher than $0.040 \%(0.064 \%)$. In the case of Sudbury with $15 \%$ FA, the prisms had a very low expansion $(0.017 \%)$ while the cylinders were close to fail having a 2-year expansion of $0.037 \%$. For the samples tested in this study, the 
cylinders are showing higher expansion compared to prisms and in some cases are showing different conclusions in terms of pass/fail in the case of concrete cast with Sudbury aggregate.

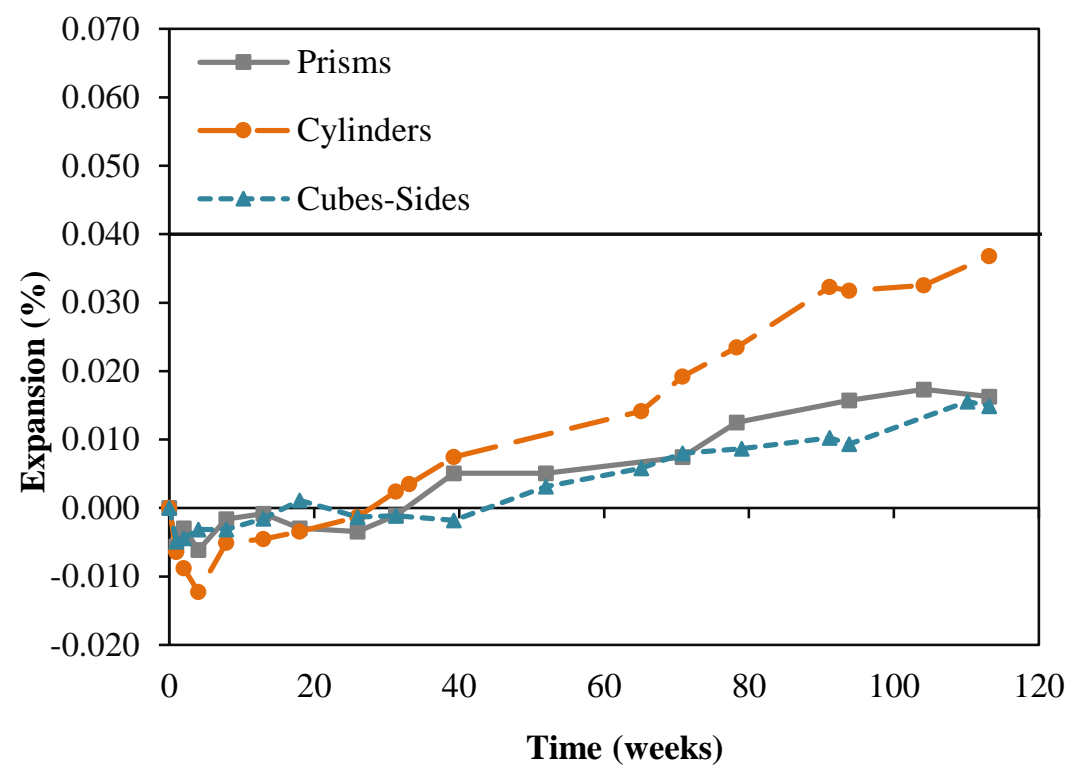

Figure 4.3: Expansion of concrete cast with Sudbury aggregate and $15 \% \mathrm{FA}$ at $38^{\circ} \mathrm{C}$

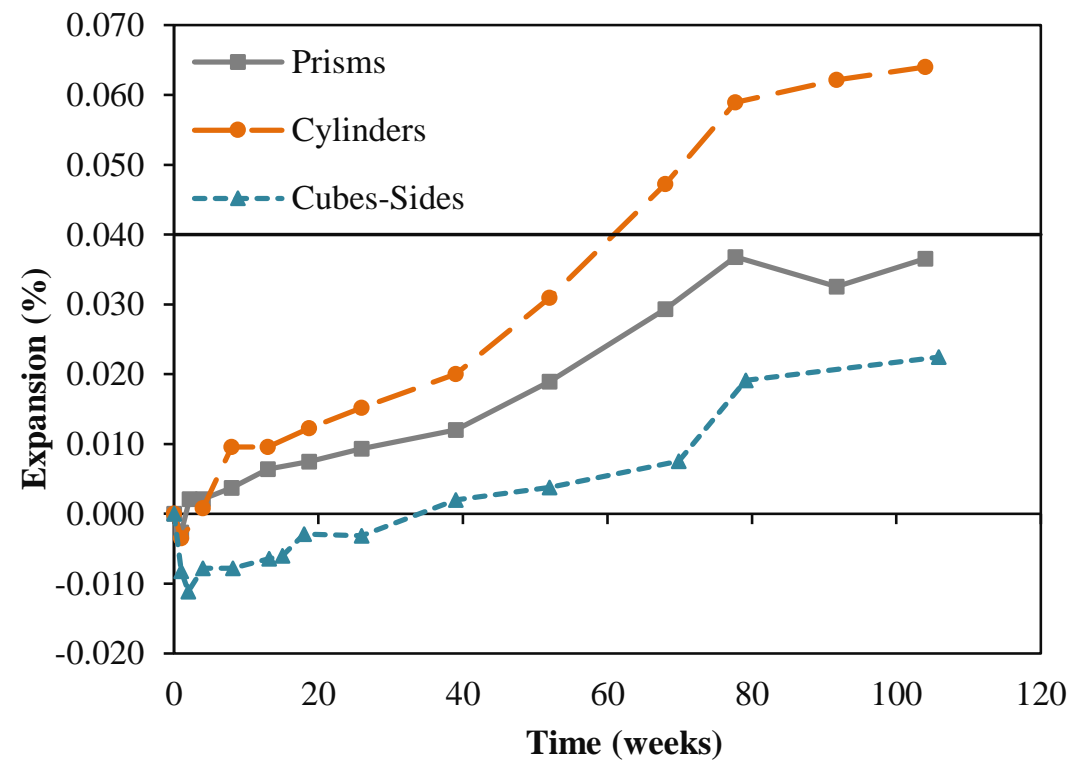

Figure 4.4: Expansion of concrete cast with Sudbury aggregate and $25 \%$ slag at $38^{\circ} \mathrm{C}$

The 2-year expansion results for Spratt samples with 15\% and 20\% FA are presented in Figure 4.5 and Figure 4.6. The minimum level of Class F FA required to pass the CPT was found to be $20 \%$ for concrete cast with Spratt aggregate. Prisms cast with 20\% FA showed an expansion of $0.035 \%$ 
below the expansion limit of $0.040 \%$ (Figure 4.6) while samples with 15\% FA had an expansion of $0.053 \%$ (Figure 4.5). Cylinders showed similar conclusions since they had same expansions as the prisms, although cylinders with 15\% FA expanded slightly more compared to prisms. The trend obtained with the Spratt samples incorporating SCM was different that that reached with Sudbury samples which showed clearly higher expansion with the cylinders compared to prisms. Spratt samples with 35\% and 50\% slag were also tested as shown in Figure 4.7 and Figure 4.8.

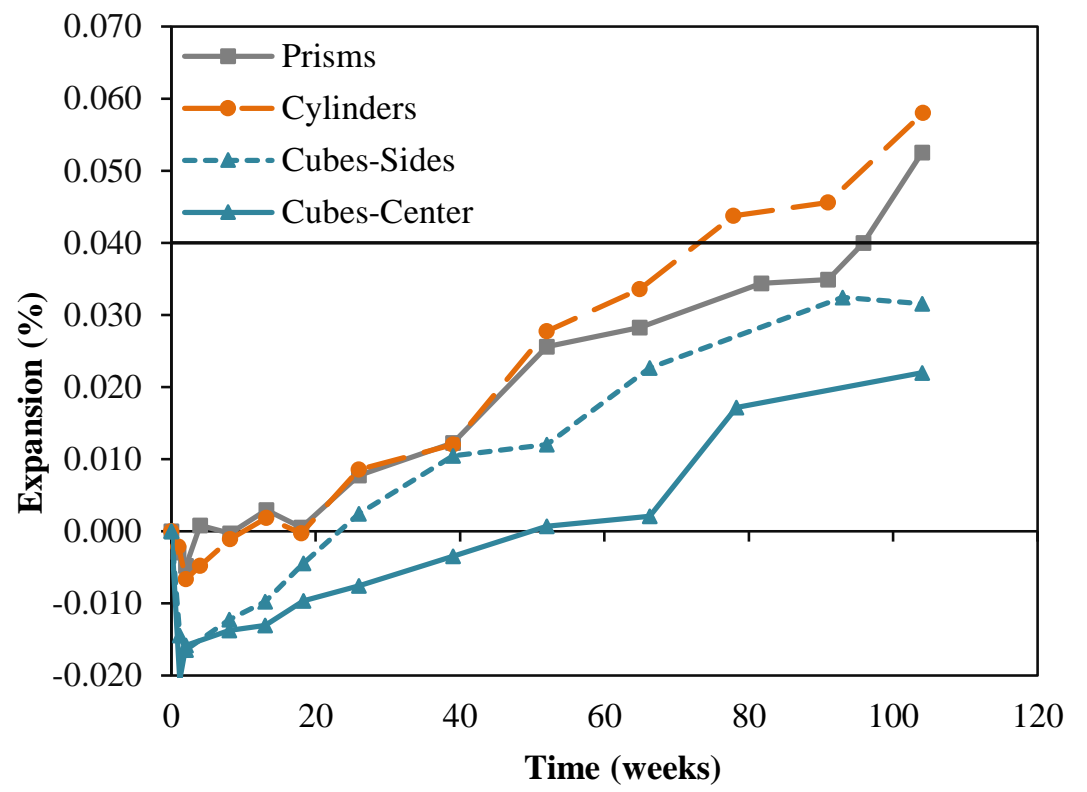

Figure 4.5: Expansion of concrete cast with Spratt aggregate and $15 \%$ FA at $38^{\circ} \mathrm{C}$

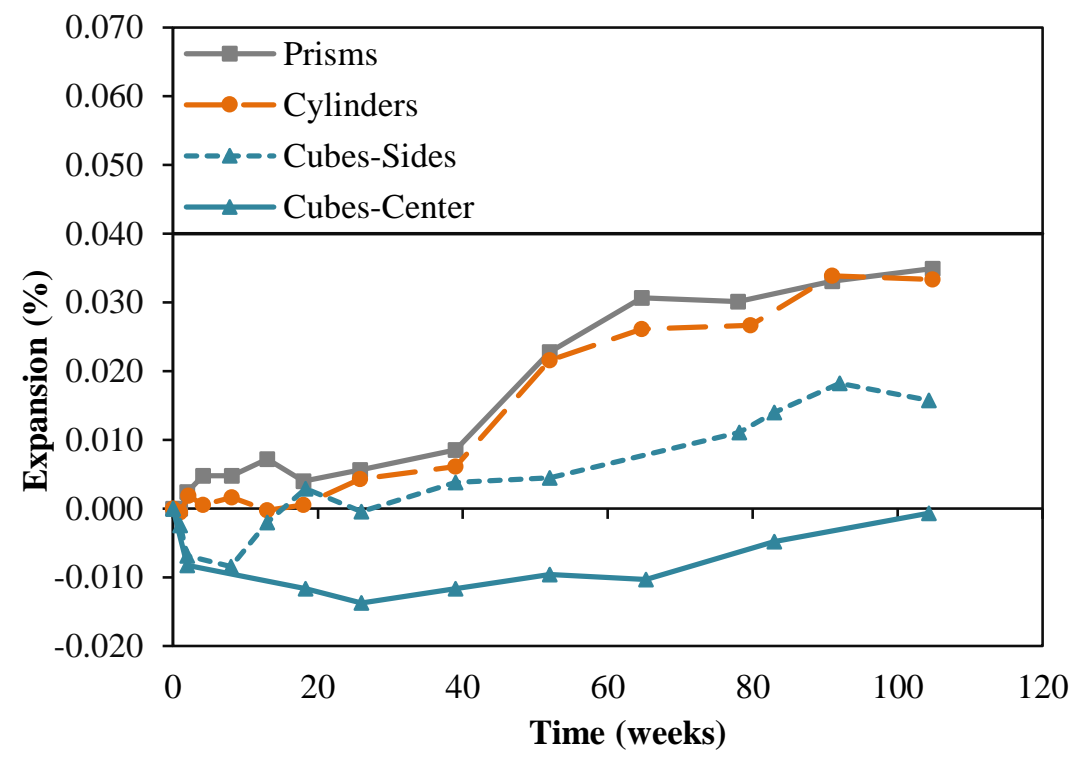

Figure 4.6: Expansion of concrete cast with Spratt aggregate and $20 \%$ FA at $38^{\circ} \mathrm{C}$ 


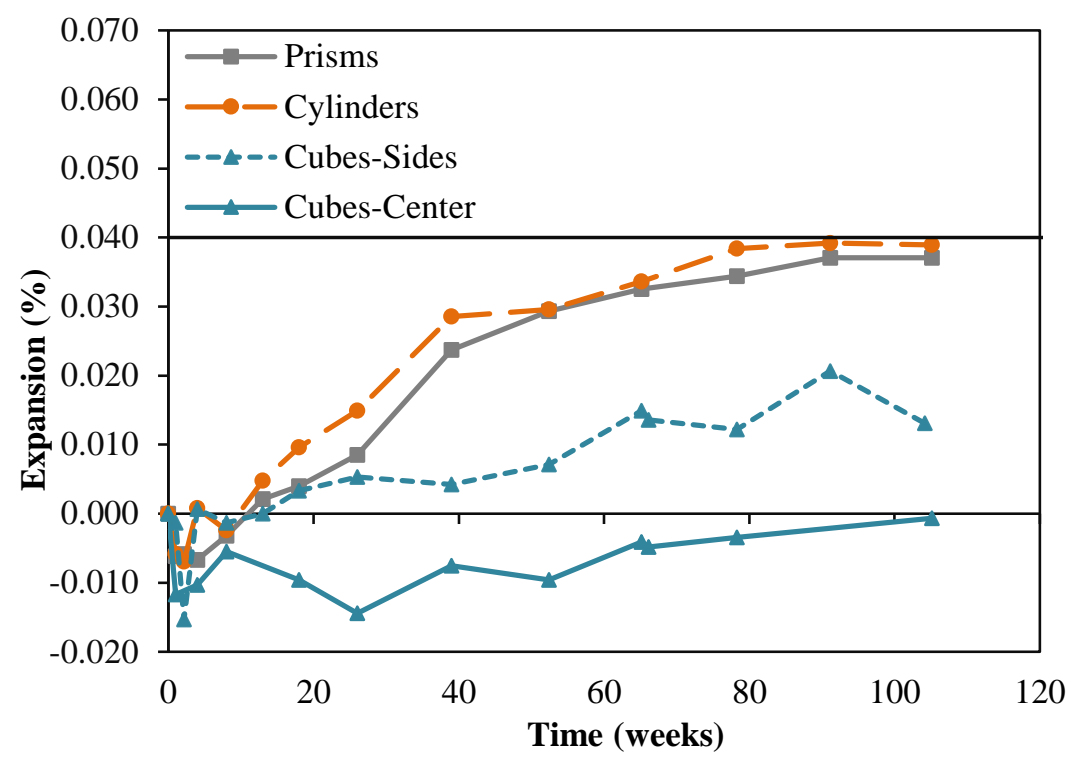

Figure 4.7: Expansion of concrete cast with Spratt aggregate and 35\% slag at $38^{\circ} \mathrm{C}$

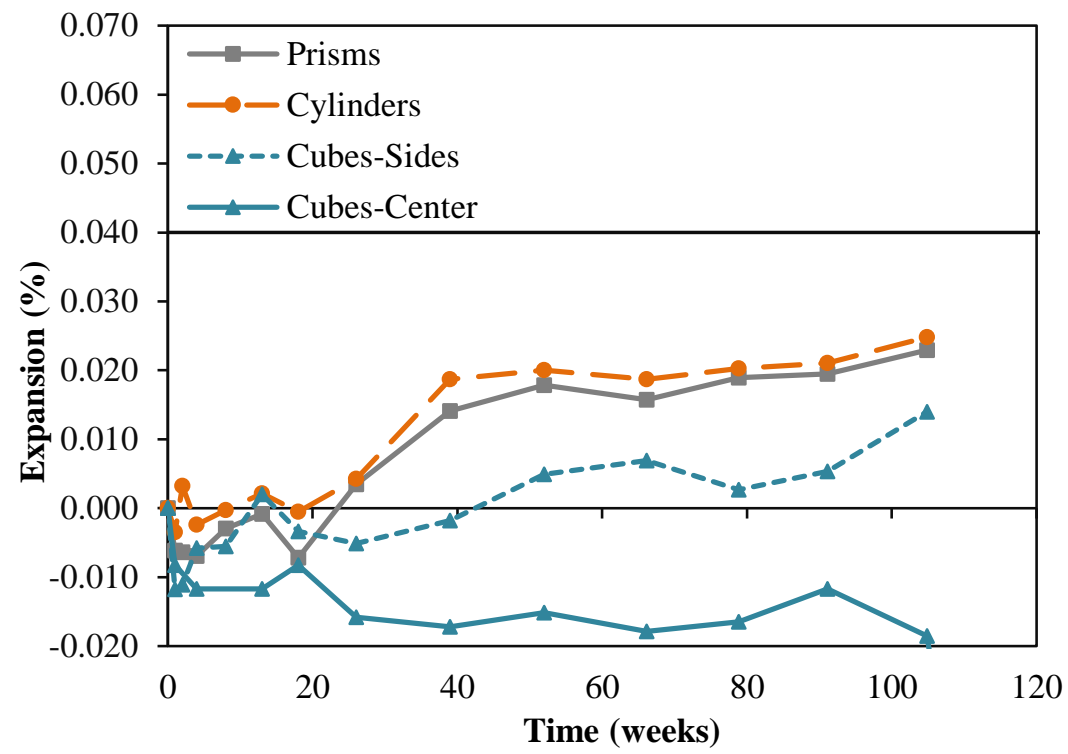

Figure 4.8: Expansion of concrete cast with Spratt aggregate and $50 \%$ slag at $38^{\circ} \mathrm{C}$

Prisms and cylinders both are showing same expansions with all the different Spratt/SCM combinations which was not observed with Sudbury/SCM combinations. Similar results for Spratt samples with GUB-8SF were obtained as shown in Figure 4.9. Spratt prisms and cylinders cast with GUB-8SF both showed a 2-year expansion of 0.039\% (Figure 4.9). Similarly, Spratt prisms and cylinders cast with GUB-8SF and 20\% FA showed close expansion at 2 years with a value of $0.011 \%$ for prisms and $0.015 \%$ for cylinders (Figure 4.11 ). In the case of Spratt samples with 
GUB-8SF and 15\% FA, the cylinders showed higher expansion (0.029\%) than the prisms expansion $(0.012 \%)$ as shown in Figure 4.10.

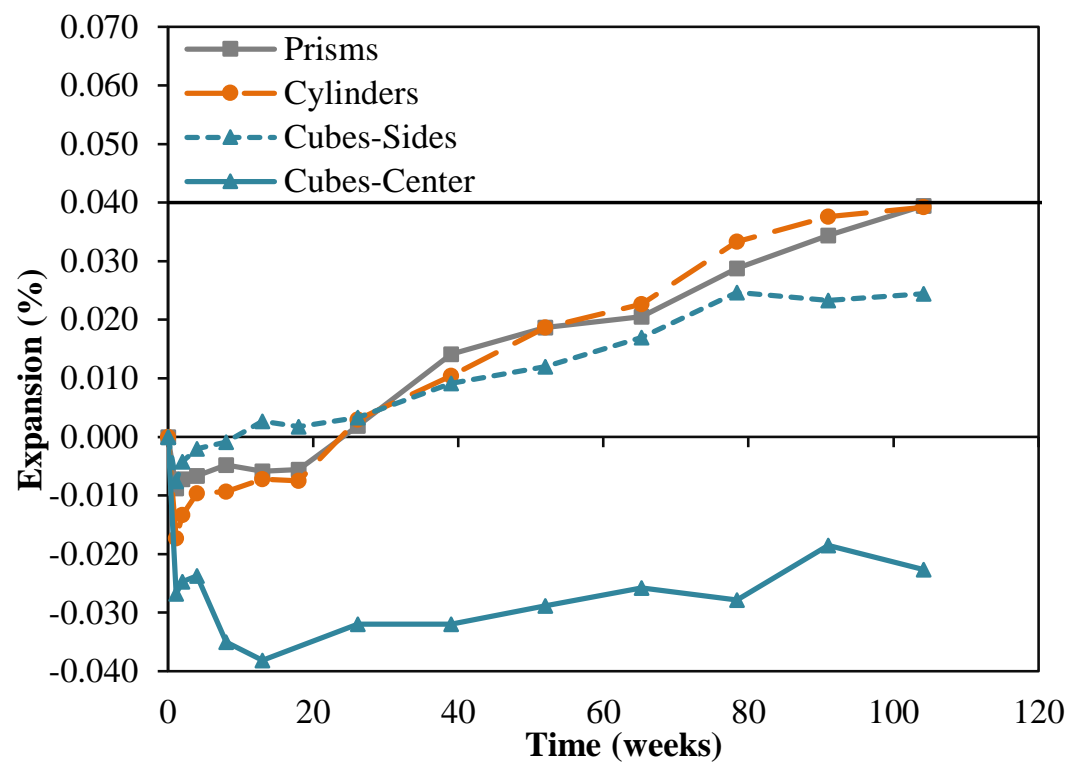

Figure 4.9: Expansion of concrete cast with Spratt aggregate and GUB-8SF at $38^{\circ} \mathrm{C}$

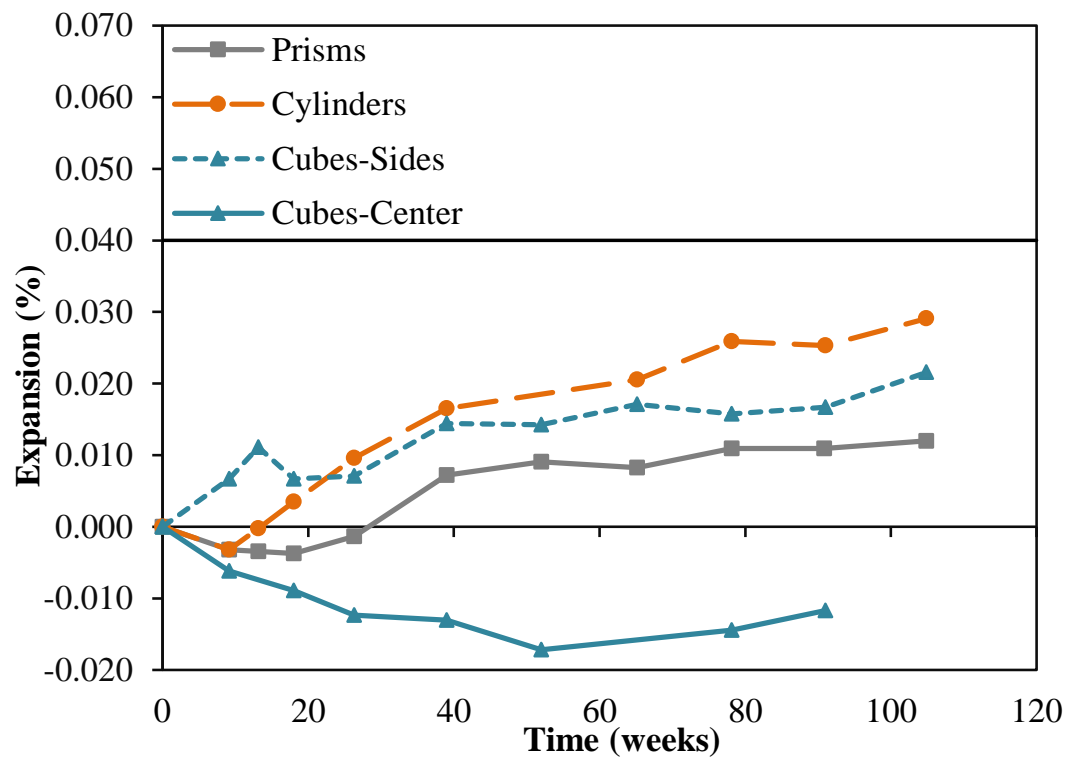

Figure 4.10: Expansion of concrete containing Spratt aggregate with GUB-8SF and 15\% FA at $3^{\circ} \mathrm{C}$ 


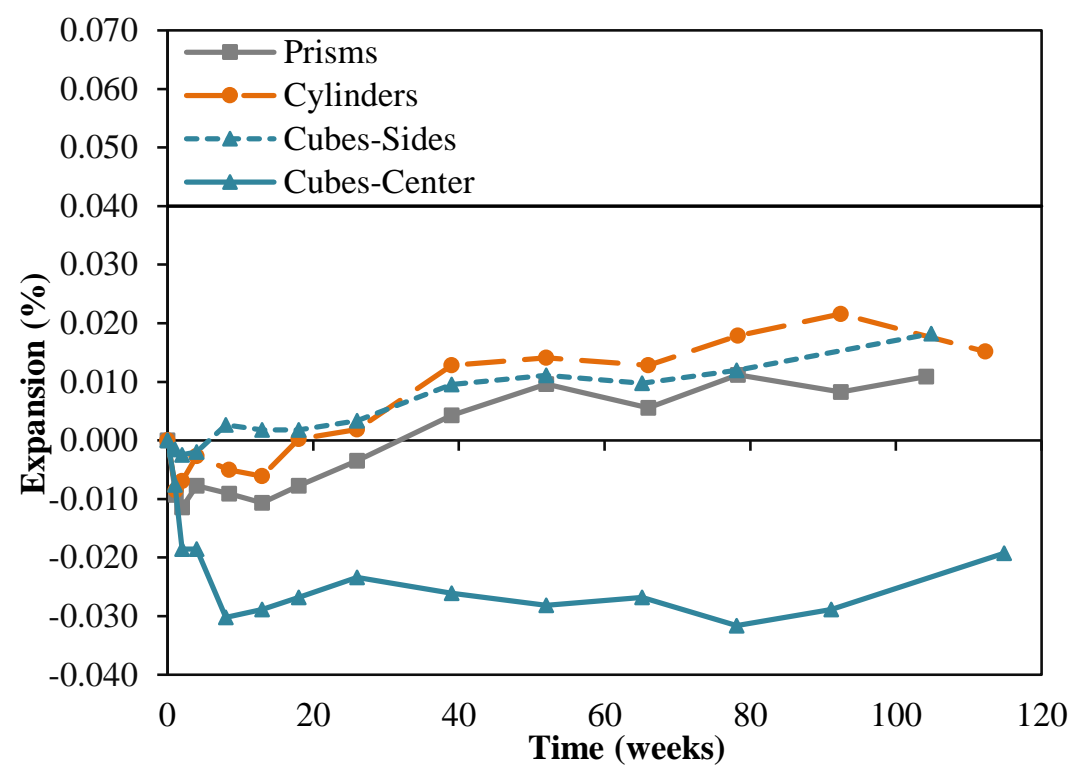

Figure 4.11: Expansion of concrete containing Spratt aggregate with GUB-8SF and 20\% FA at $3^{\circ} \mathrm{C}$

Springhill aggregate with 30\% FA were cast using prisms and cylinders and results are shown in Figure 4.12. Cylinders and prisms showed very similar expansions.

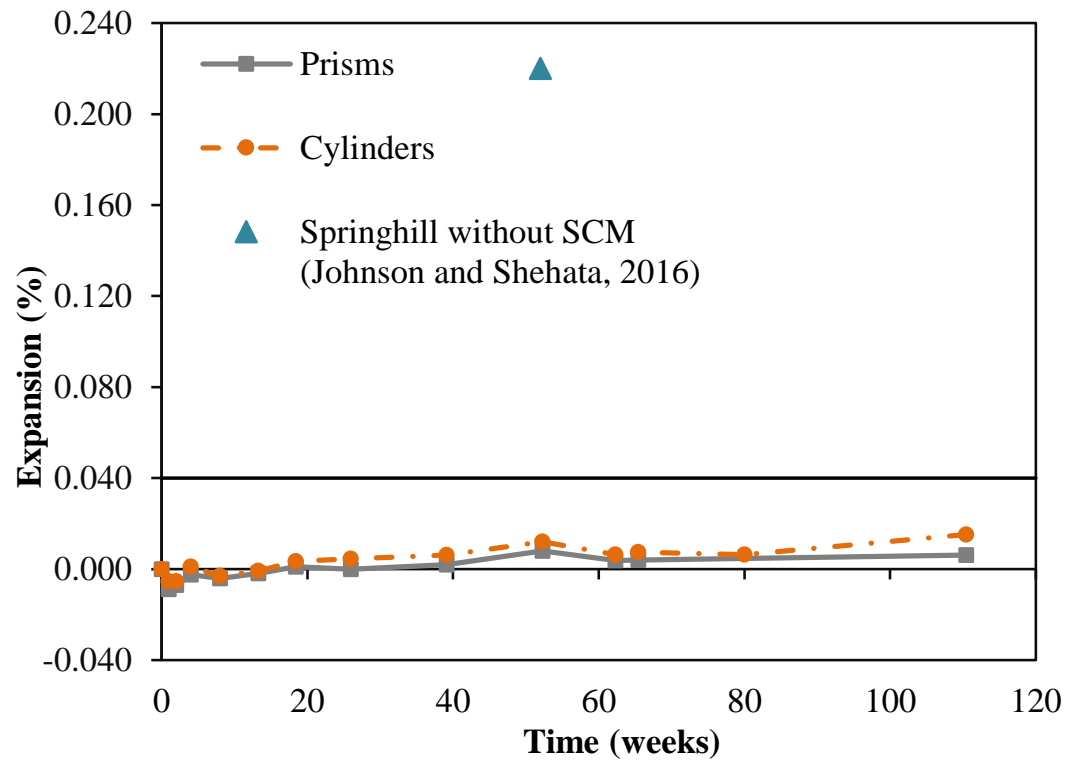

Figure 4.12: Expansion of concrete cast with Springhill aggregate and $30 \%$ FA at $38^{\circ} \mathrm{C}$

As a summary, Figure 4.13, Figure 4.14 and Figure 4.15 show a comparison between expansion of the different sample shapes for samples with no SCM, Sudbury samples with SCM and Spratt with SCM, respectively. The error bars correspond to the maximum and minimum expansion 
values in each set of three samples. Sudbury/Spratt control samples and Sudbury samples with SCM showed a statistically significant difference in expansion between prisms and cylinders as evaluated by t-test (Appendix F). For Spratt samples with SCM, all samples showed no statistically significant difference in expansion between prisms and cylinders except the case with ternary blend of GUB-8SF $+15 \%$ FA. The reasons that could explain the obtained results will be presented later in light of the alkali leaching from the concrete samples and the alkali release from aggregates.

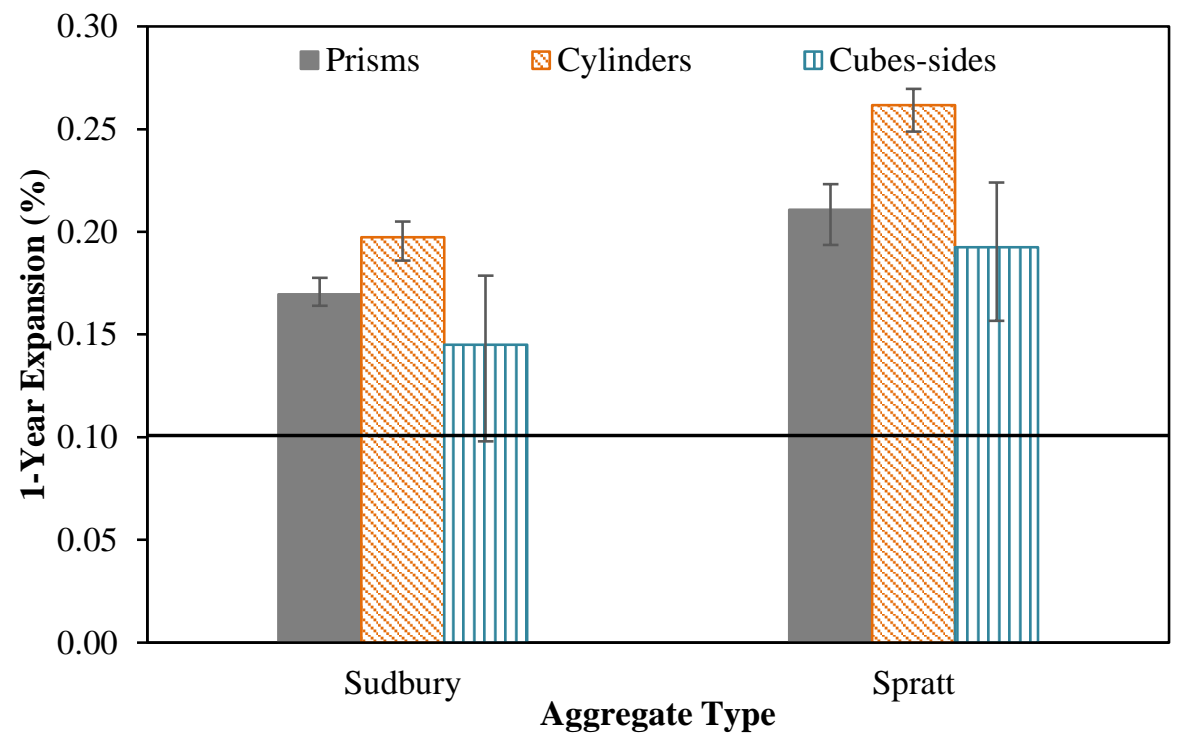

Figure 4.13: Expansion comparison of control samples with no SCM for different sample shapes

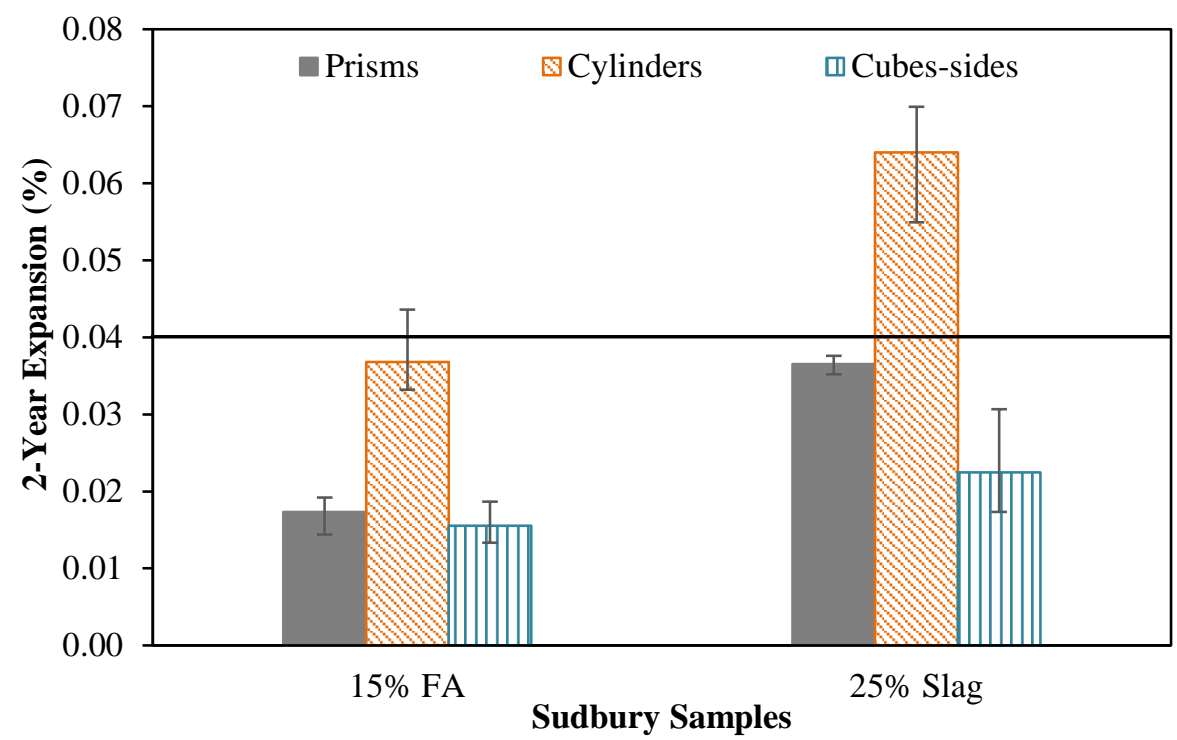

Figure 4.14: Expansion comparison of concrete cast with Sudbury and SCM for different sample shapes 


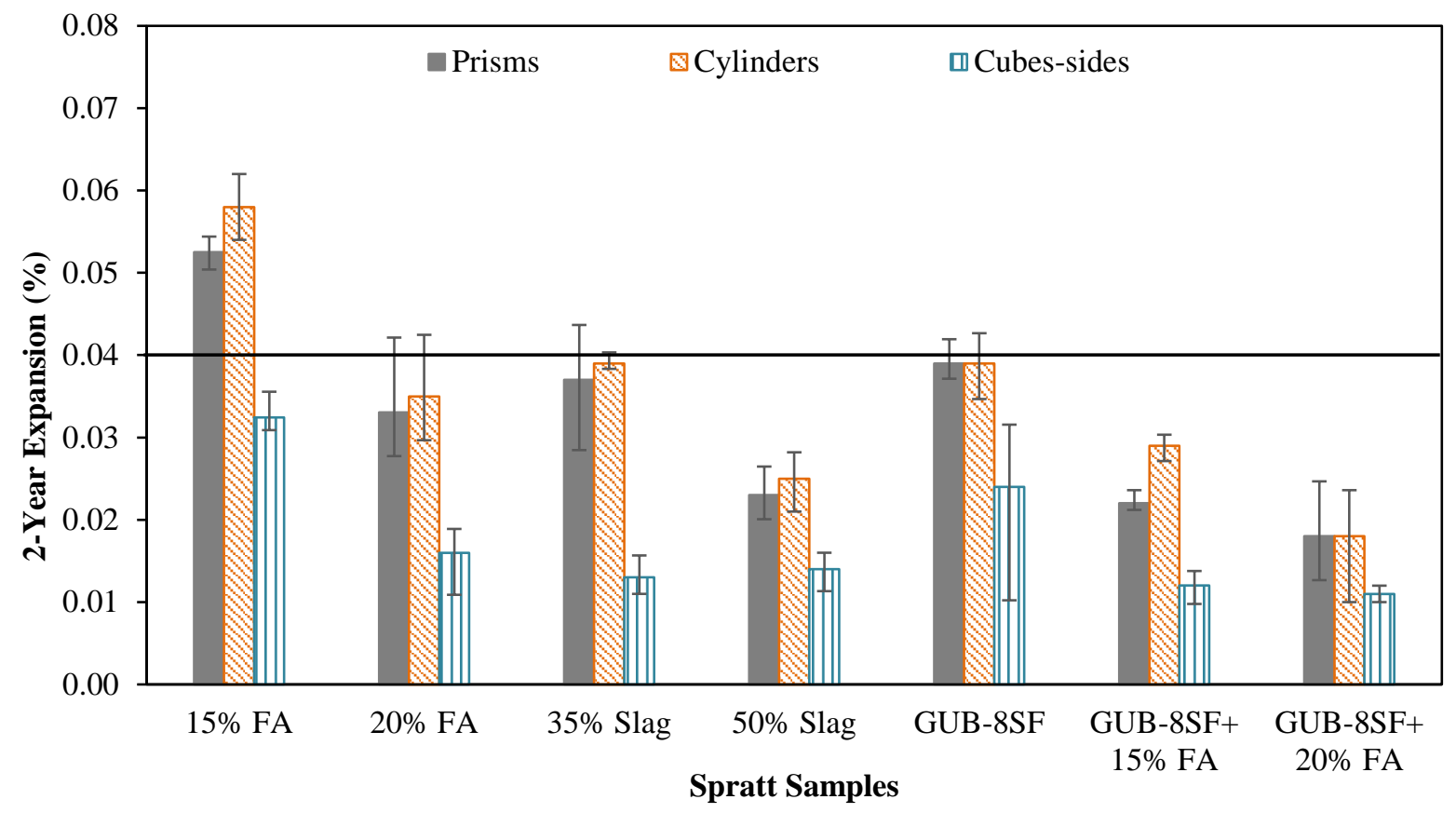

Figure 4.15: Expansion comparison of concrete cast with Spratt and SCM for different sample shapes

The coefficient of variation in each set of three cylinders or cubes was higher than that of the prisms (Appendix F). This is something to be taken into consideration when evaluating different sample shapes. The fabrication of molds in the laboratory in the case of cylinders and cubes could be the source of this variation. The manufacturing and uses of these molds may have resulted in the measuring studs being on a slight angle - instead of perfectly vertical - to the face of the samples. Using cast iron molds - as the case with the prisms - may alleviate this issue.

Figure 4.16 compares the expansion of prisms and that of the cylinders at 1 year for control samples and 2 years for samples cast with SCM. For samples cast with Spratt or Springhill aggregates, the 2-year expansions of prisms and cylinders cast with SCM both reached same conclusions in terms of passing or failing the CPT. In contrary, Sudbury samples showed a pass/fail relationship with one sample where the cylinders showed an expansion higher than $0.040 \%$ as opposed to the prisms which passed the CPT. For the other Sudbury sample, both cylinders and prisms passed the CPT however, the cylinders were very close to fail at 2 years whereas the prisms showed an expansion way below the expansion limit. Another way to interpret the obtained results in Figure 4.16 is by observing the deviation of the points from the $45^{\circ}$ line. Spratt samples with SCM are all on the line except for the Spratt cylinders cast with GUB-8SF and 15\% FA which showed higher 
expansion than the prisms. In addition, for the case of Spratt with 15\% FA, a slightly higher expansion was observed. For all Sudbury/SCM and Spratt or Sudbury control, the points are above the $45^{\circ}$ line.

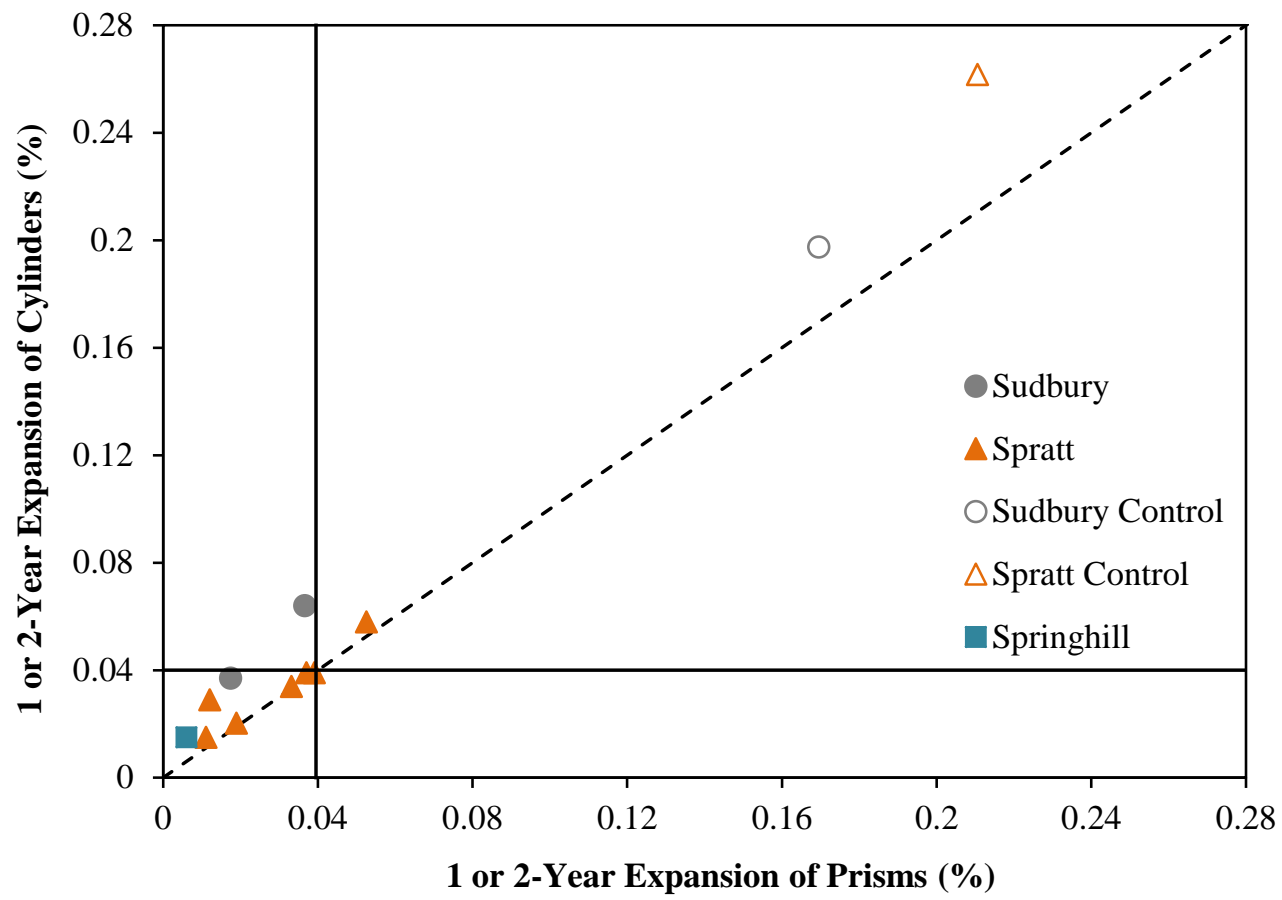

Figure 4.16: Expansion of cylinders versus prisms at 1 year for samples without SCM and 2 years for samples with SCM

In conclusion, cylinders are showing higher expansions compared to prisms in the case of Sudbury but not with Spratt/SCM combinations and Springhill with 30\% FA. Reasons for such behaviors will be explained in Section 4.1.2 and Section 4.1.3.

The cubes measured from the sides are showing either similar expansions to the prisms or the lowest expansion compared to cylinders and prisms. Similarly, the cubes measured center-tocenter showed the lowest expansion except with the Spratt control. In the latter, the expansion measured center-to-center showed higher expansion than the prisms with an expansion similar to that of the cylinders (Figure 4.2). The Sudbury cube samples were not measured center-to-center since the idea of measuring from the center came after casting the Sudbury samples.

\subsubsection{Alkali Leaching from Concrete Samples}

The alkalis leached from the concrete samples to the bottom of the containers were measured for all the sample geometries and results are presented in Figure 4.17 for Sudbury/Springhill and 
Figure 4.18 for Spratt. Sample calculations and detailed results of the concrete alkali leaching test are provided in Appendix A. Higher alkali released from concrete with Sudbury aggregate was obtained compared to concrete cast with Spratt. For example, prisms cast with Sudbury and Spratt showed an alkali leaching of $41 \%$ and $24 \%$, respectively.

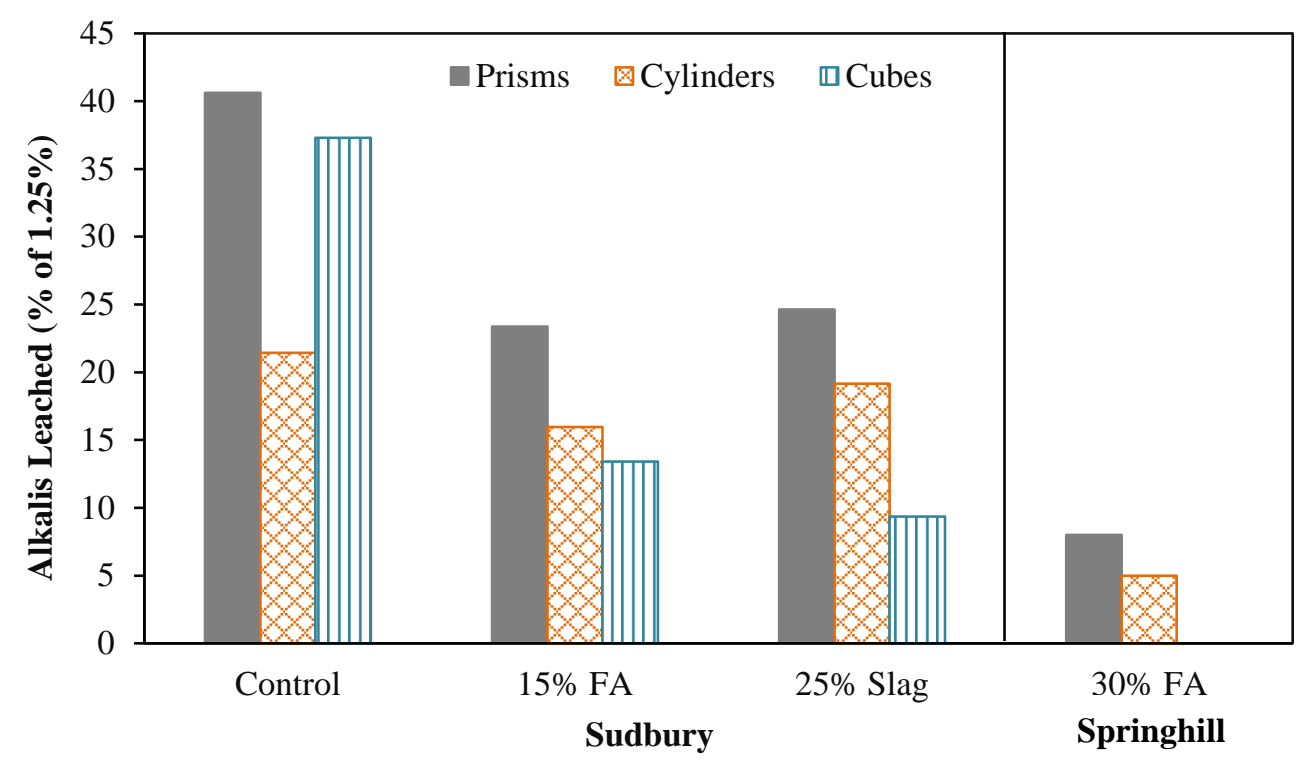

Figure 4.17: Alkalis leached from Sudbury and Springhill concrete samples at 1.5 years

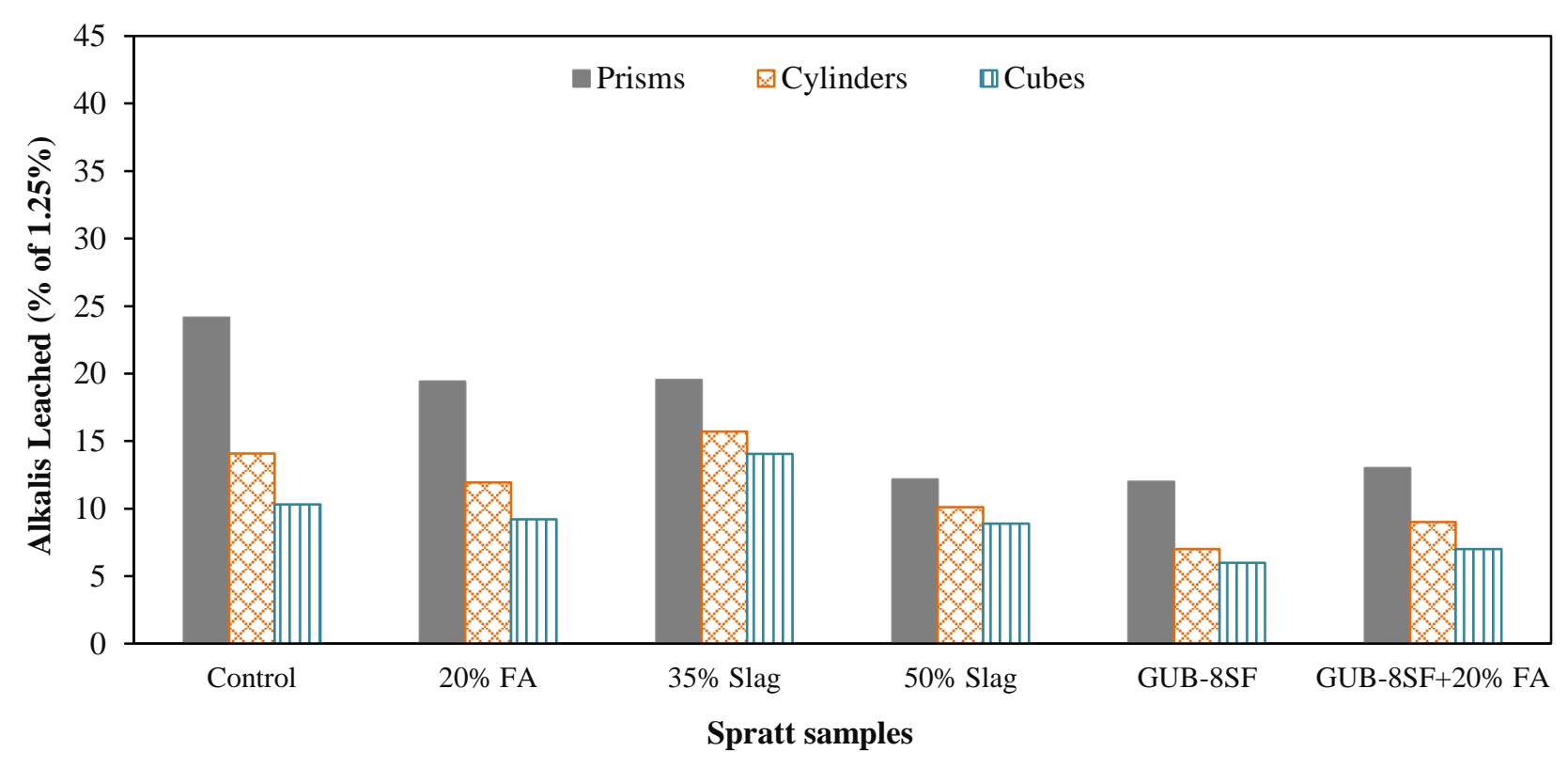

Figure 4.18: Alkalis leached from Spratt concrete samples at 1.5 years

In addition, prisms showed the highest leaching followed by cylinders and then cubes. This was the case with all the different aggregates except with the case of Sudbury control cubes which 
showed higher leaching compared to cylinders. The reasons that led to this are unknown. However, with all the other samples tested in this study, prisms showed the highest leaching. Hence, more leaching took place with smaller samples as was also reported by Bérubé, Fournier and Côté (2012), and Lindgård et al. (2013). Therefore, it would be expected to see higher expansion with the cylinders compared to prisms. This was the case with Sudbury/SCM and control Sudbury and Spratt samples. However, with Spratt/SCM combinations, cylinders and prisms showed similar expansions.

The fast reactivity of Spratt and thus its fast consumption of alkalis before leaching could be used to explain partly the lower alkali leaching from concrete cast with Spratt (24\%) compared to that with Sudbury (41\%). The expansion rate of Sudbury was four times lower than that of Spratt between 4 and 18 weeks as shown Figure 4.19(a) and Figure 4.20(a) explaining the fact that Spratt reacts faster than Sudbury. By 18 weeks, Sudbury reached only around $25 \%$ of the total 1-year expansion (Figure 4.19(b)) as compared to Spratt which already reached 60\% of the total 1-year expansion (Figure 4.20(b)). Due to its fast reactivity, Spratt could have consumed more alkalis compared to Sudbury leaving less free alkalis in the concrete pore solution to be leached out.

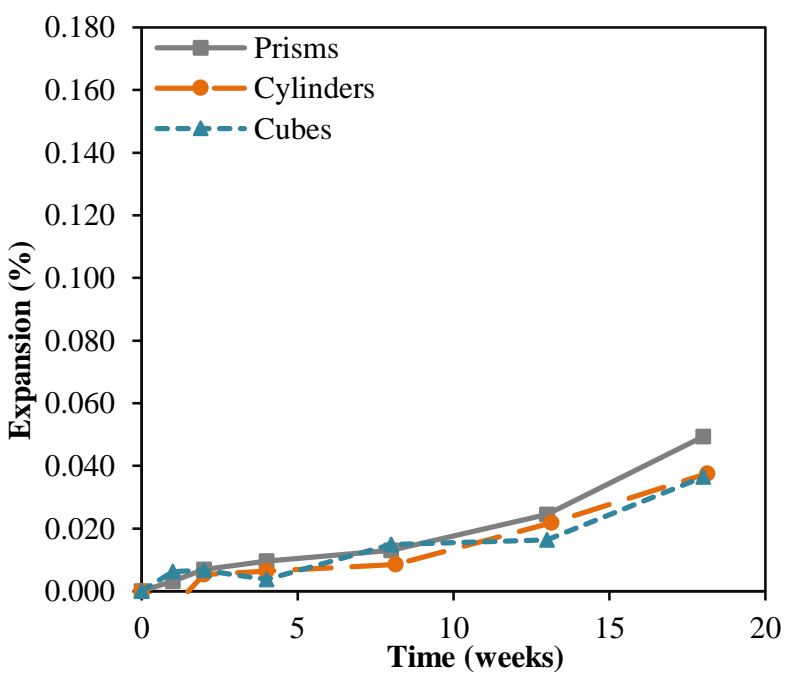

(a)

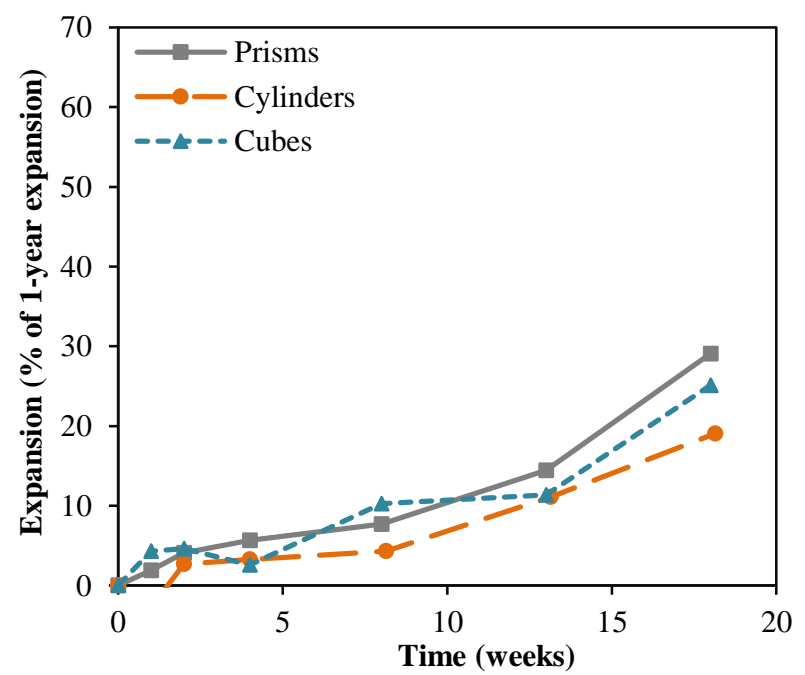

(b)

Figure 4.19: (a) Expansion of Sudbury samples without SCM until 18 weeks, (b) expansion taken as $\%$ of the total 1-year expansion 


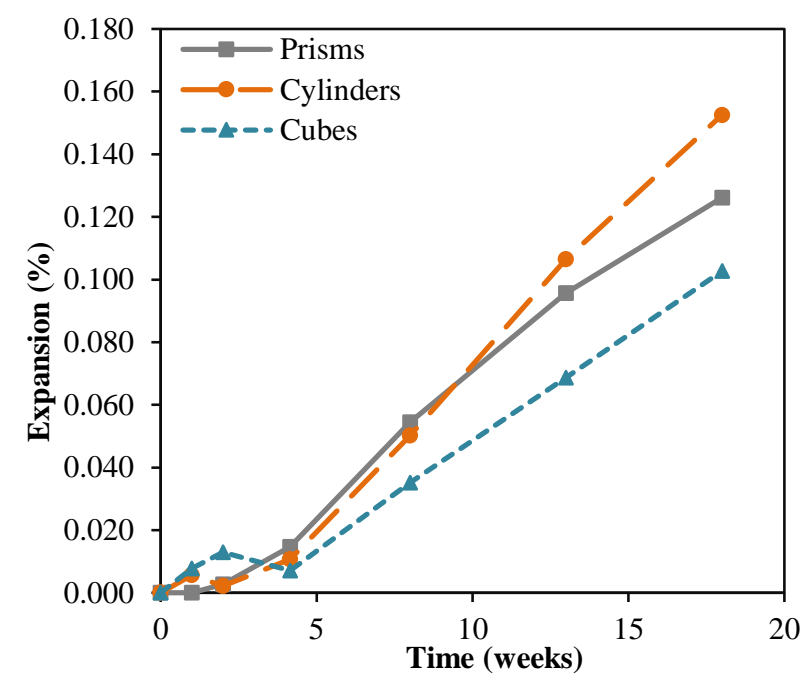

(a)

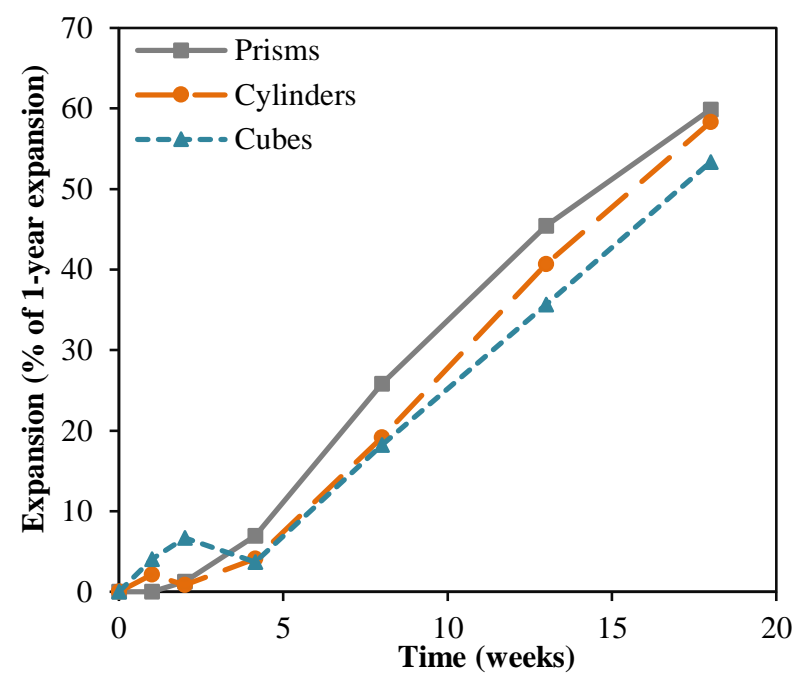

(b)

Figure 4.20: (a) Expansion of Spratt samples without SCM until 18 weeks, (b) expansion taken as $\%$ of the total 1-year expansion

Other than the slow reactivity of Sudbury, the higher alkalis contributed from Sudbury aggregate to the concrete pore solution might help in explaining the difference in the amount of alkalis leached from the concrete cast with Spratt and Sudbury as explained in Section 4.1.3.

\subsubsection{Alkali Release from Aggregates}

Alkali release from aggregates to solutions of different alkalinities was studied. The concentration of $\mathrm{Na}^{+}$released was measured in $\mathrm{KOH}$ solution and that of $\mathrm{K}^{+}$ions in $\mathrm{NaOH}$ solution. Measuring $\mathrm{Na}^{+}$in $\mathrm{KOH}$ solution is easier to trigger changes in $\mathrm{Na}^{+}$concentration of the solution and the same is valid for obtaining the concentration of $\mathrm{K}^{+}$in $\mathrm{NaOH}$ solution. Soaking in $0.70 \mathrm{M}$ solution characterizes concrete pore solution before ASR occurs a solution of $0.25 \mathrm{M}$ represents a por solution after significant expansion took place (Shehata and Thomas, 2006; Kandasamy and Shehata, 2014). The results are the average of three tested samples and are summarized in Figure 4.21 to Figure 4.23 for the samples soaked in $0.25 \mathrm{M}$ solution tested at $38^{\circ} \mathrm{C}$. Sample calculations and detailed results of the alkali release from aggregates test are provided in Appendix B. The dashed lines correspond to the samples that were shaken during the testing. 


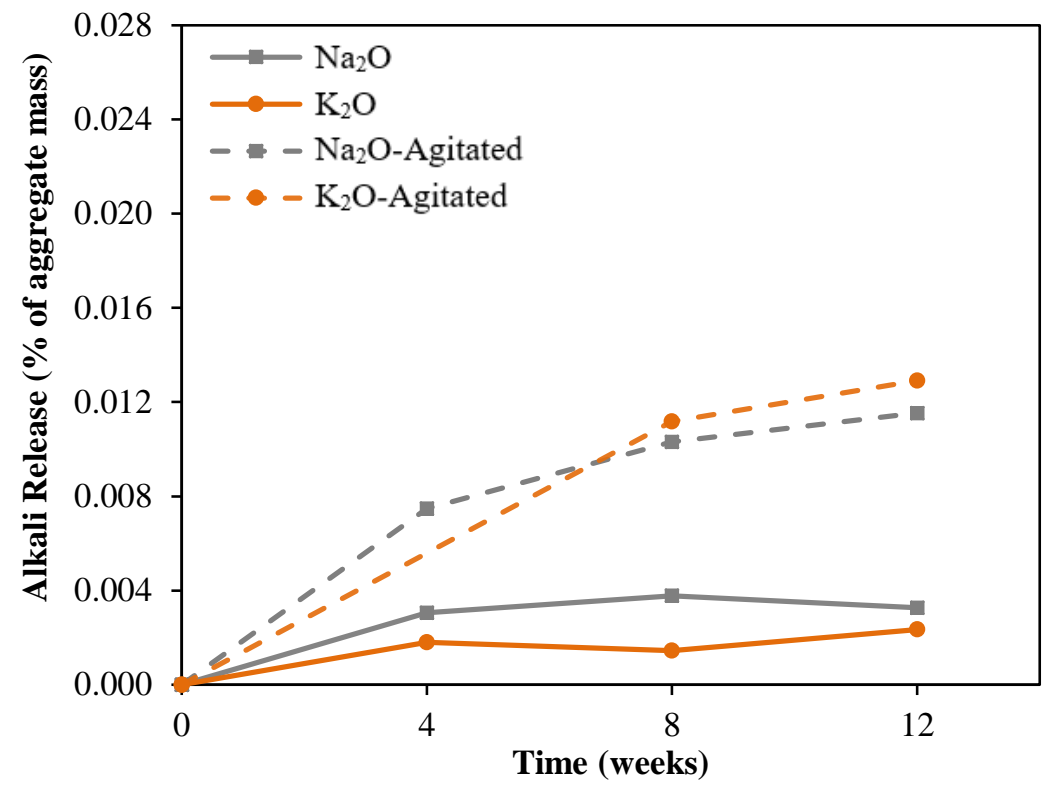

Figure 4.21: Alkali release from Sudbury aggregate at $38^{\circ} \mathrm{C}$ in alkaline solution of $0.25 \mathrm{M}$

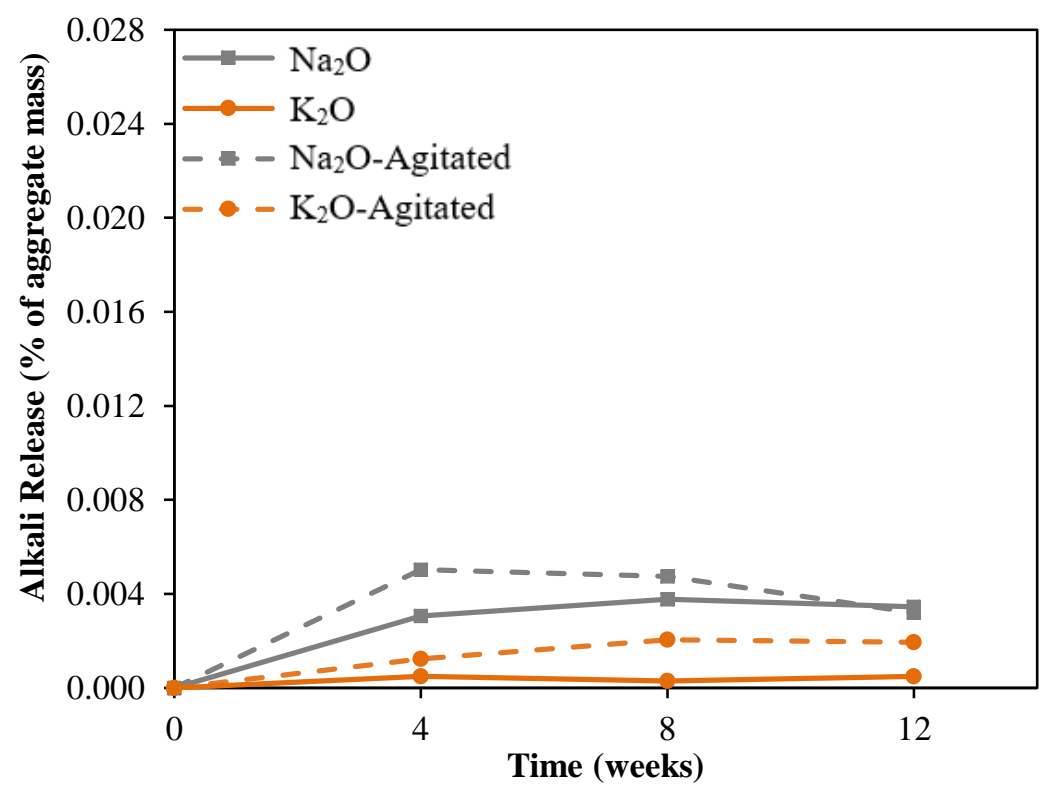

Figure 4.22: Alkali release from Spratt aggregate at $38^{\circ} \mathrm{C}$ in alkaline solution of $0.25 \mathrm{M}$ 


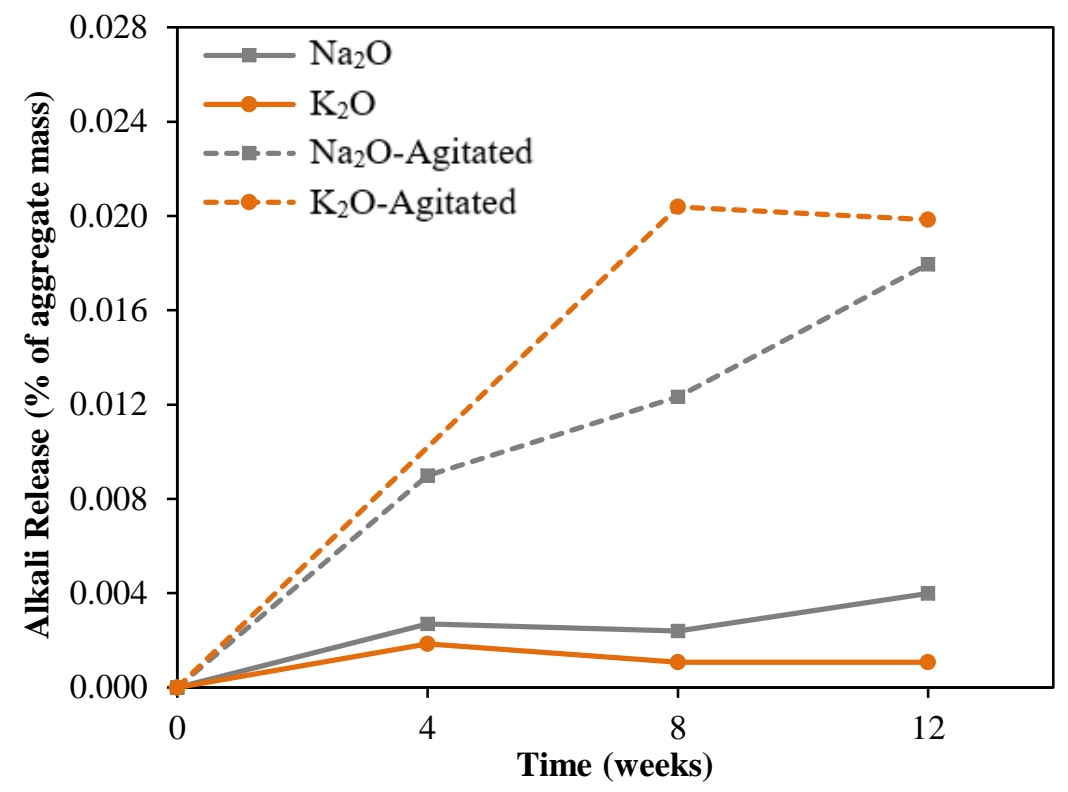

Figure 4.23: Alkali release from Springhill aggregate at $38^{\circ} \mathrm{C}$ in alkaline solution of $0.25 \mathrm{M}$

When samples are being shaken during the test, the release of alkalis from aggregates to the host solution was accelerated. In $0.25 \mathrm{M}$ solution, Springhill released the highest amount of alkalis $\left(\mathrm{Na}_{2} \mathrm{O}=0.0180 \%, \mathrm{~K}_{2} \mathrm{O}=0.0198 \%\right)$ followed by Sudbury $\left(\mathrm{Na}_{2} \mathrm{O}=0.0115 \%, \mathrm{~K}_{2} \mathrm{O}=0.0129 \%\right)$ and then Spratt $\left(\mathrm{Na}_{2} \mathrm{O}=0.0019 \%, \mathrm{~K}_{2} \mathrm{O}=0.0032 \%\right)$ which had much lower alkali release compared to the other two aggregates. Springhill, Sudbury and Spratt aggregates have a total alkali content of $3.47 \%, 4.35 \%$ and $0.09 \% \mathrm{Na}_{2} \mathrm{O}_{\mathrm{e}}$ by aggregate mass, respectively (Bérubé et al., 2002; Drolet, Duchesne and Fournier, 2017). This could, partly, explain the higher alkali leaching from concrete samples containing Sudbury as opposed to Spratt samples. Results of alkali release from aggregate into a host solution of $0.70 \mathrm{M}$ are presented in Figure 4.24 to Figure 4.26. The dashed lines correspond to the samples that have been agitated during the test period. 


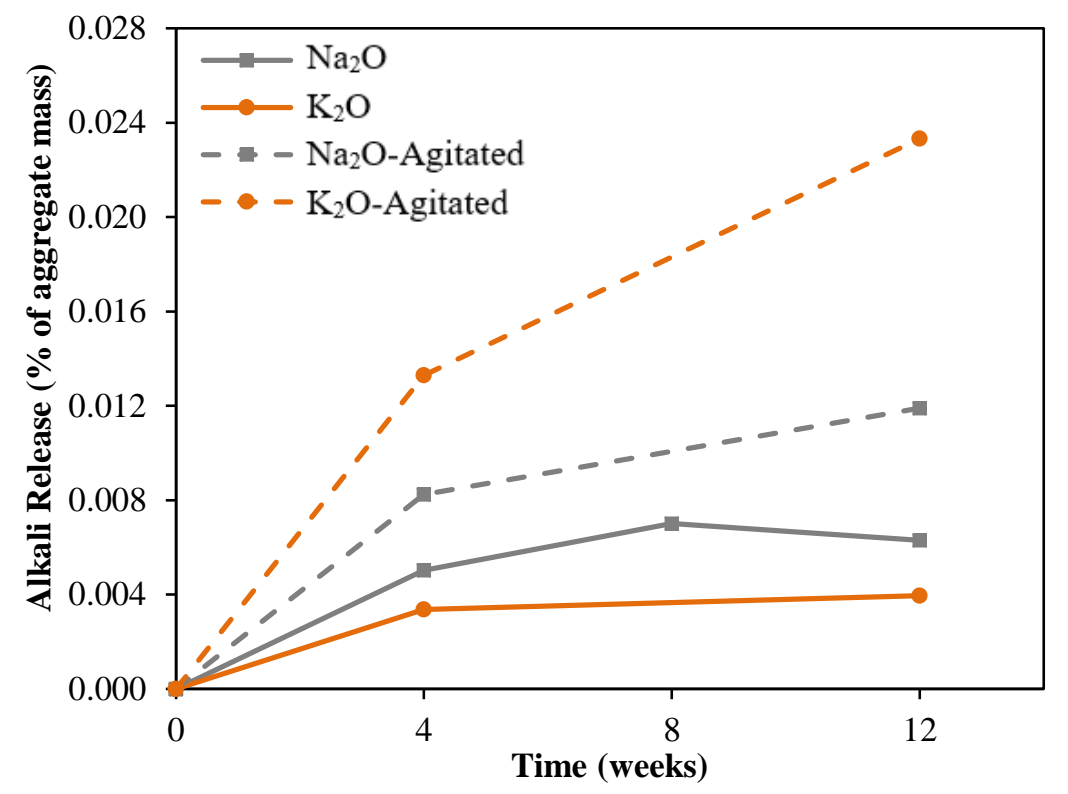

Figure 4.24: Alkali release from Sudbury aggregate at $38^{\circ} \mathrm{C}$ in alkaline solution of $0.70 \mathrm{M}$

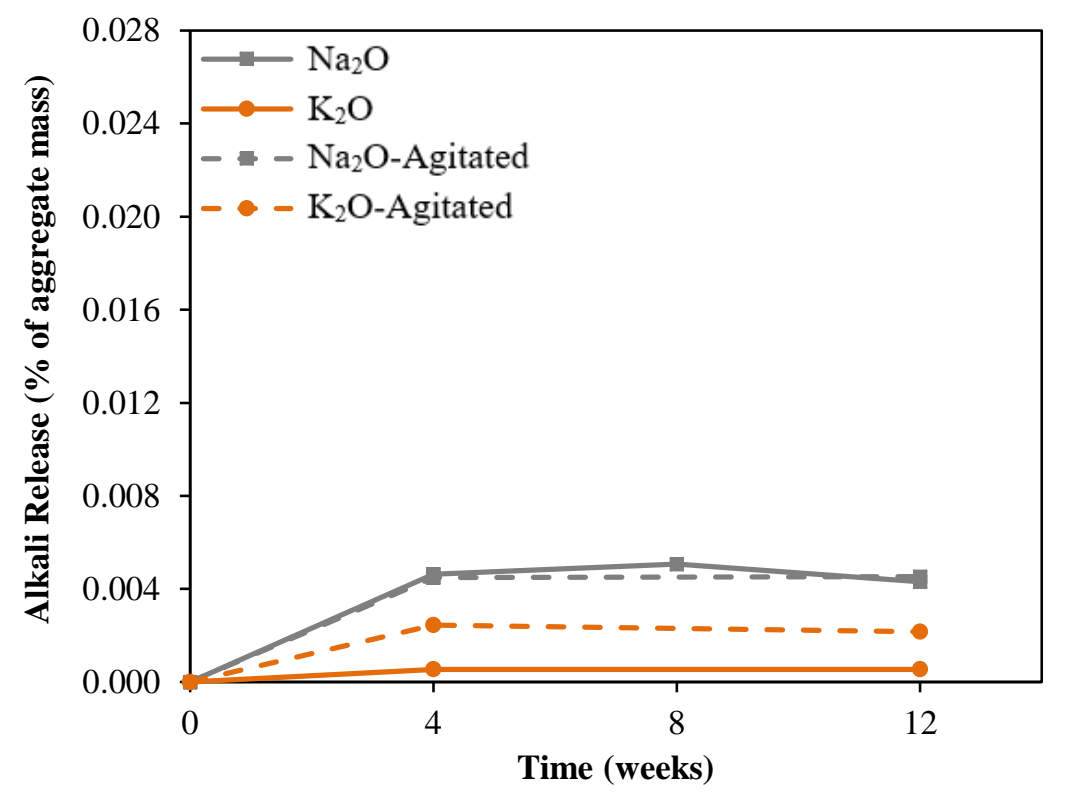

Figure 4.25: Alkali release from Spratt aggregate at $38^{\circ} \mathrm{C}$ in alkaline solution of $0.70 \mathrm{M}$ 


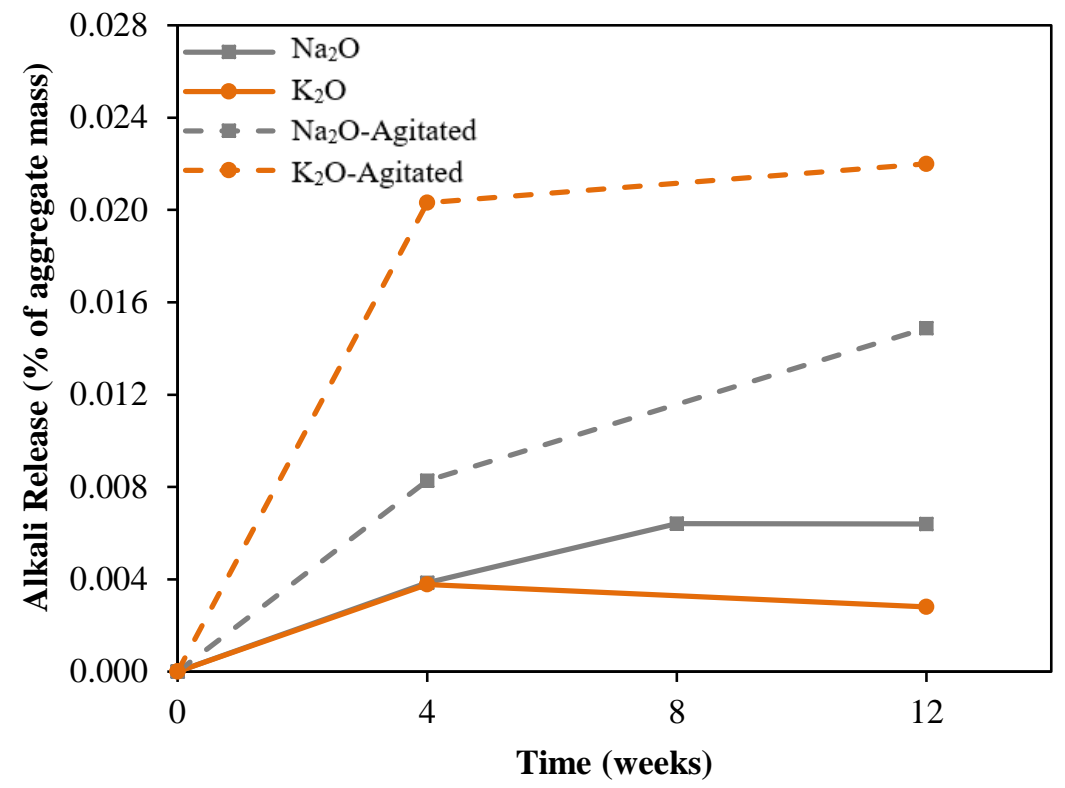

Figure 4.26: Alkali release from Springhill aggregate at $38^{\circ} \mathrm{C}$ in alkaline solution of $0.70 \mathrm{M}$

In 0.70 M solutions, Springhill and Sudbury showed higher release of alkalis compared to the minimal contribution obtained from the Spratt aggregate. In both solutions ( $0.25 \mathrm{M}$ and $0.70 \mathrm{M})$, Spratt showed very minimal contribution to the soaking solution.

Alkali release from the aggregates to the soaking solution was examined in distilled water, $0.25 \mathrm{M}$ and $0.70 \mathrm{M}$ solution. The amount of released alkalis in the different alkaline solutions are compared and results are shown from Figure 4.27 to Figure 4.32. Higher alkali release was examined in $0.70 \mathrm{M}$ followed by $0.25 \mathrm{M}$ and then in distilled water. This is in agreement with Bérubé et al. (2002) who showed higher alkali release in $0.7 \mathrm{M}$ solutions compared to saturated lime solutions. On the contrary, Yujiang, Min and Mingshu (2008) found very minimal alkali contribution into $0.7 \mathrm{M} \mathrm{NaOH}$ and $\mathrm{KOH}$ solutions and increase in alkali release when aggregates were soaked in saturated $\mathrm{Ca}(\mathrm{OH})_{2}$ solutions. It should be noted that the aggregates used in the two studies by Bérubé et al. (2002) and Yujiang, Min and Mingshu (2008) were different.

It is clear that the amount of soluble alkalis is lower than the alkalis released in $\mathrm{NaOH}$ and $\mathrm{KOH}$ solutions with all the different aggregates. Hence, the results in this study showed that the released alkalis increase in solutions of higher alkalinity. 


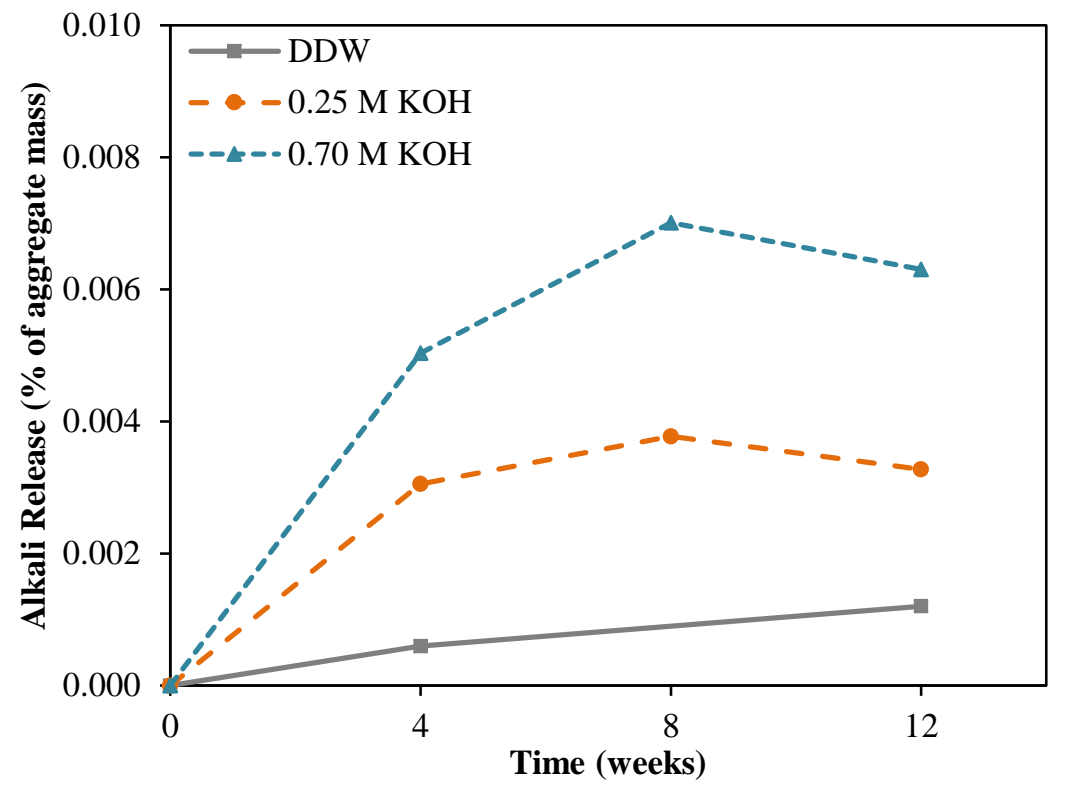

Figure 4.27: $\mathrm{Na}_{2} \mathrm{O}$ released from Sudbury aggregate to distilled water, $0.25 \mathrm{M}$ and $0.70 \mathrm{M} \mathrm{KOH}$ solutions

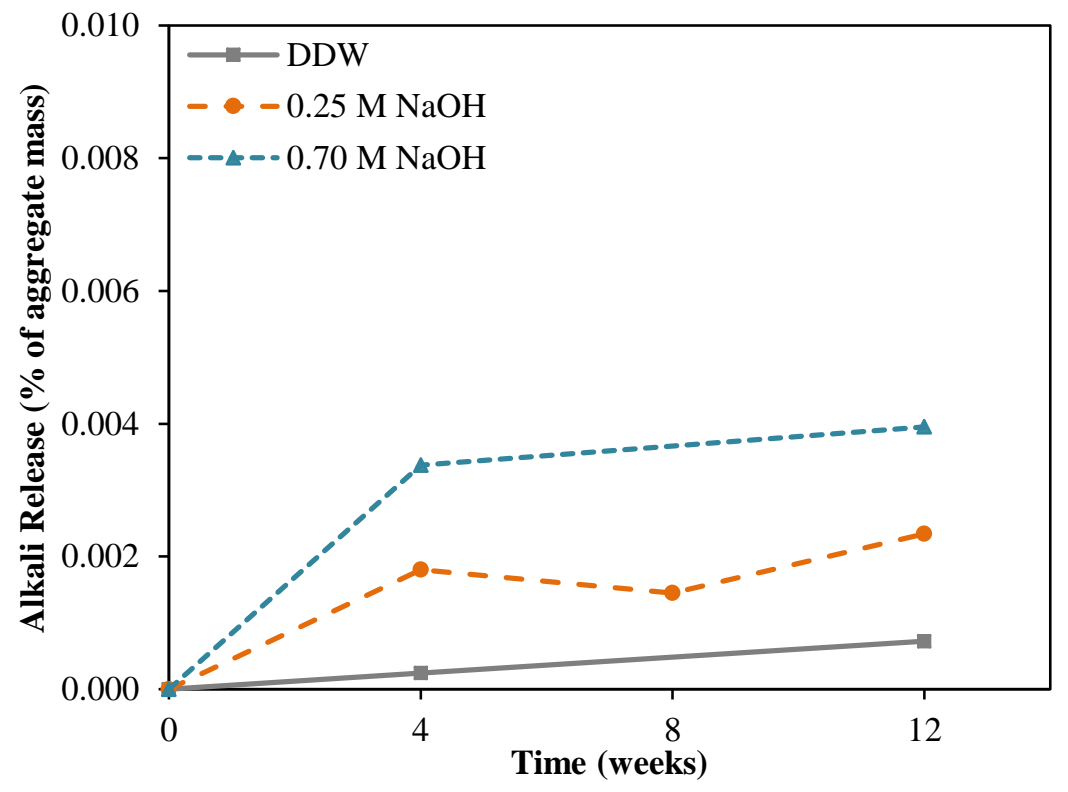

Figure 4.28: $\mathrm{K}_{2} \mathrm{O}$ released from Sudbury aggregate to distilled water, $0.25 \mathrm{M}$ and $0.70 \mathrm{M} \mathrm{NaOH}$ solutions 


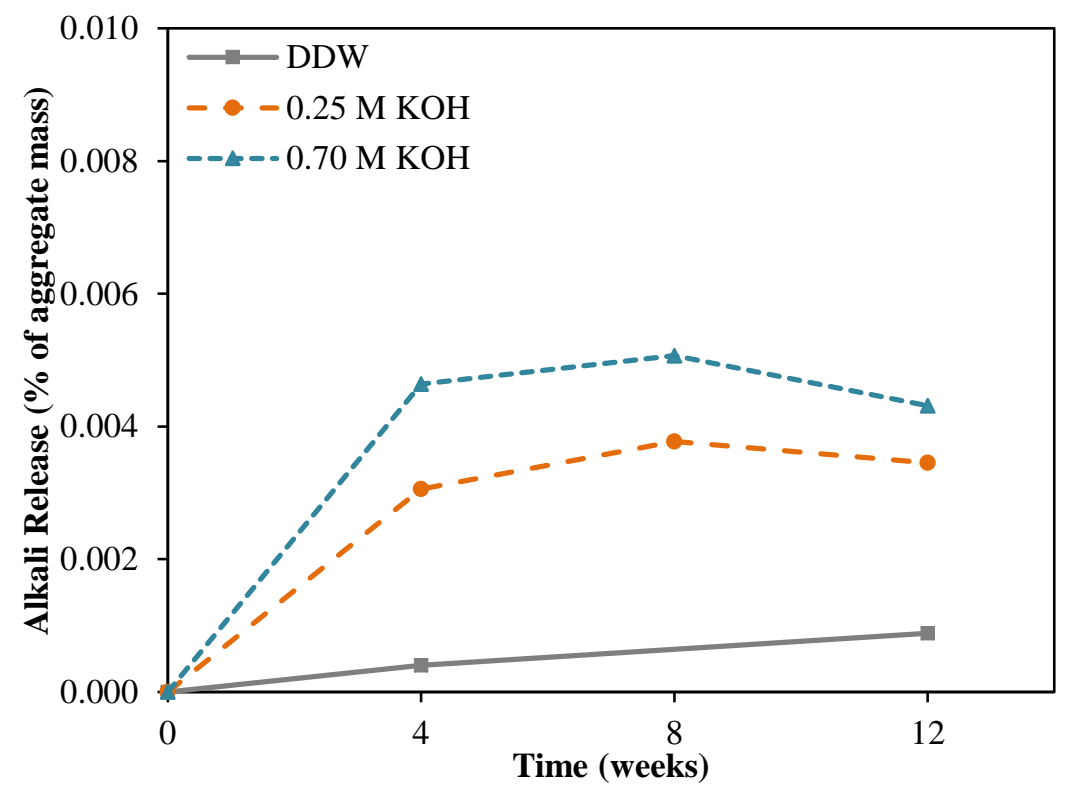

Figure 4.29: $\mathrm{Na}_{2} \mathrm{O}$ released from Spratt aggregate to distilled water, $0.25 \mathrm{M}$ and $0.70 \mathrm{M} \mathrm{KOH}$ solutions

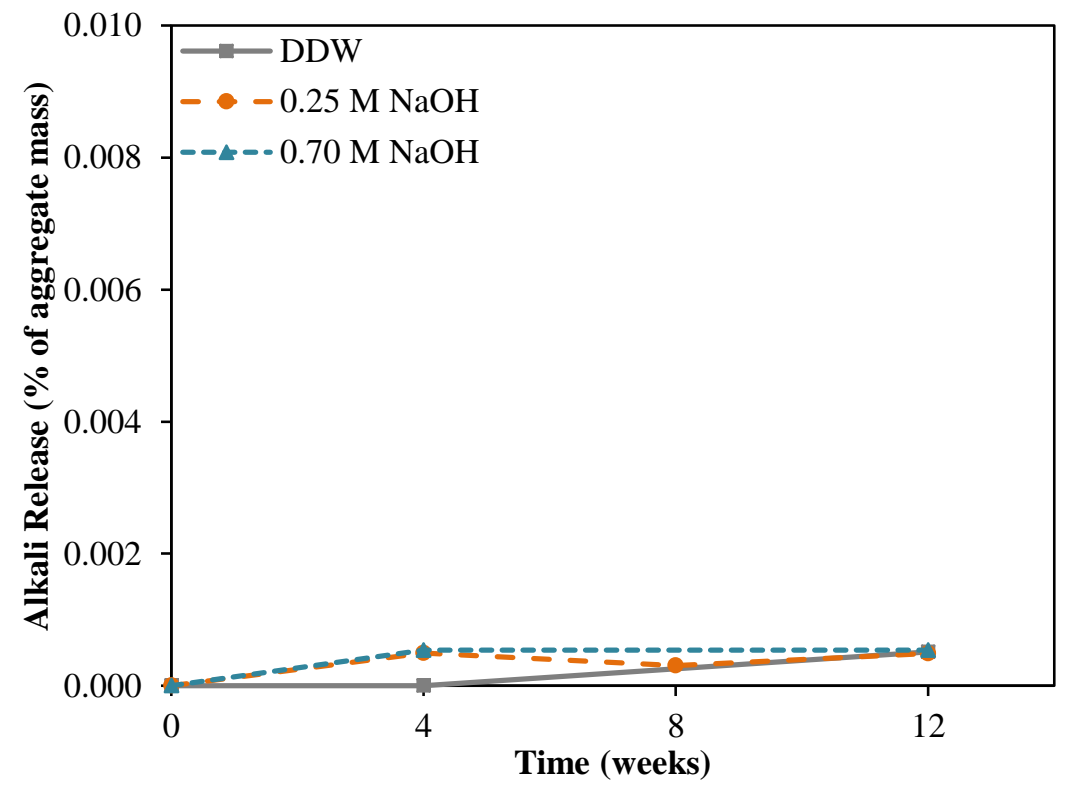

Figure 4.30: $\mathrm{K}_{2} \mathrm{O}$ released from Spratt aggregate to distilled water, $0.25 \mathrm{M}$ and $0.70 \mathrm{M} \mathrm{NaOH}$ solutions 


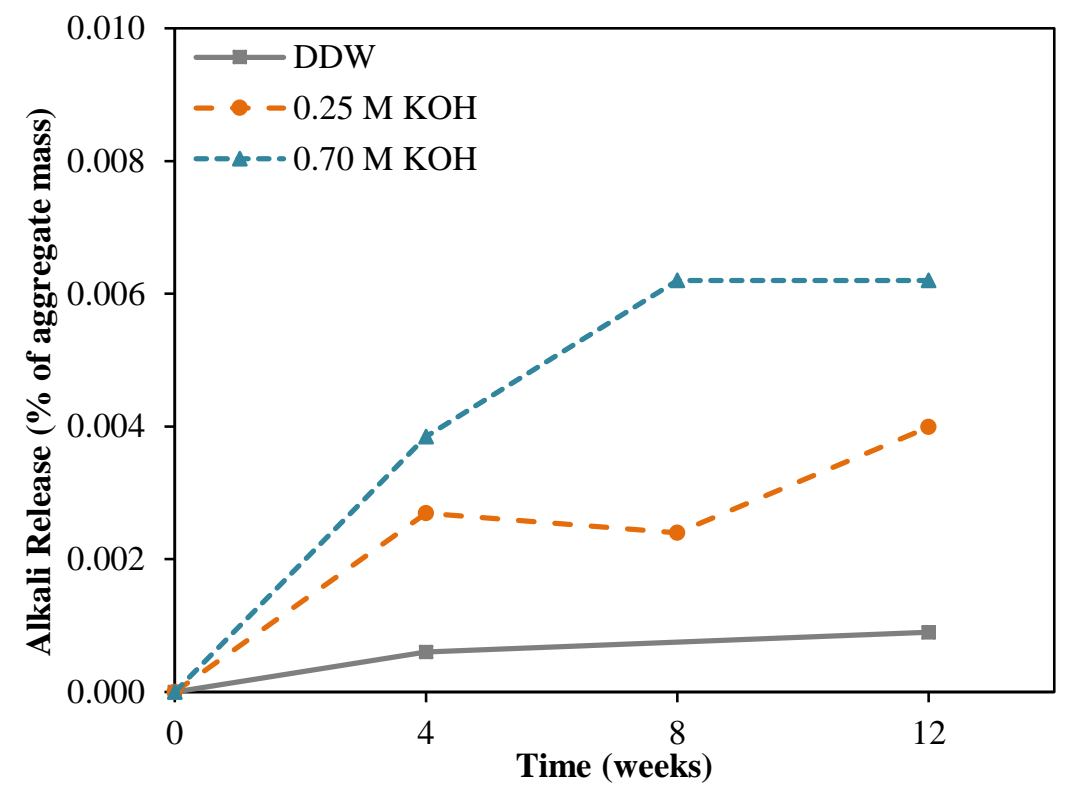

Figure 4.31: $\mathrm{Na}_{2} \mathrm{O}$ released from Springhill aggregate to distilled water, $0.25 \mathrm{M}$ and $0.70 \mathrm{M} \mathrm{KOH}$ solutions

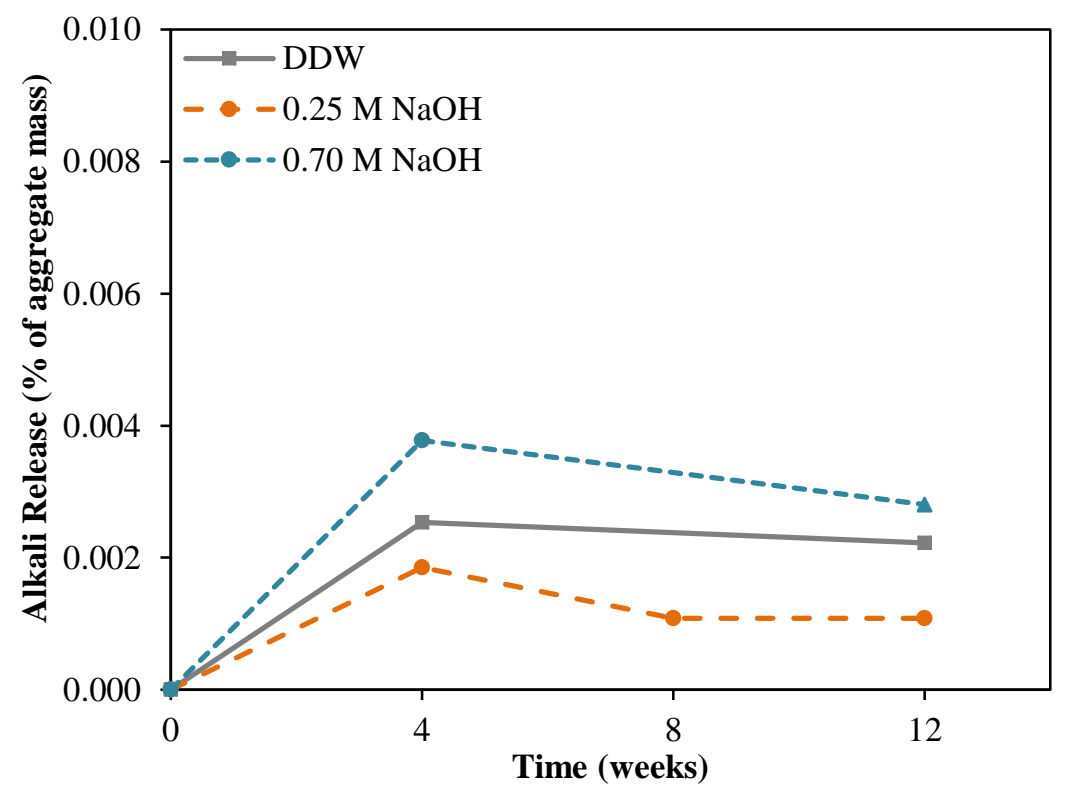

Figure 4.32: $\mathrm{K}_{2} \mathrm{O}$ released from Springhill aggregate to distilled water, $0.25 \mathrm{M}$ and $0.70 \mathrm{M} \mathrm{NaOH}$ solutions

The higher alkali release from aggregates to solution of higher alkalinity could help in explaining the higher expansion obtained with Sudbury cylinders compared to prisms. Since concrete cylinders showed lower leaching compared to prisms, it is expected that the cylinders have higher pore solution alkalinity. Hence, more release of alkalis from aggregates might occur in the cylinders leading to the observed difference in expansion between prisms and cylinders especially 
with Sudbury aggregate. In the case of Spratt samples, release of alkalis to the pore solution is very low regardless of the host solution alkalinity.

In the case of Spratt with no SCM, cylinders showed higher expansion than prisms suggesting that the difference in alkali leaching could have led to this difference in expansion. For the samples with SCM, the level of SCM used might have been enough to bind the extra alkalis in the cylinders' pore solution except in marginal cases such as Spratt with 15\% FA; slightly higher expansion was obtained with the cylinders compared to prisms. In the case of Spratt with GUB-8SF and 15\% FA, cylinders expanded more than prisms. It was shown from previous study by Thomas (2011) that silica fume will decrease the $\mathrm{OH}^{-}$concentration for the first 28 days but then starts to release alkalis into pore solution beyond 3 months. The presence of FA was shown to bind the released alkalis (Thomas, 2011). 15\% FA seem to have a limited capacity to bind the extra alkalis released from GUB-8SF specially in the cylinders which have less leaching compared to prisms leading to the difference in expansion although both passed the CPT. 20\% FA in addition to GUB-8SF was enough to bind alkalis for both cylinders and prisms leading to same expansions.

For the Springhill aggregate, although it was found that the aggregate releases higher alkalis compared to Sudbury, however, the cylinders cast with 30\% FA did not show any expansion higher than the prisms. The reason that could lead to the similarity between prisms and cylinders expansion in the case of concrete cast with Springhill aggregate and 30\% FA is the high level of FA used which might be enough to bind alkalis from both prisms' and cylinders' pore solution lowering significantly its alkalinity and leading to the very low expansion in both cases. However, more testing of Springhill aggregate with different combinations of SCM should be done since only one sample was tested here with $30 \%$ FA.

\subsubsection{Relative Humidity Measurements}

Relative humidity measurements were carried out using humidity probes to see whether the larger cross section can affect relative humidity inside the samples and thus retard expansion. Figure 4.33 presents the RH measurements obtained for Spratt control and Figure 4.34 for Spratt with 25\% FA. The vertical lines represent the day when length measurements are performed at room temperature; i.e., samples were taken out from the heat room the night before. 


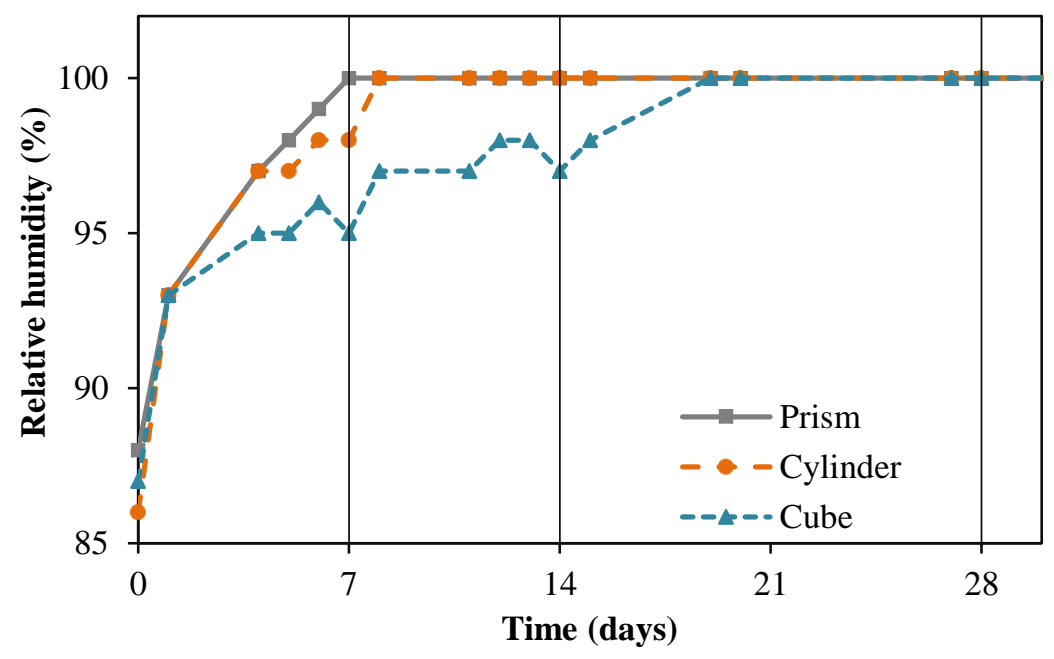

Figure 4.33: Relative humidity measurements for Spratt aggregate without SCM

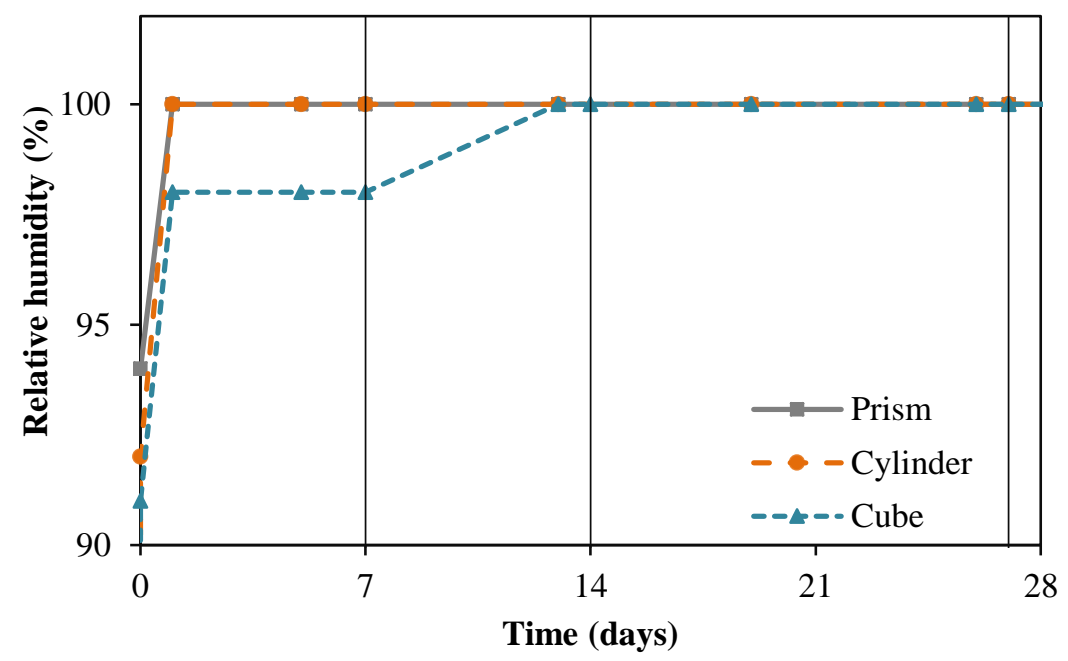

Figure 4.34: Relative humidity measurements for Spratt aggregate with $25 \%$ FA

In both samples tested, it is clear that cubes take more time to reach $100 \%$ humidity as opposed to prisms and cylinders which reach $100 \%$ humidity much faster. For Spratt control, the cubes needed three weeks to reach $100 \% \mathrm{RH}$ as opposed to prisms and cylinders which took one week. For the samples with SCM, the cubes reach $100 \%$ RH after 2 weeks. The cubes reach a 100\% RH quite fast and they are not affected later on during length measurements. Although the accuracy of the sensor reading is within 3\%, the expansion due to ASR will still be sustained at a 97\% RH (Figure 2.7). Hence, relative humidity within the samples could not be used to explain the lower expansion in the cubes compared to cylinders although cubes have the lowest leaching. The reasons are not clear yet but could be due to inaccuracy in the measurements or to restraint in cubes because of their geometric shapes. 


\subsection{Effect of Temperature on Alkali Leaching, Alkali Release and Pozzolanic Activity of SCM}

The aim of this section is to study the effect of temperature on alkali leaching from concrete samples tested at $38^{\circ} \mathrm{C}$ and $60^{\circ} \mathrm{C}$. In addition, alkali release from aggregates is examined at three different temperatures: $23^{\circ} \mathrm{C}, 38^{\circ} \mathrm{C}$ and $60^{\circ} \mathrm{C}$. Three coarse aggregates with different reactivity were tested: Sudbury, Spratt and Springhill. Also, this study was carried out to investigate the effect of temperature on pozzolanic activity of SCM and their capacity to bind alkalis. FA and slag with different replacement levels were investigated to study their degree of pozzolanic reaction and their alkali release characteristics at three different temperatures: $23^{\circ} \mathrm{C}, 38^{\circ} \mathrm{C}$ and $60^{\circ} \mathrm{C}$.

\subsubsection{Effect of Temperature on Alkali Leaching from Concrete Samples}

Leaching of alkalis from concrete samples tested at $60^{\circ} \mathrm{C}$ was measured at 1.5 years and compared to the alkali leaching from concrete samples tested at $38^{\circ} \mathrm{C}$. Results are shown in Figure 4.35 for prisms and cylinders and Figure 4.36 for the cubes. Only one set of prisms cast at $60^{\circ} \mathrm{C}$ was measured for alkali leaching. Accurate volume measurements for the other sets of prisms was not possible to obtain due to fractures occurring at the bottom of the containers causing some water to seep out. Sample calculations and detailed results are provided in Appendix A. 


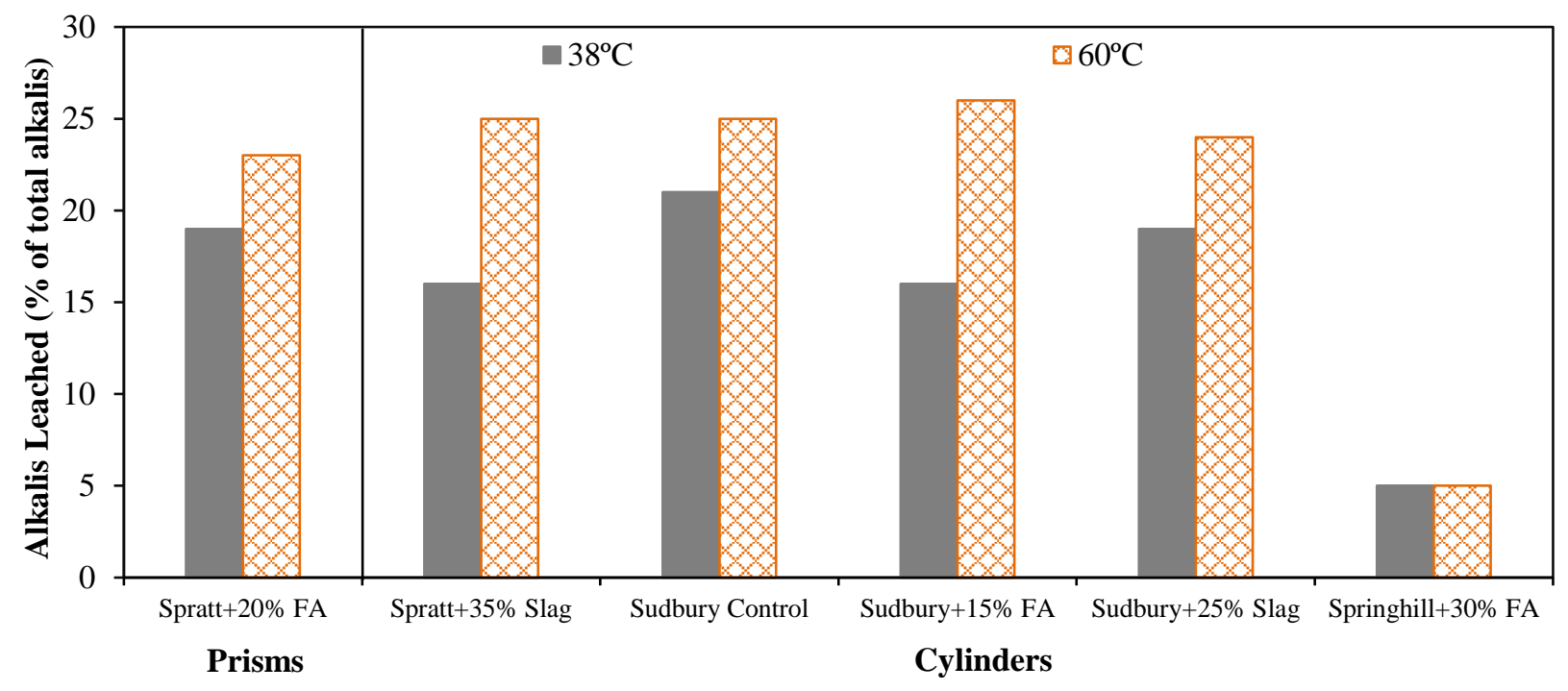

Figure 4.35: Alkalis leached from concrete prisms and cylinders tested at $38^{\circ} \mathrm{C}$ and $60^{\circ} \mathrm{C}$ at 1.5 years

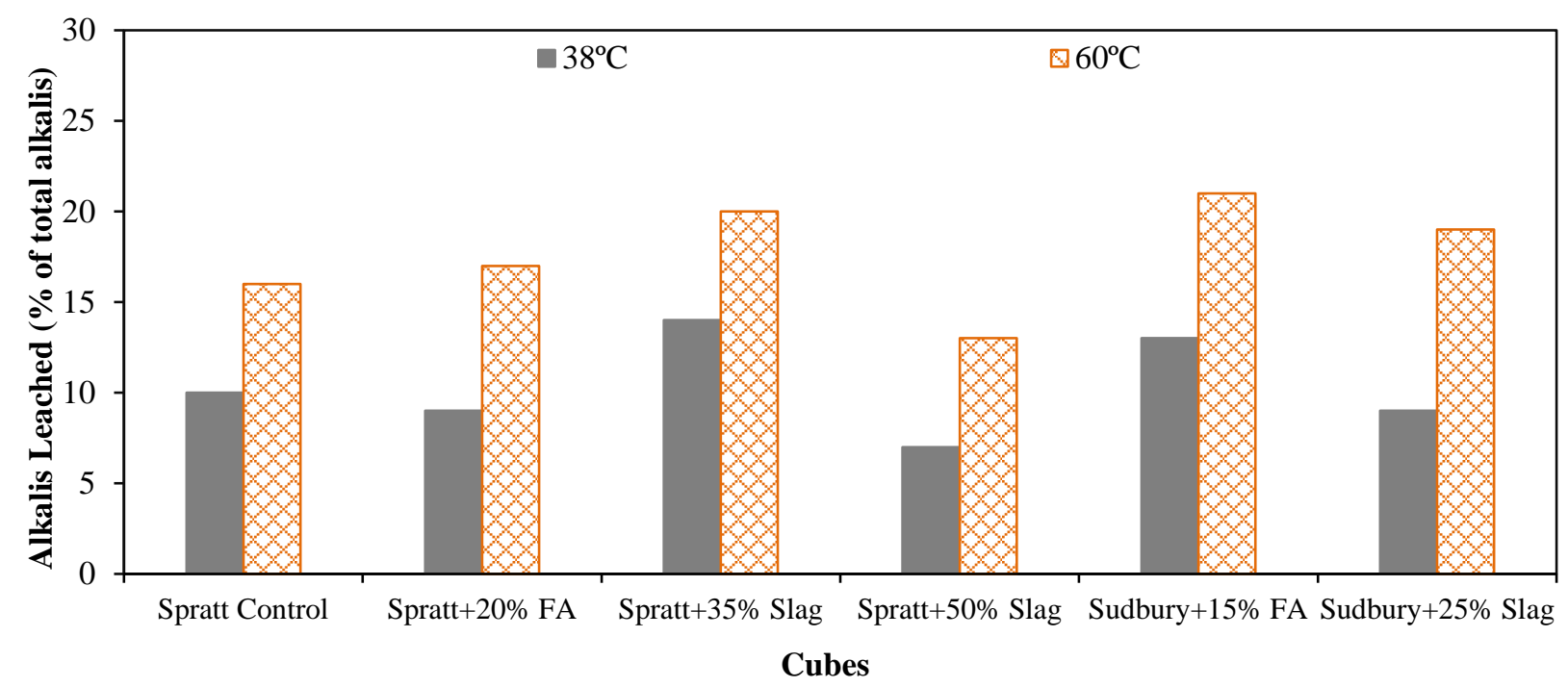

Figure 4.36: Alkalis leached from concrete cubes tested at $38^{\circ} \mathrm{C}$ and $60^{\circ} \mathrm{C}$ at 1.5 years

Higher alkali leaching from the concrete samples at $60^{\circ} \mathrm{C}$ compared to $38^{\circ} \mathrm{C}$ was obtained with all the different sample geometry and with all the different aggregate/SCM combinations. This is due to the higher diffusivity of alkalis with increased temperature (Lindgård et al., 2012). The higher alkalis leached from concrete samples at $60^{\circ} \mathrm{C}$ will lead to a concrete pore solution alkalinity lower than that of the concrete samples stored at $38^{\circ} \mathrm{C}$. As a summary, Figure 4.37 shows a comparison of the alkali leaching from concrete samples tested at $60^{\circ} \mathrm{C}$ and $38^{\circ} \mathrm{C}$ measured at 1.5 years. All the samples at $60^{\circ} \mathrm{C}$ leached more alkalis from the concrete pore solution compared to the samples at $38^{\circ} \mathrm{C}$ for Spratt and Sudbury aggregates and for all the different sample geometries. The sample 
with Springhill aggregate showed much lower alkali leaching; however, this sample contains $30 \%$ FA so lower ion diffusivity and pore solution alkalinity could be contributing factors.

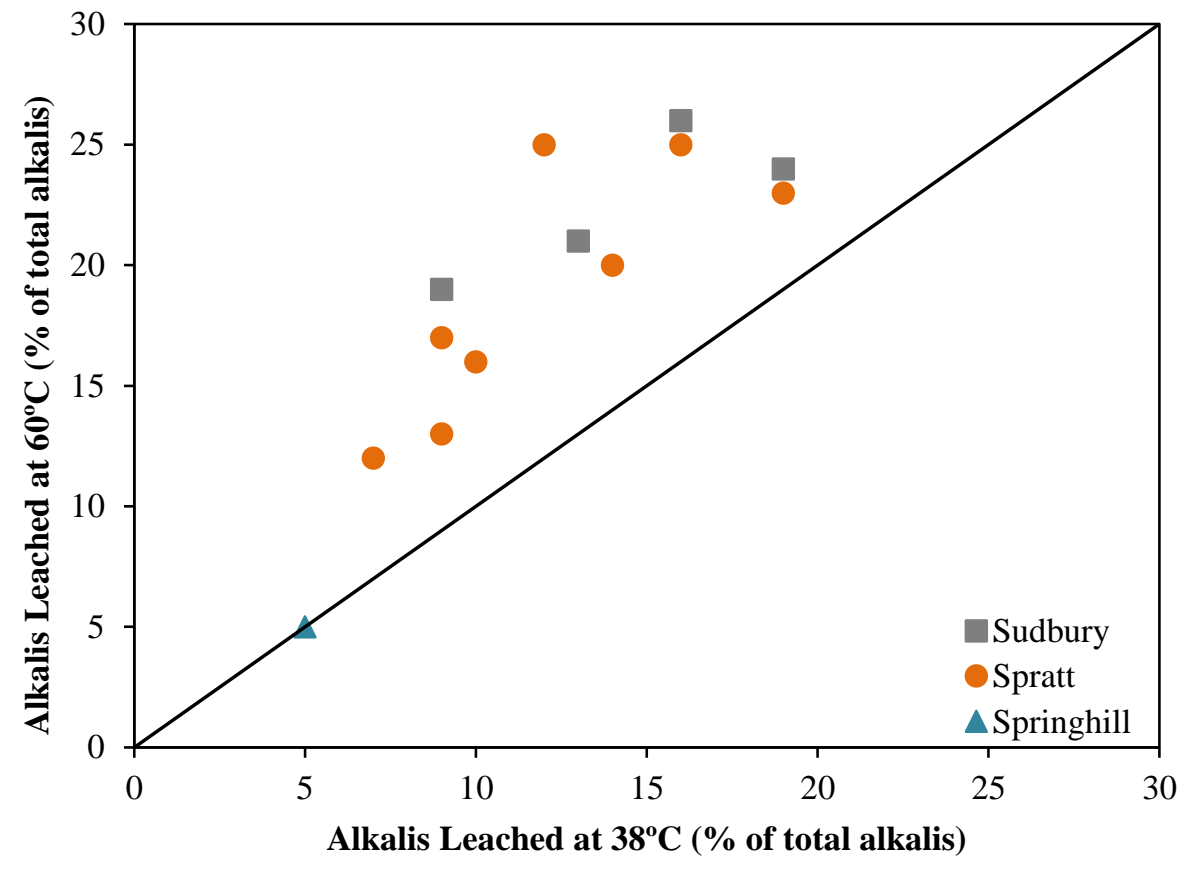

Figure 4.37: Comparison of leaching at $38^{\circ} \mathrm{C}$ and $60^{\circ} \mathrm{C}$

Factors other than alkali leaching from concrete samples are expected to be affected by temperature such as alkali release from aggregates. The alkali contribution from the aggregate to the pore solution was studied at three different temperatures: $23^{\circ} \mathrm{C}, 38^{\circ} \mathrm{C}$ and $60^{\circ} \mathrm{C}$ to understand the effect of temperature on alkali release; this is covered in Section 4.2.2.

\subsubsection{Effect of Temperature on Alkali Release from Aggregates}

Alkali release from aggregates to solutions of different alkalinity was studied at three different temperatures: $23^{\circ} \mathrm{C}, 38^{\circ} \mathrm{C}$ and $60^{\circ} \mathrm{C}$. Potassium $\left(\mathrm{K}^{+}\right)$ions were measured in $\mathrm{NaOH}$ solutions and sodium $\left(\mathrm{Na}^{+}\right)$ions in $\mathrm{KOH}$. The concentrations were converted into $\mathrm{K}_{2} \mathrm{O}$ or $\mathrm{Na}_{2} \mathrm{O}$ expressed as a percent of total aggregate mass. Sodium $\left(\mathrm{Na}^{+}\right)$concentration was measured in $\mathrm{KOH}$ solution as it is easier to trigger changes in $\mathrm{Na}^{+}$concentration of the solution and the same is valid for obtaining the concentration of $\mathrm{K}^{+}$in $\mathrm{NaOH}$ solution. The results are the average of three samples and presented in Figure 4.38 to Figure 4.41 at three different temperatures $\left(23^{\circ} \mathrm{C}, 38^{\circ} \mathrm{C}\right.$ and $\left.60^{\circ} \mathrm{C}\right)$. Sample calculations and detailed results are provided in Appendix B. The $\mathrm{K}_{2} \mathrm{O}$ release seems to not be affected by the increase in temperature for all the three aggregates tested: Sudbury, Spratt and Springhill. However, the $\mathrm{Na}_{2} \mathrm{O}$ release increases with higher temperature. Perhaps, the $\mathrm{Na}_{2} \mathrm{O}$ 
is higher in the aggregates and this is why the effect of temperature is manifested in the case of $\mathrm{Na}_{2} \mathrm{O}$ and not in the case of $\mathrm{K}_{2} \mathrm{O}$.

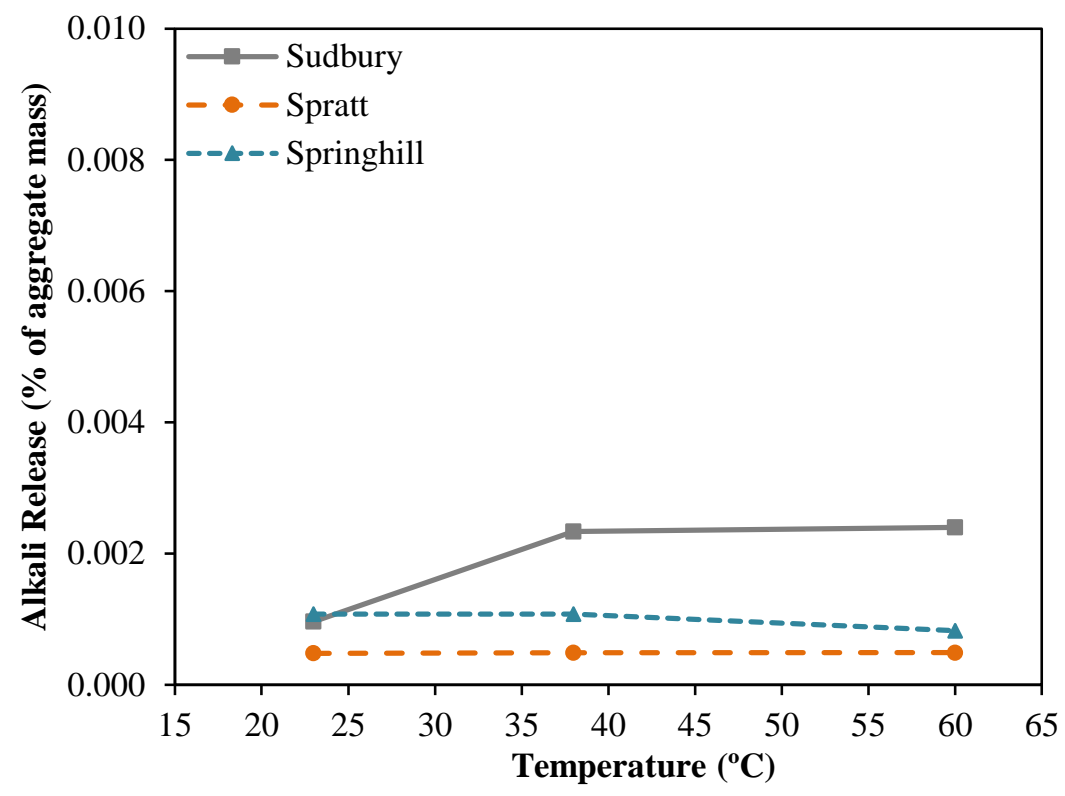

Figure 4.38: $\mathrm{K}_{2} \mathrm{O}$ release in $0.25 \mathrm{M} \mathrm{NaOH}$ solution

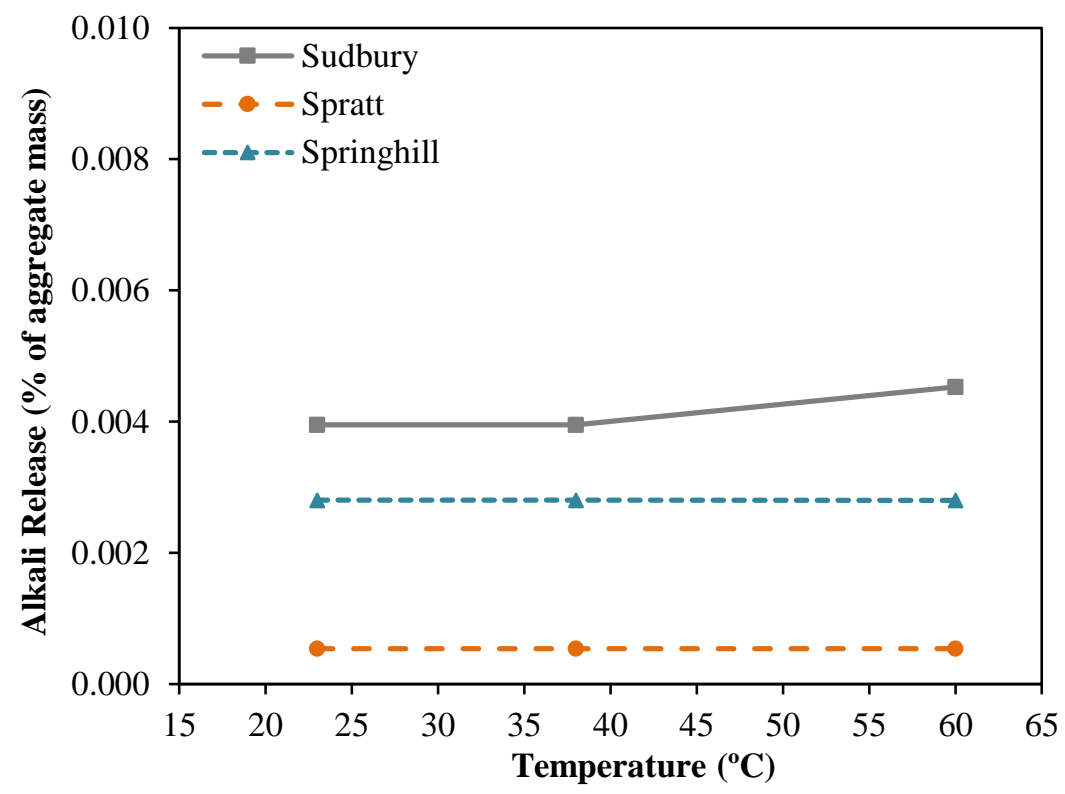

Figure 4.39: $\mathrm{K}_{2} \mathrm{O}$ release in $0.70 \mathrm{M} \mathrm{NaOH}$ solution 


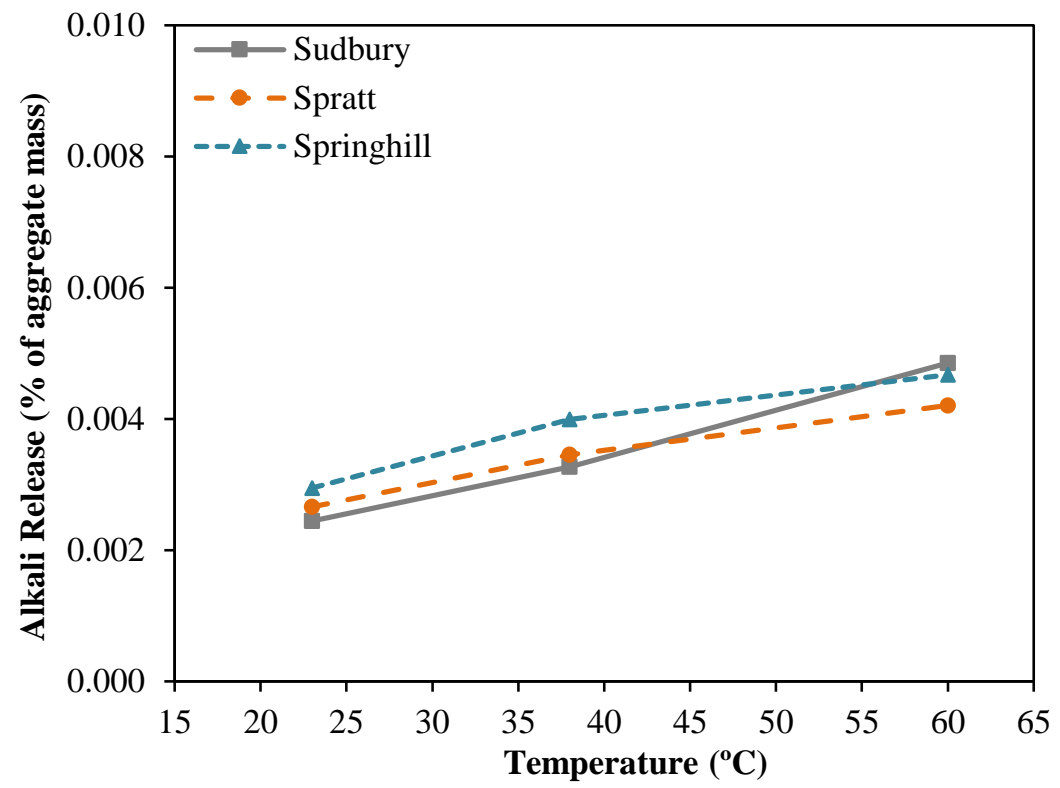

Figure 4.40: $\mathrm{Na}_{2} \mathrm{O}$ release in $0.25 \mathrm{M} \mathrm{KOH} \mathrm{solution}$

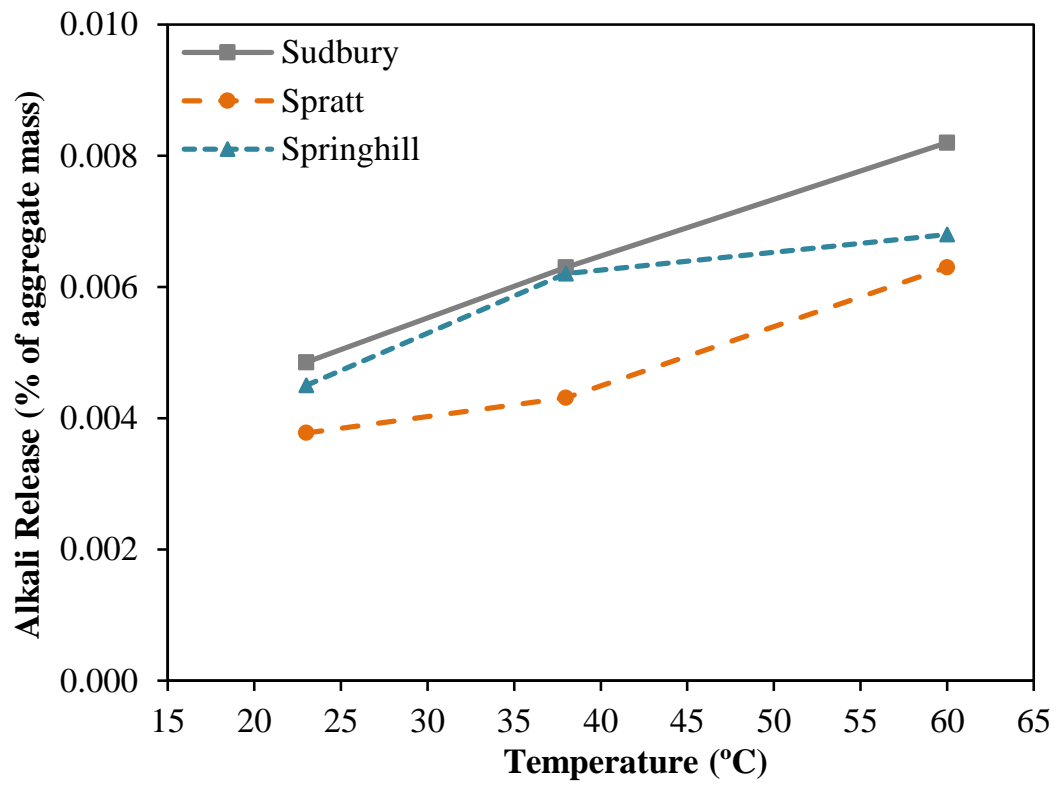

Figure 4.41: $\mathrm{Na}_{2} \mathrm{O}$ release in $0.70 \mathrm{M} \mathrm{KOH}$ solution

More release of total alkalis $\left(\mathrm{Na}_{2} \mathrm{O}_{\mathrm{e}}\right)$ from the aggregate to the host solution was obtained at $60^{\circ} \mathrm{C}$. This is shown in Figure 4.42, Figure 4.43 and Figure 4.44 presenting the total alkali release $\mathrm{Na}_{2} \mathrm{O}_{\mathrm{e}}$ into 0.25 and 0.70 M solution from Sudbury, Spratt and Springhill aggregates, respectively. This increased alkali release at higher temperature might favor the formation of ASR gel in concrete samples cast with alkali-bearing aggregates. In addition, the release of alkalis in solutions of 0.70 $\mathrm{M}$ is higher than that at $0.25 \mathrm{M}$ at all the different temperatures. Hence, it would be expected that 
more release of alkalis to concrete pore solution will occur for samples with higher pore solution alkalinity; i.e. cylinders compared to prisms.

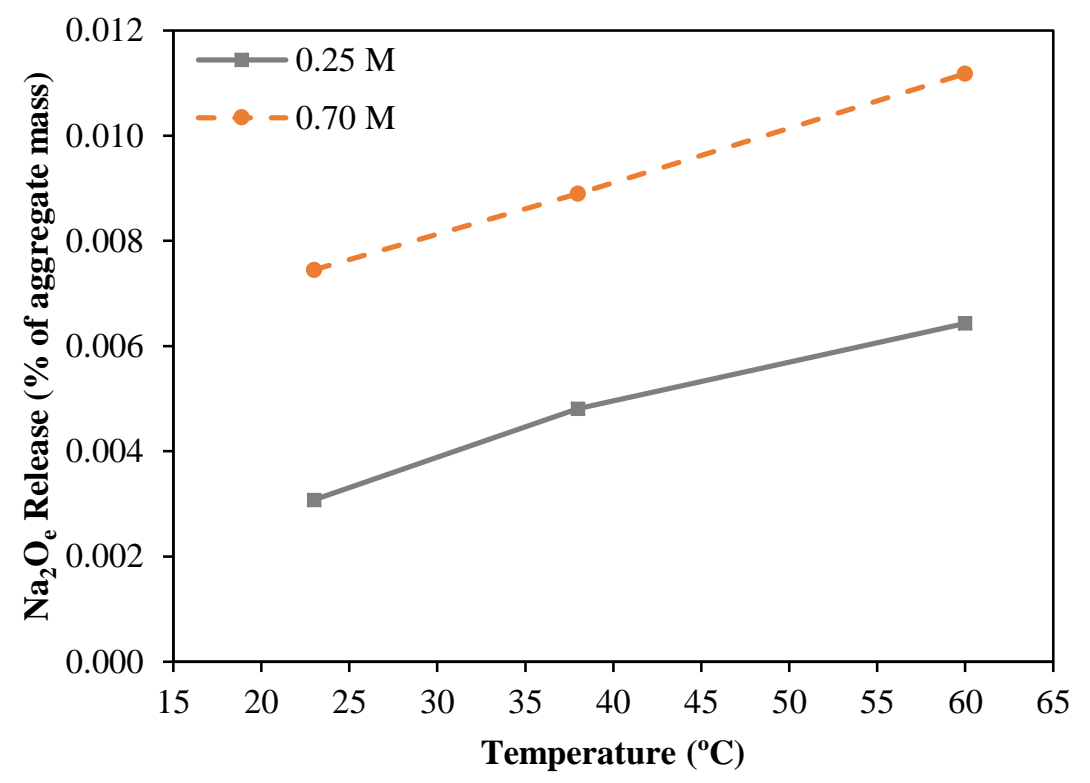

Figure 4.42: Total alkali release from Sudbury aggregate at different temperatures

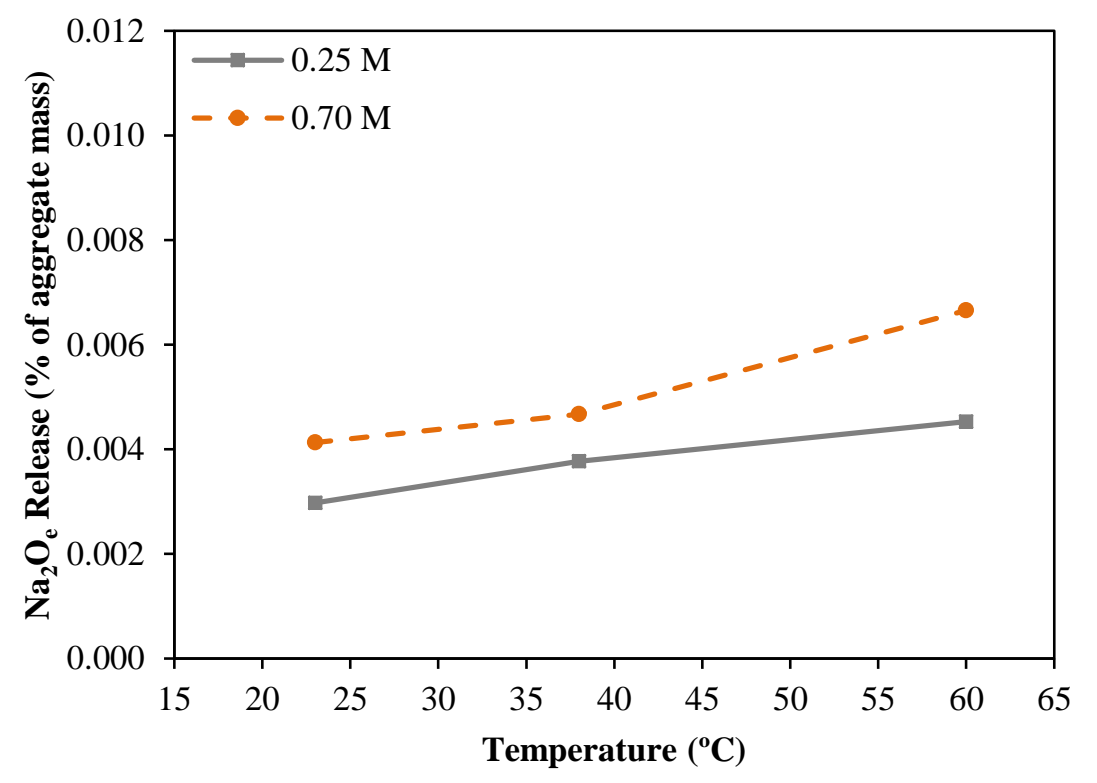

Figure 4.43: Total alkali release from Spratt aggregate at different temperatures 


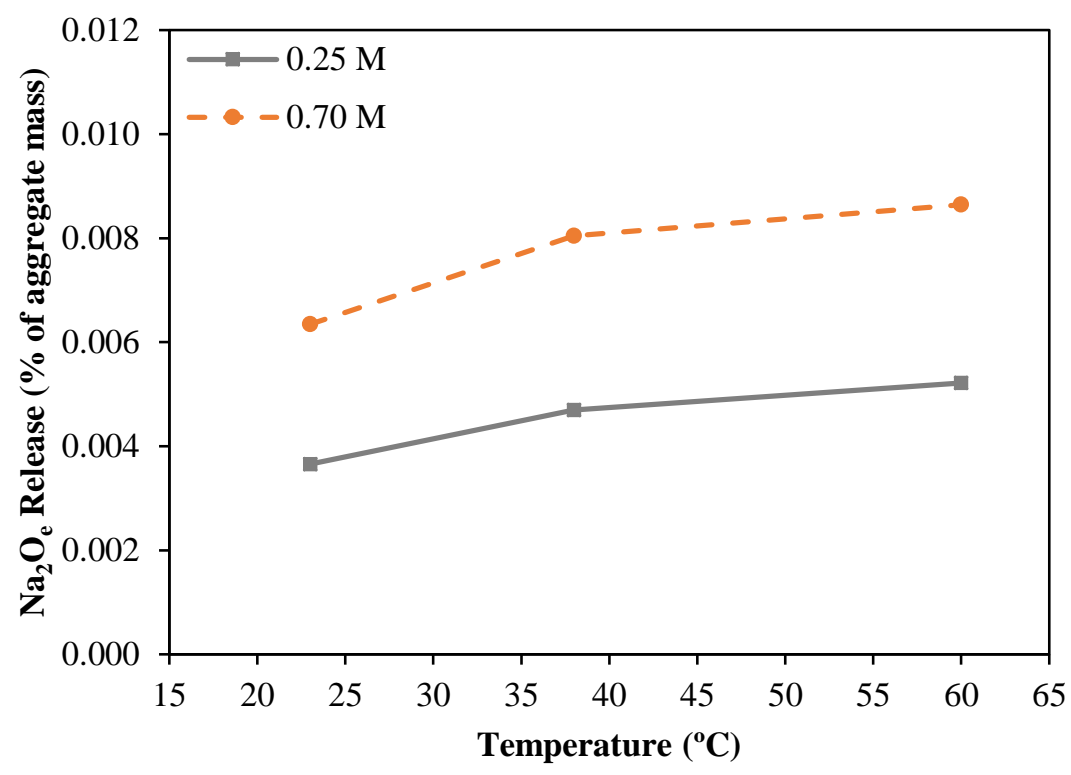

Figure 4.44: Total alkali release from Springhill aggregate at different temperatures

\subsubsection{Effect of Temperature on Pozzolanic Activity of SCM}

\section{Degree of Hydration of Cementitious Materials}

The non-evaporable water (chemically bound water) was obtained from the thermogravimetric analysis (TGA) by calculating the mass loss between $105^{\circ} \mathrm{C}$ and $1050^{\circ} \mathrm{C}$ taken as a percent of the ignited mass. The non-evaporable water was corrected for the initial loss on ignition of the cementing materials. Results of non-evaporable water of paste samples without SCM at different temperatures are shown in Figure 4.45. 


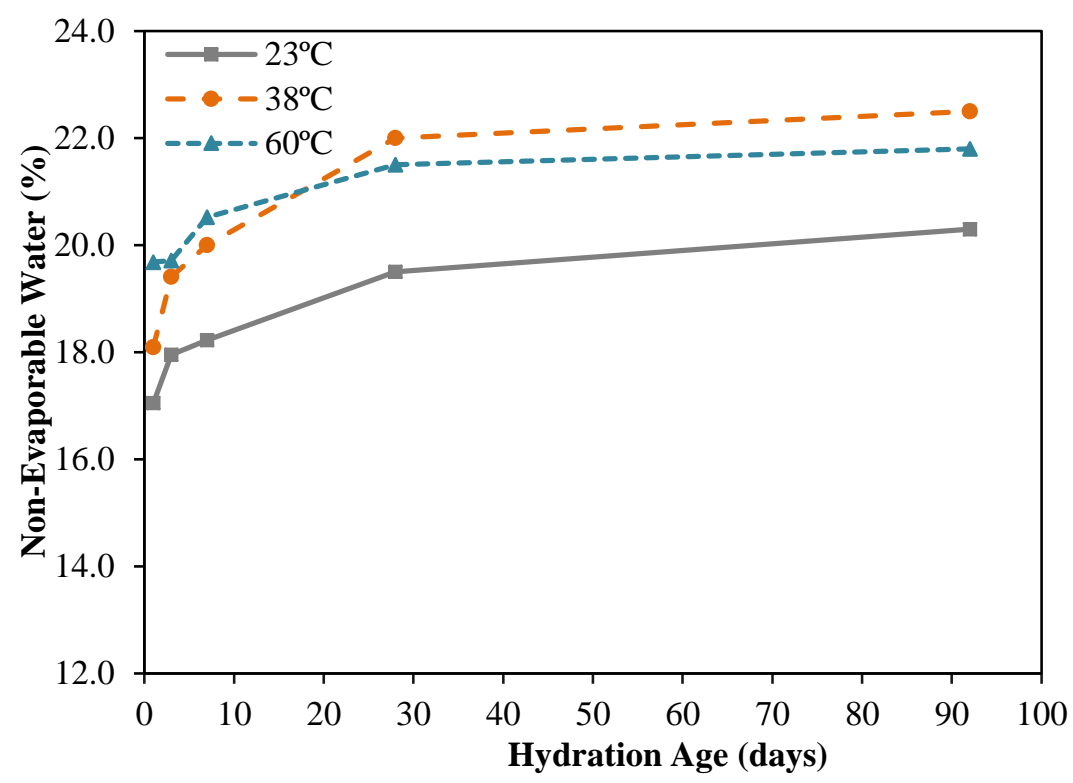

Figure 4.45: Non-evaporable water in cement paste without SCM

The paste sample tested at $60^{\circ} \mathrm{C}$ showed accelerated results until 7 days, however, the hydration started to slow down thereafter; at 28 days it reached similar value to the samples tested at $38^{\circ} \mathrm{C}$. The reason could be that at early ages, there will be formation of non-uniform distribution of the hydration products forming dense hydrated phases around the unreacted cement particles, preventing further hydration at $60^{\circ} \mathrm{C}$ (Wang et al., 2012).

PC samples cast with FA at two different replacement levels are tested for non-evaporable water and results are shown in Figure 4.46 and Figure 4.47. Similarly, increasing temperature seems to promote early hydration. Ultimately, the hydration of paste samples with SCM at $60^{\circ} \mathrm{C}$ is showing close results to the samples tested at $23^{\circ} \mathrm{C}$. Similar trends were obtained for samples cast with slag at $25 \%$ and $35 \%$ replacement levels as shown in Figure 4.48 and Figure 4.49. 


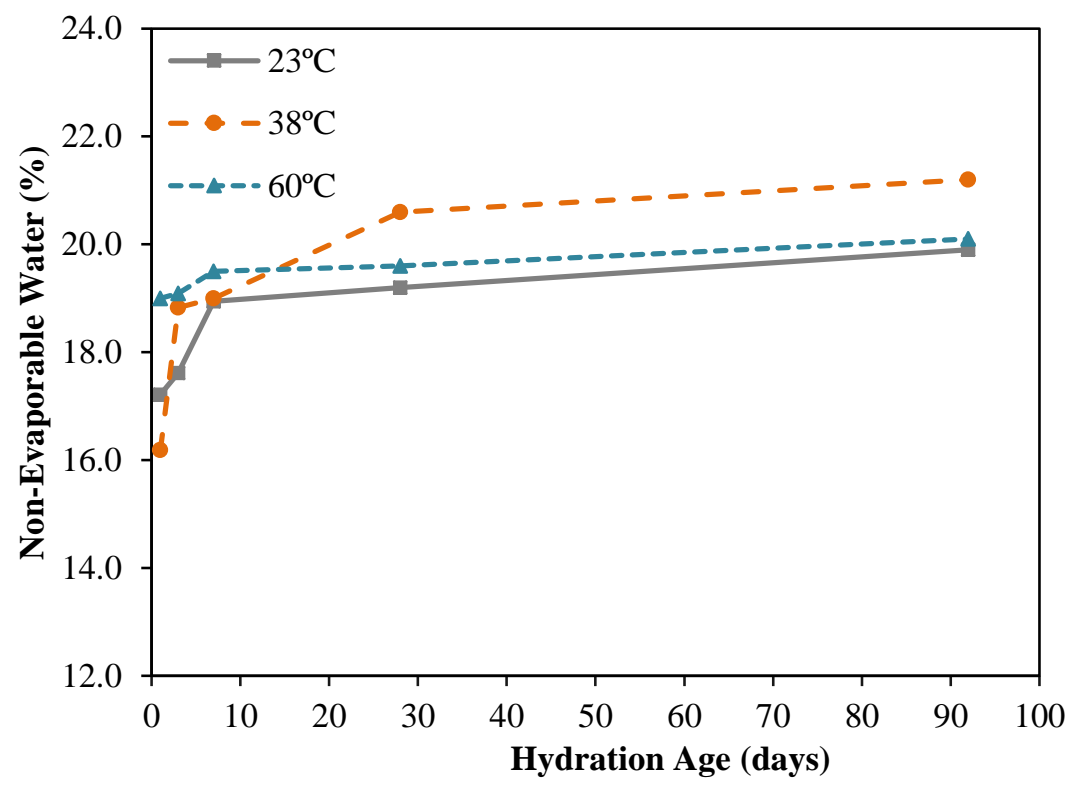

Figure 4.46: Non-evaporable water in paste with $15 \%$ FA

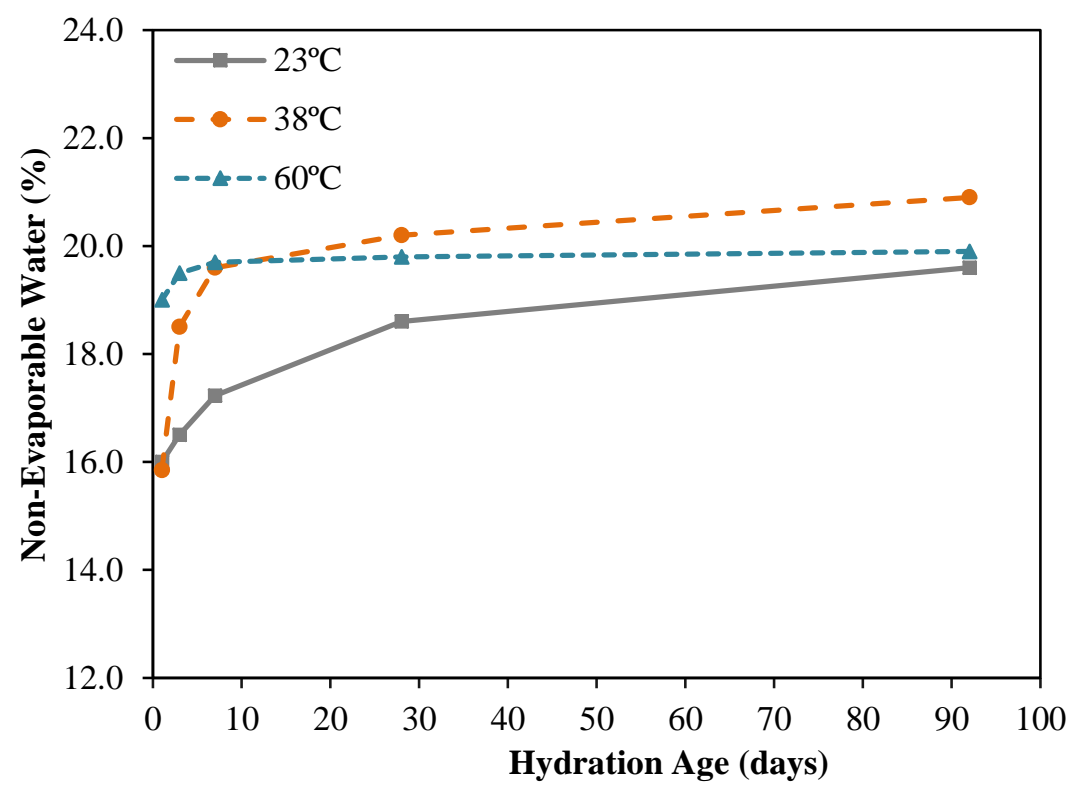

Figure 4.47: Non-evaporable water in paste with $25 \%$ FA 


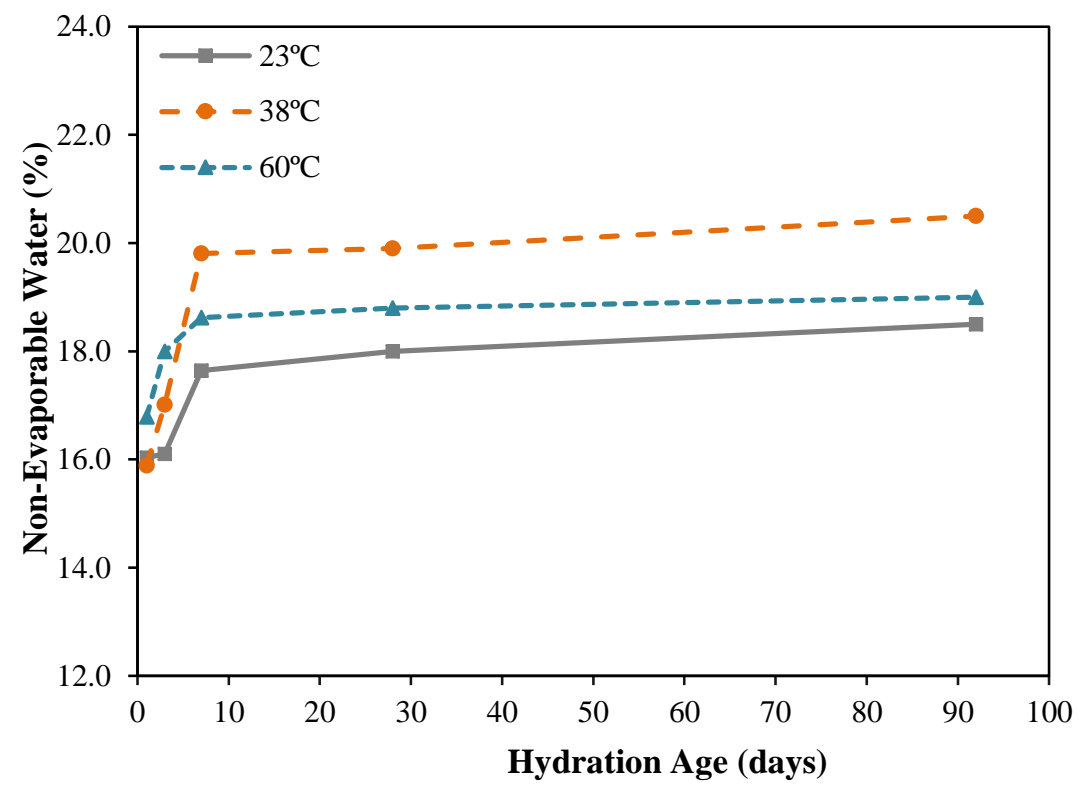

Figure 4.48: Non-evaporable water in paste with $25 \%$ Slag

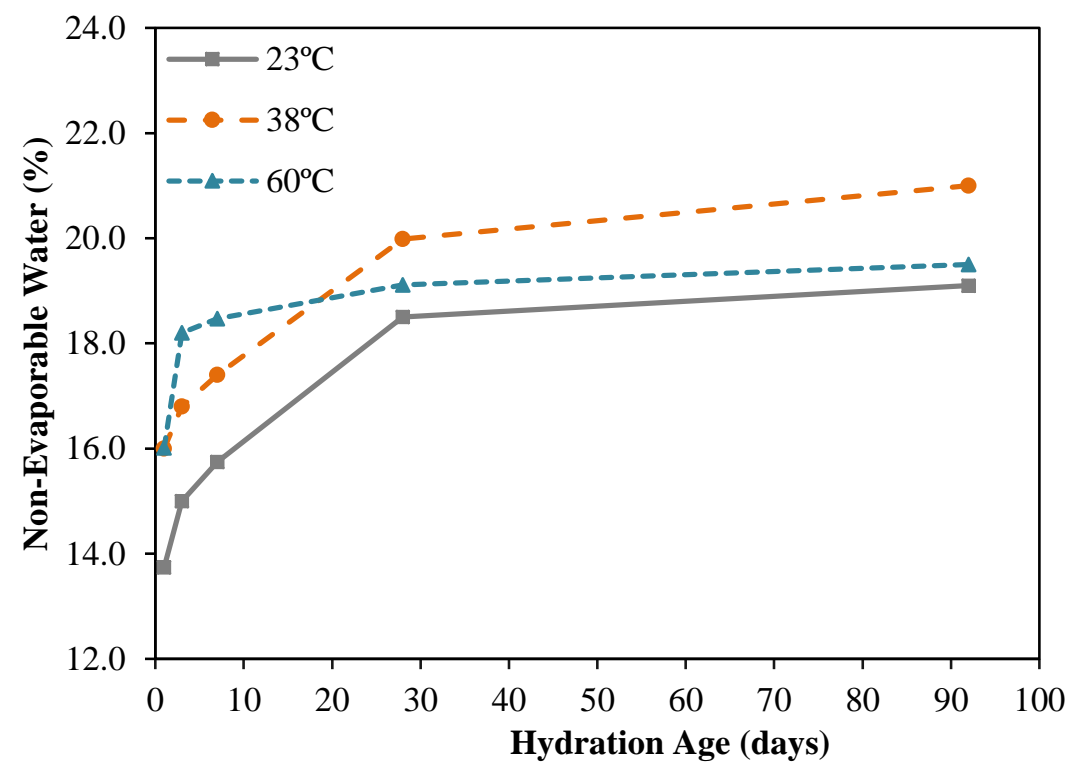

Figure 4.49: Non-evaporable water in paste with $35 \%$ Slag

\section{Degree of SCM Pozzolanic Reaction}

The amount of $\mathrm{Ca}(\mathrm{OH})_{2}$ in paste samples was measured at different temperatures using TGA analysis. In control samples without SCM, the higher the $\mathrm{Ca}(\mathrm{OH})_{2}$ formed indicates higher degree of hydration. Results of the samples at different temperatures until the age of 92 days are shown in Figure 4.50. At 92 days, the amount of $\mathrm{Ca}(\mathrm{OH})_{2}$ formed is the highest at $38^{\circ} \mathrm{C}$. This explains that more hydration is reached with samples at $38^{\circ} \mathrm{C}$. At early ages, the hydration is accelerated 
with samples at $60^{\circ} \mathrm{C}$ however at later age, the hydration is hindered at $60^{\circ} \mathrm{C}$ due to the formation of dense hydrated phases preventing further hydration. This is in line with the non-evaporable water results obtained in the previous section.

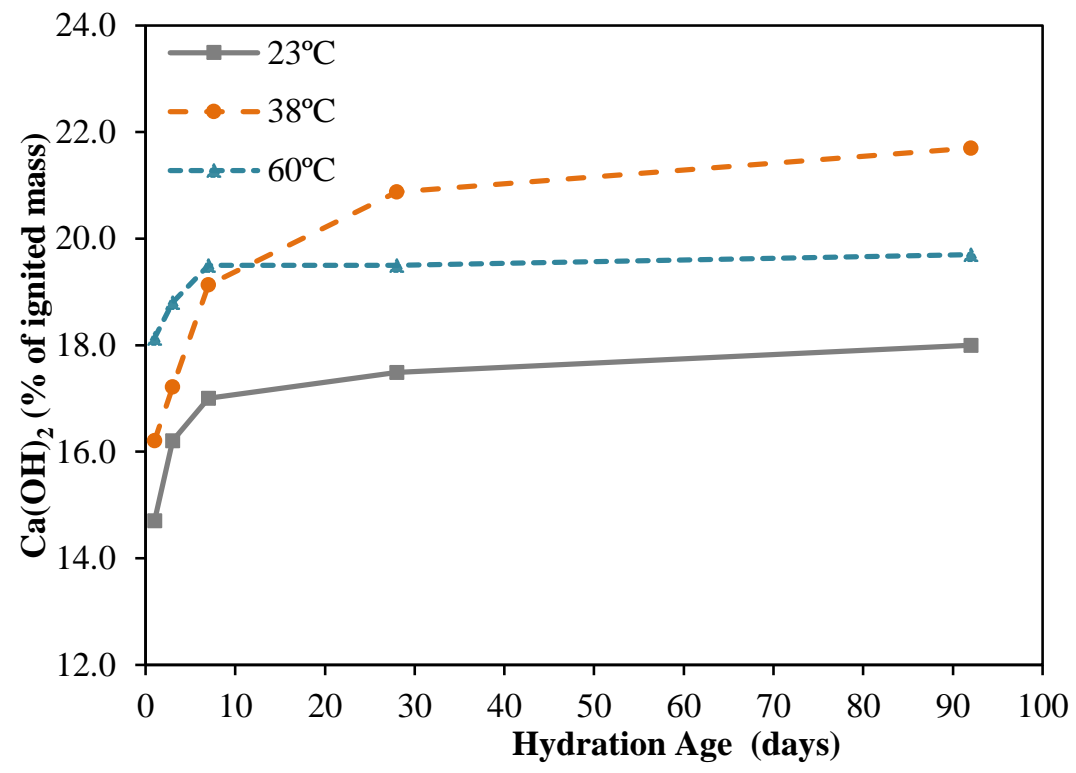

Figure 4.50: $\mathrm{Ca}(\mathrm{OH})_{2}$ in paste samples without $\mathrm{SCM}$ at different temperatures

For samples with $\mathrm{SCM}$, the $\mathrm{Ca}(\mathrm{OH})_{2}$ gives an indication of the degree of pozzolanic reaction and the ability of the hydration products to reduce pore solution alkalinity and thus prevent expansion due to ASR. The $\mathrm{Ca}(\mathrm{OH})_{2}$ obtained in samples cast with $15 \%$ and $25 \% \mathrm{FA}$ at $23^{\circ} \mathrm{C}, 38^{\circ} \mathrm{C}$ and $60^{\circ} \mathrm{C}$ are shown in Figure 4.51, Figure 4.52 and Figure 4.53, respectively. It is clear that with increased replacement levels of $\mathrm{FA}$, the amount of $\mathrm{Ca}(\mathrm{OH})_{2}$ left in the samples is lower at all temperatures. 


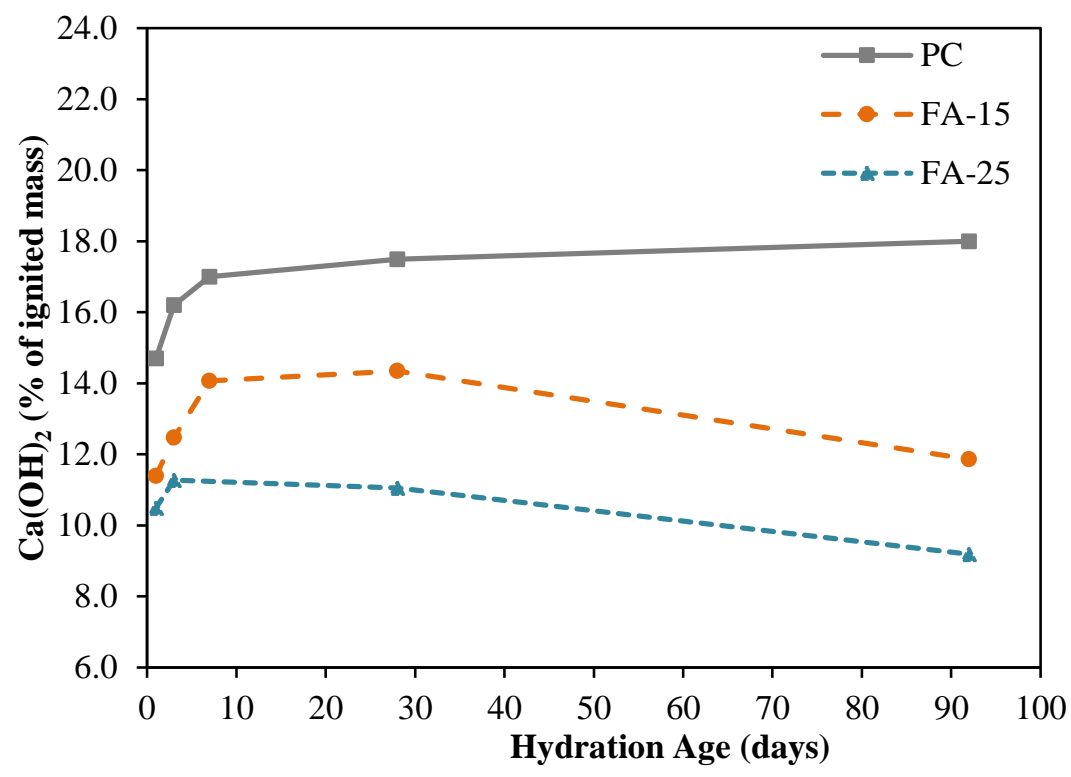

Figure 4.51: $\mathrm{Ca}(\mathrm{OH})_{2}$ in paste samples with $\mathrm{FA}$ at $23^{\circ} \mathrm{C}$

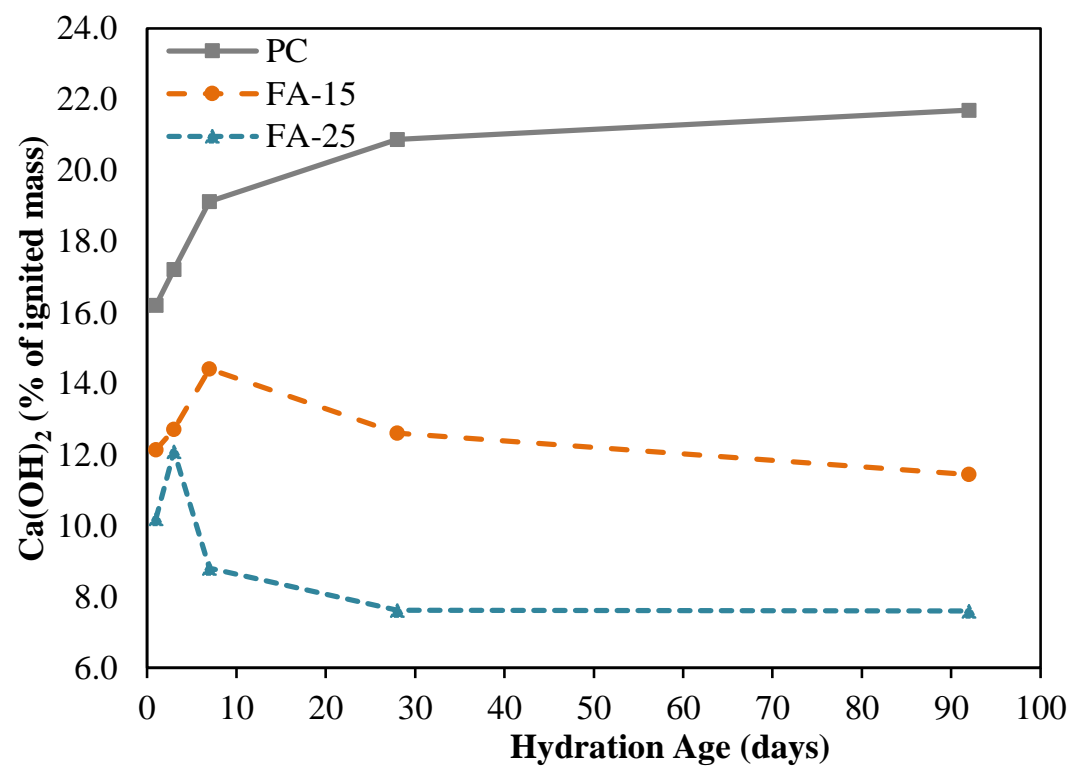

Figure 4.52: $\mathrm{Ca}(\mathrm{OH})_{2}$ in paste samples with $\mathrm{FA}$ at $38^{\circ} \mathrm{C}$ 


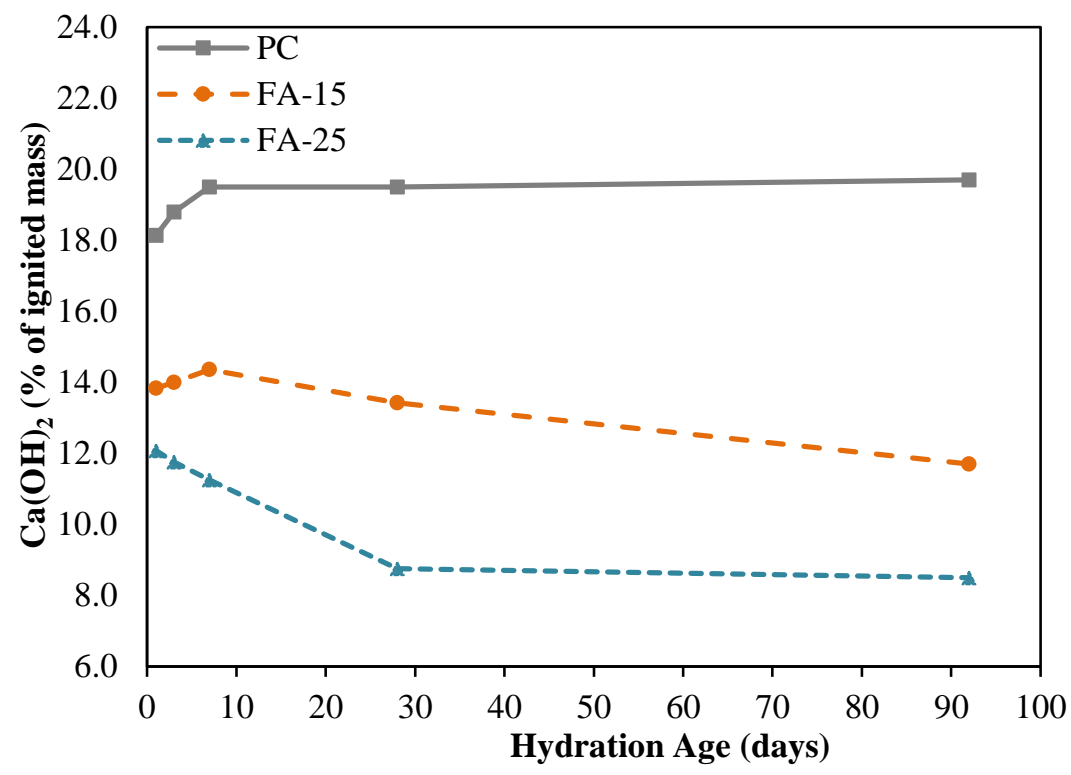

Figure 4.53: $\mathrm{Ca}(\mathrm{OH})_{2}$ in paste samples with $\mathrm{FA}$ at $60^{\circ} \mathrm{C}$

Results obtained for samples cast with $25 \%$ and $35 \%$ slag exhibited similar trends as shown in Figure 4.54, Figure 4.55 and Figure 4.56 for samples at $23^{\circ} \mathrm{C}, 38^{\circ} \mathrm{C}$ and $60^{\circ} \mathrm{C}$, respectively. However, it seems that the capacity of slag to consume $\mathrm{Ca}(\mathrm{OH})_{2}$ is lower than that of the FA. The hydration progress of slag is similar to that of the cement (Luke and Glasser, 1988). Due to the hydration of slag, a layer of hydration products is formed on the surface of unhydrated slag impeding further reaction (Luke and Glasser, 1988).

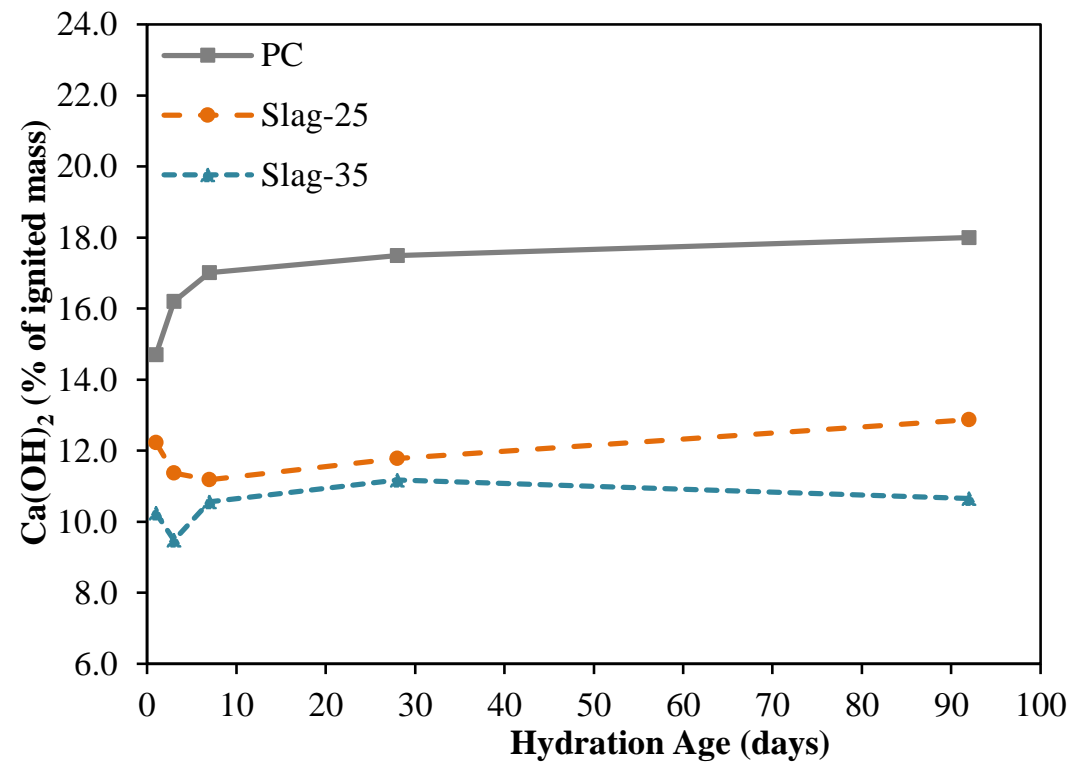

Figure 4.54: $\mathrm{Ca}(\mathrm{OH})_{2}$ in paste samples with slag at $23^{\circ} \mathrm{C}$ 


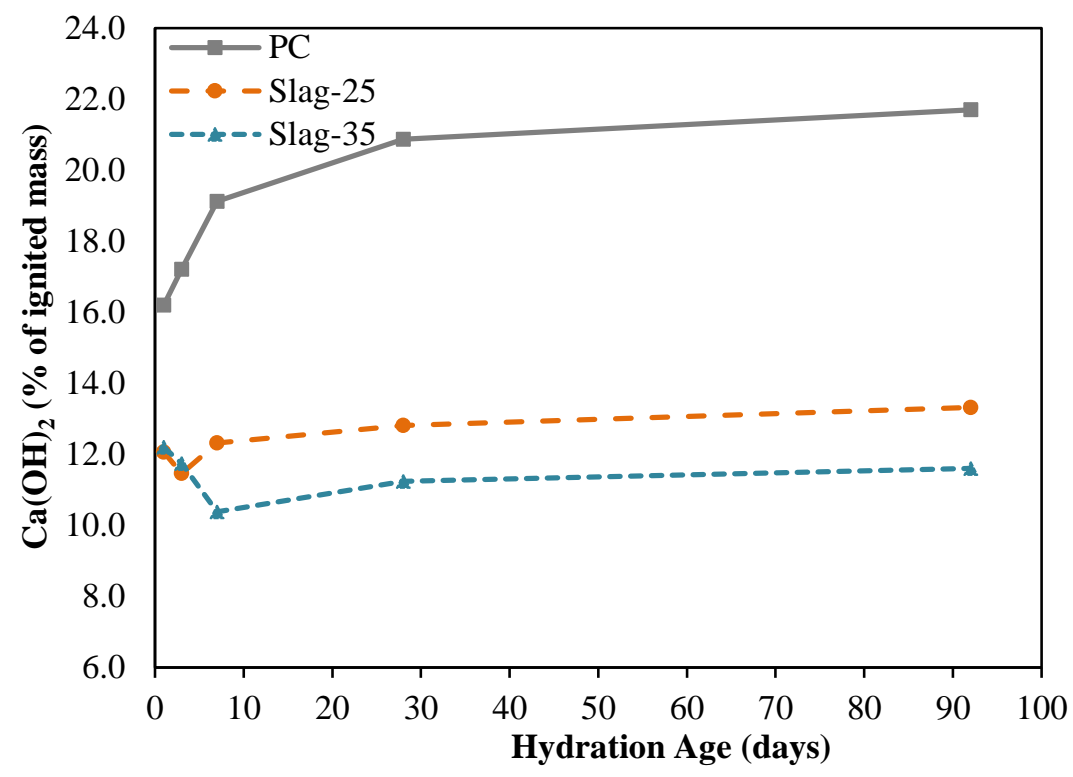

Figure 4.55: $\mathrm{Ca}(\mathrm{OH})_{2}$ in paste samples with slag at $38^{\circ} \mathrm{C}$

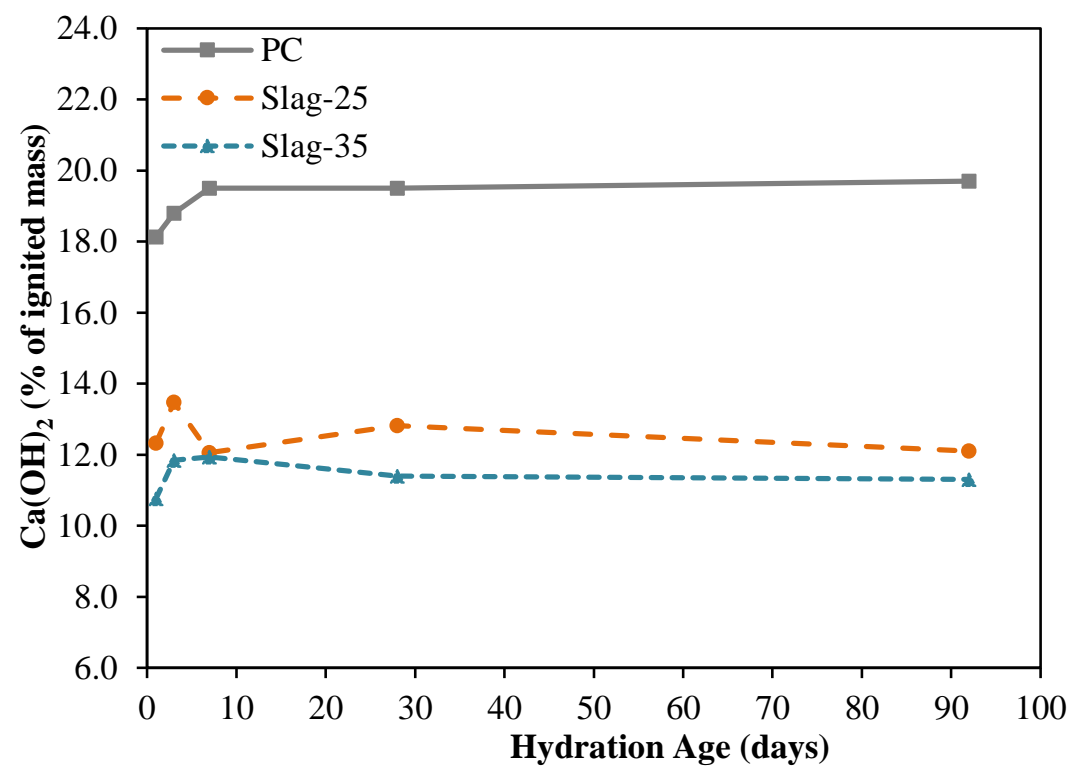

Figure 4.56: $\mathrm{Ca}(\mathrm{OH})_{2}$ in paste samples with slag at $60^{\circ} \mathrm{C}$

A way to understand the obtained results and to be able to compare them at different temperatures is to study the amount of $\mathrm{Ca}(\mathrm{OH})_{2}$ consumed by SCM. Assuming that when $15 \%$ of cement is replaced by $\mathrm{FA}$, the amount of $\mathrm{Ca}(\mathrm{OH})_{2}$ produced from the hydration of the cement is $85 \%$ of the amount of $\mathrm{Ca}(\mathrm{OH})_{2}$ originally produced when only cement control is used. Hence, the amount of $\mathrm{Ca}(\mathrm{OH})_{2}$ consumed will be the difference between this value and the formed $\mathrm{Ca}(\mathrm{OH})_{2}$ when $15 \%$ 
FA is used. As an example, calculation for the samples at $38^{\circ} \mathrm{C}$ will be shown in Table 4.1 for samples at 28 days.

Table 4.1: Sample calculation for $\mathrm{Ca}(\mathrm{OH})_{2}$ consumed by $\mathrm{SCM}$ for samples at $38^{\circ} \mathrm{C}$ at 28 days

\begin{tabular}{|c|c|c|c|c|c|}
\cline { 2 - 6 } & PC & FA-15 & FA-25 & Slag-25 & Slag-35 \\
\hline \hline $\begin{array}{c}\text { Ca(OH)2 content } \\
(\%)\end{array}$ & 20.87 & 12.61 & 7.62 & 12.81 & 11.25 \\
\hline $\begin{array}{c}\text { Ca(OH)2 content } \\
\text { from PC part of } \\
\text { sample (\%) }\end{array}$ & - & $\begin{array}{c}20.87 \times 85 \% \\
=17.74\end{array}$ & $\begin{array}{c}20.87 \times 75 \% \\
=15.65\end{array}$ & $\begin{array}{c}20.87 \times 75 \% \\
=15.65\end{array}$ & $\begin{array}{c}20.87 \times 65 \% \\
=13.57\end{array}$ \\
$\begin{array}{c}\text { Ca(OH)2 consumed } \\
\text { by SCM (\%) }\end{array}$ & - & $\begin{array}{c}17.74-12.6 \\
=5.14\end{array}$ & $\begin{array}{c}15.65-7.6 \\
=8.03\end{array}$ & $\begin{array}{c}15.65-12.81 \\
=2.85\end{array}$ & $\begin{array}{c}13.57-11.25 \\
=2.32\end{array}$ \\
\hline
\end{tabular}

Similar calculations were performed for samples at $23^{\circ} \mathrm{C}$ and $60^{\circ} \mathrm{C}$ and the results obtained at 7 , 28 and 92 days are shown in Figure 4.57, Figure 4.58 and Figure 4.59, respectively. At 7 days, the samples with lower replacement levels i.e., 15\% FA and $25 \%$ slag, showed higher consumption of $\mathrm{Ca}(\mathrm{OH})_{2}$ with higher temperatures. At higher replacement levels, 25\% FA and 35\% slag, samples at $38^{\circ} \mathrm{C}$ showed the highest consumption of $\mathrm{Ca}(\mathrm{OH})_{2}$ followed by $60^{\circ} \mathrm{C}$ and then $23^{\circ} \mathrm{C}$ having the lowest consumption. At 92 days, all the samples showed highest consumption at $38^{\circ} \mathrm{C}$ followed by $60^{\circ} \mathrm{C}$ and then at $23^{\circ} \mathrm{C}$ showing the lowest consumption compared to the other two temperatures. This could be contributed to the higher hydration of SCM aiding in consuming more $\mathrm{Ca}(\mathrm{OH})_{2}$ at $38^{\circ} \mathrm{C}$ compared to the other two temperatures. 


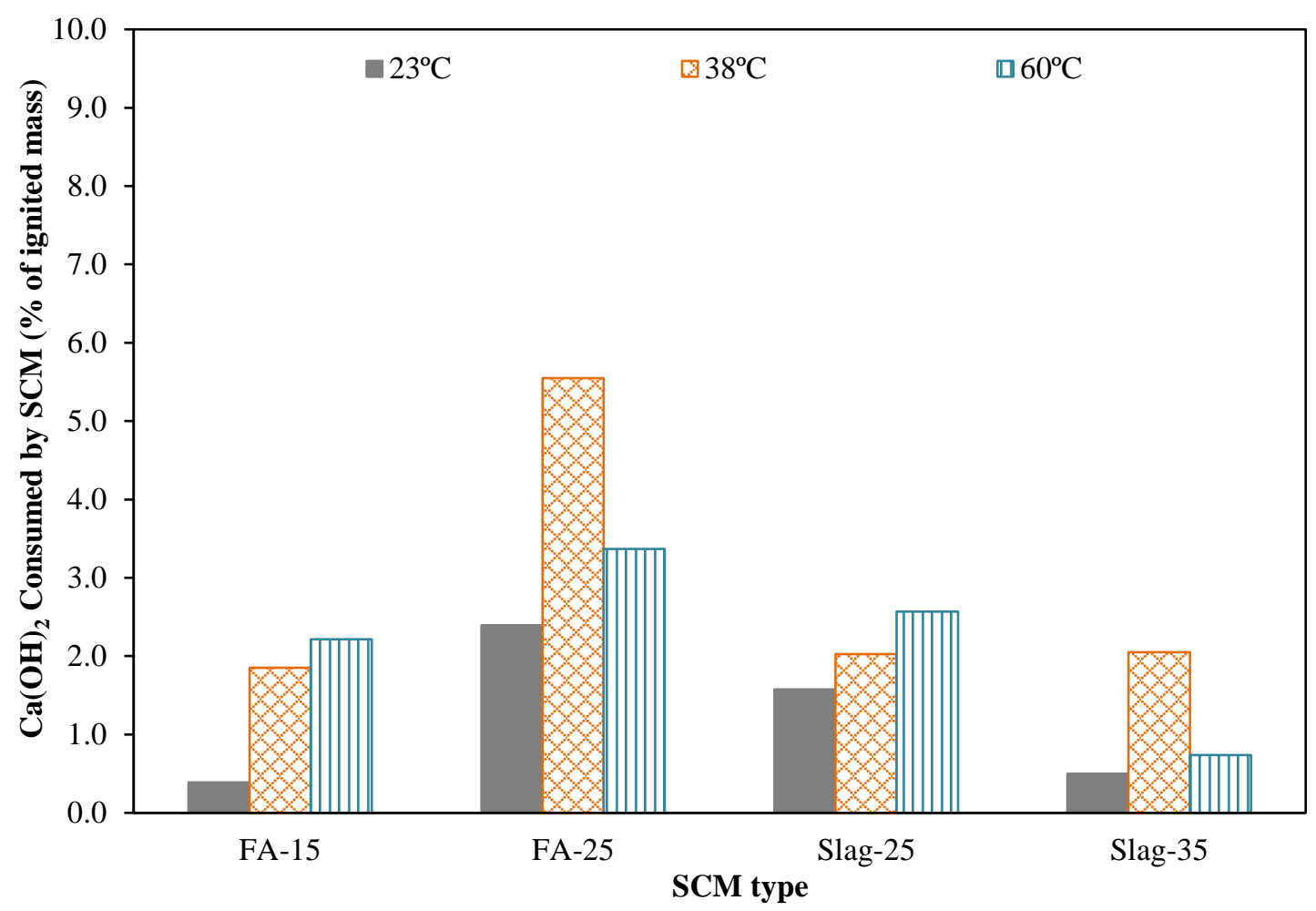

Figure 4.57: $\mathrm{Ca}(\mathrm{OH})_{2}$ consumed by $\mathrm{SCM}$ at 7 days

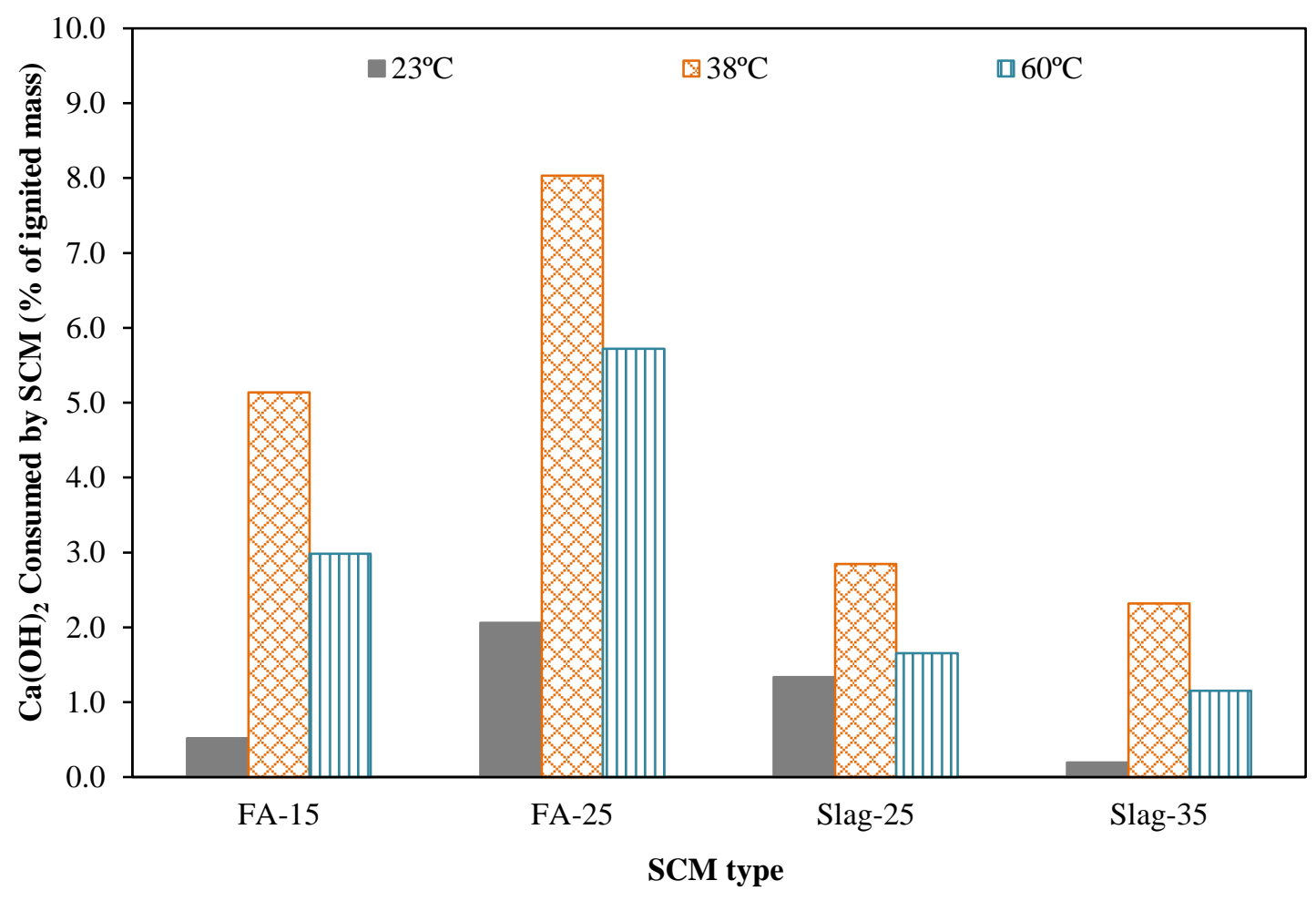

Figure 4.58: $\mathrm{Ca}(\mathrm{OH})_{2}$ consumed by $\mathrm{SCM}$ at 28 days 


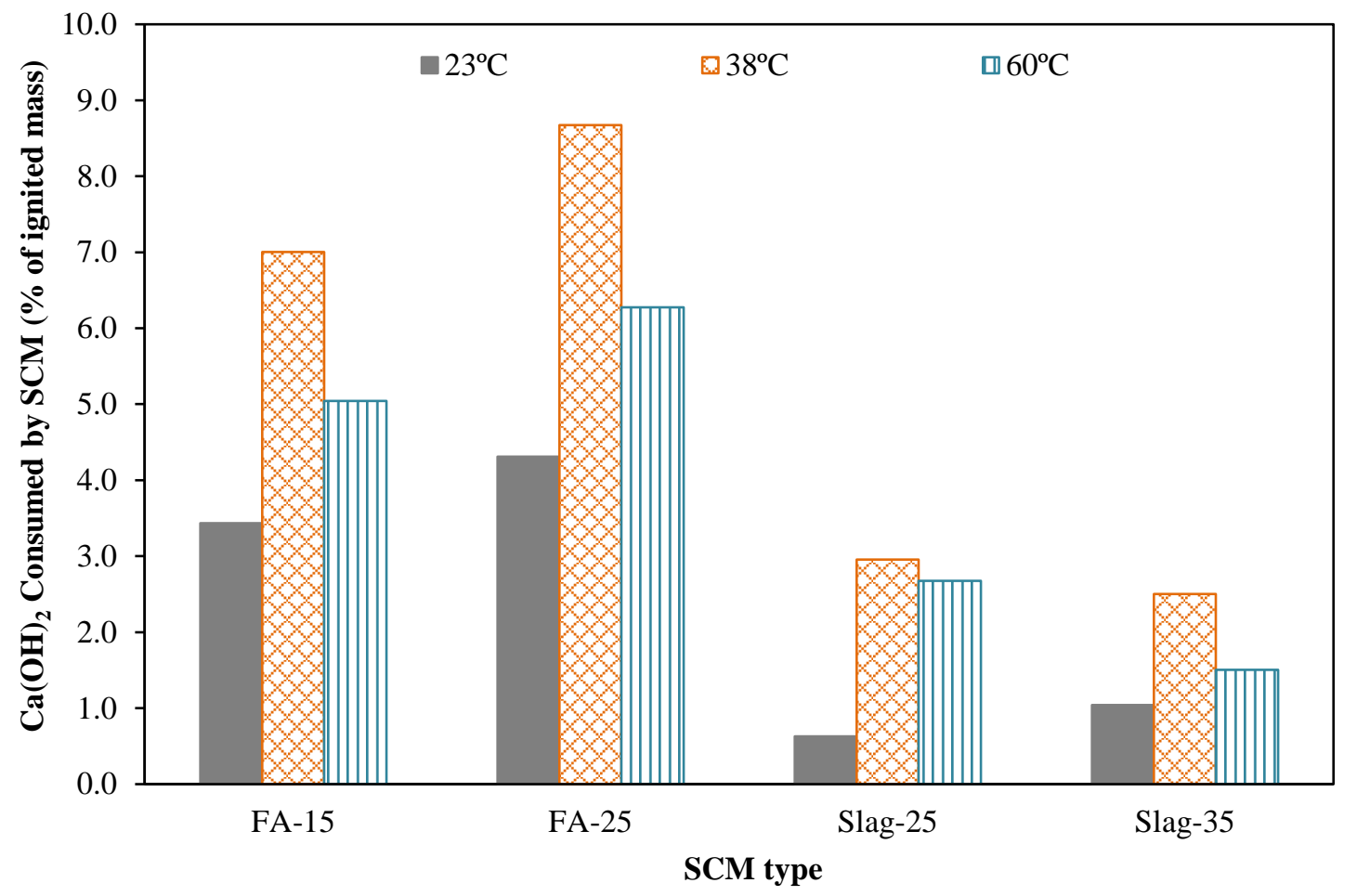

Figure 4.59: $\mathrm{Ca}(\mathrm{OH})_{2}$ consumed by $\mathrm{SCM}$ at 92 days

\section{Alkali Release from Cement with SCM}

Alkali release from the cementing materials to a solution of $0.25 \mathrm{M}$ was investigated. The $0.25 \mathrm{M}$ solution corresponds to the lowest alkalinity the concrete could drop to due to the alkali consumption by reactive aggregates (Shehata and Thomas, 2010). The available alkalis released from cementing materials to the solution will give an indication of the extent of remaining expansion that could occur at different temperatures. Paste samples containing FA or slag were tested at different replacement levels. Sample calculations and detailed results of this test are provided in Appendix D. Figure 4.60 and Figure 4.61 show the available alkalis to pore solution of $0.25 \mathrm{M}$ for paste samples containing FA at $15 \%$ and $25 \%$ replacement levels. At 92 days, there was an increase in the host solution alkalinity for all the samples at the three different temperatures. 


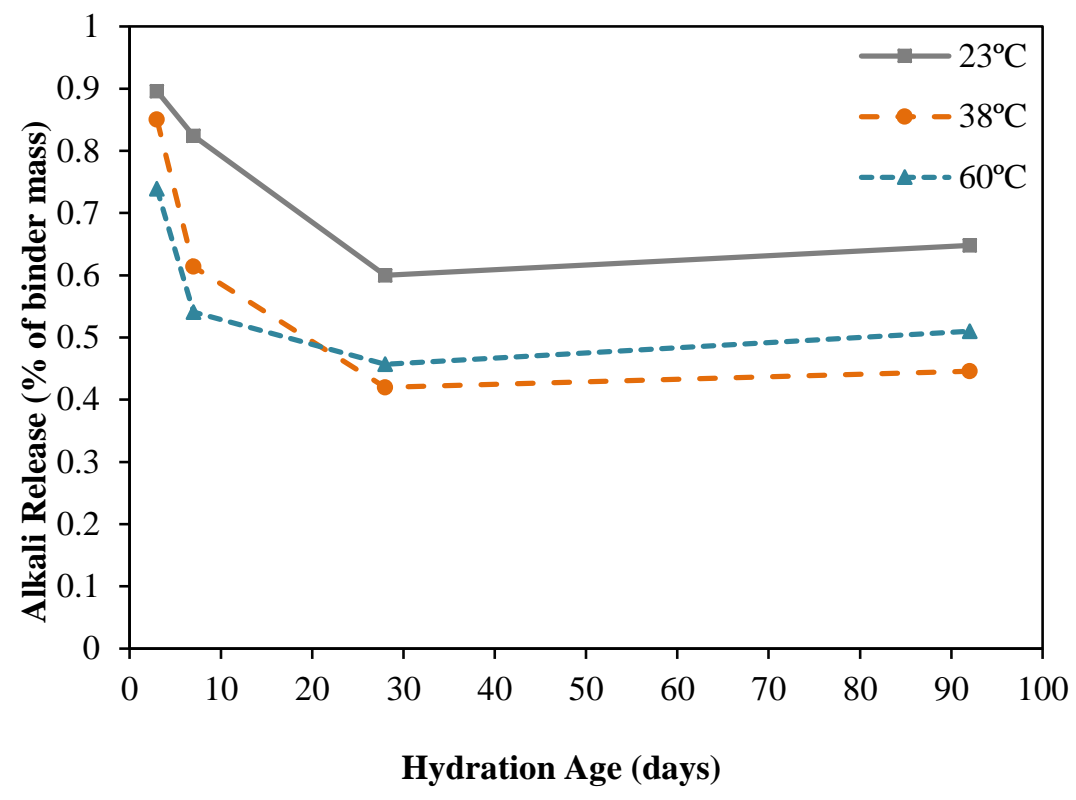

Figure 4.60: Alkali release from paste with $15 \% \mathrm{FA}$ in $0.25 \mathrm{M}$ alkaline solution

At 92 days, higher alkali release from samples at $23^{\circ} \mathrm{C}$ was obtained compared to $38^{\circ} \mathrm{C}$ and $60^{\circ} \mathrm{C}$. In other words, higher binding of alkalis by SCM is obtained at temperatures higher than $23^{\circ} \mathrm{C}$. Similar trend was observed for samples with 25\% FA and 35\% slag as shown in Figure 4.61 and Figure 4.62. The binding capacity of SCM is influenced by temperature. In general, the alkali binding follows the same trend as $\mathrm{Ca}(\mathrm{OH})_{2}$ consumption, the higher the consumption of portlandite $\mathrm{Ca}(\mathrm{OH})_{2}$ the higher the alkali binding. 


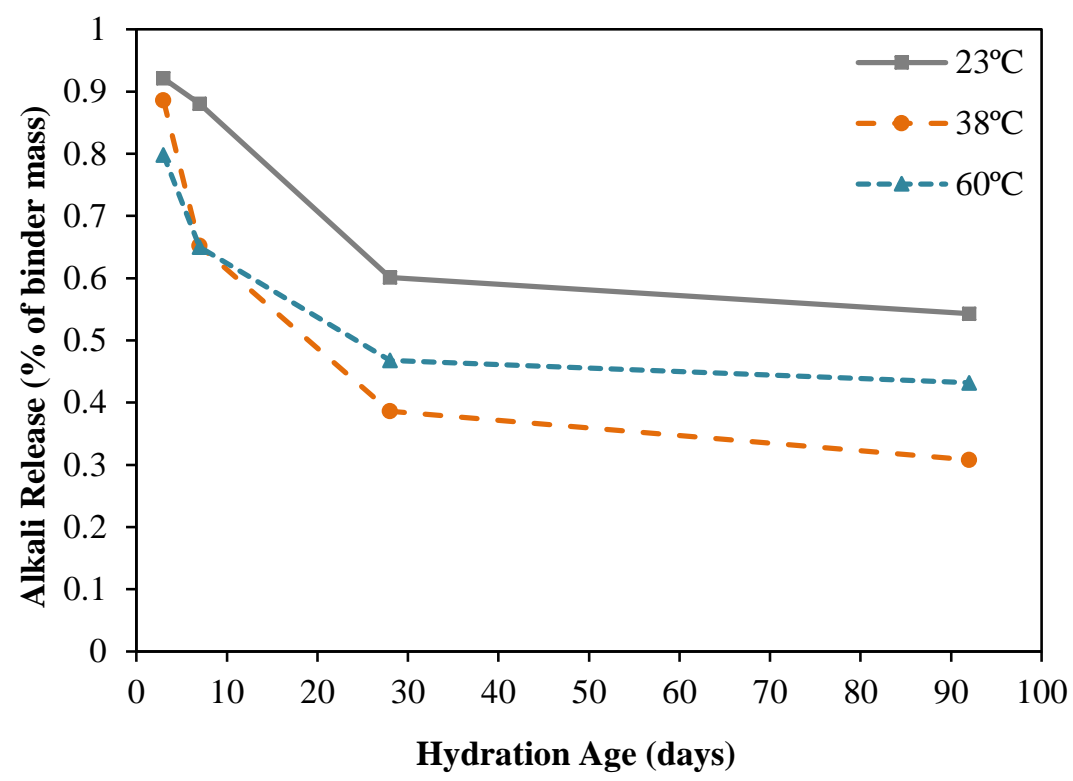

Figure 4.61: Alkali release from paste with $25 \% \mathrm{FA}$ in $0.25 \mathrm{M}$ alkaline solution

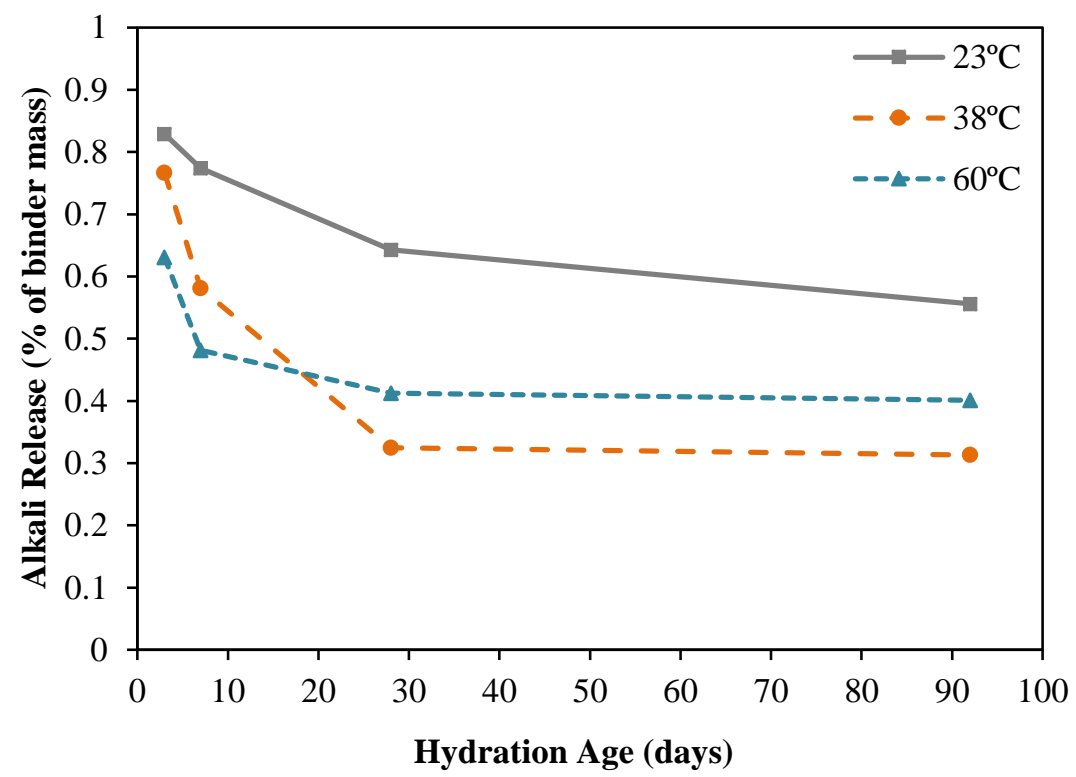

Figure 4.62: Alkali release from paste with $35 \%$ Slag in $0.25 \mathrm{M}$ alkaline solution

The aim of this study was to investigate the capacity of SCM to retain alkalis at different temperatures. It is clear that at $38^{\circ} \mathrm{C}$, the samples have a higher capacity to bind alkalis releasing less amount to the host solution compared to the samples cured at $23^{\circ} \mathrm{C}$ and $60^{\circ} \mathrm{C}$. This is in agreement with the results obtained from the $\mathrm{Ca}(\mathrm{OH})_{2}$ analysis where higher consumption of calcium hydroxide was reached at $38^{\circ} \mathrm{C}$ followed by $60^{\circ} \mathrm{C}$ and then $23^{\circ} \mathrm{C}$. 
These findings could explain the observed discrepancies in expansion obtained between the CPT and the field. In the field, the average temperatures are lower compared to the CPT temperature of $38^{\circ} \mathrm{C}$. Hence, SCM have higher binding capacity under the CPT conditions compared to the field leading to lower expansions compared to the field. This will be covered in more details under Chapter 5.

\section{$\underline{\text { Scanning Electron Microscopy Analysis }}$}

Scanning electron microscopy (SEM) was performed on paste samples with slag at $35 \%$ replacement level at the age of 2 years. The aim was to study the composition of the hydration products of the cement and compare it at different temperatures. The elements of interest were the $\mathrm{Ca} / \mathrm{Si}$ ratio, the potassium and sodium cations of the inner hydrates. Outer hydrates could not be analyzed as it was found mixed with other hydration products. For each sample, 10 points were obtained and statistical analysis of the different elements was performed to compare the results at $23^{\circ} \mathrm{C}$ and $38^{\circ} \mathrm{C}$. The data obtained were presented in Appendix G. The results showed that there is no statistically significant difference in the $\mathrm{Ca} / \mathrm{Si}$ ratio between the samples at $23^{\circ} \mathrm{C}$ and $38^{\circ} \mathrm{C}$. This suggests that the hydration products of the samples at the two temperatures have similar chemical compositions. The fact that the hydration products have the same composition while $\mathrm{Ca}(\mathrm{OH})_{2}$ consumption is higher at $38^{\circ} \mathrm{C}$ suggests that: (a) more hydration products are formed in case of the samples at $38^{\circ} \mathrm{C}$, and/or (b) the outer hydrates at $38^{\circ} \mathrm{C}$ bind more alkalis than that at $23^{\circ} \mathrm{C}$.

Pictures obtained from the SEM analysis for the paste containing 35\% slag are shown in Figure 4.63 for the samples at $23^{\circ} \mathrm{C}$ and Figure 4.64 for the samples at $38^{\circ} \mathrm{C}$.
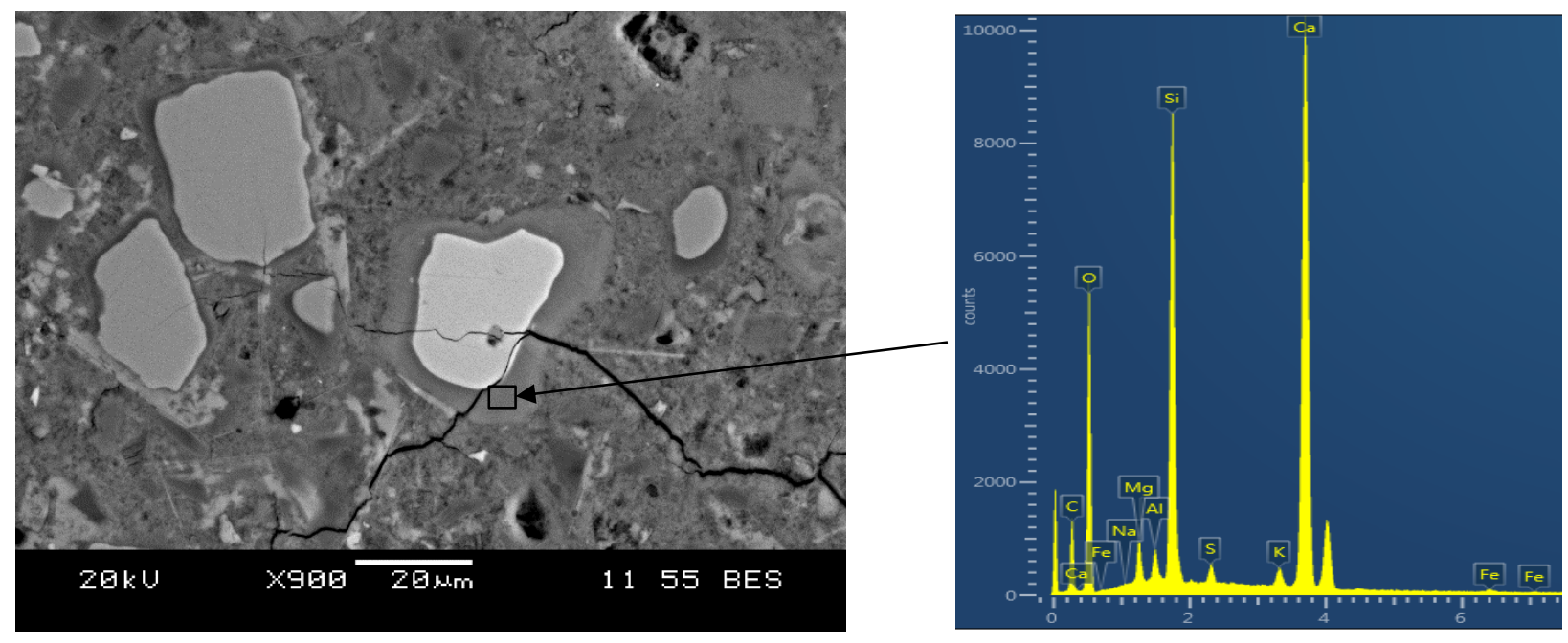


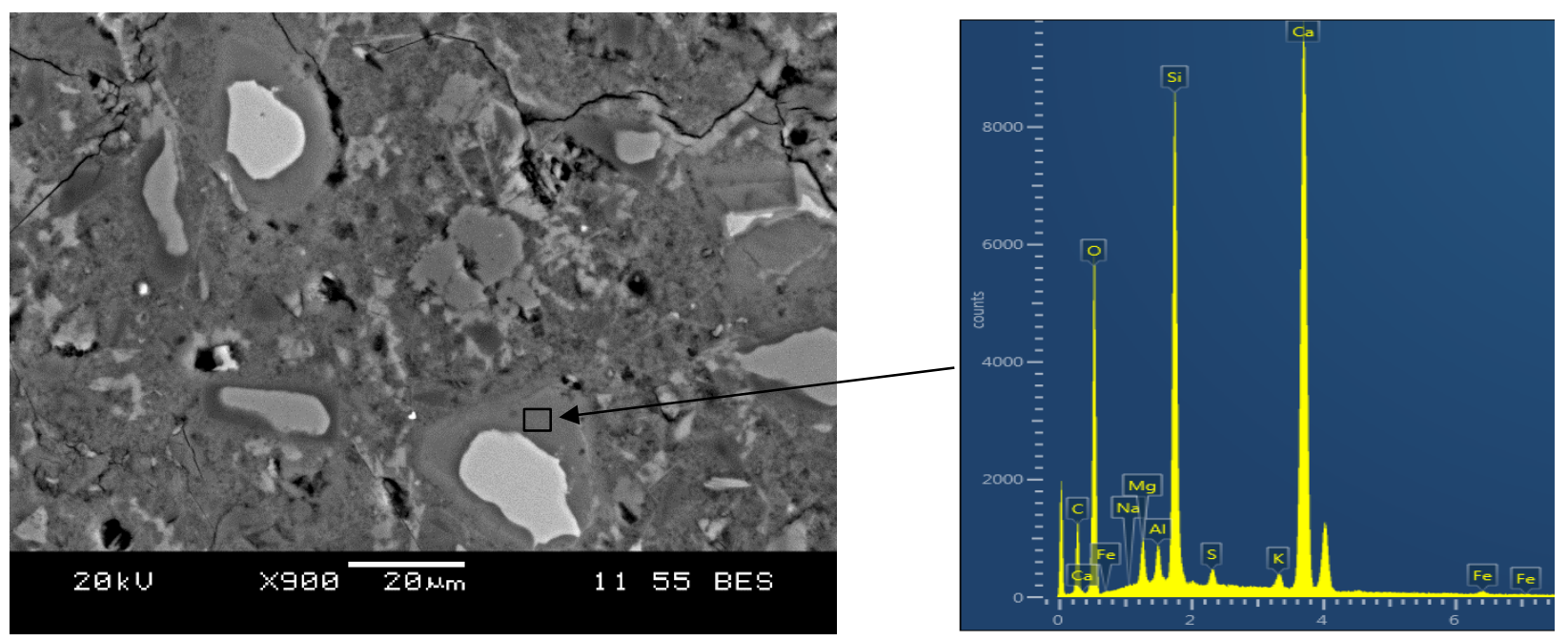

Figure 4.63: SEM of paste with $35 \%$ slag at $23^{\circ} \mathrm{C}$ tested at 2 years
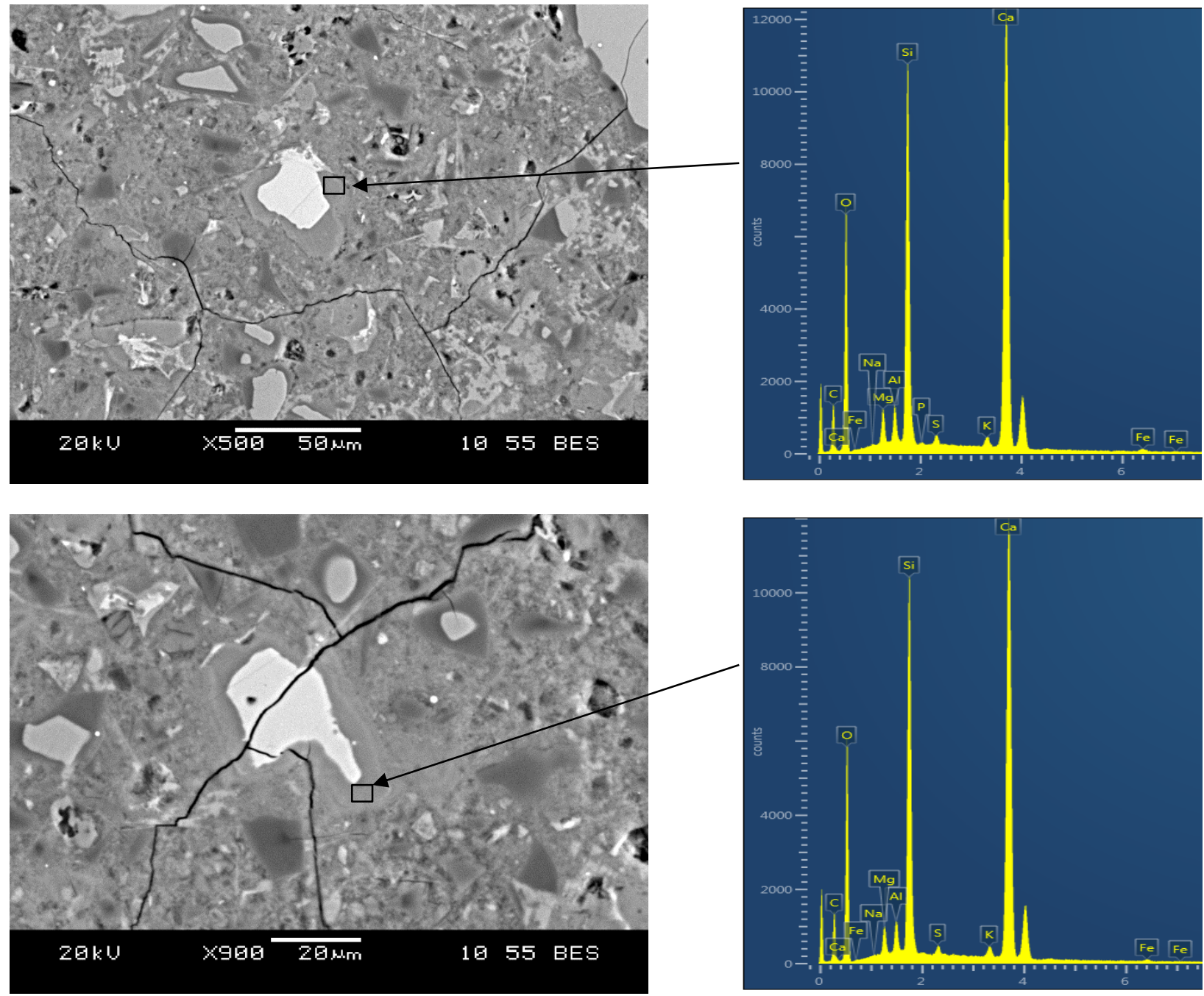

Figure 4.64: SEM of paste with $35 \%$ slag at $38^{\circ} \mathrm{C}$ tested at 2 years 


\subsection{Expansion at $60^{\circ} \mathrm{C}$}

Testing at $60^{\circ} \mathrm{C}$ was investigated to study the effect of temperature on expansion of concrete samples and analyze the possibility of shortening the test duration by increasing temperature to $60^{\circ} \mathrm{C}$. The effect of temperature on alkali leaching from concrete samples, alkali release from aggregates and pozzolanic activity of SCM studied in Section 4.2 will be used to explain the expansion results. In addition, expansion of samples at $60^{\circ} \mathrm{C}$ was compared to the samples at $38^{\circ} \mathrm{C}$ and correlation between standard test at $38^{\circ} \mathrm{C}$ and cylinders tested at $60^{\circ} \mathrm{C}$ was explored in an attempt to obtain expansion results in a shorter duration compared to the standard 2-year test.

\subsubsection{Expansion of Concrete Samples at $60^{\circ} \mathrm{C}$}

Expansion of concrete samples cast with Sudbury and Spratt aggregates without SCM were measured at $60^{\circ} \mathrm{C}$ and results are shown in Figure 4.65. For Sudbury control samples, cylinders are showing the highest expansion followed by cubes than prisms. For Spratt, prisms, cylinders and cubes measured from the sides all showed same expansion. The cubes showed the highest expansion at $60^{\circ} \mathrm{C}$ when measured center-to-center. Due to the increased alkali leaching from concrete samples at $60^{\circ} \mathrm{C}$, the pore solution alkalinity might have been lowered with all the different samples geometries leading to the close expansion results in the case of Spratt. For Sudbury, cylinders showed the highest expansion which could be due to alkali contribution from the aggregates increasing the pore solution alkalinity of cylinders. 


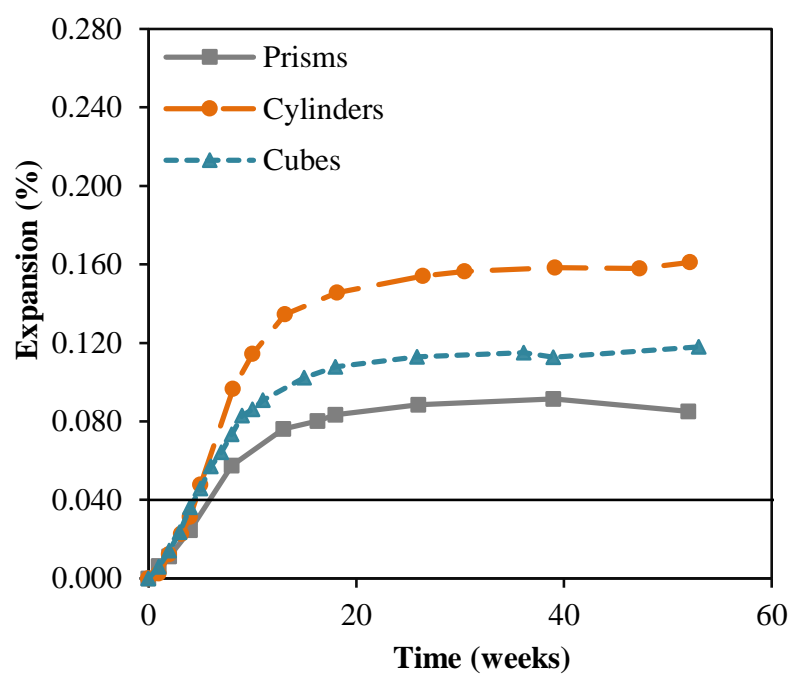

(a)

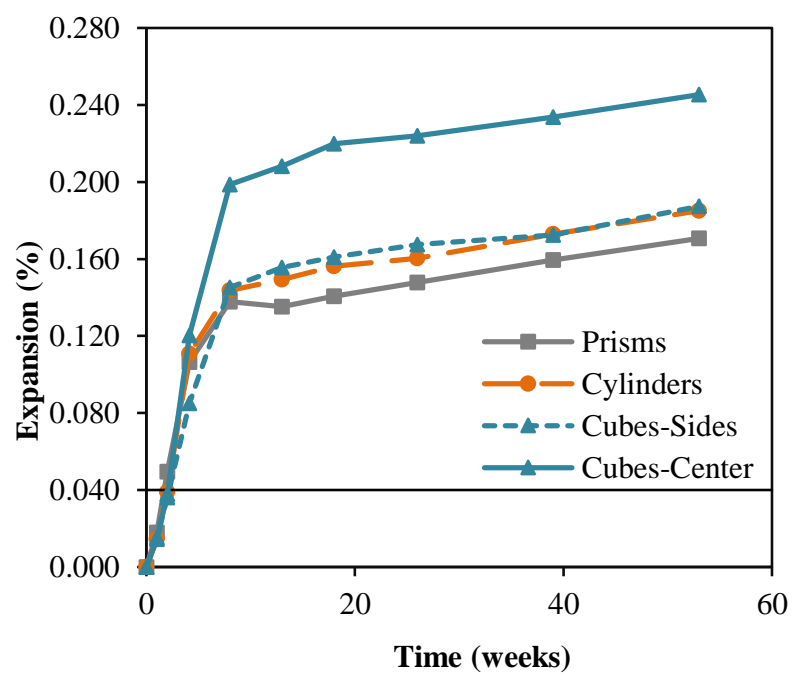

(b)

Figure 4.65: Expansion at $60^{\circ} \mathrm{C}$ of concrete cast without SCM containing (a) Sudbury and (b) Spratt

For the Spratt cubes measured center-to-center, reasons for such high expansion compared to the other sample shapes are not clear. More testing should be done to verify the obtained results. The center-to-center measurements on cubes was applied on Spratt samples with and without SCM. Sudbury samples were cast earlier than Spratt samples and were not measured center-to-center. The idea of measuring expansion at the center came up later due to the low expansion observed on the cubes measured on the sides. The 2-year expansion of Sudbury and Springhill samples with SCM are presented in Figure 4.66. For expansion up to two years, data can be found in Appendix H. In all cases, cylinders are showing higher expansion compared to prisms. This is because higher alkali leaching from prisms compared to cylinders is occurring leading to lower pore solution alkalinity and thus lower expansion. Cubes are showing the lowest expansion. 


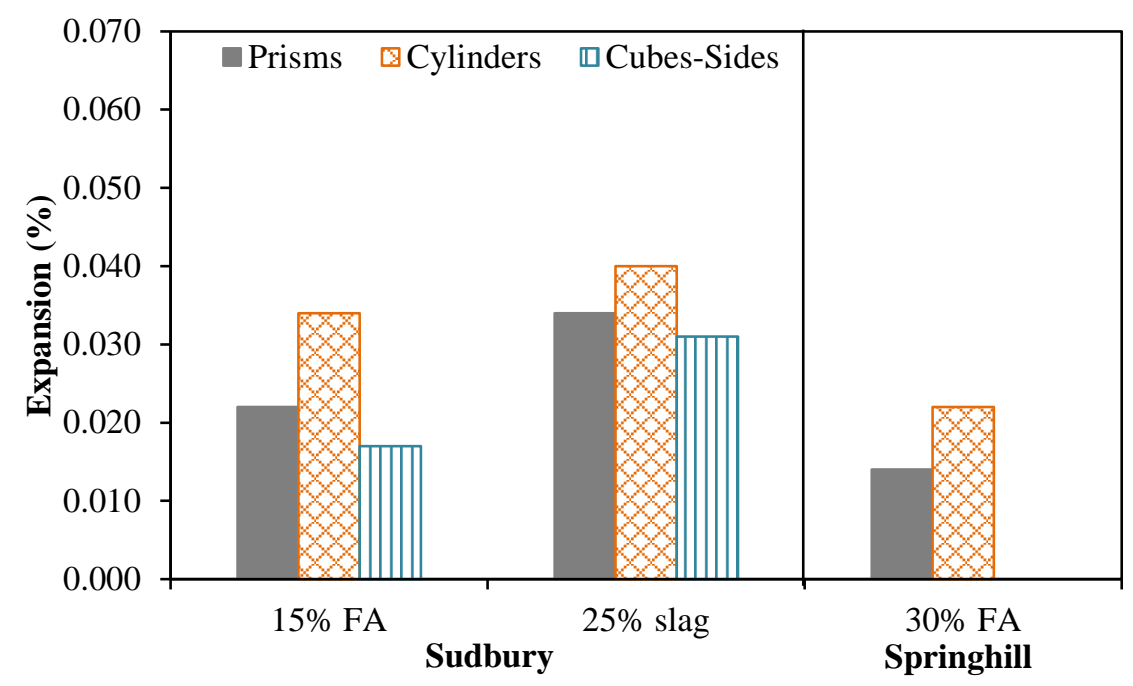

Figure 4.66: 2-year expansion of concrete cast with Sudbury or Springhill aggregates and different SCM combinations at $60^{\circ} \mathrm{C}$

Spratt samples with different combinations of SCM were cast and tested at $60^{\circ} \mathrm{C}$. The results are shown in Figure 4.67. Cylinders are showing higher expansion compared to prisms, likely due to the lower alkali leaching from the cylinders compared to prisms. This was not the case with the Spratt samples tested at $38^{\circ} \mathrm{C}$ where cylinders and prisms showed same expansion. This could be due to the lower capacity of SCM to bind alkalis at $60^{\circ} \mathrm{C}$ leading to the observed difference in expansion between prisms and cylinders. At $38^{\circ} \mathrm{C}$, the binding capacity of SCM is higher compared to samples tested at $60^{\circ} \mathrm{C}$.

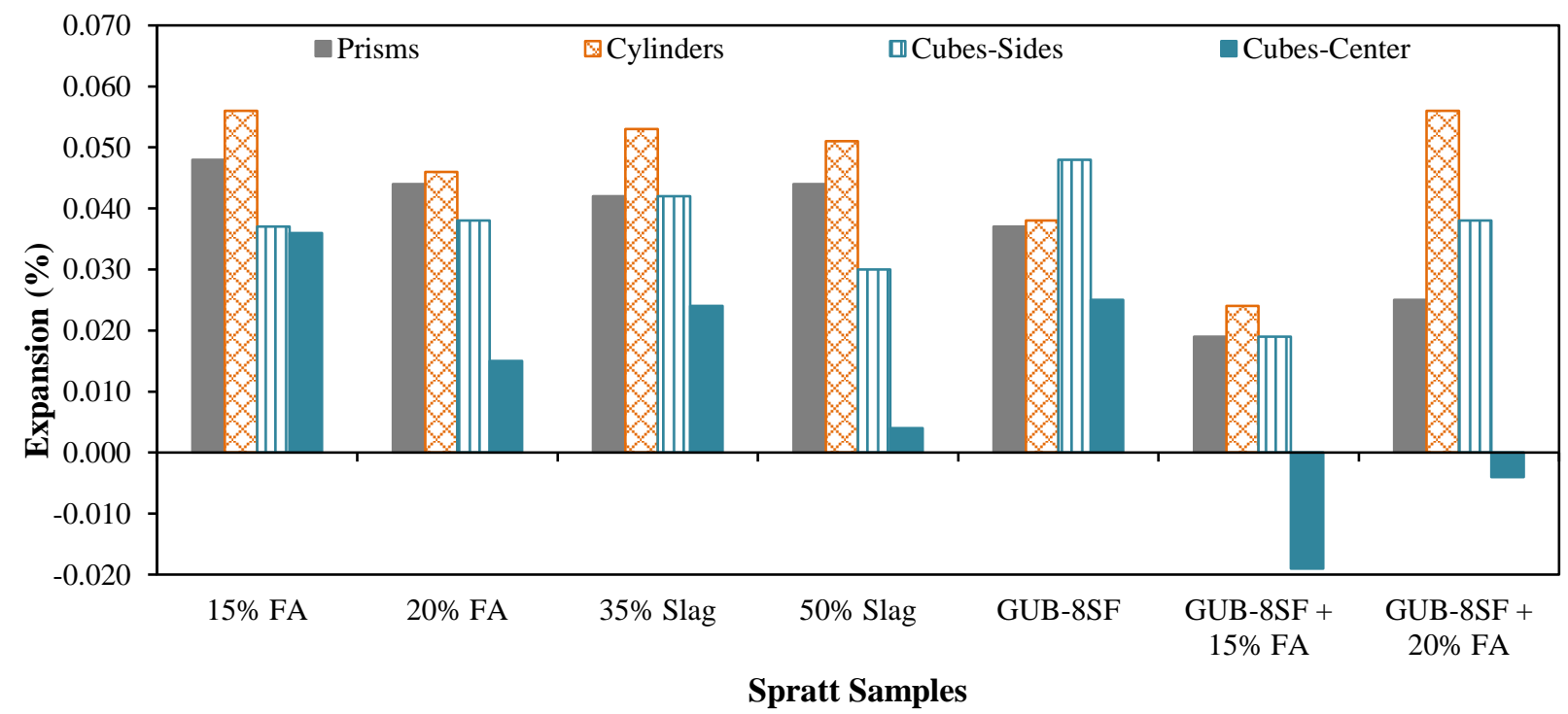

Figure 4.67: 2-year expansion of concrete cast with Spratt and different SCM combinations at $60^{\circ} \mathrm{C}$ 


\subsubsection{Comparison of expansion between $38^{\circ} \mathrm{C}$ and $60^{\circ} \mathrm{C}$}

\section{Expansion of Concrete Cast without SCM}

The expansions of prisms, cylinders and cubes were compared at two different temperatures: $38^{\circ} \mathrm{C}$ and $60^{\circ} \mathrm{C}$. Figure 4.68 shows the expansions at 6 months and 1 year for concrete samples cast with Sudbury and Figure 4.69 for Spratt samples. At 1 year, the ultimate expansions at $38^{\circ} \mathrm{C}$ are higher than the expansions at $60^{\circ} \mathrm{C}$ for all the different sample shapes and for both aggregates.

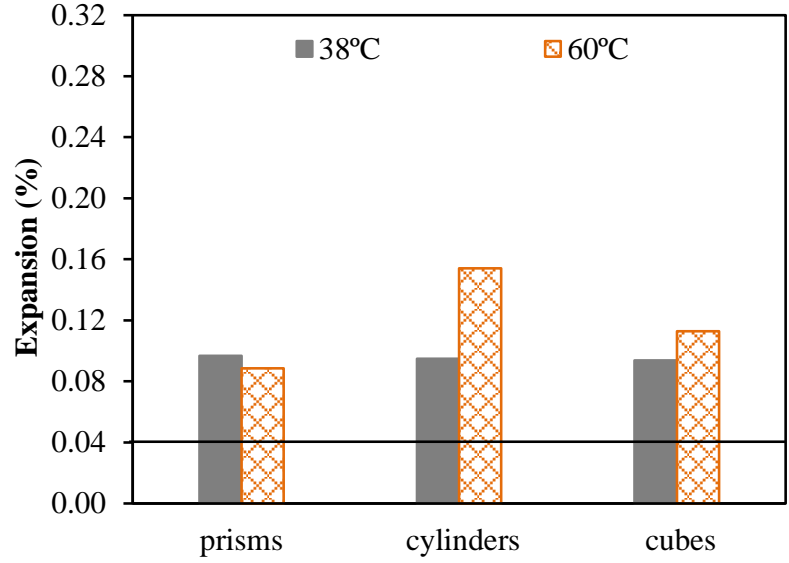

(a)

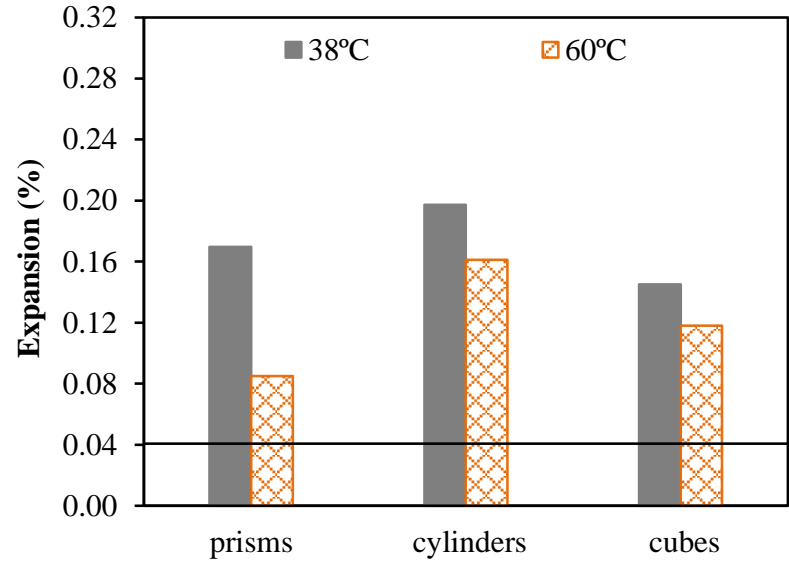

(b)

Figure 4.68: Expansion of concrete cast with Sudbury aggregate at (a) 6 months and (b) 1 year

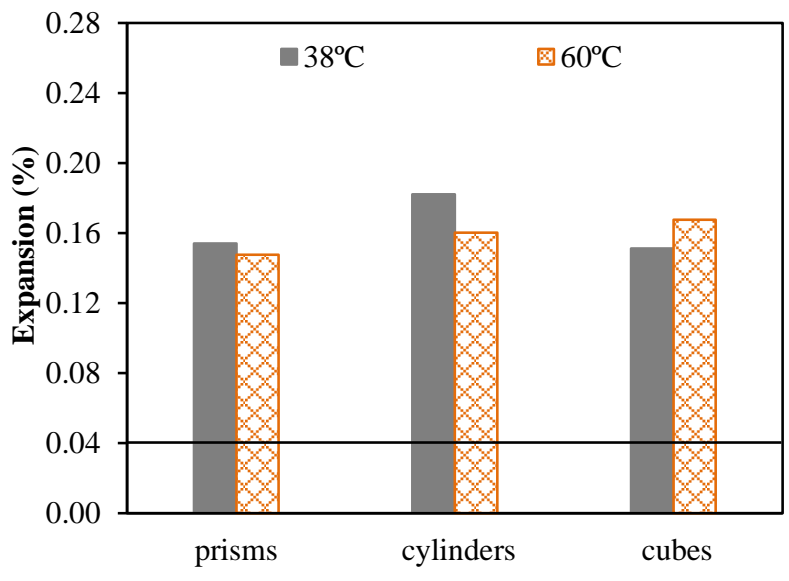

(a)

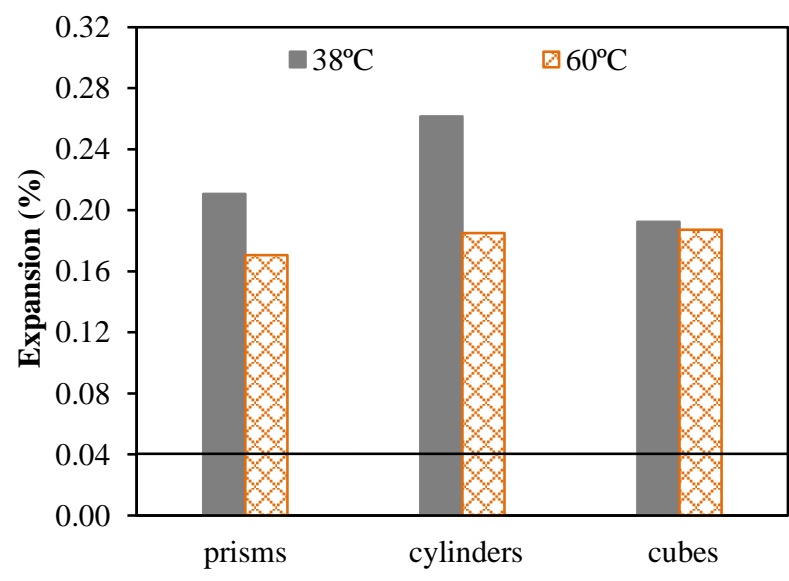

(b)

Figure 4.69: Expansion of concrete cast with Spratt aggregate at (a) 6 months and (b) 1 year

The higher alkali leaching from the concrete samples obtained at $60^{\circ} \mathrm{C}$ compared to $38^{\circ} \mathrm{C}$ explains partly the fact that control samples cast with Sudbury and Spratt showed lower ultimate expansion at $60^{\circ} \mathrm{C}$ compared to $38^{\circ} \mathrm{C}$ for all the different sample shapes. Another reason that could lead to the lower expansion obtained at $60^{\circ} \mathrm{C}$ compared to $38^{\circ} \mathrm{C}$ is the lower $\mathrm{Ca}(\mathrm{OH})_{2}$ formed at $60^{\circ} \mathrm{C}$ 
compared to $38^{\circ} \mathrm{C} . \mathrm{Ca}(\mathrm{OH})_{2}$ is needed for the gel to be viscous enough to cause damage (Chatterji, 1979; Gaboriaud et al., 2002; Rajabipour et al., 2015).

Cylinders and cubes cast with Sudbury aggregates showed higher expansion at $60^{\circ} \mathrm{C}$ compared to $38^{\circ} \mathrm{C}$ at 6 months (Figure 4.68(a)) while for Spratt, the samples showed same 6-month expansions at $38^{\circ} \mathrm{C}$ and $60^{\circ} \mathrm{C}$ for all the different sample shapes (Figure 4.69(a)). This is because Spratt samples at $60^{\circ} \mathrm{C}$ reached a plateau by 18 weeks compared to Sudbury samples as shown in Figure 4.70 and Figure 4.71 for Sudbury and Spratt control samples, respectively. Testing at $60^{\circ} \mathrm{C}$ shows promising results in terms of obtaining expansion in shorter duration.

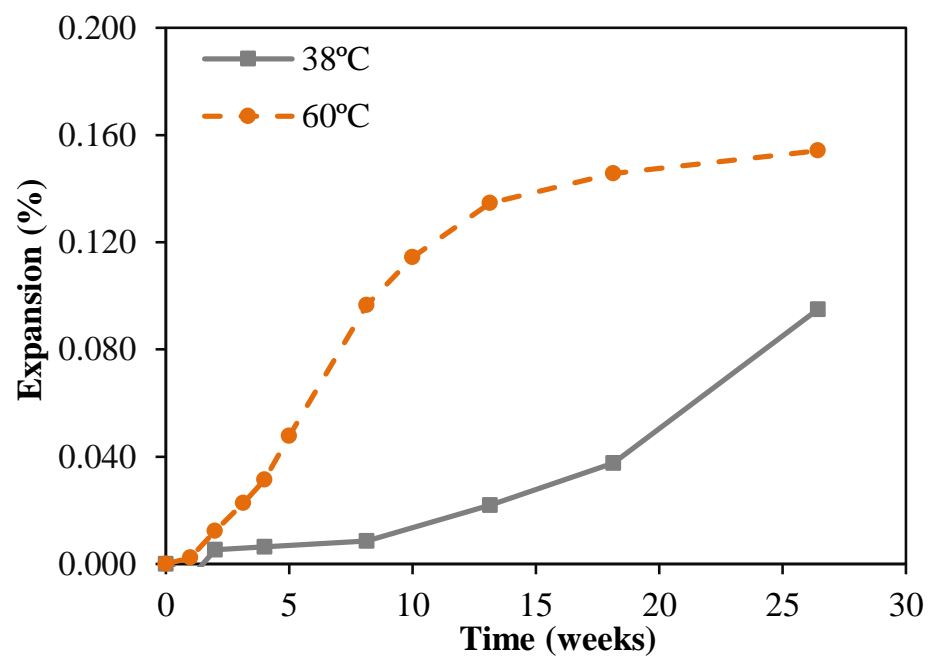

Figure 4.70: Expansion of cylinders cast with Sudbury aggregates

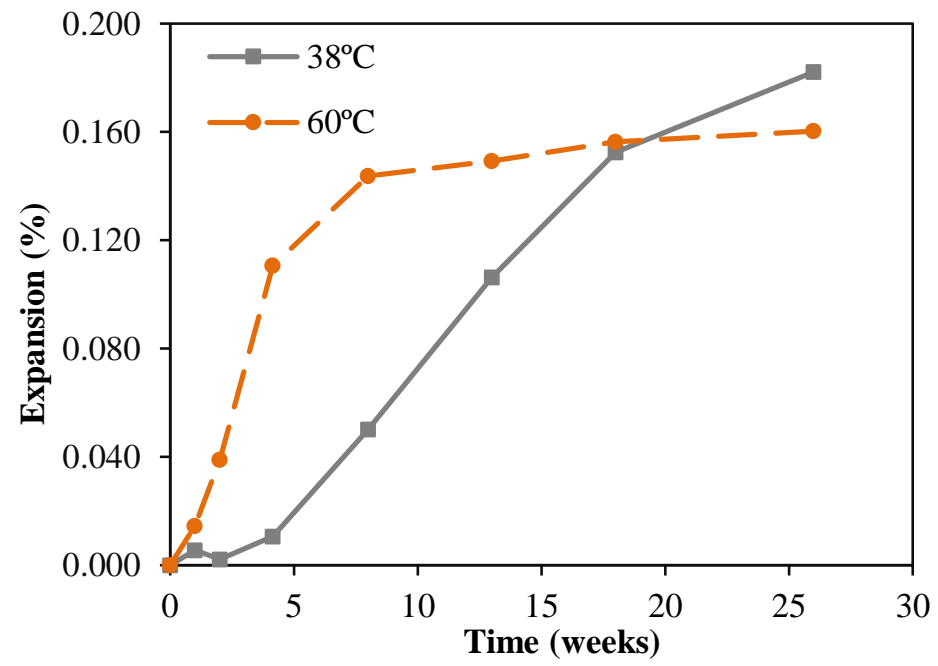

Figure 4.71: Expansion of cylinders cast with Spratt aggregates 


\section{Expansion of Concrete Cast with SCM}

The expansions at 1 year and 2 years for concrete cast with Sudbury aggregates are presented in Figure 4.72 for samples with $15 \%$ FA, and Figure 4.73 for samples with $25 \%$ slag. The expansions of Sudbury samples with SCM are showing close results at $38^{\circ} \mathrm{C}$ and $60^{\circ} \mathrm{C}$, except with Sudbury cylinders cast with $25 \%$ slag.

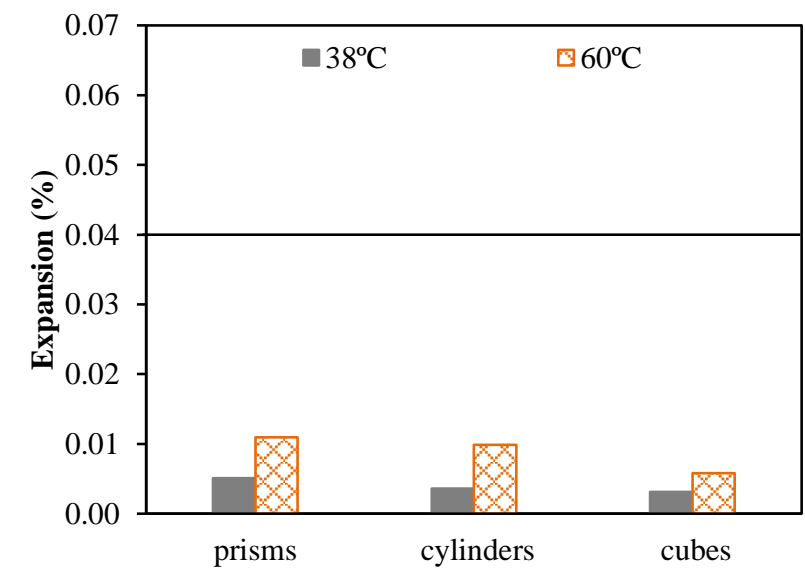

(a)

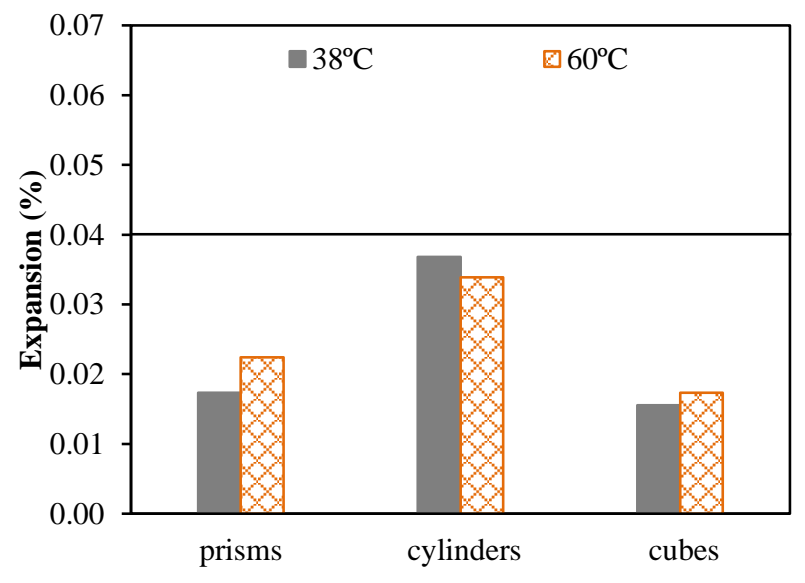

(b)

Figure 4.72: Expansion of concrete cast with Sudbury and 15\% FA at (a) 1 year and (b) 2 years

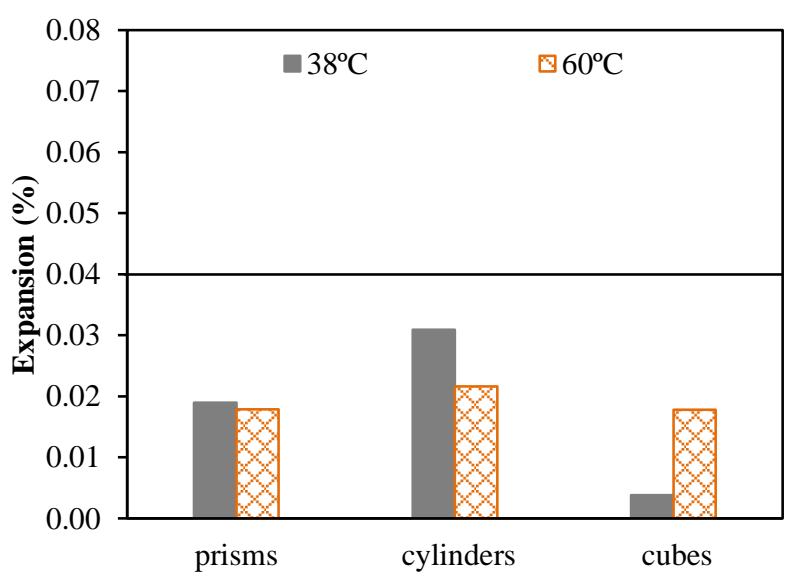

(a)

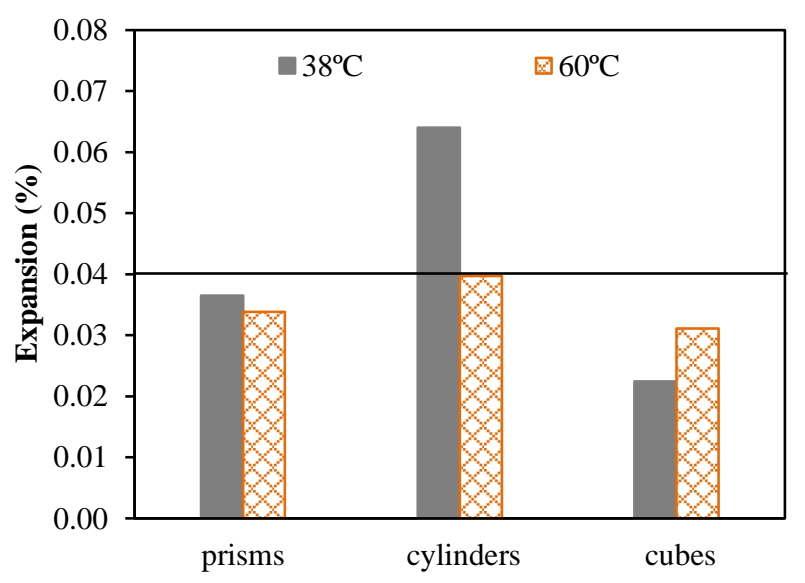

(b)

Figure 4.73: Expansion of concrete cast with Sudbury and 25\% slag at (a) 1 year and (b) 2 years

The expansions at 1 and 2 years are compared for Spratt samples with SCM at $38^{\circ} \mathrm{C}$ and $60^{\circ} \mathrm{C}$ and results are shown from Figure 4.74 to Figure 4.77. The expansions of concrete samples cast with Spratt and $15 \% \mathrm{FA}$ are close at $38^{\circ} \mathrm{C}$ and $60^{\circ} \mathrm{C}$ for all the different sample shapes. At higher replacement levels, Spratt samples at $60^{\circ} \mathrm{C}$ showed higher expansion compared to $38^{\circ} \mathrm{C}$ for all the different sample shapes (Spratt with 20\% FA, 35\% and 50\% slag). 
In addition, at 1 year, the expansions for the samples at $60^{\circ} \mathrm{C}$ were higher than the samples at $38^{\circ} \mathrm{C}$ for all the different Spratt/SCM combinations and with all the different sample shapes.

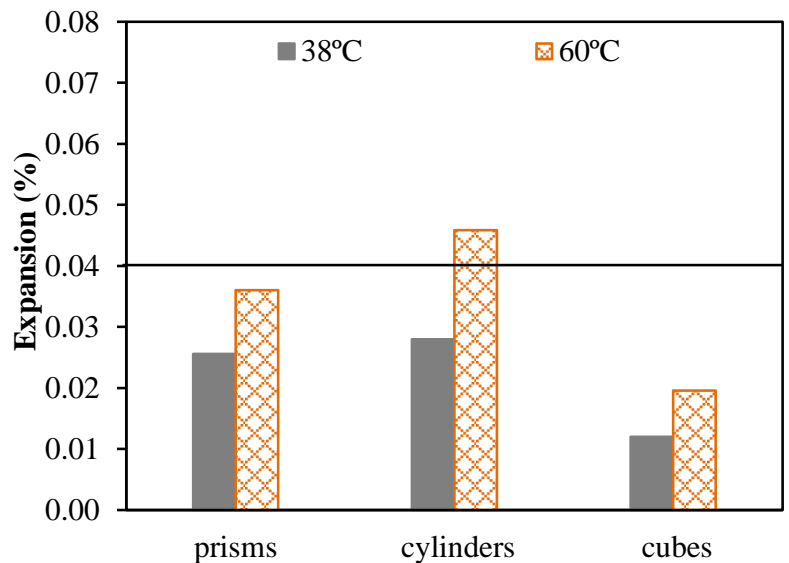

(a)

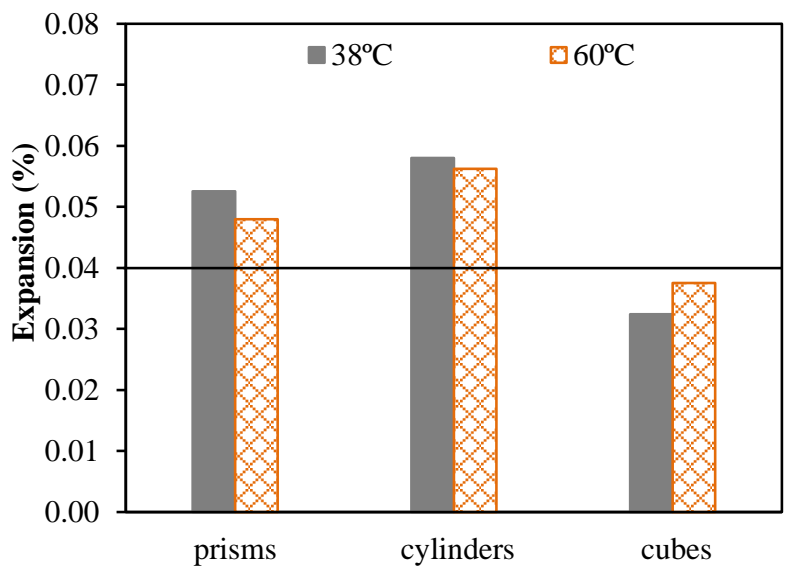

(b)

Figure 4.74: Expansion of concrete cast with Spratt and 15\% FA at (a) 1 year and (b) 2 years

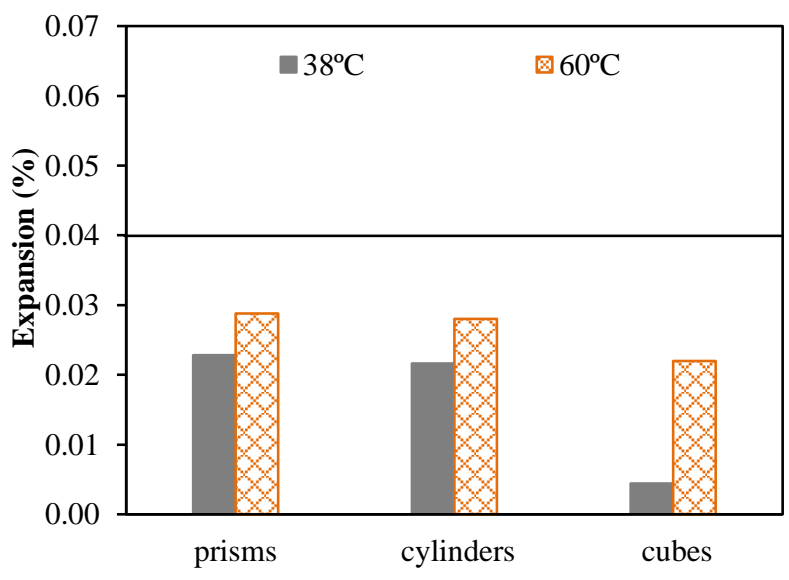

(a)

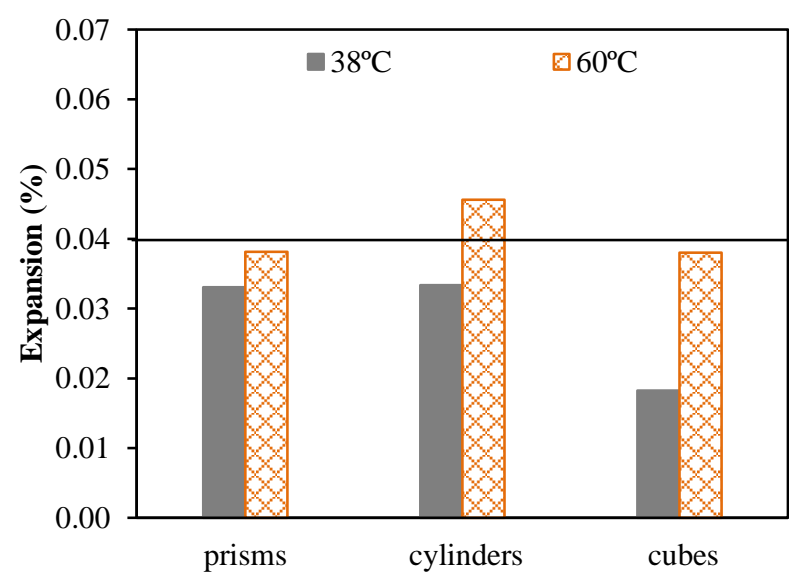

(b)

Figure 4.75: Expansion of concrete cast with Spratt and 20\% FA at (a) 1 year and (b) 2 years 


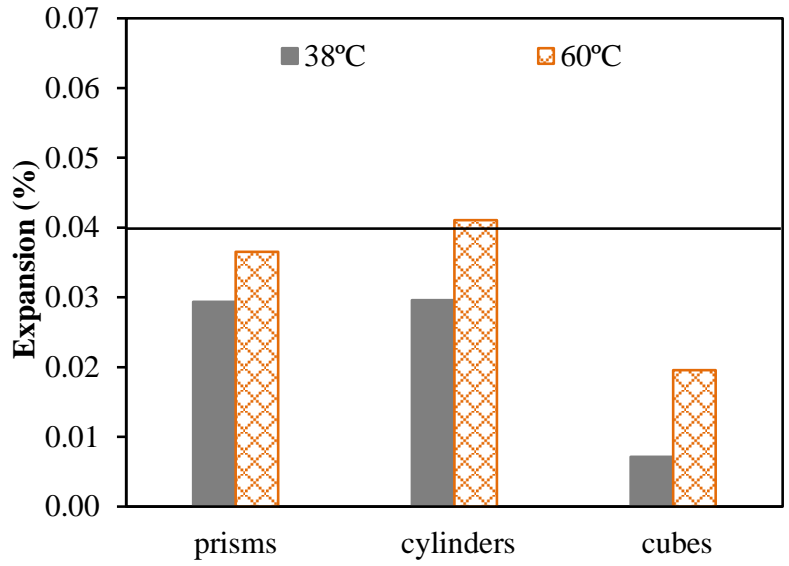

(a)

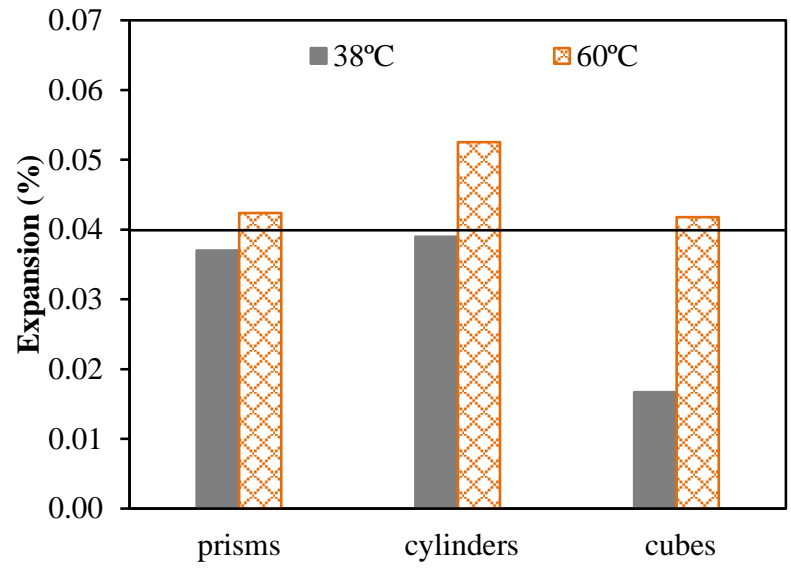

(b)

Figure 4.76: Expansion of concrete cast with Spratt and 35\% Slag at (a) 1 year and (b) 2 years

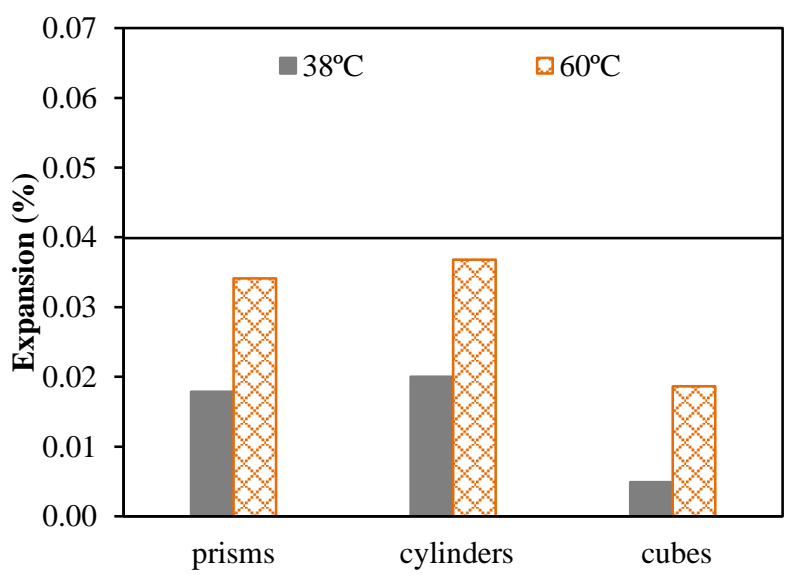

(a)

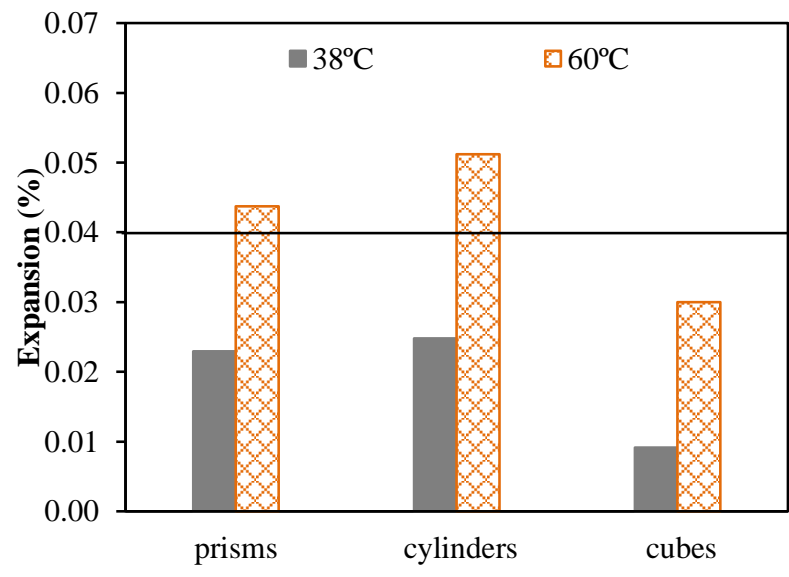

(b)

Figure 4.77: Expansion of concrete cast with Spratt and 50\% Slag at (a) 1 year and (b) 2 years

Similarly, Spratt samples with GUB-8SF were compared at the two temperatures and results are shown from Figure 4.78 to Figure 4.80. For samples with GUB-8SF or GUB-8SF+15\%FA, the 2year expansions are similar at both temperatures except with the cubes cast with GUB-8SF. The latter had a higher expansion at $60^{\circ} \mathrm{C}$ compared to $38^{\circ} \mathrm{C}$. At higher replacement level - GUB-8SF $+20 \% \mathrm{FA}$ - all the samples at $60^{\circ} \mathrm{C}$ showed higher expansion compared to $38^{\circ} \mathrm{C}$ at 2 years. 


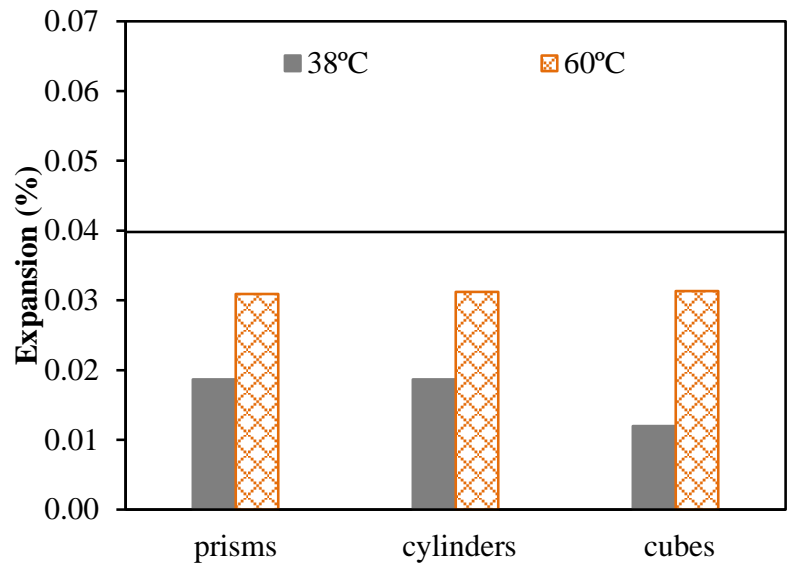

(a)

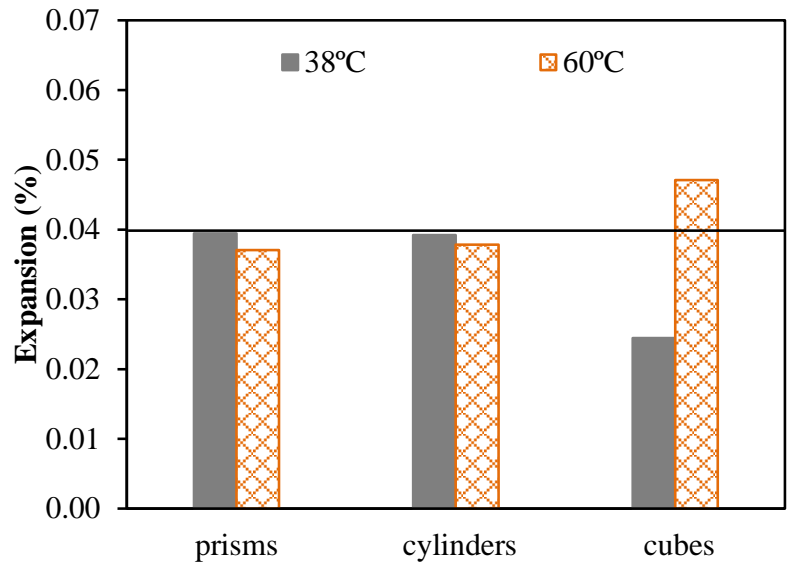

(b)

Figure 4.78: Expansion of concrete cast with Spratt and GUB-8SF at (a) 1 year and (b) 2 years

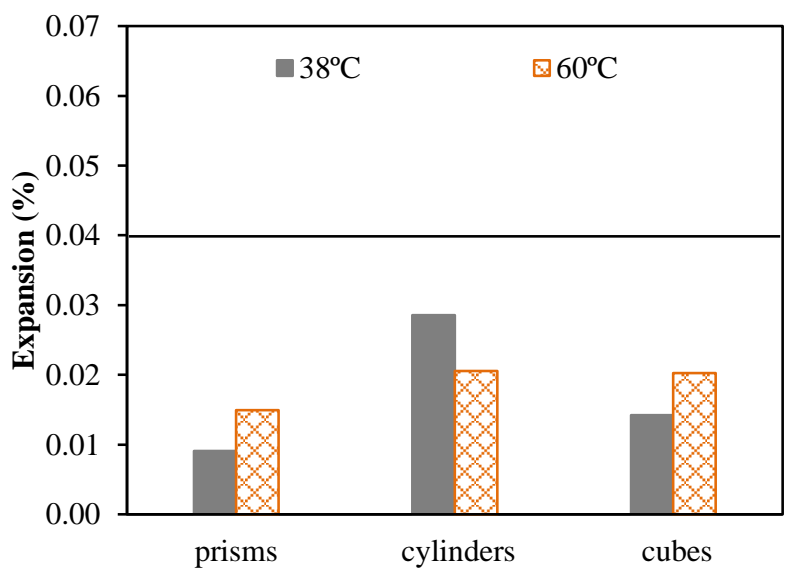

(a)

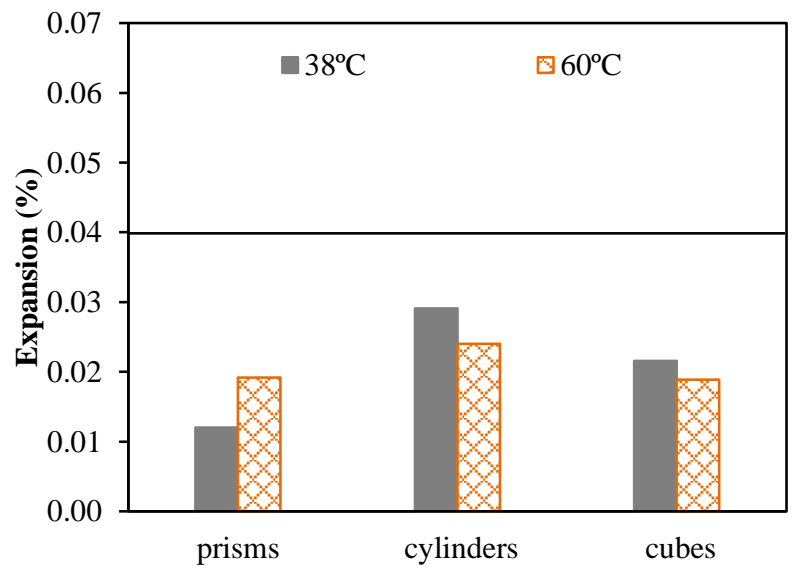

(b)

Figure 4.79: Expansion of concrete containing Spratt with GUB-8SF and 15\% FA at (a) 1 year and (b) 2 years 


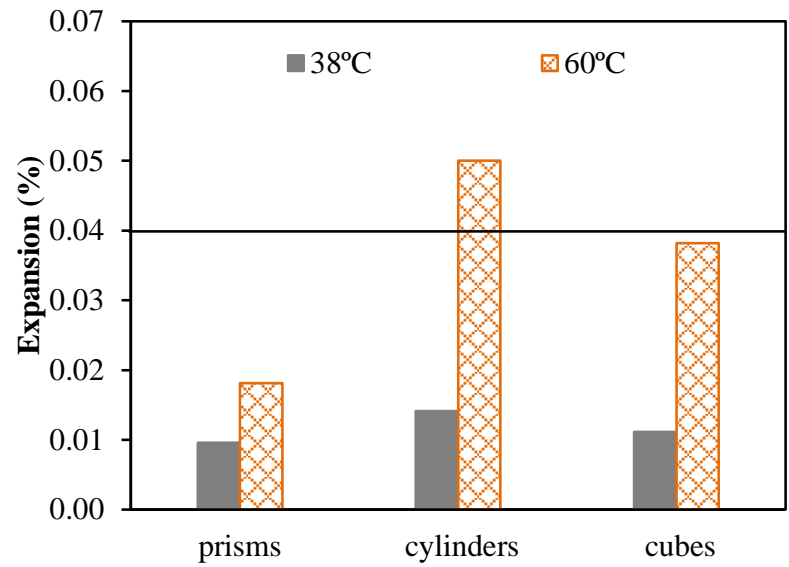

(a)

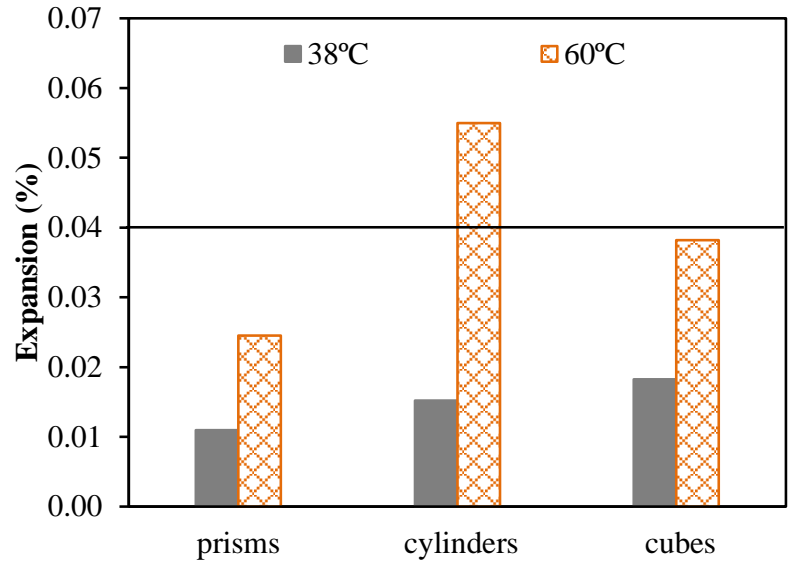

(b)

Figure 4.80: Expansion of concrete containing Spratt with GUB-8SF and 20\% FA at (a) 1 year and (b) 2 years

Springhill samples with $30 \%$ FA showed higher expansion at $60^{\circ} \mathrm{C}$ compared to $38^{\circ} \mathrm{C}$ at 1 and 2 years as shown in Figure 4.81.

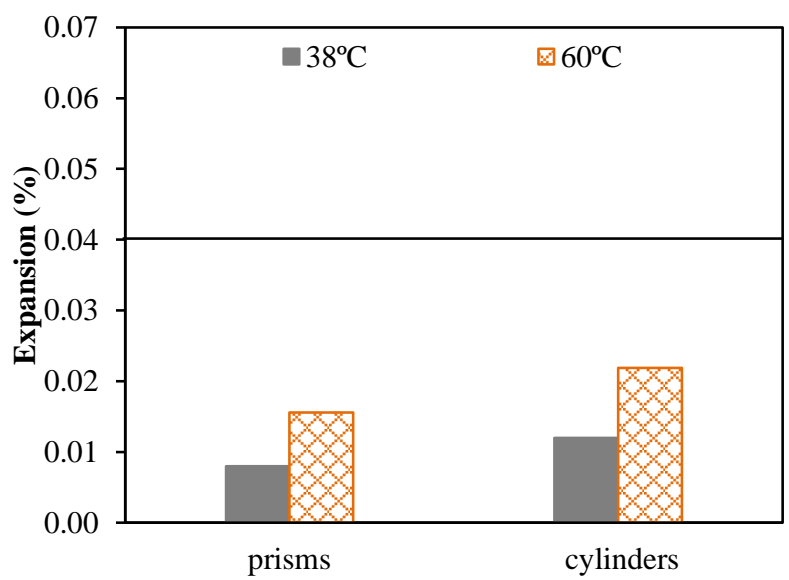

(a)

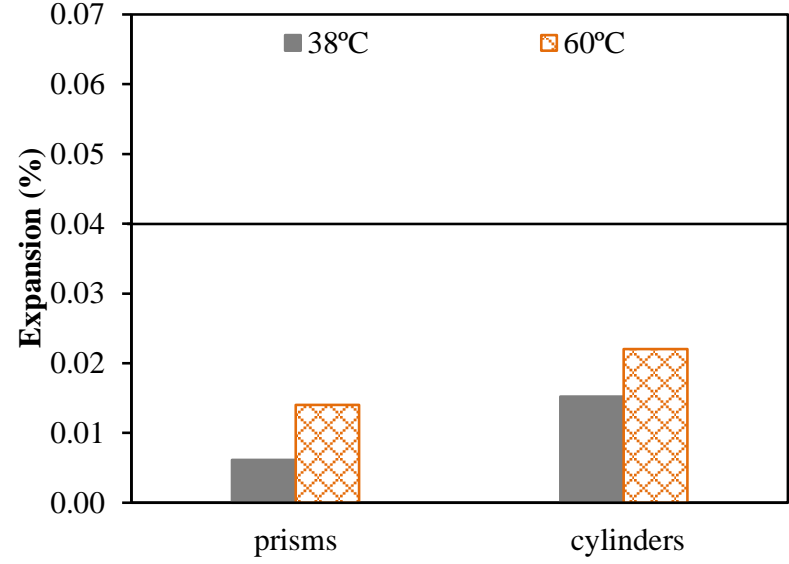

(b)

Figure 4.81: Expansion of concrete cast with Springhill and 30\% FA at (a) 1 year and (b) 2 years

In summary, control samples without SCM are showing lower ultimate values at $60^{\circ} \mathrm{C}$ compared to $38^{\circ} \mathrm{C}$. For samples with low replacement levels of SCM, the expansion at both temperatures are close to each other however with higher replacement levels, the expansion at $60^{\circ} \mathrm{C}$ showed higher expansion than samples at $38^{\circ} \mathrm{C}$ at 2 years.

For control samples, the higher alkali leaching and perhaps lower $\mathrm{Ca}(\mathrm{OH})_{2}$ at $60^{\circ} \mathrm{C}$ caused lower ultimate expansion compared to $38^{\circ} \mathrm{C}$. In the case of samples with SCM, factors other than the increased leaching are affecting the results. The ultimate expansion at $60^{\circ} \mathrm{C}$ is higher with all 
SCM/aggregate combinations except for samples with low replacement levels of SCM. This shows that alkali leaching from the samples is not the only factor affecting the results at $60^{\circ} \mathrm{C}$. The increased expansion could be due to the effect of temperature on alkali release form aggregates (discussed in Section 4.2.2) and/or the pozzolanic activity of SCM at different temperatures (discussed in Section 4.2.3). Due to the increased contribution of alkalis from the aggregates at $60^{\circ} \mathrm{C}$, the pore solution alkalinity will be increased which might explain partly the higher expansion in Spratt/Sudbury samples with SCM combinations at high replacement level. At low replacement levels of SCM or with control samples, the ultimate expansions at $60^{\circ} \mathrm{C}$ were not higher although there is more release of alkalis. This is because control samples or samples with low replacement levels leach more alkalis compared to samples with high levels of SCM leading to a decrease in pore solution alkalinity which might have overcome the effect of the release of alkalis. Also, at lower pore solution alkalinity, the release of alkalis from the aggregate was shown to be reduced. Another reason - and perhaps the most significant - that could lead to higher expansion at $60^{\circ} \mathrm{C}$ with some aggregates/SCM combinations is the higher binding capacity of SCM at $38^{\circ} \mathrm{C}$ compared to $60^{\circ} \mathrm{C}$. This was observed more when higher replacement levels of SCM were used.

The CPT testing temperature of $38^{\circ} \mathrm{C}$ is higher compared to the average temperature of structures undergoing ASR in the field. The higher binding capacity of SCM at $38^{\circ} \mathrm{C}$ could explain the discrepancy between the expansion results in the field and under laboratory testing conditions.

At 1 year, the samples at $60^{\circ} \mathrm{C}$ showed accelerated results compared to the same samples cast at $38^{\circ} \mathrm{C}$ for all the different geometries. Correlation between expansion results obtained at $38^{\circ} \mathrm{C}$ and $60^{\circ} \mathrm{C}$ are presented in Section 4.3.3. In addition, testing at $60^{\circ} \mathrm{C}$ might reflect better the expansion in the field since the binding capacity of the $\mathrm{SCM}$ at $60^{\circ} \mathrm{C}$ is lower compared to the standard CPT or in other words, closer to the binding capacity at $23^{\circ} \mathrm{C}$.

\subsubsection{Correlation Between Expansion Results at $38^{\circ} \mathrm{C}$ and $60^{\circ} \mathrm{C}$}

One of the challenges of the CPT is its long testing duration which takes two years to evaluate the efficacy of SCM in mitigating expansion due to ASR. The aim of this section is to find correlation between the expansion of cylinders tested at $60^{\circ} \mathrm{C}$ and the standard 2-year expansion of prisms at $38^{\circ} \mathrm{C}$ in an attempt to reach same conclusions as the CPT in terms of pass/fail but in shorter duration. 
Figure 4.82 shows correlation between the 6-month expansion of cylinders at $60^{\circ} \mathrm{C}$ and the expansion of standard prisms at 1 year for control samples and 2 years for samples with SCM. For Spratt samples with $15 \%$ FA, cylinders at $60^{\circ} \mathrm{C}$ showed an expansion lower than $0.040 \%(0.019 \%)$ at 6 months and passed the CPT contradicting the expansion results of the CPT at 2 years - which failed the CPT. Another way to look at it is the deviation of the points from the equity line where most of them are below the line showing higher values for the prisms at $38^{\circ} \mathrm{C}$ compared to cylinders at $60^{\circ} \mathrm{C}$. Hence, measuring expansion of cylinders at $60^{\circ} \mathrm{C}$ at 6 months seems to underestimate the expansion obtained at 2 years.

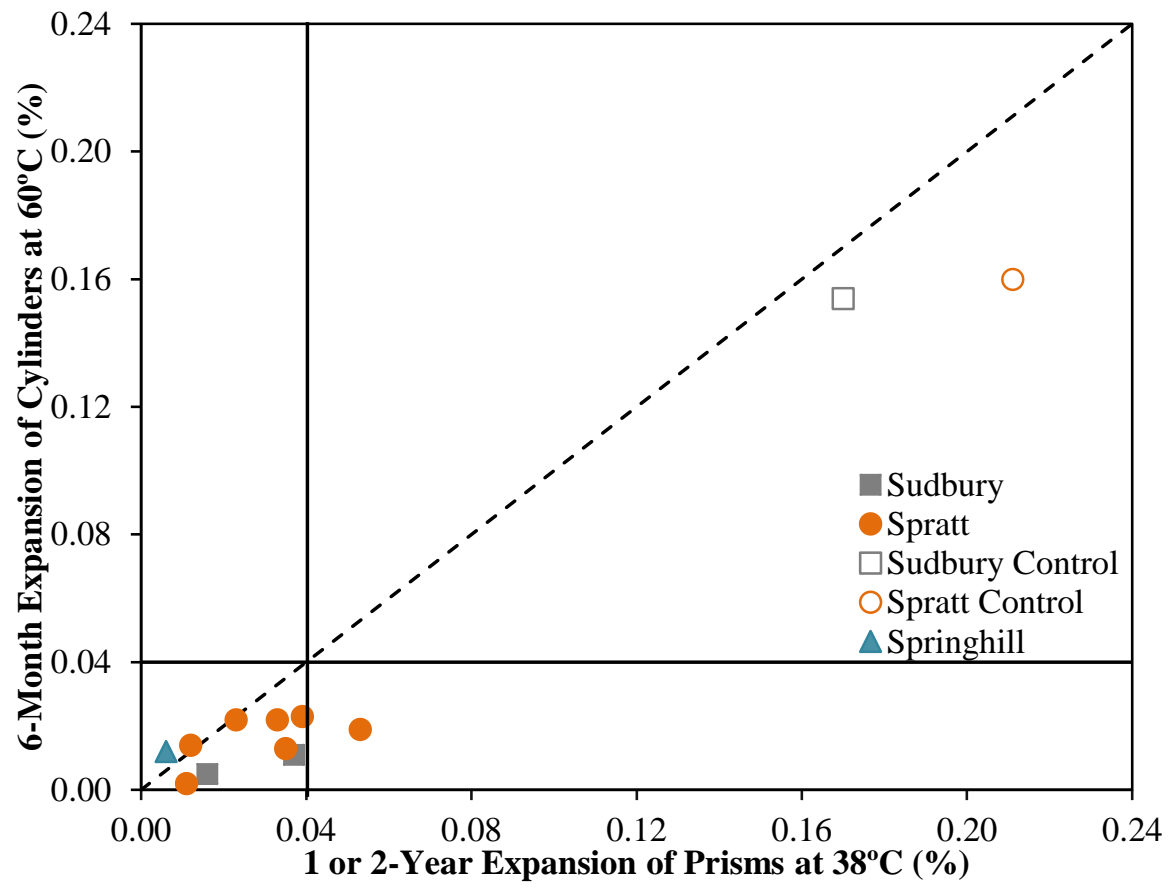

Figure 4.82: Correlation between the 6-month expansion of cylinders at $60^{\circ} \mathrm{C}$ and the expansion of standard prisms at 1 year for control samples and 2 years for samples with SCM

The 1-year expansion of cylinders at $60^{\circ} \mathrm{C}$ were compared to the 2-year prisms expansion at $38^{\circ} \mathrm{C}$ as shown in Figure 4.83 to see if testing at $60^{\circ} \mathrm{C}$ can reduce the testing period by $50 \%$ when cylinders are used. Looking at the cylinders' expansion at $60^{\circ} \mathrm{C}$ at 1 year, same conclusions are drawn in terms of pass/fail the CPT for samples with SCM. Control samples are not included in this comparison as there is no point of running the test for one year at $60^{\circ} \mathrm{C}$ at the time that the expansion at $38^{\circ} \mathrm{C}$ is higher as discussed before. 


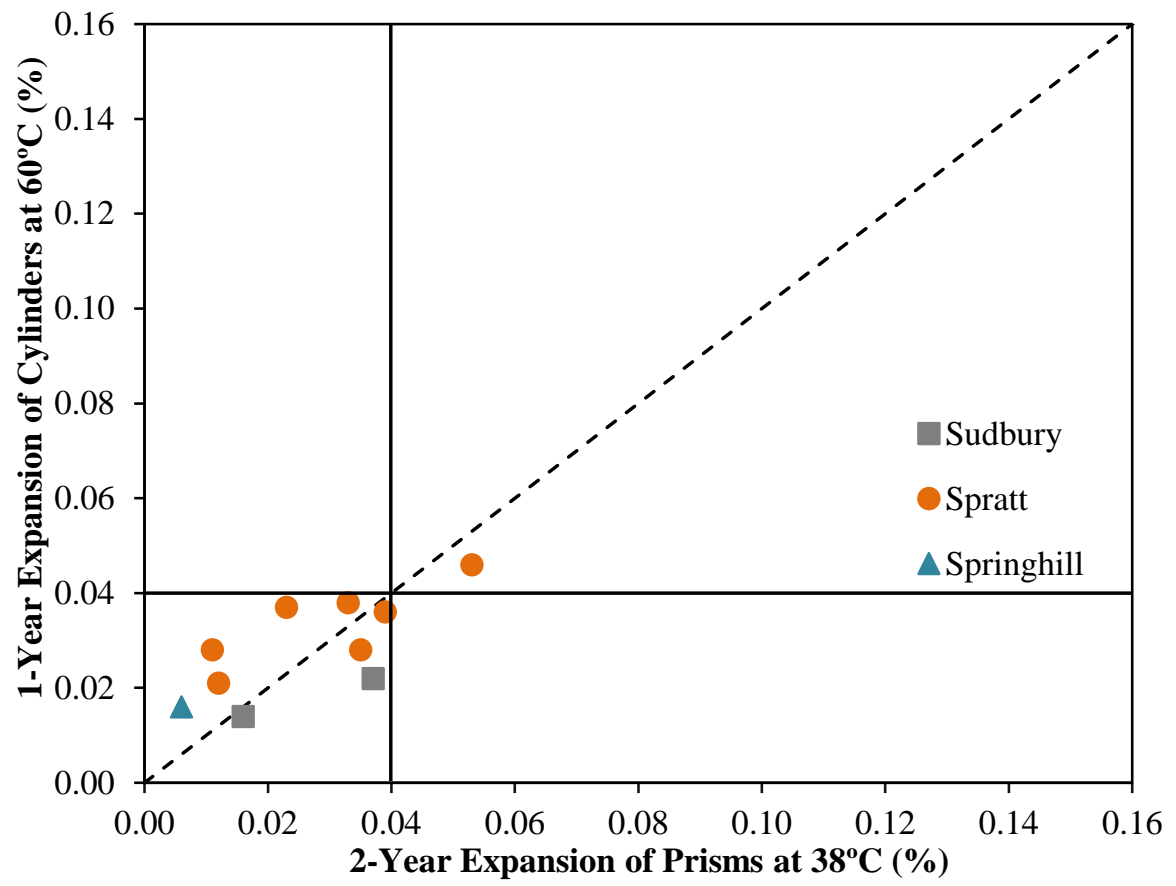

Figure 4.83: Correlation between the 1-year expansion of cylinders at $60^{\circ} \mathrm{C}$ and the 2-year expansion of prisms at $38^{\circ} \mathrm{C}$ for samples with SCM

Both expansions obtained from the prisms at 2 years at $38^{\circ} \mathrm{C}$ and the cylinders at 1 year at $60^{\circ} \mathrm{C}$ showed a pass/pass or fail/fail relationship for all the samples. However, although there was a pass/pass relationship for the Sudbury samples with $25 \%$ slag, the expansion of the cylinders at $60^{\circ} \mathrm{C}$ at 1 year was much lower than the prisms expansion at $38^{\circ} \mathrm{C}$ at 2 years. The reasons for this behavior might be the higher alkali leaching from concrete samples at $60^{\circ} \mathrm{C}$ causing the alkalis released from the aggregates to readily leach out. This may not be the case at $38^{\circ} \mathrm{C}$ where alkalis released from aggregates do not leach quickly and contribute more to ASR. Due to the nature of Sudbury aggregate - a slowly reacting aggregate - it needs the alkalis to stay within the samples for a good period of time for expansion or reaction to occur. In conclusion, the 2-year expansion of prisms with $\mathrm{SCM}$ at $38^{\circ} \mathrm{C}$ can be obtained with the cylinders in 1 year at $60^{\circ} \mathrm{C}$ particularly for Spratt. Although at $60^{\circ} \mathrm{C}$, more leaching is occurring, but the cylinders leach less compared to prisms. In addition, the increase in temperature will accelerate the ASR reaction. Hence, by reducing leaching and accelerating the reaction, the same conclusions obtained with the standard prisms at 2 years at $38^{\circ} \mathrm{C}$ can be reached with the cylinders at $60^{\circ} \mathrm{C}$ at 1 year. However, it should be noted that more samples need to be tested to confirm the applicability of the above finding to a wide range of aggregate/cementing blends. 
Since the 2-year expansions of cylinders at $38^{\circ} \mathrm{C}$ are showing higher values compared to the standard CPT, it is relevant to compare the 2-year expansion of cylinders at $38^{\circ} \mathrm{C}$ with the 1-year accelerated results of the cylinders at $60^{\circ} \mathrm{C}$. Figure 4.84 shows a comparison between the 2-year expansion of cylinders at $38^{\circ} \mathrm{C}$ and the 1-year expansion of cylinders at $60^{\circ} \mathrm{C}$ for samples with SCM.

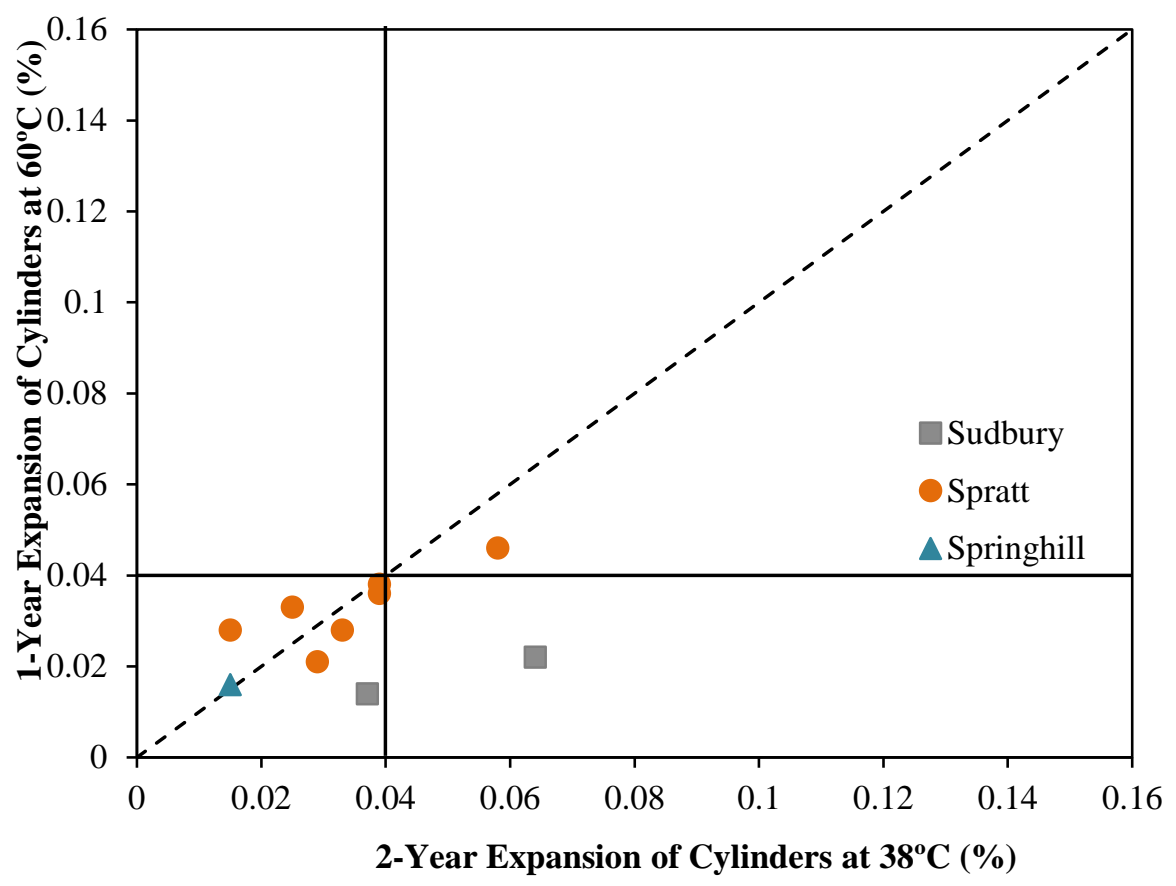

Figure 4.84: Correlation between the 1-year expansion of cylinders at $60^{\circ} \mathrm{C}$ and the 2-year expansion of cylinders at $38^{\circ} \mathrm{C}$ for samples with SCM

From Figure 4.84, there is good correlation between the 1-year expansions of cylinders at $38^{\circ} \mathrm{C}$ and the 1-year expansions of cylinders at $60^{\circ} \mathrm{C}$ in the case of Spratt and Springhill. However, with Sudbury, one case showed pass/pass relationship although the cylinders at $38^{\circ} \mathrm{C}$ were about to fail as opposed to the cylinders at $60^{\circ} \mathrm{C}$, it was still way below the expansion limit. The other case showed pass/fail relationship.

In order to reduce further the leaching and accelerate the reaction further, same cylinders were cast but each cylinder was stored separately in a different container with a concrete-to-air volume ratio (0.3) higher compared to three cylinders in one container $(0.2)$. It is believed that the higher the volume ratio of concrete-to-air, lower leaching and then higher expansion could be obtained (Bérubé, Fournier and Côté, 2012). Sudbury and Spratt aggregates were cast with different SCM combinations and the average expansion of three cylinders from the same mix is reported. The 6- 
month expansion results of the cylinders stored each in a different container were compared to the 6-month expansion of three cylinders stored in same container as shown in Figure 4.85.

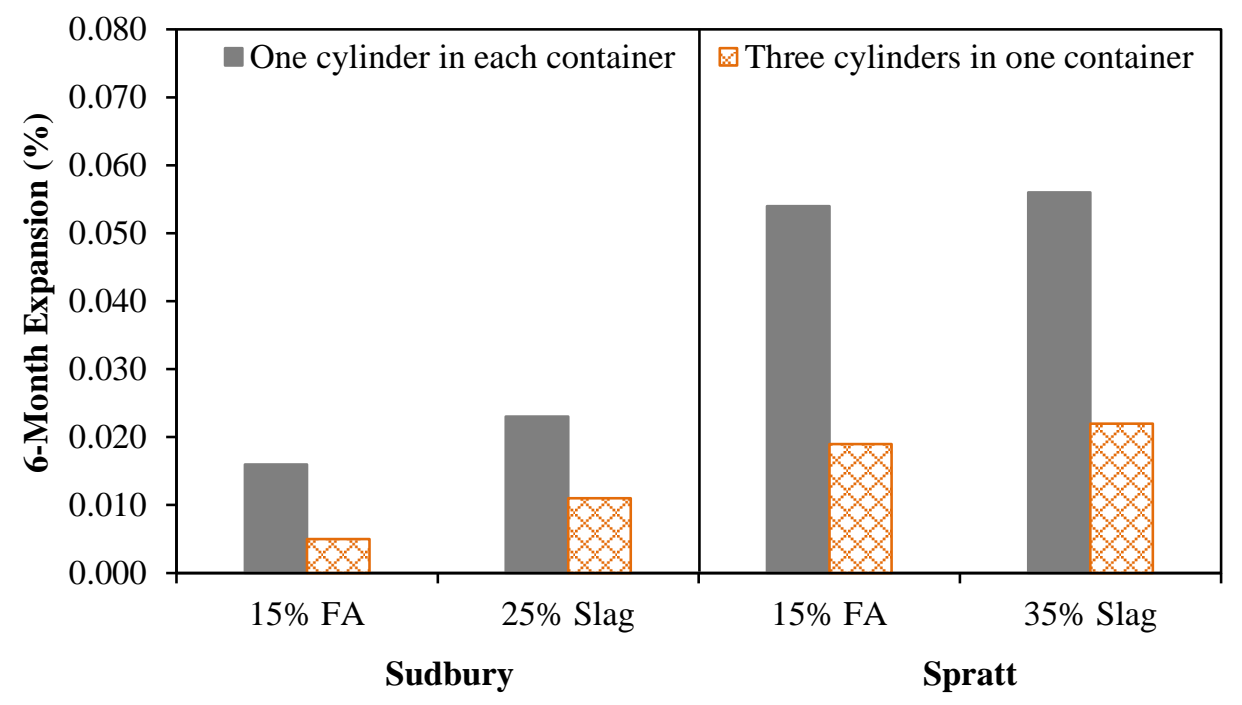

Figure 4.85: 6-month expansion of cylinders at $60^{\circ} \mathrm{C}$ put in different containers

It is evident that the expansion will be increased when the concrete-to-air volume is higher. Figure 4.86 shows a comparison between the 6-month expansion of the cylinders - each stored in a separate container - at $60^{\circ} \mathrm{C}$ and the standard 2-year expansion of prisms and cylinders at $38^{\circ} \mathrm{C}$ for Sudbury samples. Comparing the 6-month expansion of the cylinders - stored each in a different container - and the standard CPT at 2 years, there was a pass/pass relationship for both Sudbury samples showing that the testing duration could be reduced to 6 months instead of 2 years. 


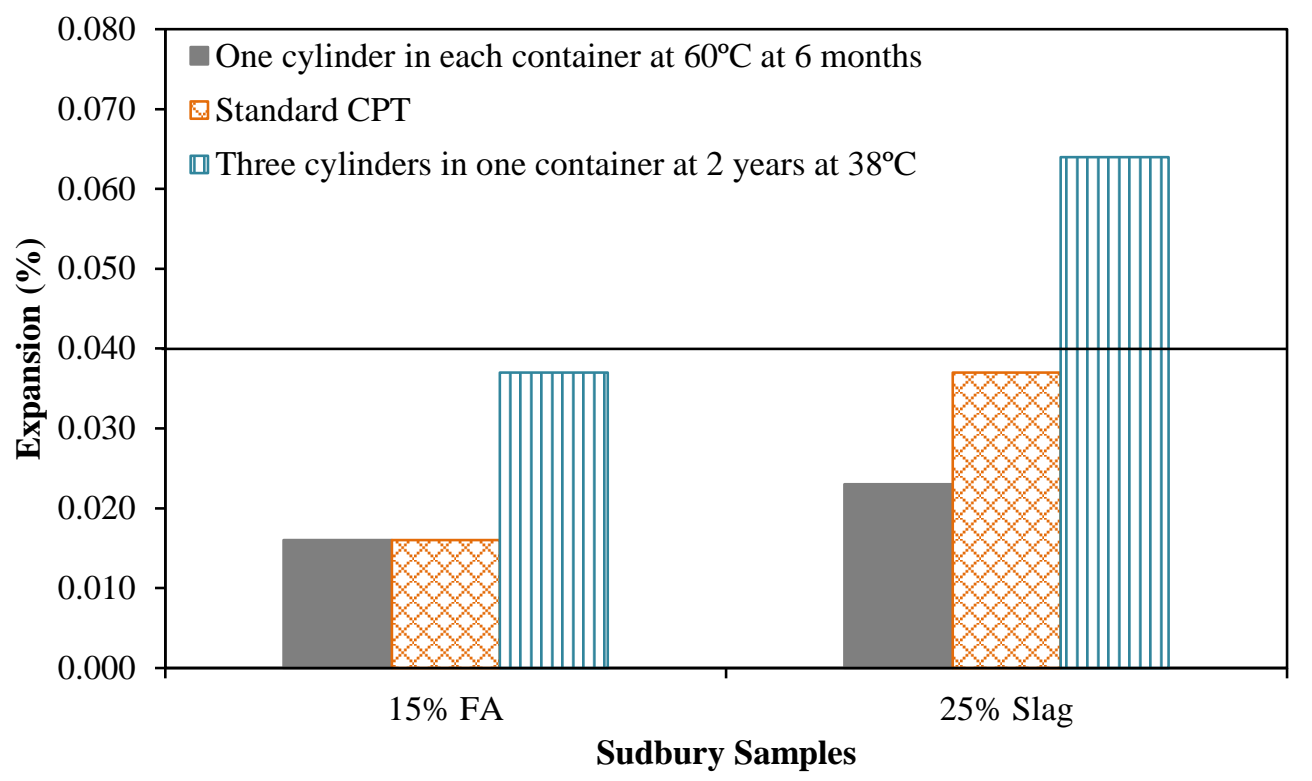

Figure 4.86: Expansion comparison of cylinders at $60^{\circ} \mathrm{C}$ at 6 months and prisms/cylinders at $38^{\circ} \mathrm{C}$ at 2 years

Looking at the 2-year expansion of cylinders at $38^{\circ} \mathrm{C}$, although expansion was increased with higher concrete-to-air volume, but the 6-month expansion of the cylinders stored in different containers did not reach the 2-year expansion obtained with the three cylinders at $38^{\circ} \mathrm{C}$ yet. Expansion will still be monitored to see if expansion could be obtained in shorter duration compared to the standard 2 years.

For Spratt samples, 18-week expansion of the cylinders stored each in a separate container were compared to the standard 2-year test and results are shown in Figure 4.87. With Spratt, a fast reactive aggregate, the expansion of the cylinders at 18 weeks was close to the expansion obtained with the standard CPT and the cylinders tested at $38^{\circ} \mathrm{C}$ where three cylinders are stored in the same container reaching same conclusions in terms of pass/fail. 


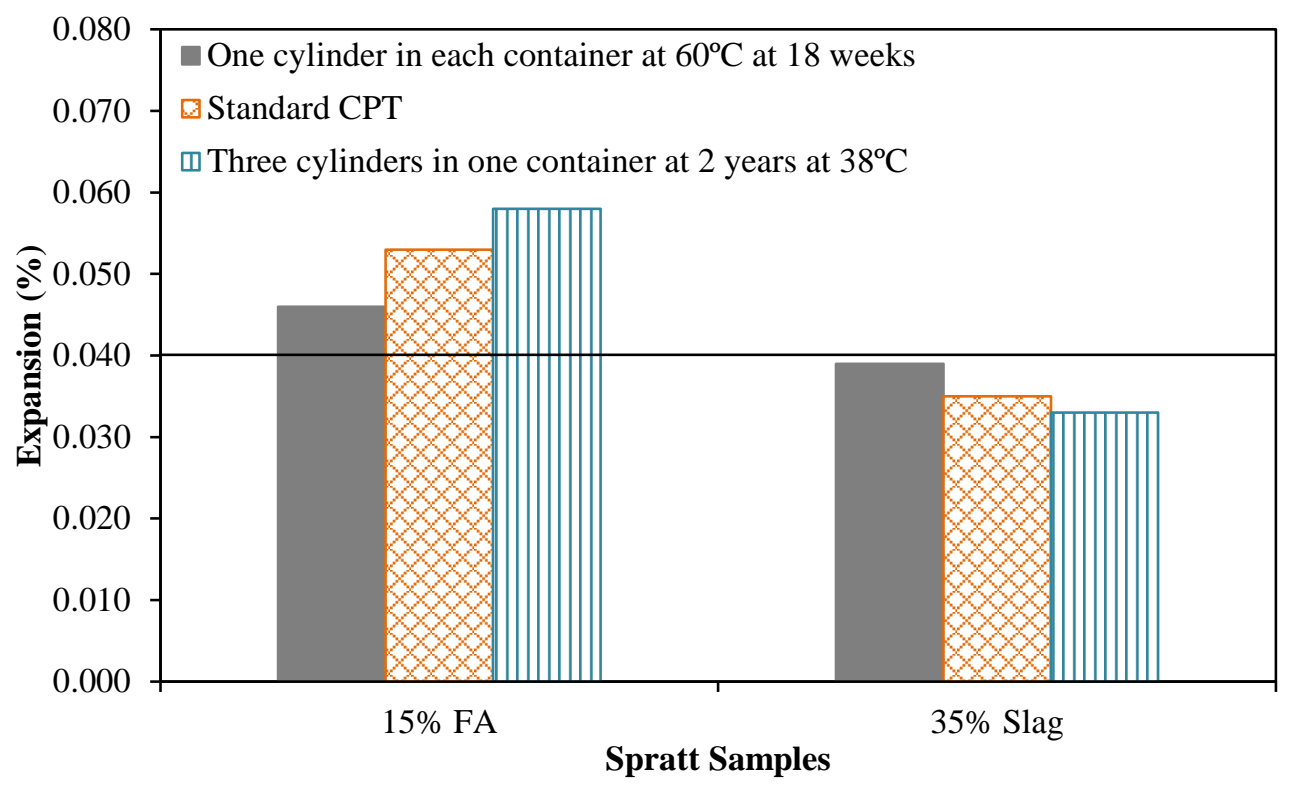

Figure 4.87: Expansion comparison of cylinders at $60^{\circ} \mathrm{C}$ at 18 weeks and prisms/cylinders at $38^{\circ} \mathrm{C}$ at 2 years

In conclusion, by testing at $60^{\circ} \mathrm{C}$ and using cylinders where each is stored in a separate container, the leaching will be reduced and expansion could be reached within 6 months compared to the standard CPT. In addition, testing one cylinder separately could be beneficial since it is less heavy compared to three cylinders in one container and will provide more space in the oven due to their smaller volume. However, this was done on two sets of samples only for each type of aggregates. More testing is needed to confirm the obtained results.

\subsubsection{Long-Term Expansion at Room Temperature}

After 2 years of testing the samples at their designated temperatures, they were taken out and kept at $23^{\circ} \mathrm{C}$ to study the effect of pore solution alkalinity (which goes up at lower temperature) on expansion and the change in gel viscosity at lower temperature (Swamy, 1992). The expansions of samples cast with Sudbury aggregates are shown in Figure 4.88, Figure 4.89 and Figure 4.90 for control, and for samples with $15 \%$ FA and with $25 \%$ slag, respectively. The zero reading corresponds to the next day after the samples were taken out at 2 years from $60^{\circ} \mathrm{C}$ or $38^{\circ} \mathrm{C}$ and put at $23^{\circ} \mathrm{C}$. The slight increase in expansion observed in the samples taken out from $60^{\circ} \mathrm{C}$ to $23^{\circ} \mathrm{C}$ could be explained by the fact that at $60^{\circ} \mathrm{C}$, calcium sulfoaluminate hydrates decomposed leading to an increase in $\mathrm{SO}_{4}{ }^{2-}$ concentration in solution. In order to maintain equilibrium, the concentration of $\mathrm{OH}^{-}$will drop (Lindgård et al., 2012). In addition, the subsequent reduction in $\mathrm{pH}$ will reduce the rate of dissolution of the silica from the reactive aggregates (Fournier et al., 2019). 
When the samples are moved from $60^{\circ} \mathrm{C}$ to $23^{\circ} \mathrm{C}$, the ettringite will form and the $\mathrm{OH}^{-}$concentration will increase again. At higher alkalinity, the release of alkalis from the aggregates will be increased as was shown previously in Section 4.1.3. This could explain the observed increase in expansion in the cylinders due to their higher volume reducing leaching further. Although cubes had the lowest leaching, however, they did not show very high increase in expansion. It should be noted that the increase in expansion observed in Sudbury cylinders (control and 25\% slag) taken from $60^{\circ} \mathrm{C}$ to $23^{\circ} \mathrm{C}$ is too high and could not be solely attributed to the increase in $\mathrm{OH}^{-}$concentration and/or the gel viscosity which was shown to increase with lower temperature (Leemann and Merz, 2012; Lindgård et al., 2012). Reasons for such high increase in expansion are not clear. 


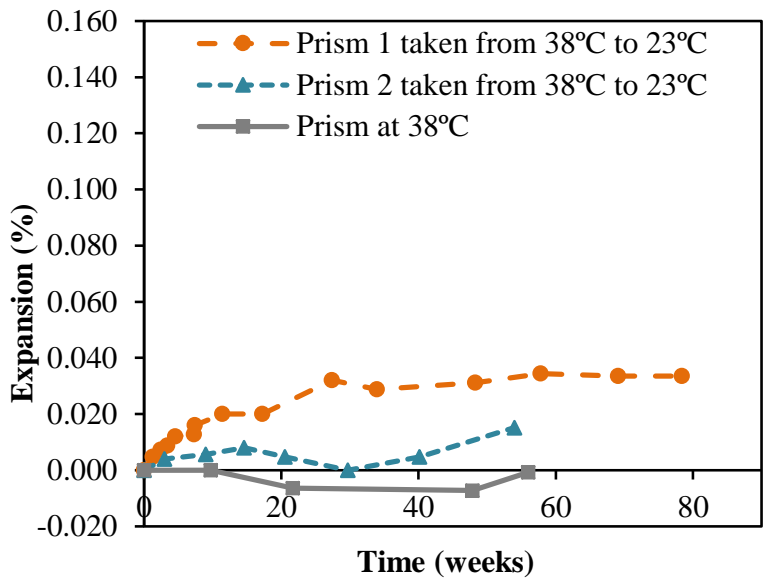

(a)

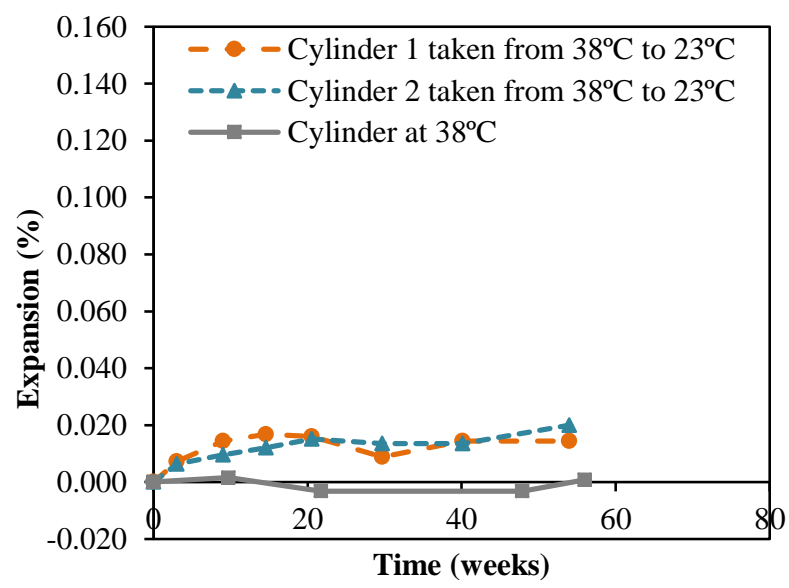

(a)

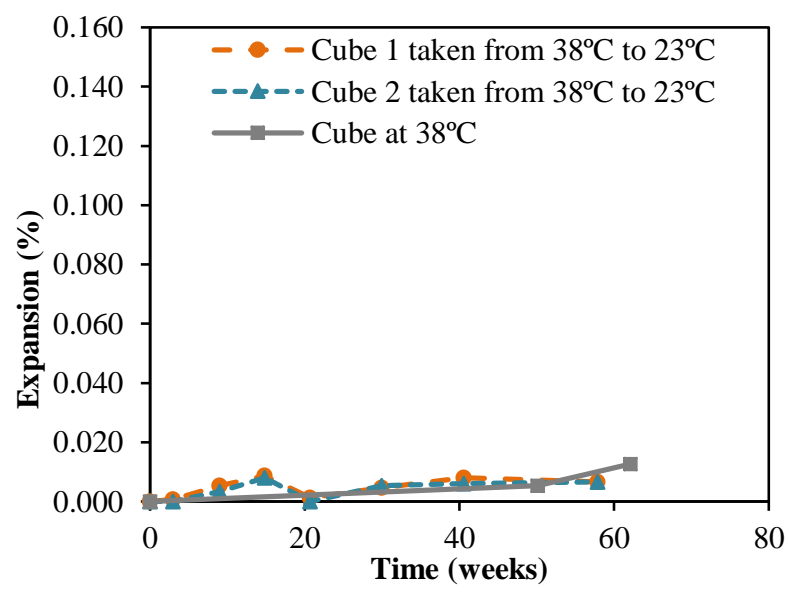

(a)

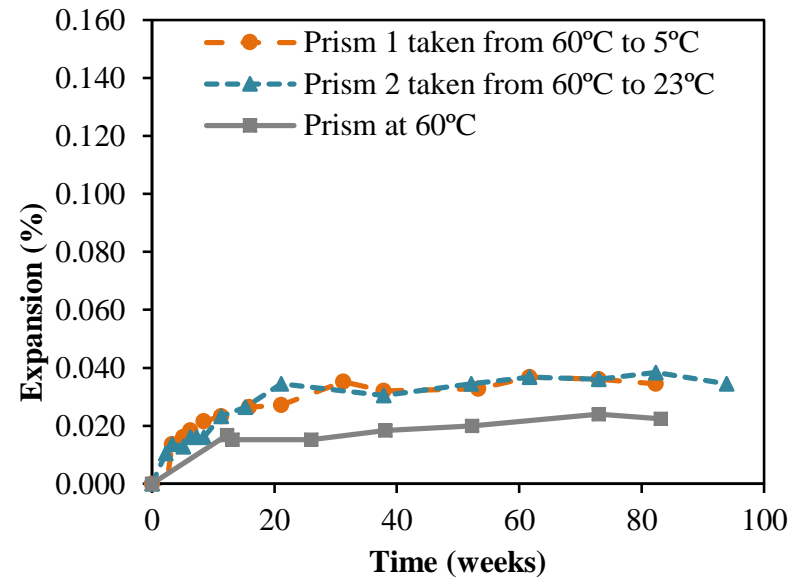

(b)

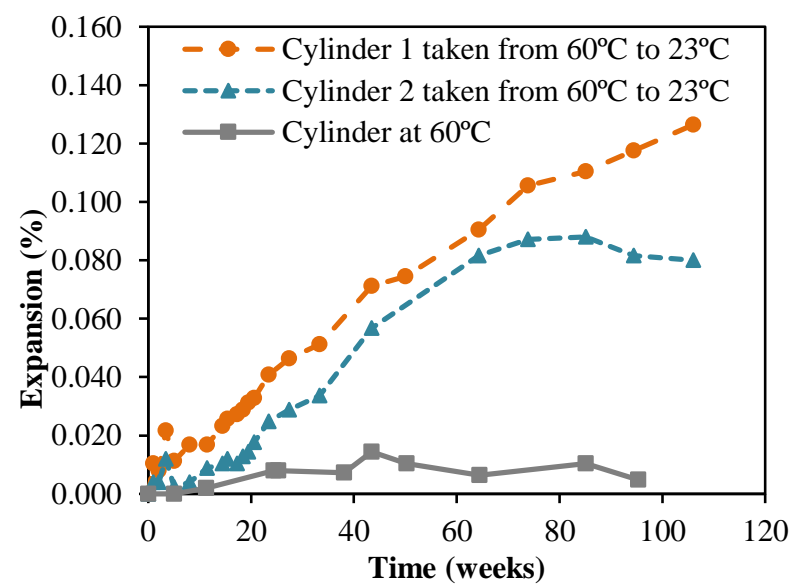

(b)

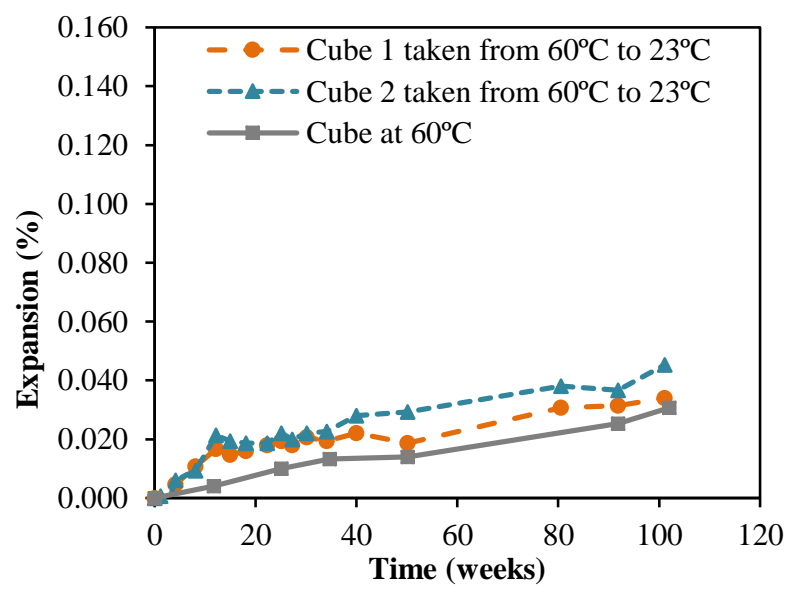

(b)

Figure 4.88: Expansion of Sudbury samples without SCM at $23^{\circ} \mathrm{C}$ taken from (a) $38^{\circ} \mathrm{C}$ and (b) $60^{\circ} \mathrm{C}$ 


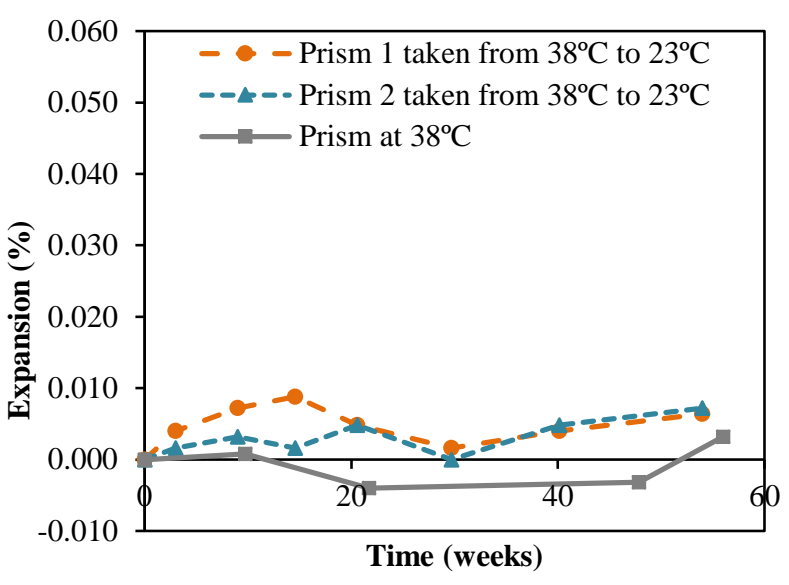

(a)

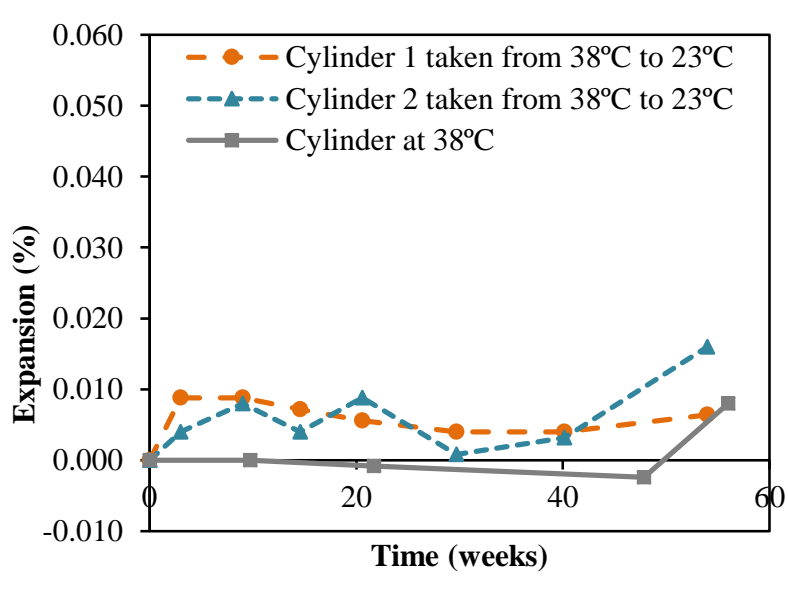

(a)

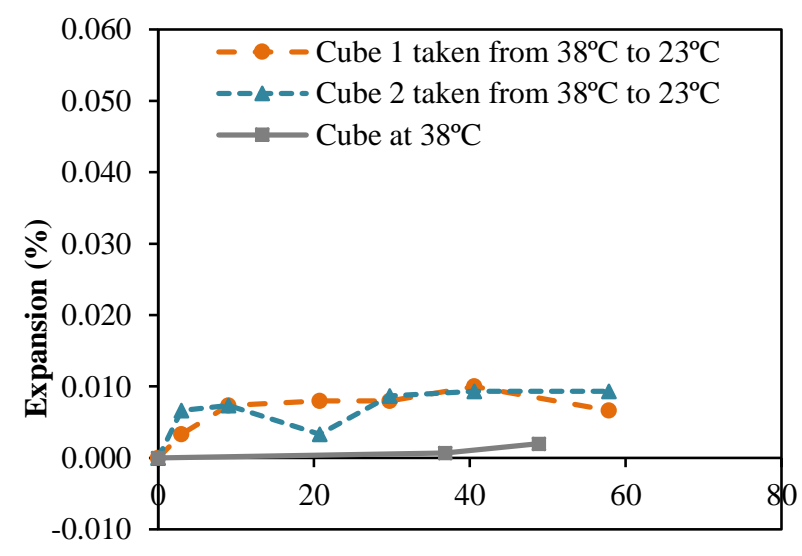

Time (weeks)

(a)

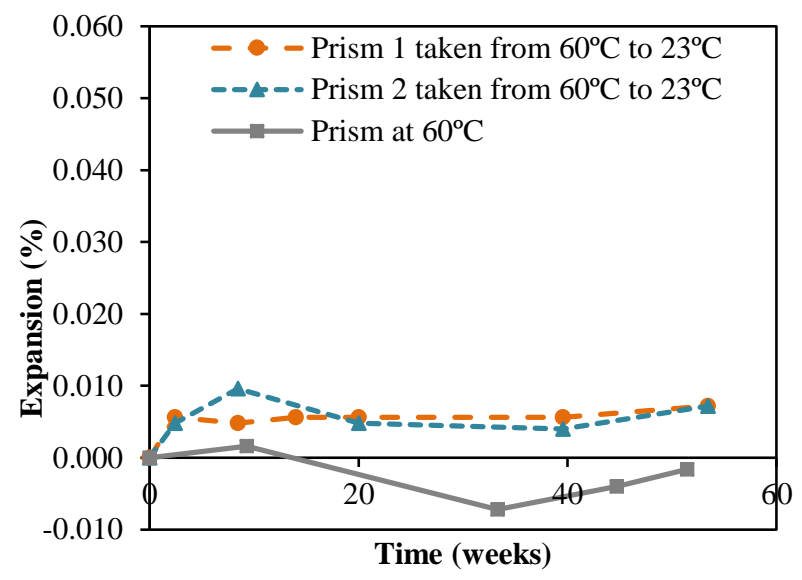

(b)

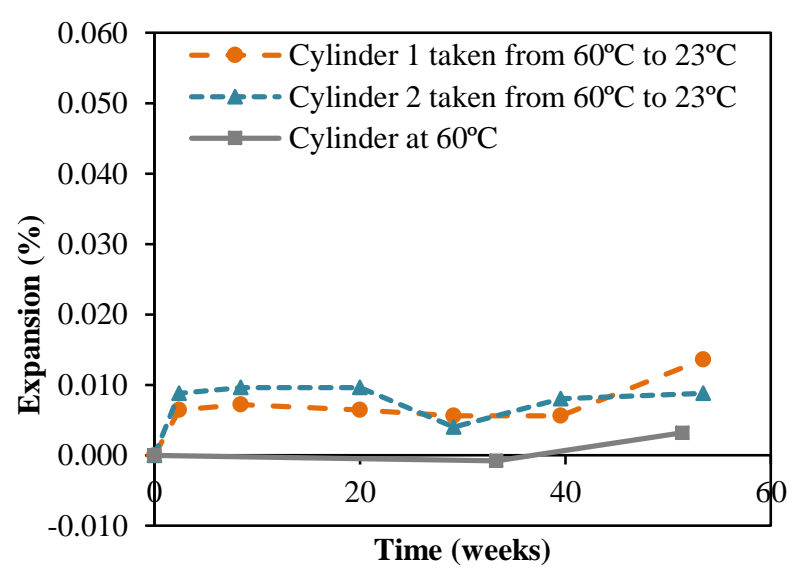

(b)

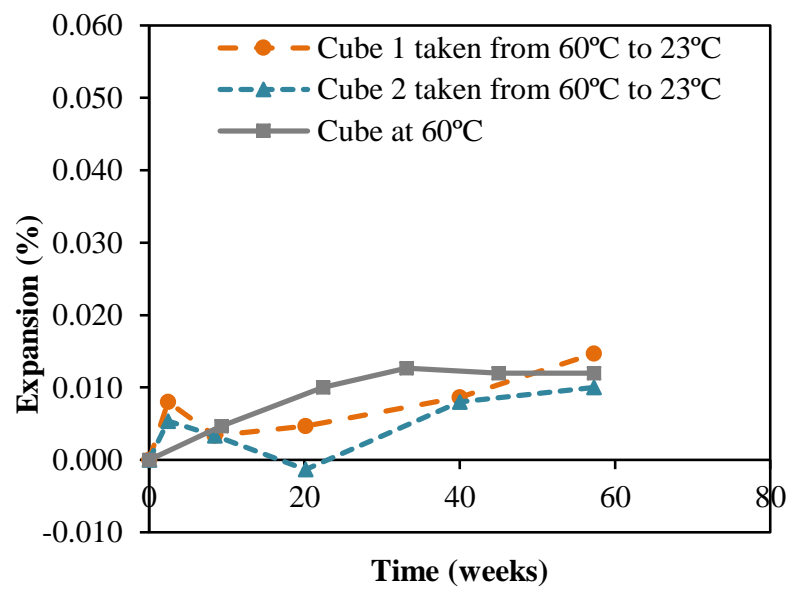

(b)

Figure 4.89: Expansion of Sudbury samples with $15 \%$ FA at $23^{\circ} \mathrm{C}$ taken from (a) $38^{\circ} \mathrm{C}$ and (b) $60^{\circ} \mathrm{C}$ 


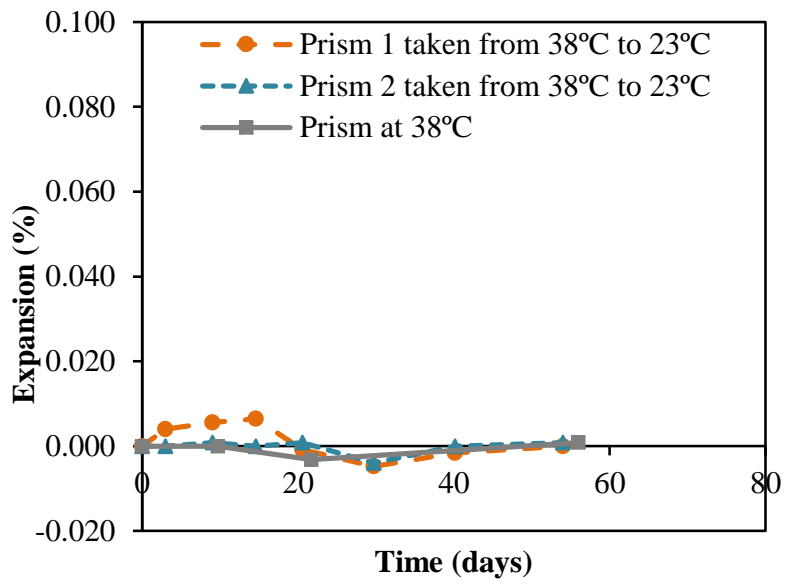

(a)

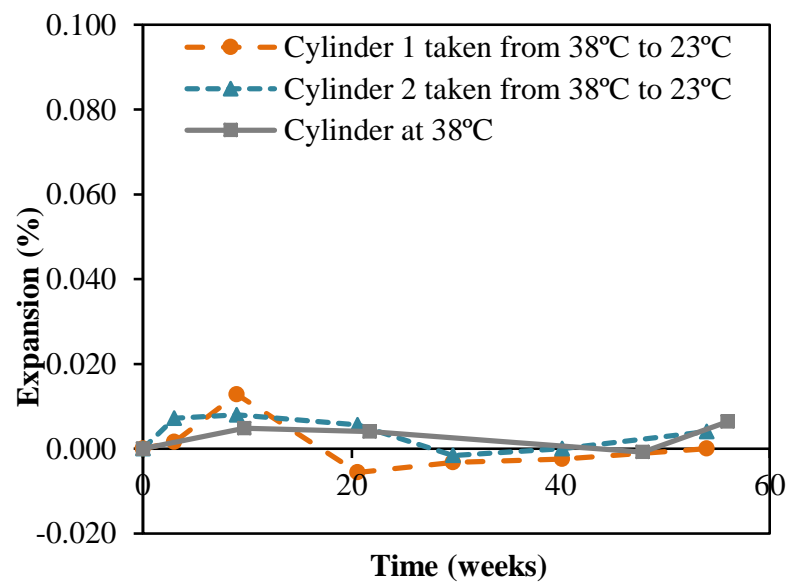

(a)

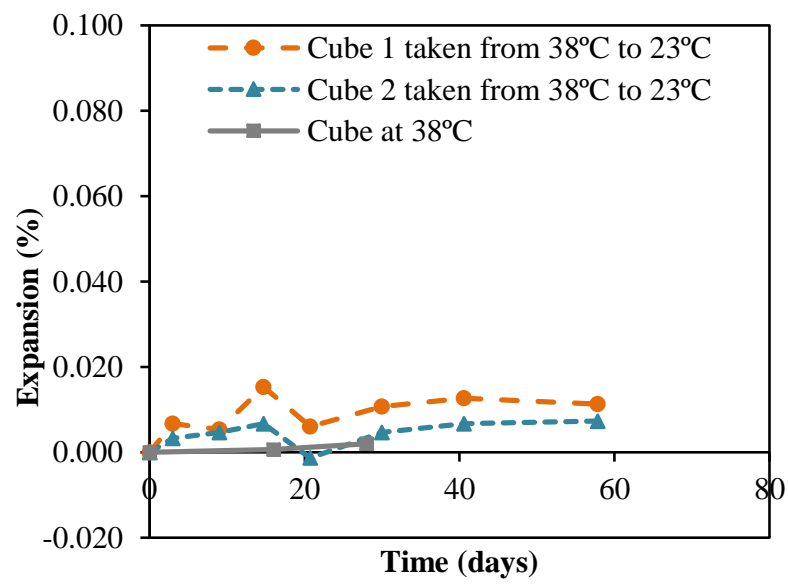

(a)

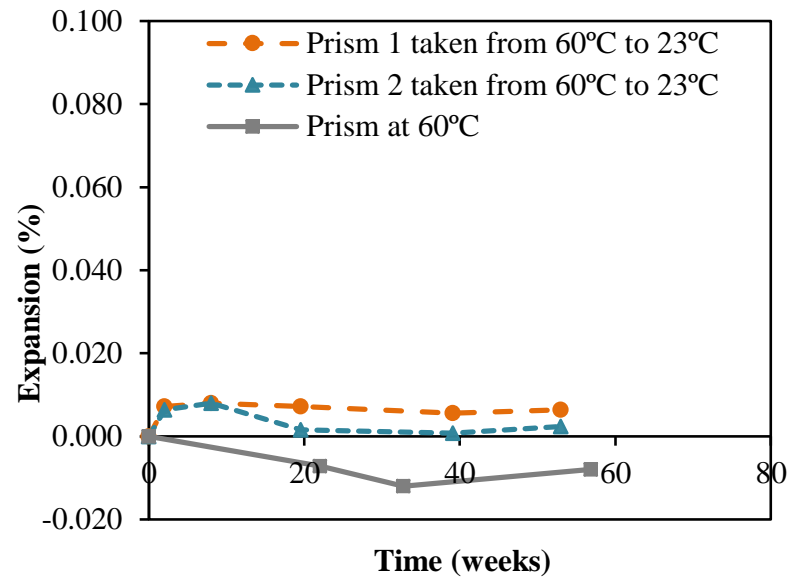

(b)

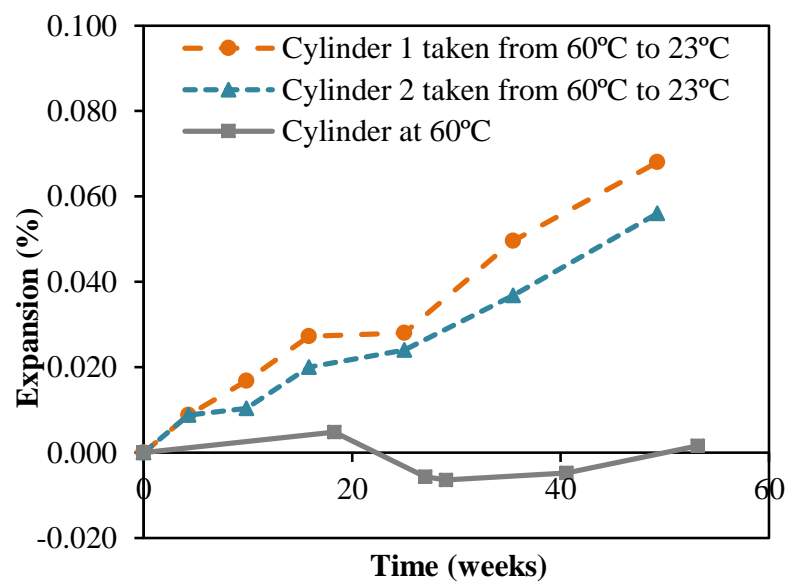

(b)

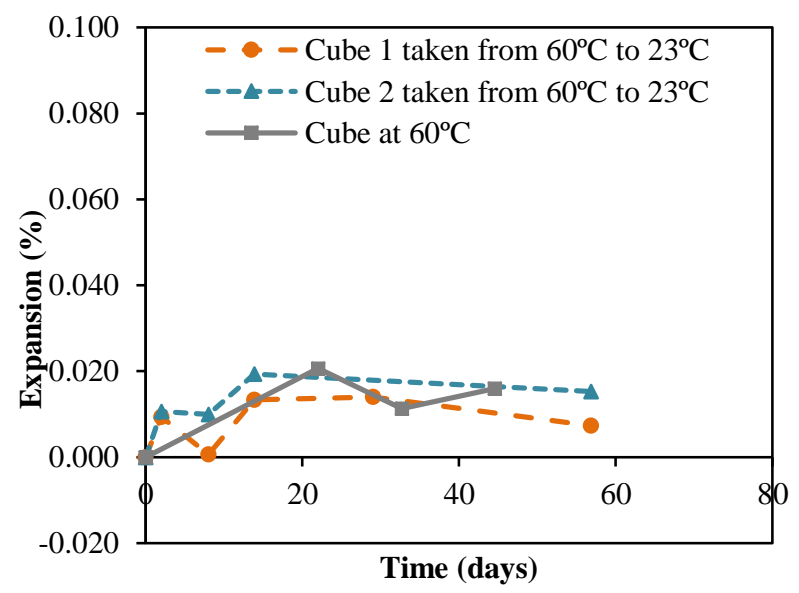

(b)

Figure 4.90: Expansion of Sudbury samples with $25 \%$ slag at $23^{\circ} \mathrm{C}$ taken from (a) $38^{\circ} \mathrm{C}$ and (b) $6^{\circ} \mathrm{C}$ 
With Spratt samples, no expansion was observed when the samples were moved from $60^{\circ} \mathrm{C}$ to $23^{\circ} \mathrm{C}$ as shown in Figure 4.91, Figure 4.92, Figure 4.93. This could be attributed to the low release of alkalis from Spratt aggregates. Similar results of Spratt samples with other combinations of SCM were obtained and are shown in Appendix I. Taking out the samples from $60^{\circ} \mathrm{C}$ to $23 \mathrm{C}^{\circ}$ was to see if it is possible to accelerate the expansion at $60^{\circ} \mathrm{C}$ for the first few weeks and then put the samples out to continue expanding. The samples are supposed to be taken out earlier than 2 years. It is suggested to do the test again and see whether when the samples are moved out from $60^{\circ} \mathrm{C}$ to $23^{\circ} \mathrm{C}$ higher expansion could be reached compared to testing at $60^{\circ} \mathrm{C}$ only. Previous work showed that the viscosity of the gel increases with lower temperature (Leemann and Merz, 2012; Lindgård et al., 2012). However, for the samples tested in this research, there is no evidence that the gel viscosity increased when the samples were moved from $38^{\circ} \mathrm{C}$ to $23^{\circ} \mathrm{C}$. 


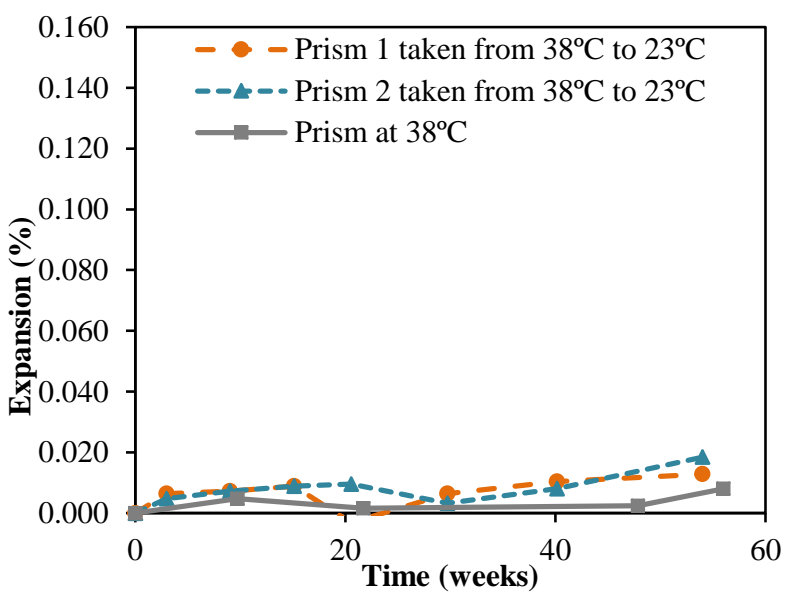

(a)

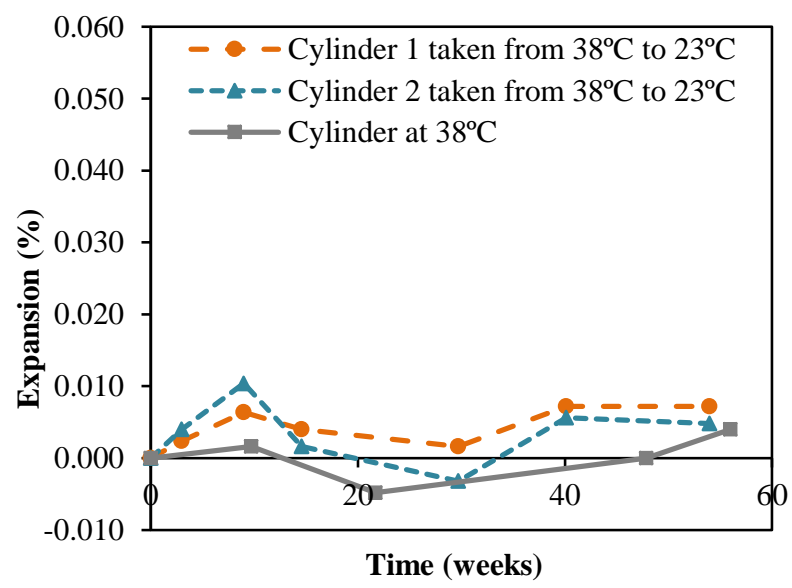

(a)

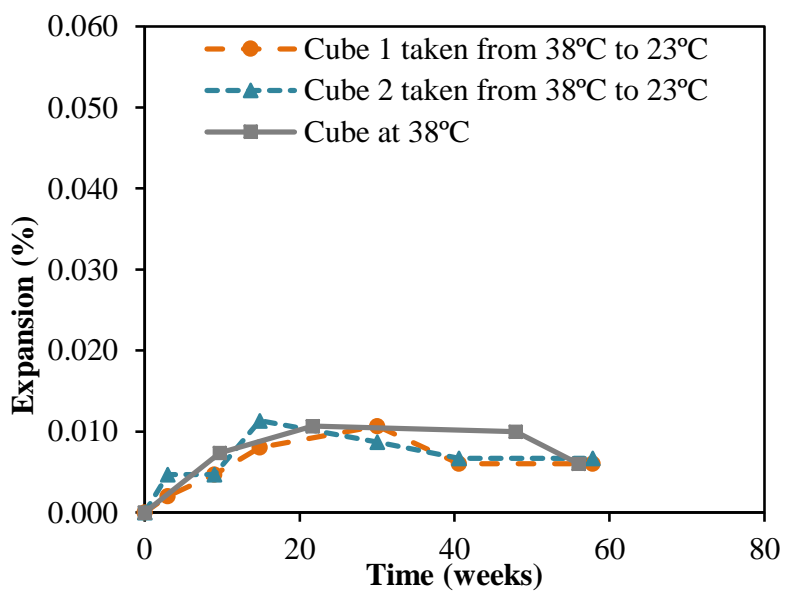

(a)

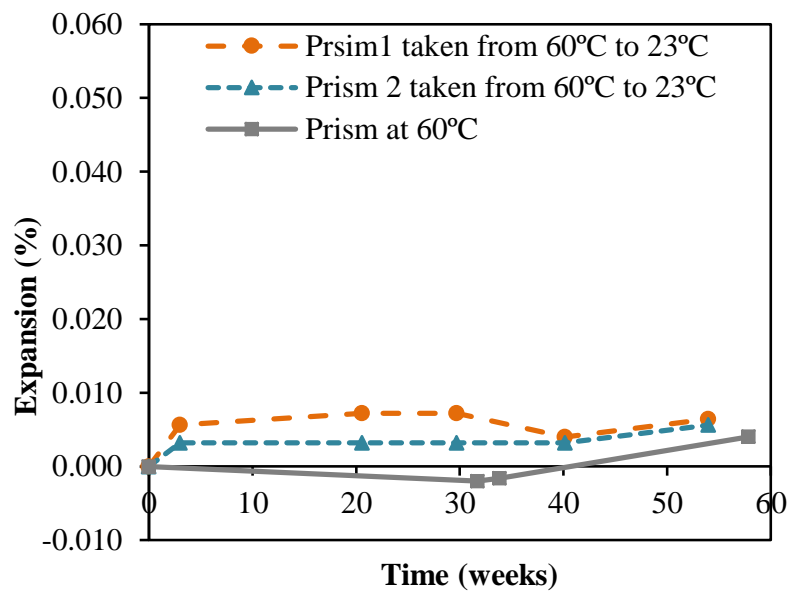

(b)

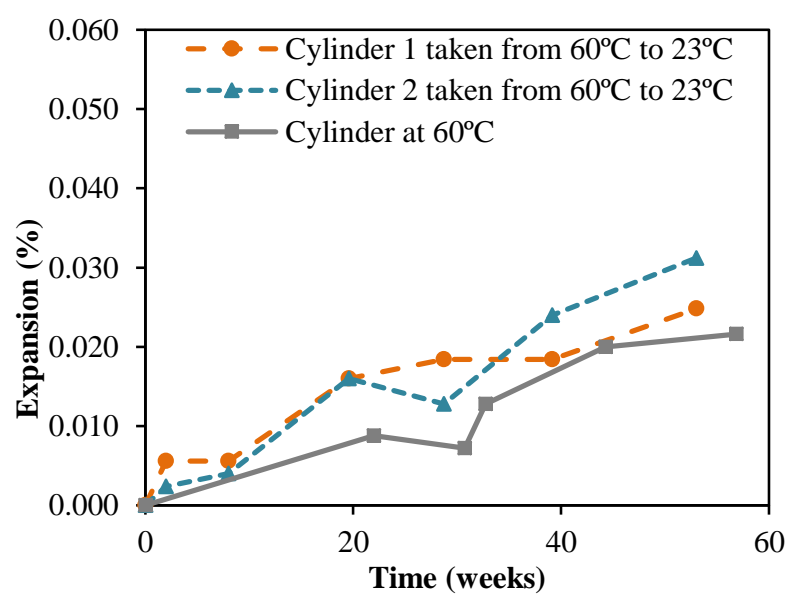

(b)

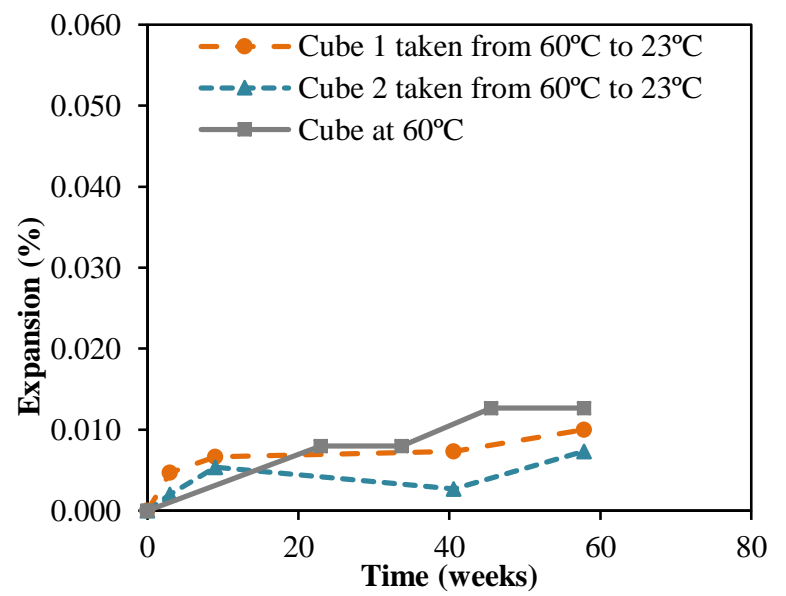

(b)

Figure 4.91: Expansion of Spratt samples without SCM at $23^{\circ} \mathrm{C}$ taken from (a) $38^{\circ} \mathrm{C}$ and (b) $60^{\circ} \mathrm{C}$ 


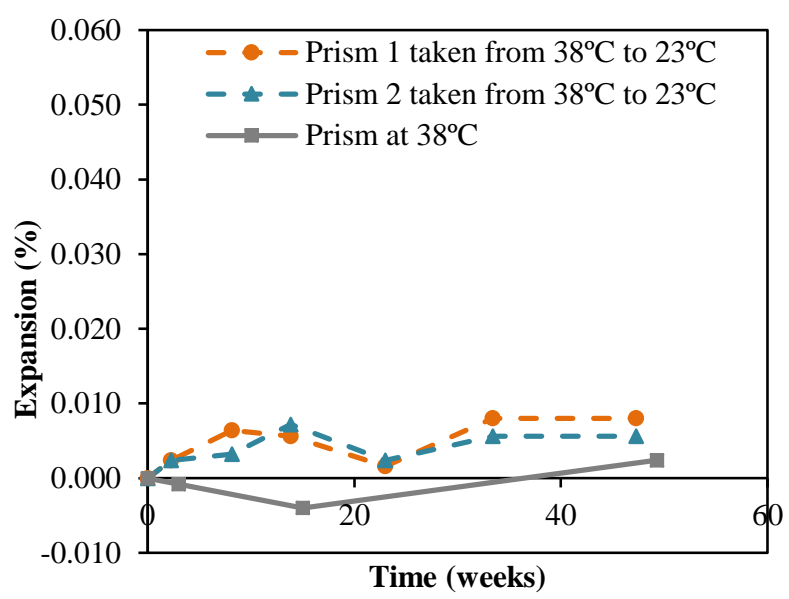

(a)

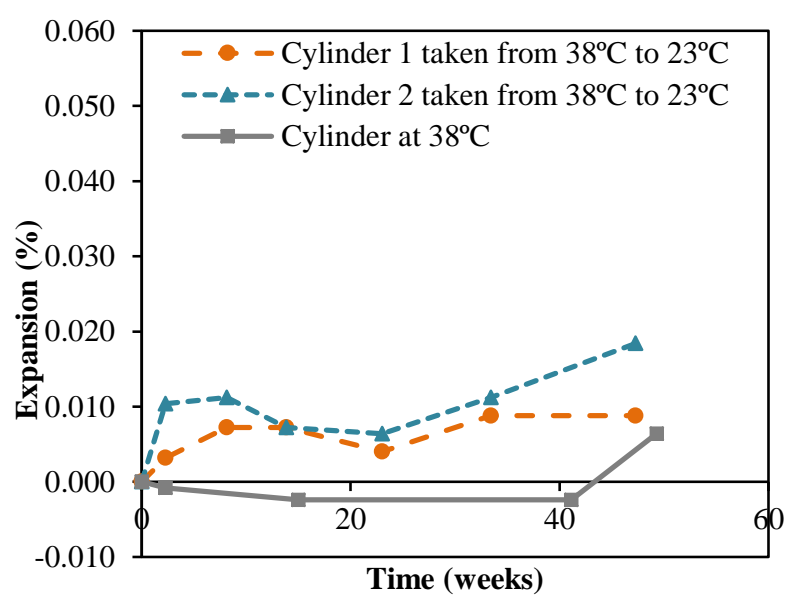

(a)

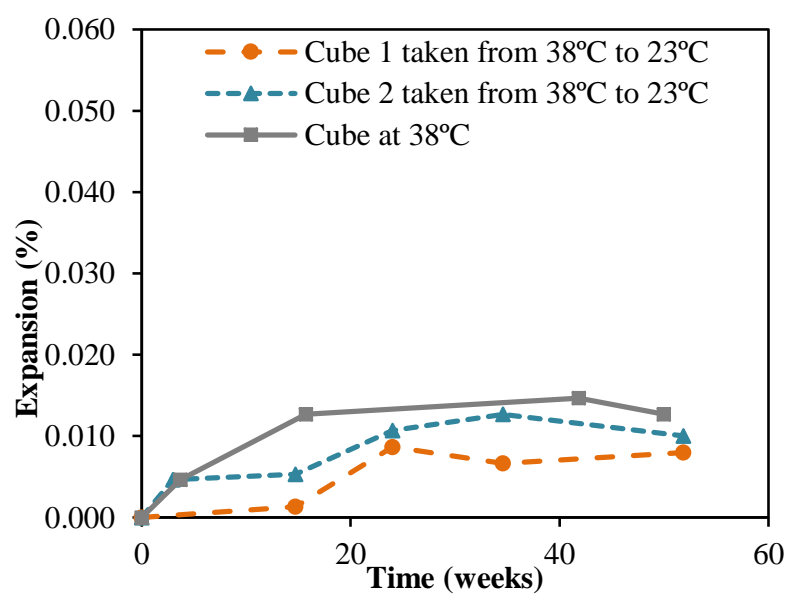

(a)

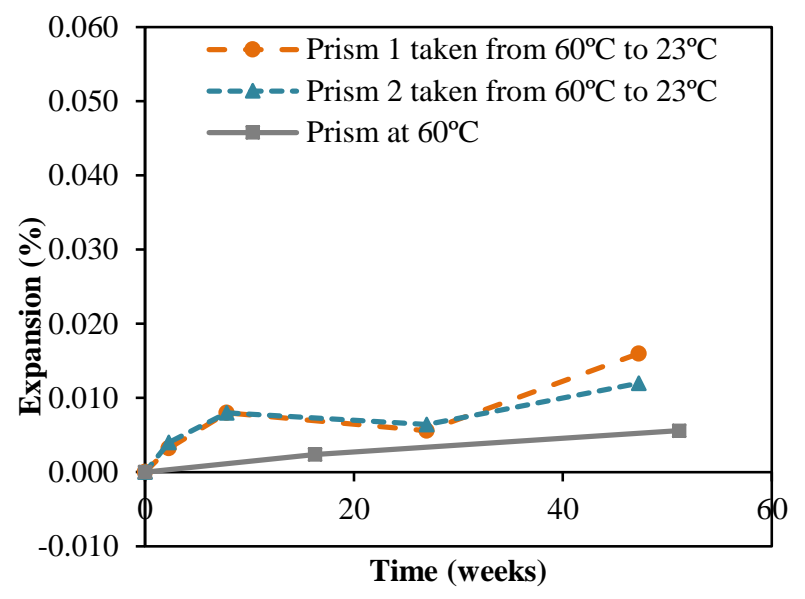

(b)

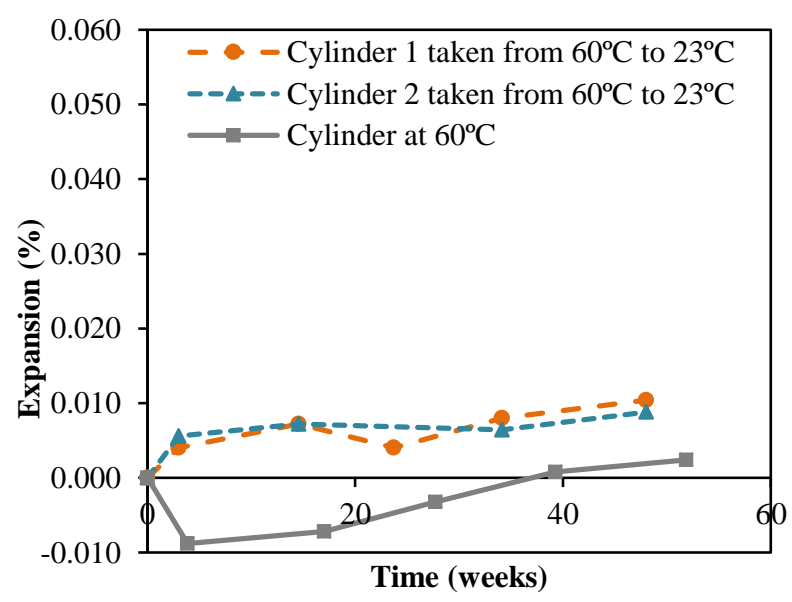

(b)

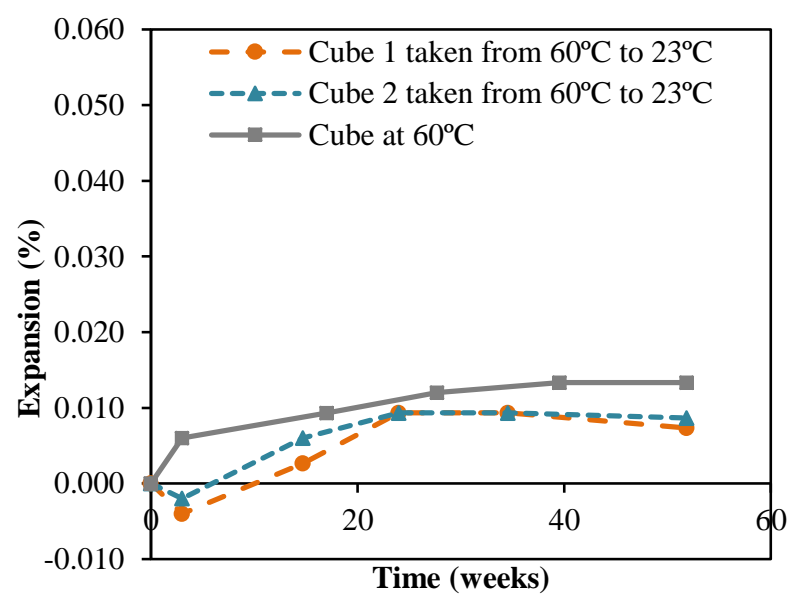

(b)

Figure 4.92: Expansion of Spratt samples with $20 \%$ FA at $23^{\circ} \mathrm{C}$ taken from (a) $38^{\circ} \mathrm{C}$ and (b) $60^{\circ} \mathrm{C}$ 


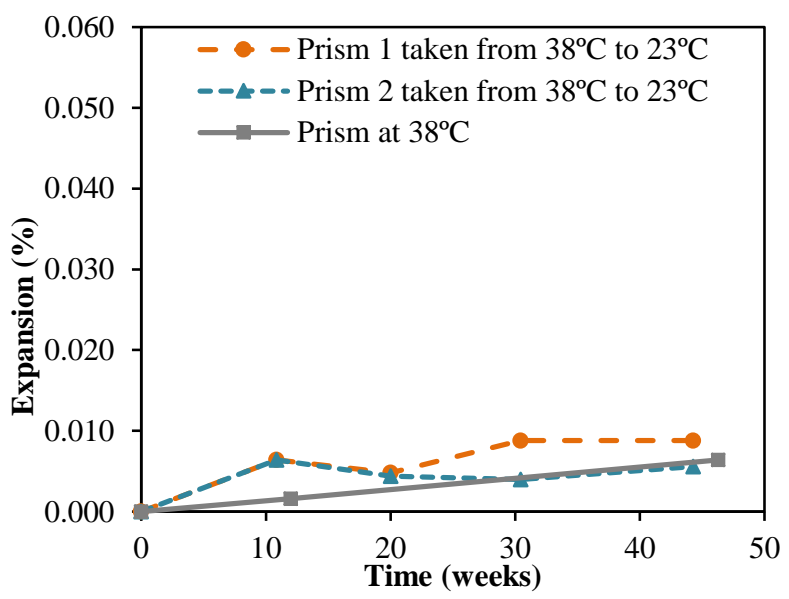

(a)

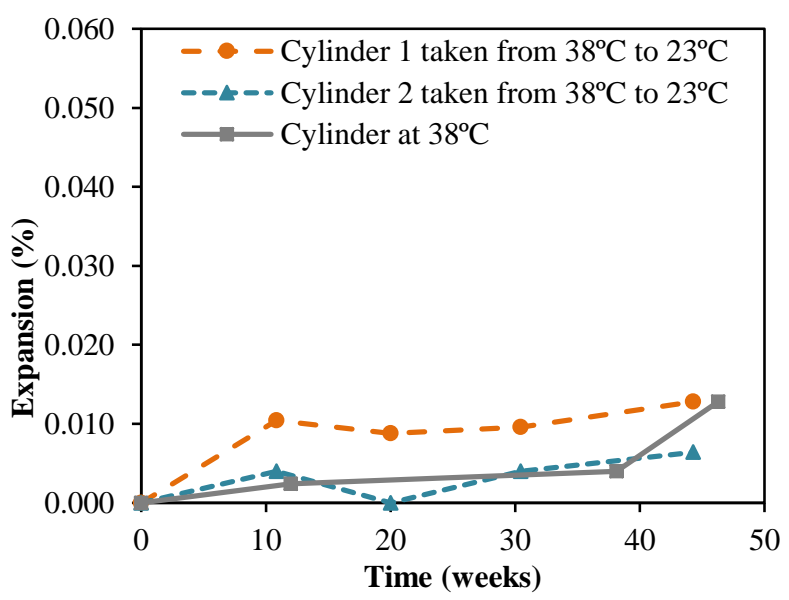

(b)

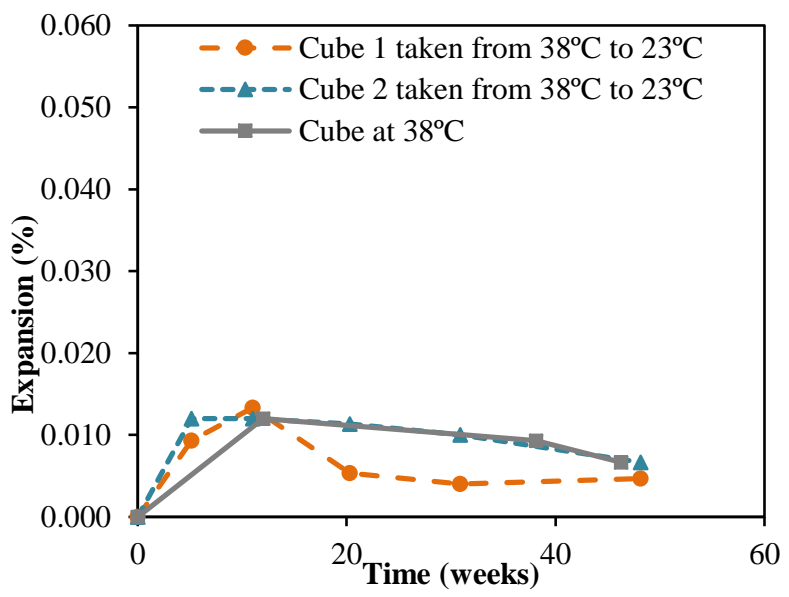

(a)

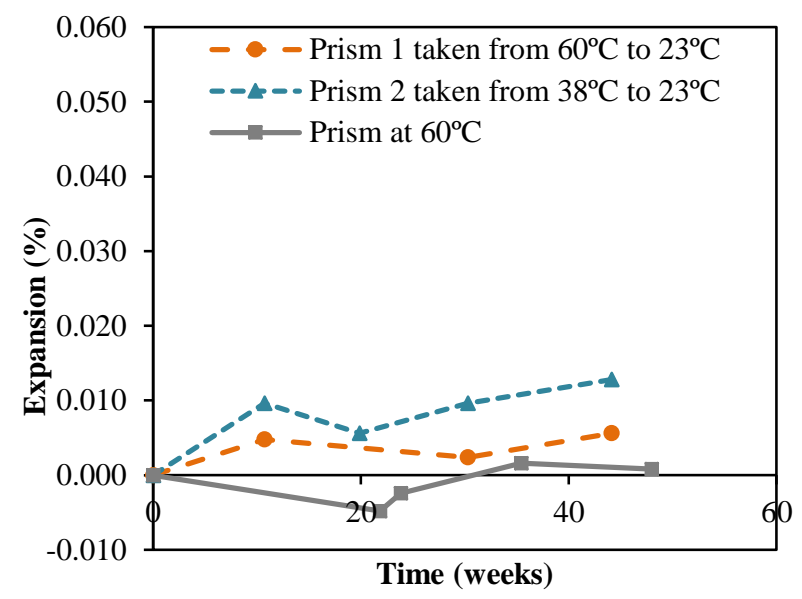

(b)

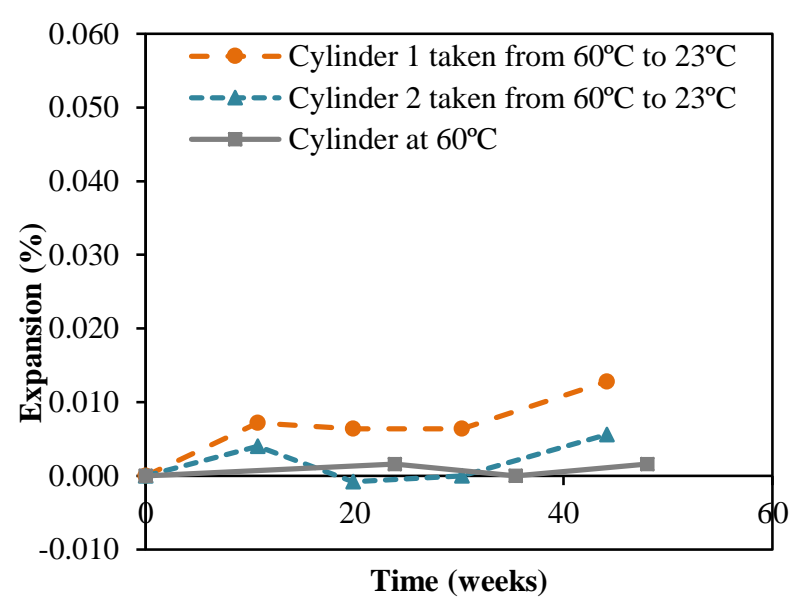

(b)

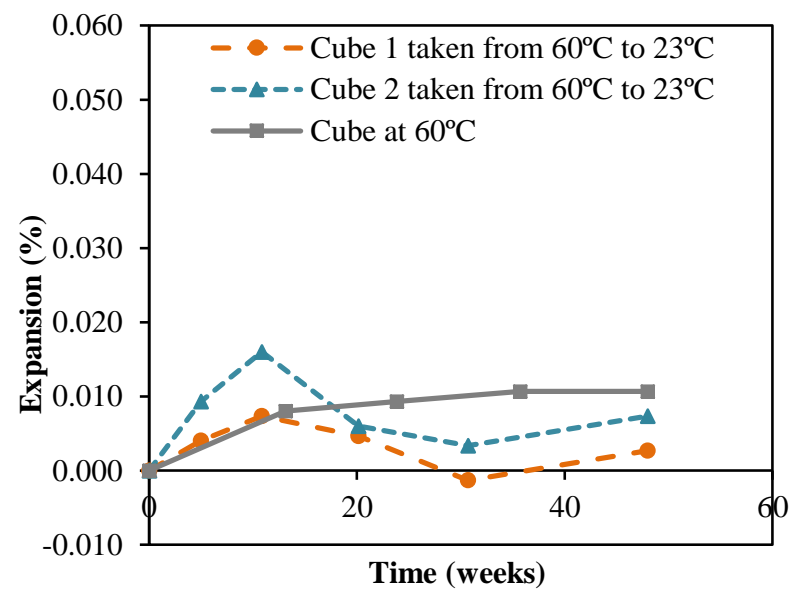

(b)

Figure 4.93: Expansion of Spratt samples with $35 \%$ Slag at $23^{\circ} \mathrm{C}$ taken from (a) $38^{\circ} \mathrm{C}$ and (b) $60^{\circ} \mathrm{C}$ 


\subsection{Ways to Determine the Alkali Threshold for Different Aggregates}

This section examines the possibility of determining the threshold of alkalis that is required to trigger expansion in concrete with different aggregates. This is carried out by testing concrete at different alkali content and correcting the alkali levels based on the amount of alkalis leached. If the threshold is determined, the level/type of SCM needed to mitigate expansion can be established based on available data on effects of SCM on pore solution alkalinity. Samples cast at different alkali content and others soaked in alkaline solutions are investigated and a way to predict the minimum alkali level that will trigger expansion in concrete will be suggested for Sudbury and Spratt coarse aggregates as well as Springhill fine aggregate.

\subsubsection{Alkali Threshold for Concrete Cast with Sudbury Coarse Aggregate}

Cylinders containing Sudbury aggregate were cast with PC of different alkali content. The 1-year expansion and leaching results are shown in Figure 4.94. Expansion up to 1 year of cylinders cast with Sudbury at different alkali content can be found in Appendix J. The top horizontal axis relates to the corresponding pore solution alkalinity of the PC (obtained from equation (2) in Section 2.2.2). Sudbury cylinders showed a safe alkali level of $0.83 \% \mathrm{Na}_{2} \mathrm{O}_{\mathrm{e}}(0.58 \mathrm{M})$ beyond which the expansion started to increase above $0.040 \%$.

Despite the leaching in the cylinders, a way to predict the minimum level of alkali content that will trigger expansion above $0.040 \%$ is proposed in this study. Based on Figure 4.94, the alkali content that will lead to an expansion of $0.040 \%$ is $0.83 \% \mathrm{Na}_{2} \mathrm{O}_{\mathrm{e}}$ for cylinders cast with Sudbury aggregate. This alkali content is reduced by the leached alkalis of $21 \%$ leading to a pore solution alkalinity of $0.66 \% \mathrm{Na}_{2} \mathrm{O}_{\mathrm{e}}$, or $0.46 \mathrm{M}$. This threshold will be the minimum alkali content beyond which the expansion will be higher than $0.040 \%$. 


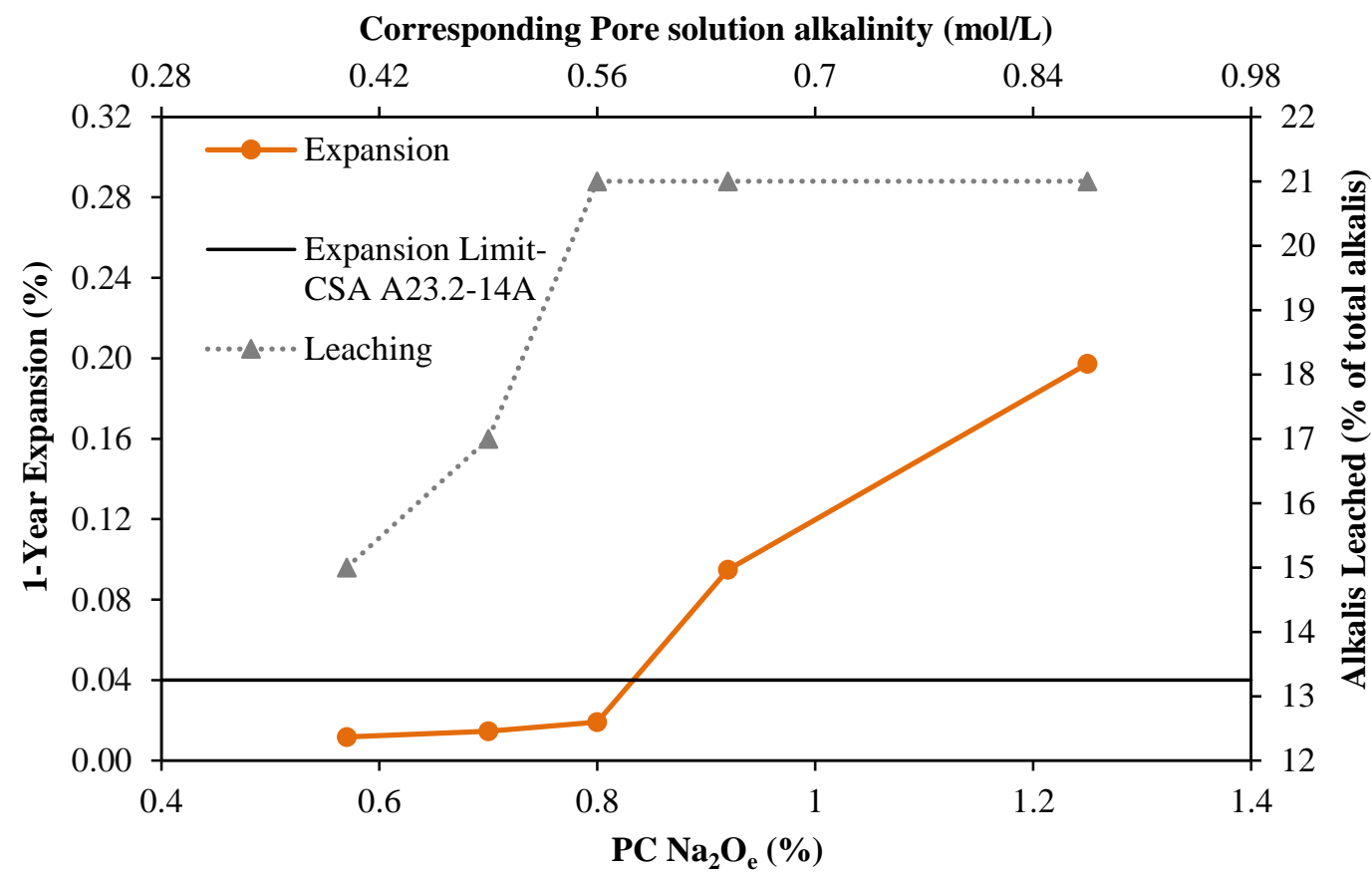

Figure 4.94: 1-year expansion and leaching results of cylinders cast with Sudbury at different PC alkali content

\subsubsection{Alkali Threshold for Concrete Cast with Spratt Coarse Aggregate}

Similarly, Spratt cylinders were cast with cement of different alkali content and expansion results at 1 year are shown in Figure 4.95. Expansion up to 1 year of cylinders cast with Spratt at different alkali content can be found in Appendix J. Spratt cylinders showed a safe alkali level of 0.59\% $\mathrm{Na}_{2} \mathrm{O}_{\mathrm{e}}(0.41 \mathrm{M})$ beyond which the expansion started to increase above $0.040 \%$. Spratt aggregate required a lower alkali level to trigger expansion in the cylinders compared to Sudbury. This was the case when CPT was used to evaluate the threshold (Shehata and Thomas, 2010). 


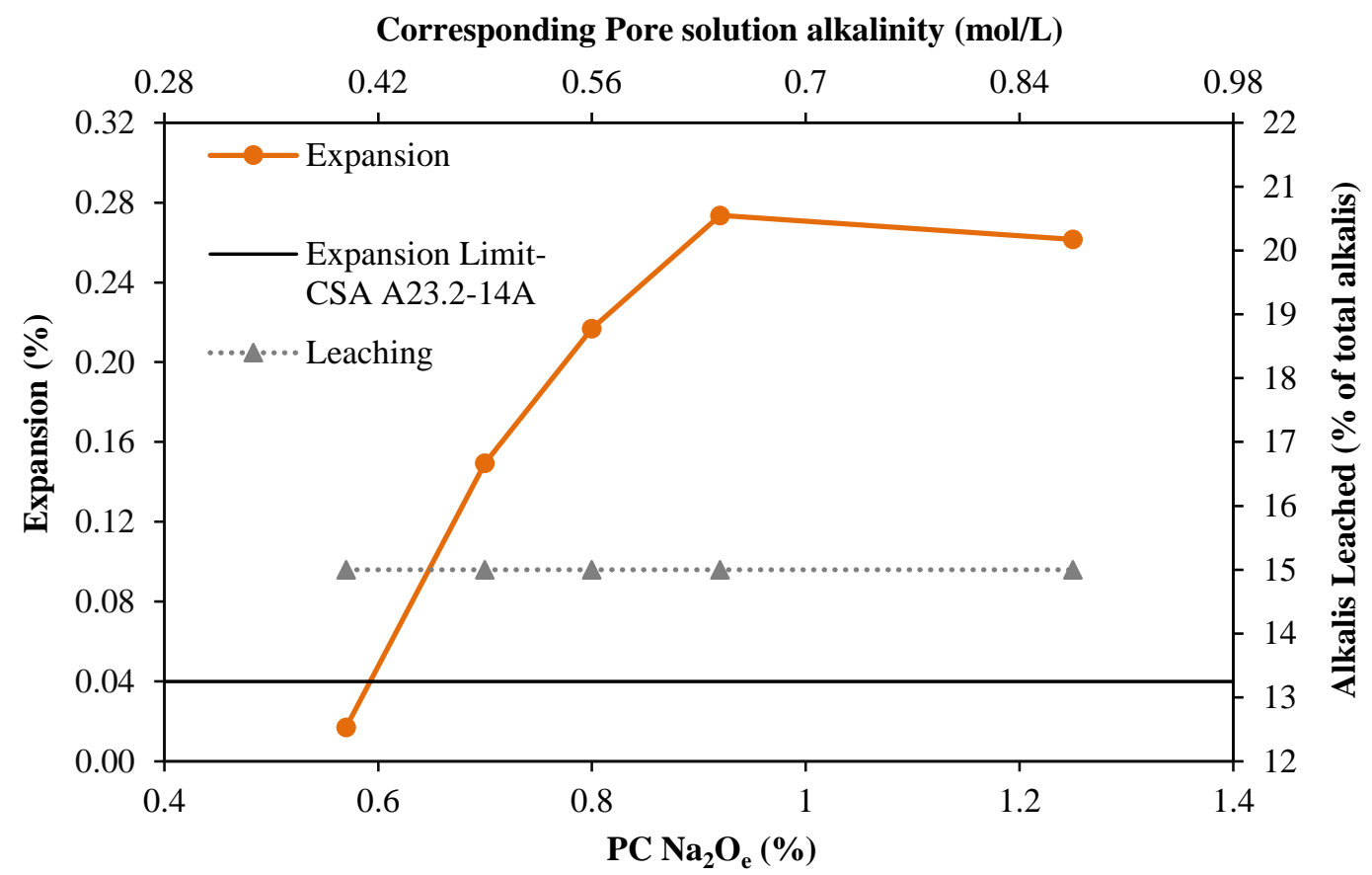

Figure 4.95: 1-year expansion and leaching results of cylinders cast with Spratt at different PC alkali content

For Spratt coarse aggregate, the same procedure is followed to obtain the threshold. The alkali content leading to a $0.040 \%$ expansion in the cylinders was found to be $0.59 \% \mathrm{Na}_{2} \mathrm{O}_{\text {e }}$. Reducing the leaching of $15 \%$, the minimum alkali content that will trigger expansion above $0.040 \%$ was found to be $0.50 \% \mathrm{Na}_{2} \mathrm{O}_{\mathrm{e}}$, or $0.35 \mathrm{M}$.

\subsubsection{Alkali Threshold for Concrete Cast with Springhill Fine Aggregate}

The Springhill fine aggregate was tested with PC of different alkalinity using the CPT and the results at 1 year are shown in Figure 4.96. Expansion up to 1 year of prisms cast with Springhill aggregate at different alkali content can be found in Appendix J. As shown, concrete cast with Springhill aggregate needs very high PC alkali content of $1.06 \% \mathrm{Na}_{2} \mathrm{O}_{e}(0.74 \mathrm{M})$ to show expansion above $0.040 \%$. 


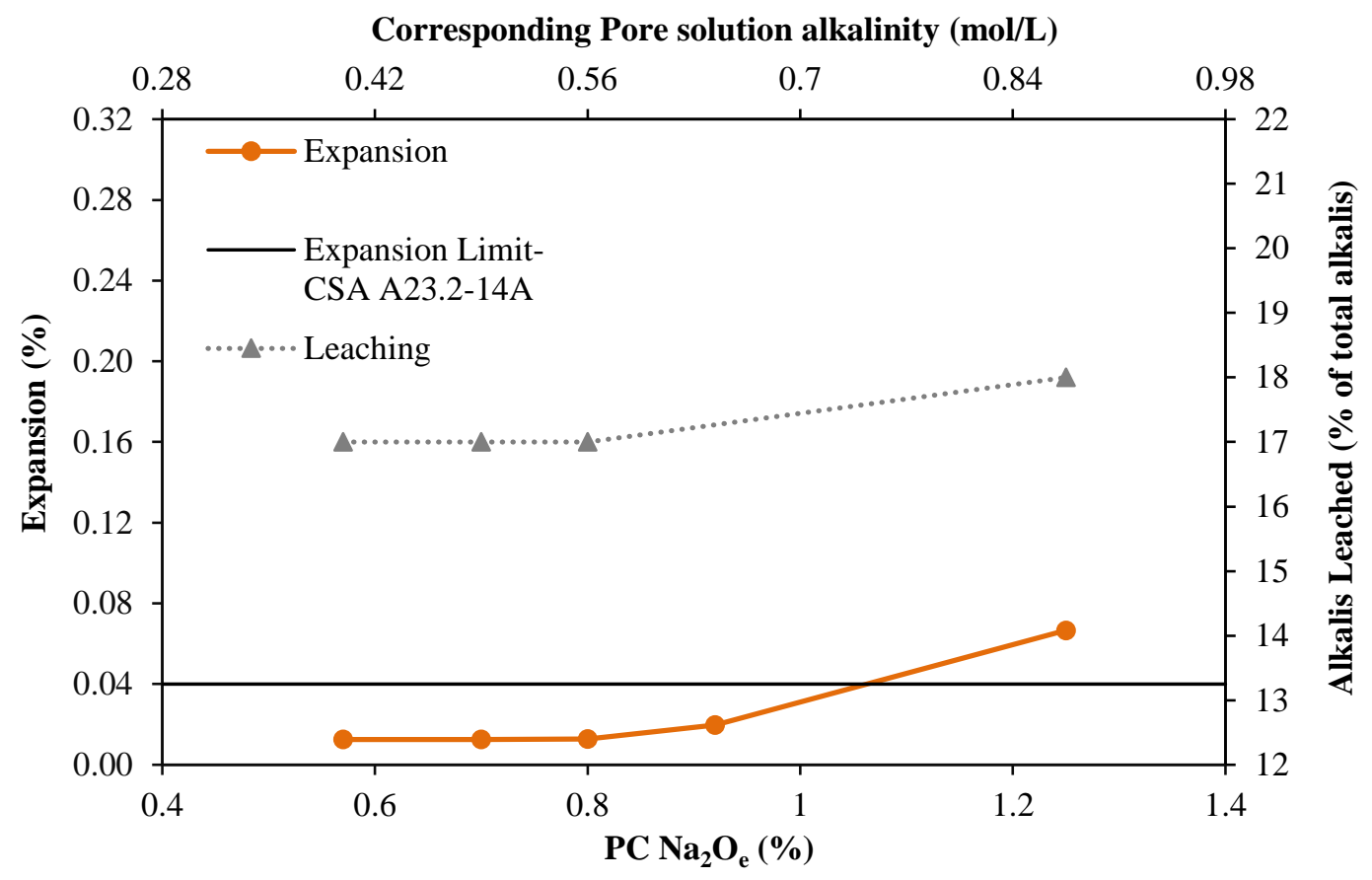

Figure 4.96: 1-year CPT expansion and leaching results of prisms cast with Springhill fine aggregate at different $\mathrm{PC}$ alkali content

For Springhill fine aggregate, the threshold alkali level needed to cause expansion above $0.040 \%$ is $0.88 \% \mathrm{Na}_{2} \mathrm{O}_{\mathrm{e}}(0.62 \mathrm{M})$. It could be concluded that maintaining the pore solution alkalinity of concrete above this critical alkali content will keep showing expansion. This calculated threshold alkali level could be used to determine the minimum SCM required to reduce the pore solution alkalinity of concrete below this level preventing expansion as will be explained in Chapter 5 .

\subsubsection{Soaking Samples in Alkaline Solutions}

Soaking samples in alkaline solutions of different concentration was done as a way to find the level of alkalinity that triggers expansion of concrete prisms cast with Spratt aggregate and GU0.95. The 1-year expansion results of the soaked concrete prisms are presented in Figure 4.97. 


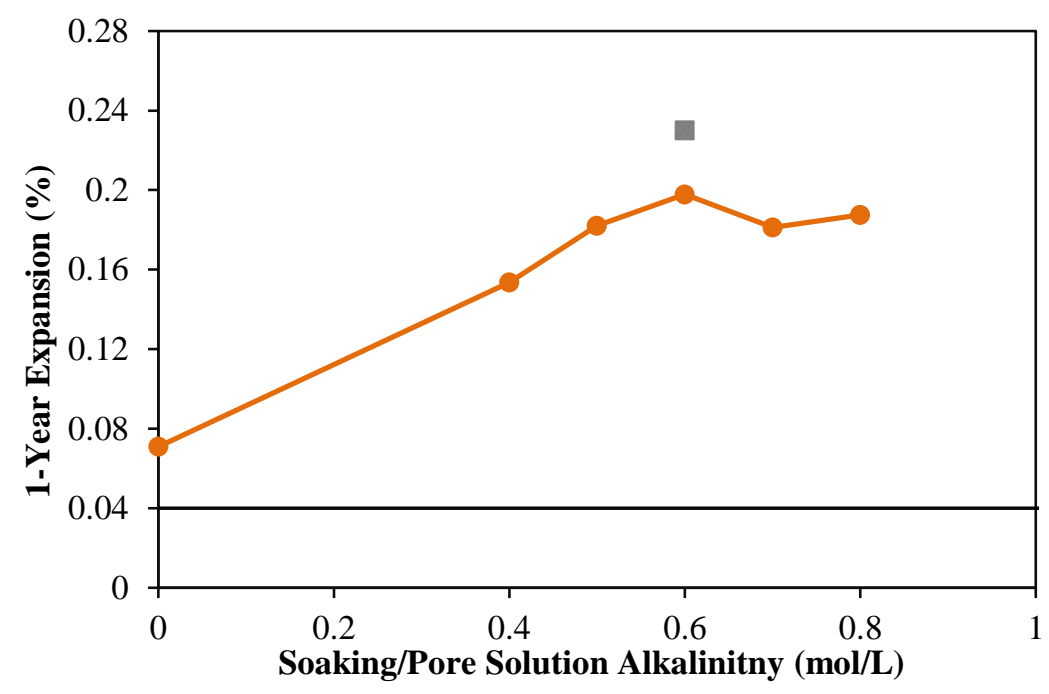

Figure 4.97: 1-year expansion of Spratt prisms in alkaline solutions

Soaking prisms cast with GU-0.95 in DDW and saturated $\mathrm{Ca}(\mathrm{OH})_{2}$ solution showed an expansion higher than $0.040 \%$ with a value of $0.081 \%$ and $0.076 \%$ for samples soaked in DDW and lime solution, respectively. It was expected that due to alkali leaching Spratt samples soaked in water or lime solution will not show expansion higher than $0.040 \%$. However, due to the nature of the Spratt aggregate, ASR reaction might perhaps be faster than the rate of alkali leaching from the prisms to the water/lime solution. The expansion at early ages was studied to understand the role of the soaking host solution on ASR expansion. Figure 4.98 shows the expansion of the concrete prisms soaked in different host solutions at early age.

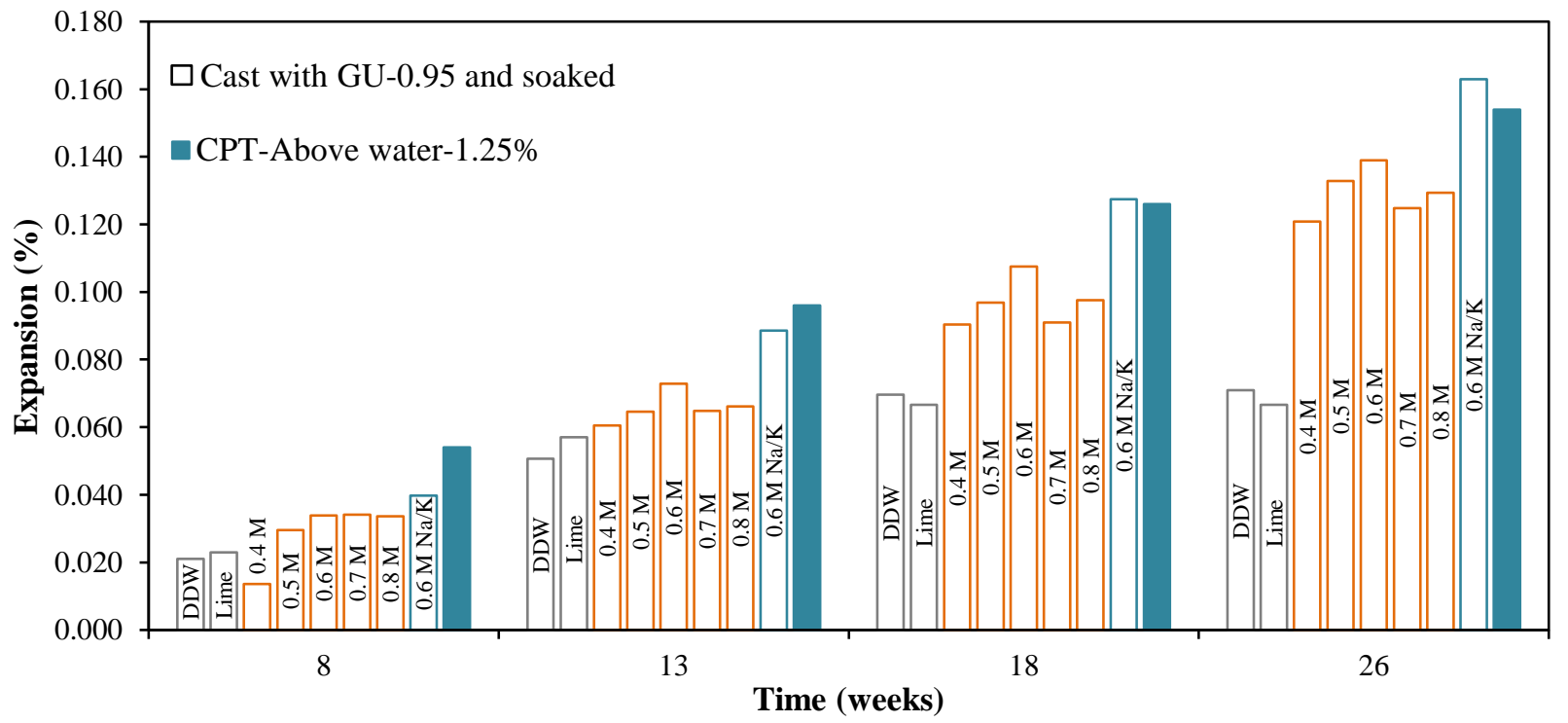

Figure 4.98: Expansion of Spratt prisms at different ages 
It is clear from the figure that the expansions at 8 and 13 weeks are similar for all the prisms soaked in the different solutions. However, at 18 weeks, difference in expansion starts to show between the samples soaked in water or lime compared to the samples soaked in alkaline solutions. This could be explained by the fact that at early age, migration of alkalis or leaching is not significant. However, the effect of leaching starts to show at 18 weeks and it becomes very significant by 26 weeks. The expansion at 26 weeks of the samples soaked in water and lime is much lower than the expansion obtained in the samples soaked in alkaline solutions. This shows that the initial PC alkali content affects greatly the expansion at early age regardless of the host solution alkalinity. The samples soaked in $\mathrm{NaOH}$ solutions showed lower expansion than the prisms soaked in $\mathrm{NaOH}$ and $\mathrm{KOH}$ solution with the same $\mathrm{Na} / \mathrm{K}$ ratio as that of the cement. This difference in expansion also started to show at 18 weeks. This means that leaching of $\mathrm{K}^{+}$ions started to occur from the samples soaked only in $\mathrm{NaOH}$ leading to lower expansion.

Soaking samples in alkaline solutions will help preventing leaching from concrete samples. Looking from the other side, diffusion of the ions from the host solution to the core of the samples might not have a significant effect on expansion. The expansions of samples soaked in 0.6, 0.7, $0.8 \mathrm{M} \mathrm{NaOH}$ solutions are close to each other. This could be due to the low permeability of the samples hindering the diffusion of the ions from the soaking solution to the core of the samples as was reported also by Bérubé and Frenette (1994). Hence, the effect of preventing leaching by soaking samples is more pronounced than the effect of increasing the alkalinity in the prisms' cores. However, soaked samples will keep showing expansion even after one year as shown in Figure 4.99 which is not the case with samples stored above water tested using the CPT. This confirms that the alkalis are taking time to reach the cores of the prisms. Samples stored above water, after 1 year, will stop expanding due to the alkali leaching and/or the consumption of the alkalis by the ASR lowering the pore solution alkalinity below alkali the threshold explained in Section 4.4.2. 


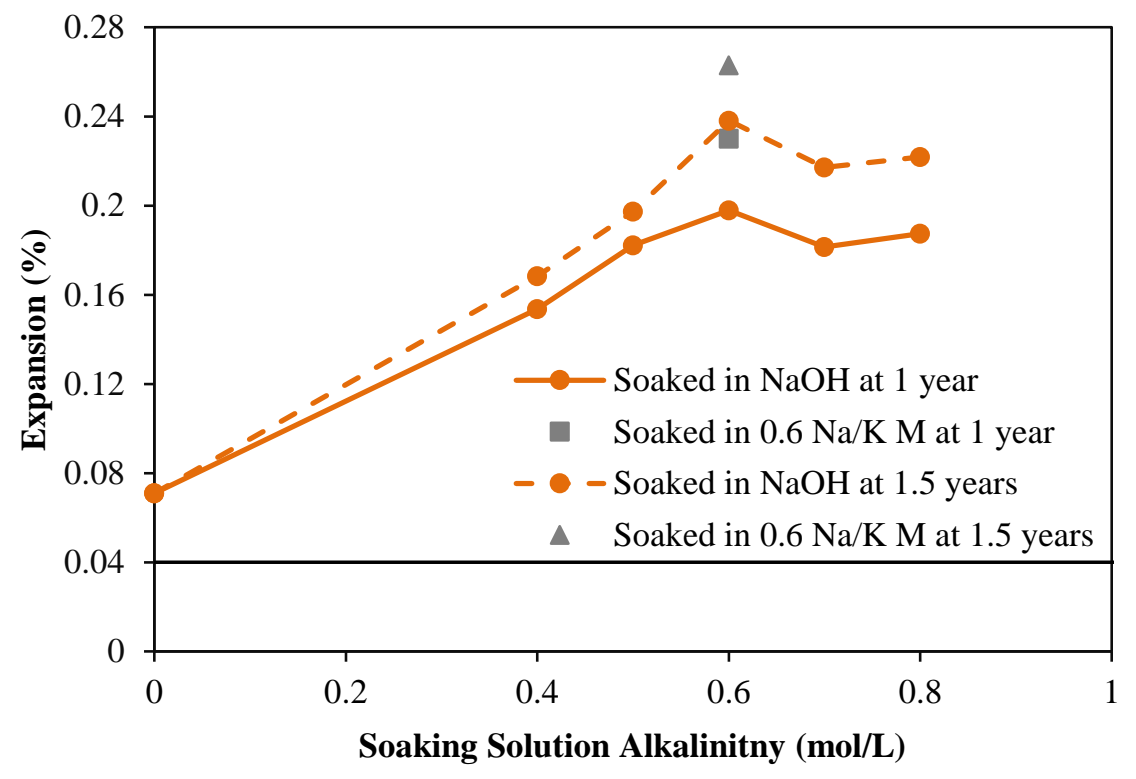

Figure 4.99: Expansion comparison of Spratt samples with different pore solution alkalinity at 1 year and 1.5 years

Concrete Spratt samples cast with GU-0.57 and soaked in an alkaline solution of $0.4 \mathrm{M}$ mimicking its pore solution were tested and results showed an expansion of $0.038 \%$ at 6 months as shown in Figure 4.100. At 1 year, the prisms cast with GU-0.57 and soaked in $0.4 \mathrm{M}$ solution are expected to show an expansion higher than $0.040 \%$ and fail the CPT. This is in line with the threshold alkali content for Spratt obtained from Section 4.4.2 which showed that the alkalinity should be above $0.50 \% \mathrm{Na}_{2} \mathrm{O}_{\mathrm{e}}$, or $0.35 \mathrm{M}$ to trigger expansion. For Spratt prisms cast with GU-0.57 and soaked in $0.4 \mathrm{M}$ solution with same $\mathrm{Na} / \mathrm{K}$ ratio as the cement, the expansion already reached an expansion $(0.063 \%)$ higher than $0.040 \%$ at 6 months.

In addition, the rate of expansion for Spratt prisms with GU-0.57 at early age is lower than that of the Spratt samples cast with GU-0.95 and soaked in the same solution. The significance or importance of the cement alkali content is manifested in Figure 4.100. 


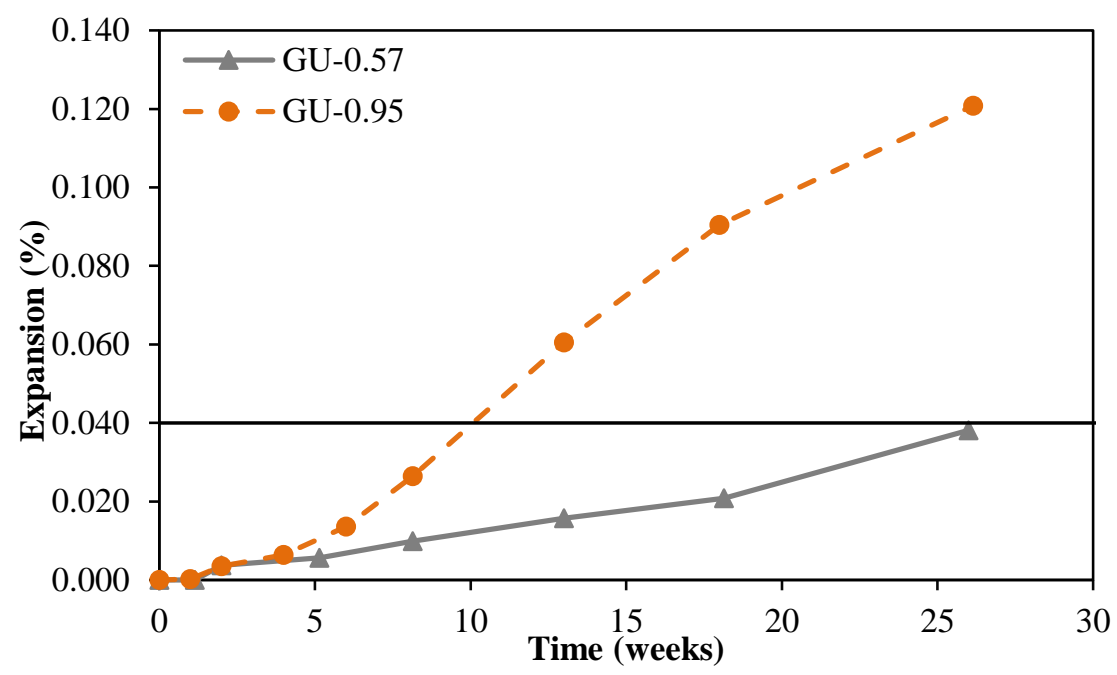

Figure 4.100: Expansion up to 26 weeks for Spratt prisms soaked in 0.4 M solution

In conclusion, soaking samples in different solutions showed that alkali leaching is not very significant at early age and that expansion until 13 weeks is not greatly affected by the host solution alkalinity but is more affected by the initial PC alkali content. However, soaking samples in alkaline solution might overestimate the expansion due to the abundant supply of alkalis. In the field, concrete has limited alkalis and will show a lower rate of expansion at later age due to consumption of alkalis.

Soaking samples in alkaline solution corresponding to the pore solution alkalinity of the concrete could give an indication of the alkali level above which expansion will increase beyond $0.040 \%$ to confirm the results obtained when testing samples above water (following the CPT standards) as presented in Section 4.4.2. 


\subsection{Residual Expansion of Structures affected by ASR - Sudbury Bridge Barriers}

This section presents results from a study focusing on understanding the factors influencing the remaining expansion of ASR affected structures suffering different levels of deterioration. In addition, concrete prisms and cylinders cast with RCA aggregates were tested and compared to virgin samples to understand the role of remaining and additional alkali on residual expansion.

\subsubsection{Factors Affecting Residual Expansion in Sudbury Bridge Barriers}

\section{Expansion of Field Samples and Extracted Cores}

The residual expansions of bridge barriers with different levels of deterioration were monitored for 3.5 years and the results are shown in Figure 4.101. The low deteriorated barriers showed higher expansion than the high deteriorated ones. The expansion of low deteriorated barriers $(0.076 \%)$ was double that of the highly deteriorated ones $(0.040 \%)$ at 3.5 years.

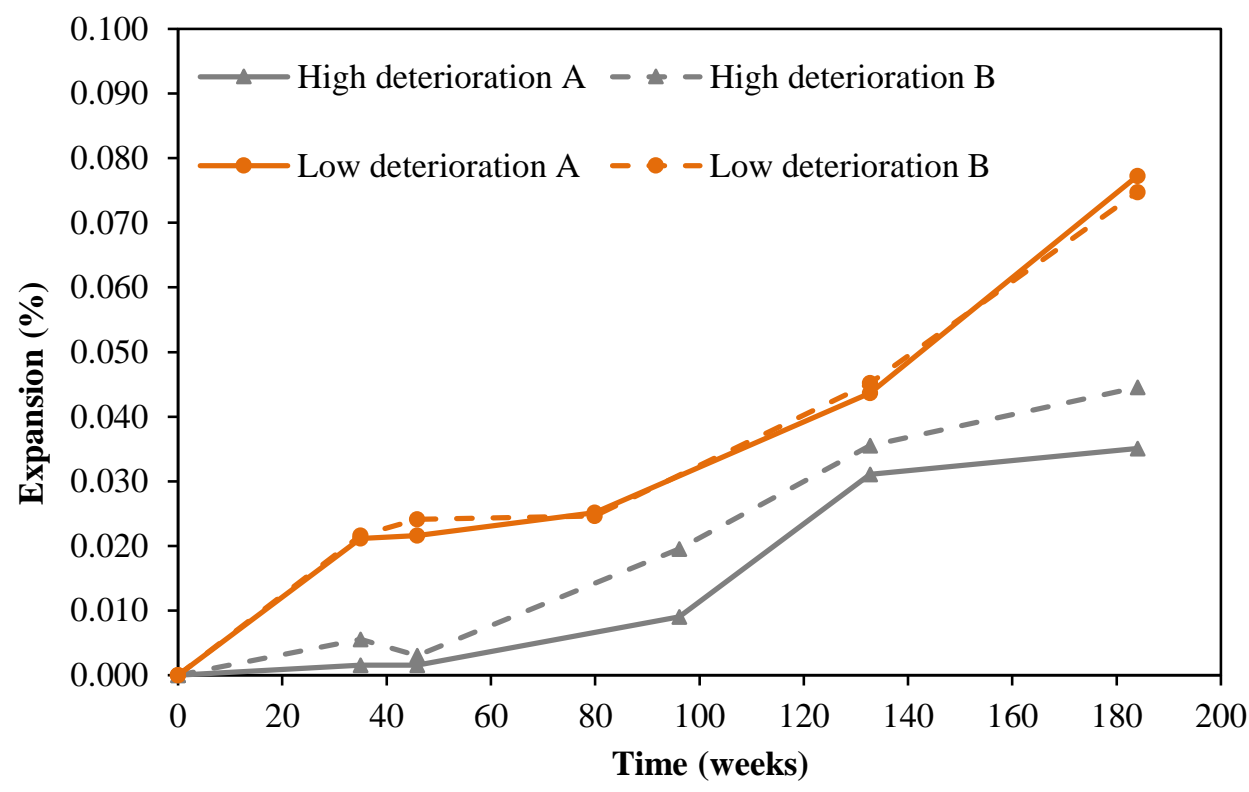

Figure 4.101: Expansion of low and high deteriorated bridge barriers

The availability of more cracks in the high deteriorated barriers might accommodate the ASR gel without causing cracks as opposed to low deteriorated barriers. In addition, the cracks could also increase the alkali leaching and the dislocation of the ASR gel contributing to the lower expansion but at the same time will allow the ingress of alkalis to the cores in case de-icers are used.

Figure 4.102 shows signs of leaching at different phases from the already present cracks on the high deteriorated barriers which indicate that the availability of cracks will make the transport of 
materials including alkalis easier. Figure 4.103 shows less signs of leaching on the low deteriorated barriers.

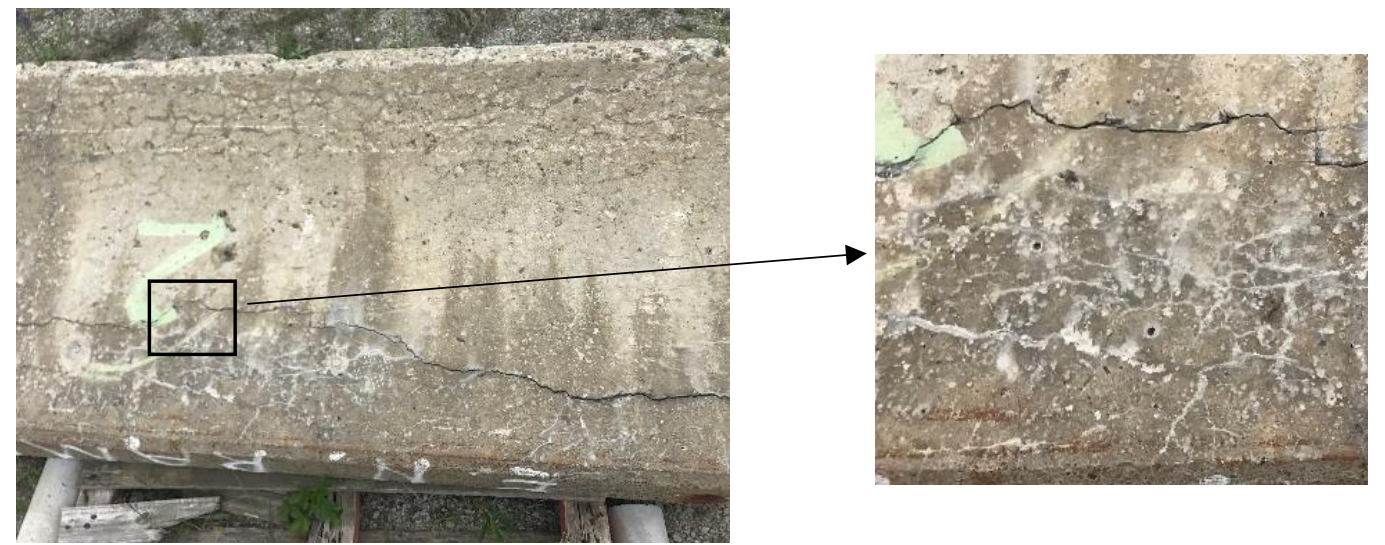

Figure 4.102: High deteriorated barrier after 3.5 years

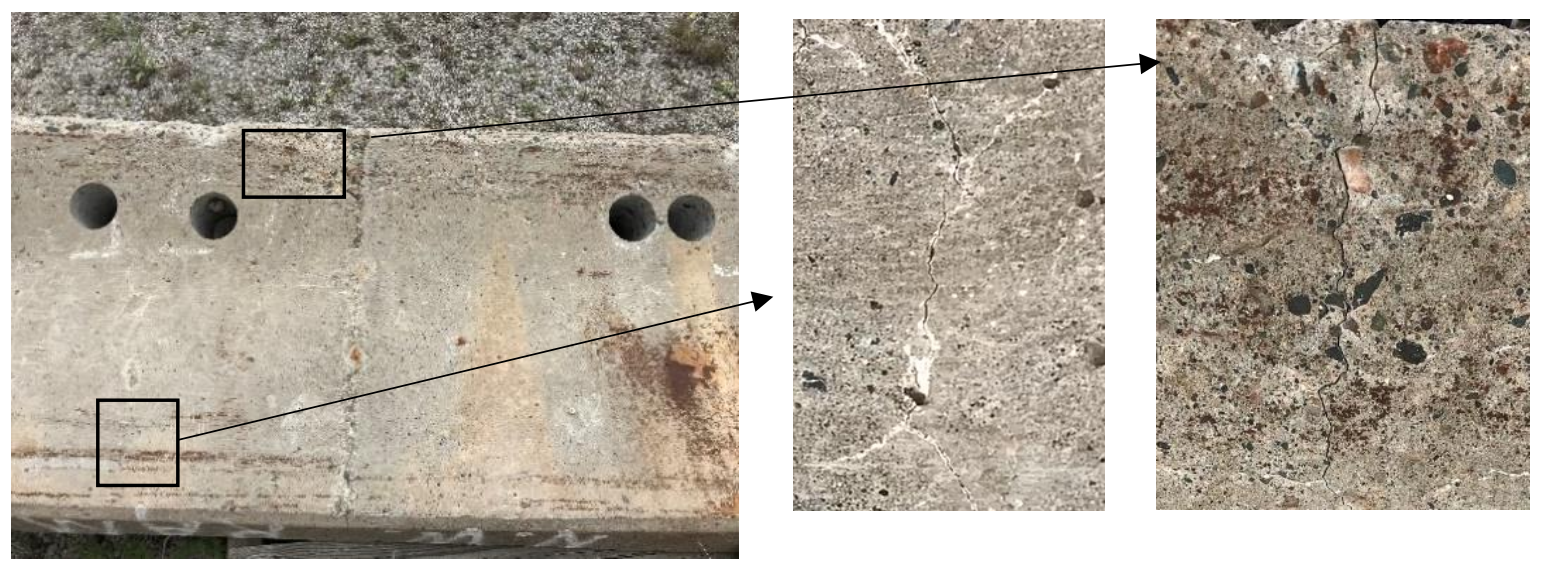

Figure 4.103: Low deteriorated barrier after 3.5 years

Cores extracted from the same barriers were measured for expansion in the laboratory - under the testing conditions of the CPT - and the average expansions are presented in Figure 4.104. The expansion of low deteriorated cores $(0.10 \%)$ stored above water at $38^{\circ} \mathrm{C}$ was also double that of the high deteriorated ones $(0.05 \%)$ confirming the results obtained from the field. 


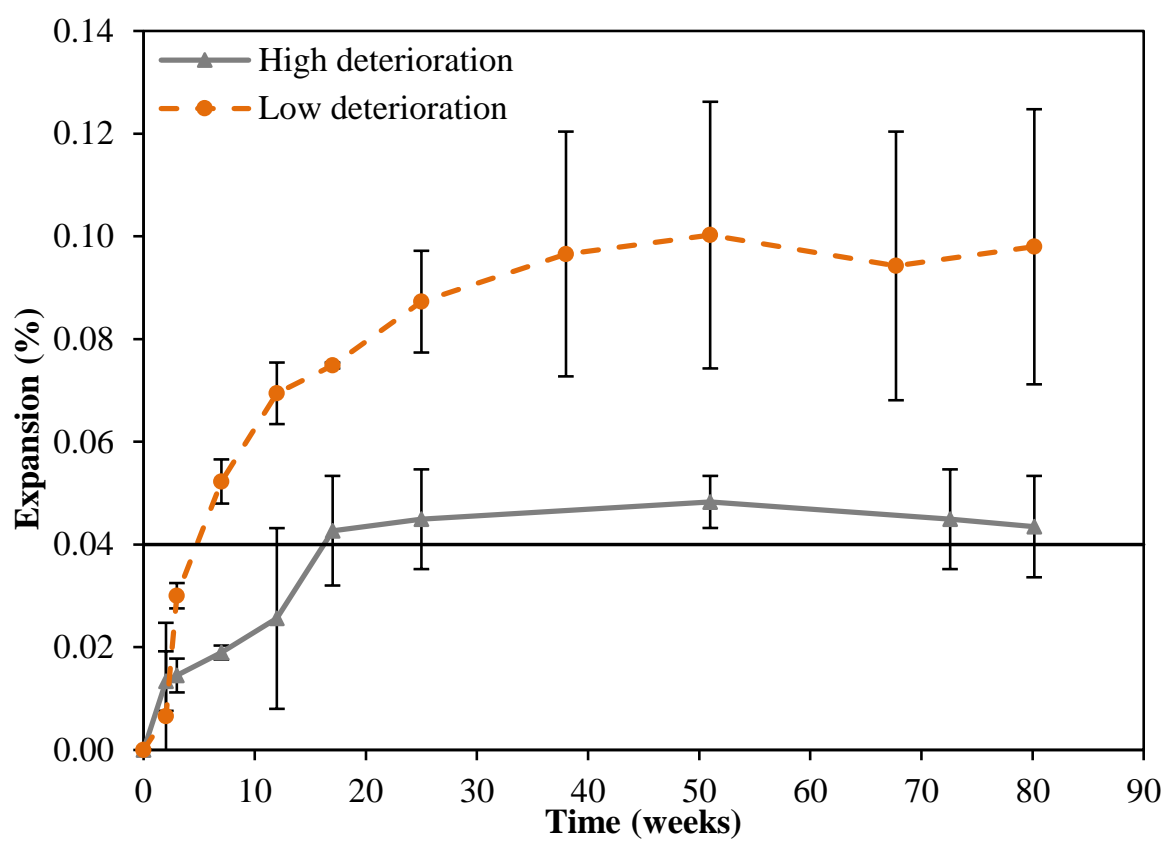

Figure 4.104: Expansion of cores stored above water at $38^{\circ} \mathrm{C}$

Damage rating index analysis was applied to one high and one low deteriorated cores and showed that both cores had the same increase in the DRI after 1 year above water (MacDonald et al., 2019). The increase was mainly attributed to the increase in the amount of cracks in the cement with and without ASR gel in addition to open cracks without ASR and debonding in the coarse aggregate which are signs of severe deterioration in concrete affected by ASR (MacDonald et al., 2019). This shows that both cores are undergoing same level of deterioration however perhaps due to the availability of more cracks in the high deteriorated samples, the gel is being accommodated without showing further expansion.

\section{Role of Remaining Reactive Silica in Residual Expansion}

In order to explain the observed difference in remaining life of structures affected by ASR, the cores were soaked in different alkaline solutions to see if further expansion is produced when a supply of alkalis exists. Under actual field conditions a possible source of alkalis could be de-icing salts - such as $\mathrm{NaCl}$ - that may react within concrete and transforms to $\mathrm{NaOH}$. At $0.4 \mathrm{M}$, the alkalinity of the solution was not high enough to trigger expansion. At $0.6 \mathrm{M}$, expansion was clear and the low deteriorated cores still showed higher expansion compared to the high deteriorated cores although both were soaked in same alkaline solution as shown in Figure 4.105. 


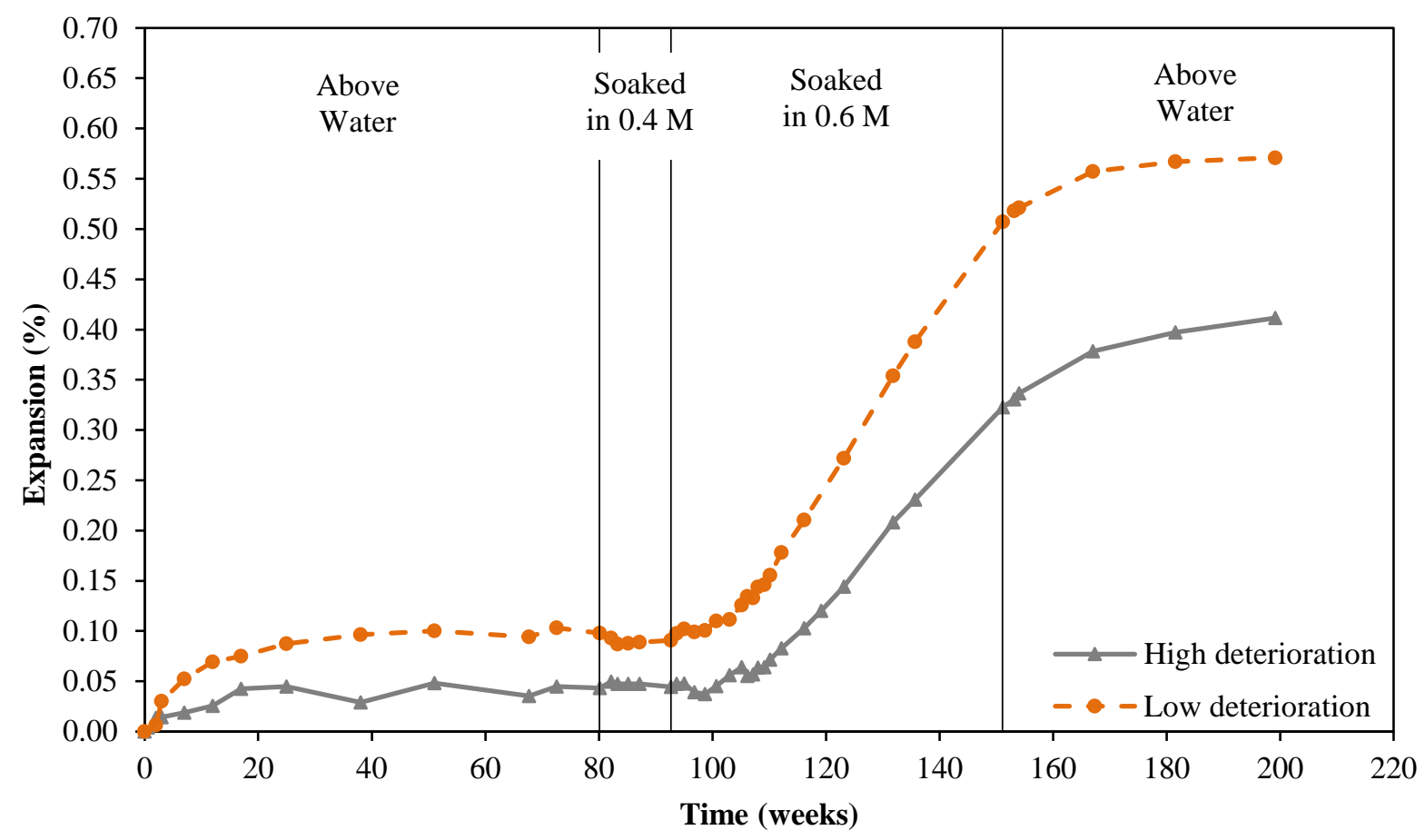

Figure 4.105: Expansion of extracted cores soaked in alkaline solutions at $38^{\circ} \mathrm{C}$

The pore solution alkalinity of concrete structures also affects the residual expansion in the field. The alkalinity could be reduced due to leaching (Bérubé, Fournier and Côté, 2012; Sinno and Shehata, 2019) and/or increased due to external supply of alkalis from de-icers and sea water (Heisig et al., 2016). Hence, the minimum level of alkalis above which the expansion is triggered is important to know to understand whether the concrete structures will undergo further expansion or not. For concrete cast with Sudbury aggregate, a critical pore solution alkalinity between $0.4 \mathrm{M}$ and $0.6 \mathrm{M}$ will trigger expansion above $0.040 \%$ as shown in Figure 4.105 (This is confirmed by the minimum threshold of $0.46 \mathrm{M}$ obtained in Section 4.4.1). Looking at the first 12 weeks, it should be noted from Figure 4.106 that a pore solution of $0.4 \mathrm{M}$ will not cause any expansion higher than $0.040 \%$ even if the samples were kept for more time. When soaked in $0.6 \mathrm{M}$ (Figure 4.107), the rate of expansion was increasing significantly specially after 6 weeks of soaking stating that a pore solution alkalinity higher than $0.4 \mathrm{M}$ should be maintained to see residual expansion whether in cores or barriers. 


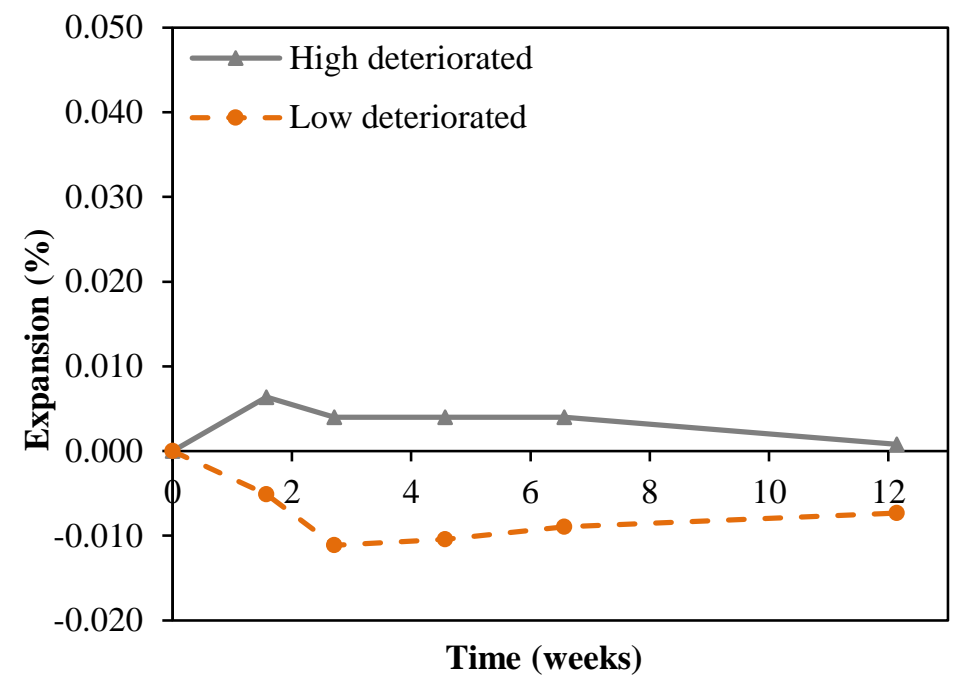

Figure 4.106: 12-week expansion of extracted cores soaked in $0.4 \mathrm{M}$ alkaline solution

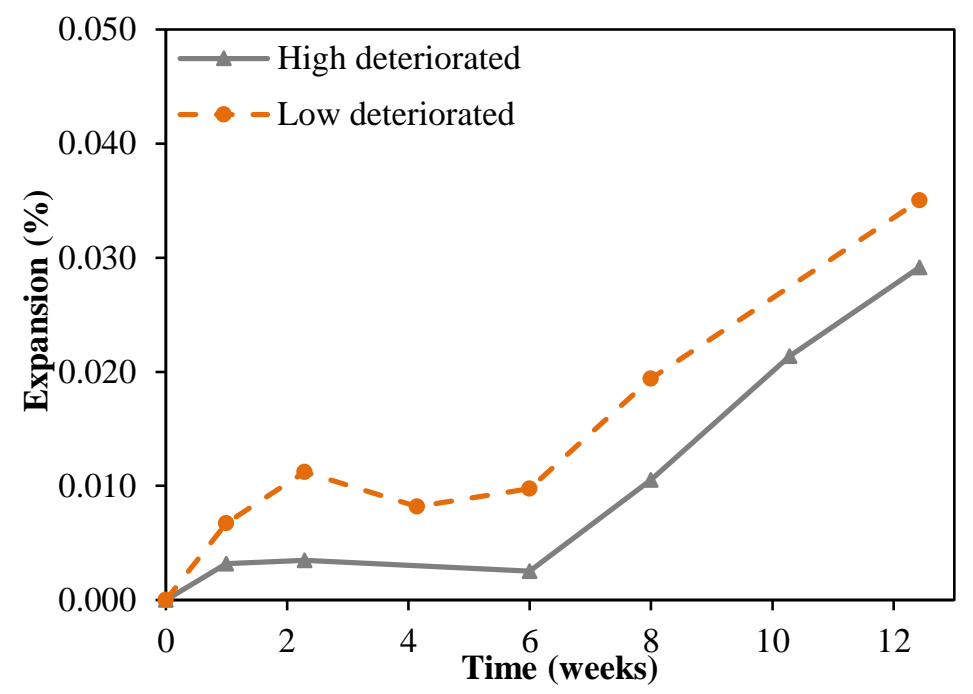

Figure 4.107: 12-week expansion of extracted cores soaked in $0.6 \mathrm{M}$ alkaline solution

Compared to testing above water, when soaked in alkaline solution, the reaction was intense throughout the samples to the extent that expansion was clear for both level of deterioration regardless of the cracking in high deteriorated samples. It should be noted that the rate of expansion was still higher in low deteriorated cores. The higher remained silica in the low deteriorated cores could have contributed to the higher rate of expansion obtained in the low deteriorated cores.

Core samples with high and low levels of deterioration are shown in Figure 4.108. More cracking was observed in the low deteriorated cores after soaking in $0.6 \mathrm{M}$ solution. It was observed also that the cracks are getting wider specially in the low deteriorated cores which prove the higher expansion observed. 


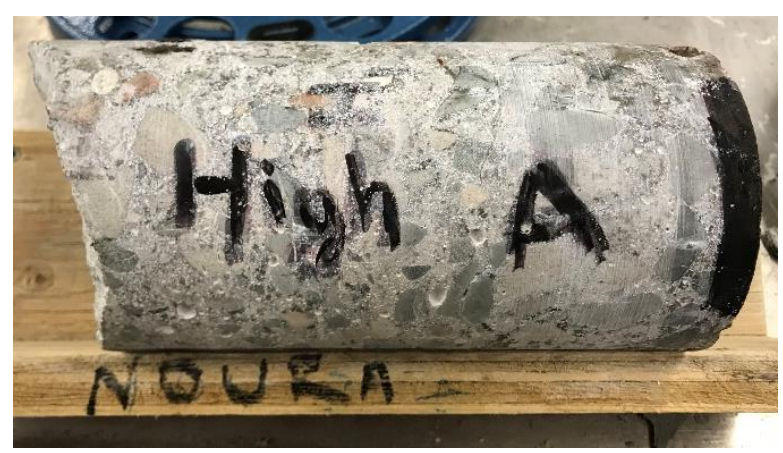

(a)

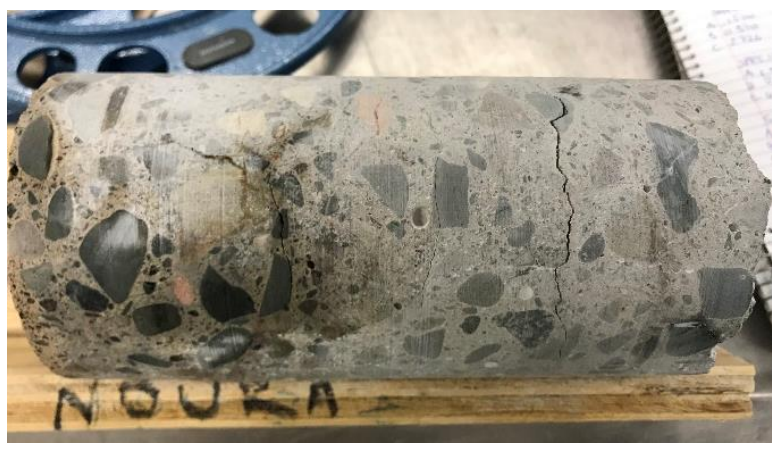

(b)

Figure 4.108: (a) High deteriorated and (b) low deteriorated cores after soaking in $0.6 \mathrm{M}$ solution

\section{Role of Alkali in Remaining Expansion of Structures Affected by ASR}

The remained alkalis in structures affected by ASR will affect the residual expansion. Chunks of concrete were obtained from high and low deteriorated barriers to study the alkali content in the pore solution of concrete structures cast with Sudbury. The chunks were crushed until $50 \mathrm{~g}$ passed $4.75 \mathrm{~mm}$ sieve and retained on $2.36 \mathrm{~mm}$ sieve and $50 \mathrm{~g}$ passing $2.36 \mathrm{~mm}$ sieve and retained on $1.18 \mathrm{~mm}$ sieve. The crushed samples were soaked in saturated lime solution and shaken for 7 days. The amount of alkalis released from the concrete chunks to the host lime solution was calculated and reported as percent of the Portland cement mass. It was believed that the cement used was 360 $\mathrm{kg} / \mathrm{m}^{3}$ and the density of concrete is $2359 \mathrm{~kg} / \mathrm{m}^{3}$. Chunks of concrete obtained from low and high deteriorated barriers were tested and the results reported are the average of three samples as shown in Figure 4.109. Sample calculations and results of this test are provided in Appendix E.

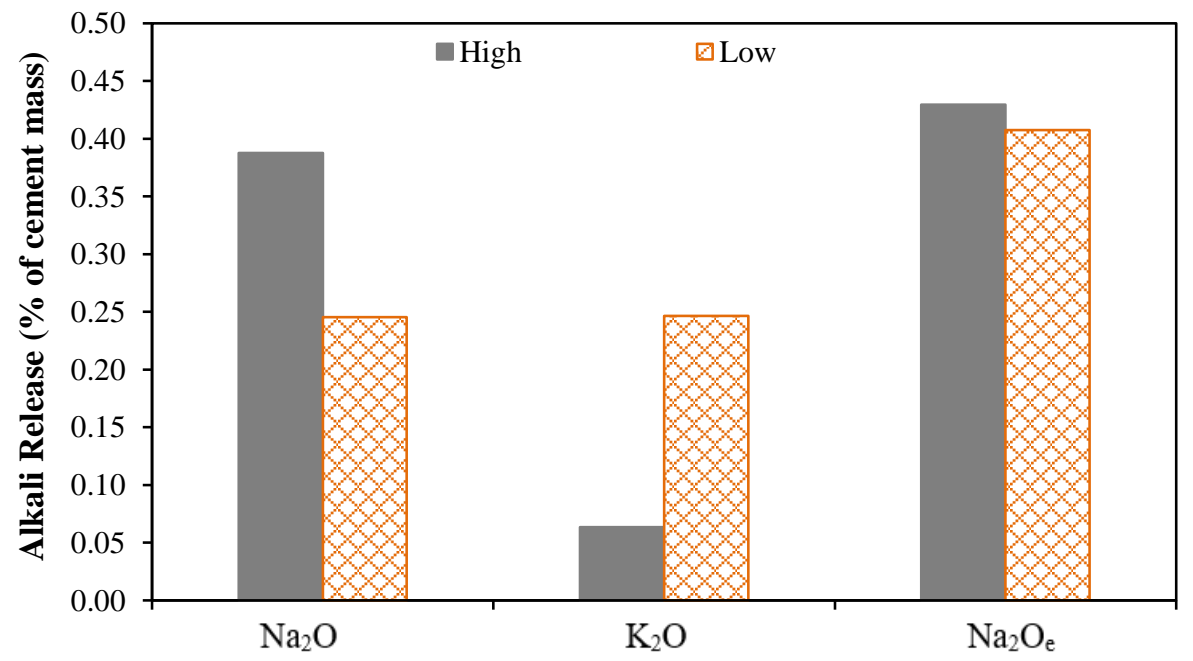

Figure 4.109: Released alkalis from concrete chunks to saturated lime solution 
The total $\mathrm{Na}_{2} \mathrm{O}_{\mathrm{e}}$ released from the concrete chunks obtained from the high and low deteriorated barriers were the same with $0.43 \%$ and $0.41 \% \mathrm{Na}_{2} \mathrm{O}_{e}$, respectively. Looking closely at the values, the low deteriorated concrete chunks had four times more $\mathrm{K}_{2} \mathrm{O}$. However, the $\mathrm{Na}_{2} \mathrm{O}$ in the high deteriorated samples $(0.388 \%)$ is higher than that of the low deteriorated ones $(0.246 \%)$. The high $\mathrm{Na}_{2} \mathrm{O}$ content of chunks with high deterioration level could not be completely from the cement since a typical $\mathrm{Na}_{2} \mathrm{O}$ content of $\mathrm{PC}$ in Ontario is around $0.24 \%$. In addition, Sudbury aggregate could contribute to the alkali release during their service life. However, Sudbury was found to release more $\mathrm{K}_{2} \mathrm{O}$ compared to $\mathrm{Na}_{2} \mathrm{O}$. Hence, the high alkali content is likely to be attributed to the alkalis from de-icers. This was more visible in the high deteriorated samples confirming that diffusion of alkalis into the barriers (from which the concrete chunks were taken) is easier due to the availability of more cracks. The results obtained confirm the ones from the DRI which showed that both cores are undergoing the same level of deterioration. The $\mathrm{NaCl}$ from sodium chloride deicer salt could have been converted into $\mathrm{NaOH}$ which contributes into the formation of ASR gel (Bérubé and Frenette, 1994).

\section{Predicting Residual Expansion}

Expansion of cores under laboratory conditions at 4 months and that of the barriers in field at 3.5 years were compared and the results are shown in Figure 4.110. Due to the accelerated conditions in the lab, the expansion obtained with the cores at 4 months took 3.5 years to be reached under field exposure due to ASR in addition to other deterioration mechanisms such as freezing and thawing. The expansion of the cores in the lab was 10.5 times faster than the barriers expansion. 


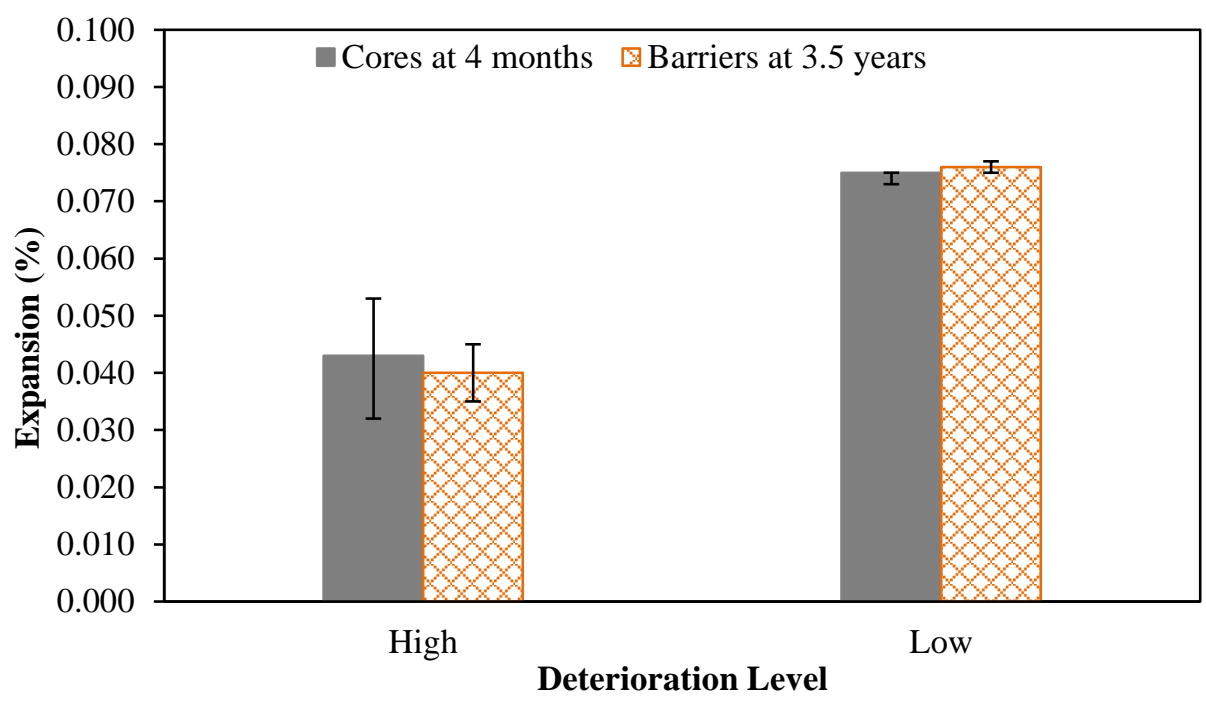

Figure 4.110: Comparison of expansion between the bridge barriers and the extracted cores

However, it should be noted that the cores' expansion after 26 weeks above water ceased (Figure 4.104) as compared to the bridge barriers which are still showing an increase in expansion in the field (slope in Figure 4.101 is still steep). This confirms that the alkalinity in the bridge barriers is still above 0.46 M (found from Section 4.4.1 to be the minimum level required to sustain expansion) allowing for more residual expansion as opposed to the small size cores which leach more. Hence, it would be expected that the ultimate expansion in the field might be higher compared to the expansion obtained from the cores. It was shown by several studies that small samples leach more compared to larger size samples (Bérubé, Fournier and Côté, 2012; Lindgård et al., 2013; Sinno and Shehata, 2019). It could be concluded that measuring cores' expansion above water might not reflect the ultimate residual expansion under field exposure due to the excessive leaching in small size samples, specially that the cores could have been disturbed during extraction leading to the formation of more cracks. This will increase the leaching and will help in the gel dislocation causing less pressure. In addition, based on DRI investigation, measuring expansion in cores taken from structures might not be reflective of the real damage the structure is undergoing. The DRI showed that both barriers had same level of deterioration which was not reflected by the expansion results. Hence, it could be concluded that DRI study in addition to expansion measurements of the barriers are needed to evaluate the residual expansion in the field. The conditions of the structure should also be considered when evaluating residual expansion. Structures with open cracks may not show same level of damage as structures without open cracks despite similar level of reactivity. 


\subsubsection{Expansion of Concrete Containing RCA Produced from Bridge Panels}

Samples were cast with virgin Sudbury aggregate and RCA produced from the same bridge where the barriers were obtained and were compared to understand the effect of the alkali and reactive silica contents on potential expansion. Two mix designs were used with different cement contents: (1) standard mix with $420 \mathrm{~kg} / \mathrm{m}^{3}$ cement as specified in CSA A23.2-14A (2014) and (2) bridge mix which is believed to have $360 \mathrm{~kg} / \mathrm{m}^{3}$ cement content. The 1-year expansion results of cylinders are presented in Figure 4.111. Cylinders cast with RCA-L and RCA-H aggregates showed higher expansion than the concrete cast with virgin Sudbury aggregate with both the standard and the bridge mixes. This explains that the higher alkali content in samples cast with RCA aggregates coupled with the swelling of the existing gel - will lead to higher expansion (Piersanti et al., 2015).

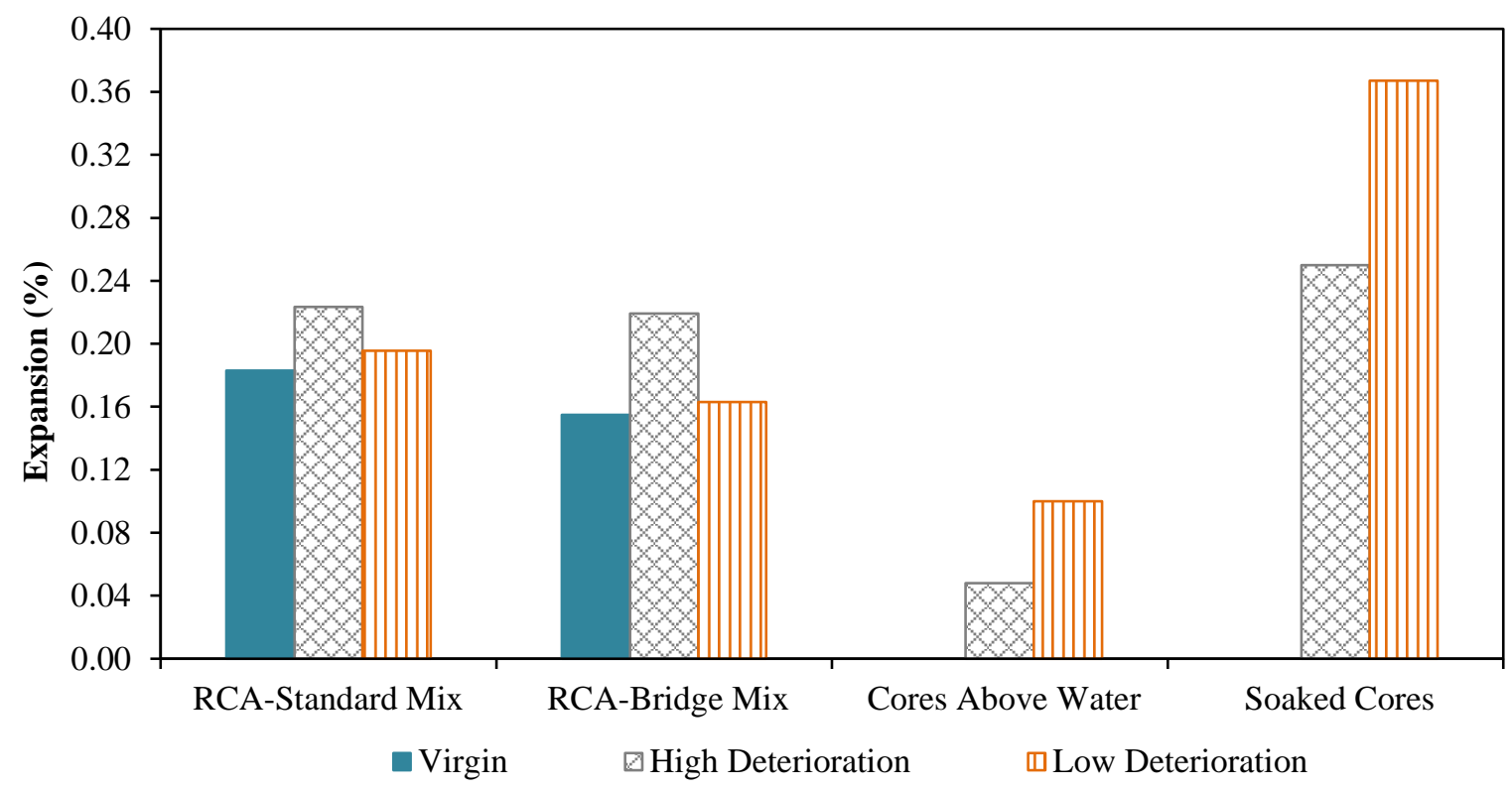

Figure 4.111: Expansion of concrete cylinders cast with Sudbury virgin and RCA samples

In addition, RCA samples showed higher expansion compared to the extracted cores stored under the same conditions - above water at $38^{\circ} \mathrm{C}$. This could be due to the higher cement content in samples cast with RCA in addition to the already present cracks in the extracted cores which will allow the gel to expand without exerting too much pressure. By exposing new surfaces in the RCA samples, more remaining silica will contribute as well to the high expansion. The samples cast with RCA aggregates and $1.25 \% \mathrm{Na}_{2} \mathrm{O}_{\mathrm{e}}$ showed lower expansion than cores soaked in $0.6 \mathrm{M}$ solution confirming that the non-exhausted supply of alkalis will lead to the observed difference in expansion. When abundant supply of alkalis is provided to the soaked cores, they showed 
intense expansion much higher than RCA samples with the same level of deterioration. This confirms that in the cores there is still remaining silica that did not react yet in both high and low deteriorated sample.

Concrete cast with RCA-L showed slightly lower expansion than concrete with RCA-H. This could be due to the existence of more gel in the high deteriorated samples. The exposure of new faces in the aggregates that did not react yet is another factor leading to high expansion although this is the case for high and low deteriorated samples (Piersanti et al., 2015). In addition, the increased alkalis from the de-icer salts as was shown previously could have led to the higher expansion observed in concrete cast with RCA-H. Similar trends were also obtained with the prisms samples as shown in Figure 4.112. The 1-year expansion results of the concrete prisms were obtained from Piersanti (2015).

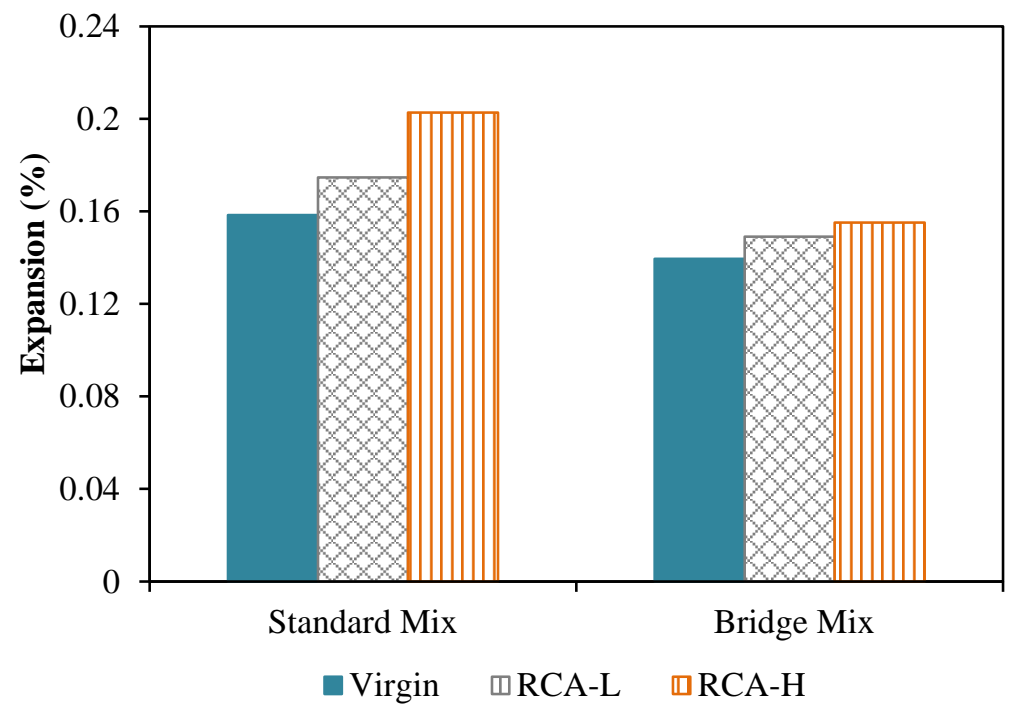

Figure 4.112: 1-year expansion of concrete prisms cast with Sudbury virgin and RCA samples The expansion after 1 year was monitored and results at 2 years are presented in Figure 4.113 for prisms and Figure 4.114 for cylinders using the standard mix. 


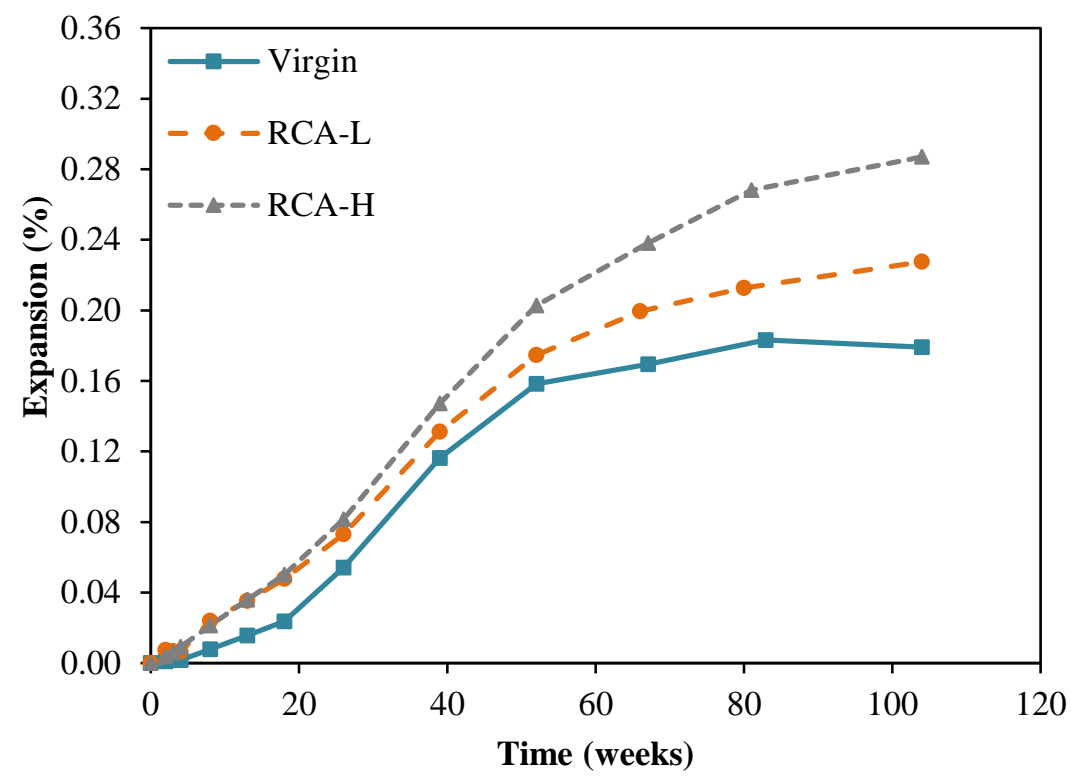

Figure 4.113: Expansion of prisms cast with Sudbury using the standard mix

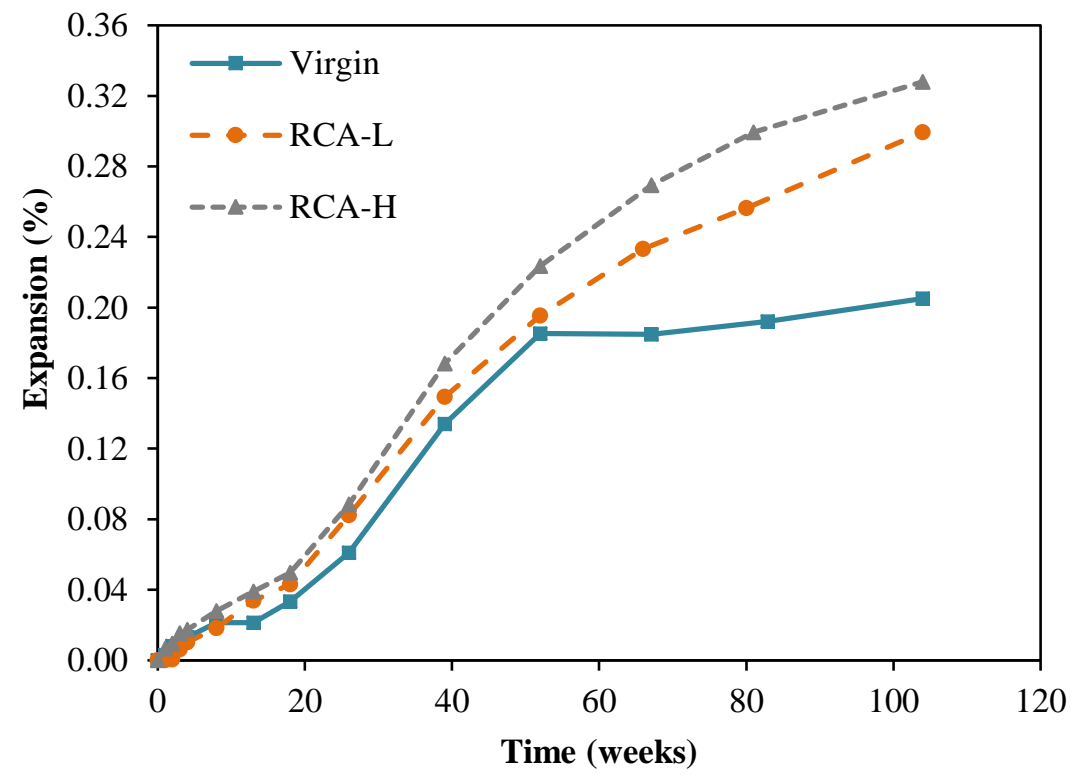

Figure 4.114: Expansion of cylinders cast with Sudbury using the standard mix

It is clear that with the standard mix, the samples cast with RCA aggregates are still showing expansion after 1 year as opposed to virgin samples which ceased expanding or its rate of expansion was lower than RCA samples. This could be attributed to the higher alkalinity in the pore solution of RCA samples taking more time to leach out. The trend was more clear with cylinders as compared to the prisms of higher surface area to volume ratio. The high pore solution alkalinity of RCA samples coupled with the reduced leaching in cylinders compared to prisms will 
lead to the continued expansion in the cylinders cast with RCA. Similar trend was observed with the bridge mix as shown in Figure 4.115 and Figure 4.116 but was not very clear as the standard $\operatorname{mix}$.

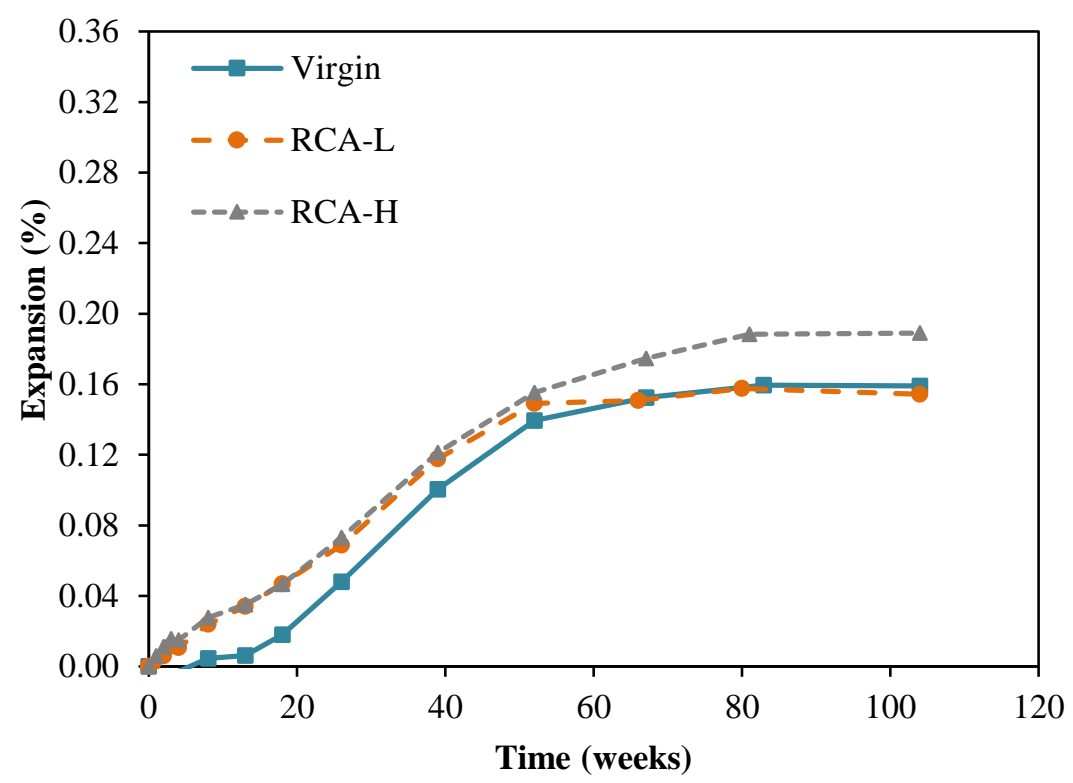

Figure 4.115: Expansion of prisms cast with Sudbury using the bridge mix

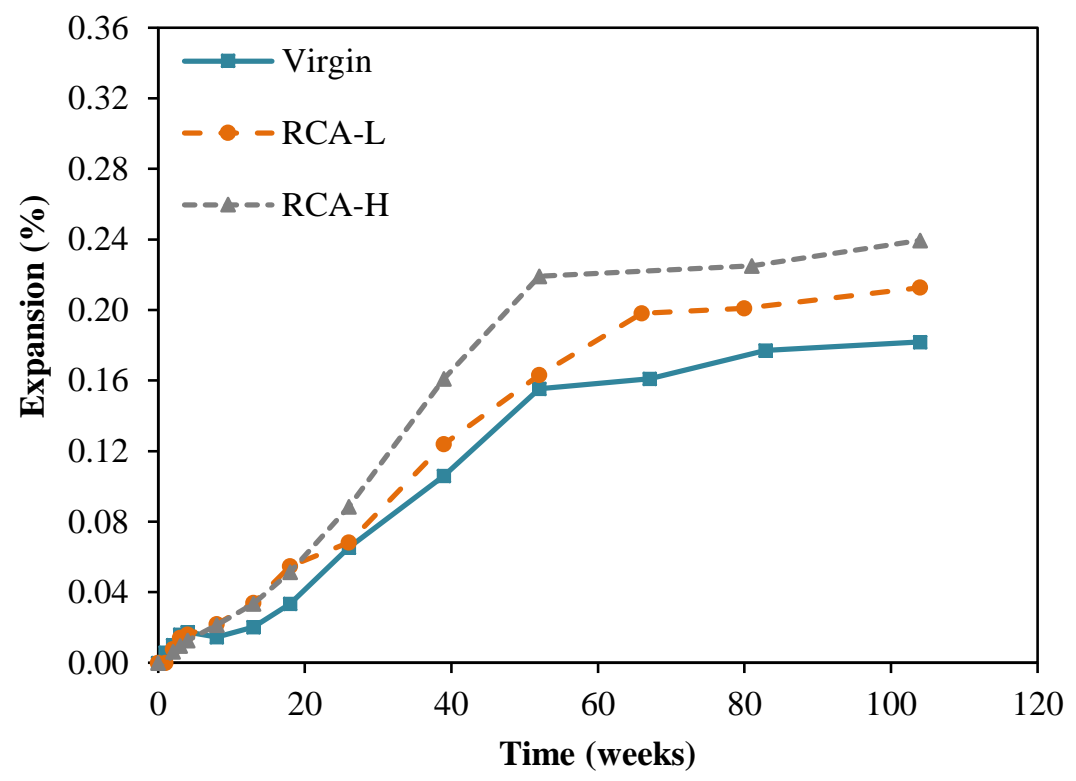

Figure 4.116: Expansion of cylinders cast with Sudbury using the bridge mix 


\subsubsection{Applicability of Sample Geometry on Recycled Concrete Aggregate}

The expansion of cylinders cast with RCA was higher than that of the prisms due to the larger cross-section of the $100 \mathrm{~mm}$-cylinders compared to the standard $75 \mathrm{~mm}$-prism. The alkalis will take more time to be leached out in the cylinders compared to the prisms. The lower surface area to volume ratio of the cylinders (0.05) compared to the prisms $(0.06)$ reduced the amount of leaching in the cylinders. The expansions of prisms and cylinders were compared at 1 year as shown in Figure 4.117.

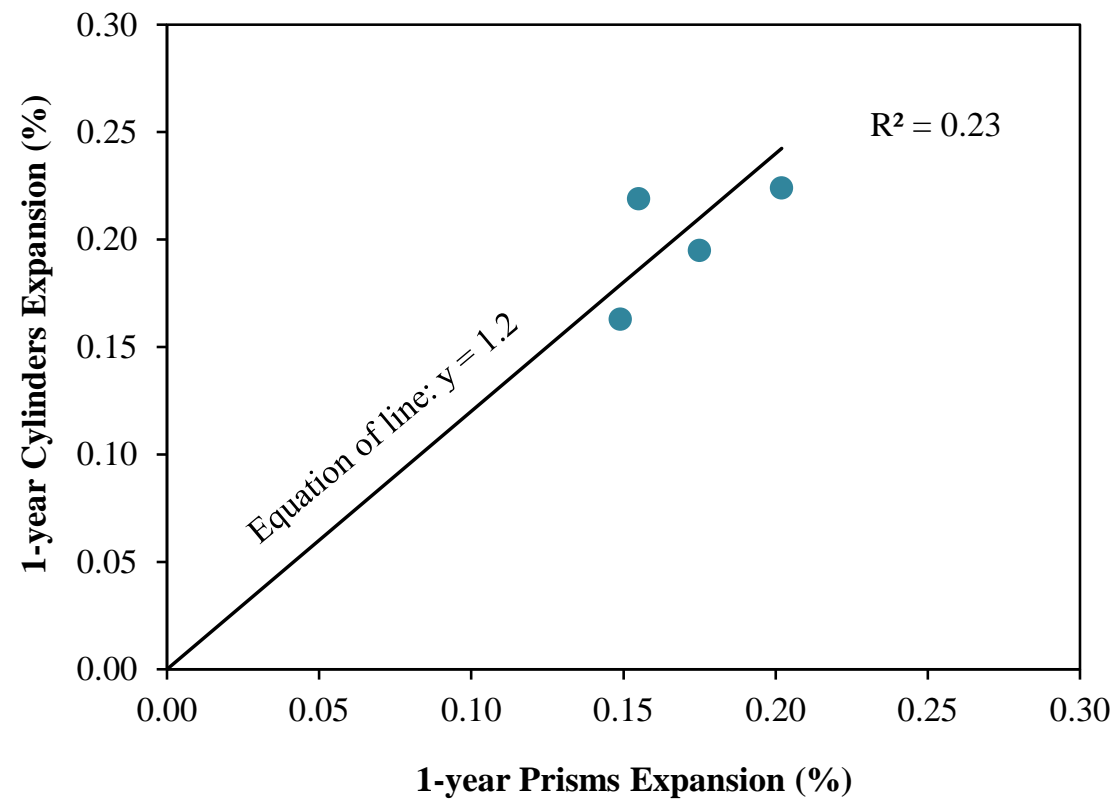

Figure 4.117: 1-year expansion of prisms and cylinders cast with Sudbury RCA

The expansions of cylinders and prisms do not seem to show good correlation at 1 year. As opposed to virgin aggregates, when Sudbury and Spratt cylinders are compared to the prisms at $1.25 \%$ $\mathrm{Na}_{2} \mathrm{O}_{e}$, the 1-year expansions were higher than that of the prisms by a ratio of 1.28 . This expansion ratio corresponds to the surface area to volume ratio of standard 75-mm prisms to cylinders ( $\varnothing 100$ by $285 \mathrm{~mm}$ ). In the case of RCA samples, the surface area to volume ratio of standard prisms to cylinders ( $\varnothing 100$ by $200 \mathrm{~mm}$ ) is 1.2. However, no correlation was obtained as was shown in Figure 4.117. The 2-year expansions of prisms and cylinders were compared and results are shown in Figure 4.118 showing good correlation $\left(\mathrm{R}^{2}=0.91\right)$. The ratio of expansion between cylinders and prisms is similar to that of the surface area to volume ratio of prisms to cylinders (1.2). 


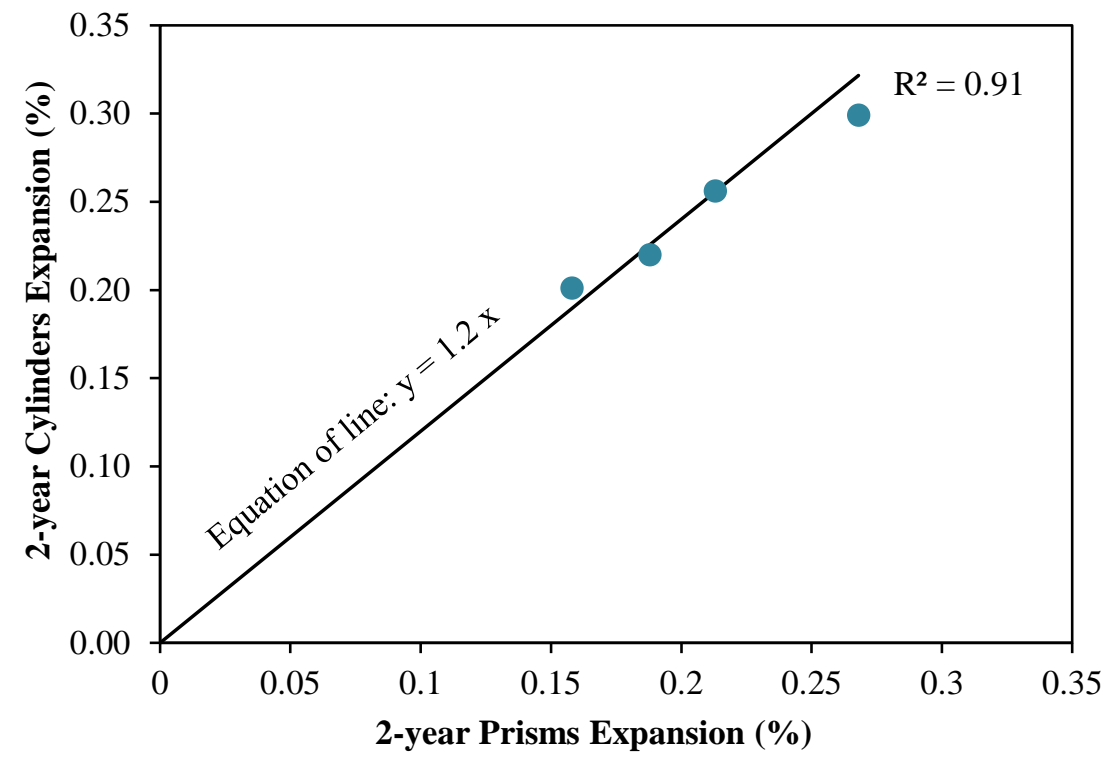

Figure 4.118: 2-year expansion of prisms and cylinders cast with Sudbury RCA

At 1 year, the difference in expansion between prisms and cylinders obtained from the same mix was not significant. However, after 1 year, the cylinders continued to expand at a faster rate compared to prisms. Hence, with RCA, more time was needed to show the difference in expansion between prisms and cylinders as opposed to virgin samples which was shown by 1 year. This could be due to the higher amount of paste in RCA samples leading to a higher initial alkalinity causing similar expansion until significant amount of leaching had occurred specially with the smaller size samples - prisms - to start showing the difference in expansion. 


\subsection{Evaluating the Potential Alkali-Silica Reactivity of Mineral Fillers}

The purpose of this section is to study the effect of filler size and replacement level on the expansion due to ASR using the AMBT and the CPT. In addition, this research focuses on adapting and adopting the current accelerated mortar bar test to evaluate reactivity of mineral fillers. Based on the obtained results, modifications to the standard tests are suggested since there is no current test methods available to study the potential reactivity of fillers.

\subsubsection{Effect of Replacement Level on Workability of Mortars}

Samples with carbonate filler (CF) at 10, 15, 20, 30 and 100\% replacement levels taken from the finest portion of sand 1 were tested to check the effect of fillers addition on workability of mortars. The results obtained are presented in Figure 4.119.

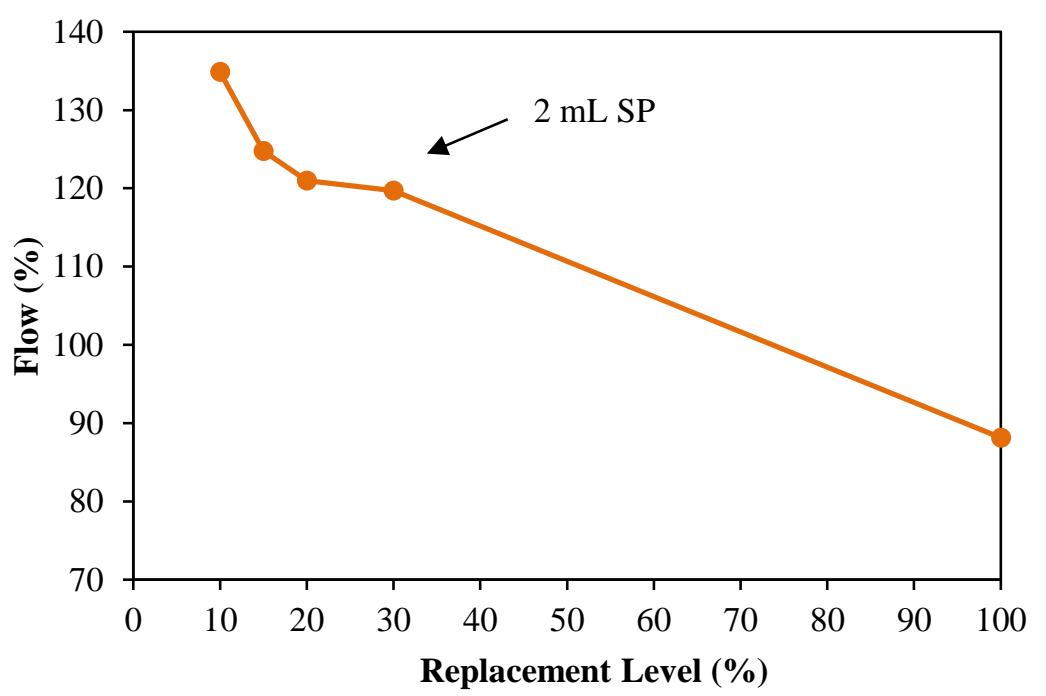

Figure 4.119: Flow results of sand 1 with different replacement levels of CF taken from sand finest portion

As shown in the figure, there is a decrease in workability of mortars with the increase of the mineral filler replacement level. Similar results were observed with sand 2 except that sand 2 is finer having a higher fineness modulus leading to a lower flow compared to the same samples cast with sand 1. Similar trend was obtained with the other mineral fillers.

\subsubsection{Effect of Replacement Method on Workability of Mortars}

Non-reactive sand samples (sand 2) cast with carbonate, carbonate silica and SH fillers at $20 \%$ replacement level from the sand finest portion and from total graded sand were cast and flow was 
analyzed to understand the effect of different replacement methods on workability. Figure 4.120 shows the flow results obtained from the two different replacement methods.

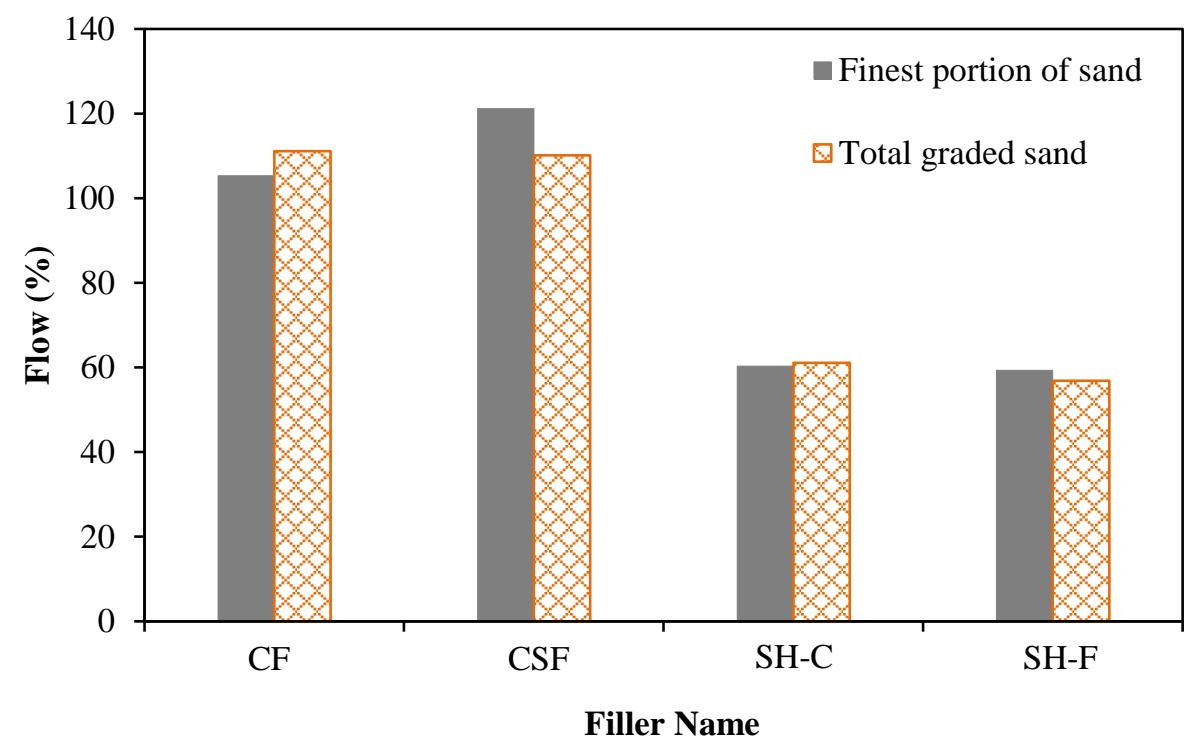

Figure 4.120: Comparison of flow results between the two different replacement methods of fillers at $20 \%$ replacement level

As shown in the figure, the difference in workability was very minimal between the two methods. A maximum difference of $11 \%$ between the two methods was observed for samples with carbonate silica filler. It can be concluded that both methods had the same effect on the flow of mortars. Similar results were obtained for the carbonate silica filler tested with sand 1.

From another side, as Figure 4.120 indicates, there is a difference between workability of samples with carbonate, carbonate silica and SH fillers. The flow of samples with carbonate and carbonate silica fillers are between $100 \%$ and $120 \%$. However, for the SH filler samples, it is much lower with around $60 \%$ for both SH-C and SH-F fillers. This might be due to the difference in fillers' sizes. The maximum size of SH filler was smaller than $75 \mu \mathrm{m}$. However, carbonate silica filler had $30 \%$ of its sample with material coarser than $75 \mu \mathrm{m}$ as shown in the gradation curve in Figure 3.2. Hence, with smaller size mineral fillers, the decrease in workability compared to control samples is more evident. Although the workability of SH filler samples was low, it was still possible to place the samples in their molds and compact them in a similar way to other samples. Coarser gradation of the SH-C (SH-C-70\% passing $75 \mu \mathrm{m}$ ) was also tested and its flow $(89.1 \%$ ) was higher compared to the SH-C-100\% passing $75 \mu \mathrm{m}(60.4 \%)$ at $20 \%$ replacement level. 


\subsubsection{Effect of Replacement Method on Mortars Expansion}

The replacement methods of mineral fillers might have a different impact on expansion. 10\%, 15\% and $20 \%$ replacement levels from both sands by carbonate silica filler were tested using the AMBT for the two replacement methods. The results are shown in Figure 4.121 and Figure 4.122 for sand 1 and Figure 4.123 and Figure 4.124 for sand 2. The presented results are obtained by taking the average of three samples. The testing duration was extended to 56 days to see the behavior of fillers not only at 14 days as per CSA A23.2-25A (2014). The reasons for extending the testing duration will be explained in more details later.

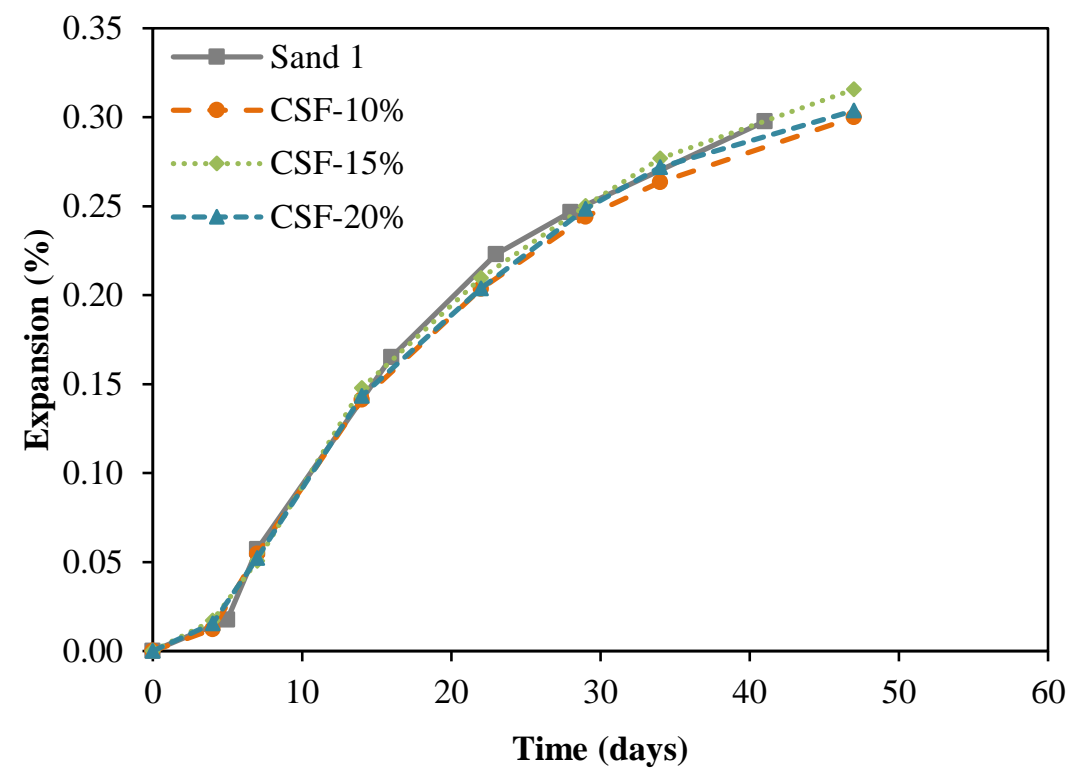

Figure 4.121: Expansion of sand 1 with CSF at different replacement levels taken as percent from finest portion 


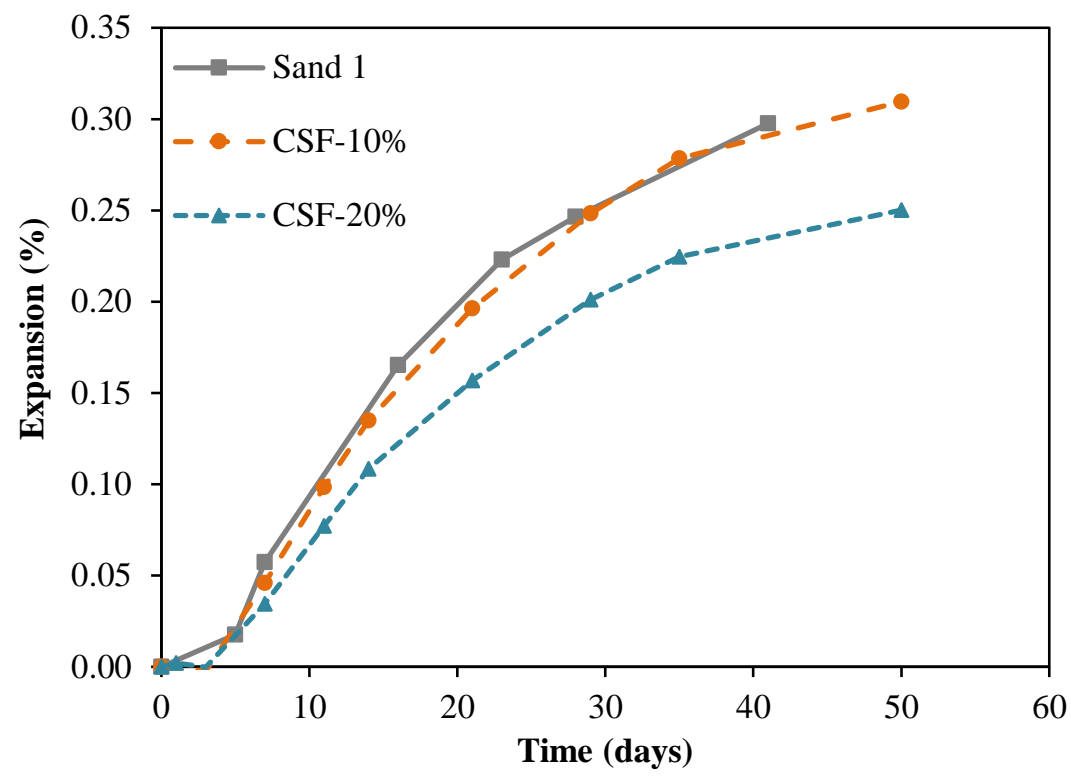

Figure 4.122: Expansion of sand 1 with CSF at different replacement levels taken as percent from total graded sand

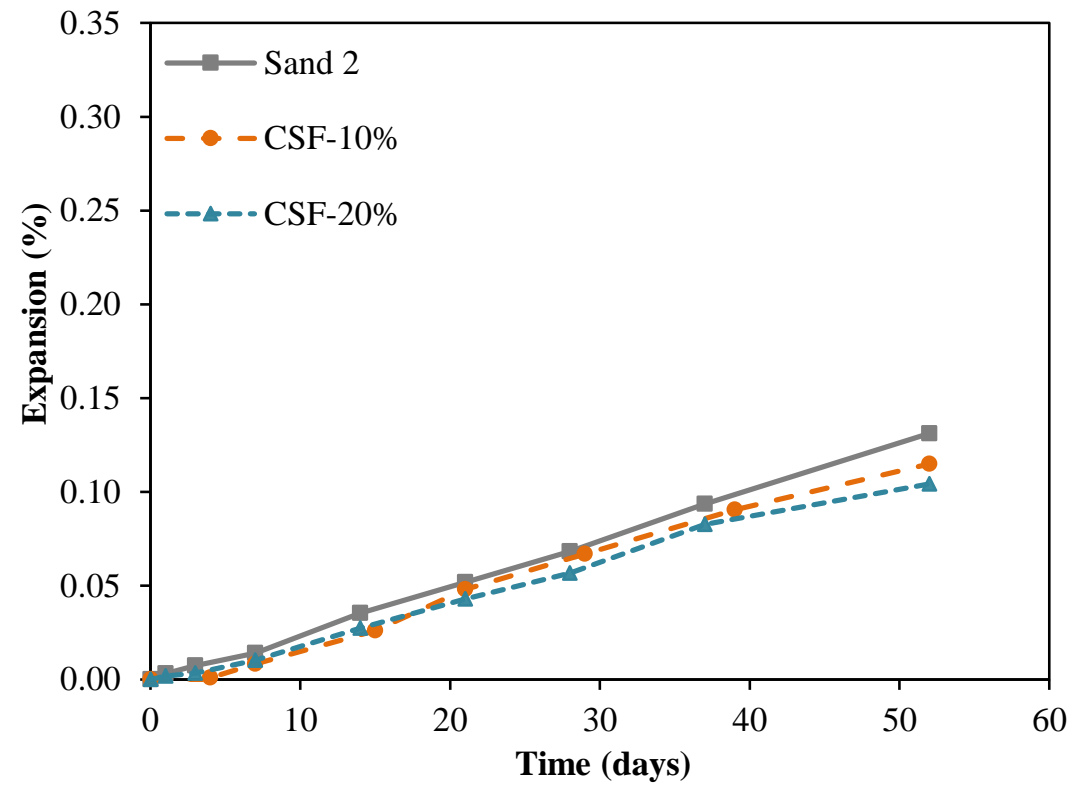

Figure 4.123: Expansion of sand 2 with CSF at different replacement levels taken as percent from finest portion 


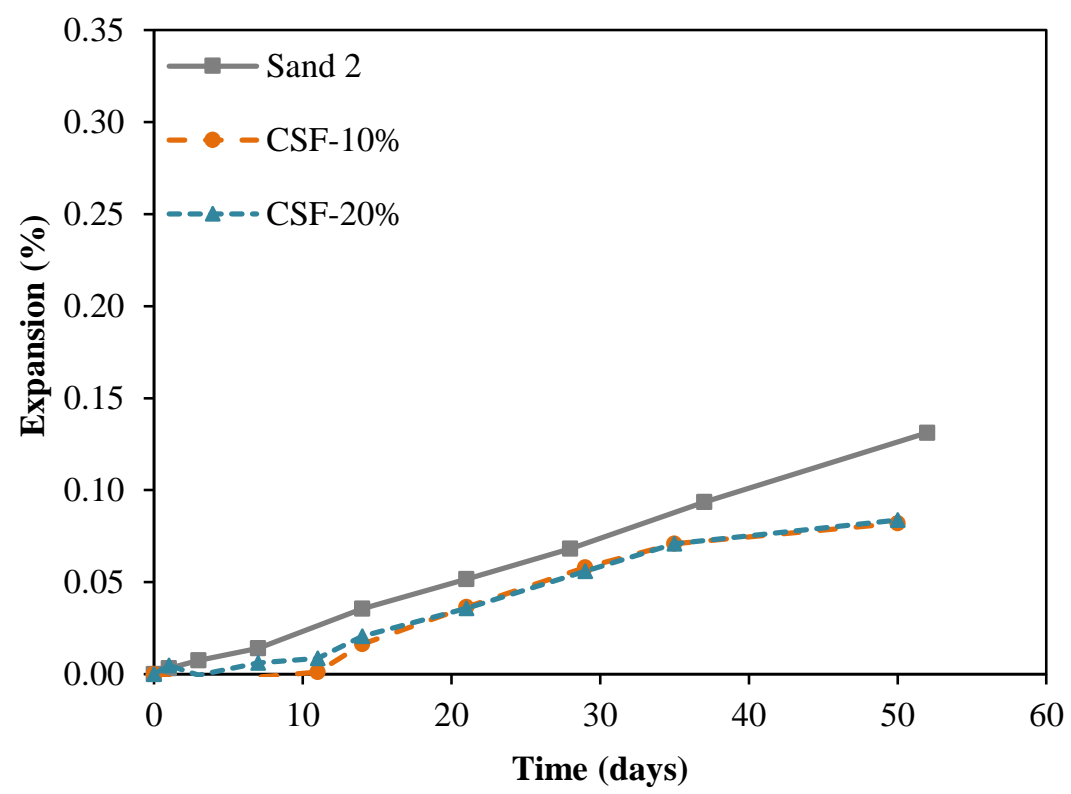

Figure 4.124: Expansion of CSF at different replacement levels taken as percent from total graded sand 2

As shown in the above figures, at $80^{\circ} \mathrm{C}$, sand 1 is a reactive sand when tested using the AMBT showing an expansion (0.17\%) higher than $0.15 \%$ at 14 days as opposed to sand 2 , non-reactive sand, with an expansion of $0.04 \%$. The expansion of the samples with carbonate silica filler at $10 \%, 15 \%$ and $20 \%$ taken from sand finest portion were the same as the control sample as shown in Figure 4.121. However, in Figure 4.122, when replacing the total graded sand with 20\% carbonate silica filler, the expansion was lower than the control with a value of $0.24 \%$ for the carbonate silica filler sample and $0.30 \%$ for the control at 41 days. The difference obtained between the two samples $(0.06 \%)$ is outside the acceptable range of the within-laboratory precision stated in ASTM C1260 (2014) which specifies that it should be lower than 8.3\% of the mean expansion $(8.3 \% * 0.27 \%=0.02 \%)$. This difference in expansion between the two methods might be due to the fact that the finest portion of the sand has lost reactivity as compared to the particles of larger sizes. Thus, when replacing from the finest portion, the reactivity of the sample is probably not affected as compared to the replacement from the total graded sand. In this method, sand is being removed from the larger size aggregates as well, which perhaps are more responsible for the expansion. The same behavior was observed with sand 2 (Figure 4.123 and Figure 4.124). However, the difference was not that clear since the sand is non-reactive. The same behavior was observed with samples containing SH filler as will be shown in next section. 


\subsubsection{Reactivity of Mineral Fillers}

For testing mineral fillers reactivity, the non-reactive sand 2 was used to obtain more representative results. An aggregate is deemed reactive when an expansion of $0.150 \%$ is obtained at 14 days as per CSA A23.2-27A (2014). For siliceous limestone aggregate from St. Lawrence Lowlands, a lower expansion limit of $0.100 \%$ is recommended (CSA A23.2-27A, 2014). For testing reactivity of mineral fillers, an expansion limit of $0.100 \%$ is used.

\section{Carbonate Filler}

The mineral fillers studied are obtained from different sources, i.e. they might have different reactivity and thus expansion. The carbonate filler is known to be non-reactive since it does not contain silica. Figure 4.125 present the expansion results of the carbonate filler with sand 2 confirming the non-reactivity of the carbonate filler.

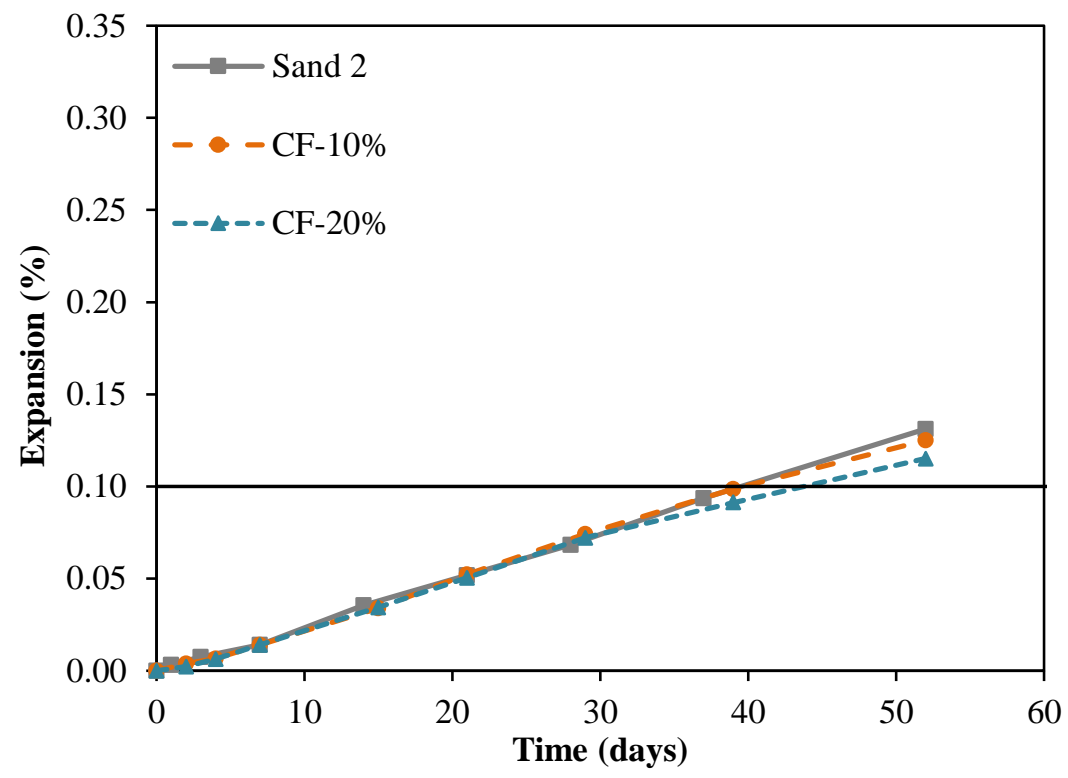

Figure 4.125: Expansion of sand 2 with CF at different replacement levels taken as percent from finest portion

The carbonate filler and the carbonate silica filler did not show any expansion higher than control sand 2. Although carbonate silica filler has $23 \%$ silicate materials, however it did not show any expansion higher than the control samples with sand 2. This suggests that maybe the filler is not reactive or has lost reactivity when grinded to its small size. 


\section{Springhill Filler}

Since coarse and fine aggregates from the same source might have different effect on ASR expansion, $\mathrm{SH}$, from coarse and fine aggregates, were crushed separately to test the effect of mineral fillers from each fraction (coarse or fine) on expansion. The expansion results of the $\mathrm{SH}$ C and SH-F fillers at 20\% replacement level are reported in Figure 4.126. The size of the filler is smaller than $75 \mu \mathrm{m}$.

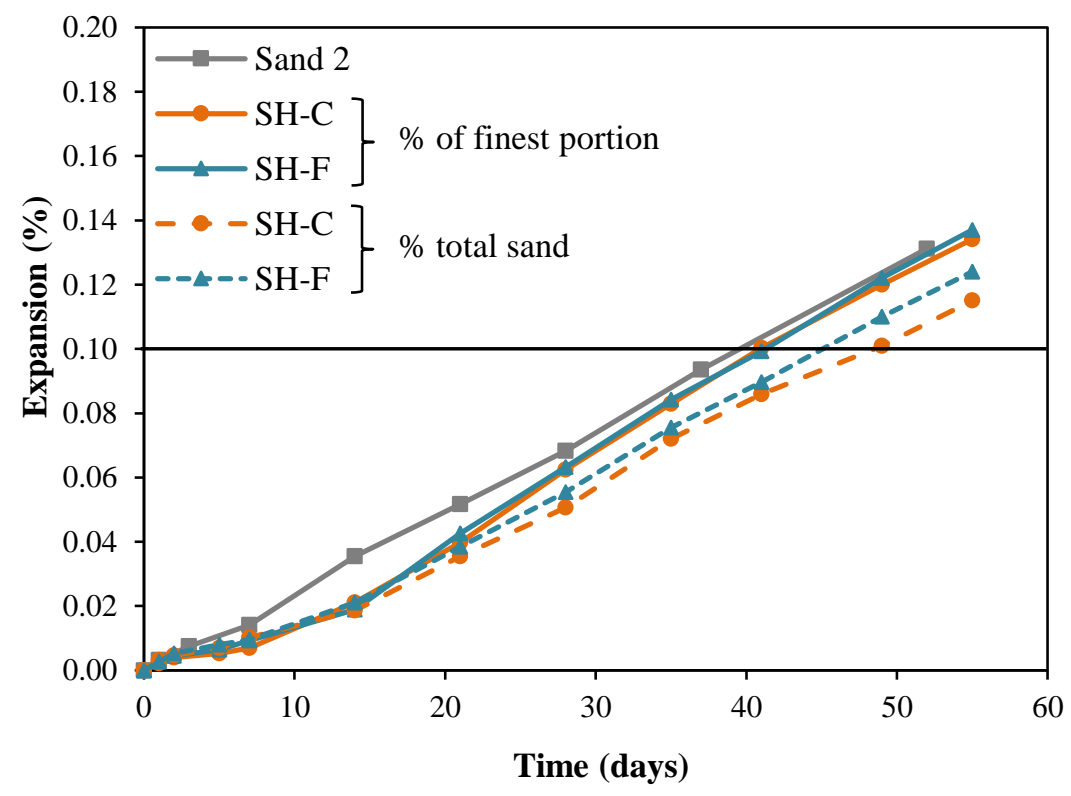

Figure 4.126: Expansion of sand 2 with $20 \%$ SH-100\% passing $75 \mu \mathrm{m}$

At 56 days, the expansions of SH-C and SH-F fillers with the same replacement method are similar as shown in Figure 4.126 suggesting that they have same reactivity. When compared to the nonreactive sand 2, the samples with fillers replaced from total graded sand showed slightly lower expansion compared to the other replacement method as expected (Section 4.6.3). In addition, the SH samples with $20 \%$ replacement level from both methods did not show any expansion higher that the non-reactive sand. This finding was not expected since the SH filler was obtained from an extremely reactive aggregate. The reactivity of SH filler is still not clear whether the filler has lost reactivity when ground to passing $75 \mu \mathrm{m}$.

To investigate whether or not the materials passing $75 \mu \mathrm{m}$ of Springhill has a pozzolanic reactivity, a sample of Spratt aggregate with $20 \%$ SH-C filler was tested. The expansion results are presented in Figure 4.127. 


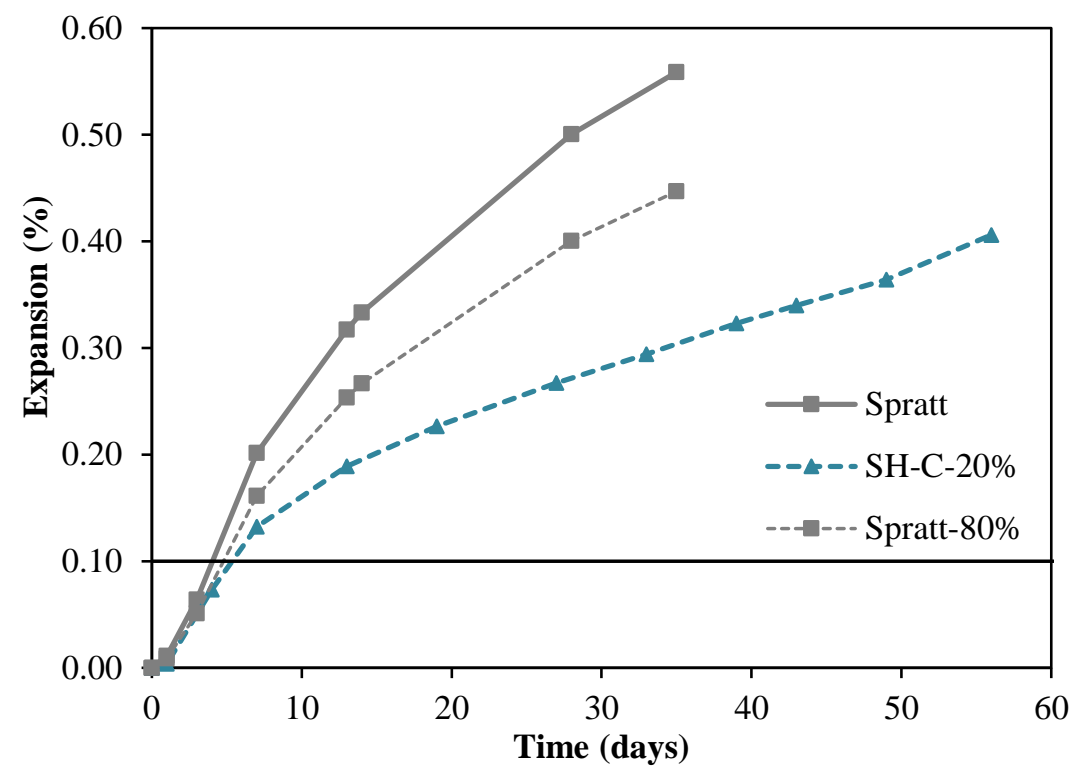

Figure 4.127: Expansion of Spratt with $20 \%$ SH-C-100\% passing $75 \mu \mathrm{m}$ filler taken from total graded sand

The results show that the sample with SH-C filler (100\% passing $75 \mu \mathrm{m})$ had lower expansion than the control. Assuming that in case $80 \%$ of the Spratt sample was considered, the expansion will be reduced to $0.45 \%(80 \% * 0.56 \%)$ at 35 days, it will still be higher than the Spratt sample with $20 \%$ SH-C $(0.32 \%)$ suggesting that the SH-C filler might be pozzolanic. However, this decrease in expansion might be due to the mere fact that the sample with SH-C had 20\% less of Spratt reactive aggregate.

SH samples with different gradation, $70 \%$ passing $75 \mu \mathrm{m}$ and $30 \%$ passing $150 \mu \mathrm{m}$ and retained on $75 \mu \mathrm{m}$ sieve, were tested. This size is selected to have a gradation similar to commercial mineral fillers available in the market. This will enable a better prediction of reactivity of mineral fillers produced from reactive stones. Samples with this gradation were cast at 10\% and 20\% replacement levels taken from sand finest portion and expansion results at 14 days are shown in Figure 4.128 for the two different gradations. It should be noted that the replacement level was taken from the finest portion of sand since higher expansion could be obtained compared to replacement taken from the total graded sand due to the reasons that were explained above (Section 4.6.3). 


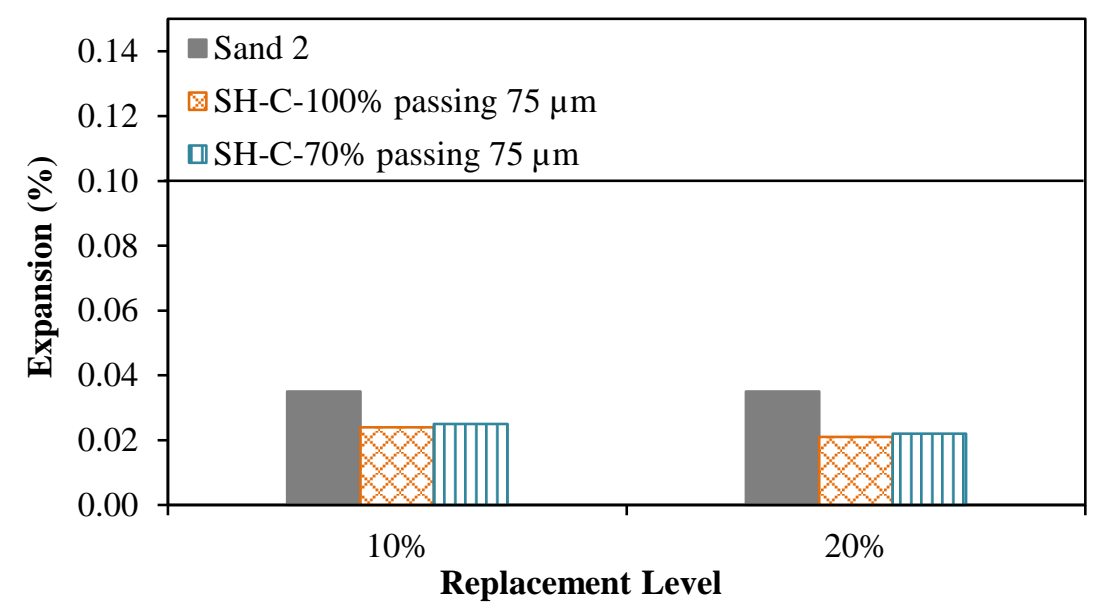

Figure 4.128: Expansion of sand 2 with $\mathrm{SH}$ filler at 14 days

The filler obtained from Springhill reactive aggregate did not show any expansion higher than the non-reactive sand 2 at 14 days. The filler with both gradations had an expansion below $0.10 \%$ limit specified at 14 days. Similarly, at 28 days, the only sample that showed an expansion higher than $0.10 \%$ was sand 2 cast with SH-C-70\% passing $75 \mu \mathrm{m}$ at 20\% replacement level with an expansion of $0.11 \%$ as shown in Figure 4.129. Measurements were taken up to 56 days as shown in Figure 4.130 .

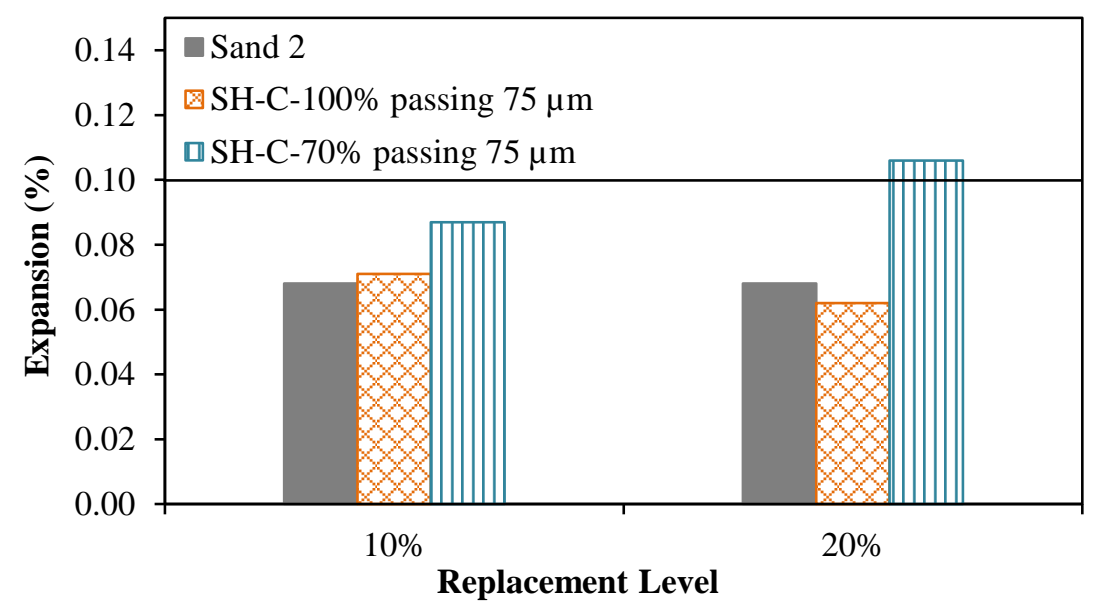

Figure 4.129: Expansion of sand 2 with $\mathrm{SH}$ filler at 28 days 


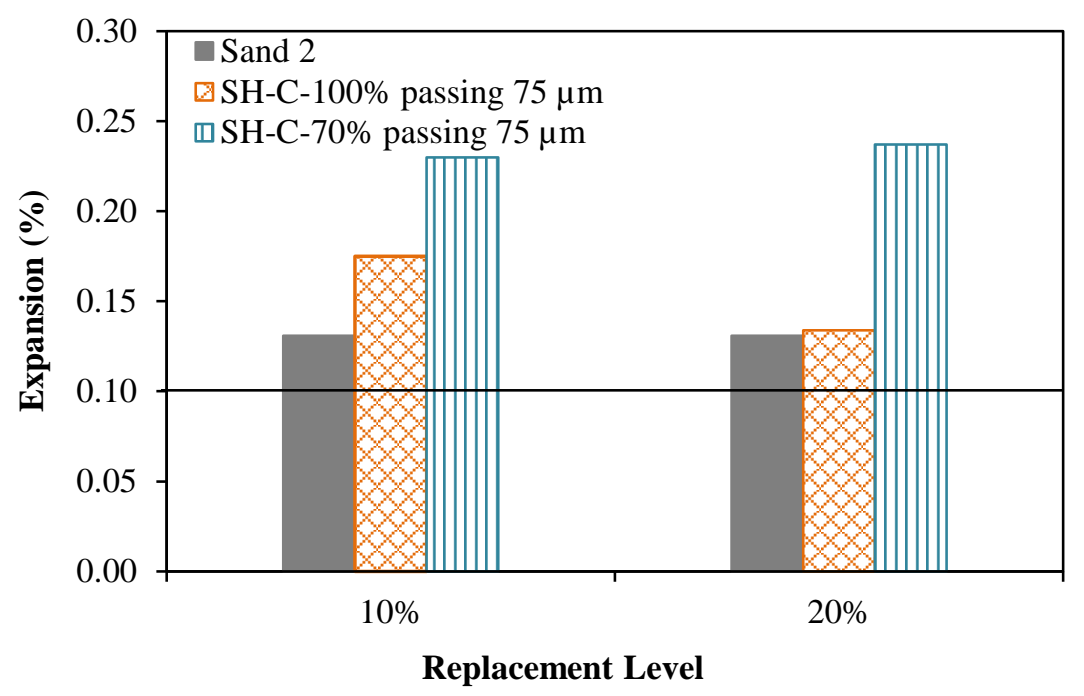

Figure 4.130: Expansion of sand 2 with $\mathrm{SH}$ filler at 56 days

For the filler finer than $75 \mu \mathrm{m}$ at $20 \%$ replacement level, no expansion higher than the non-reactive sand was observed. However, with the same filler but coarser gradation, an expansion of $0.24 \%$ compared to $0.13 \%$ for the non-reactive sand was obtained at 56 days. The difference in expansion between the same filler with different gradations might be due to the fact that the larger surface area might result in very low disruptive expansion or it might slow the expansion due to the required large amount of alkalis needed to trigger the expansion. The latter reason could be the explanation of why the expansion took place at later age. Moreover, the reduced permeability due to the filler's fine size might hinder the alkalis in solution to reach inside the core blocking further expansion.

At $10 \%$ replacement level, the expansion of both coarse and fine filler was higher than the nonreactive sand 2. However, the expansion of the finer filler at $10 \%$ replacement level, was lower than the coarse filler at the same replacement level. This might also be due to the reduced permeability. It should be noted also that the expansion of the SH filler with $100 \%$ passing sieve $75 \mu \mathrm{m}$ was higher at $10 \%$ replacement level compared to $20 \%$ replacement level. This could help explaining that at higher replacement level, the permeability of the sample is reduced more hindering the expansion.

The behavior of reactive fillers is not clearly understood yet. Thus, more testing should be done to evaluate the reactivity of $\mathrm{SH}$ filler using the concrete prism test which is a more reliable test 
method. It should also be stated that testing beyond 14 days was required to see expansion in mortar bar samples with mineral filler.

In order to better understand whether the filler either lost reactivity when grinded to small size, or its permeability was reduced due to the addition of the filler, concrete prisms were tested using the concrete prism test as will be explained in Section 4.6.5. In CPT, the alkalinity of the cement is increased to $1.25 \% \mathrm{Na}_{2} \mathrm{O}_{\mathrm{e}}$ and $\mathrm{NaOH}$ pellets are added while mixing as opposed to the AMBT. In the latter, the silica will react with the alkalis coming from an external source i.e., the host soaking solution which might take more time to reach the core of the samples depending on its permeability. Hence, testing using the CPT will give an indication of whether the observed expansion with the AMBT are due to reduced permeability or to the large amount of alkalis needed to trigger the expansion in samples cast with mineral fillers.

\subsubsection{Concrete Prism Test on Mineral Fillers}

Concrete prisms were cast using SH-C obtained from the coarse Springhill aggregate. Two gradations were tested using the CPT. SH-C-70\% passing $75 \mu \mathrm{m}$ was tested at 5, 10 and $20 \%$ replacement levels and SH-C-100\% passing $75 \mu \mathrm{m}$ was cast at $10 \%$ replacement level. The expansion results of the concrete prisms with $\mathrm{SH}-\mathrm{C}$ using the two gradations are presented in Figure 4.131.

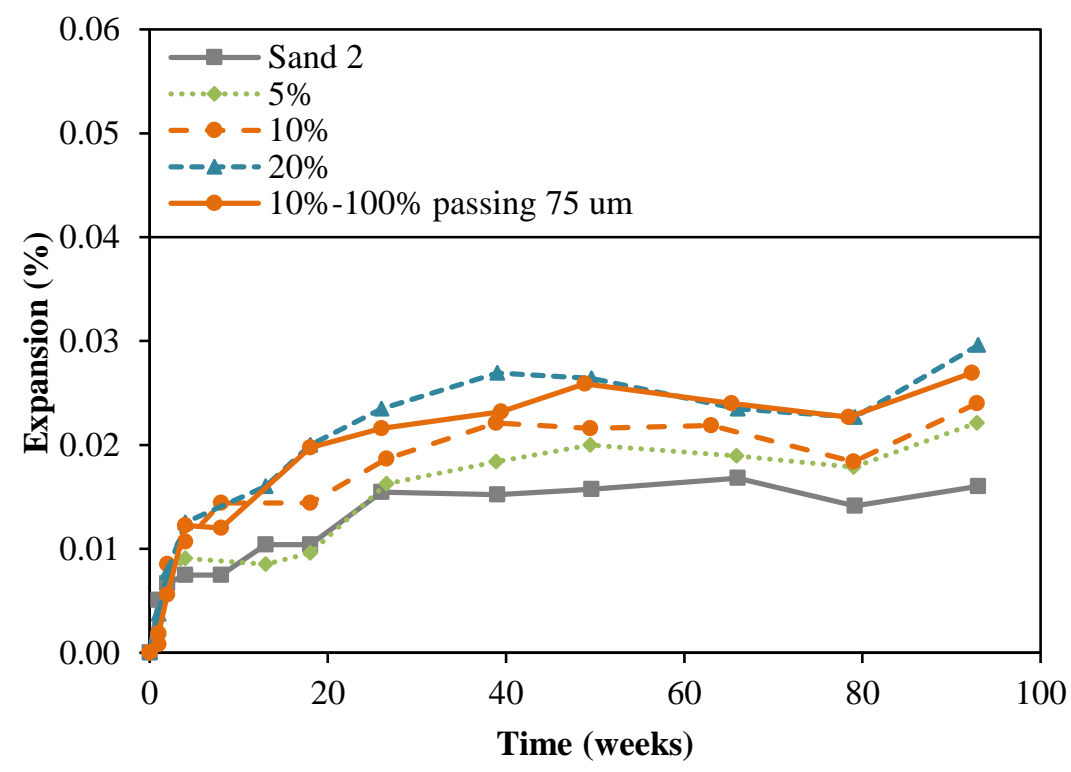

Figure 4.131: CPT expansion of $\mathrm{SH}$ at different replacement levels 
Prisms cast with SH filler expanded slightly higher than the non-reactive sand 2 but the expansion was still lower than $0.040 \%$ at 2 year with the highest expansion of $0.023 \%$ for the SH-C-70\% passing $75 \mu \mathrm{m}$ at $20 \%$ replacement level and SH-C-100\% passing $75 \mu \mathrm{m}$ at $10 \%$ replacement. If this filler was used in a concrete cast with an aggregate that has a marginal expansion below $0.040 \%$, the samples might fail the concrete prism test.

In the case of the mortar bars, the reasons discussed that could lead to the observed low expansions were either due to the fact that (1) the reduced permeability will block the alkalis to reach the inside of the samples and/or (2) the high surface area of the filler will need very high alkali content to trigger expansion. When tested using the CPT, the alkalis were available inside the samples which might explain that the permeability is not the major factor leading to the low expansion with the SH-C fillers tested using the CPT knowing that the fillers are obtained from an extremely reactive aggregate. Despite the fact that permeability might not explain the low expansion observed in the CPT, however, it could slow the rate of expansion at early ages. This suggests that the pore solution alkalinity should be high enough to be able to trigger expansion due to the large surface area of the fillers.

The alkali leaching from concrete samples cast with SH-C filler at different replacement levels was tested and results are presented in Table 4.2 showing that with higher replacement level of fillers, the alkali leaching from the samples will be reduced. This is due to the increased surface area when higher filler content is added reducing permeability of the samples and thus reducing alkali leaching form concrete samples. The lowest alkali leaching (11\%) corresponds to the samples with SH-C-70\% passing $75 \mu \mathrm{m}$ at 20\% replacement level and SH-C-100\% passing $75 \mu \mathrm{m}$ at $10 \%$ replacement level. This explains the fact that they showed higher expansion compared to the rest of the samples with the CPT. In this case, the alkali content is reduced to $1.11 \% \mathrm{Na}_{2} \mathrm{O}_{\mathrm{e}}$ $(89 \% * 1.25 \%)$ after correcting for leaching. Hence, even with a pore solution alkalinity of $1.11 \%$, the samples were not able to show expansion higher than $0.040 \%$. 
Table 4.2: Alkalis leached from concrete with SH-C filler at 1 year (\% of total alkalis)

\begin{tabular}{ccc}
\hline Replacement Level (\%) & $\mathbf{7 0 \%}$ passing $\mathbf{7 5} \boldsymbol{\mu m}$ & $\mathbf{1 0 0 \%}$ passing $\mathbf{7 5} \boldsymbol{\mu m}$ \\
\hline \hline $\mathbf{0}$ & & 16 \\
\hline $\mathbf{5}$ & 15 & - \\
\hline $\mathbf{1 0}$ & 14 & 11 \\
\hline $\mathbf{2 0}$ & 11 & - \\
\hline
\end{tabular}

In the field, normally the alkalinity of the cement is around $1 \% \mathrm{Na}_{2} \mathrm{O}_{\text {e }}$ which means, it might not be an issue in real life if this filler was used since even with $1.11 \% \mathrm{Na}_{2} \mathrm{O}_{e}$, Springhill prisms were not able to show expansion higher than $0.040 \%$. Thus, the alkalinity of the cement used in structures is not high enough to cause expansion. However, external sources of alkalis and/or the release of alkalis from alkali-bearing aggregates could lead to an increase in alkali content in the concrete pore solution which should be taken into consideration in such cases (Dhir, Dyer and Tang, 2009; Heisig et al., 2016).

\subsubsection{Scanning Electron Microscopy Analysis}

SEM analysis was done on two different mortar samples: (1) carbonate silica filler, and (2) SH-C$70 \%$ passing $75 \mu \mathrm{m}$ both at $20 \%$ replacement level taken from finest portion of sand 2 . The carbonate silica sample did not show any sign of ASR gel. This could confirm that the silica might not be reactive or it has lost reactivity causing very low disruptive expansion when grinded to this small size. For the Springhill filler, pictures of ASR gel obtained from SEM analysis are shown in Figure 4.132. 

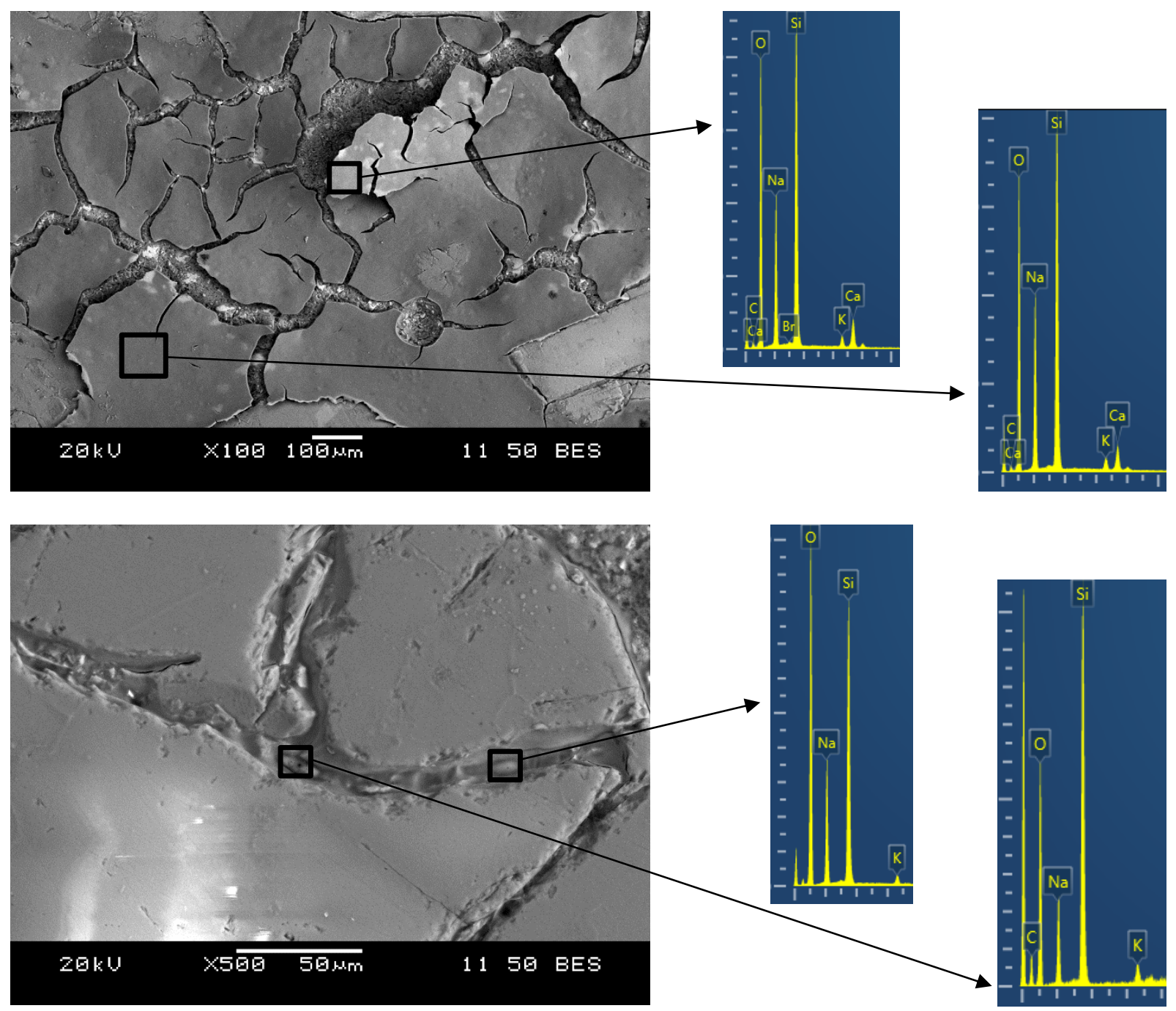

Figure 4.132: SEM Analysis of SH-C-70\% passing $75 \mu \mathrm{m}$ at $20 \%$ replacement level from sand finest portion

The observed ASR gel in SH-C filler suggests that fillers obtained from reactive aggregates could still show expansion if enough alkalis are provided. Due to the ample supply of alkalis in the AMBT, expansion higher than the non-reactive sand 2 was obtained for the samples with coarser SH filler; however, the duration of the test was increased to 56 days instead of the specified 14 days in the standard. This was needed since due to the reduced permeability of the samples, the alkalis will take more time to reach the core of the samples and hence the expansion was observed at later age. In contrary, with the CPT, since the alkalis are limited and will be consumed and/or leached, the alkalinity of the pore solution is reduced and thus there might not be enough alkalis to trigger expansion depending on the fillers sensitivity to pore solution alkalinity. However, in case alkali-bearing aggregates are used or the structure might be susceptible to alkalis from 
external sources such as de-icers more attention in terms of preventive measures might be needed to avoid deleterious effect in the field at late ages.

In conclusion, the AMBT could be used to test the reactivity of mineral fillers. However, some modifications to the standard test described in ASTM C1260 (2014) and CSA A23.2-25A (2014) should be considered such as:

(1) Increasing the testing duration to 56 days instead of 14 days to be able to see the expansion due to the time needed for the alkalis to reach the core of the samples.

(2) Testing the fillers with a non-reactive fine aggregate having an expansion below $0.10 \%$ at 14 days as specified in the standard.

(3) Replacing the sand with fillers and take it as a percent from the finest portion of the sand since it will show higher expansion than in case the filler was taken as a replacement from the total graded sand.

(4) Using fillers with the following size: $70 \%$ passing $75 \mu \mathrm{m}$ sieve and $30 \%$ passing $150 \mu \mathrm{m}$ sieve and retained on $75 \mu \mathrm{m}$ sieve, which is the gradation of commercially available fillers.

(5) Limiting the replacement level of the filler from the sand to $10 \%$.

If no expansion higher than the non-reactive sand or the expansion was not greater than $8.3 \%$ of the control expansion (8.3\% is within-laboratory precision stated in ASTM C1260 (2014)) at 56 days using the modified AMBT (provided that both tests are done at the same lab and by the same technician), the filler is deemed suitable for use in concrete. Fillers showing expansion higher than the within-laboratory precision of $8.3 \%$ should be rejected. In the case the filler will be used, reactivity of the filler should be tested using the CPT and preventive measures should be implemented if required. Under the concrete prism test, the samples with filler should show expansion lower than the control sample. This restricted limit is suggested as the use of filler - if inert - is expected to reduce the expansion in both mortar bars and concrete prism test. If expansion was higher than the control but still less than $0.040 \%$, caution should be taken if the filler was used in structures subjected to external source of alkalis or could release alkalis to its pore solution from the aggregates. Of course, if the expansion is higher than $0.040 \%$, the filler is not suitable for use in concrete unless preventive measures are used. 


\section{Chapter 5}

\section{Summary and Discussion}

This section summarizes the results obtained in this research and addresses the objectives presented under Chapter 1. First, reasons for the discrepancies in expansion between the field and laboratory samples are presented (Section 5.1 and Section 5.4) and a new approach to determine the minimum level of SCM required to mitigate expansion is proposed (Section 5.2). Expansion data from the field obtained from other studies are investigated (Section 5.3) to: (1) see whether testing cylinders instead of 75-mm standard prisms correlates better with the field, and (2) to validate the proposed approach of determining the minimum SCM level to prevent expansion in the field. In addition, examining the possibility of reducing the testing duration of the concrete prism test is discussed in Section 5.5. Moreover, ways to assess residual life of structures affected by ASR are examined (Section 5.6). Finally, a new test for evaluating the potential alkali-silica reactivity of mineral fillers in concrete will be presented in Section 5.7. The main contributions of the thesis are summarized in Section 5.8.

\subsection{Understanding the factors affecting expansion of concrete due to ASR}

Higher amount of alkalis leached from concrete cast with Sudbury, a moderately reactive aggregate, compared to samples cast with Spratt, a highly reactive aggregate. This could be attributed to: (1) the higher alkali contribution from Sudbury aggregate increasing the total alkalis in the concrete pore solution leading to more leaching, and (2) the slow reactivity of Sudbury - as was shown from the lower rate of expansion in Figure 4.19 - leaving more alkalis available for leaching before the alkali-silica reaction occurs. Due to their lower surface area-to-volume ratio, cylinders were shown to leach less compared to prisms. The reduced alkali leaching from cylinders in addition to the high alkali release from Sudbury could explain the higher expansion obtained with Sudbury cylinders compared to prisms. Furthermore, the lower alkali leaching in cylinders may lead to higher pore solution alkalinity compared to prisms promoting further alkali release from Sudbury aggregate. The higher alkali release from aggregates to solutions of higher alkalinity 
could be explained by the fact that higher $\mathrm{pH}$ will promote the attack of the reactive silica and thus liberation of the alkalis from the aggregate (Douglas and El-Shamy, 1967; Dhir, Dyer and Tang, 2009). The higher amount of hydroxyl ions present in the solution will favor the breakdown of the siloxane bonds $\left(\equiv \mathrm{Si}-\mathrm{O}^{-}\right.$) in the glass which will be then occupied by $\mathrm{H}^{+}, \mathrm{Na}^{+}$or $\mathrm{K}^{+}$ions (Douglas and El-Shamy, 1967; Dhir, Dyer and Tang, 2009). All the aggregates tested in this research showed higher alkali release to solutions of higher alkalinity. In the case of Spratt without SCM, cylinders showed higher expansion compared to prisms which could be supported by the higher alkali leaching in prisms compared to cylinders. For Spratt/SCM combinations, cylinders and prisms showed same expansions. The very low alkali release from Spratt coupled with SCM ability to bind alkalis could have led to close pore solution alkalinities between cylinders and prisms as opposed to the case of Sudbury aggregate. It is worth noting that when marginal level of SCM was used with Spratt; i.e. $15 \%$ FA and GUB-8SF+15\% FA, the cylinders had slightly higher expansions compared to prisms, maybe because this SCM replacement level might not be enough to bind the extra alkalis in the cylinders pore solution.

In addition to the aggregate type, some factors could lead to the reduced alkali leaching in the cylinders compared to prisms. First, the lower the volume ratio of air-to-samples will lead to lower alkali leaching as reported by Bérubé, Fournier and Côté (2012) and Costa, Mangialardi and Paolini (2017). In this research, the storage containers were the same for prisms and cylinders. However, three cylinders put in one container have higher volume compared to three prisms leading to a lower air-to-concrete ratio for the cylinders. This could have contributed to the lower alkali leaching in cylinders. For the cubes, the air-to-concrete volume ratio is smaller compared to that of the cylinders reducing alkali leaching further in the cubes.

In terms of expansion, the orientation of the casting plane was reported to affect expansion; the expansion due to ASR was shown to be higher in the direction perpendicular to the casting plane (Smaoui et al., 2004). Cylinders cast vertically are expected to show higher axial expansion than prisms cast horizontally. This is because more surface area of the reactive flat and elongated particles is exposed in the direction of the casting plane (Smaoui et al., 2004). Spratt was found to have higher flat and elongated particles compared to Sudbury (Table 3.2 and Table 3.3). However, cylinders and prisms cast with Spratt aggregate/SCM showed same expansion leading to the assumption that the orientation of the casting plane was not an important factor in ASR expansion 
in this research. In any case, if the casting direction is a factor in showing a difference in expansion due to ASR in samples cast vertically compared to horizontally as reported by Smaoui et al. (2004), in this study, it favors higher expansion in the case of cylinders - cast vertically - correlating better with the field. Finally, although the volume of the cylinders is higher, it was not affected adversely by relative humidity. Cylinders showed $100 \%$ humidity most of the time. Due to their large volume, cubes showed the lowest alkali leaching, however, they did not show an expansion higher than the cylinders. The reasons might be due to inaccuracy in the measurements or to expansion restraint produced because of the cubes' geometric shapes. The findings in Fournier, Nkinamubanzi and Chevrier (2004) showing that cubical field blocks had lower expansion than slabs may support the hypothesis that the sample shape could affect expansion. This needs further investigation.

The above factors favor the use of cylinders compared to prisms because cylinders will reduce leaching and higher expansion could be achieved with some aggregates. It is evident from this research that using cylinders instead of prisms can help in obtaining better correlation with larger samples exposed to field conditions specially for slowly reactive aggregates and/or alkali-bearing aggregates that contribute significant amount of alkalis to the pore solution. However, more testing of other aggregates with a wide range of SCM is needed to validate the results on a wider range of samples.

\subsection{Predicting the minimum level of SCM needed to reduce ASR expansion}

The threshold alkali content above which expansion starts to increase beyond $0.040 \%$ were found to be: $0.66 \%(0.46 \mathrm{M}), 0.50 \%(0.35 \mathrm{M})$ and $0.88 \%(0.62 \mathrm{M}) \mathrm{Na}_{2} \mathrm{O}_{\mathrm{e}}$ for Sudbury, Spratt coarse aggregates and Springhill sand, respectively. Details of the procedure used to obtain these thresholds were covered in Section 4.4. Finding the right type and level of SCM that will keep the pore solution of concrete below this threshold is important to prevent expansion due to ASR. Thomas (2011) found a linear relationship between pore solution alkalinity (moles/L) and binder (cement + SCM) composition: $\left(\mathrm{Na}_{2} \mathrm{O}_{\mathrm{e}} \mathrm{x} \mathrm{CaO}\right) /\left(\mathrm{SiO}_{2}\right)^{2}$. Based on the threshold obtained, the pore solution alkalinity could be used to obtain $\left(\mathrm{Na}_{2} \mathrm{O}_{\mathrm{e}} \mathrm{x} \mathrm{CaO}\right) /\left(\mathrm{SiO}_{2}\right)^{2}$ using the equation $\mathrm{y}=6.0304 \mathrm{x}$ 
as shown in Figure 5.1. The blue line corresponds to Spratt, the red line for Sudbury and green is for Springhill fine aggregate. Table 5.1 summarizes the different terms for each aggregate.

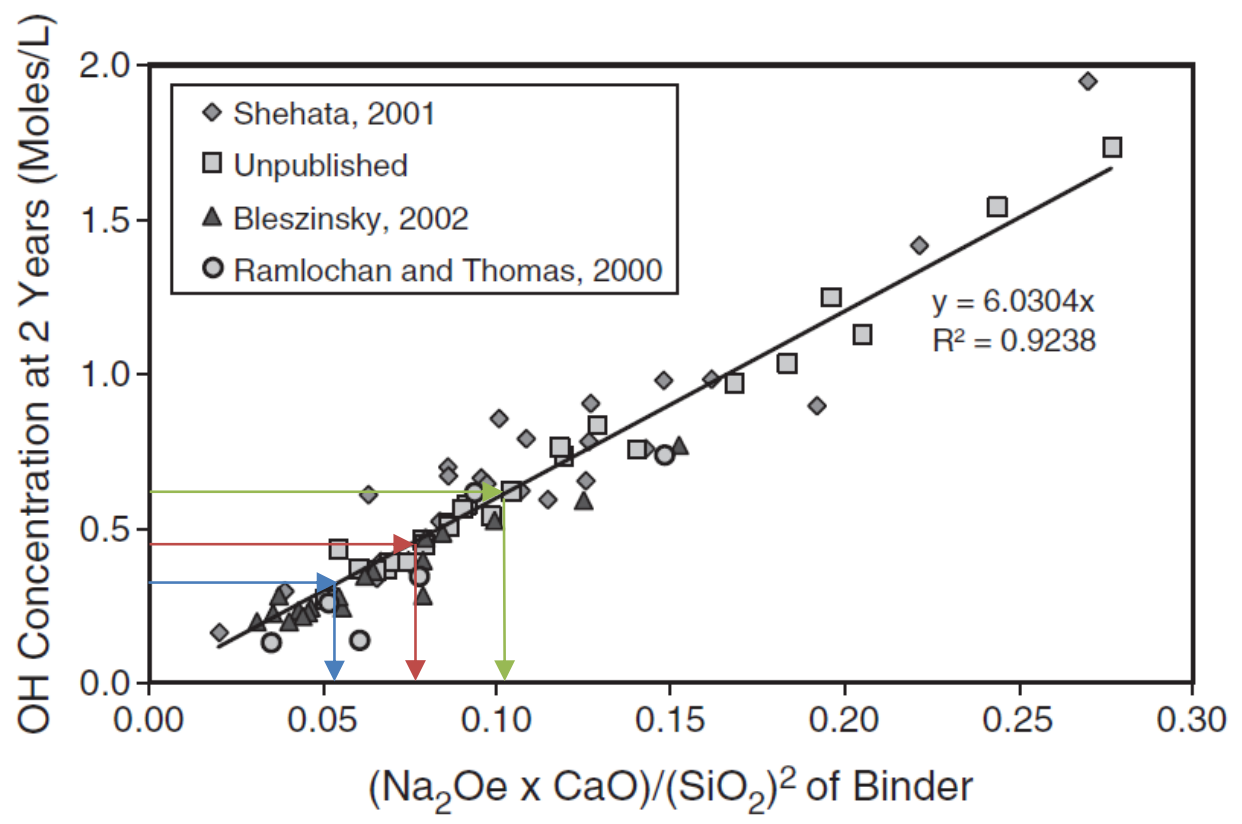

Figure 5.1: Effect of binder chemical composition on pore solution alkalinity of pastes at 2 years (Thomas, 2011)

Table 5.1: Correlation between threshold alkali content and binder composition

\begin{tabular}{ccc}
\hline & $y=$ threshold alkali level & $\mathbf{x}=\left(\mathrm{Na}_{2} \mathrm{O}_{\mathrm{e}} \mathbf{x} \mathrm{CaO}\right) /\left(\mathrm{SiO}_{2}\right)^{2}$ \\
\hline \hline Sudbury (coarse) & 0.46 & 0.0763 \\
Spratt (coarse) & 0.35 & 0.0580 \\
Springhill (Fine) & 0.62 & 0.1028 \\
\hline
\end{tabular}

The term $\left(\mathrm{Na}_{2} \mathrm{O}_{\mathrm{e}} \times \mathrm{CaO}\right) /\left(\mathrm{SiO}_{2}\right)^{2}$ depends on the type of SCM and the cement to be used in concrete. Each type will lead to a different replacement level needed to reduce expansion. To be able to find the replacement level needed to mitigate expansion, the term should be adjusted based on the chemical composition of the cement and SCM. Assuming RL is the \% replacement level needed to cause an expansion of $0.040 \%$ and knowing the chemical compositions of the binders to be used, the following equations will be replaced in the $\left(\mathrm{Na}_{2} \mathrm{O}_{\mathrm{e}} \times \mathrm{CaO}\right) /\left(\mathrm{SiO}_{2}\right)^{2}$ term:

$$
\begin{aligned}
\mathrm{Na}_{2} \mathrm{O}_{\mathrm{e}} & =(100-\mathrm{RL}) * \mathrm{Na}_{2} \mathrm{O}_{\mathrm{e}(\mathrm{PC})}+\mathrm{RL}^{*} \mathrm{Na}_{2} \mathrm{O}_{\mathrm{e}(\mathrm{SCM})} \\
\mathrm{CaO} & =(100-\mathrm{RL}) * \mathrm{CaO}_{(\mathrm{PC})}+\mathrm{RL}^{*} \mathrm{CaO}_{(\mathrm{SCM})} \\
\mathrm{SiO}_{2} & =(100-\mathrm{RL}) * \mathrm{SiO}_{2}(\mathrm{PC})+\mathrm{RL}^{*} \mathrm{SiO}_{2(\mathrm{SCM})}
\end{aligned}
$$


Where $\mathrm{Na}_{2} \mathrm{O}_{\mathrm{e}(\mathrm{PC})}, \mathrm{CaO}_{(\mathrm{PC})}$, and $\mathrm{SiO}_{2}$ (PC) correspond to the chemical composition of the $\mathrm{PC}$ and $\mathrm{Na}_{2} \mathrm{O}_{\mathrm{e}(\mathrm{SCM})}, \mathrm{CaO}_{(\mathrm{SCM})}$, and $\mathrm{SiO}_{2}$ (SCM) for the SCM.

Replacing these terms in the above equation will give the replacement level that will reduce expansion to $0.040 \%$. Using GU-0.99 and SCM investigated in this study, Table 5.2 gives a summary of the minimum SCM needed to reduce expansion in concrete cast with these three types of aggregates.

Table 5.2: Minimum SCM level needed to reduce expansion

\begin{tabular}{ccc}
\hline & Class F FA & Slag \\
\hline \hline Sudbury (coarse) & $30 \%$ & $35 \%$ \\
Spratt (coarse) & $40 \%$ & $50 \%$ \\
Springhill (fine) & $20 \%$ & $20 \%$ \\
\hline
\end{tabular}

It should be noted that the above findings correspond to the case where no leaching is occurring which might correlate better with the field since in the field the leaching is very reduced due to the larger sample size. The minimum levels of SCM required to reduce expansion below $0.040 \%$ obtained from the threshold calculations were compared to the values in the actual CPT standard as shown in Table 5.3.

Table 5.3: Comparison of SCM levels obtained from CPT and threshold calculations

\begin{tabular}{ccccc}
\hline $\begin{array}{c}\text { Minimum level of SCM (\%) } \\
\text { obtained from }\end{array}$ & \multicolumn{2}{c}{ Sudbury } & \multicolumn{2}{c}{ Spratt } \\
\cline { 2 - 5 } & Class F FA & Slag & Class F FA & Slag \\
\hline \hline CPT & 15 & 25 & 20 & 35 \\
Threshold & 30 & 35 & 40 & 50 \\
\hline
\end{tabular}

It is clear that the minimum levels required based on the threshold alkali content are much higher compared to the actual values of the CPT. Due to the high leaching occurring in the small size prisms, lower replacement levels of SCM are required to reduce expansion. When these levels are used in the field, higher expansions were observed due to the reduced leaching in large samples leading to discrepancies in expansion between laboratory testing and field samples. In conclusion, higher SCM content might be needed to stop the expansion in the field compared to the levels obtained in the CPT specified in the standard. 
In CSA A23.2-14A (2014), the alkalinity of the cement in the prisms was increased by $25 \%$ to compensate for the leaching that will occur. Table 5.4 and Table 5.5 below show a summary of the PC alkali content after correcting for leaching at 1 year. Based on the results in Table 5.4 and Table 5.5, the initial PC alkali content in the cylinders should be increased by an average of $23 \%$ in the case of Sudbury and $18 \%$ in the case of Spratt to compensate for the leaching that will occur. Hence, with the prisms the initial PC alkali content is supposed to be increased by more than $21 \%$ (average of $18 \%$ and $23 \%$ ) to compensate for leaching which is not in line with the findings of the current CSA A23.2-14A (2014) standard stating that the cement alkalinity should be increased by only $25 \%$ in the prisms.

Table 5.4: PC alkali content of Sudbury cylinders after correcting for leaching at 1 year

\begin{tabular}{ccc}
\hline $\begin{array}{c}\text { Initial PC Alkali } \\
\text { Content }\end{array}$ & $\begin{array}{c}\text { Alkali Content of PC after } \\
\text { Correcting for Leaching }\end{array}$ & $\begin{array}{c}\text { Ratio of Initial/Corrected } \\
\text { Alkali Content }\end{array}$ \\
\hline \hline $\mathbf{0 . 5 7}$ & 0.48 & 1.18 \\
\hline $\mathbf{0 . 7}$ & 0.58 & 1.21 \\
\hline $\mathbf{0 . 8}$ & 0.63 & 1.27 \\
\hline $\mathbf{0 . 9 2}$ & 0.78 & 1.18 \\
\hline $\mathbf{1 . 2 5}$ & 0.98 & 1.27 \\
\hline
\end{tabular}

Table 5.5: PC alkali content of Spratt cylinders after correcting for leaching at 1 year

\begin{tabular}{ccc}
\hline $\begin{array}{c}\text { Initial PC Alkali } \\
\text { Content }\end{array}$ & $\begin{array}{c}\text { Alkali Content of PC after } \\
\text { Correcting for Leaching }\end{array}$ & $\begin{array}{c}\text { Ratio of Initial/Corrected } \\
\text { Alkali Content }\end{array}$ \\
\hline $\mathbf{0 . 5 7}$ & 0.48 & 1.18 \\
\hline $\mathbf{0 . 7}$ & 0.60 & 1.18 \\
\hline $\mathbf{0 . 8}$ & 0.68 & 1.18 \\
\hline $\mathbf{0 . 9 2}$ & 0.78 & 1.18 \\
\hline
\end{tabular}

\subsection{Relationship Between Laboratory and Field Expansions}

The expansion results obtained in this study were compared to those from field samples to see if a particular lab sample geometry/size correlates better with the field samples. The expansion results were obtained from the literature (Fournier, Nkinamubanzi and Chevrier, 2004; Ideker et al., 2012; 
Fournier et al., 2018). Blocks with the following dimensions $0.4 \times 0.4 \times 0.7 \mathrm{~m}$ were cast and stored in CANMET outdoor site in Ottawa, Ontario. Similar mix design as the CPT was used in terms of cementing materials content $\left(420 \mathrm{~kg} / \mathrm{m}^{3}\right)$ and coarse aggregate volume ratio of 0.6 (Ideker et al., 2012). The water to cementing materials ratio used was between 0.36 to 0.42 which is similar to the ratio used in this research (0.42) (Fournier, Nkinamubanzi and Chevrier, 2004). Sudbury and Spratt aggregates were used for the field blocks in addition to Class F FA or silica fume. Expansion in the field was measured for 15 years and reported (Ideker et al., 2012; Fournier et al., 2018). Airentraining admixtures was added for the outdoor exposure blocks which is not the case for the laboratory samples done in this research.

At 10 years, blocks under field conditions cast with no added alkali showed good correlation with the CPT at 2 years for all the different aggregates studied by Fournier, Nkinamubanzi and Chevrier (2004). However, at 15 years, Ideker et al. (2012) reported discrepancies between field and laboratory expansions where the field blocks showed higher expansion than expected with some aggregates/SCM combinations.

Sudbury samples cast with 20\% Class F FA showed a 2-year CPT expansion of $0.008 \%$ and $0.023 \%$ in the field at 15 years (Fournier, Nkinamubanzi and Chevrier, 2004; Ideker et al., 2012). While both values showed an expansion lower than $0.040 \%$, it is clear that the field expansion of blocks at 15 years is higher than the 2-year CPT expansion for this type of aggregate/SCM combination. With $15 \%$ Class F FA, the field block samples are supposed to show an expansion higher than $0.023 \%$ (expansion of samples with 20\% FA) at 15 years. In this research, prisms cast with Sudbury and 15\% FA had a 2-year CPT expansion of $0.016 \%$ while the cylinders showed a higher expansion of $0.037 \%$ which agrees with the expected field expansion $(>0.023 \%)$.

In addition to field blocks, slabs of following dimensions $0.7 \times 0.7 \times 0.15 \mathrm{~m}$ were cast with the same mix design and exposure conditions as the blocks (Fournier, Nkinamubanzi and Chevrier,2004). Sudbury samples with $20 \%$ Class F FA passed the CPT at 2 years $(0.008 \%)$ but showed a 10-year expansion in the field slabs of $0.039 \%$ (Fournier, Nkinamubanzi and Chevrier, 2004). With 15\% FA, the field slab samples are expected to show an expansion higher than $0.039 \%$ at 10 years. In this research, Sudbury prisms cast $15 \%$ FA had a 2-year expansion of $0.016 \%$ while cylinders showed an expansion of $0.037 \%$, correlating much better to the field slabs expansion. 
It is worth noting that the field slabs had an expansion higher than that of the blocks at 10 years. Fournier, Nkinamubanzi and Chevrier (2004) explained that expansion obtained on the sides of the blocks were lower than that of the expansion measured on the surface due to exposure of the surface to higher moisture. The reported block expansions were the average of four longitudinal measurements, two taken on the top and two on the sides of the blocks.

Blocks tested under field conditions in Fournier, Nkinamubanzi and Chevrier (2004), Ideker et al. (2012) and Fournier et al. (2018) were used to verify the results obtained from applying the method explained in Section 5.2 to predict the minimum level of SCM replacement needed to reduce expansion. The method used to obtain the minimum level of SCM is based on the chemical composition of the SCM and requires knowing the threshold alkalinity above which expansion is triggered. Using the chemical composition for FA2 (Class F FA) from the study by Fournier et al. (2018) and since the threhsold alkali content for Sudbury and Spratt were obtained in this thesis, the minimum levels of SCM needed to lower expansion are $20 \%$ and $30 \%$ for Sudbury and Spratt, respectively. Looking at the field samples used in Fournier et al. (2018), Spratt blocks with 20\% FA2 showed an expansion of $0.062 \%$ at 15 years and with $30 \%$, the expansion was $0.015 \%$ confirming that $30 \%$ FA2 is needed to reduce expansion below $0.040 \%$ for concrete cast with Spratt. Similarly, with Sudbury, at 15 years, an expansion of $0.023 \%$ was obtained in the blocks when using $20 \%$ FA2 and $0.039 \%$ expansion for the slabs at 10 years validating the minimum level of SCM obtained from the calculations (20\% for Sudbury). The following method to obtain the minimum level required to reduce expansion in the field showed promising results. However, more testing should be done on a variety of aggregates with different reactivity and more combinations of SCM/aggregates.

\subsection{SCM Capacity to Reduce Expansion Due to ASR at Different Temperatures}

In this research, the mechanism by which SCM prevent expansion due to ASR was investigated. Understanding the mechanism by which SCM binds alkalis is important to be able to analyze the

difference in expansion obtained at different temperatures. From the paste study, there was evidence that more release of alkalis from cementing materials to solution of $0.25 \mathrm{M}$ is obtained at $23^{\circ} \mathrm{C}$ compared to samples at $38^{\circ} \mathrm{C}$. This is in agreement with the results obtained from the 
$\mathrm{Ca}(\mathrm{OH})_{2}$ analysis where higher consumption of calcium hydroxide was reached at $38^{\circ} \mathrm{C}$ compared to $23^{\circ} \mathrm{C}$.

These findings could explain - at least partly - the observed discrepancies in expansion obtained between the CPT and the field. In the field, the average temperatures are lower compared to the temperature of $38^{\circ} \mathrm{C}$ at which the concrete prism test is carried. Hence, SCM have higher binding capacity under the CPT leading to lower expansions compared to the field. This could be explained by the fact that more hydration is occurring at $38^{\circ} \mathrm{C}$ allowing more binding of alkalis and more consumption of $\mathrm{Ca}(\mathrm{OH})_{2}$ which is not the case in the field. These discrepancies in expansion between field and lab results are mainly attributed to two reasons: (1) the increased leaching in the laboratory samples compared to field blocks in addition to (2) the higher binding capacity of the SCM observed under the CPT.

At $60^{\circ} \mathrm{C}$, SCM capacity to bind alkalis and to consume $\mathrm{Ca}(\mathrm{OH})_{2}$ was found to be reduced compared to $38^{\circ} \mathrm{C}$. However, it was still higher than SCM samples at $23^{\circ} \mathrm{C}$. Hydration at $60^{\circ} \mathrm{C}$ is accelerated at early age but the ultimate hydration is reduced due to the formation of non-uniform hydration products preventing further hydration (Wang et al., 2012). Relating to the expansion results, samples with high replacement levels of SCM showed higher ultimate expansion at $60^{\circ} \mathrm{C}$ compared to the samples at $38^{\circ} \mathrm{C}$. This could be attributed to the lower capacity of SCM to bind alkalis at $60^{\circ} \mathrm{C}$.

Higher temperature showed accelerated results at early age compared to samples at $38^{\circ} \mathrm{C}$. The long testing duration of the concrete prism test is a challenge where many researchers are trying to find accelerated methods to obtain results in shorter duration. However, there is no agreement on a unique test method to be used yet. In section 5.5, an accelerated test method is proposed and could be adopted since good correlation was obtained with the standard concrete prism test.

\subsection{Develop an accelerated test method to evaluate alkali-silica reaction in}

\section{concrete}

In order to develop an accelerated test method, understanding the factors affecting expansion at $60^{\circ} \mathrm{C}$ is needed. In summary, increasing temperature to $60^{\circ} \mathrm{C}$ will result in lower ultimate expansion 
in the control due to the increased leaching. In addition, it was shown that the ASR reaction rate is accelerated at $60^{\circ} \mathrm{C}$ leading to higher expansions at early age compared to the samples at $38^{\circ} \mathrm{C}$. The rate of expansion is accelerated for all the samples at $60^{\circ} \mathrm{C}$ whether cast with SCM or without. For samples with SCM, higher expansion is obtained at $60^{\circ} \mathrm{C}$ compared to $38^{\circ} \mathrm{C}$. This could be attributed to the following reasons:

(1) Higher release of alkalis from aggregates to the pore solution at $60^{\circ} \mathrm{C}$,

(2) Lower consumption of $\mathrm{Ca}(\mathrm{OH})_{2}$ in samples at $60^{\circ} \mathrm{C}$ compared to $38^{\circ} \mathrm{C}$,

(3) Lower alkali binding capacity at $60^{\circ}$ compared to $38^{\circ} \mathrm{C}$.

Although for samples without SCM, there is also more release of alkalis from the aggregates to the pore solution at $60^{\circ} \mathrm{C}$, it seems that the alkali leaching from the concrete samples is governing. For samples cast with SCM, the alkali leaching is reduced due to the lower permeability of the concrete when SCM is added. Hence, factors other than alkali leaching are affecting the expansion results attributed mainly to the capacity of SCM to bind alkalis at $60^{\circ} \mathrm{C}$. Difference in expansion between samples cast at $38^{\circ} \mathrm{C}$ and $60^{\circ} \mathrm{C}$ was more evident with higher SCM replacement levels.

An accelerated test was developed to be able to obtain the CPT results in faster duration. Increasing temperature showed higher leaching compared to the standard concrete prism test due to the higher diffusivity of alkalis with increased temperatures (Lindgård et al., 2012). By using cylinders, alkali leaching will be reduced and by increasing temperature acceleration of the reaction will be obtained. Hence, the same conclusions obtained with the standard prisms at 2 years could be reached at 1 year with the cylinders at $60^{\circ} \mathrm{C}$ reducing the testing duration by $50 \%$.

Researches have shown that increasing the concrete-to-air volume ratio will reduce leaching (Bérubé, Fournier and Côté, 2012). In this research, this ratio was increased to 0.3 by using smaller containers fitting one cylinder instead of the standard containers used with 3 cylinders having a ratio of 0.2 or 0.14 in the case of 3 prisms in one container. For Sudbury, good correlation was obtained between the 6-month expansion of the cylinders - stored each in a different container - at $60^{\circ} \mathrm{C}$ and the standard 2-year expansion of prisms tested at $38^{\circ} \mathrm{C}$. For Spratt, the correlation was obtained at 18 weeks showing pass/pass or fail/fail relationship.

The better correlation found between cylinders at $38^{\circ} \mathrm{C}$ and the field expansion led to comparison of the 2-year expansion of cylinders at $38^{\circ} \mathrm{C}$ with the expansion results from testing cylinders at 
$60^{\circ} \mathrm{C}$. There was good correlation in the case of Spratt at 18 weeks with the cylinders stored each in a separate container. With Sudbury, the 2-year expansion of cylinders at $38^{\circ} \mathrm{C}$ showed higher values compared to the 6-month results of cylinders at $60^{\circ} \mathrm{C}$. Due to the nature of Sudbury - slowly reactive aggregate - its expansion rate might still be slower compared to the rate of alkali leaching. Measurements of the cylinders stored each in a separate container will be monitored to see whether the 2-year cylinders expansion at $38^{\circ} \mathrm{C}$ could be obtained by 1 year or earlier.

In conclusion, testing cylinders at $60^{\circ} \mathrm{C}$ using smaller containers showed promising result in terms

of reaching conclusions faster than the standard CPT testing duration of 2 years. However, more samples need to be tested to confirm the applicability of the above finding to a wider range of aggregate/cementing blends.

\subsection{Predicting Remaining Life of Structures Affected by ASR}

Depending on the level of deterioration in structures undergoing ASR, many factors could affect residual expansion. Low deteriorated concrete structures will prevent alkalis from leaching out and dislocating the gel which could contribute to the expansion due to ASR. For highly deteriorated samples, more leaching is occurring due to the availability of more cracks leading to a lower pore solution compared to low deteriorated samples. In addition, more remained silica available to react in the low deteriorated elements could be another reason that could affect residual expansion.

On the other hand, the presence of more cracks in high deteriorated structures could lead to an increase in the pore solution alkalinity due to the de-icing salts spread during winter. During this research, it was found that the alkali contribution from concrete chunks obtained from the barriers to saturated lime solution was the same for low and high deteriorated samples. The $\mathrm{Na}_{2} \mathrm{O}$ released in the high deteriorated samples was higher compared to the low deteriorated ones confirming that deicer salts contributed to the increase in alkali release in the high deteriorated samples.

The above factors contribute to the remaining life of structures in the field. Damage rating index analysis showed similar damage in the concrete cores extracted from high and low deteriorated barriers (MacDonald et al., 2019) as opposed to the expansion results which showed higher values for low deteriorated samples. The ASR gel formed in high deteriorated samples might not exert 
enough pressure compared to low deteriorated samples due to the availability of more cracks. In the case of cores and barriers tested in this research, there was a difference in expansion maybe because no restraints are affecting the results. However, in more restrained structures (larger structures), high deteriorated samples could show much higher expansion and more damage.

It could be concluded that measuring cores' expansion above water might not reflect the real deterioration under field exposure, specially that the cores could have been disturbed during extraction leading to the formation of more cracks. Hence, DRI study in addition to expansion measurements in the field are needed to evaluate the residual expansion. The conditions of the structure should also be considered when evaluating residual expansion. Structures with open cracks may not show same level of damage as structures without open cracks despite similar level of reactivity.

\subsection{Develop a Test Method to Evaluate Alkali-Silica Reactivity of Mineral Fillers}

Although the AMBT is an aggressive test, however, it was adopted and adapted to develop a test method in order to evaluate the reactivity of mineral fillers. Some modifications to the standard AMBT test described in CSA A23.2-25A (2014) and ASTM C1260 (2014) should be considered as was explained in Section 4.6. Due to the low permeability of samples with fillers, the testing duration of the AMBT was extended to 56 days instead of the standard 14 days to be able to see the expansion due to the time that the alkalis will take to reach the core of the samples.

To test the reactivity of the fillers, the expansion at 56 days need to be compared to the control samples without filler. If no expansion higher than the non-reactive sand was obtained at 56 days using the modified AMBT, the filler is safe to be used in concrete structures. If an expansion higher than $8.3 \%$ of the non-reactive sand $(8.3 \%$ is the within-laboratory precision specified in ASTM C1260 (2014)) was obtained at 56 days, the filler is not suitable for use in concrete. In case the filler is used, more testing with the CPT is needed to see whether preventive measures are required. This test method was applied on three fillers in this research with only one reactive filler. However, more fillers are required to be tested to validate the results and to check the applicability of the developed test on a wider range of fillers. 


\subsection{Main Contribution of the Thesis}

1. Understanding the factors which lead to discrepancies between field and laboratory results

The work described here helps explain the discrepancies between field and the standard concrete prism test. The high alkali leaching in the prisms and the higher binding capacity of SCM under the CPT conditions are the two main factors leading to difference in expansion between field and laboratory samples.

2. Developing an enhanced test method to evaluate alkali-silica reaction in concrete and to predict the minimum level of SCM required to mitigate ASR

The results of this research showed that testing cylinders ( $\varnothing 100$ by $285 \mathrm{~mm}$ ) instead of standard 75-mm prisms will reduce leaching and will correlate better with the field depending on the type of aggregates. In addition, a new approach to predict the minimum level of SCM needed to mitigate expansion in the field was proposed based on the threshold alkali content and the chemical composition of cementing materials. This approach showed promising results and good correlation with the field.

\section{Investigating the capacity of SCM to bind alkalis at different temperatures}

The ability of SCM to bind alkalis is affected by temperature. At $38^{\circ} \mathrm{C}, \mathrm{SCM}$ consume twice the amount of $\mathrm{Ca}(\mathrm{OH})_{2}$ compared to that consumed at $23^{\circ} \mathrm{C}$ and release less alkalis to pore solution of $0.25 \mathrm{M}$ representing the pore solution alkalinity of concrete after significant expansion occurs due to ASR. At $60^{\circ} \mathrm{C}, \mathrm{SCM}$ consume $40 \%$ less $\mathrm{Ca}(\mathrm{OH})_{2}$ compared to $38^{\circ} \mathrm{C}$. The fact that the binding capacity changes with the change in temperature, expansion of concrete samples cast with SCM is affected. Samples cast with SCM at high replacement levels expand more compared to same samples cast at $38^{\circ} \mathrm{C}$.

\section{Developing a rapid test to evaluate ASR by testing at $60^{\circ} \mathrm{C}$ instead of $38^{\circ} \mathrm{C}$}

One of the main challenges of the CPT is the long testing duration. Testing cylinders at $60^{\circ} \mathrm{C}$ and reducing the air-to-concrete volume ratio showed faster results compared to the standard CPT. By testing cylinders ( $\varnothing 100$ by $285 \mathrm{~mm}$ ) using a cylindrical container with the following dimensions: 
$\emptyset 150$ by $420 \mathrm{~mm}$ (fitting one cylinder), the preliminary expansion results showed that the standard CPT results could be obtained in a shorter time - 26 weeks.

\section{Assessing remaining expansion in concrete structures affected by ASR}

Structures undergoing different levels of deterioration showed different expansion in the field. Factors affecting remaining life of structures undergoing ASR were studied and it was concluded that expansion measurements of cores alone might not reflect the real deterioration occurring inside a structure. Damage rating index investigation of cores will help in understanding the deterioration occurring inside a structure. DRI in addition to expansion measurements in the field are important to explain the remaining life of structures. In addition, the conditions of the structure should also be considered when evaluating residual expansion.

\section{Developing a fast test method to evaluate potential alkali-silica reactivity of mineral fillers in concrete}

A new and fast test method to evaluate alkali-silica reactivity of mineral fillers in concrete was developed by adopting and adapting the AMBT. Some modifications to the standard AMBT are required to be able to test fillers' reactivity reliably including extending the testing duration to 56 days instead of 14 days. As an evaluation criterion, if no expansion higher than the non-reactive sand at 56 days is obtained, the filler is deemed suitable for use in concrete. Otherwise, the filler should be rejected or it could be used if preventive measures are implemented. 


\section{Chapter 6}

\section{Conclusions and Recommendations for Further Study}

The following conclusions could be drawn from this thesis:

1. Prisms used in the CPT have excessive leaching compared to larger-volume samples, cubes or cylinders. With the use of cylinders, reduced leaching was reached showing, in some cases, higher expansion due to ASR.

2. For the two aggregates tested in this thesis, one aggregate was found to release more alkalis to test solutions representing concrete pore fluid. The alkalis released from the aggregate was increased in solutions of higher alkalinity.

3. Cylinders seem to correlate better with the field samples due to their ability to show higher expansion in the laboratory specially with slowly reactive aggregates and/or aggregates that contribute significant amount of alkalis to concrete pore solution. However, the results were obtained on a limited number of aggregate/SCM combinations. Hence, more samples should be tested to validate the above findings to a wider range of aggregates/SCM combinations.

4. The cubes did not show higher expansion than that of the cylinders when measured sideto-side although they - cubes - had the lowest leaching. This could be due to restraints effect in the cubes. For Spratt samples without SCM, cubes measured from center-to-center showed same expansion as the cylinders at $38^{\circ} \mathrm{C}$ or even higher expansion than the cylinders when tested at $60^{\circ} \mathrm{C}$. The cubes might show higher expansion than the cylinders depending on the direction of measurements.

5. The cement alkalinity of cylindrical concrete samples need to be increased by $25 \%$ to compensate for the alkali leaching. Hence, the cement alkalinity of concrete prisms - which 
leach more compared to cylinders - are supposed to be increased by more than $25 \%$ to compensate for leaching which is not in line with the CPT standard requirements.

6. The threshold alkali content needed to trigger expansion can be used to find the right amount of SCM needed to reduce the pore solution alkalinity below this level and to reduce expansion due to ASR. This requires the use of a relationship between SCM chemical composition and pore solution alkalinity.

7. The binding capacity of SCM and their ability to consume $\mathrm{Ca}(\mathrm{OH})_{2}$ under CPT conditions is higher compared to field which might lead to lower expansion in the CPT compared to the field. Two reasons that could lead to discrepancies between field and laboratory samples: (1) excessive leaching in the CPT, and (2) the higher binding capacity of SCM at $38^{\circ} \mathrm{C}$.

8. Testing at $60^{\circ} \mathrm{C}$ showed lower ultimate expansion in samples without SCM due to the increased leaching at higher temperatures compared to $38^{\circ} \mathrm{C}$. For samples with SCM, higher expansion was obtained at $60^{\circ} \mathrm{C}$ compared to $38^{\circ} \mathrm{C}$. One of the reasons that could lead to higher expansion at $60^{\circ} \mathrm{C}$ is the lower binding capacity of the SCM compared to the samples cast at $38^{\circ} \mathrm{C}$. With all the samples - with or without SCM - expansion was accelerated at early age.

9. By increasing temperature to $60^{\circ} \mathrm{C}$ and using cylinders, the expansion is accelerated and leaching is reduced leading to faster results compared to the concrete prism test standard duration of 2 years. In addition, increasing the concrete-to-air volume ratio will further accelerate the results.

10. Low deteriorated concrete elements showed higher expansion that that of the high deteriorated structures. The expansion of cores at 16 weeks took 3.5 years to be obtained in the field. The cores stopped expanding due to leaching as opposed to the barriers. The expansion in cores might not reflect the real damage occurring in the structures as evaluated by the Damage Rating Index (DRI).

11. The workability of samples cast with mineral fillers will be reduced with the increase of the fillers' replacement levels and with reduced size of filler. For samples of $0-100 \mu \mathrm{m}$, it 
is recommended to use superplasticizer for a replacement level above 20\%. For samples with particles smaller than $75 \mu \mathrm{m}$, the use of superplasticizer is recommended at levels above $10 \%$.

12. For testing mineral fillers, the replacement method does not seem to have an effect on workability of samples. Whether the replacement is taken from the total graded sand or from the sand finest portion, the workability was almost the same at $20 \%$ replacement level.

13. Replacing the finest portion of the sand by fillers gives higher expansion than replacing a percent of the total graded sand. This might be due to the fact that when using the first replacement method, the finest portion is being removed which might have already lost reactivity compared to coarser particles.

14. With the AMBT, mineral fillers with $70 \%$ materials passing $75 \mu \mathrm{m}$ showed higher expansion than samples with max size of $75 \mu \mathrm{m}$ which showed same expansion as that of the control samples. This could be due to the lower permeability of the samples with fillers. With the AMBT, the alkalis are provided from the host solution which might not be able to get into the core due to the low permeability of the samples when fillers are added. To be able to show the expansion in the coarser filler, the standard duration of the AMBT was extended to 56 days. With the Springhill filler, expansion higher than the control sand was obtained in the CPT at 1 year with both filler sizes however, the expansion was still lower than $0.040 \%$. 
The following recommendations are suggested for further studies:

1. Modeling state of stresses and stress concentrations in cubes is recommended to understand the reasons for the observed low expansion obtained here. Although cubes were found to have the lowest leaching, they showed lowest expansion compared to other sample shapes or similar to that of the prisms in some cases when measured side-to-side. It was believed that this could be attributed to some restraints effect due to the cubes' shape. In some cases, expansion similar to the cylinders or higher was obtained when measured center-to-center. Modeling will help in understanding the effect of shape on the expansion variation in the cubes.

2. The coefficient of variation in each set of three cylinders or cubes was higher than that of the prisms. It is believed to be due to the molds' fabrication in the laboratory. Using cast iron molds - as the case with the prisms - may alleviate this issue.

3. Testing at $60^{\circ} \mathrm{C}$ and using lower air-to-concrete volume ratio showed accelerated results compared to the standard concrete prism test. However, more testing with different aggregate/SCM combinations is recommended to validate the obtained results.

4. Testing concrete samples at $60^{\circ} \mathrm{C}$ for the first 26 weeks and then storing them at $23^{\circ} \mathrm{C}$ is recommended to see whether higher expansion results compared to testing only at $60^{\circ} \mathrm{C}$ could be obtained or not.

5. More paste study is recommended with other binary and ternary blends to study their binding capacity and their ability to consume $\mathrm{Ca}(\mathrm{OH})_{2}$. In addition, testing paste samples at lower temperature $\left(+5^{\circ} \mathrm{C}\right)$ to investigate their capacity to bind alkalis compared to $21^{\circ} \mathrm{C}$ since this represents to some extent the average temperature in Canada during winter. Using an environmental chamber to simulate the temperature variation between summer and winter in Canada could be a good way to better simulate the capacity of SCM to bind alkalis in the field.

6. Testing aggregates similar to the ones used in field blocks (Fournier, Nkinamubanzi and Chevrier, 2004; Ideker et al., 2012; Fournier et al., 2018) is needed to validate the method proposed in this research to predict the minimum SCM level needed to reduce pore solution alkalinity to below the threshold. 
7. Casting concrete samples with different alkali content and soaking them in corresponding alkaline solution could help in confirming or analyzing the results obtained from the threshold alkali content calculations for samples stored above water.

8. Expansion measurements in cores might not reflect the real deterioration in structures affected by ASR. Finding better ways to predict remaining life of structures affected by ASR is needed.

9. Testing more fillers with different reactivity levels is required to validate the modified AMBT proposed in this thesis to evaluate the potential reactivity of mineral fillers. 


\section{Appendices}




\section{Appendix A}

Calculations and results of the total amount of $\mathrm{Na}_{2} \mathrm{O}_{e}$ leached from concrete samples expressed as a percent of the initial alkali content 


\begin{tabular}{|c|c|c|}
\hline Row \# & Units & Description \\
\hline 1 & ppm & $\mathrm{Na}^{+}$Concentration obtained by flame photometer before dilution \\
\hline 2 & ppm & $\mathrm{K}^{+}$Concentration obtained by flame photometer before dilution \\
\hline 3 & $\mathrm{~L}$ & Volume of water at the bottom of the bucket/container \\
\hline 4 & $\mathrm{~kg}$ & Mass of cement needed to cast 3 prisms or 3 cylinders or 1 cube \\
\hline 5 & $\%$ & $\begin{array}{l}\text { Initial \% of alkali per mass of cement (i.e. } 1.25 \% \text { for the samples which } \\
\text { alkalinity was raised to } 1.25 \% \text { ) }\end{array}$ \\
\hline 6 & $\mathrm{~g} / \mathrm{L}$ & $\begin{array}{l}\mathrm{Na}^{+} \text {Concentration in } \mathrm{g} / \mathrm{L} \\
\quad=\text { Row } 1 / 1000\end{array}$ \\
\hline 7 & $\mathrm{~g} / \mathrm{L}$ & $\begin{array}{c}\mathrm{K}^{+} \text {Concentration in } \mathrm{g} / \mathrm{L} \\
=\text { Row } 2 / 1000\end{array}$ \\
\hline 8 & $\mathrm{~mol} / \mathrm{L}$ & $\begin{array}{c}\mathrm{Na}^{+} \text {Concentration in mol/L } \\
=\text { Row } 6 / 22.9898(\text { molar mass of } \mathrm{Na})\end{array}$ \\
\hline 9 & $\mathrm{~mol} / \mathrm{L}$ & $\begin{aligned} & \mathrm{K}^{+} \text {Concentration in } \mathrm{mol} / \mathrm{L} \\
= & \text { Row } 7 / 39.0983(\text { molar mass of } \mathrm{K})\end{aligned}$ \\
\hline 10 & $\mathrm{~mol} / \mathrm{L}$ & $\begin{array}{l}\text { Total alkali }\left(\mathrm{Na}^{+}+\mathrm{K}^{+}\right) \text {concentration } \\
=\text { Row } 8+\text { Row } 9\end{array}$ \\
\hline 11 & mol & $\begin{array}{l}\text { Total alkali in moles } \\
=\text { Row } 10 * \text { Row } 3\end{array}$ \\
\hline 12 & mol & $\begin{array}{l}\text { Total alkali in moles expressed as } \mathrm{Na}_{2} \mathrm{O}_{\mathrm{e}} \\
=\text { Row } 11 / 2\end{array}$ \\
\hline 13 & $\mathrm{~g}$ & $\begin{array}{c}\text { Total mass of } \mathrm{Na}_{2} \mathrm{O}_{\mathrm{e}} \\
=\text { Row } 12 * 61.9789\left(\text { molar mass of } \mathrm{Na}_{2} \mathrm{O}\right)\end{array}$ \\
\hline 14 & $\%$ & $\begin{array}{l}\text { Total alkali taken as } \% \text { by mass of cement } \\
\quad=(\text { Row } 13 / 1000) / \text { Row } 4 * 100\end{array}$ \\
\hline 15 & $\%$ & $\begin{array}{r}\text { Total } \mathrm{Na}_{2} \mathrm{O}_{\mathrm{e}} \text { by mass of cement taken as } \% \text { of the initial alkali content } \\
=(\text { Row } 14 / \text { Row } 5) * 100\end{array}$ \\
\hline
\end{tabular}




\begin{tabular}{|c|c|c|c|c|c|c|c|c|c|c|c|c|c|c|}
\hline \multicolumn{15}{|c|}{ SUDBURY AT $38^{\circ} \mathrm{C}$} \\
\hline \multirow{3}{*}{$\begin{array}{c}\text { Row } \\
\#\end{array}$} & \multicolumn{5}{|c|}{ Control } & \multicolumn{4}{|c|}{$15 \% \mathrm{FA}$} & \multicolumn{5}{|c|}{$25 \%$ Slag } \\
\hline & \multirow{2}{*}{ Prisms } & \multirow{2}{*}{ Cylinders } & \multicolumn{3}{|c|}{ Cubes } & \multirow{2}{*}{ Prisms } & \multirow{2}{*}{ Cylinders } & \multicolumn{2}{|c|}{ Cubes } & \multirow{2}{*}{ Prisms } & \multirow{2}{*}{ Cylinders } & \multicolumn{3}{|c|}{ Cubes } \\
\hline & & & $\mathbf{A}$ & $\mathbf{B}$ & $\mathbf{C}$ & & & $\mathbf{A}$ & $\mathbf{B}$ & & & $\mathbf{A}$ & $\mathbf{B}$ & $\mathbf{C}$ \\
\hline 1 & 1660 & 775 & 1040 & 820 & 800 & 1075 & 900 & 260 & 238 & 720 & 740 & 120 & 133 & 125 \\
\hline 2 & 4700 & 3175 & 2820 & 2260 & 2400 & 2175 & 1850 & 700 & 925 & 2080 & 2160 & 867 & 600 & 525 \\
\hline 3 & 1.7201 & 2.1217 & 1.7451 & 2.3585 & 2.2295 & 1.5800 & 1.7850 & 2.3680 & 1.9073 & 1.78 & 1.87 & 2.097 & 1.538 & 1.602 \\
\hline 4 & 2.0198 & 2.8203 & 1.4175 & 1.4175 & 1.4175 & 1.7168 & 2.3973 & 1.2049 & 1.2049 & 1.5148 & 2.1152 & 1.0631 & 1.0631 & 1.0631 \\
\hline 5 & 1.25 & 1.25 & 1.25 & 1.25 & 1.25 & 1.25 & 1.25 & 1.25 & 1.25 & 1.25 & 1.25 & 1.25 & 1.25 & 1.25 \\
\hline 6 & 1.66 & 0.78 & 1.04 & 0.82 & 0.80 & 1.08 & 0.90 & 0.26 & 0.24 & 0.72 & 0.74 & 0.12 & 0.13 & 0.13 \\
\hline 7 & 4.70 & 3.18 & 2.82 & 2.26 & 2.4 & 2.18 & 1.85 & 0.70 & 0.925 & 2.08 & 2.16 & 0.87 & 0.60 & 0.53 \\
\hline 8 & 0.072 & 0.034 & 0.045 & 0.036 & 0.035 & 0.047 & 0.039 & 0.011 & 0.010 & 0.031 & 0.032 & 0.005 & 0.006 & 0.005 \\
\hline 9 & 0.120 & 0.081 & 0.072 & 0.058 & 0.061 & 0.056 & 0.047 & 0.018 & 0.024 & 0.053 & 0.055 & 0.022 & 0.015 & 0.013 \\
\hline 10 & 0.192 & 0.115 & 0.117 & 0.093 & 0.096 & 0.102 & 0.086 & 0.029 & 0.034 & 0.085 & 0.087 & 0.027 & 0.021 & 0.019 \\
\hline 11 & 0.331 & 0.244 & 0.205 & 0.220 & 0.214 & 0.162 & 0.154 & 0.069 & 0.065 & 0.150 & 0.164 & 0.057 & 0.033 & 0.030 \\
\hline 12 & 0.165 & 0.122 & 0.102 & 0.110 & 0.107 & 0.081 & 0.070 & 0.038 & 0.032 & 0.075 & 0.082 & 0.029 & 0.016 & 0.015 \\
\hline 13 & 10.257 & 7.556 & 6.347 & 6.832 & 6.645 & 5.013 & 4.783 & 2.144 & 2.009 & 4.662 & 5.067 & 1.780 & 1.008 & 0.937 \\
\hline 14 & 0.51 & 0.27 & 0.45 & 0.48 & 0.47 & 0.29 & 0.20 & 0.18 & 0.17 & 0.31 & 0.24 & 0.17 & 0.09 & 0.09 \\
\hline 15 & 41 & 21 & 36 & 39 & 38 & 23 & 16 & 14 & 13 & 25 & 19 & 13 & 8 & 7 \\
\hline
\end{tabular}




\begin{tabular}{|c|c|c|c|c|c|c|c|c|c|}
\hline \multicolumn{10}{|c|}{ SUDBURY AT $60^{\circ} \mathrm{C}$} \\
\hline \multirow{3}{*}{ Row \# } & \multirow{3}{*}{$\begin{array}{c}\text { Control } \\
\text { Cylinders }\end{array}$} & \multicolumn{4}{|c|}{$15 \% \mathrm{FA}$} & \multicolumn{4}{|c|}{$25 \%$ Slag } \\
\hline & & \multirow{2}{*}{ Cylinders } & \multicolumn{3}{|c|}{ Cubes } & \multirow{2}{*}{ Cylinders } & \multicolumn{3}{|c|}{ Cubes } \\
\hline & & & $\mathbf{A}$ & B & $\mathbf{C}$ & & $\mathbf{A}$ & $\mathbf{B}$ & $\mathbf{C}$ \\
\hline 1 & 900 & 1525 & 2120 & 2100 & 1417 & 1040 & 2400 & 1260 & 1150 \\
\hline 2 & 3700 & 2850 & 3380 & 3740 & 2733 & 3100 & 3980 & 3560 & 3657 \\
\hline 3 & 2.1217 & 1.8247 & 0.5308 & 0.5286 & 0.5363 & 1.65 & 0.5650 & 0.5876 & 0.5835 \\
\hline 4 & 2.8203 & 2.3973 & 1.2049 & 1.2049 & 1.2049 & 2.1152 & 1.0631 & 1.0631 & 1.0631 \\
\hline 5 & 1.25 & 1.25 & 1.25 & 1.25 & 1.25 & 1.25 & 1.25 & 1.25 & 1.25 \\
\hline 6 & 0.99 & 1.53 & 2.12 & 2.10 & 1.417 & 1.04 & 2.40 & 1.26 & 1.15 \\
\hline 7 & 3.79 & 2.85 & 3.38 & 3.74 & 2.733 & 3.10 & 3.98 & 3.56 & 3.57 \\
\hline 8 & 0.039 & 0.066 & 0.092 & 0.091 & 0.062 & 0.045 & 0.104 & 0.055 & 0.050 \\
\hline 9 & 0.095 & 0.073 & 0.086 & 0.096 & 0.070 & 0.079 & 0.102 & 0.091 & 0.091 \\
\hline 10 & 0.134 & 0.139 & 0.179 & 0.187 & 0.132 & 0.125 & 0.206 & 0.146 & 0.141 \\
\hline 11 & 0.284 & 0.254 & 0.095 & 0.099 & 0.071 & 0.205 & 0.116 & 0.086 & 0.082 \\
\hline 12 & 0.142 & 0.127 & 0.047 & 0.049 & 0.035 & 0.103 & 0.058 & 0.043 & 0.041 \\
\hline 13 & 8.796 & 7.873 & 2.939 & 3.063 & 2.186 & 6.367 & 3.610 & 2.656 & 2.554 \\
\hline 14 & 0.31 & 0.33 & 0.24 & 0.25 & 0.18 & 0.30 & 0.30 & 0.25 & 0.24 \\
\hline 15 & 25 & 26 & 20 & 20 & 15 & 24 & 24 & 20 & 19 \\
\hline
\end{tabular}




\begin{tabular}{|c|c|c|c|c|c|c|c|c|c|c|c|c|c|c|c|}
\hline \multicolumn{16}{|c|}{ SPRATT AT $38^{\circ} \mathrm{C}$} \\
\hline \multirow{3}{*}{$\begin{array}{c}\text { Row } \\
\#\end{array}$} & \multicolumn{5}{|c|}{ Control } & \multicolumn{5}{|c|}{$20 \%$ FA } & \multicolumn{5}{|c|}{$35 \%$ Slag } \\
\hline & \multirow{2}{*}{ Prisms } & \multirow{2}{*}{ Cylinders } & \multicolumn{3}{|c|}{ Cubes } & \multirow{2}{*}{ Prisms } & \multirow{2}{*}{ Cylinders } & \multicolumn{3}{|c|}{ Cubes } & \multirow{2}{*}{ Prisms } & \multirow{2}{*}{ Cylinders } & \multicolumn{3}{|c|}{ Cubes } \\
\hline & & & $\mathbf{A}$ & B & $\mathbf{C}$ & & & $\mathbf{A}$ & $\mathbf{B}$ & $\mathbf{C}$ & & & $\mathbf{A}$ & B & $\mathbf{C}$ \\
\hline 1 & 700 & 500 & 440 & 380 & 567 & 620 & 420 & 740 & 660 & 567 & 480 & 600 & 820 & 900 & 840 \\
\hline 2 & 3000 & 2500 & 3460 & 3680 & 4433 & 1240 & 1100 & 2200 & 2140 & 1860 & 1220 & 1300 & 2140 & 2440 & 2440 \\
\hline 3 & 1.835 & 1.8693 & 0.5017 & 0.5221 & 0.4719 & 2.155 & 2.340 & 0.5211 & 0.4755 & 0.5615 & 1.9867 & 1.9566 & 0.5634 & 0.5367 & 0.5178 \\
\hline 4 & 2.0198 & 2.8203 & 1.4175 & 1.4175 & 1.4175 & 1.6158 & 2.2562 & 1.134 & 1.134 & 1.134 & 1.3129 & 1.8332 & 0.9214 & 0.9214 & 0.9214 \\
\hline 5 & 1.25 & 1.25 & 1.25 & 1.25 & 1.25 & 1.25 & 1.25 & 1.25 & 1.25 & 1.25 & 1.25 & 1.25 & 1.25 & 1.25 & 1.25 \\
\hline 6 & 0.7 & 0.5 & 0.44 & 0.38 & 0.567 & 0.62 & 0.42 & 0.74 & 0.66 & 0.567 & 0.48 & 0.6 & 0.82 & 0.9 & 0.84 \\
\hline 7 & 3 & 2.5 & 3.46 & 3.68 & 4.433 & 1.24 & 1.1 & 2.2 & 2.14 & 1.86 & 1.22 & 1.3 & 2.14 & 2.44 & 2.44 \\
\hline 8 & 0.030 & 0.022 & 0.019 & 0.017 & 0.025 & 0.027 & 0.018 & 0.032 & 0.029 & 0.025 & 0.021 & 0.026 & 0.035 & 0.039 & 0.037 \\
\hline 9 & 0.077 & 0.064 & 0.088 & 0.094 & 0.113 & 0.032 & 0.028 & 0.056 & 0.055 & 0.048 & 0.031 & 0.033 & 0.055 & 0.062 & 0.062 \\
\hline 10 & 0.107 & 0.086 & 0.108 & 0.111 & 0.138 & 0.059 & 0.046 & 0.088 & 0.083 & 0.072 & 0.052 & 0.059 & 0.090 & 0.102 & 0.099 \\
\hline 11 & 0.197 & 0.160 & 0.054 & 0.058 & 0.065 & 0.126 & 0.109 & 0.046 & 0.040 & 0.041 & 0.103 & 0.116 & 0.051 & 0.055 & 0.051 \\
\hline 12 & 0.098 & 0.080 & 0.027 & 0.029 & 0.033 & 0.063 & 0.054 & 0.023 & 0.020 & 0.020 & 0.052 & 0.058 & 0.025 & 0.027 & 0.026 \\
\hline 13 & 6.095 & 4.964 & 1.673 & 1.790 & 2.019 & 3.919 & 3.365 & 1.428 & 1.230 & 1.257 & 3.207 & 3.599 & 1.578 & 1.689 & 1.588 \\
\hline 14 & 0.30 & 0.18 & 0.12 & 0.13 & 0.14 & 0.24 & 0.15 & 0.13 & 0.11 & 0.11 & 0.24 & 0.20 & 0.17 & 0.18 & 0.17 \\
\hline 15 & 24 & 14 & 9 & 10 & 11 & 19 & 12 & 10 & 9 & 9 & 20 & 16 & 14 & 15 & 14 \\
\hline
\end{tabular}




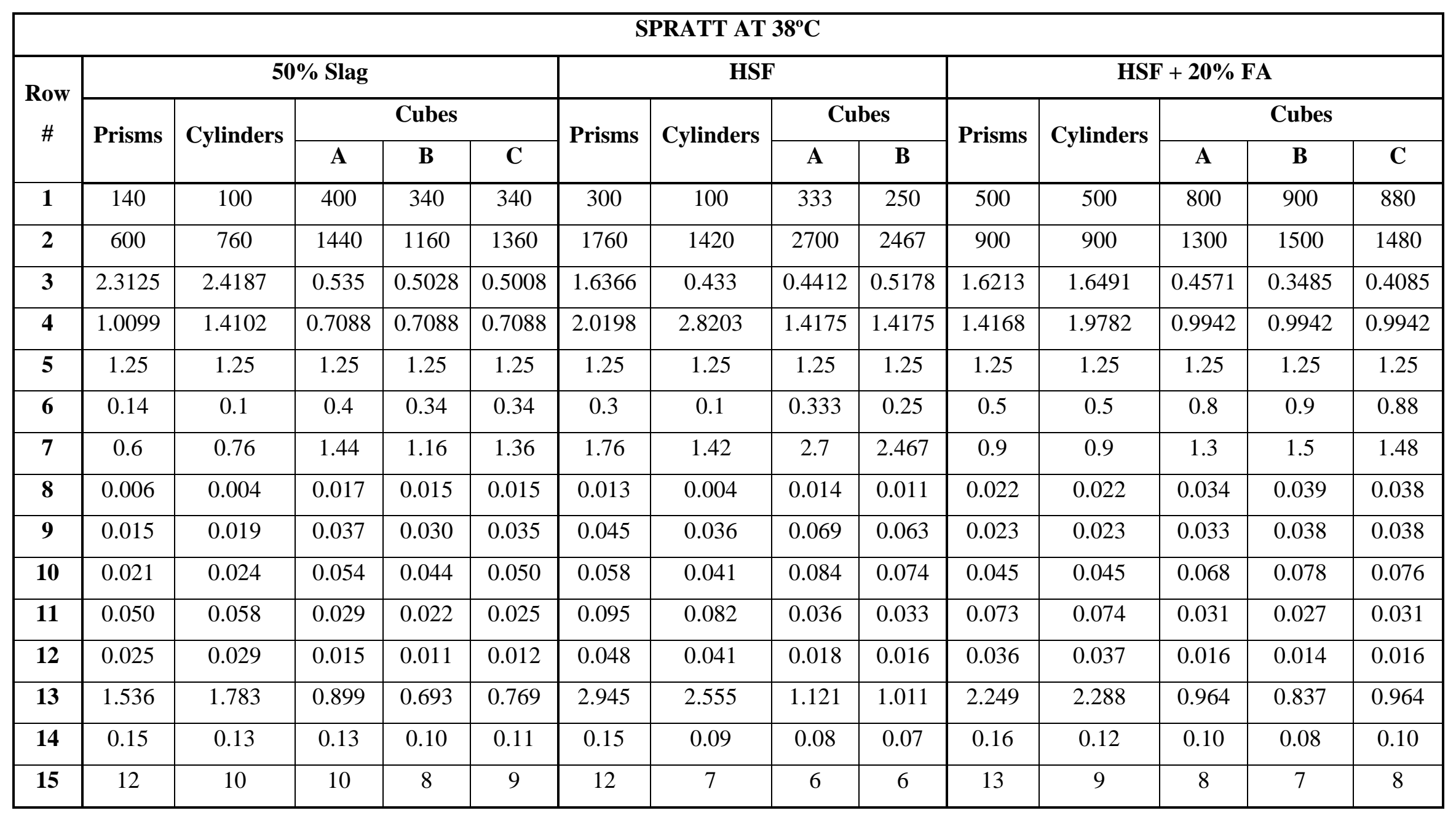




\begin{tabular}{|c|c|c|c|c|c|c|c|c|c|c|c|c|c|}
\hline \multicolumn{14}{|c|}{ SPRATT AT $60^{\circ} \mathrm{C}$} \\
\hline \multirow{3}{*}{$\begin{array}{c}\text { Row } \\
\#\end{array}$} & \multicolumn{3}{|c|}{ Control } & \multicolumn{4}{|c|}{$20 \%$ FA } & \multicolumn{4}{|c|}{$35 \%$ Slag } & \multirow{3}{*}{$\begin{array}{c}50 \% \text { Slag } \\
\text { Cube } \\
\text { B }\end{array}$} & \multirow{3}{*}{$\begin{array}{c}\text { GUB-8SF + } \\
20 \% \text { FA } \\
\text { Cube } \\
\text { C }\end{array}$} \\
\hline & & Cubes & & \multirow{2}{*}{ Prisms } & \multicolumn{3}{|c|}{ Cubes } & \multirow{2}{*}{ Cylinders } & \multicolumn{3}{|c|}{ Cubes } & & \\
\hline & $\mathbf{A}$ & $\mathbf{B}$ & $\mathbf{C}$ & & $\mathbf{A}$ & B & $\mathbf{C}$ & & $\mathbf{A}$ & B & $\mathbf{C}$ & & \\
\hline 1 & 980 & 1440 & 1917 & 720 & 1633 & 1420 & 1400 & 660 & 1200 & 1120 & 1220 & 600 & 1500 \\
\hline 2 & 4180 & 4800 & 5240 & 1580 & 3300 & 3340 & 3771 & 2740 & 3240 & 3280 & 3760 & 1860 & 2400 \\
\hline 3 & 0.5395 & 0.5387 & 0.4484 & 2.1311 & 0.5221 & 0.5445 & 0.4926 & 1.874 & 0.5224 & 0.5378 & 0.5186 & 0.5025 & 0.3596 \\
\hline 4 & 1.4175 & 1.4175 & 1.4175 & 1.6158 & 1.134 & 1.134 & 1.134 & 1.8332 & 0.9214 & 0.9214 & 0.9214 & 0.7088 & 0.9942 \\
\hline 5 & 1.25 & 1.25 & 1.25 & 1.25 & 1.25 & 1.25 & 1.25 & 1.25 & 1.25 & 1.25 & 1.25 & 1.25 & 1.25 \\
\hline 6 & 0.98 & 1.44 & 1.917 & 0.72 & 1.633 & 1.42 & 1.4 & 0.66 & 1.2 & 1.12 & 1.22 & 0.6 & 1.5 \\
\hline 7 & 4.18 & 4.8 & 5.24 & 1.58 & 3.3 & 3.34 & 3.771 & 2.74 & 3.24 & 3.28 & 3.76 & 1.86 & 2.4 \\
\hline 8 & 0.043 & 0.063 & 0.083 & 0.031 & 0.071 & 0.062 & 0.061 & 0.029 & 0.052 & 0.049 & 0.053 & 0.026 & 0.065 \\
\hline 9 & 0.107 & 0.123 & 0.134 & 0.040 & 0.084 & 0.085 & 0.096 & 0.070 & 0.083 & 0.084 & 0.096 & 0.048 & 0.061 \\
\hline 10 & 0.150 & 0.185 & 0.217 & 0.072 & 0.155 & 0.147 & 0.157 & 0.099 & 0.135 & 0.133 & 0.149 & 0.074 & 0.127 \\
\hline 11 & 0.081 & 0.100 & 0.097 & 0.153 & 0.081 & 0.080 & 0.078 & 0.185 & 0.071 & 0.071 & 0.077 & 0.037 & 0.046 \\
\hline 12 & 0.040 & 0.050 & 0.049 & 0.076 & 0.041 & 0.040 & 0.039 & 0.093 & 0.035 & 0.036 & 0.039 & 0.019 & 0.023 \\
\hline 13 & 2.500 & 3.095 & 3.021 & 4.737 & 2.515 & 2.484 & 2.402 & 5.737 & 2.187 & 2.210 & 2.398 & 1.147 & 1.411 \\
\hline 14 & 0.18 & 0.22 & 0.21 & 0.29 & 0.22 & 0.22 & 0.21 & 0.31 & 0.24 & 0.24 & 0.26 & 0.16 & 0.15 \\
\hline 15 & 14 & 17 & 17 & 23 & 18 & 18 & 17 & 25 & 19 & 19 & 21 & 13 & 12 \\
\hline
\end{tabular}




\begin{tabular}{|c|c|c|c|}
\hline \multicolumn{3}{|c|}{ SPRINGHILL + 30\% FA } \\
\hline \multirow{2}{*}{ Row \# } & \multicolumn{2}{|c|}{$\mathbf{3 8}^{\circ} \mathbf{C}$} & $\mathbf{6 0}^{\circ} \mathbf{C}$ \\
\cline { 2 - 4 } & Prisms & Cylinders & Cylinders \\
\hline $\mathbf{1}$ & 467 & 300 & 360 \\
\hline $\mathbf{2}$ & 450 & 420 & 440 \\
\hline $\mathbf{3}$ & 1.4273 & 1.6952 & 1.5679 \\
\hline $\mathbf{4}$ & 1.4138 & 1.9742 & 1.9742 \\
\hline $\mathbf{5}$ & 1.25 & 1.25 & 1.25 \\
\hline $\mathbf{6}$ & 0.467 & 0.3 & 0.36 \\
\hline $\mathbf{7}$ & 0.45 & 0.42 & 0.44 \\
\hline $\mathbf{8}$ & 0.020 & 0.013 & 0.016 \\
\hline $\mathbf{9}$ & 0.012 & 0.011 & 0.011 \\
\hline $\mathbf{1 0}$ & 0.032 & 0.024 & 0.027 \\
\hline $\mathbf{1 1}$ & 0.045 & 0.040 & 0.042 \\
\hline $\mathbf{1 2}$ & 0.023 & 0.020 & 0.021 \\
\hline $\mathbf{1 3}$ & 1.407 & 1.250 & 1.308 \\
\hline $\mathbf{1 4}$ & 0.10 & 0.06 & 0.07 \\
\hline $\mathbf{1 5}$ & 8 & 5 & 5 \\
\hline & & & \\
\hline
\end{tabular}




\begin{tabular}{|c|c|c|c|c|c|c|c|c|c|c|c|c|}
\hline \multicolumn{9}{|c|}{ CYLINDERS AT DIFFERENT ALKALI CONTENT } & \multirow{2}{*}{\multicolumn{4}{|c|}{$\begin{array}{c}\text { PRISMS AT DIFFERENT ALAKLI CONTENT } \\
\text { SPRINGHILL }\end{array}$}} \\
\hline \multirow{2}{*}{ Row \# } & \multicolumn{4}{|c|}{ SUDBURY } & \multicolumn{4}{|c|}{ SPRATT } & & & & \\
\hline & 0.57 & 0.7 & 0.8 & 0.92 & 0.57 & 0.7 & 0.8 & 0.92 & 0.57 & 0.7 & 0.8 & 1.25 \\
\hline 1 & 700 & 800 & 900 & 600 & 600 & 700 & 300 & 600 & 600 & 600 & 500 & 1600 \\
\hline 2 & 1400 & 2600 & 3800 & 4600 & 1800 & 2600 & 3000 & 4500 & 1200 & 2100 & 2300 & 4000 \\
\hline 3 & 1.1853 & 1.0967 & 1.12 & 1.2491 & 1.097 & 0.9707 & 1.2 & 0.8659 & 1.1433 & 0.9966 & 1.0935 & 0.8665 \\
\hline 4 & 2.8203 & 2.8203 & 2.8203 & 2.8203 & 2.8203 & 2.8203 & 2.8203 & 2.8203 & 2.0198 & 2.0198 & 2.0198 & 2.0198 \\
\hline 5 & 0.57 & 0.7 & 0.8 & 0.92 & 0.57 & 0.7 & 0.8 & 0.92 & 0.57 & 0.7 & 0.8 & 1.25 \\
\hline 6 & 0.7 & 0.8 & 0.9 & 0.6 & 0.6 & 0.7 & 0.3 & 0.6 & 0.6 & 0.6 & 0.5 & 1.6 \\
\hline 7 & 1.4 & 2.6 & 3.8 & 4.6 & 1.8 & 2.6 & 3 & 4.5 & 1.2 & 2.1 & 2.3 & 4 \\
\hline 8 & 0.030 & 0.035 & 0.039 & 0.026 & 0.026 & 0.030 & 0.013 & 0.026 & 0.026 & 0.026 & 0.022 & 0.070 \\
\hline 9 & 0.036 & 0.066 & 0.097 & 0.118 & 0.046 & 0.066 & 0.077 & 0.115 & 0.031 & 0.054 & 0.059 & 0.102 \\
\hline 10 & 0.066 & 0.101 & 0.136 & 0.144 & 0.072 & 0.097 & 0.090 & 0.141 & 0.057 & 0.080 & 0.081 & 0.172 \\
\hline 11 & 0.079 & 0.111 & 0.153 & 0.180 & 0.079 & 0.094 & 0.108 & 0.122 & 0.065 & 0.080 & 0.088 & 0.149 \\
\hline 12 & 0.039 & 0.056 & 0.076 & 0.090 & 0.040 & 0.047 & 0.054 & 0.061 & 0.032 & 0.040 & 0.044 & 0.074 \\
\hline 13 & 2.434 & 3.443 & 4.732 & 5.565 & 2.452 & 2.916 & 3.339 & 3.789 & 2.012 & 2.465 & 2.730 & 4.616 \\
\hline 14 & 0.09 & 0.12 & 0.17 & 0.20 & 0.09 & 0.10 & 0.12 & 0.13 & 0.10 & 0.12 & 0.14 & 0.23 \\
\hline 15 & 15 & 17 & 21 & 21 & 15 & 15 & 15 & 15 & 17 & 17 & 17 & 18 \\
\hline
\end{tabular}




\section{Appendix B}

Calculations and results of the total amount of $\mathrm{Na}_{2} \mathrm{O}_{e}$ released from aggregate samples expressed as a percent of the aggregate mass 


\begin{tabular}{|c|c|c|}
\hline Col \# & Units & Description \\
\hline 1 & ppm & $\mathrm{K}^{+}$concentration obtained by flame photometer before dilution \\
\hline 2 & $\mathrm{~mL}$ & Volume of solution $=100$ \\
\hline 3 & $\mathrm{~g}$ & Aggregate mass $=100$ \\
\hline 4 & $\mathrm{mmol} / \mathrm{L}$ & $\begin{array}{c}\mathrm{K}^{+} \text {concentration in mol/L } \\
=\text { Col. } 1 / 1000 / 39.0983(\text { molar mass of } \mathrm{K})\end{array}$ \\
\hline 5 & $\mathrm{mmol}$ & $\begin{aligned} & \text { Total } \mathrm{K}^{+} \text {in moles } \\
= & \text { Col. } 4 * \text { Col. } 2 / 1000\end{aligned}$ \\
\hline 6 & $\mathrm{mmol}$ & Total $\mathrm{K}_{2} \mathrm{O}$ in moles $=$ Col. $5 / 2$ \\
\hline 7 & $\mathrm{~g}$ & $\begin{array}{c}\text { Total mass of } \mathrm{K}_{2} \mathrm{O} \\
=\text { Col. } 6 * 94.2\left(\text { molar mass of } \mathrm{K}_{2} \mathrm{O}\right)\end{array}$ \\
\hline 8 & $\%$ & $\begin{array}{l}\text { Total } \mathrm{K}_{2} \mathrm{O} \text { taken as a } \% \text { by mass of sample } \\
\quad=(\text { Col. } 7 / \text { Col. } 3) * 100\end{array}$ \\
\hline 9 & $\%$ & Average of $\mathrm{K}_{2} \mathrm{O}$ released from aggregates (Avg. of Col. 8) \\
\hline
\end{tabular}

\begin{tabular}{|c|c|c|}
\hline Col \# & Units & Description \\
\hline 1 & $\mathrm{ppm}$ & $\mathrm{Na}^{+}$concentration obtained by flame photometer before dilution \\
\hline 2 & $\mathrm{~mL}$ & Volume of solution $=100$ \\
\hline 3 & $\mathrm{~g}$ & Aggregate mass $=100$ \\
\hline 4 & $\mathrm{mmol} / \mathrm{L}$ & $\begin{array}{l}\quad \mathrm{Na}^{+} \text {concentration in mol/L } \\
=\text { Col. } 1 / 22.9898(\text { molar mass of } \mathrm{Na})\end{array}$ \\
\hline 5 & $\mathrm{mmol}$ & $\begin{aligned} & \text { Total } \mathrm{Na}^{+} \text {in moles } \\
= & \text { Col. } 4 * \text { Col. } 2 / 1000\end{aligned}$ \\
\hline 6 & $\mathrm{mmol}$ & Total $\mathrm{Na}_{2} \mathrm{O}$ in moles $=$ Col. $5 / 2$ \\
\hline 7 & $\mathrm{~g}$ & $\begin{array}{c}\text { Total mass of } \mathrm{Na}_{2} \mathrm{O} \\
=\text { Col. } 6 / 1000 * 61.9788\left(\text { molar mass of } \mathrm{Na}_{2} \mathrm{O}\right)\end{array}$ \\
\hline 8 & $\%$ & $\begin{array}{l}\text { Total } \mathrm{Na}_{2} \mathrm{O} \text { taken as a } \% \text { by mass of sample } \\
=(\text { Col. } 7 / \mathrm{Col} .3) * 100\end{array}$ \\
\hline 9 & $\%$ & Average of $\mathrm{Na}_{2} \mathrm{O}$ released from aggregates (Avg. of Col. 8) \\
\hline
\end{tabular}




\begin{tabular}{|c|c|c|c|c|c|c|c|c|c|c|c|}
\hline \multirow{20}{*}{ 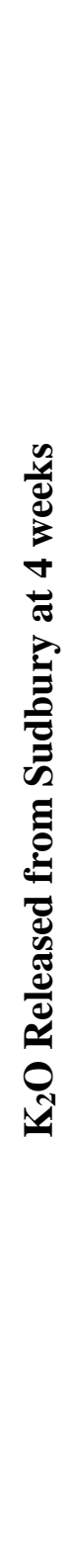 } & $\operatorname{Temp}\left({ }^{\circ} \mathrm{C}\right)$ & Soak Solution Alkalinity & 1 & 2 & 3 & 4 & 5 & 6 & 7 & 8 & 9 \\
\hline & \multirow{5}{*}{$2^{\circ} \mathrm{C}$} & \multirow{3}{*}{$0.25 \mathrm{NaOH}$} & 12.4 & 100 & 100 & 0.316 & 0.032 & 0.016 & 0.0015 & 0.0015 & \multirow{3}{*}{0.0016} \\
\hline & & & 12.0 & 100 & 100 & 0.307 & 0.031 & 0.015 & 0.0014 & 0.0014 & \\
\hline & & & 14.8 & 100 & 100 & 0.379 & 0.038 & 0.019 & 0.0018 & 0.0018 & \\
\hline & & \multirow{2}{*}{$0.7 \mathrm{NaOH}$} & 24.0 & 100 & 100 & 0.614 & 0.061 & 0.031 & 0.0029 & 0.0029 & \multirow{2}{*}{0.0027} \\
\hline & & & 20.0 & 100 & 100 & 0.512 & 0.051 & 0.026 & 0.0024 & 0.0024 & \\
\hline & \multirow{6}{*}{$38^{\circ} \mathrm{C}$} & DDW & 2 & 100 & 100 & 0.051 & 0.005 & 0.003 & 0.0002 & 0.0002 & 0.0002 \\
\hline & & \multirow{3}{*}{$0.25 \mathrm{NaOH}$} & 12 & 100 & 100 & 0.307 & 0.031 & 0.015 & 0.0014 & 0.0014 & \multirow{3}{*}{0.0018} \\
\hline & & & 14.8 & 100 & 100 & 0.379 & 0.038 & 0.019 & 0.0018 & 0.0018 & \\
\hline & & & 18 & 100 & 100 & 0.460 & 0.046 & 0.023 & 0.0022 & 0.0022 & \\
\hline & & \multirow{2}{*}{$0.7 \mathrm{NaOH}$} & 28 & 100 & 100 & 0.716 & 0.072 & 0.036 & 0.0034 & 0.0034 & \multirow{2}{*}{0.0034} \\
\hline & & & 28 & 100 & 100 & 0.716 & 0.072 & 0.036 & 0.0034 & 0.0034 & \\
\hline & \multirow{3}{*}{$38^{\circ} \mathrm{C}$-Shaking } & \multirow{3}{*}{$0.7 \mathrm{NaOH}$} & 117.6 & 100 & 100 & 3.008 & 0.301 & 0.150 & 0.0142 & 0.0142 & \multirow{3}{*}{0.0133} \\
\hline & & & 109.6 & 100 & 100 & 2.803 & 0.280 & 0.140 & 0.0132 & 0.0132 & \\
\hline & & & 104 & 100 & 100 & 2.660 & 0.266 & 0.133 & 0.0125 & 0.0125 & \\
\hline & \multirow{5}{*}{$60^{\circ} \mathrm{C}$} & \multirow{3}{*}{$0.25 \mathrm{NaOH}$} & 18.4 & 100 & 100 & 0.471 & 0.047 & 0.024 & 0.0022 & 0.0022 & \multirow{3}{*}{0.0024} \\
\hline & & & 22 & 100 & 100 & 0.563 & 0.056 & 0.028 & 0.0027 & 0.0027 & \\
\hline & & & 20 & 100 & 100 & 0.512 & 0.051 & 0.026 & 0.0024 & 0.0024 & \\
\hline & & \multirow{2}{*}{$0.7 \mathrm{NaOH}$} & 32 & 100 & 100 & 0.818 & 0.082 & 0.041 & 0.0039 & 0.0039 & \multirow{2}{*}{0.0040} \\
\hline & & & 35.2 & 100 & 100 & 0.900 & 0.090 & 0.045 & 0.0042 & 0.0042 & \\
\hline
\end{tabular}




\begin{tabular}{|c|c|c|c|c|c|c|c|c|c|c|c|}
\hline \multirow{26}{*}{ 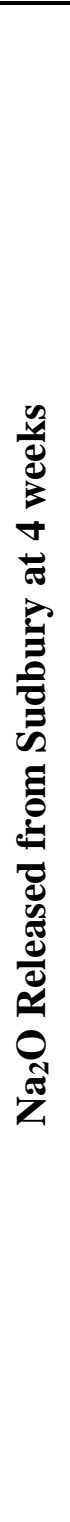 } & Temp $\left({ }^{\circ} \mathrm{C}\right)$ & Soak Solution Alkalinity & 1 & 2 & 3 & 4 & 5 & 6 & 7 & 8 & 9 \\
\hline & \multirow{6}{*}{$2^{\circ} \mathrm{C}$} & \multirow{3}{*}{$0.25 \mathrm{KOH}$} & 12.8 & 100 & 100 & 0.557 & 0.056 & 0.028 & 0.0017 & 0.0017 & \multirow{3}{*}{0.0024} \\
\hline & & & 16.8 & 100 & 100 & 0.731 & 0.073 & 0.037 & 0.0023 & 0.0023 & \\
\hline & & & 24.2 & 100 & 100 & 1.053 & 0.105 & 0.053 & 0.0033 & 0.0033 & \\
\hline & & \multirow{3}{*}{$0.7 \mathrm{KOH}$} & 46.4 & 100 & 100 & 2.018 & 0.202 & 0.101 & 0.0063 & 0.0063 & \multirow{3}{*}{0.0061} \\
\hline & & & 45.6 & 100 & 100 & 1.983 & 0.198 & 0.099 & 0.0061 & 0.0061 & \\
\hline & & & 44 & 100 & 100 & 1.914 & 0.191 & 0.096 & 0.0059 & 0.0059 & \\
\hline & \multirow{7}{*}{$38^{\circ} \mathrm{C}$} & DDW & 4.4 & 100 & 100 & 0.191 & 0.019 & 0.010 & 0.0006 & 0.0006 & 0.0006 \\
\hline & & \multirow{3}{*}{$0.25 \mathrm{KOH}$} & 20 & 100 & 100 & 0.870 & 0.087 & 0.043 & 0.0027 & 0.0027 & \multirow{3}{*}{0.0031} \\
\hline & & & 24 & 100 & 100 & 1.044 & 0.104 & 0.052 & 0.0032 & 0.0032 & \\
\hline & & & 24 & 100 & 100 & 1.044 & 0.104 & 0.052 & 0.0032 & 0.0032 & \\
\hline & & \multirow{3}{*}{$0.7 \mathrm{KOH}$} & 39.2 & 100 & 100 & 1.705 & 0.171 & 0.085 & 0.0053 & 0.0053 & \multirow{3}{*}{0.0050} \\
\hline & & & 40 & 100 & 100 & 1.740 & 0.174 & 0.087 & 0.0054 & 0.0054 & \\
\hline & & & 32.8 & 100 & 100 & 1.427 & 0.143 & 0.071 & 0.0044 & 0.0044 & \\
\hline & \multirow{6}{*}{$38^{\circ} \mathrm{C}$-Shaking } & \multirow{3}{*}{$0.25 \mathrm{KOH}$} & 52 & 100 & 100 & 2.262 & 0.226 & 0.113 & 0.0070 & 0.0070 & \multirow{3}{*}{0.0075} \\
\hline & & & 58.4 & 100 & 100 & 2.540 & 0.254 & 0.127 & 0.0079 & 0.0079 & \\
\hline & & & 56 & 100 & 100 & 2.436 & 0.244 & 0.122 & 0.0075 & 0.0075 & \\
\hline & & \multirow{3}{*}{$0.7 \mathrm{KOH}$} & 55.2 & 100 & 100 & 2.401 & 0.240 & 0.120 & 0.0074 & 0.0074 & \multirow{3}{*}{0.0082} \\
\hline & & & 64 & 100 & 100 & 2.784 & 0.278 & 0.139 & 0.0086 & 0.0086 & \\
\hline & & & 64 & 100 & 100 & 2.784 & 0.278 & 0.139 & 0.0086 & 0.0086 & \\
\hline & \multirow{6}{*}{$60^{\circ} \mathrm{C}$} & \multirow{3}{*}{$0.25 \mathrm{KOH}$} & 21.6 & 100 & 100 & 0.940 & 0.094 & 0.047 & 0.0029 & 0.0029 & \multirow{3}{*}{0.0027} \\
\hline & & & 22 & 100 & 100 & 0.957 & 0.096 & 0.048 & 0.0030 & 0.0030 & \\
\hline & & & 15.6 & 100 & 100 & 0.679 & 0.068 & 0.034 & 0.0021 & 0.0021 & \\
\hline & & \multirow{3}{*}{ 0.7 КОН } & 53.6 & 100 & 100 & 2.331 & 0.233 & 0.117 & 0.0072 & 0.0072 & \multirow{3}{*}{0.0065} \\
\hline & & & 48 & 100 & 100 & 2.088 & 0.209 & 0.104 & 0.0065 & 0.0065 & \\
\hline & & & 44 & 100 & 100 & 1.914 & 0.191 & 0.096 & 0.0059 & 0.0059 & \\
\hline
\end{tabular}




\begin{tabular}{|c|c|c|c|c|c|c|c|c|c|c|c|}
\hline \multirow{5}{*}{ 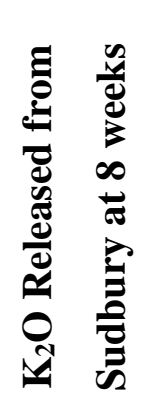 } & Temp $\left({ }^{\circ} \mathrm{C}\right)$ & $\begin{array}{c}\text { Soak Solution } \\
\text { Alkalinity }\end{array}$ & 1 & 2 & 3 & 4 & 5 & 6 & 7 & 8 & 9 \\
\hline & $23^{\circ} \mathrm{C}$ & $0.25 \mathrm{NaOH}$ & 14 & 100 & 100 & 0.358 & 0.036 & 0.018 & 0.0017 & 0.0017 & 0.0017 \\
\hline & $38^{\circ} \mathrm{C}$ & $0.25 \mathrm{NaOH}$ & 12 & 100 & 100 & 0.307 & 0.031 & 0.015 & 0.0014 & 0.0014 & 0.0014 \\
\hline & $38^{\circ} \mathrm{C}$-Shaking & $0.25 \mathrm{NaOH}$ & 92.8 & 100 & 100 & 2.374 & 0.237 & 0.119 & 0.0112 & 0.0112 & 0.0112 \\
\hline & $60^{\circ} \mathrm{C}$ & $0.25 \mathrm{NaOH}$ & 12 & 100 & 100 & 0.307 & 0.031 & 0.015 & 0.0014 & 0.0014 & 0.0014 \\
\hline
\end{tabular}




\begin{tabular}{|c|c|c|c|c|c|c|c|c|c|c|c|}
\hline \multirow{22}{*}{ 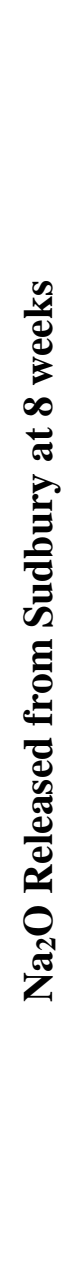 } & Temp $\left({ }^{\circ} \mathrm{C}\right)$ & Soak Solution Alkalinity & 1 & 2 & 3 & 4 & 5 & 6 & 7 & 8 & 9 \\
\hline & \multirow{6}{*}{$23^{\circ} \mathrm{C}$} & \multirow{3}{*}{$0.25 \mathrm{KOH}$} & 18.4 & 100 & 100 & 0.800 & 0.080 & 0.040 & 0.0025 & 0.0025 & \multirow{3}{*}{0.0029} \\
\hline & & & 23.2 & 100 & 100 & 1.009 & 0.101 & 0.050 & 0.0031 & 0.0031 & \\
\hline & & & 24 & 100 & 100 & 1.044 & 0.104 & 0.052 & 0.0032 & 0.0032 & \\
\hline & & \multirow{3}{*}{$0.7 \mathrm{KOH}$} & 52 & 100 & 100 & 2.262 & 0.226 & 0.113 & 0.0070 & 0.0070 & \multirow{3}{*}{0.0065} \\
\hline & & & 40 & 100 & 100 & 1.740 & 0.174 & 0.087 & 0.0054 & 0.0054 & \\
\hline & & & 52 & 100 & 100 & 2.262 & 0.226 & 0.113 & 0.0070 & 0.0070 & \\
\hline & \multirow{6}{*}{$38^{\circ} \mathrm{C}$} & \multirow{3}{*}{$0.25 \mathrm{KOH}$} & 33.6 & 100 & 100 & 1.462 & 0.146 & 0.073 & 0.0045 & 0.0045 & \multirow{3}{*}{0.0038} \\
\hline & & & 22.4 & 100 & 100 & 0.974 & 0.097 & 0.049 & 0.0030 & 0.0030 & \\
\hline & & & 28 & 100 & 100 & 1.218 & 0.122 & 0.061 & 0.0038 & 0.0038 & \\
\hline & & \multirow{3}{*}{$0.7 \mathrm{KOH}$} & 60 & 100 & 100 & 2.610 & 0.261 & 0.130 & 0.0081 & 0.0081 & \multirow{3}{*}{0.0070} \\
\hline & & & 48 & 100 & 100 & 2.088 & 0.209 & 0.104 & 0.0065 & 0.0065 & \\
\hline & & & 48 & 100 & 100 & 2.088 & 0.209 & 0.104 & 0.0065 & 0.0065 & \\
\hline & \multirow{3}{*}{$38^{\circ} \mathrm{C}$-Shaking } & \multirow{3}{*}{$0.25 \mathrm{KOH}$} & 72 & 100 & 100 & 3.132 & 0.313 & 0.157 & 0.0097 & 0.0097 & \multirow{3}{*}{0.0103} \\
\hline & & & 80.8 & 100 & 100 & 3.515 & 0.351 & 0.176 & 0.0109 & 0.0109 & \\
\hline & & & 76.8 & 100 & 100 & 3.341 & 0.334 & 0.167 & 0.0104 & 0.0104 & \\
\hline & \multirow{6}{*}{$60^{\circ} \mathrm{C}$} & \multirow{3}{*}{$0.25 \mathrm{KOH}$} & 20.8 & 100 & 100 & 0.905 & 0.090 & 0.045 & 0.0028 & 0.0028 & \multirow{3}{*}{0.0036} \\
\hline & & & 27.2 & 100 & 100 & 1.183 & 0.118 & 0.059 & 0.0037 & 0.0037 & \\
\hline & & & 32.8 & 100 & 100 & 1.427 & 0.143 & 0.071 & 0.0044 & 0.0044 & \\
\hline & & \multirow{3}{*}{$0.7 \mathrm{KOH}$} & 67.2 & 100 & 100 & 2.923 & 0.292 & 0.146 & 0.0091 & 0.0091 & \multirow{3}{*}{0.0082} \\
\hline & & & 56 & 100 & 100 & 2.436 & 0.244 & 0.122 & 0.0075 & 0.0075 & \\
\hline & & & 60 & 100 & 100 & 2.610 & 0.261 & 0.130 & 0.0081 & 0.0081 & \\
\hline
\end{tabular}




\begin{tabular}{|c|c|c|c|c|c|c|c|c|c|c|c|}
\hline$n$ & $\operatorname{Temp}\left({ }^{\circ} \mathrm{C}\right)$ & Soak Solution Alkalinity & 1 & 2 & 3 & 4 & 5 & 6 & 7 & 8 & 9 \\
\hline 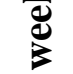 & \multirow{2}{*}{$23^{\circ} \mathrm{C}$} & $0.25 \mathrm{NaOH}$ & 8 & 100 & 100 & 0.205 & 0.020 & 0.010 & 0.0010 & 0.0010 & 0.0010 \\
\hline \multirow{8}{*}{ 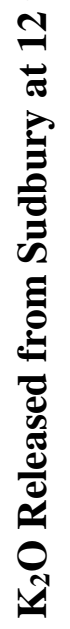 } & & $0.7 \mathrm{NaOH}$ & 33 & 100 & 100 & 0.844 & 0.084 & 0.042 & 0.0040 & 0.0040 & 0.0040 \\
\hline & \multirow{3}{*}{$38^{\circ} \mathrm{C}$} & DDW & 6 & 100 & 100 & 0.153 & 0.015 & 0.008 & 0.0007 & 0.0007 & 0.0007 \\
\hline & & $0.25 \mathrm{NaOH}$ & 19.4 & 100 & 100 & 0.497 & 0.050 & 0.025 & 0.0023 & 0.0023 & 0.0023 \\
\hline & & $0.7 \mathrm{NaOH}$ & 32.8 & 100 & 100 & 0.839 & 0.084 & 0.042 & 0.0040 & 0.0040 & 0.0040 \\
\hline & \multirow{2}{*}{$38^{\circ} \mathrm{C}-$-Shaking } & $0.25 \mathrm{NaOH}$ & 107.2 & 100 & 100 & 2.742 & 0.274 & 0.137 & 0.0129 & 0.0129 & 0.0129 \\
\hline & & $0.7 \mathrm{NaOH}$ & 193.6 & 100 & 100 & 4.952 & 0.495 & 0.248 & 0.0233 & 0.0233 & 0.0233 \\
\hline & \multirow{2}{*}{$60^{\circ} \mathrm{C}$} & $0.25 \mathrm{NaOH}$ & 19.6 & 100 & 100 & 0.501 & 0.050 & 0.025 & 0.0024 & 0.0024 & 0.0024 \\
\hline & & $0.7 \mathrm{NaOH}$ & 37.6 & 100 & 100 & 0.962 & 0.096 & 0.048 & 0.0045 & 0.0045 & 0.0045 \\
\hline
\end{tabular}




\begin{tabular}{|c|c|c|c|c|c|c|c|c|c|c|c|}
\hline \multirow{18}{*}{ 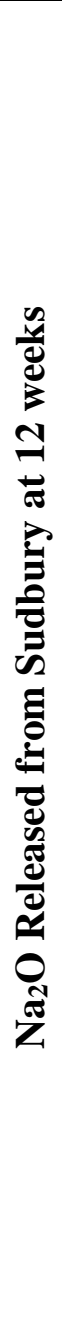 } & $\operatorname{Temp}\left({ }^{\circ} \mathrm{C}\right)$ & Soak Solution Alkalinity & 1 & 2 & 3 & 4 & 5 & 6 & 7 & 8 & 9 \\
\hline & \multirow{4}{*}{$23^{\circ} \mathrm{C}$} & \multirow{3}{*}{$0.25 \mathrm{KOH}$} & 12 & 100 & 100 & 0.522 & 0.052 & 0.026 & 0.0016 & 0.0016 & \multirow{3}{*}{0.0024} \\
\hline & & & 24 & 100 & 100 & 1.044 & 0.104 & 0.052 & 0.0032 & 0.0032 & \\
\hline & & & 18.4 & 100 & 100 & 0.800 & 0.080 & 0.040 & 0.0025 & 0.0025 & \\
\hline & & $0.7 \mathrm{KOH}$ & 36 & 100 & 100 & 1.566 & 0.157 & 0.078 & 0.0049 & 0.0049 & 0.0049 \\
\hline & \multirow{5}{*}{$38^{\circ} \mathrm{C}$} & DDW & 8.8 & 100 & 100 & 0.383 & 0.038 & 0.019 & 0.0012 & 0.0012 & 0.0012 \\
\hline & & \multirow{3}{*}{$0.25 \mathrm{KOH}$} & 21.6 & 100 & 100 & 0.940 & 0.094 & 0.047 & 0.0029 & 0.0029 & \multirow{3}{*}{0.0033} \\
\hline & & & 31.2 & 100 & 100 & 1.356 & 0.136 & 0.068 & 0.0042 & 0.0042 & \\
\hline & & & 20 & 100 & 100 & 0.870 & 0.087 & 0.043 & 0.0027 & 0.0027 & \\
\hline & & 0.7 КОН & 47 & 100 & 100 & 2.044 & 0.204 & 0.102 & 0.0063 & 0.0063 & 0.0063 \\
\hline & \multirow{4}{*}{$38^{\circ} \mathrm{C}$-Shaking } & \multirow{3}{*}{$0.25 \mathrm{KOH}$} & 88 & 100 & 100 & 3.828 & 0.383 & 0.191 & 0.0119 & 0.0119 & \multirow{3}{*}{0.0115} \\
\hline & & & 90.4 & 100 & 100 & 3.932 & 393 & 0.197 & 0.0122 & 0.0122 & \\
\hline & & & 78.4 & 100 & 100 & 3.410 & 0.341 & 0.171 & 0.0106 & 0.0106 & \\
\hline & & $0.7 \mathrm{KOH}$ & 88 & 100 & 100 & 3.828 & 0.383 & 0.191 & 0.0119 & 0.0119 & 0.0119 \\
\hline & \multirow{4}{*}{$60^{\circ} \mathrm{C}$} & \multirow{3}{*}{$0.25 \mathrm{KOH}$} & 36 & 100 & 100 & 1.566 & 0.157 & 0.078 & 0.0049 & 0.0049 & \multirow{3}{*}{0.0049} \\
\hline & & & 40 & 100 & 100 & 1.740 & 0.174 & 0.087 & 0.0054 & 0.0054 & \\
\hline & & & 32 & 100 & 100 & 1.392 & 0.139 & 0.070 & 0.0043 & 0.0043 & \\
\hline & & 0.7 КОН & 60.6 & 100 & 100 & 2.636 & 0.264 & 0.132 & 0.0082 & 0.0082 & 0.0082 \\
\hline
\end{tabular}




\begin{tabular}{|c|c|c|c|c|c|c|c|c|c|c|c|}
\hline \multirow{21}{*}{ 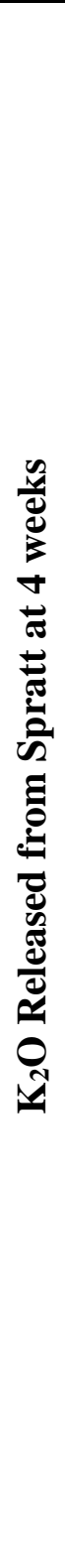 } & $\operatorname{Temp}\left({ }^{\circ} \mathrm{C}\right)$ & Soak Solution Alkalinity & 1 & 2 & 3 & 4 & 5 & 6 & 7 & 8 & 9 \\
\hline & \multirow{5}{*}{$23^{\circ} \mathrm{C}$} & \multirow{3}{*}{$0.25 \mathrm{NaOH}$} & 3.64 & 100 & 100 & 0.158 & 0.016 & 0.008 & 0.0005 & 0.0005 & \multirow{3}{*}{0.0006} \\
\hline & & & 4.96 & 100 & 100 & 0.216 & 0.022 & 0.011 & 0.0007 & 0.0007 & \\
\hline & & & 4.96 & 100 & 100 & 0.216 & 0.022 & 0.011 & 0.0007 & 0.0007 & \\
\hline & & \multirow{2}{*}{$0.7 \mathrm{NaOH}$} & 4 & 100 & 100 & 0.174 & 0.017 & 0.009 & 0.0005 & 0.0005 & \multirow{2}{*}{0.0006} \\
\hline & & & 4.8 & 100 & 100 & 0.209 & 0.021 & 0.010 & 0.0006 & 0.0006 & \\
\hline & \multirow{6}{*}{$38^{\circ} \mathrm{C}$} & DDW & 0 & 100 & 100 & 0.000 & 0.000 & 0.000 & 0.0000 & 0.0000 & 0.0000 \\
\hline & & \multirow{3}{*}{$0.25 \mathrm{NaOH}$} & 1.76 & 100 & 100 & 0.077 & 0.008 & 0.004 & 0.0002 & 0.0002 & \multirow{3}{*}{0.0005} \\
\hline & & & 4.6 & 100 & 100 & 0.200 & 0.020 & 0.010 & 0.0006 & 0.0006 & \\
\hline & & & 4.64 & 100 & 100 & 0.202 & 0.020 & 0.010 & 0.0006 & 0.0006 & \\
\hline & & \multirow{2}{*}{$0.7 \mathrm{NaOH}$} & 4 & 100 & 100 & 0.174 & 0.017 & 0.009 & 0.0005 & 0.0005 & \multirow{2}{*}{0.0005} \\
\hline & & & 4 & 100 & 100 & 0.174 & 0.017 & 0.009 & 0.0005 & 0.0005 & \\
\hline & \multirow{4}{*}{$38^{\circ} \mathrm{C}$-Shaking } & $0.25 \mathrm{NaOH}$ & 9.1 & 100 & 100 & 0.397 & 0.040 & 0.020 & 0.0012 & 0.0012 & 0.0012 \\
\hline & & \multirow{3}{*}{$0.7 \mathrm{NaOH}$} & 16.8 & 100 & 100 & 0.731 & 0.073 & 0.037 & 0.0023 & 0.0023 & \multirow{3}{*}{0.0024} \\
\hline & & & 17.6 & 100 & 100 & 0.766 & 0.077 & 0.038 & 0.0024 & 0.0024 & \\
\hline & & & 20 & 100 & 100 & 0.870 & 0.087 & 0.043 & 0.0027 & 0.0027 & \\
\hline & \multirow{5}{*}{$60^{\circ} \mathrm{C}$} & \multirow{3}{*}{$0.25 \mathrm{NaOH}$} & 4 & 100 & 100 & 0.174 & 0.017 & 0.009 & 0.0005 & 0.0005 & \multirow{3}{*}{0.0008} \\
\hline & & & 5 & 100 & 100 & 0.217 & 0.022 & 0.011 & 0.0007 & 0.0007 & \\
\hline & & & 8.2 & 100 & 100 & 0.357 & 0.036 & 0.018 & 0.0011 & 0.0011 & \\
\hline & & \multirow{2}{*}{$0.7 \mathrm{NaOH}$} & 4 & 100 & 100 & 0.174 & 0.017 & 0.009 & 0.0005 & 0.0005 & \multirow{2}{*}{0.0006} \\
\hline & & & 4.8 & 100 & 100 & 0.209 & 0.021 & 0.010 & 0.0006 & 0.0006 & \\
\hline
\end{tabular}




\begin{tabular}{|c|c|c|c|c|c|c|c|c|c|c|c|}
\hline \multirow{26}{*}{ 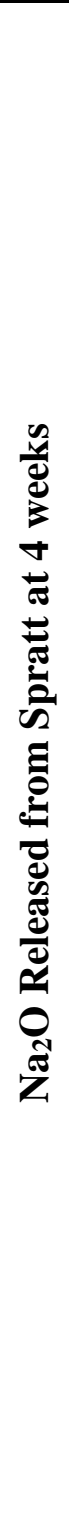 } & Temp $\left({ }^{\circ} \mathbf{C}\right)$ & Soak Solution Alkalinity & 1 & 2 & 3 & 4 & 5 & 6 & 7 & 8 & 9 \\
\hline & \multirow{6}{*}{$23^{\circ} \mathrm{C}$} & \multirow{3}{*}{$0.25 \mathrm{KOH}$} & 14 & 100 & 100 & 0.609 & 0.061 & 0.030 & 0.0019 & 0.0019 & \multirow{3}{*}{0.022} \\
\hline & & & 14.4 & 100 & 100 & 0.626 & 0.063 & 0.031 & 0.0019 & 0.0019 & \\
\hline & & & 20.7 & 100 & 100 & 0.899 & 0.090 & 0.045 & 0.0028 & 0.0028 & \\
\hline & & \multirow{3}{*}{$0.7 \mathrm{KOH}$} & 44 & 100 & 100 & 1.914 & 0.191 & 0.096 & 0.0059 & 0.0059 & \multirow{3}{*}{0.0061} \\
\hline & & & 44 & 100 & 100 & 1.914 & 0.191 & 0.096 & 0.0059 & 0.0059 & \\
\hline & & & 48.4 & 100 & 100 & 2.123 & 0.212 & 0.106 & 0.0066 & 0.0066 & \\
\hline & \multirow{7}{*}{$3^{\circ} \mathrm{C}$} & DDW & 4.4 & 100 & 100 & 0.191 & 0.019 & 0.010 & 0.0006 & 0.0006 & 0.0006 \\
\hline & & \multirow{3}{*}{$0.25 \mathrm{KOH}$} & 24 & 100 & 100 & 1.044 & 0.104 & 0.052 & 0.0032 & 0.0032 & \multirow{3}{*}{0.0031} \\
\hline & & & 21.6 & 100 & 100 & 0.940 & 0.094 & 0.047 & 0.0029 & 0.0029 & \\
\hline & & & 22.8 & 100 & 100 & 0.992 & 0.099 & 0.050 & 0.0031 & 0.0031 & \\
\hline & & \multirow{3}{*}{$0.7 \mathrm{KOH}$} & 37.6 & 100 & 100 & 1.636 & 0.164 & 0.082 & 0.0051 & 0.0051 & \multirow{3}{*}{0.0046} \\
\hline & & & 28.8 & 100 & 100 & 1.253 & 0.125 & 0.063 & 0.0039 & 0.0039 & \\
\hline & & & 36.8 & 100 & 100 & 1.601 & 0.160 & 0.080 & 0.0050 & 0.0050 & \\
\hline & \multirow{6}{*}{$38^{\circ} \mathrm{C}$-Shaking } & \multirow{3}{*}{$0.25 \mathrm{KOH}$} & 40 & 100 & 100 & 1.740 & 0.174 & 0.087 & 0.0054 & 0.0054 & \multirow{3}{*}{0.0050} \\
\hline & & & 36 & 100 & 100 & 1.566 & 0.157 & 0.078 & 0.0049 & 0.0049 & \\
\hline & & & 36 & 100 & 100 & 1.566 & 0.157 & 0.078 & 0.0049 & 0.0049 & \\
\hline & & \multirow{3}{*}{$0.7 \mathrm{KOH}$} & 36 & 100 & 100 & 1.566 & 0.157 & 0.078 & 0.0049 & 0.0049 & \multirow{3}{*}{0.0045} \\
\hline & & & 24 & 100 & 100 & 1.044 & 0.104 & 0.052 & 0.0032 & 0.0032 & \\
\hline & & & 40 & 100 & 100 & 1.740 & 0.174 & 0.087 & 0.0054 & 0.0054 & \\
\hline & \multirow{6}{*}{$60^{\circ} \mathrm{C}$} & \multirow{3}{*}{$0.25 \mathrm{KOH}$} & 20.8 & 100 & 100 & 0.905 & 0.090 & 0.045 & 0.0028 & 0.0028 & \multirow{3}{*}{0.0026} \\
\hline & & & 22.8 & 100 & 100 & 0.992 & 0.099 & 0.050 & 0.0031 & 0.0031 & \\
\hline & & & 14.8 & 100 & 100 & 0.644 & 0.064 & 0.032 & 0.0020 & 0.0020 & \\
\hline & & \multirow{3}{*}{$0.7 \mathrm{KOH}$} & 49.6 & 100 & 100 & 2.157 & 0.216 & 0.108 & 0.0067 & 0.0067 & \multirow{3}{*}{0.0069} \\
\hline & & & 52 & 100 & 100 & 2.262 & 0.226 & 0.113 & 0.0070 & 0.0070 & \\
\hline & & & 52 & 100 & 100 & 2.262 & 0.226 & 0.113 & 0.0070 & 0.0070 & \\
\hline
\end{tabular}




\begin{tabular}{|c|c|c|c|c|c|c|c|c|c|c|c|}
\hline \multirow{5}{*}{ 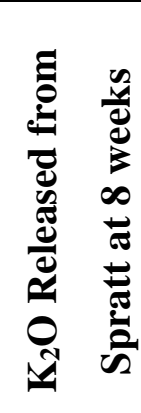 } & Temp $\left({ }^{\circ} \mathrm{C}\right)$ & $\begin{array}{c}\text { Soak Solution } \\
\text { Alkalinity }\end{array}$ & 1 & 2 & 3 & 4 & 5 & 6 & 7 & 8 & 9 \\
\hline & $23^{\circ} \mathrm{C}$ & $0.25 \mathrm{NaOH}$ & 3.64 & 100 & 100 & 0.158 & 0.016 & 0.008 & 0.0005 & 0.0005 & 0.0005 \\
\hline & $38^{\circ} \mathrm{C}$ & $0.25 \mathrm{NaOH}$ & 2.24 & 100 & 100 & 0.097 & 0.010 & 0.005 & 0.0003 & 0.0003 & 0.0003 \\
\hline & $38^{\circ} \mathrm{C}$-Shaking & $0.25 \mathrm{NaOH}$ & 15.2 & 100 & 100 & 0.661 & 0.066 & 0.033 & 0.0020 & 0.0020 & 0.0020 \\
\hline & $60^{\circ} \mathrm{C}$ & $0.25 \mathrm{NaOH}$ & 2 & 100 & 100 & 0.087 & 0.009 & 0.004 & 0.0003 & 0.0003 & 0.0003 \\
\hline
\end{tabular}




\begin{tabular}{|c|c|c|c|c|c|c|c|c|c|c|c|}
\hline \multirow{22}{*}{ 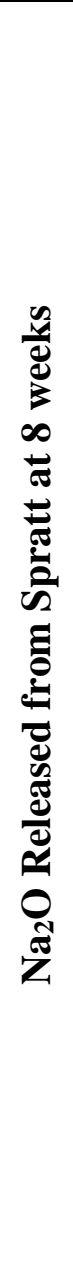 } & Temp $\left({ }^{\circ} \mathrm{C}\right)$ & Soak Solution Alkalinity & 1 & 2 & 3 & 4 & 5 & 6 & 7 & 8 & 9 \\
\hline & \multirow{6}{*}{$23^{\circ} \mathrm{C}$} & \multirow{3}{*}{$0.25 \mathrm{KOH}$} & 6.4 & 100 & 100 & 0.278 & 0.028 & 0.014 & 0.0009 & 0.0009 & \multirow{3}{*}{0.0012} \\
\hline & & & 12.0 & 100 & 100 & 0.522 & 0.052 & 0.026 & 0.0016 & 0.0016 & \\
\hline & & & 8.0 & 100 & 100 & 0.348 & 0.035 & 0.017 & 0.0011 & 0.0011 & \\
\hline & & \multirow{3}{*}{$0.7 \mathrm{KOH}$} & 48.0 & 100 & 100 & 2.088 & 0.209 & 0.104 & 0.0065 & 0.0065 & \multirow{3}{*}{0.0065} \\
\hline & & & 56.0 & 100 & 100 & 2.436 & 0.244 & 0.122 & 0.0075 & 0.0075 & \\
\hline & & & 41.0 & 100 & 100 & 1.783 & 0.178 & 0.089 & 0.0055 & 0.0055 & \\
\hline & \multirow{6}{*}{$38^{\circ} \mathrm{C}$} & \multirow{3}{*}{$0.25 \mathrm{KOH}$} & 28.0 & 100 & 100 & 1.218 & 0.122 & 0.061 & 0.0038 & 0.0038 & \multirow{3}{*}{0.0038} \\
\hline & & & 28.8 & 100 & 100 & 1.253 & 0.125 & 0.063 & 0.0039 & 0.0039 & \\
\hline & & & 28.0 & 100 & 100 & 1.218 & 0.122 & 0.061 & 0.0038 & 0.0038 & \\
\hline & & \multirow{3}{*}{$0.7 \mathrm{KOH}$} & 36.0 & 100 & 100 & 1.566 & 0.157 & 0.078 & 0.0049 & 0.0049 & \multirow{3}{*}{0.0051} \\
\hline & & & 36.0 & 100 & 100 & 1.566 & 0.157 & 0.078 & 0.0049 & 0.0049 & \\
\hline & & & 41.0 & 100 & 100 & 1.783 & 0.178 & 0.089 & 0.0055 & 0.0055 & \\
\hline & \multirow{3}{*}{$38^{\circ} \mathrm{C}$-Shaking } & \multirow{3}{*}{$0.25 \mathrm{KOH}$} & 40.8 & 100 & 100 & 1.775 & 0.177 & 0.089 & 0.0055 & 0.0055 & \multirow{3}{*}{0.0047} \\
\hline & & & 28.8 & 100 & 100 & 1.253 & 0.125 & 0.063 & 0.0039 & 0.0039 & \\
\hline & & & 36.0 & 100 & 100 & 1.566 & 0.157 & 0.078 & 0.0049 & 0.0049 & \\
\hline & \multirow{6}{*}{$60^{\circ} \mathrm{C}$} & \multirow{3}{*}{$0.25 \mathrm{KOH}$} & 28.0 & 100 & 100 & 1.218 & 0.122 & 0.061 & 0.0038 & 0.0038 & \multirow{3}{*}{0.0033} \\
\hline & & & 24.8 & 100 & 100 & 1.079 & 0.108 & 0.054 & 0.0033 & 0.0033 & \\
\hline & & & 20.0 & 100 & 100 & 0.870 & 0.087 & 0.043 & 0.0027 & 0.0027 & \\
\hline & & \multirow{3}{*}{$0.7 \mathrm{KOH}$} & 48.0 & 100 & 100 & 2.088 & 0.209 & 0.104 & 0.0065 & 0.0065 & \multirow{3}{*}{0.0063} \\
\hline & & & 48.0 & 100 & 100 & 2.088 & 0.209 & 0.104 & 0.0065 & 0.0065 & \\
\hline & & & 44.0 & 100 & 100 & 1.914 & 0.191 & 0.096 & 0.0059 & 0.0059 & \\
\hline
\end{tabular}




\begin{tabular}{|c|c|c|c|c|c|c|c|c|c|c|c|}
\hline & $\operatorname{Temp}\left({ }^{\circ} \mathrm{C}\right)$ & Soak Solution Alkalinity & 1 & 2 & 3 & 4 & 5 & 6 & 7 & 8 & 9 \\
\hline 这 & \multirow{2}{*}{$23^{\circ} \mathrm{C}$} & $0.25 \mathrm{NaOH}$ & 3.56 & 100 & 100 & 0.155 & 0.015 & 0.008 & 0.0005 & 0.0005 & 0.0005 \\
\hline \multirow{8}{*}{ 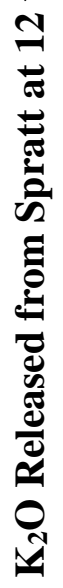 } & & $0.7 \mathrm{NaOH}$ & 4 & 100 & 100 & 0.174 & 0.017 & 0.009 & 0.0005 & 0.0005 & 0.0005 \\
\hline & \multirow{3}{*}{$38^{\circ} \mathrm{C}$} & DDW & 3.8 & 100 & 100 & 0.165 & 0.017 & 0.008 & 0.0005 & 0.0005 & 0.0005 \\
\hline & & $0.25 \mathrm{NaOH}$ & 3.64 & 100 & 100 & 0.158 & 0.016 & 0.008 & 0.0005 & 0.0005 & 0.0005 \\
\hline & & $0.7 \mathrm{NaOH}$ & 4 & 100 & 100 & 0.174 & 0.017 & 0.009 & 0.0005 & 0.0005 & 0.0005 \\
\hline & \multirow{2}{*}{$38^{\circ} \mathrm{C}-S h a k i n g$} & $0.25 \mathrm{NaOH}$ & 14.4 & 100 & 100 & 0.636 & 0.063 & 0.031 & 0.0019 & 0.0019 & 0.0019 \\
\hline & & $0.7 \mathrm{NaOH}$ & 16 & 100 & 100 & 0.696 & 0.070 & 0.035 & 0.0022 & 0.0022 & 0.0022 \\
\hline & \multirow{2}{*}{$60^{\circ} \mathrm{C}$} & $0.25 \mathrm{NaOH}$ & 3.65 & 100 & 100 & 0.159 & 0.016 & 0.008 & 0.0005 & 0.0005 & 0.0005 \\
\hline & & $0.7 \mathrm{NaOH}$ & 4 & 100 & 100 & 0.174 & 0.017 & 0.009 & 0.0005 & 0.0005 & 0.0005 \\
\hline
\end{tabular}




\begin{tabular}{|c|c|c|c|c|c|c|c|c|c|c|c|}
\hline \multirow{18}{*}{ 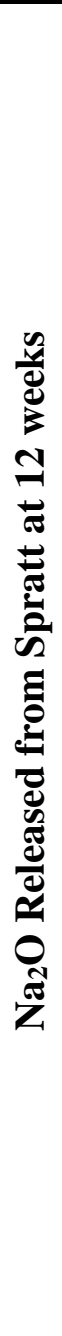 } & $\operatorname{Temp}\left({ }^{\circ} \mathrm{C}\right)$ & Soak Solution Alkalinity & 1 & 2 & 3 & 4 & 5 & 6 & 7 & 8 & 9 \\
\hline & \multirow{4}{*}{$23^{\circ} \mathrm{C}$} & \multirow{3}{*}{$0.25 \mathrm{KOH}$} & 27.2 & 100 & 100 & 1.183 & 0.118 & 0.059 & 0.0037 & 0.0037 & \multirow{3}{*}{0.0027} \\
\hline & & & 24.0 & 100 & 100 & 1.044 & 0.104 & 0.052 & 0.0032 & 0.0032 & \\
\hline & & & 8.0 & 100 & 100 & 0.348 & 0.035 & 0.017 & 0.0011 & 0.0011 & \\
\hline & & $0.7 \mathrm{KOH}$ & 28.0 & 100 & 100 & 1.218 & 0.122 & 0.061 & 0.0038 & 0.0038 & 0.0038 \\
\hline & \multirow{5}{*}{$38^{\circ} \mathrm{C}$} & DDW & 6.56 & 100 & 100 & 0.285 & 0.029 & 0.014 & 0.0009 & 0.0009 & 0.0009 \\
\hline & & \multirow{3}{*}{$0.25 \mathrm{KOH}$} & 28.8 & 100 & 100 & 1.253 & 0.125 & 0.063 & 0.0039 & 0.0039 & \multirow{3}{*}{0.0035} \\
\hline & & & 28.0 & 100 & 100 & 1.218 & 0.122 & 0.061 & 0.0038 & 0.0038 & \\
\hline & & & 20.0 & 100 & 100 & 0.870 & 0.087 & 0.043 & 0.0027 & 0.0027 & \\
\hline & & $0.7 \mathrm{KOH}$ & 32.0 & 100 & 100 & 1.392 & 0.139 & 0.070 & 0.0043 & 0.0043 & 0.0043 \\
\hline & \multirow{4}{*}{$38^{\circ} \mathrm{C}-S h a k i n g$} & \multirow{3}{*}{$0.25 \mathrm{KOH}$} & 20.0 & 100 & 100 & 0.870 & 0.087 & 0.043 & 0.0027 & 0.0027 & \multirow{3}{*}{0.0032} \\
\hline & & & 30.4 & 100 & 100 & 1.322 & 0.132 & 0.066 & 0.0041 & 0.0041 & \\
\hline & & & 20.8 & 100 & 100 & 0.905 & 0.090 & 0.045 & 0.0028 & 0.0028 & \\
\hline & & $0.7 \mathrm{KOH}$ & 33.6 & 100 & 100 & 1.462 & 0.146 & 0.073 & 0.0045 & 0.0045 & 0.0045 \\
\hline & \multirow{4}{*}{$60^{\circ} \mathrm{C}$} & \multirow{3}{*}{$0.25 \mathrm{KOH}$} & 33.6 & 100 & 100 & 1.462 & 0.146 & 0.073 & 0.0045 & 0.0045 & \multirow{3}{*}{0.0042} \\
\hline & & & 32.0 & 100 & 100 & 1.392 & 0.139 & 0.070 & 0.0043 & 0.0043 & \\
\hline & & & 28.0 & 100 & 100 & 1.218 & 0.122 & 0.061 & 0.0038 & 0.0038 & \\
\hline & & $0.7 \mathrm{KOH}$ & 47.8 & 100 & 100 & 2.079 & 0.208 & 0.104 & 0.0064 & 0.0064 & 0.0064 \\
\hline
\end{tabular}




\begin{tabular}{|c|c|c|c|c|c|c|c|c|c|c|c|}
\hline \multirow{19}{*}{ 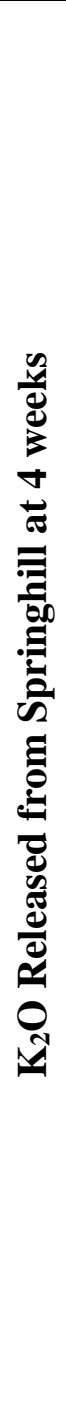 } & $\operatorname{Temp}\left({ }^{\circ} \mathrm{C}\right)$ & Soak Solution Alkalinity & 1 & 2 & 3 & 4 & 5 & 6 & 7 & 8 & 9 \\
\hline & \multirow{5}{*}{$23^{\circ} \mathrm{C}$} & \multirow{3}{*}{$0.25 \mathrm{NaOH}$} & 21.6 & 100 & 100 & 0.941 & 0.094 & 0.047 & 0.0029 & 0.0029 & \multirow{3}{*}{0.0026} \\
\hline & & & 18.0 & 100 & 100 & 0.783 & 0.078 & 0.039 & 0.0024 & 0.0024 & \\
\hline & & & 18.0 & 100 & 100 & 0.783 & 0.078 & 0.039 & 0.0024 & 0.0024 & \\
\hline & & \multirow{2}{*}{$0.7 \mathrm{NaOH}$} & 28.0 & 100 & 100 & 1.218 & 0.122 & 0.061 & 0.0038 & 0.0038 & \multirow{2}{*}{0.0037} \\
\hline & & & 27.0 & 100 & 100 & 1.174 & 0.117 & 0.059 & 0.0036 & 0.0036 & \\
\hline & \multirow{6}{*}{$38^{\circ} \mathrm{C}$} & DDW & 18.8 & 100 & 100 & 0.818 & 0.082 & 0.041 & 0.0025 & 0.0025 & 0.0025 \\
\hline & & \multirow{3}{*}{$0.25 \mathrm{NaOH}$} & 10.0 & 100 & 100 & 0.435 & 0.043 & 0.022 & 0.0013 & 0.0013 & \multirow{3}{*}{0.0019} \\
\hline & & & 15.2 & 100 & 100 & 0.661 & 0.066 & 0.033 & 0.0020 & 0.0020 & \\
\hline & & & 16 & 100 & 100 & 0.696 & 0.070 & 0.035 & 0.0022 & 0.0022 & \\
\hline & & \multirow{2}{*}{$0.7 \mathrm{NaOH}$} & 28.0 & 100 & 100 & 1.218 & 0.122 & 0.061 & 0.0038 & 0.0038 & \multirow{2}{*}{0.0038} \\
\hline & & & 28.0 & 100 & 100 & 1.218 & 0.122 & 0.061 & 0.0038 & 0.0038 & \\
\hline & \multirow{3}{*}{$38^{\circ} \mathrm{C}$-Shaking } & \multirow{3}{*}{$0.7 \mathrm{NaOH}$} & 155.2 & 100 & 100 & 6.751 & 0.675 & 0.338 & 0.0209 & 0.0209 & \multirow{3}{*}{0.0203} \\
\hline & & & 143.2 & 100 & 100 & 6.229 & 0.623 & 0.311 & 0.0193 & 0.0193 & \\
\hline & & & 153.6 & 100 & 100 & 6.681 & 0.668 & 0.334 & 0.0207 & 0.0207 & \\
\hline & \multirow{4}{*}{$60^{\circ} \mathrm{C}$} & \multirow{3}{*}{$0.25 \mathrm{NaOH}$} & 8.0 & 100 & 100 & 0.348 & 0.036 & 0.018 & 0.0011 & 0.0011 & \multirow{3}{*}{0.0011} \\
\hline & & & 8.0 & 100 & 100 & 0.348 & 0.036 & 0.018 & 0.0011 & 0.0011 & \\
\hline & & & 8.0 & 100 & 100 & 0.348 & 0.036 & 0.018 & 0.0011 & 0.0011 & \\
\hline & & $0.7 \mathrm{NaOH}$ & 20 & 100 & 100 & 0.870 & 0.087 & 0.043 & 0.0027 & 0.0027 & 0.0027 \\
\hline
\end{tabular}




\begin{tabular}{|c|c|c|c|c|c|c|c|c|c|c|c|}
\hline \multirow{26}{*}{ 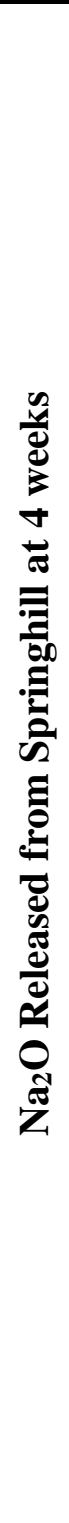 } & Temp $\left({ }^{\circ} \mathbf{C}\right)$ & Soak Solution Alkalinity & 1 & 2 & 3 & 4 & 5 & 6 & 7 & 8 & 9 \\
\hline & \multirow{6}{*}{$23^{\circ} \mathrm{C}$} & \multirow{3}{*}{$0.25 \mathrm{KOH}$} & 6.4 & 100 & 100 & 0.278 & 0.028 & 0.014 & 0.0009 & 0.0009 & \multirow{3}{*}{0.0014} \\
\hline & & & 9.2 & 100 & 100 & 0.400 & 0.040 & 0.020 & 0.0012 & 0.0012 & \\
\hline & & & 16.0 & 100 & 100 & 0.696 & 0.070 & 0.035 & 0.0022 & 0.0022 & \\
\hline & & \multirow{3}{*}{$0.7 \mathrm{KOH}$} & 52.0 & 100 & 100 & 2.262 & 0.226 & 0.113 & 0.0070 & 0.0070 & \multirow{3}{*}{0.0060} \\
\hline & & & 37.6 & 100 & 100 & 1.636 & 0.164 & 0.082 & 0.0051 & 0.0051 & \\
\hline & & & 45.0 & 100 & 100 & 1.957 & 0.196 & 0.098 & 0.0061 & 0.0061 & \\
\hline & \multirow{7}{*}{$3^{\circ} \mathrm{C}$} & DDW & 4.8 & 100 & 100 & 0.209 & 0.021 & 0.010 & 0.0006 & 0.0006 & 0.0006 \\
\hline & & \multirow{3}{*}{$0.25 \mathrm{KOH}$} & 20.0 & 100 & 100 & 0.870 & 0.087 & 0.043 & 0.0027 & 0.0027 & \multirow{3}{*}{0.0028} \\
\hline & & & 20.8 & 100 & 100 & 0.905 & 0.090 & 0.045 & 0.0028 & 0.0028 & \\
\hline & & & 22.0 & 100 & 100 & 0.957 & 0.096 & 0.048 & 0.0030 & 0.0030 & \\
\hline & & \multirow{3}{*}{$0.7 \mathrm{KOH}$} & 29.6 & 100 & 100 & 1.288 & 0.129 & 0.064 & 0.0040 & 0.0040 & \multirow{3}{*}{0.0038} \\
\hline & & & 32.8 & 100 & 100 & 1.427 & 0.143 & 0.071 & 0.0044 & 0.0044 & \\
\hline & & & 23.2 & 100 & 100 & 1.009 & 0.101 & 0.050 & 0.0031 & 0.0031 & \\
\hline & \multirow{6}{*}{$38^{\circ} \mathrm{C}$-Shaking } & \multirow{3}{*}{$0.25 \mathrm{KOH}$} & 68.0 & 100 & $\overline{100}$ & 2.958 & 0.296 & 0.148 & 0.0092 & 0.0092 & \multirow{3}{*}{0.0090} \\
\hline & & & 68.0 & 100 & 100 & 2.958 & 0.296 & 0.148 & 0.0092 & 0.0092 & \\
\hline & & & 64.0 & 100 & 100 & 2.784 & 0.278 & 0.139 & 0.0086 & 0.0086 & \\
\hline & & \multirow{3}{*}{$0.7 \mathrm{KOH}$} & 59.2 & 100 & 100 & 2.575 & 0.258 & 0.129 & 0.0080 & 0.0080 & \multirow{3}{*}{0.0083} \\
\hline & & & 64.0 & 100 & 100 & 2.784 & 0.278 & 0.139 & 0.0086 & 0.0086 & \\
\hline & & & 60.8 & 100 & 100 & 2.645 & 0.264 & 0.132 & 0.0082 & 0.0082 & \\
\hline & \multirow{6}{*}{$60^{\circ} \mathrm{C}$} & \multirow{3}{*}{$0.25 \mathrm{KOH}$} & 18.4 & 100 & 100 & 0.800 & 0.080 & 0.040 & 0.0025 & 0.0025 & \multirow{3}{*}{0.0023} \\
\hline & & & 19.3 & 100 & 100 & 0.837 & 0.084 & 0.042 & 0.0026 & 0.0026 & \\
\hline & & & 13.6 & 100 & 100 & 0.592 & 0.059 & 0.030 & 0.0018 & 0.0018 & \\
\hline & & \multirow{3}{*}{$0.7 \mathrm{KOH}$} & 39.2 & 100 & 100 & 1.705 & 0.171 & 0.085 & 0.0053 & 0.0053 & \multirow{3}{*}{0.0055} \\
\hline & & & 44 & 100 & 100 & 1.914 & 0.191 & 0.096 & 0.0059 & 0.0059 & \\
\hline & & & 39.2 & 100 & 100 & 1.705 & 0.171 & 0.085 & 0.0053 & 0.0053 & \\
\hline
\end{tabular}




\begin{tabular}{|c|c|c|c|c|c|c|c|c|c|c|c|}
\hline \multirow{5}{*}{ 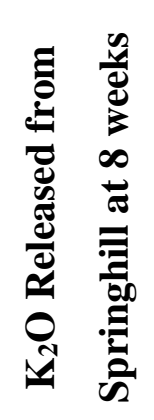 } & $\operatorname{Temp}\left({ }^{\circ} \mathrm{C}\right)$ & $\begin{array}{c}\text { Soak Solution } \\
\text { Alkalinity }\end{array}$ & 1 & 2 & 3 & 4 & 5 & 6 & 7 & 8 & 9 \\
\hline & \multirow{2}{*}{$23^{\circ} \mathrm{C}$} & $0.25 \mathrm{NaOH}$ & 12.0 & 100 & 100 & 0.522 & 0.052 & 0.026 & 0.0016 & 0.0016 & 0.0016 \\
\hline & & $0.25 \mathrm{NaOH}$ & 8.0 & 100 & 100 & 0.348 & 0.035 & 0.017 & 0.0011 & 0.0011 & 0.0011 \\
\hline & $38^{\circ} \mathrm{C}$-Shaking & $0.25 \mathrm{NaOH}$ & 151.2 & 100 & 100 & 6.577 & 0.658 & 0.329 & 0.0204 & 0.0204 & 0.0204 \\
\hline & $60^{\circ} \mathrm{C}$ & $0.25 \mathrm{NaOH}$ & 8.0 & 100 & 100 & 0.348 & 0.035 & 0.017 & 0.0011 & 0.0011 & 0.0011 \\
\hline
\end{tabular}




\begin{tabular}{|c|c|c|c|c|c|c|c|c|c|c|c|}
\hline \multirow{22}{*}{ 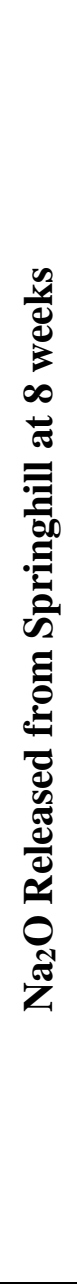 } & Temp $\left({ }^{\circ} \mathrm{C}\right)$ & Soak Solution Alkalinity & 1 & 2 & 3 & 4 & 5 & 6 & 7 & 8 & 9 \\
\hline & \multirow{6}{*}{$2^{\circ} \mathrm{C}$} & \multirow{3}{*}{$0.25 \mathrm{KOH}$} & 5.6 & 100 & 100 & 0.244 & 0.024 & 0.012 & 0.0008 & 0.0008 & \multirow{3}{*}{0.0017} \\
\hline & & & 19.2 & 100 & 100 & 0.835 & 0.084 & 0.042 & 0.0026 & 0.0026 & \\
\hline & & & 12 & 100 & 100 & 0.522 & 0.052 & 0.026 & 0.0016 & 0.0016 & \\
\hline & & \multirow{3}{*}{$0.7 \mathrm{KOH}$} & 44.0 & 100 & 100 & 1.914 & 0.191 & 0.096 & 0.0059 & 0.0059 & \multirow{3}{*}{0.0058} \\
\hline & & & 44.0 & 100 & 100 & 1.914 & 0.191 & 0.096 & 0.0059 & 0.0059 & \\
\hline & & & 41.3 & 100 & 100 & 1.798 & 0.180 & 0.090 & 0.0056 & 0.0056 & \\
\hline & \multirow{6}{*}{$38^{\circ} \mathrm{C}$} & \multirow{3}{*}{$0.25 \mathrm{KOH}$} & 17.6 & 100 & 100 & 0.766 & 0.077 & 0.038 & 0.0024 & 0.0024 & \multirow{3}{*}{0.0025} \\
\hline & & & 20.0 & 100 & 100 & 0.870 & 0.087 & 0.043 & 0.0027 & 0.0027 & \\
\hline & & & 17.6 & 100 & 100 & 0.766 & 0.077 & 0.038 & 0.0024 & 0.0024 & \\
\hline & & \multirow{3}{*}{$0.7 \mathrm{KOH}$} & 48.0 & 100 & 100 & 2.088 & 0.209 & 0.104 & 0.0065 & 0.0065 & \multirow{3}{*}{0.0064} \\
\hline & & & 44.0 & 100 & 100 & 1.914 & 0.191 & 0.096 & 0.0059 & 0.0059 & \\
\hline & & & 50.7 & 100 & 100 & 2.204 & 0.220 & 0.110 & 0.0068 & 0.0068 & \\
\hline & \multirow{3}{*}{$38^{\circ} \mathrm{C}$-Shaking } & \multirow{3}{*}{$0.25 \mathrm{KOH}$} & 88.8 & 100 & 100 & 3.863 & 0.386 & 0.193 & 0.0120 & 0.0120 & \multirow{3}{*}{0.0123} \\
\hline & & & 86.4 & 100 & 100 & 3.758 & 0.376 & 0.188 & 0.0116 & 0.0116 & \\
\hline & & & 99.2 & 100 & 100 & 4.315 & 0.431 & 0.216 & 0.0134 & 0.0134 & \\
\hline & \multirow{6}{*}{$60^{\circ} \mathrm{C}$} & \multirow{3}{*}{$0.25 \mathrm{KOH}$} & 14.0 & 100 & 100 & 0.609 & 0.061 & 0.030 & 0.0019 & 0.0019 & \multirow{3}{*}{0.0021} \\
\hline & & & 20.0 & 100 & 100 & 0.870 & 0.087 & 0.043 & 0.0027 & 0.0027 & \\
\hline & & & 12 & 100 & 100 & 0.522 & 0.052 & 0.026 & 0.0016 & 0.0016 & \\
\hline & & \multirow{3}{*}{$0.7 \mathrm{KOH}$} & 54.4 & 100 & 100 & 2.366 & 0.237 & 0.118 & 0.0073 & 0.0073 & \multirow{3}{*}{0.0065} \\
\hline & & & 44.0 & 100 & 100 & 1.914 & 0.191 & 0.096 & 0.0059 & 0.0059 & \\
\hline & & & 47.0 & 100 & 100 & 2.044 & 0.204 & 0.102 & 0.0063 & 0.0063 & \\
\hline
\end{tabular}




\begin{tabular}{|c|c|c|c|c|c|c|c|c|c|c|c|}
\hline$\theta$ & $\operatorname{Temp}\left({ }^{\circ} \mathrm{C}\right)$ & Soak Solution Alkalinity & 1 & 2 & 3 & 4 & 5 & 6 & 7 & 8 & 9 \\
\hline 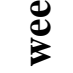 & \multirow{2}{*}{$23^{\circ} \mathrm{C}$} & $0.25 \mathrm{NaOH}$ & 8.0 & 100 & 100 & 0.348 & 0.035 & 0.017 & 0.0011 & 0.0011 & 0.0011 \\
\hline 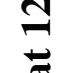 & & $0.7 \mathrm{NaOH}$ & 21.0 & 100 & 100 & 0.913 & 0.091 & 0.046 & 0.0028 & 0.0028 & 0.0028 \\
\hline : & \multirow{3}{*}{$38^{\circ} \mathrm{C}$} & DDW & 16.48 & 100 & 100 & 0.717 & 0.072 & 0.036 & 0.0022 & 0.0022 & 0.0022 \\
\hline 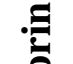 & & $0.25 \mathrm{NaOH}$ & 8.0 & 100 & 100 & 0.348 & 0.035 & 0.017 & 0.0011 & 0.0011 & 0.0011 \\
\hline$\Xi$ & & $0.7 \mathrm{NaOH}$ & 20.8 & 100 & 100 & 0.905 & 0.090 & 0.045 & 0.0028 & 0.0028 & 0.0028 \\
\hline$=$ & \multirow{2}{*}{$38^{\circ} \mathrm{C}$-Shaking } & $0.25 \mathrm{NaOH}$ & 134.0 & 100 & 100 & 5.829 & 0.583 & 0.291 & 0.0181 & 0.0181 & 0.0181 \\
\hline $\mathbb{E}^{2}$ & & $0.7 \mathrm{NaOH}$ & 163.2 & 100 & 100 & 7.099 & 0.710 & 0.355 & 0.0220 & 0.0220 & 0.0220 \\
\hline 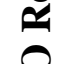 & \multirow{2}{*}{$60^{\circ} \mathrm{C}$} & $0.25 \mathrm{NaOH}$ & 6.0 & 100 & 100 & 0.261 & 0.027 & 0.013 & 0.0008 & 0.0008 & 0.0008 \\
\hline$\approx$ & & $0.7 \mathrm{NaOH}$ & 20.0 & 100 & 100 & 0.870 & 0.089 & 0.044 & 0.0028 & 0.0028 & 0.0028 \\
\hline
\end{tabular}




\begin{tabular}{|c|c|c|c|c|c|c|c|c|c|c|c|}
\hline \multirow{18}{*}{ 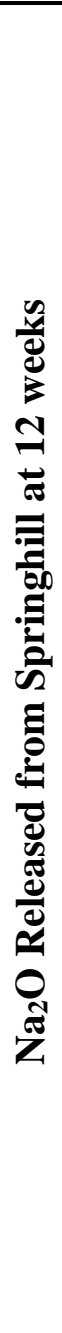 } & Temp $\left({ }^{\circ} \mathrm{C}\right)$ & Soak Solution Alkalinity & 1 & 2 & 3 & 4 & 5 & 6 & 7 & 8 & 9 \\
\hline & \multirow{4}{*}{$23^{\circ} \mathrm{C}$} & \multirow{3}{*}{$0.25 \mathrm{KOH}$} & 24 & 100 & 100 & 1.044 & 0.104 & 0.052 & 0.0032 & 0.0032 & \multirow{3}{*}{0.0029} \\
\hline & & & 24 & 100 & 100 & 1.044 & 0.104 & 0.052 & 0.0032 & 0.0032 & \\
\hline & & & 17.6 & 100 & 100 & 0.766 & 0.077 & 0.038 & 0.0024 & 0.0024 & \\
\hline & & $0.7 \mathrm{KOH}$ & 33.6 & 100 & 100 & 1.462 & 0.146 & 0.073 & 0.0045 & 0.0045 & 0.0045 \\
\hline & \multirow{5}{*}{$38^{\circ} \mathrm{C}$} & DDW & 6.44 & 100 & 100 & 0.280 & 0.028 & 0.014 & 0.0009 & 0.0009 & 0.0009 \\
\hline & & \multirow{3}{*}{$0.25 \mathrm{KOH}$} & 36 & 100 & 100 & 1.566 & 0.157 & 0.078 & 0.0049 & 0.0049 & \multirow{3}{*}{0.0040} \\
\hline & & & 33.6 & 100 & 100 & 1.462 & 0.146 & 0.073 & 0.0045 & 0.0045 & \\
\hline & & & 19.2 & 100 & 100 & 0.835 & 0.084 & 0.042 & 0.0026 & 0.0026 & \\
\hline & & $0.7 \mathrm{KOH}$ & 46.2 & 100 & 100 & 2.010 & 0.201 & 0.100 & 0.0062 & 0.0062 & 0.0062 \\
\hline & \multirow{4}{*}{$38^{\circ} \mathrm{C}$-Shaking } & \multirow{3}{*}{$0.25 \mathrm{KOH}$} & 148.8 & 100 & 100 & 6.472 & 0.647 & 0.324 & 0.0201 & 0.0201 & \multirow{3}{*}{0.0180} \\
\hline & & & 132.8 & 100 & 100 & 5.776 & 0.578 & 0.289 & 0.0179 & 0.0179 & \\
\hline & & & 118 & 100 & 100 & 5.133 & 0.513 & 0.257 & 0.0159 & 0.0159 & \\
\hline & & 0.7 КОН & 110.4 & 100 & 100 & 4.802 & 0.480 & 0.240 & 0.0149 & 0.0149 & 0.0149 \\
\hline & \multirow{4}{*}{$60^{\circ} \mathrm{C}$} & \multirow{3}{*}{$0.25 \mathrm{KOH}$} & 36 & 100 & 100 & 1.566 & 0.157 & 0.078 & 0.0049 & 0.0049 & \multirow{3}{*}{0.0047} \\
\hline & & & 40.8 & 100 & 100 & 1.775 & 0.177 & 0.089 & 0.0055 & 0.0055 & \\
\hline & & & 27.2 & 100 & 100 & 1.183 & 0.118 & 0.059 & 0.0037 & 0.0037 & \\
\hline & & $0.7 \mathrm{KOH}$ & 50.6 & 100 & 100 & 2.201 & 0.220 & 0.110 & 0.0068 & 0.0068 & 0.0068 \\
\hline
\end{tabular}




\section{Appendix C}

\section{Thermogravimetric analysis of paste samples}




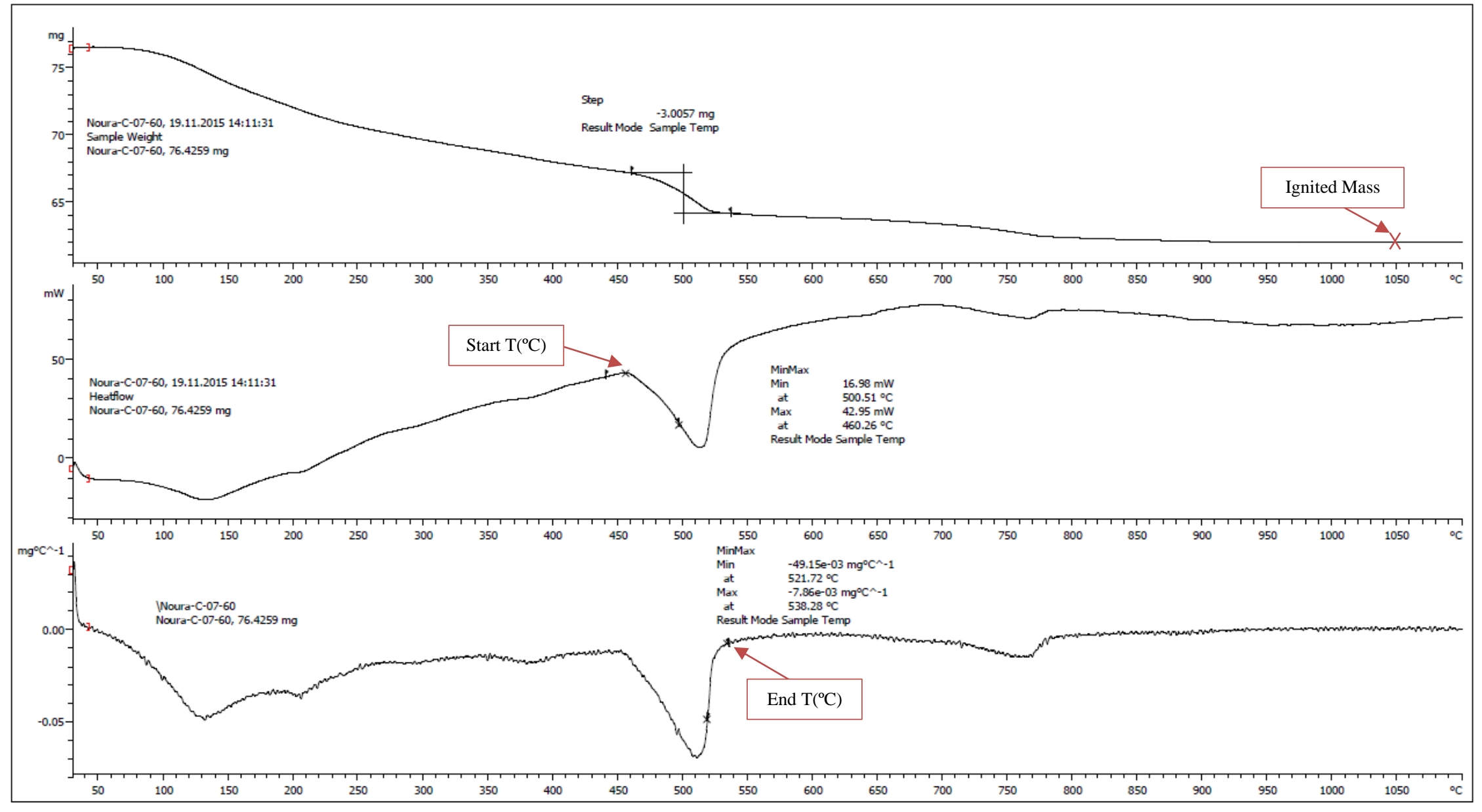

water in $\mathrm{Ca}(\mathrm{OH})_{2}=$ mass loss @ start $T\left(\stackrel{\circ}{\circ}^{\circ}\right)-$ mass loss @ end $T(\stackrel{\circ}{\circ} \mathrm{C})$

$$
\mathrm{Ca}(\mathrm{OH})_{2} \text { content }(\%)=\frac{\text { water in } \mathrm{Ca}(\mathrm{OH})_{2} * 4.1127}{\text { Ignited } \operatorname{mass} @\left(1050^{\circ} \mathrm{C}\right)} * 100
$$




\section{Appendix D}

Calculations and results of the total amount of $\mathrm{Na}_{2} \mathrm{O}_{\mathrm{e}}$ released from paste samples expressed as a percent of the sample mass 


\begin{tabular}{|c|c|c|}
\hline Row \# & Units & Description \\
\hline 1 & $\mathrm{~mol} / \mathrm{L}$ & Initial $\mathrm{Na}^{+}$Concentration in the solution before dilution \\
\hline 2 & $\mathrm{~mol} / \mathrm{L}$ & Initial $\mathrm{K}^{+}$Concentration in the solution before dilution \\
\hline 3 & $\mathrm{~mol} / \mathrm{L}$ & Final $\mathrm{Na}^{+}$Concentration in the solution before dilution \\
\hline 4 & $\mathrm{~mol} / \mathrm{L}$ & Final $\mathrm{K}^{+}$Concentration in the solution before dilution \\
\hline 5 & $\mathrm{~mL}$ & Volume of solution \\
\hline 6 & $\mathrm{~g}$ & Mass of dry sample \\
\hline 7 & $\%$ & CBW obtained from TGA analysis \\
\hline 8 & $\mathrm{~g}$ & $\begin{array}{c}\text { Ignited mass } \\
=\text { Row } 6 /(1+\text { Row } 7)\end{array}$ \\
\hline 9 & $\%$ & $\begin{array}{c}\text { LOI of cementing materials } \\
=\left(\text { LOI }_{\mathrm{PC}} \times \mathrm{PC} \text { content }\right)+\left(\mathrm{LOI}_{\mathrm{SCM}} \times \mathrm{SCM} \text { content }\right)\end{array}$ \\
\hline 10 & $\mathrm{~g}$ & $\begin{aligned} & \text { Corrected CM mass } \\
= & \text { Row } 8 *(1+\text { Row } 9)\end{aligned}$ \\
\hline 11 & $\mathrm{~mol} / \mathrm{L}$ & $\begin{array}{l}\text { Change in } \mathrm{Na}^{+} \text {concentration } \\
\quad=\text { Row } 3-\text { Row } 1\end{array}$ \\
\hline 12 & $\mathrm{~mol} / \mathrm{L}$ & $\begin{array}{l}\text { Change in } \mathrm{K}^{+} \text {concentration } \\
\quad=\text { Row } 4-\text { Row } 2\end{array}$ \\
\hline 13 & $\mathrm{~mol} / \mathrm{L}$ & $\begin{array}{c}\text { Change in total alkali }\left(\mathrm{Na}^{+}+\mathrm{K}^{+}\right) \text {concentration } \\
=\text { Row } 11+\text { Row } 12\end{array}$ \\
\hline 14 & mol & $\begin{aligned} & \text { Total alkali in moles } \\
= & \text { Row } 13 * \text { Row } 5 / 1000\end{aligned}$ \\
\hline 15 & mol & $\begin{array}{c}\text { Total alkali in moles expressed as } \mathrm{Na}_{2} \mathrm{O}_{\mathrm{e}} \\
=\text { Row } 14 / 2\end{array}$ \\
\hline 16 & $\mathrm{~g}$ & $\begin{array}{c}\text { Total mass of } \mathrm{Na}_{2} \mathrm{O}_{\mathrm{e}} \\
=\text { Row } 15 * 61.9788\left(\text { molar mass of } \mathrm{Na}_{2} \mathrm{O}\right)\end{array}$ \\
\hline 17 & $\%$ & $\begin{array}{l}\text { Total alkali released as \% of CM mass } \\
\quad=\text { Row } 16 / \text { Row } 10 * 100\end{array}$ \\
\hline 18 & $\%$ & Average of alkali released from paste samples (Avg. of Row 17) \\
\hline
\end{tabular}




\begin{tabular}{|c|c|c|c|c|c|c|c|c|}
\hline \multicolumn{9}{|c|}{ 15\% FA cured at 23.C } \\
\hline \multirow{2}{*}{ Row \# } & \multicolumn{3}{|c|}{ Curing Age (days) } \\
\cline { 2 - 10 } & \multicolumn{2}{|c|}{$\mathbf{3}$} & \multicolumn{2}{|c|}{$\mathbf{7}$} & \multicolumn{2}{c|}{$\mathbf{2 8}$} \\
\hline $\mathbf{1}$ & 0.1183 & 0.1183 & 0.1183 & 0.1183 & 0.1183 & 0.1183 & 0.1183 & 0.1183 \\
\hline $\mathbf{2}$ & 0.1330 & 0.1330 & 0.1330 & 0.1330 & 0.1330 & 0.1330 & 0.1330 & 0.1330 \\
\hline $\mathbf{3}$ & 0.1196 & 0.1199 & 0.1218 & 0.1198 & 0.1217 & 0.1201 & 0.1201 & 0.1208 \\
\hline $\mathbf{4}$ & 0.1563 & 0.1569 & 0.1520 & 0.1545 & 0.1467 & 0.1475 & 0.1489 & 0.1484 \\
\hline $\mathbf{5}$ & 15 & 15 & 15 & 15 & 15 & 15 & 15 & 15 \\
\hline $\mathbf{6}$ & 1.500 & 1.500 & 1.500 & 1.500 & 1.500 & 1.500 & 1.500 & 1.500 \\
\hline $\mathbf{7}$ & 17.98 & 17.98 & 19.34 & 19.34 & 19.60 & 19.60 & 20.32 & 20.32 \\
\hline $\mathbf{8}$ & 1.271 & 1.271 & 1.257 & 1.257 & 1.254 & 1.254 & 1.247 & 1.247 \\
\hline $\mathbf{9}$ & 2.09 & 2.09 & 2.09 & 2.09 & 2.09 & 2.09 & 2.09 & 2.09 \\
\hline $\mathbf{1 0}$ & 1.298 & 1.298 & 1.283 & 1.283 & 1.280 & 1.280 & 1.273 & 1.273 \\
\hline $\mathbf{1 1}$ & 0.00130 & 0.00157 & 0.00348 & 0.00152 & 0.00339 & 0.00174 & 0.00174 & 0.00252 \\
\hline $\mathbf{1 2}$ & 0.02328 & 0.02389 & 0.01899 & 0.02149 & 0.01371 & 0.01445 & 0.01586 & 0.01535 \\
\hline $\mathbf{1 3}$ & 0.0246 & 0.02546 & 0.0225 & 0.02301 & 0.0171 & 0.01619 & 0.0176 & 0.01787 \\
\hline $\mathbf{1 4}$ & 0.000369 & 0.000382 & 0.000337 & 0.000345 & 0.000257 & 0.000243 & 0.000264 & 0.000268 \\
\hline $\mathbf{1 5}$ & 0.000184 & 0.000191 & 0.000168 & 0.000173 & 0.000128 & 0.000121 & 0.000132 & 0.000134 \\
\hline $\mathbf{1 6}$ & 0.011427 & 0.011834 & 0.010443 & 0.010696 & 0.007950 & 0.007527 & 0.008181 & 0.008307 \\
\hline $\mathbf{1 7}$ & 0.880 & 0.912 & 0.814 & 0.833 & 0.621 & 0.588 & 0.643 & 0.653 \\
\hline $\mathbf{1 8}$ & & 0.896 & & & & 0.824 & & 0.648 \\
\hline
\end{tabular}




\begin{tabular}{|c|c|c|c|c|c|c|c|c|}
\hline \multicolumn{9}{|c|}{$15 \%$ FA cured at $38^{\circ} \mathrm{C}$} \\
\hline \multirow{2}{*}{ Row \# } & \multicolumn{8}{|c|}{ Curing Age (days) } \\
\hline & \multicolumn{2}{|c|}{3} & \multicolumn{2}{|c|}{7} & \multicolumn{2}{|c|}{28} & \multicolumn{2}{|c|}{92} \\
\hline 1 & 0.1183 & 0.1183 & 0.1183 & 0.1183 & 0.1183 & 0.1183 & 0.1183 & 0.1183 \\
\hline 2 & 0.1330 & 0.1330 & 0.1330 & 0.1330 & 0.1330 & 0.1330 & 0.1330 & 0.1330 \\
\hline 3 & 0.1185 & 0.1201 & 0.1204 & 0.1196 & 0.1187 & 0.1201 & 0.1192 & 0.1195 \\
\hline 4 & 0.1560 & 0.1550 & 0.1482 & 0.1484 & 0.1438 & 0.1431 & 0.1442 & 0.1440 \\
\hline 5 & 15 & 15 & 15 & 15 & 15 & 15 & 15 & 15 \\
\hline 6 & 1.500 & 1.500 & 1.500 & 1.500 & 1.500 & 1.500 & 1.500 & 1.500 \\
\hline 7 & 19.22 & 19.22 & 19.40 & 19.40 & 21.03 & 21.03 & 21.64 & 21.64 \\
\hline 8 & 1.258 & 1.258 & 1.256 & 1.256 & 1.239 & 1.239 & 1.233 & 1.233 \\
\hline 9 & 2.09 & 2.09 & 2.09 & 2.09 & 2.09 & 2.09 & 2.09 & 2.09 \\
\hline 10 & 1.284 & 1.284 & 1.283 & 1.283 & 1.265 & 1.265 & 1.259 & 1.259 \\
\hline 11 & 0.00022 & 0.00174 & 0.00204 & 0.00130 & 0.00043 & 0.00174 & 0.00087 & 0.00122 \\
\hline 12 & 0.02302 & 0.02200 & 0.01519 & 0.01535 & 0.01074 & 0.01013 & 0.01115 & 0.01100 \\
\hline 13 & 0.0232 & 0.02374 & 0.0172 & 0.01665 & 0.0112 & 0.01187 & 0.0120 & 0.01222 \\
\hline 14 & 0.000349 & 0.000356 & 0.000259 & 0.000250 & 0.000168 & 0.000178 & 0.000180 & 0.000183 \\
\hline 15 & 0.000174 & 0.000178 & 0.000129 & 0.000125 & 0.000084 & 0.000089 & 0.000090 & 0.000092 \\
\hline 16 & 0.010802 & 0.011035 & 0.008013 & 0.007741 & 0.005196 & 0.005517 & 0.005589 & 0.005679 \\
\hline 17 & 0.841 & 0.859 & 0.625 & 0.604 & 0.411 & 0.436 & 0.444 & 0.451 \\
\hline 18 & \multicolumn{2}{|c|}{0.850} & \multicolumn{2}{|c|}{0.615} & \multicolumn{2}{|c|}{0.424} & \multicolumn{2}{|c|}{0.448} \\
\hline
\end{tabular}




\begin{tabular}{|c|c|c|c|c|c|c|c|c|}
\hline \multicolumn{9}{|c|}{$15 \%$ FA cured at $60^{\circ} \mathrm{C}$} \\
\hline \multirow{2}{*}{ Row \# } & \multicolumn{8}{|c|}{ Curing Age (days) } \\
\hline & \multicolumn{2}{|c|}{3} & \multicolumn{2}{|c|}{7} & \multicolumn{2}{|c|}{28} & \multicolumn{2}{|c|}{92} \\
\hline 1 & 0.1183 & 0.1183 & 0.1183 & 0.1183 & 0.1183 & 0.1183 & 0.1183 & 0.1183 \\
\hline 2 & 0.1330 & 0.1330 & 0.1330 & 0.1330 & 0.1330 & 0.1330 & 0.1330 & 0.1330 \\
\hline 3 & 0.1198 & 0.1209 & 0.1196 & 0.1201 & 0.1185 & 0.1201 & 0.1194 & 0.1205 \\
\hline 4 & 0.1520 & 0.1507 & 0.1455 & 0.1458 & 0.1456 & 0.1436 & 0.1458 & 0.1448 \\
\hline 5 & 15 & 15 & 15 & 15 & 15 & 15 & 15 & 15 \\
\hline 6 & 1.500 & 1.500 & 1.500 & 1.500 & 1.500 & 1.500 & 1.500 & 1.500 \\
\hline 7 & $19.49 \%$ & $19.49 \%$ & $19.91 \%$ & $19.91 \%$ & $20.01 \%$ & $20.01 \%$ & $20.52 \%$ & $20.52 \%$ \\
\hline 8 & 1.255 & 1.255 & 1.251 & 1.251 & 1.250 & 1.250 & 1.245 & 1.245 \\
\hline 9 & $2.09 \%$ & $2.09 \%$ & $2.09 \%$ & $2.09 \%$ & $2.09 \%$ & $2.09 \%$ & $2.09 \%$ & $2.09 \%$ \\
\hline 10 & 1.282 & 1.282 & 1.277 & 1.277 & 1.276 & 1.276 & 1.271 & 1.271 \\
\hline 11 & 0.00152 & 0.00261 & 0.00130 & 0.00174 & 0.00022 & 0.00174 & 0.00109 & 0.00217 \\
\hline 12 & 0.01899 & 0.01765 & 0.01246 & 0.01276 & 0.01261 & 0.01054 & 0.01279 & 0.01177 \\
\hline 13 & 0.0205 & 0.02026 & 0.0138 & 0.01450 & 0.0128 & 0.01228 & 0.0139 & 0.01394 \\
\hline 14 & 0.000308 & 0.000304 & 0.000206 & 0.000218 & 0.000192 & 0.000184 & 0.000208 & 0.000209 \\
\hline 15 & 0.000154 & 0.000152 & 0.000103 & 0.000109 & 0.000096 & 0.000092 & 0.000104 & 0.000105 \\
\hline 16 & 0.009533 & 0.009418 & 0.006397 & 0.006742 & 0.005963 & 0.005708 & 0.006451 & 0.006481 \\
\hline 17 & 0.744 & 0.735 & 0.501 & 0.528 & 0.467 & 0.447 & 0.508 & 0.510 \\
\hline 18 & \multicolumn{2}{|c|}{0.740} & \multicolumn{2}{|c|}{0.515} & \multicolumn{2}{|c|}{0.457} & \multicolumn{2}{|c|}{0.509} \\
\hline
\end{tabular}




\begin{tabular}{|c|c|c|c|c|c|c|c|c|}
\hline \multicolumn{9}{|c|}{$25 \%$ FA cured at $23^{\circ} \mathrm{C}$} \\
\hline \multirow{2}{*}{ Row \# } & \multicolumn{8}{|c|}{ Curing Age (days) } \\
\hline & \multicolumn{2}{|c|}{3} & \multicolumn{2}{|c|}{7} & \multicolumn{2}{|c|}{28} & \multicolumn{2}{|c|}{92} \\
\hline 1 & 0.1305 & 0.1305 & 0.1305 & 0.1305 & 0.1305 & 0.1305 & 0.1305 & 0.1305 \\
\hline 2 & 0.1727 & 0.1727 & 0.1727 & 0.1727 & 0.1727 & 0.1727 & 0.1727 & 0.1727 \\
\hline 3 & 0.1414 & 0.1491 & 0.1414 & 0.1430 & 0.1305 & 0.1348 & 0.1414 & 0.1344 \\
\hline 4 & 0.1886 & 0.1791 & 0.1862 & 0.1850 & 0.1898 & 0.1844 & 0.1760 & 0.1843 \\
\hline 5 & 20 & 20 & 20 & 20 & 20 & 20 & 20 & 20 \\
\hline 6 & 2.0005 & 2.0000 & 2.0002 & 2.0000 & 2.0002 & 2.0000 & 1.9997 & 2.0000 \\
\hline 7 & 16.82 & 16.82 & 17.56 & 17.56 & 18.96 & 18.96 & 19.98 & 19.98 \\
\hline 8 & 1.7125 & 1.7121 & 1.7014 & 1.7013 & 1.6815 & 1.6813 & 1.6668 & 1.6670 \\
\hline 9 & 1.92 & 1.92 & $1.92 \%$ & 1.92 & 1.92 & 1.92 & 1.92 & 1.92 \\
\hline 10 & 1.7454 & 0.168 & 1.7341 & 1.7339 & 1.7137 & 1.7135 & 1.6987 & 1.6990 \\
\hline 11 & 0.010874 & 0.018617 & 0.010874 & 0.012527 & 0.000000 & 0.004350 & 0.010874 & 0.003915 \\
\hline 12 & 0.015987 & 0.006395 & 0.013557 & 0.012355 & 0.017138 & 0.011767 & 0.003325 & 0.011664 \\
\hline 13 & 0.026862 & 0.025012 & 0.024432 & 0.024882 & 0.017138 & 0.016116 & 0.014200 & 0.015579 \\
\hline 14 & 0.000537 & 0.000500 & 0.000489 & 0.000498 & 0.000343 & 0.000322 & 0.000284 & 0.000312 \\
\hline 15 & 0.000269 & 0.000250 & 0.000244 & 0.000249 & 0.000171 & 0.000161 & 0.000142 & 0.000156 \\
\hline 16 & 0.016648 & 0.015502 & 0.015142 & 0.015422 & 0.010622 & 0.009989 & 0.008801 & 0.009656 \\
\hline 17 & 0.954 & 0.888 & 0.873 & 0.889 & 0.620 & 0.583 & 0.518 & 0.568 \\
\hline 18 & \multicolumn{2}{|c|}{0.921} & \multicolumn{2}{|c|}{0.881} & \multicolumn{2}{|c|}{0.602} & \multicolumn{2}{|c|}{0.543} \\
\hline
\end{tabular}




\begin{tabular}{|c|c|c|c|c|c|c|c|c|}
\hline \multicolumn{9}{|c|}{$25 \%$ FA cured at $38^{\circ} \mathrm{C}$} \\
\hline \multirow{2}{*}{ Row \# } & \multicolumn{8}{|c|}{ Curing Age (days) } \\
\hline & \multicolumn{2}{|c|}{3} & \multicolumn{2}{|c|}{7} & \multicolumn{2}{|c|}{28} & \multicolumn{2}{|c|}{92} \\
\hline 1 & 0.1305 & 0.1305 & 0.1305 & 0.1305 & 0.1305 & 0.1305 & 0.1305 & 0.1305 \\
\hline 2 & 0.1727 & 0.1727 & 0.1727 & 0.1727 & 0.1727 & 0.1727 & 0.1727 & 0.1727 \\
\hline 3 & 0.1359 & 0.1362 & 0.1359 & 0.1352 & 0.1305 & 0.1305 & 0.1359 & 0.1305 \\
\hline 4 & 0.1918 & 0.1913 & 0.1855 & 0.1855 & 0.1829 & 0.1835 & 0.1759 & 0.1807 \\
\hline 5 & 20 & 20 & 20 & 20 & 20 & 20 & 20 & 20 \\
\hline 6 & 1.9999 & 2.0000 & 1.9999 & 2.0000 & 2.0003 & 2.0000 & 2.0006 & 2.0000 \\
\hline 7 & 18.85 & 18.85 & 19.98 & 19.98 & 20.59 & 20.59 & 21.30 & 21.30 \\
\hline 8 & 1.6826 & 1.6827 & 1.6669 & 1.6670 & 1.6588 & 1.6585 & 1.6493 & 1.6488 \\
\hline 9 & 1.92 & 1.92 & 1.92 & 1.92 & 1.92 & 1.92 & 1.92 & 1.92 \\
\hline 10 & 1.7149 & 1.7150 & 1.6989 & 1.6990 & 1.6906 & 1.6904 & 1.6809 & 1.6804 \\
\hline 11 & 0.005437 & 0.005742 & 0.005437 & 0.004741 & 0.000000 & 0.000000 & 0.005437 & 0.000000 \\
\hline 12 & 0.019185 & 0.018673 & 0.012790 & 0.012790 & 0.010232 & 0.010846 & 0.003197 & 0.008083 \\
\hline 13 & 0.024622 & 0.024415 & 0.018227 & 0.017531 & 0.010232 & 0.010846 & 0.008635 & 0.008083 \\
\hline 14 & 0.000492 & 0.000488 & 0.000365 & 0.000351 & 0.000205 & 0.000217 & 0.000173 & 0.000162 \\
\hline 15 & 0.000246 & 0.000244 & 0.000182 & 0.000175 & 0.000102 & 0.000108 & 0.000086 & 0.000081 \\
\hline 16 & 0.015260 & 0.015132 & 0.011297 & 0.010865 & 0.006342 & 0.006722 & 0.005352 & 0.005010 \\
\hline 17 & 0.890 & 0.882 & 0.665 & 0.640 & 0.375 & 0.398 & 0.318 & 0.298 \\
\hline 18 & \multicolumn{2}{|c|}{0.886} & \multicolumn{2}{|c|}{0.653} & \multicolumn{2}{|c|}{0.387} & \multicolumn{2}{|c|}{0.308} \\
\hline
\end{tabular}




\begin{tabular}{|c|c|c|c|c|c|c|c|c|}
\hline \multicolumn{9}{|c|}{$25 \%$ FA cured at $60^{\circ} \mathrm{C}$} \\
\hline \multirow{2}{*}{ Row \# } & \multicolumn{8}{|c|}{ Curing Age (days) } \\
\hline & \multicolumn{2}{|c|}{3} & \multicolumn{2}{|c|}{7} & \multicolumn{2}{|c|}{28} & \multicolumn{2}{|c|}{92} \\
\hline 1 & 0.1305 & 0.1305 & 0.1305 & 0.1305 & 0.1305 & 0.1305 & 0.1305 & 0.1305 \\
\hline 2 & 0.1727 & 0.1727 & 0.1727 & 0.1727 & 0.1727 & 0.1727 & 0.1727 & 0.1727 \\
\hline 3 & 0.1359 & 0.1362 & 0.1305 & 0.1214 & 0.1305 & 0.1301 & 0.1392 & 0.1305 \\
\hline 4 & 0.1886 & 0.1893 & 0.1918 & 0.1982 & 0.1859 & 0.1855 & 0.1763 & 0.1839 \\
\hline 5 & 20 & 20 & 20 & 20 & 20 & 20 & 20 & 20 \\
\hline 6 & 2.0005 & 2.0000 & 2.0005 & 2.0000 & 2.0005 & 2.0000 & 2.0000 & 2.0000 \\
\hline 7 & 19.87 & 19.87 & 20.08 & 20.08 & 20.18 & 20.18 & 20.28 & 20.28 \\
\hline 8 & 1.6688 & 1.6684 & 1.6660 & 1.6656 & 1.6646 & 1.6642 & 1.6628 & 1.6628 \\
\hline 9 & 1.92 & 1.92 & $1.92 \%$ & 1.92 & $1.92 \%$ & 1.92 & $1.92 \%$ & 1.92 \\
\hline 10 & 1.7008 & 1.7004 & 1.6979 & 1.6975 & 1.6965 & 1.6961 & 1.6946 & 1.6946 \\
\hline 11 & 0.005437 & 0.005742 & 0.000000 & -0.009134 & 0.000000 & -0.000435 & 0.008700 & 0.000000 \\
\hline 12 & 0.015987 & 0.016627 & 0.019185 & 0.025580 & 0.013250 & 0.012790 & 0.003683 & 0.011255 \\
\hline 13 & 0.021424 & 0.022368 & 0.019185 & 0.016445 & 0.013250 & 0.012355 & 0.012383 & 0.011255 \\
\hline 14 & 0.000428 & 0.000447 & 0.000384 & 0.000329 & 0.000265 & 0.000247 & 0.000248 & 0.000225 \\
\hline 15 & 0.000214 & 0.000224 & 0.000192 & 0.000164 & 0.000133 & 0.000124 & 0.000124 & 0.000113 \\
\hline 16 & 0.013279 & 0.013864 & 0.011890 & 0.010192 & 0.008212 & 0.007657 & 0.007675 & 0.006976 \\
\hline 17 & 0.781 & 0.815 & 0.700 & 0.600 & 0.484 & 0.451 & 0.453 & 0.412 \\
\hline 18 & \multicolumn{2}{|c|}{0.798} & \multicolumn{2}{|c|}{0.650} & \multicolumn{2}{|c|}{0.468} & \multicolumn{2}{|c|}{0.433} \\
\hline
\end{tabular}




\begin{tabular}{|c|c|c|c|c|c|c|c|c|}
\hline \multicolumn{9}{|c|}{$35 \%$ Slag cured at $23^{\circ} \mathrm{C}$} \\
\hline \multirow{2}{*}{ Row \# } & \multicolumn{8}{|c|}{ Curing Age (days) } \\
\hline & \multicolumn{2}{|c|}{3} & \multicolumn{2}{|c|}{7} & \multicolumn{2}{|c|}{28} & \multicolumn{2}{|c|}{92} \\
\hline 1 & 0.1009 & 0.0748 & 0.1009 & 0.0748 & 0.1009 & 0.0748 & 0.1009 & 0.0748 \\
\hline 2 & 0.1412 & 0.1259 & 0.1412 & 0.1259 & 0.1412 & 0.1259 & 0.1412 & 0.1259 \\
\hline 3 & 0.1087 & 0.0766 & 0.1027 & 0.0770 & 0.1013 & 0.0757 & 0.1016 & 0.0757 \\
\hline 4 & 0.1586 & 0.1463 & 0.1611 & 0.1461 & 0.1582 & 0.1432 & 0.1571 & 0.1383 \\
\hline 5 & 15 & 15 & 15 & 15 & 15 & 15 & 15 & 15 \\
\hline 6 & 1.5000 & 1.5000 & 1.5000 & 1.5000 & 1.5000 & 1.5000 & 1.5003 & 1.4999 \\
\hline 7 & 15.34 & 15.34 & 16.10 & 16.10 & 18.92 & 18.92 & 19.53 & 19.53 \\
\hline 8 & 1.3005 & 1.3005 & 1.2920 & 1.2920 & 1.2614 & 1.2614 & 1.2552 & 1.2548 \\
\hline 9 & 2.25 & 2.25 & 2.25 & 2.25 & 2.25 & 2.25 & 2.25 & 2.25 \\
\hline 10 & 1.3298 & 1.3298 & 1.3211 & 1.3211 & 1.2898 & 1.2898 & 1.2834 & 1.2831 \\
\hline 11 & 0.007830 & 0.001740 & 0.001740 & 0.002175 & 0.000435 & 0.000870 & 0.000652 & 0.000870 \\
\hline 12 & 0.017394 & 0.020464 & 0.019901 & 0.020208 & 0.016985 & 0.017394 & 0.015859 & 0.012432 \\
\hline 13 & 0.025224 & 0.022204 & 0.021641 & 0.022383 & 0.017420 & 0.018264 & 0.016512 & 0.013302 \\
\hline 14 & 0.000378 & 0.000333 & 0.000325 & 0.000336 & 0.000261 & 0.000274 & 0.000248 & 0.000213 \\
\hline 15 & 0.000189 & 0.000167 & 0.000162 & 0.000168 & 0.000131 & 0.000137 & 0.000124 & 0.000106 \\
\hline 16 & 0.011725 & 0.010321 & 0.010060 & 0.010404 & 0.008097 & 0.008490 & 0.007675 & 0.006595 \\
\hline 17 & 0.882 & 0.776 & 0.761 & 0.788 & 0.628 & 0.658 & 0.598 & 0.514 \\
\hline 18 & \multicolumn{2}{|c|}{0.829} & \multicolumn{2}{|c|}{0.775} & \multicolumn{2}{|c|}{0.643} & \multicolumn{2}{|c|}{0.556} \\
\hline
\end{tabular}




\begin{tabular}{|c|c|c|c|c|c|c|c|c|}
\hline \multicolumn{9}{|c|}{$35 \%$ Slag cured at $38^{\circ} \mathrm{C}$} \\
\hline \multirow{2}{*}{ Row \# } & \multicolumn{8}{|c|}{ Curing Age (days) } \\
\hline & \multicolumn{2}{|c|}{3} & \multicolumn{2}{|c|}{7} & \multicolumn{2}{|c|}{28} & \multicolumn{2}{|c|}{92} \\
\hline 1 & 0.1009 & 0.0748 & 0.1009 & 0.0748 & 0.1009 & 0.0748 & 0.1009 & 0.0748 \\
\hline 2 & 0.1412 & 0.1259 & 0.1412 & 0.1259 & 0.1412 & 0.1259 & 0.1412 & 0.1259 \\
\hline 3 & 0.1066 & 0.0760 & 0.1044 & 0.0748 & 0.1013 & 0.0753 & 0.1010 & 0.0752 \\
\hline 4 & 0.1576 & 0.1458 & 0.1541 & 0.1420 & 0.1494 & 0.1346 & 0.1500 & 0.1327 \\
\hline 5 & 15 & 15 & 15 & 15 & 15 & 15 & 15 & 15 \\
\hline 6 & 1.5000 & 1.5000 & 1.5000 & 1.5000 & 1.5000 & 1.5000 & 1.5002 & 1.5001 \\
\hline 7 & 17.18 & 17.18 & 17.79 & 17.79 & 20.44 & 20.44 & 21.47 & 21.47 \\
\hline 8 & 1.2801 & 1.2801 & 1.2734 & 1.2734 & 1.2455 & 1.2455 & 1.2350 & 1.2349 \\
\hline 9 & 2.25 & 2.25 & 2.25 & 2.25 & 2.25 & 2.25 & 2.25 & 2.25 \\
\hline 10 & 1.3089 & 1.3089 & 1.3021 & 1.3021 & 1.2735 & 1.2735 & 1.2628 & 1.2627 \\
\hline 11 & 0.005655 & 0.001218 & 0.003480 & 0.000000 & 0.000435 & 0.000435 & 0.000087 & 0.000348 \\
\hline 12 & 0.016371 & 0.019952 & 0.012943 & 0.016115 & 0.008185 & 0.008748 & 0.008799 & 0.006804 \\
\hline 13 & 0.022026 & 0.021170 & 0.016423 & 0.016115 & 0.008620 & 0.009183 & 0.008886 & 0.007152 \\
\hline 14 & 0.000330 & 0.000318 & 0.000246 & 0.000242 & 0.000129 & 0.000138 & 0.000133 & 0.000122 \\
\hline 15 & 0.000165 & 0.000159 & 0.000123 & 0.000121 & 0.000065 & 0.000069 & 0.000067 & 0.000061 \\
\hline 16 & 0.010238 & 0.009841 & 0.007634 & 0.007491 & 0.004007 & 0.004269 & 0.004131 & 0.003768 \\
\hline 17 & 0.782 & 0.752 & 0.586 & 0.575 & 0.315 & 0.335 & 0.327 & 0.298 \\
\hline 18 & \multicolumn{2}{|c|}{0.767} & \multicolumn{2}{|c|}{0.581} & \multicolumn{2}{|c|}{0.325} & \multicolumn{2}{|c|}{0.313} \\
\hline
\end{tabular}




\begin{tabular}{|c|c|c|c|c|c|c|c|c|}
\hline \multicolumn{9}{|c|}{ 35\% Slag cured at 60'C } \\
\hline \multirow{2}{*}{ Row \# } & \multicolumn{2}{|c|}{ Curing Age (days) } \\
\cline { 2 - 10 } & \multicolumn{2}{|c|}{$\mathbf{3}$} & \multicolumn{2}{|c|}{$\mathbf{7}$} & \multicolumn{2}{c|}{$\mathbf{2 8}$} \\
\hline $\mathbf{1}$ & 0.1009 & 0.0748 & 0.1009 & 0.0748 & 0.1009 & 0.0748 & 0.1009 & 0.0748 \\
\hline $\mathbf{2}$ & 0.1412 & 0.1259 & 0.1412 & 0.1259 & 0.1412 & 0.1259 & 0.1412 & 0.1259 \\
\hline $\mathbf{3}$ & 0.1044 & 0.0753 & 0.1009 & 0.0750 & 0.1009 & 0.0750 & 0.1009 & 0.0750 \\
\hline $\mathbf{4}$ & 0.1560 & 0.1422 & 0.1547 & 0.1389 & 0.1528 & 0.1369 & 0.1525 & 0.1347 \\
\hline $\mathbf{5}$ & 15 & 15 & 15 & 15 & 15 & 15 & 15 & 15 \\
\hline $\mathbf{6}$ & 1.5000 & 1.5000 & 1.5000 & 1.5000 & 1.5000 & 1.5000 & 1.5000 & 1.5001 \\
\hline $\mathbf{7}$ & 18.61 & 18.61 & 18.88 & 18.88 & 19.54 & 19.54 & 19.94 & 19.94 \\
\hline $\mathbf{8}$ & 1.2647 & 1.2647 & 1.2617 & 1.2617 & 1.2548 & 1.2548 & 1.2506 & 1.2506 \\
\hline $\mathbf{9}$ & 2.25 & 2.25 & 2.25 & 2.25 & 2.25 & 2.25 & 2.25 & 2.25 \\
\hline $\mathbf{1 0}$ & 1.2931 & 1.2931 & 1.2901 & 1.2901 & 1.2830 & 1.2830 & 1.2788 & 1.2788 \\
\hline $\mathbf{1 1}$ & 0.003480 & 0.000435 & 0.000000 & 0.000174 & 0.000000 & 0.000174 & 0.000000 & 0.000174 \\
\hline $\mathbf{1 2}$ & 0.014836 & 0.016371 & 0.013506 & 0.013046 & 0.011613 & 0.010999 & 0.011255 & 0.008851 \\
\hline $\mathbf{1 3}$ & 0.018316 & 0.016806 & 0.013506 & 0.013220 & 0.011613 & 0.011173 & 0.011255 & 0.009024 \\
\hline $\mathbf{1 4}$ & 0.000275 & 0.000252 & 0.000203 & 0.000198 & 0.000174 & 0.000168 & 0.000169 & 0.000162 \\
\hline $\mathbf{1 5}$ & 0.000137 & 0.000126 & 0.000101 & 0.000099 & 0.000087 & 0.000084 & 0.000084 & 0.000081 \\
\hline $\mathbf{1 6}$ & 0.008514 & 0.007812 & 0.006278 & 0.006145 & 0.005398 & 0.005194 & 0.005232 & 0.005034 \\
\hline $\mathbf{1 7}$ & 0.658 & 0.604 & 0.487 & 0.476 & 0.421 & 0.405 & 0.409 & 0.394 \\
\hline $\mathbf{1 8}$ & & 0.631 & & 0.482 & & 0.413 & & 0.402 \\
\hline & & & & & & & \\
\hline
\end{tabular}


Appendix E

Calculations and results of the total amount of $\mathrm{Na}_{2} \mathrm{O}_{e}$ released from concrete chunks obtained from bridge barriers expressed as a percent of the cement mass 


\begin{tabular}{|c|c|c|}
\hline Col \# & Units & Description \\
\hline 1 & ppm & $\mathrm{Na}^{+}$concentration obtained by flame photometer before dilution \\
\hline 2 & ppm & $\mathrm{K}^{+}$concentration obtained by flame photometer before dilution \\
\hline 3 & $\mathrm{~g}$ & Aggregate mass $=100$ \\
\hline 4 & $\mathrm{~mol} / \mathrm{L}$ & $\begin{array}{c}\mathrm{Na}^{+} \text {concentration in mol/L } \\
=\text { Col. } 1 / 1000 / 22.9898(\text { molar mass of } \mathrm{Na})\end{array}$ \\
\hline 5 & $\mathrm{~mol} / \mathrm{L}$ & $\begin{array}{c}\mathrm{K}^{+} \text {concentration in mol/L } \\
=\text { Col. } 2 / 1000 / 39.0983(\text { molar mass of } \mathrm{K})\end{array}$ \\
\hline 6 & mol & $\begin{array}{c}\text { Total } \mathrm{Na}^{+} \text {in moles } \\
=\text { Col. } 4 * 0.110(\text { volume of solution })\end{array}$ \\
\hline 7 & mol & $\begin{array}{l}\text { Total } \mathrm{K}^{+} \text {in moles } \\
=\text { Col. } 5 * 0.110\end{array}$ \\
\hline 8 & mol & Total $\mathrm{Na}_{2} \mathrm{O}$ in moles $=$ Col. $6 / 2$ \\
\hline 9 & mol & Total $\mathrm{K}_{2} \mathrm{O}$ in moles $=$ Col. $7 / 2$ \\
\hline 10 & $\mathrm{~g}$ & $\begin{array}{c}\text { Total mass of } \mathrm{Na}_{2} \mathrm{O} \\
=\text { Col. } 8 * 61.9788\left(\text { molar mass of } \mathrm{Na}_{2} \mathrm{O}\right)\end{array}$ \\
\hline 11 & $\mathrm{~g}$ & $\begin{array}{c}\text { Total mass of } \mathrm{K}_{2} \mathrm{O} \\
=\text { Col. } 9 * 94.2\left(\text { molar mass of } \mathrm{K}_{2} \mathrm{O}\right)\end{array}$ \\
\hline 12 & $\%$ & $\begin{array}{l}\text { Total } \mathrm{Na}_{2} \mathrm{O} \text { taken as a } \% \text { by mass of sample } \\
\quad=(\text { Col. } 10 / \text { Col. } 3) * 100\end{array}$ \\
\hline 13 & $\%$ & $\begin{array}{l}\text { Total } \mathrm{K}_{2} \mathrm{O} \text { taken as a \% by mass of sample } \\
=(\text { Col. } 11 / \text { Col. } 3) * 100\end{array}$ \\
\hline 14 & $\%$ & $\begin{array}{c}\text { Total } \mathrm{Na}_{2} \mathrm{O} \text { taken as a } \% \text { by mass of cement } \\
=\left(\text { Col. } 12 / 15.3^{*}\right) * 100 \\
* \text { RCA density }=2359 \mathrm{~kg} / \mathrm{m}^{3}, \text { cement content }=360 \mathrm{~kg} / \mathrm{m}^{3} \text {, mass of cement }(\mathrm{g}) \\
\text { in RCA sample of } 100 \mathrm{~g} \text { will be equal }=\text { volume of } 100 \mathrm{~g} * \text { cement content } \\
=(100 / 1000 / 2359) * 360 / 1000\end{array}$ \\
\hline 15 & $\%$ & $\begin{array}{c}\text { Total } \mathrm{K}_{2} \mathrm{O} \text { taken as a \% by mass of cement } \\
=(\text { Col. 13/15.3)*100 }\end{array}$ \\
\hline 16 & $\%$ & Average of $\mathrm{Na}_{2} \mathrm{O}$ released from RCA (Avg. of Col. 14) \\
\hline 17 & $\%$ & Average of $\mathrm{K}_{2} \mathrm{O}$ released from RCA (Avg. of Col. 15) \\
\hline 18 & $\%$ & $\begin{array}{l}\text { Average total } \mathrm{Na}_{2} \mathrm{O}_{\mathrm{e}} \text { taken as a } \% \text { by mass of cement } \\
=\mathrm{Col} .16+0.658 * \text { Col. } 17\end{array}$ \\
\hline
\end{tabular}




\begin{tabular}{|c|c|c|c|c|c|c|c|c|c|c|c|}
\hline $\begin{array}{c}\text { Deterioration } \\
\text { Level }\end{array}$ & $\begin{array}{c}\text { Sample } \\
\#\end{array}$ & $\mathbf{1}$ & $\mathbf{2}$ & $\mathbf{3}$ & $\mathbf{4}$ & $\mathbf{5}$ & $\mathbf{6}$ & $\mathbf{7}$ & $\mathbf{8}$ & $\mathbf{9}$ & $\mathbf{1 0}$ \\
\hline \multirow{3}{*}{ High } & $\mathbf{1}$ & 424 & 76 & 100 & 0.0184 & 0.0019 & 0.0020 & 0.0002 & 0.0010 & 0.0001 & 0.0629 \\
\cline { 2 - 12 } & $\mathbf{2}$ & 396 & 72 & 100 & 0.0172 & 0.0018 & 0.0019 & 0.0002 & 0.0009 & 0.0001 & 0.0587 \\
\cline { 2 - 12 } & $\mathbf{3}$ & 380 & 72 & 100 & 0.0165 & 0.0018 & 0.0018 & 0.0002 & 0.0009 & 0.0001 & 0.0563 \\
\hline \multirow{3}{*}{ Low } & $\mathbf{1}$ & 253 & 280 & 100 & 0.0110 & 0.0072 & 0.0012 & 0.0008 & 0.0006 & 0.0004 & 0.0376 \\
\cline { 2 - 11 } & $\mathbf{2}$ & 253 & 287 & 100 & 0.0110 & 0.0073 & 0.0012 & 0.0008 & 0.0006 & 0.0004 & 0.0376 \\
\cline { 2 - 11 } & $\mathbf{3}$ & 253 & 287 & 100 & 0.0110 & 0.0073 & 0.0012 & 0.0008 & 0.0006 & 0.0004 & 0.0376 \\
\hline
\end{tabular}

\begin{tabular}{|c|c|c|c|c|c|c|c|c|c|}
\hline $\begin{array}{c}\text { Deterioration } \\
\text { Level }\end{array}$ & $\begin{array}{c}\text { Sample } \\
\#\end{array}$ & 11 & 12 & 13 & 14 & 15 & 16 & 17 & 18 \\
\hline \multirow{3}{*}{ High } & 1 & 0.0101 & 0.0629 & 0.0101 & 0.4109 & 0.0658 & \multirow{3}{*}{0.388} & \multirow{3}{*}{0.064} & \multirow{3}{*}{0.429} \\
\hline & 2 & 0.0095 & 0.0587 & 0.0095 & 0.3838 & 0.0624 & & & \\
\hline & 3 & 0.0095 & 0.0563 & 0.0095 & 0.3682 & 0.0624 & & & \\
\hline \multirow{3}{*}{ Low } & 1 & 0.0371 & 0.0376 & 0.0371 & 0.24555 & 0.2425 & \multirow{3}{*}{0.246} & \multirow{3}{*}{0.246} & \multirow{3}{*}{0.408} \\
\hline & 2 & 0.0380 & 0.0376 & 0.0380 & 0.2455 & 0.2483 & & & \\
\hline & 3 & 0.0380 & 0.0376 & 0.0380 & 0.2455 & 0.2483 & & & \\
\hline
\end{tabular}


Appendix F

Statistical Analysis of concrete expansion samples using t-test and coefficient of variation 


\begin{tabular}{|c|c|c|c|c|c|c|c|c|}
\hline \multicolumn{9}{|c|}{ F-Test to study the difference in variance between prisms and cylinders } \\
\hline \multicolumn{2}{|c|}{ Sample Type } & Sample \# & A & $\mathrm{B}$ & $\mathrm{C}$ & F-Stat & F-Critical & Equal Variance*? \\
\hline \multirow{6}{*}{ Sudbury } & \multirow{2}{*}{ Control } & Prisms & 0.164 & 0.178 & 0.167 & \multirow{2}{*}{2.0} & \multirow{2}{*}{19} & \multirow{2}{*}{ Yes } \\
\hline & & Cylinders & 0.205 & 0.201 & 0.186 & & & \\
\hline & \multirow{2}{*}{$15 \% \mathrm{FA}$} & Prisms & 0.014 & 0.018 & 0.019 & \multirow{2}{*}{5.3} & \multirow{2}{*}{19} & \multirow{2}{*}{ Yes } \\
\hline & & Cylinders & 0.034 & 0.044 & 0.034 & & & \\
\hline & \multirow{2}{*}{$25 \%$ Slag } & Prisms & 0.037 & 0.038 & 0.035 & \multirow{2}{*}{42.6} & \multirow{2}{*}{19} & \multirow{2}{*}{ No } \\
\hline & & Cylinders & 0.055 & 0.067 & 0.07 & & & \\
\hline \multirow{16}{*}{ Spratt } & \multirow{2}{*}{ Control } & Prisms & 0.223 & 0.194 & 0.215 & \multirow{2}{*}{1.9} & \multirow{2}{*}{19} & \multirow{2}{*}{ Yes } \\
\hline & & Cylinders & 0.266 & 0.270 & 0.249 & & & \\
\hline & \multirow{2}{*}{$15 \% \mathrm{FA}$} & Prisms & 0.050 & 0.054 & 0.053 & \multirow{2}{*}{7.9} & \multirow{2}{*}{19} & \multirow{2}{*}{ Yes } \\
\hline & & Cylinders & - & 0.058 & 0.050 & & & \\
\hline & \multirow{2}{*}{$20 \%$ FA } & Prisms & 0.030 & 0.044 & 0.031 & \multirow{2}{*}{1.4} & \multirow{2}{*}{19} & \multirow{2}{*}{ Yes } \\
\hline & & Cylinders & 0.031 & 0.028 & 0.041 & & & \\
\hline & \multirow{2}{*}{$35 \%$ Slag } & Prisms & 0.040 & 0.045 & 0.030 & \multirow{2}{*}{45.3} & \multirow{2}{*}{19} & \multirow{2}{*}{ No } \\
\hline & & Cylinders & 0.038 & 0.038 & 0.040 & & & \\
\hline & \multirow{2}{*}{$50 \%$ Slag } & Prisms & 0.026 & 0.022 & 0.02 & 13 & 10 & Yes \\
\hline & & Cylinders & 0.021 & 0.026 & 0.028 & 1.3 & 19 & res \\
\hline & GUR_8SF & Prisms & 0.042 & 0.038 & 0.038 & 25 & 19 & Yes \\
\hline & ה & Cylinders & 0.035 & 0.04 & 0.043 & $2 . J$ & 19 & $10 \mathrm{~s}$ \\
\hline & GUB- & Prisms & 0.011 & 0.014 & 0.011 & & & \\
\hline & $\begin{array}{c}0.35+15 \% \\
F A\end{array}$ & Cylinders & 0.030 & 0.030 & 0.027 & 1.4 & 19 & Yes \\
\hline & GUB- & Prisms & 0.006 & 0.018 & 0.010 & & & \\
\hline & $\begin{array}{c}0 \mathrm{~S} F+\angle 0 \% \\
\mathrm{FA}\end{array}$ & Cylinders & 0.021 & 0.007 & 0.018 & 1.4 & 19 & res \\
\hline
\end{tabular}

*The variances are assumed to be equal when $-\mathrm{f}_{\text {critical }}<\mathrm{f}_{\text {stat }}<\mathrm{t}_{\text {critical. }}$. In this case, a t-test assuming equal variances between the two sets is considered otherwise $t$-test with unequal variances is performed. 


\begin{tabular}{|c|c|c|c|c|}
\hline \multicolumn{5}{|c|}{ Statistical analysis to study the difference in expansion between prisms and cylinders } \\
\hline \multicolumn{2}{|c|}{ Sample Type } & \multirow{2}{*}{$\frac{\text { T-Stat }}{-3.91}$} & \multirow{2}{*}{$\begin{array}{c}\text { T-critical } \\
2.78\end{array}$} & \multirow{2}{*}{$\begin{array}{c}\text { Statistically } \\
\text { Different*? } \\
\text { Yes }\end{array}$} \\
\hline \multirow{3}{*}{ Sudbury } & Control & & & \\
\hline & $15 \% \mathrm{FA}$ & -5.35 & 2.78 & Yes \\
\hline & $25 \%$ Slag & -5.91 & 4.30 & Yes \\
\hline \multirow{8}{*}{ Spratt } & Control & -4.65 & 2.78 & Yes \\
\hline & $15 \% \mathrm{FA}$ & -0.56 & 3.18 & No \\
\hline & $20 \%$ FA & 0.27 & 2.78 & No \\
\hline & $35 \%$ Slag & -0.12 & 4.30 & No \\
\hline & $50 \%$ Slag & -0.66 & 2.78 & No \\
\hline & GUB-8SF & 0.05 & 2.78 & No \\
\hline & GUB-8SF+15\% FA & -13.64 & 2.78 & Yes \\
\hline & GUB-8SF+20\% FA & -0.79 & 2.78 & No \\
\hline
\end{tabular}

$*$ The expansion difference between prisms and cylinders is considered statistically significant if $\mathrm{t}_{\text {stat }}>\mathrm{t}_{\text {critical }}$ or $\mathrm{t}_{\text {stat }}<-\mathrm{t}_{\text {critical }}$.

\begin{tabular}{|c|c|c|c|c|c|c|c|}
\hline \multicolumn{8}{|c|}{ Coefficient of variation (COV) between three samples from same set } \\
\hline \multirow{2}{*}{\multicolumn{2}{|c|}{ Sample Type }} & \multicolumn{2}{|c|}{ Prisms } & \multicolumn{2}{|c|}{ Cylinders } & \multicolumn{2}{|c|}{ Cubes } \\
\hline & & Average & $\mathrm{COV}$ & Average & $\mathrm{COV}$ & Average & $\mathrm{COV}$ \\
\hline \multirow{3}{*}{ Sudbury } & Control & 0.171 & 3.4 & 0.197 & 13.7 & 0.145 & 23.6 \\
\hline & $15 \% \mathrm{FA}$ & 0.017 & 12.1 & 0.037 & 25.6 & 0.015 & 21.4 \\
\hline & $25 \%$ Slag & 0.037 & 2.7 & 0.064 & 10.2 & 0.022 & 26.2 \\
\hline \multirow{8}{*}{ Spratt } & Control & 0.211 & 5.9 & 0.262 & 3.5 & 0.192 & 14.4 \\
\hline & $15 \% \mathrm{FA}$ & 0.053 & 3.1 & 0.058 & - & 0.032 & 7.0 \\
\hline & $20 \%$ FA & 0.035 & 18.4 & 0.033 & 16.3 & 0.016 & 23.0 \\
\hline & $35 \%$ Slag & 0.038 & 16.6 & 0.040 & 2.4 & 0.017 & 11.8 \\
\hline & $50 \%$ Slag & 0.023 & 11.5 & 0.025 & 12.1 & 0.014 & 14.0 \\
\hline & GUB-8SF & 0.039 & 5.3 & 0.039 & 8.4 & 0.024 & 39.9 \\
\hline & GUB- $8 \mathrm{SF}+15 \%$ FA & 0.012 & 9.4 & 0.029 & 4.7 & 0.022 & 7.7 \\
\hline & GUB- $8 \mathrm{SF}+20 \% \mathrm{FA}$ & 0.011 & 45.6 & 0.015 & 38.2 & 0.018 & 19.9 \\
\hline
\end{tabular}

- COV could not be obtained because one sample was broken before the 2-year expansion measurements. 


\section{Appendix G}

Statistical analysis of the data obtained from SEM for paste samples with $35 \%$ slag 


\begin{tabular}{|c|c|c|c|c|c|}
\hline \multicolumn{7}{|c|}{ Paste samples with 35\% Slag at $\mathbf{2 3}^{\mathbf{}} \mathbf{C}$} \\
\hline Spectrum & $\mathbf{C a}$ & $\mathbf{S i}$ & $\mathbf{C a} / \mathbf{S i}$ & $\mathbf{N a}$ & $\mathbf{K}$ \\
\hline $\mathbf{1}$ & 17.4 & 10.8 & 1.61 & 0.1 & 0.4 \\
\hline $\mathbf{2}$ & 15.3 & 10.3 & 1.49 & 0 & 0.5 \\
\hline $\mathbf{3}$ & 16.9 & 10.8 & 1.56 & 0 & 0.5 \\
\hline $\mathbf{4}$ & 17.4 & 9.9 & 1.76 & 0 & 0.3 \\
\hline $\mathbf{5}$ & 16.1 & 10.7 & 1.50 & 0 & 0.4 \\
\hline $\mathbf{6}$ & 16.6 & 11 & 1.51 & 0 & 0.4 \\
\hline $\mathbf{7}$ & 16.9 & 10 & 1.69 & 0.1 & 0.4 \\
\hline $\mathbf{8}$ & 17.2 & 11.3 & 1.52 & 0.1 & 0.4 \\
\hline $\mathbf{9}$ & 16.4 & 10.7 & 1.53 & 0.1 & 0.4 \\
\hline $\mathbf{1 0}$ & 16.8 & 11.1 & 1.51 & 0 & 0.4 \\
\hline Avg & 16.7 & 10.66 & 1.57 & 0.04 & 0.41 \\
\hline
\end{tabular}

\begin{tabular}{|c|c|c|c|c|c|}
\hline \multicolumn{7}{|c|}{ Paste samples with 35\% Slag at 38 $\mathbf{0}^{\mathbf{C}}$} \\
\hline Spectrum & $\mathbf{C a}$ & $\mathbf{S i}$ & $\mathbf{C a} / \mathbf{S i}$ & $\mathbf{N a}$ & $\mathbf{K}$ \\
\hline $\mathbf{1}$ & 16.5 & 10.2 & 1.62 & 0 & 0.3 \\
\hline $\mathbf{2}$ & 16.6 & 11.1 & 1.50 & 0.1 & 0.3 \\
\hline $\mathbf{3}$ & 17.5 & 11.6 & 1.51 & 0 & 0.4 \\
\hline $\mathbf{4}$ & 18.6 & 11.1 & 1.68 & 0.1 & 0.3 \\
\hline $\mathbf{5}$ & 18.3 & 11.1 & 1.65 & 0.1 & 0.3 \\
\hline $\mathbf{6}$ & 18 & 11.3 & 1.59 & 0.1 & 0.3 \\
\hline $\mathbf{7}$ & 18.4 & 10.6 & 1.74 & 0.1 & 0.2 \\
\hline $\mathbf{8}$ & 17.8 & 10.6 & 1.68 & 0 & 0.3 \\
\hline $\mathbf{9}$ & 19.3 & 10.8 & 1.79 & 0 & 0.2 \\
\hline $\mathbf{1 0}$ & 17.2 & 10.4 & 1.65 & 0.1 & 0.4 \\
\hline $\mathbf{A v g}$ & 17.82 & 10.88 & 1.64 & 0.06 & 0.30 \\
\hline
\end{tabular}

\begin{tabular}{|l|l|l|l|}
\hline p-value & $\mathbf{C a} / \mathbf{S i}=0.100$ & $\mathbf{N a}=0.398$ & $\mathbf{K}=0.001$ \\
\hline
\end{tabular}


Appendix $\mathrm{H}$

Expansion of concrete samples cast at $60^{\circ} \mathrm{C}$ 


\begin{tabular}{|c|c|c|c|c|c|c|c|c|c|c|c|c|}
\hline \multicolumn{13}{|c|}{ Sudbury $+15 \%$ FA at $60^{\circ} \mathrm{C}$} \\
\hline \multirow{2}{*}{$\begin{array}{c}\text { Time } \\
\text { (weeks) }\end{array}$} & \multicolumn{4}{|c|}{ Prisms } & \multicolumn{4}{|c|}{ Cylinders } & \multicolumn{4}{|c|}{ Cubes } \\
\hline & $\mathbf{A}$ & B & $\mathbf{C}$ & Average & $\mathbf{A}$ & B & $\mathbf{C}$ & Average & $\mathbf{A}$ & $\mathbf{B}$ & $\mathbf{C}$ & Average \\
\hline $\mathbf{0}$ & 0.000 & 0.000 & 0.000 & 0.000 & 0.000 & 0.000 & 0.000 & 0.000 & 0.000 & 0.000 & 0.000 & 0.000 \\
\hline 1 & 0.002 & 0.002 & 0.002 & 0.002 & 0.001 & -0.006 & -0.002 & -0.002 & -0.001 & -0.001 & -0.007 & -0.003 \\
\hline 2 & 0.002 & 0.002 & 0.002 & 0.002 & -0.003 & -0.010 & -0.005 & -0.006 & 0.002 & 0.007 & -0.004 & 0.002 \\
\hline 4 & 0.002 & 0.002 & 0.002 & 0.002 & -0.006 & -0.010 & -0.007 & -0.008 & 0.001 & 0.006 & -0.005 & 0.001 \\
\hline 8 & 0.004 & 0.005 & 0.005 & 0.005 & 0.002 & -0.006 & 0.000 & -0.002 & 0.003 & 0.005 & -0.002 & 0.002 \\
\hline 13 & 0.006 & 0.007 & 0.010 & 0.008 & 0.005 & 0.000 & 0.000 & 0.002 & 0.005 & 0.007 & 0.001 & 0.005 \\
\hline 18 & 0.006 & 0.008 & 0.010 & 0.008 & 0.006 & 0.001 & 0.003 & 0.003 & 0.005 & 0.007 & 0.003 & 0.005 \\
\hline 26 & 0.010 & 0.010 & 0.014 & 0.011 & 0.008 & 0.000 & 0.006 & 0.005 & 0.005 & 0.006 & -0.001 & 0.004 \\
\hline 39 & 0.010 & 0.011 & 0.014 & 0.012 & 0.016 & 0.010 & 0.014 & 0.014 & 0.009 & 0.009 & 0.000 & 0.006 \\
\hline 52 & 0.009 & 0.008 & 0.016 & 0.011 & 0.018 & 0.013 & 0.013 & 0.014 & 0.007 & 0.009 & 0.001 & 0.006 \\
\hline 65 & 0.013 & 0.013 & 0.023 & 0.016 & 0.031 & 0.010 & 0.022 & 0.021 & 0.011 & 0.017 & 0.004 & 0.011 \\
\hline 80 & 0.013 & 0.014 & 0.022 & 0.016 & 0.036 & 0.019 & 0.029 & 0.028 & 0.017 & 0.018 & 0.010 & 0.015 \\
\hline 93 & 0.014 & 0.016 & 0.026 & 0.019 & 0.044 & 0.021 & 0.031 & 0.032 & 0.015 & 0.019 & 0.012 & 0.015 \\
\hline 104 & 0.018 & 0.018 & 0.031 & 0.022 & 0.043 & 0.024 & 0.034 & 0.034 & 0.019 & 0.021 & 0.013 & 0.017 \\
\hline
\end{tabular}




\begin{tabular}{|c|c|c|c|c|c|c|c|c|c|c|c|c|}
\hline \multicolumn{13}{|c|}{ Sudbury $+25 \%$ Slag at $60^{\circ} \mathrm{C}$} \\
\hline \multirow{2}{*}{$\begin{array}{c}\text { Time } \\
\text { (weeks) }\end{array}$} & \multicolumn{4}{|c|}{ Prisms } & \multicolumn{4}{|c|}{ Cylinders } & \multicolumn{4}{|c|}{ Cubes } \\
\hline & $\mathbf{A}$ & B & $\mathbf{C}$ & Average & $\mathbf{A}$ & B & $\mathbf{C}$ & Average & $\mathbf{A}$ & $\mathbf{B}$ & $\mathbf{C}$ & Average \\
\hline $\mathbf{0}$ & 0.000 & 0.000 & 0.000 & 0.000 & 0.000 & 0.000 & 0.000 & 0.000 & 0.000 & 0.000 & 0.000 & 0.000 \\
\hline 1 & 0.001 & 0.003 & 0.000 & 0.001 & 0.008 & 0.003 & 0.000 & 0.004 & 0.000 & -0.002 & -0.003 & -0.002 \\
\hline 2 & 0.006 & 0.006 & 0.003 & 0.005 & 0.008 & 0.004 & 0.006 & 0.006 & 0.001 & -0.002 & -0.003 & -0.001 \\
\hline 4 & 0.012 & 0.014 & 0.012 & 0.013 & 0.002 & 0.002 & -0.002 & 0.001 & 0.005 & 0.003 & 0.001 & 0.003 \\
\hline 8 & 0.012 & 0.018 & 0.016 & 0.015 & 0.017 & 0.012 & 0.014 & 0.014 & 0.004 & 0.002 & 0.002 & 0.003 \\
\hline 13 & 0.012 & 0.018 & 0.016 & 0.015 & 0.017 & 0.014 & 0.014 & 0.015 & 0.011 & 0.008 & 0.004 & 0.008 \\
\hline 18 & 0.018 & 0.014 & 0.016 & 0.016 & 0.015 & 0.014 & 0.013 & 0.014 & 0.012 & 0.014 & 0.010 & 0.012 \\
\hline 26 & 0.012 & 0.018 & 0.018 & 0.016 & 0.016 & 0.007 & 0.011 & 0.011 & 0.011 & 0.011 & 0.005 & 0.009 \\
\hline 39 & 0.015 & 0.018 & 0.013 & 0.015 & 0.017 & 0.020 & 0.019 & 0.019 & 0.017 & 0.015 & 0.009 & 0.014 \\
\hline 52 & 0.018 & 0.020 & 0.016 & 0.018 & 0.024 & 0.022 & 0.018 & 0.022 & 0.020 & 0.019 & 0.015 & 0.018 \\
\hline 65 & 0.029 & 0.030 & 0.023 & 0.027 & 0.036 & 0.030 & 0.027 & 0.031 & 0.023 & 0.023 & 0.019 & 0.022 \\
\hline 80 & 0.030 & 0.034 & 0.031 & 0.031 & 0.035 & 0.034 & 0.033 & 0.034 & 0.019 & 0.017 & 0.013 & 0.016 \\
\hline 93 & 0.027 & 0.031 & 0.029 & 0.029 & 0.039 & 0.034 & 0.035 & 0.036 & 0.023 & 0.022 & 0.017 & 0.021 \\
\hline 104 & 0.031 & 0.037 & 0.034 & 0.034 & 0.042 & 0.038 & 0.039 & 0.040 & 0.033 & 0.033 & 0.027 & 0.031 \\
\hline
\end{tabular}




\begin{tabular}{|c|c|c|c|c|c|c|c|c|}
\hline \multicolumn{9}{|c|}{ Spratt $+15 \%$ FA at $60^{\circ} \mathrm{C}$} \\
\hline \multirow{2}{*}{$\begin{array}{c}\text { Time } \\
\text { (weeks) }\end{array}$} & \multicolumn{4}{|c|}{ Prisms } & \multicolumn{4}{|c|}{ Cylinders } \\
\hline & $\mathbf{A}$ & B & C & Average & A & B & C & Average \\
\hline $\mathbf{0}$ & 0.000 & 0.000 & 0.000 & 0.000 & 0.000 & 0.000 & 0.000 & 0.000 \\
\hline 1 & 0.002 & 0.003 & 0.002 & 0.003 & 0.002 & 0.000 & -0.001 & 0.000 \\
\hline 2 & -0.002 & -0.002 & -0.002 & -0.002 & 0.002 & -0.001 & 0.007 & 0.003 \\
\hline 4 & 0.002 & 0.004 & 0.003 & 0.003 & 0.005 & -0.001 & -0.001 & 0.001 \\
\hline 8 & 0.009 & 0.011 & 0.011 & 0.010 & 0.006 & 0.000 & 0.006 & 0.004 \\
\hline 13 & 0.013 & 0.013 & 0.014 & 0.013 & 0.010 & 0.017 & 0.015 & 0.014 \\
\hline 18 & 0.015 & 0.017 & 0.018 & 0.017 & 0.021 & 0.022 & 0.021 & 0.021 \\
\hline 26 & 0.022 & 0.021 & 0.028 & 0.023 & 0.018 & 0.022 & 0.018 & 0.019 \\
\hline 39 & 0.024 & 0.023 & 0.030 & 0.026 & 0.038 & 0.042 & 0.038 & 0.039 \\
\hline 52 & 0.033 & 0.033 & 0.042 & 0.036 & 0.045 & 0.049 & 0.044 & 0.046 \\
\hline 65 & 0.036 & 0.033 & 0.045 & 0.038 & 0.042 & 0.050 & 0.044 & 0.045 \\
\hline 80 & 0.042 & 0.038 & 0.049 & 0.043 & 0.045 & 0.046 & 0.037 & 0.043 \\
\hline 93 & 0.041 & 0.036 & 0.051 & 0.043 & 0.059 & 0.065 & 0.060 & 0.061 \\
\hline 104 & 0.046 & 0.042 & 0.056 & 0.048 & 0.058 & 0.058 & 0.052 & 0.056 \\
\hline
\end{tabular}




\begin{tabular}{|c|c|c|c|c|c|c|c|c|}
\hline \multicolumn{9}{|c|}{ Spratt $+15 \%$ FA at $60^{\circ} \mathrm{C}$} \\
\hline \multirow{2}{*}{$\begin{array}{c}\text { Time } \\
\text { (weeks) }\end{array}$} & \multicolumn{4}{|c|}{ Cubes-Sides } & \multicolumn{4}{|c|}{ Cubes-Center } \\
\hline & A & B & C & Average & A & B & C & Average \\
\hline $\mathbf{0}$ & 0.000 & 0.000 & 0.000 & 0.000 & 0.000 & 0.000 & 0.000 & 0.000 \\
\hline 1 & -0.013 & -0.010 & -0.016 & -0.013 & -0.012 & -0.012 & -0.016 & -0.014 \\
\hline 2 & -0.015 & -0.015 & -0.010 & -0.013 & -0.008 & -0.012 & -0.021 & -0.014 \\
\hline 4 & -0.006 & -0.006 & -0.005 & -0.006 & -0.004 & -0.014 & -0.021 & -0.013 \\
\hline 8 & -0.006 & -0.006 & -0.005 & -0.006 & -0.002 & -0.002 & 0.014 & 0.003 \\
\hline 13 & -0.004 & -0.007 & -0.003 & -0.005 & 0.000 & -0.004 & -0.010 & -0.005 \\
\hline 18 & 0.002 & 0.003 & 0.003 & 0.003 & -0.002 & 0.000 & 0.002 & 0.000 \\
\hline 26 & 0.008 & 0.009 & 0.013 & 0.010 & 0.008 & 0.006 & 0.004 & 0.006 \\
\hline 39 & 0.021 & 0.016 & 0.021 & 0.019 & 0.019 & 0.014 & 0.021 & 0.018 \\
\hline 52 & 0.017 & 0.019 & 0.023 & 0.020 & 0.016 & 0.023 & 0.016 & 0.019 \\
\hline 65 & 0.025 & 0.027 & 0.036 & 0.030 & 0.019 & 0.014 & 0.023 & 0.019 \\
\hline 80 & - & 0.019 & 0.029 & 0.024 & - & 0.027 & 0.037 & 0.032 \\
\hline 93 & 0.039 & 0.033 & 0.041 & 0.038 & 0.008 & - & 0.023 & 0.015 \\
\hline 104 & 0.034 & 0.032 & 0.044 & 0.037 & 0.031 & 0.037 & 0.039 & 0.036 \\
\hline
\end{tabular}




\begin{tabular}{|c|c|c|c|c|c|c|c|c|}
\hline \multicolumn{9}{|c|}{ Spratt $+20 \%$ FA at $60^{\circ} \mathrm{C}$} \\
\hline \multirow{2}{*}{$\begin{array}{c}\text { Time } \\
\text { (weeks) }\end{array}$} & \multicolumn{4}{|c|}{ Prisms } & \multicolumn{4}{|c|}{ Cylinders } \\
\hline & $\mathbf{A}$ & B & C & Average & A & B & $\mathbf{C}$ & Average \\
\hline $\mathbf{0}$ & 0.000 & 0.000 & 0.000 & 0.000 & 0.000 & 0.000 & 0.000 & 0.000 \\
\hline 1 & 0.000 & 0.000 & 0.002 & 0.001 & -0.002 & 0.002 & 0.000 & 0.000 \\
\hline 2 & 0.005 & 0.002 & 0.008 & 0.005 & -0.004 & -0.001 & -0.003 & -0.003 \\
\hline 4 & 0.005 & 0.000 & 0.004 & 0.003 & -0.002 & 0.000 & 0.001 & -0.001 \\
\hline 8 & 0.013 & 0.005 & 0.011 & 0.010 & 0.001 & 0.002 & 0.003 & 0.002 \\
\hline 13 & 0.010 & 0.010 & 0.018 & 0.013 & 0.001 & 0.008 & 0.009 & 0.006 \\
\hline 18 & 0.016 & 0.009 & 0.012 & 0.012 & 0.008 & 0.010 & 0.009 & 0.009 \\
\hline 26 & 0.018 & 0.015 & 0.018 & 0.017 & 0.016 & 0.011 & 0.012 & 0.013 \\
\hline 39 & 0.025 & 0.015 & 0.019 & 0.020 & 0.026 & 0.024 & 0.022 & 0.024 \\
\hline 52 & 0.034 & 0.025 & 0.028 & 0.029 & 0.030 & 0.026 & 0.028 & 0.028 \\
\hline 65 & 0.045 & 0.031 & 0.033 & 0.036 & 0.042 & 0.042 & 0.045 & 0.043 \\
\hline 80 & 0.046 & 0.029 & 0.035 & 0.037 & - & - & - & - \\
\hline 93 & 0.048 & 0.030 & 0.036 & 0.038 & 0.050 & 0.050 & 0.054 & 0.052 \\
\hline 104 & 0.055 & 0.035 & 0.042 & 0.044 & 0.050 & 0.044 & 0.043 & 0.046 \\
\hline
\end{tabular}




\begin{tabular}{|c|c|c|c|c|c|c|c|c|}
\hline \multicolumn{9}{|c|}{ Spratt + 20\% FA at 60 } \\
\hline \multirow{2}{*}{$\begin{array}{c}\text { Time } \\
\text { weeks) }\end{array}$} & $\mathbf{A}$ & $\mathbf{B}$ & $\mathbf{C}$ & Average & $\mathbf{A}$ & $\mathbf{3}$ & $\mathbf{C}$ & Average \\
\hline $\mathbf{0}$ & 0.000 & 0.000 & 0.000 & 0.000 & 0.000 & 0.000 & 0.000 & 0.000 \\
\hline $\mathbf{1}$ & 0.003 & 0.008 & -0.001 & 0.004 & -0.012 & -0.014 & -0.016 & -0.014 \\
\hline $\mathbf{2}$ & -0.003 & 0.006 & -0.002 & 0.000 & -0.002 & -0.008 & -0.021 & -0.010 \\
\hline $\mathbf{8}$ & -0.002 & 0.005 & -0.004 & 0.000 & -0.004 & -0.012 & -0.014 & -0.010 \\
\hline $\mathbf{1 3}$ & 0.003 & 0.009 & 0.001 & 0.004 & -0.016 & 0.000 & -0.006 & -0.008 \\
\hline $\mathbf{1 8}$ & 0.010 & 0.018 & 0.011 & 0.013 & -0.006 & -0.002 & -0.002 & -0.003 \\
\hline $\mathbf{2 6}$ & 0.013 & 0.018 & 0.013 & 0.014 & -0.002 & 0.000 & -0.008 & -0.003 \\
\hline $\mathbf{3 9}$ & 0.013 & 0.021 & 0.014 & 0.016 & 0.002 & 0.008 & 0.002 & 0.004 \\
\hline $\mathbf{5 2}$ & 0.017 & 0.030 & 0.019 & 0.022 & 0.000 & 0.012 & 0.004 & 0.005 \\
\hline $\mathbf{6 5}$ & 0.039 & 0.053 & 0.043 & 0.045 & 0.000 & 0.016 & 0.008 & 0.008 \\
\hline $\mathbf{8 0}$ & 0.025 & 0.039 & 0.024 & 0.028 & 0.008 & 0.023 & 0.004 & 0.012 \\
\hline $\mathbf{9 3}$ & 0.029 & 0.052 & 0.031 & 0.037 & -0.004 & 0.021 & 0.004 & 0.007 \\
\hline $\mathbf{1 0 4}$ & 0.030 & 0.053 & 0.031 & 0.038 & 0.012 & 0.021 & 0.012 & 0.015 \\
\hline
\end{tabular}




\begin{tabular}{|c|c|c|c|c|c|c|c|c|}
\hline \multicolumn{9}{|c|}{ Spratt $+35 \%$ Slag at $60^{\circ} \mathrm{C}$} \\
\hline \multirow{2}{*}{$\begin{array}{c}\text { Time } \\
\text { (weeks) }\end{array}$} & \multicolumn{4}{|c|}{ Prisms } & \multicolumn{4}{|c|}{ Cylinders } \\
\hline & $\mathbf{A}$ & B & C & Average & A & B & $\mathbf{C}$ & Average \\
\hline $\mathbf{0}$ & 0.000 & 0.000 & 0.000 & 0.000 & 0.000 & 0.000 & 0.000 & 0.000 \\
\hline 1 & 0.004 & 0.006 & 0.004 & 0.005 & 0.008 & 0.017 & 0.004 & 0.010 \\
\hline 2 & 0.003 & 0.002 & 0.000 & 0.002 & 0.007 & 0.009 & 0.005 & 0.007 \\
\hline 4 & 0.004 & 0.005 & 0.000 & 0.003 & 0.006 & 0.010 & 0.006 & 0.007 \\
\hline 8 & 0.012 & 0.006 & 0.003 & 0.007 & 0.008 & 0.009 & 0.010 & 0.009 \\
\hline 13 & 0.012 & 0.010 & 0.010 & 0.010 & 0.013 & 0.006 & 0.003 & 0.007 \\
\hline 18 & 0.010 & 0.006 & 0.011 & 0.009 & 0.018 & 0.030 & 0.012 & 0.020 \\
\hline 26 & 0.016 & 0.010 & 0.018 & 0.015 & 0.018 & 0.035 & 0.012 & 0.022 \\
\hline 39 & 0.025 & 0.023 & 0.032 & 0.027 & 0.033 & 0.050 & 0.021 & 0.034 \\
\hline 52 & 0.046 & 0.027 & 0.036 & 0.037 & 0.038 & 0.058 & 0.027 & 0.041 \\
\hline 65 & 0.041 & 0.027 & 0.039 & 0.036 & 0.038 & 0.061 & 0.027 & 0.042 \\
\hline 80 & 0.034 & 0.021 & 0.031 & 0.029 & 0.039 & 0.063 & 0.027 & 0.043 \\
\hline 93 & 0.046 & 0.032 & 0.045 & 0.041 & 0.046 & 0.070 & 0.032 & 0.049 \\
\hline 104 & 0.046 & 0.031 & 0.050 & 0.042 & 0.047 & 0.075 & 0.035 & 0.053 \\
\hline
\end{tabular}




\begin{tabular}{|c|c|c|c|c|c|c|c|c|}
\hline \multicolumn{9}{|c|}{ Spratt $+35 \%$ Slag at $60^{\circ} \mathrm{C}$} \\
\hline \multirow{2}{*}{$\begin{array}{c}\text { Time } \\
\text { (weeks) }\end{array}$} & \multicolumn{4}{|c|}{ Cubes-Sides } & \multicolumn{4}{|c|}{ Cubes-Center } \\
\hline & $\mathbf{A}$ & B & C & Average & $\mathbf{A}$ & B & C & Average \\
\hline $\mathbf{0}$ & 0.000 & 0.000 & 0.000 & 0.000 & 0.000 & 0.000 & 0.000 & 0.000 \\
\hline 1 & 0.007 & 0.011 & -0.001 & 0.006 & 0.006 & -0.004 & -0.002 & 0.000 \\
\hline 2 & -0.005 & -0.005 & -0.017 & -0.009 & -0.021 & -0.023 & -0.010 & -0.018 \\
\hline 4 & -0.003 & 0.002 & -0.015 & -0.005 & -0.021 & -0.010 & 0.016 & -0.005 \\
\hline 8 & 0.006 & 0.009 & -0.007 & 0.003 & 0.002 & 0.004 & 0.012 & 0.006 \\
\hline 13 & 0.012 & 0.008 & -0.002 & 0.006 & 0.000 & 0.002 & 0.019 & 0.007 \\
\hline 18 & 0.019 & 0.021 & 0.002 & 0.014 & -0.014 & 0.006 & 0.000 & -0.003 \\
\hline 26 & 0.020 & 0.020 & 0.007 & 0.016 & 0.002 & 0.012 & 0.006 & 0.007 \\
\hline 39 & 0.019 & 0.024 & 0.004 & 0.016 & -0.002 & 0.010 & 0.012 & 0.007 \\
\hline 52 & 0.022 & 0.025 & 0.011 & 0.020 & 0.008 & 0.016 & 0.021 & 0.015 \\
\hline 65 & 0.034 & 0.037 & 0.023 & 0.031 & 0.021 & 0.019 & 0.023 & 0.021 \\
\hline 80 & 0.035 & 0.039 & 0.030 & 0.035 & 0.021 & 0.027 & 0.027 & 0.025 \\
\hline 93 & 0.039 & 0.042 & 0.036 & 0.039 & 0.019 & 0.033 & 0.021 & 0.024 \\
\hline 104 & 0.040 & 0.046 & 0.039 & 0.042 & 0.023 & 0.033 & 0.016 & 0.024 \\
\hline
\end{tabular}




\begin{tabular}{|c|c|c|c|c|c|c|c|c|}
\hline \multicolumn{9}{|c|}{ Spratt $+50 \%$ Slag at $60^{\circ} \mathrm{C}$} \\
\hline \multirow{2}{*}{$\begin{array}{c}\text { Time } \\
\text { (weeks) }\end{array}$} & \multicolumn{4}{|c|}{ Prisms } & \multicolumn{4}{|c|}{ Cylinders } \\
\hline & A & B & C & Average & A & B & $\mathbf{C}$ & Average \\
\hline $\mathbf{0}$ & 0.000 & 0.000 & 0.000 & 0.000 & 0.000 & 0.000 & 0.000 & 0.000 \\
\hline 1 & -0.002 & 0.002 & 0.002 & 0.001 & -0.004 & -0.014 & -0.006 & -0.008 \\
\hline 2 & 0.000 & 0.000 & 0.006 & 0.002 & 0.000 & -0.011 & -0.009 & -0.007 \\
\hline 4 & -0.001 & -0.001 & 0.007 & 0.002 & 0.002 & -0.010 & -0.008 & -0.005 \\
\hline 8 & 0.002 & 0.003 & 0.003 & 0.003 & 0.006 & 0.001 & -0.010 & -0.001 \\
\hline 13 & 0.009 & 0.009 & 0.008 & 0.009 & 0.012 & 0.010 & 0.007 & 0.010 \\
\hline 18 & 0.008 & 0.009 & 0.002 & 0.006 & 0.011 & 0.006 & 0.010 & 0.009 \\
\hline 26 & 0.018 & 0.018 & 0.010 & 0.015 & 0.022 & 0.022 & 0.021 & 0.022 \\
\hline 39 & 0.028 & 0.030 & 0.019 & 0.026 & 0.032 & 0.030 & 0.028 & 0.030 \\
\hline 52 & 0.034 & 0.040 & 0.028 & 0.034 & 0.038 & 0.038 & 0.034 & 0.037 \\
\hline 65 & 0.033 & 0.037 & 0.025 & 0.031 & 0.033 & 0.035 & 0.032 & 0.033 \\
\hline 80 & 0.034 & 0.038 & 0.029 & 0.034 & 0.042 & 0.042 & 0.043 & 0.043 \\
\hline 93 & 0.040 & 0.043 & 0.036 & 0.040 & 0.041 & 0.044 & 0.042 & 0.042 \\
\hline 104 & 0.043 & 0.049 & 0.039 & 0.044 & 0.050 & 0.051 & 0.052 & 0.051 \\
\hline
\end{tabular}




\begin{tabular}{|c|c|c|c|c|c|c|c|c|}
\hline \multicolumn{9}{|c|}{ Spratt $+50 \%$ Slag at $60^{\circ} \mathrm{C}$} \\
\hline \multirow{2}{*}{$\begin{array}{c}\text { Time } \\
\text { (weeks) }\end{array}$} & \multicolumn{4}{|c|}{ Cubes-Sides } & \multicolumn{4}{|c|}{ Cubes-Center } \\
\hline & $\mathbf{A}$ & $\mathbf{B}$ & $\mathbf{C}$ & Average & $\mathbf{A}$ & B & $\mathbf{C}$ & Average \\
\hline $\mathbf{0}$ & 0.000 & 0.000 & 0.000 & 0.000 & 0.000 & 0.000 & 0.000 & 0.000 \\
\hline 1 & -0.011 & 0.003 & -0.005 & -0.004 & 0.000 & 0.000 & -0.004 & -0.001 \\
\hline 2 & -0.009 & -0.001 & -0.004 & -0.005 & -0.008 & 0.000 & -0.008 & -0.005 \\
\hline 4 & -0.007 & -0.001 & -0.004 & -0.004 & -0.008 & -0.002 & -0.010 & -0.007 \\
\hline 8 & -0.007 & 0.001 & -0.003 & -0.003 & 0.019 & -0.002 & -0.006 & 0.003 \\
\hline 13 & 0.003 & 0.020 & 0.007 & 0.010 & -0.006 & -0.008 & -0.006 & -0.007 \\
\hline 18 & 0.004 & 0.007 & 0.004 & 0.005 & -0.002 & 0.002 & -0.004 & -0.001 \\
\hline 26 & 0.000 & 0.007 & 0.005 & 0.004 & -0.004 & 0.002 & -0.004 & -0.002 \\
\hline 39 & 0.003 & 0.010 & 0.010 & 0.008 & -0.002 & 0.000 & 0.000 & -0.001 \\
\hline 52 & 0.015 & 0.021 & 0.020 & 0.019 & 0.000 & -0.004 & 0.000 & -0.001 \\
\hline 65 & 0.017 & 0.025 & 0.027 & 0.023 & -0.002 & -0.004 & 0.004 & -0.001 \\
\hline 80 & 0.016 & 0.025 & 0.025 & 0.022 & 0.000 & 0.000 & - & 0.000 \\
\hline 93 & 0.020 & 0.029 & 0.027 & 0.025 & -0.004 & 0.004 & 0.004 & 0.001 \\
\hline 104 & 0.018 & 0.037 & 0.035 & 0.030 & 0.000 & 0.006 & 0.006 & 0.004 \\
\hline
\end{tabular}




\begin{tabular}{|c|c|c|c|c|c|c|c|c|}
\hline \multicolumn{9}{|c|}{ Spratt + GUB-8SF at $60^{\circ} \mathrm{C}$} \\
\hline \multirow{2}{*}{$\begin{array}{c}\text { Time } \\
\text { (weeks) }\end{array}$} & \multicolumn{4}{|c|}{ Prisms } & \multicolumn{4}{|c|}{ Cylinders } \\
\hline & $\mathbf{A}$ & $\mathbf{B}$ & $\mathbf{C}$ & Average & $\mathbf{A}$ & B & $\mathbf{C}$ & Average \\
\hline $\mathbf{0}$ & 0.000 & 0.000 & 0.000 & 0.000 & 0.000 & 0.000 & 0.000 & 0.000 \\
\hline 1 & -0.004 & -0.009 & -0.006 & -0.006 & -0.011 & -0.009 & -0.010 & -0.010 \\
\hline 2 & -0.003 & -0.006 & -0.004 & -0.004 & -0.007 & -0.006 & -0.008 & -0.007 \\
\hline 4 & 0.000 & -0.001 & -0.001 & -0.001 & -0.003 & -0.002 & -0.002 & -0.002 \\
\hline 8 & 0.006 & 0.006 & 0.004 & 0.005 & 0.001 & 0.002 & 0.003 & 0.002 \\
\hline 13 & 0.015 & 0.005 & 0.010 & 0.010 & 0.005 & 0.012 & 0.010 & 0.009 \\
\hline 18 & 0.018 & 0.016 & 0.014 & 0.016 & 0.012 & 0.018 & 0.016 & 0.015 \\
\hline 26 & 0.027 & 0.018 & 0.022 & 0.023 & 0.022 & 0.023 & 0.023 & 0.023 \\
\hline 39 & 0.032 & 0.023 & 0.024 & 0.026 & 0.024 & 0.026 & 0.029 & 0.026 \\
\hline 52 & 0.037 & 0.026 & 0.030 & 0.031 & 0.027 & 0.033 & 0.034 & 0.031 \\
\hline 65 & 0.041 & 0.031 & 0.032 & 0.035 & 0.031 & 0.038 & 0.038 & 0.036 \\
\hline 80 & 0.038 & 0.027 & 0.030 & 0.031 & 0.027 & 0.040 & 0.037 & 0.035 \\
\hline 93 & 0.042 & 0.029 & 0.031 & 0.034 & 0.031 & 0.040 & 0.036 & 0.036 \\
\hline 104 & 0.044 & 0.033 & 0.034 & 0.037 & 0.033 & 0.044 & 0.037 & 0.038 \\
\hline
\end{tabular}




\begin{tabular}{|c|c|c|c|c|c|c|c|c|}
\hline \multicolumn{9}{|c|}{ Spratt + GUB-8SF at $60^{\circ} \mathrm{C}$} \\
\hline \multirow{2}{*}{$\begin{array}{c}\text { Time } \\
\text { (weeks) }\end{array}$} & \multicolumn{4}{|c|}{ Cubes-Sides } & \multicolumn{4}{|c|}{ Cubes-Center } \\
\hline & A & B & C & Average & A & B & $\mathbf{C}$ & Average \\
\hline $\mathbf{0}$ & 0.000 & 0.000 & 0.000 & 0.000 & 0.000 & 0.000 & 0.000 & 0.000 \\
\hline 1 & -0.009 & -0.009 & -0.007 & -0.009 & -0.021 & -0.019 & -0.008 & -0.016 \\
\hline 2 & -0.007 & -0.007 & -0.010 & -0.008 & -0.012 & -0.016 & -0.012 & -0.014 \\
\hline 4 & 0.000 & -0.005 & -0.003 & -0.003 & -0.016 & -0.019 & -0.014 & -0.016 \\
\hline 8 & 0.000 & 0.001 & 0.003 & 0.001 & -0.023 & -0.014 & -0.014 & -0.017 \\
\hline 13 & 0.007 & 0.005 & 0.005 & 0.006 & -0.008 & -0.021 & -0.004 & -0.011 \\
\hline 18 & 0.007 & 0.009 & 0.007 & 0.008 & 0.002 & -0.014 & -0.006 & -0.006 \\
\hline 26 & 0.0028 & 0.017 & 0.027 & 0.024 & -0.008 & -0.006 & -0.004 & -0.006 \\
\hline 39 & 0.023 & 0.022 & 0.019 & 0.021 & -0.002 & 0.000 & 0.006 & 0.001 \\
\hline 52 & 0.033 & 0.034 & 0.027 & 0.031 & 0.000 & 0.010 & 0.012 & 0.008 \\
\hline 65 & 0.031 & 0.034 & 0.029 & 0.031 & 0.000 & 0.016 & 0.012 & 0.010 \\
\hline 80 & 0.051 & 0.046 & 0.047 & 0.048 & 0.006 & 0.021 & 0.031 & 0.019 \\
\hline 93 & 0.052 & 0.051 & 0.042 & 0.048 & 0.010 & 0.021 & 0.029 & 0.020 \\
\hline 104 & 0.051 & 0.047 & 0.043 & 0.047 & 0.019 & 0.027 & 0.029 & 0.025 \\
\hline
\end{tabular}




\begin{tabular}{|c|c|c|c|c|c|c|c|c|}
\hline \multicolumn{7}{|c|}{ Spratt + GUB-8SF and 15\% FA at 60 } \\
\hline \multirow{2}{*}{$\begin{array}{c}\text { Time } \\
\text { (weeks) }\end{array}$} & $\mathbf{A}$ & $\mathbf{B}$ & $\mathbf{C}$ & Average & A & B & C & Average \\
\hline $\mathbf{0}$ & 0.000 & 0.000 & 0.000 & 0.000 & 0.000 & 0.000 & 0.000 & 0.000 \\
\hline $\mathbf{1}$ & -0.006 & -0.002 & -0.006 & -0.005 & -0.004 & -0.001 & -0.003 & -0.003 \\
\hline $\mathbf{2}$ & -0.006 & -0.002 & -0.008 & -0.005 & -0.006 & -0.002 & -0.002 & -0.003 \\
\hline $\mathbf{4}$ & 0.001 & 0.002 & 0.001 & 0.001 & 0.001 & 0.006 & 0.006 & 0.004 \\
\hline $\mathbf{8}$ & 0.002 & 0.005 & 0.000 & 0.002 & 0.002 & 0.009 & 0.009 & 0.007 \\
\hline $\mathbf{1 3}$ & 0.002 & 0.005 & 0.003 & 0.003 & 0.006 & 0.010 & 0.009 & 0.008 \\
\hline $\mathbf{1 8}$ & 0.004 & 0.006 & 0.004 & 0.005 & 0.010 & 0.013 & 0.010 & 0.011 \\
\hline $\mathbf{2 6}$ & 0.009 & 0.017 & 0.014 & 0.013 & 0.011 & 0.012 & 0.019 & 0.014 \\
\hline $\mathbf{3 9}$ & 0.006 & 0.011 & 0.008 & 0.009 & 0.013 & 0.019 & 0.018 & 0.017 \\
\hline $\mathbf{5 2}$ & 0.016 & 0.016 & 0.013 & 0.015 & 0.016 & 0.026 & 0.020 & 0.021 \\
\hline $\mathbf{6 5}$ & 0.014 & 0.018 & 0.014 & 0.015 & 0.016 & 0.024 & 0.020 & 0.020 \\
\hline $\mathbf{8 0}$ & 0.017 & 0.022 & 0.018 & 0.019 & 0.004 & 0.017 & 0.013 & 0.011 \\
\hline $\mathbf{9 3}$ & 0.014 & 0.014 & 0.015 & 0.014 & 0.021 & 0.026 & 0.025 & 0.024 \\
\hline $\mathbf{1 0 4}$ & 0.021 & 0.018 & 0.018 & 0.019 & 0.022 & 0.030 & 0.020 & 0.024 \\
\hline
\end{tabular}




\begin{tabular}{|c|c|c|c|c|c|c|c|c|}
\hline \multicolumn{9}{|c|}{ Spratt + GUB-8SF and 15\% FA at 60 } \\
\hline \multirow{2}{*}{$\begin{array}{c}\text { Time } \\
(\text { weeks })\end{array}$} & $\mathbf{A}$ & $\mathbf{B}$ & $\mathbf{C}$ & Average & A & B & C & Average \\
\hline $\mathbf{0}$ & 0.000 & 0.000 & 0.000 & 0.000 & 0.000 & 0.000 & 0.000 & 0.000 \\
\hline $\mathbf{1}$ & 0.003 & 0.005 & 0.003 & 0.004 & -0.010 & -0.006 & -0.012 & -0.010 \\
\hline $\mathbf{2}$ & -0.003 & -0.002 & -0.003 & -0.003 & -0.014 & -0.012 & -0.016 & -0.014 \\
\hline $\mathbf{4}$ & 0.001 & 0.003 & 0.001 & 0.002 & -0.019 & -0.008 & -0.016 & -0.014 \\
\hline $\mathbf{8}$ & 0.001 & 0.001 & 0.000 & 0.001 & -0.027 & -0.019 & -0.023 & -0.023 \\
\hline $\mathbf{1 3}$ & 0.012 & 0.009 & 0.009 & 0.010 & -0.019 & -0.014 & -0.019 & -0.017 \\
\hline $\mathbf{1 8}$ & 0.009 & 0.007 & 0.011 & 0.009 & -0.023 & -0.010 & 0.002 & -0.010 \\
\hline $\mathbf{2 6}$ & 0.016 & 0.015 & 0.017 & 0.016 & -0.014 & -0.010 & 0.006 & -0.006 \\
\hline $\mathbf{3 9}$ & 0.017 & 0.015 & 0.019 & 0.017 & -0.008 & -0.008 & -0.023 & -0.013 \\
\hline $\mathbf{5 2}$ & 0.021 & 0.017 & 0.023 & 0.020 & -0.006 & -0.006 & -0.016 & -0.010 \\
\hline $\mathbf{6 5}$ & 0.020 & 0.015 & 0.019 & 0.018 & -0.010 & 0.000 & -0.023 & -0.011 \\
\hline $\mathbf{8 0}$ & 0.033 & 0.029 & 0.032 & 0.032 & -0.014 & 0.000 & -0.006 & -0.007 \\
\hline $\mathbf{9 3}$ & 0.034 & 0.017 & 0.044 & 0.032 & -0.004 & -0.010 & -0.025 & -0.013 \\
\hline $\mathbf{1 0 4}$ & 0.024 & 0.001 & 0.032 & 0.019 & -0.014 & -0.019 & -0.023 & -0.019 \\
\hline
\end{tabular}




\begin{tabular}{|c|c|c|c|c|c|c|c|c|}
\hline \multicolumn{9}{|c|}{ Spratt + GUB-8SF and $20 \%$ FA at $60^{\circ} \mathrm{C}$} \\
\hline \multirow{2}{*}{$\begin{array}{c}\text { Time } \\
\text { (weeks) }\end{array}$} & \multicolumn{4}{|c|}{ Prisms } & \multicolumn{4}{|c|}{ Cylinders } \\
\hline & $\mathbf{A}$ & $\mathbf{B}$ & $\mathbf{C}$ & Average & $\mathbf{A}$ & $\mathbf{B}$ & $\mathbf{C}$ & Average \\
\hline $\mathbf{0}$ & 0.000 & 0.000 & 0.000 & 0.000 & 0.000 & - & 0.000 & 0.000 \\
\hline 1 & -0.005 & -0.004 & -0.001 & -0.003 & 0.003 & - & 0.003 & 0.003 \\
\hline 2 & -0.004 & -0.007 & 0.002 & -0.003 & 0.007 & - & 0.008 & 0.008 \\
\hline 4 & 0.004 & 0.002 & 0.006 & 0.004 & 0.014 & - & 0.010 & 0.012 \\
\hline 8 & 0.004 & -0.002 & 0.006 & 0.002 & 0.019 & - & 0.018 & 0.018 \\
\hline 13 & 0.002 & -0.001 & 0.003 & 0.001 & 0.016 & - & 0.019 & 0.018 \\
\hline 18 & 0.002 & -0.002 & 0.003 & 0.001 & 0.022 & - & 0.029 & 0.026 \\
\hline 26 & 0.002 & 0.002 & 0.006 & 0.003 & 0.023 & - & 0.027 & 0.025 \\
\hline 39 & 0.010 & 0.012 & 0.013 & 0.012 & 0.034 & - & 0.038 & 0.036 \\
\hline 52 & 0.018 & 0.017 & 0.020 & 0.018 & 0.050 & - & 0.050 & 0.050 \\
\hline 65 & 0.013 & 0.015 & 0.016 & 0.015 & 0.050 & - & 0.059 & 0.055 \\
\hline 80 & 0.022 & 0.022 & 0.026 & 0.023 & 0.050 & - & 0.057 & 0.053 \\
\hline 93 & 0.014 & 0.018 & 0.023 & 0.018 & 0.056 & - & 0.069 & 0.055 \\
\hline 104 & 0.022 & 0.020 & 0.032 & 0.025 & 0.052 & - & 0.058 & 0.055 \\
\hline
\end{tabular}




\begin{tabular}{|c|c|c|c|c|c|c|c|c|}
\hline \multicolumn{9}{|c|}{ Spratt + GUB-8SF and 20\% FA at 60 } \\
\hline \multirow{2}{*}{$\begin{array}{c}\text { Time } \\
(\text { weeks })\end{array}$} & $\mathbf{A}$ & $\mathbf{B}$ & $\mathbf{C}$ & Average & A & B & C & Average \\
\hline $\mathbf{0}$ & 0.000 & 0.000 & 0.000 & 0.000 & 0.000 & 0.000 & 0.000 & 0.000 \\
\hline $\mathbf{1}$ & 0.003 & 0.009 & 0.003 & 0.005 & -0.021 & 0.000 & -0.023 & -0.014 \\
\hline $\mathbf{2}$ & 0.008 & 0.009 & 0.003 & 0.007 & -0.019 & -0.016 & -0.025 & -0.020 \\
\hline $\mathbf{4}$ & 0.008 & 0.009 & 0.005 & 0.007 & -0.010 & -0.019 & -0.019 & -0.016 \\
\hline $\mathbf{8}$ & 0.007 & 0.011 & 0.006 & 0.008 & -0.019 & -0.035 & -0.033 & -0.029 \\
\hline $\mathbf{1 3}$ & 0.010 & 0.017 & 0.009 & 0.012 & -0.023 & -0.025 & -0.019 & -0.022 \\
\hline $\mathbf{1 8}$ & 0.009 & 0.011 & 0.010 & 0.010 & -0.019 & -0.021 & -0.010 & -0.016 \\
\hline $\mathbf{2 6}$ & 0.013 & 0.017 & 0.014 & 0.015 & -0.012 & -0.021 & -0.012 & -0.015 \\
\hline $\mathbf{3 9}$ & 0.020 & 0.025 & 0.019 & 0.021 & -0.016 & -0.021 & -0.012 & -0.016 \\
\hline $\mathbf{5 2}$ & 0.021 & 0.023 & 0.022 & 0.022 & -0.016 & -0.021 & -0.031 & -0.023 \\
\hline $\mathbf{6 5}$ & 0.026 & 0.027 & 0.027 & 0.026 & -0.004 & -0.014 & -0.006 & -0.008 \\
\hline $\mathbf{8 0}$ & 0.026 & 0.032 & 0.029 & 0.029 & -0.006 & 0.000 & 0.004 & -0.001 \\
\hline $\mathbf{9 3}$ & 0.022 & 0.027 & 0.021 & 0.024 & -0.006 & -0.010 & -0.004 & -0.007 \\
\hline $\mathbf{1 0 4}$ & 0.039 & 0.039 & 0.037 & 0.038 & -0.008 & -0.006 & 0.002 & -0.004 \\
\hline
\end{tabular}




\begin{tabular}{|c|c|c|c|c|c|c|c|c|}
\hline \multicolumn{9}{|c|}{ Springhill $+30 \%$ FA at $60^{\circ} \mathrm{C}$} \\
\hline \multirow{2}{*}{$\begin{array}{c}\text { Time } \\
\text { (weeks) }\end{array}$} & \multicolumn{4}{|c|}{ Prisms } & \multicolumn{4}{|c|}{ Cylinders } \\
\hline & $\mathbf{A}$ & B & C & Average & A & B & C & Average \\
\hline $\mathbf{0}$ & 0.000 & 0.000 & 0.000 & 0.000 & 0.000 & 0.000 & 0.000 & 0.000 \\
\hline 1 & -0.007 & -0.002 & -0.004 & -0.004 & -0.010 & -0.001 & -0.004 & -0.005 \\
\hline 2 & -0.007 & -0.002 & -0.004 & -0.005 & -0.011 & -0.002 & -0.003 & -0.005 \\
\hline 4 & -0.004 & 0.004 & -0.001 & 0.000 & -0.006 & 0.002 & -0.002 & -0.002 \\
\hline 8 & 0.000 & 0.005 & -0.001 & 0.001 & -0.008 & 0.003 & 0.005 & 0.000 \\
\hline 13 & 0.004 & 0.010 & 0.003 & 0.006 & 0.001 & 0.006 & 0.012 & 0.006 \\
\hline 18 & 0.008 & 0.012 & 0.007 & 0.009 & 0.004 & 0.010 & 0.013 & 0.009 \\
\hline 26 & 0.006 & 0.012 & 0.008 & 0.009 & 0.042 & 0.010 & 0.014 & 0.012 \\
\hline 39 & 0.009 & 0.008 & 0.010 & 0.010 & 0.006 & 0.017 & 0.022 & 0.015 \\
\hline 52 & 0.014 & 0.022 & 0.017 & 0.016 & 0.017 & 0.023 & 0.026 & 0.022 \\
\hline 65 & 0.011 & 0.014 & 0.010 & 0.011 & 0.014 & 0.020 & 0.022 & 0.018 \\
\hline 80 & 0.014 & 0.014 & 0.014 & 0.014 & 0.009 & 0.021 & 0.022 & 0.017 \\
\hline 104 & 0.013 & 0.015 & 0.015 & 0.014 & 0.016 & 0.026 & 0.030 & 0.024 \\
\hline
\end{tabular}




\section{Appendix I}

Long-term expansion of Spratt samples at $23^{\circ} \mathrm{C}$ 


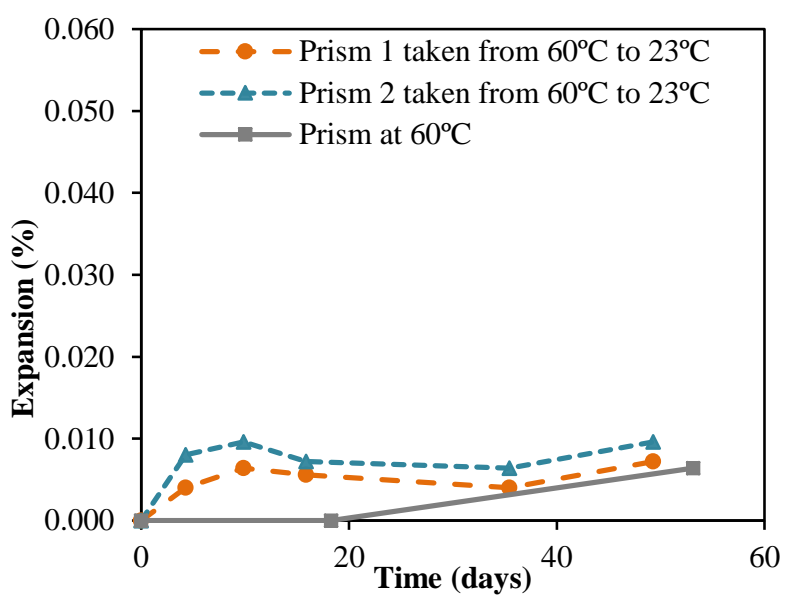

(a)

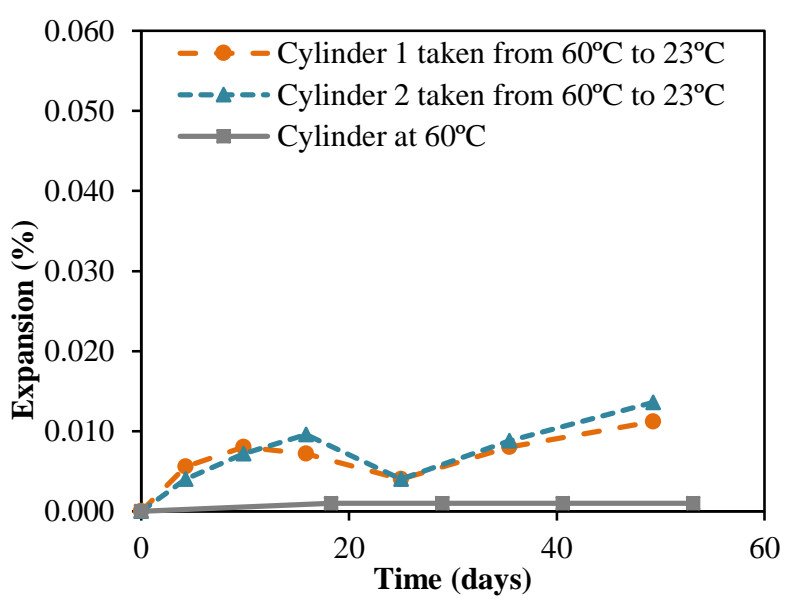

(a)

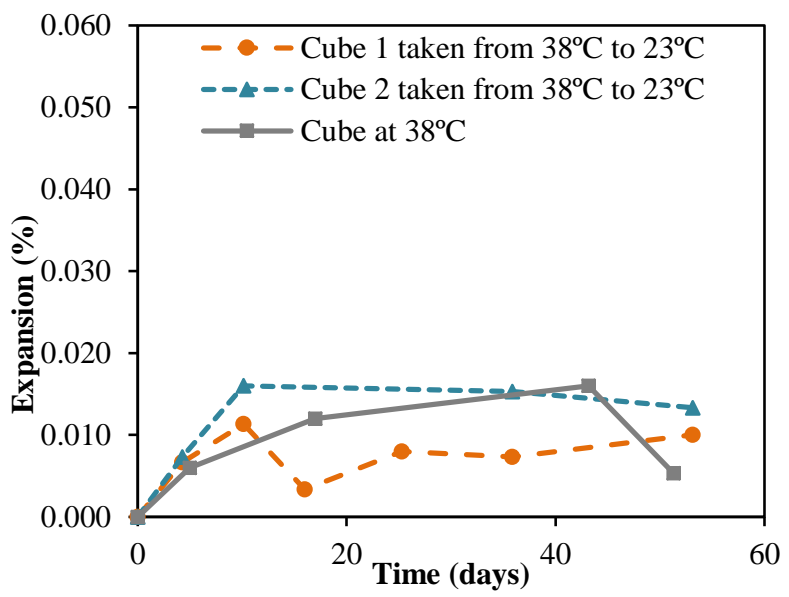

(a)

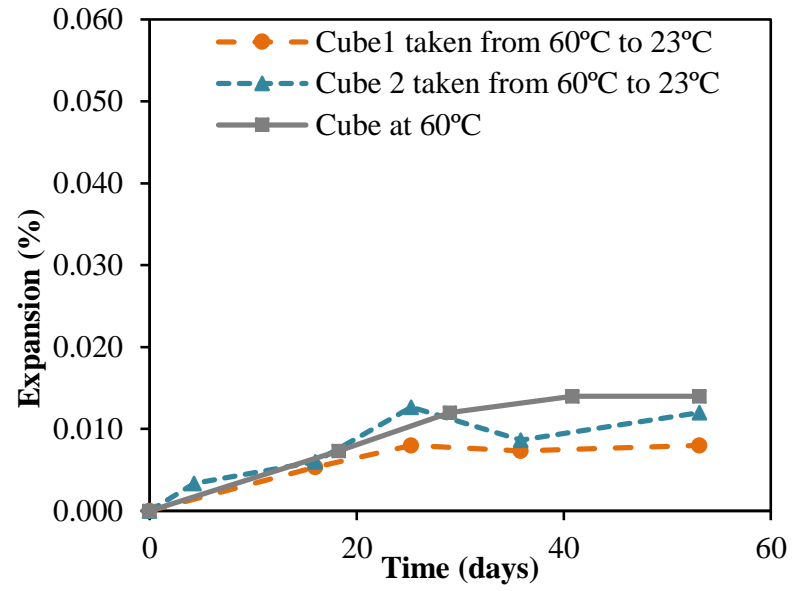

(b)

Long-term expansion of Spratt samples with $15 \% \mathrm{FA}$ at $23^{\circ} \mathrm{C}$ taken from (a) $38^{\circ} \mathrm{C}$ and (b) $60^{\circ} \mathrm{C}$ 


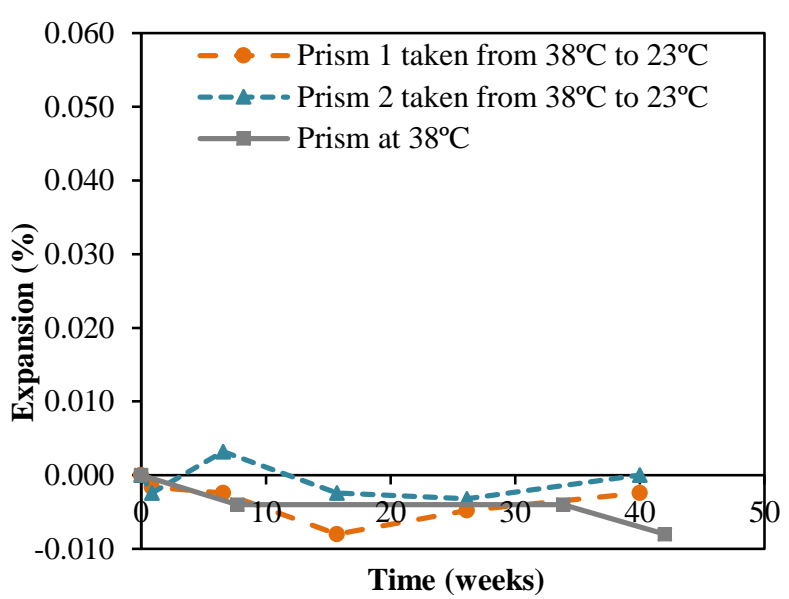

(a)

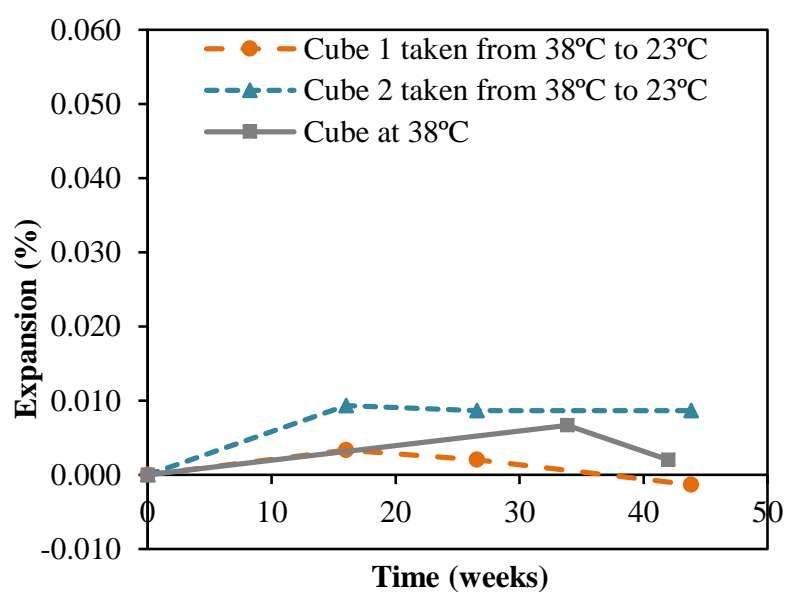

(a)

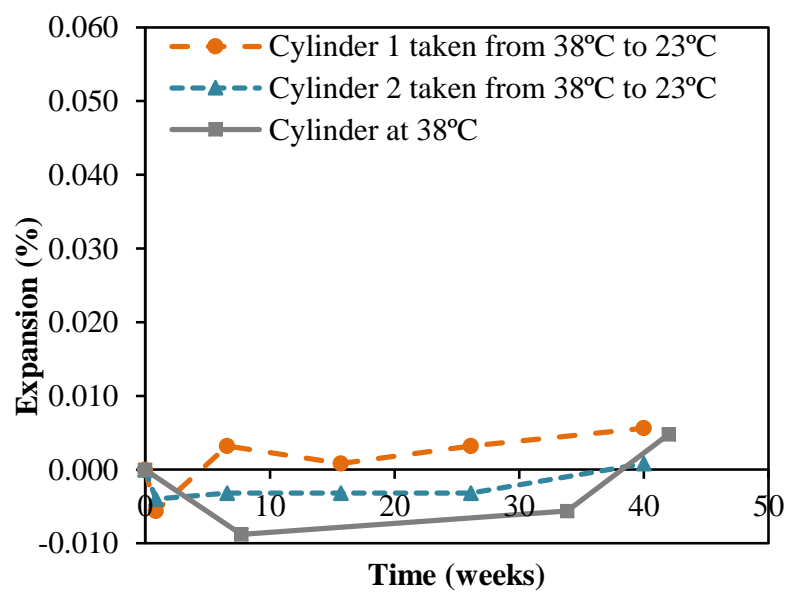

(a)

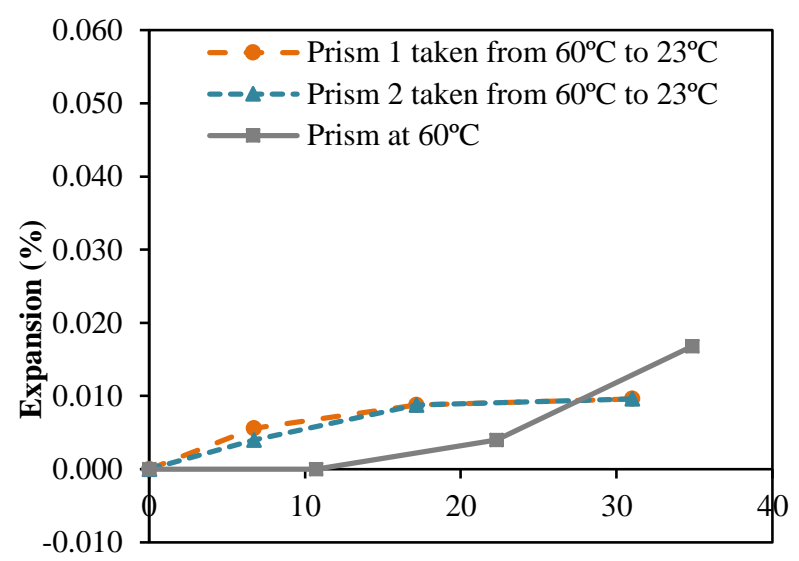

Time (weeks)

(b)

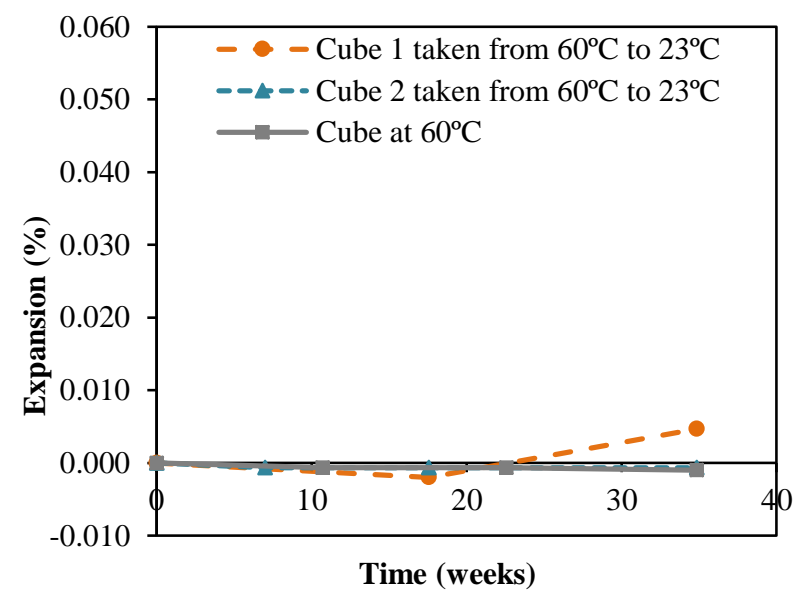

(b)

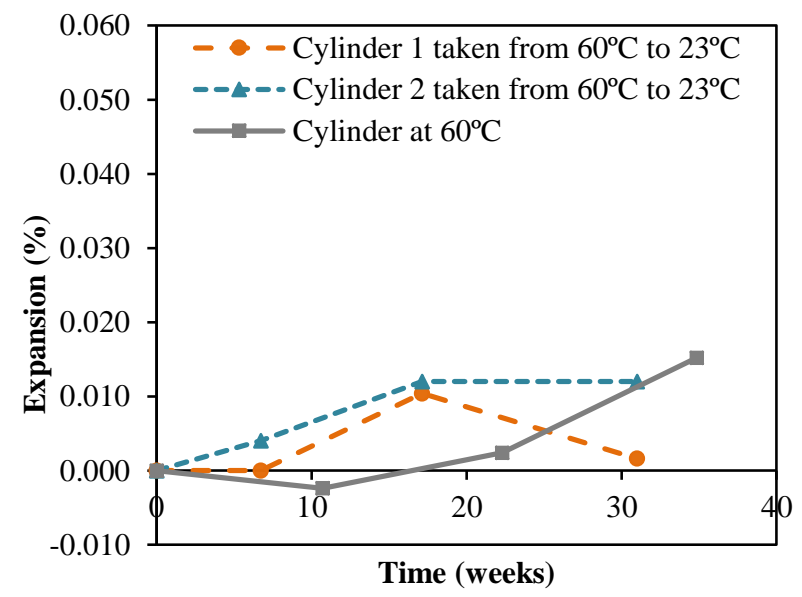

(b)

\section{Long-term expansion of Spratt samples with $50 \%$ Slag at $23^{\circ} \mathrm{C}$ taken from (a) $38^{\circ} \mathrm{C}$ and (b) $6^{\circ} \mathrm{C}$}



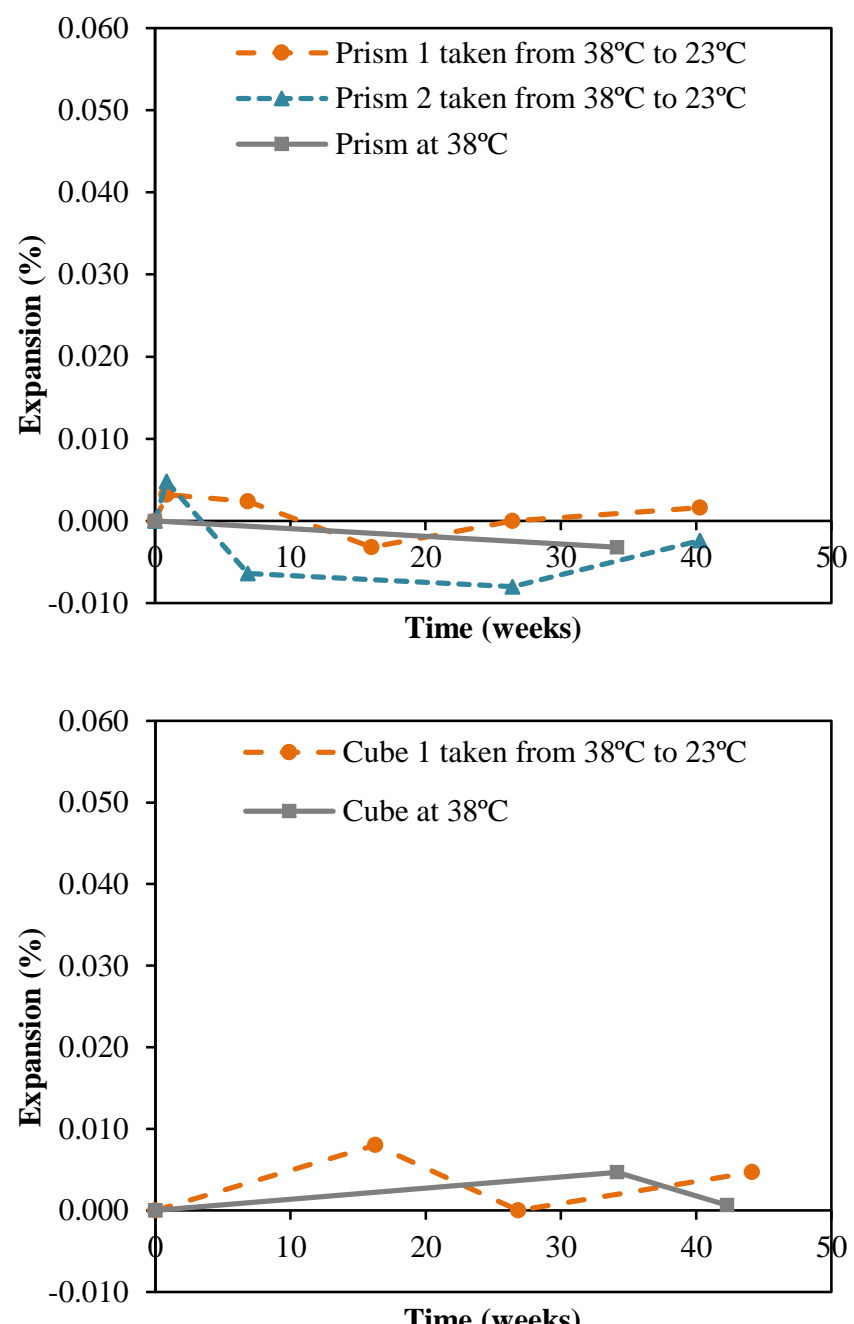

Time (weeks)

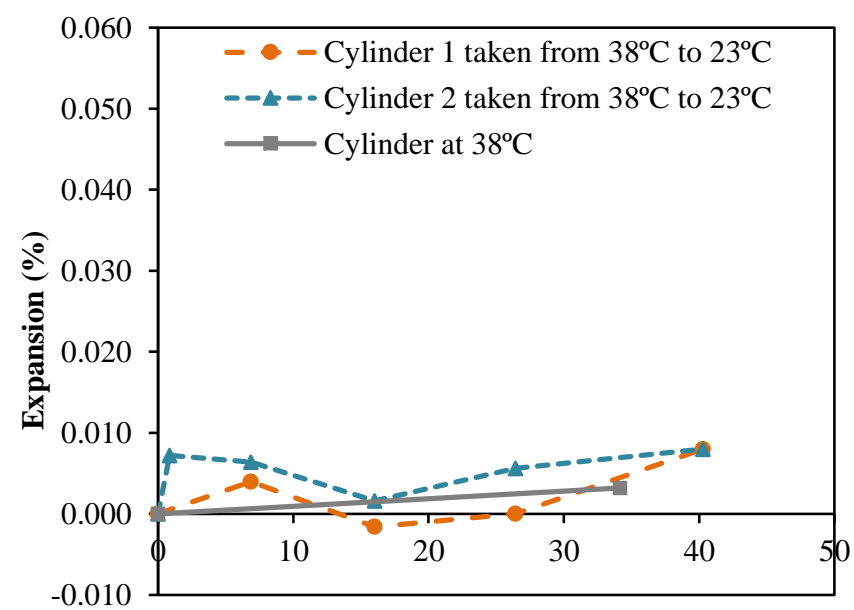

Time (weeks)

\section{Long-term expansion of Spratt samples with GUB-8SF at $23^{\circ} \mathrm{C}$ taken from $38^{\circ} \mathrm{C}$}



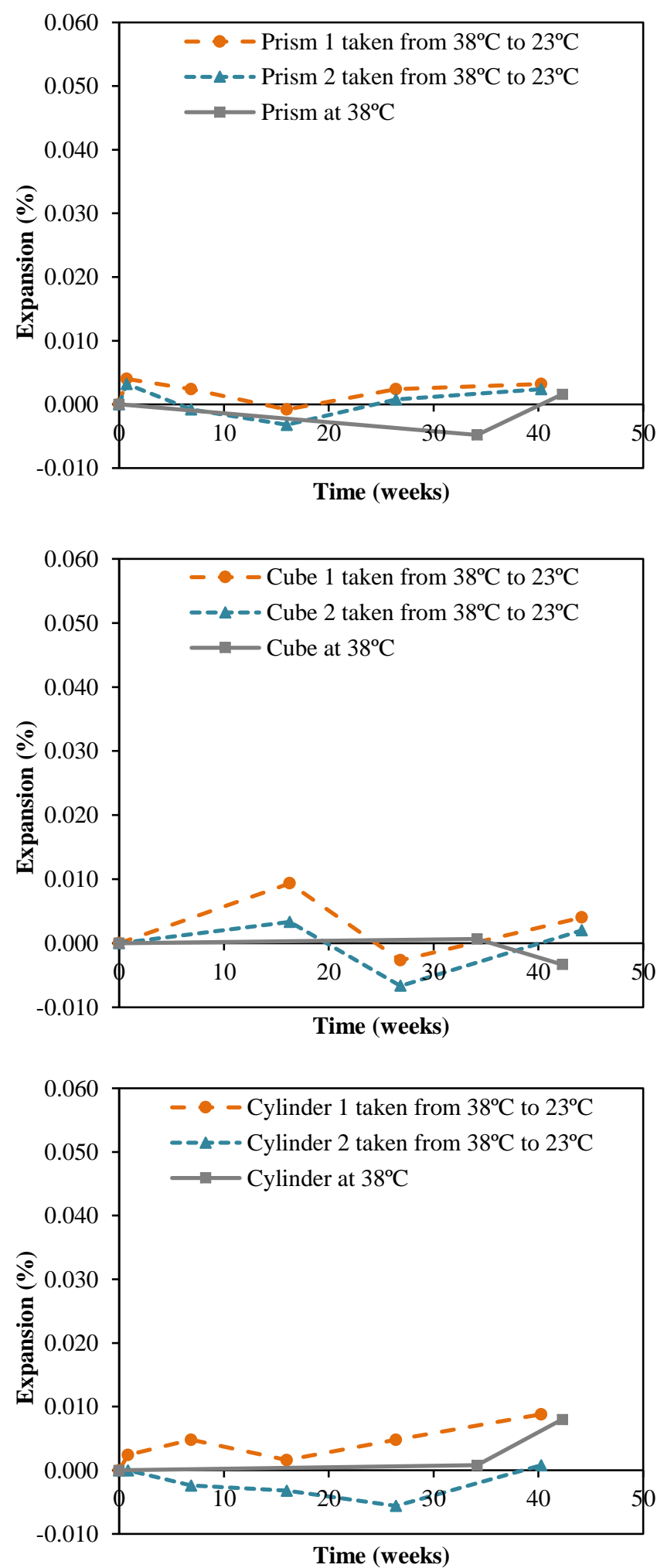

Long-term expansion of Spratt samples with GUB-8SF $+15 \%$ FA at $23^{\circ} \mathrm{C}$ taken from $38^{\circ} \mathrm{C}$ 

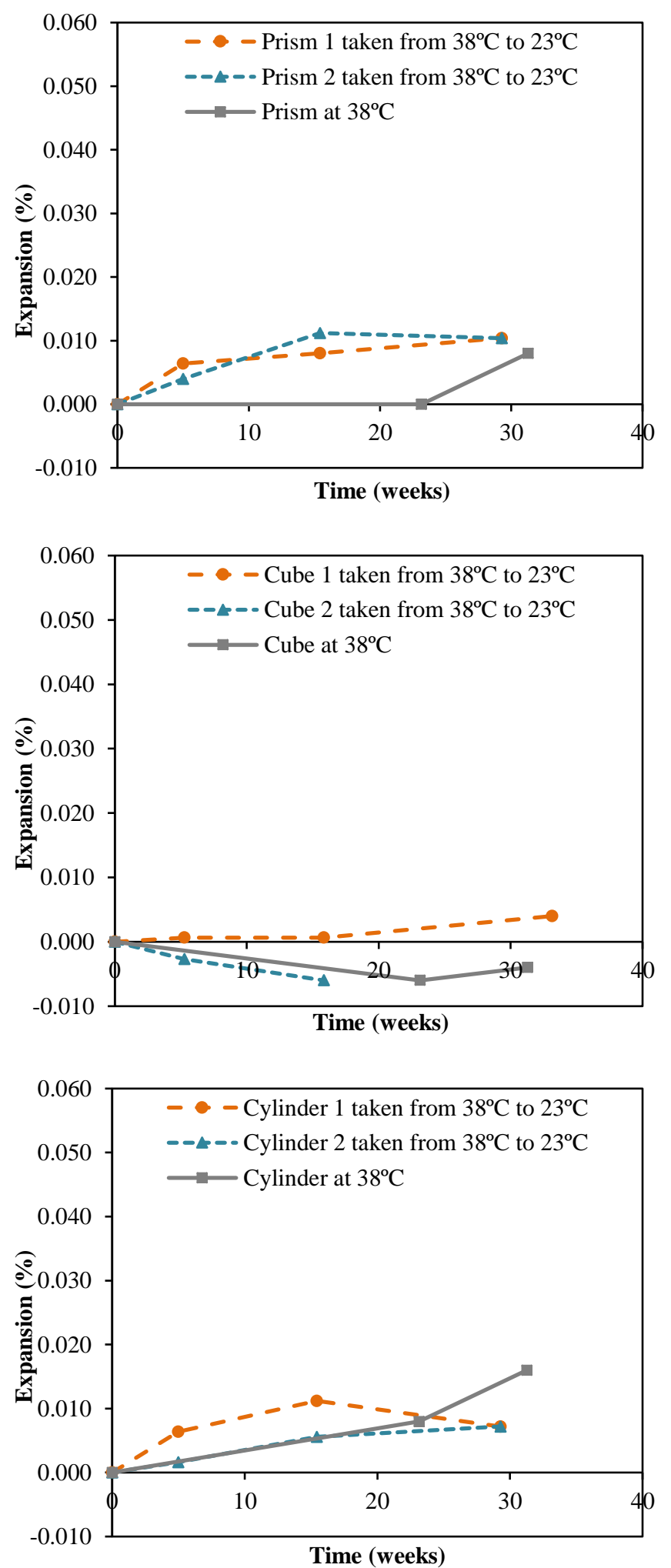

Long-term expansion of Spratt samples with GUB-8SF $+20 \%$ FA at $23^{\circ} \mathrm{C}$ taken from $38^{\circ} \mathrm{C}$ 


\section{Appendix J}

Expansion of concrete samples cast at different alkali content 


\begin{tabular}{|c|c|c|c|c|}
\hline \multicolumn{5}{|c|}{ Sudbury Cylinders at $\mathbf{0 . 5 7 \%} \mathbf{~ N a}_{2} \mathbf{O}_{\mathbf{e}}$} \\
\hline Time (weeks) & $\mathbf{A}$ & $\mathbf{B}$ & $\mathbf{C}$ & Average \\
\hline $\mathbf{0}$ & 0.000 & 0.000 & 0.000 & 0.000 \\
\hline $\mathbf{1}$ & 0.004 & -0.005 & -0.006 & -0.002 \\
\hline $\mathbf{2}$ & 0.010 & 0.003 & 0.004 & 0.006 \\
\hline $\mathbf{4}$ & 0.014 & 0.005 & 0.007 & 0.009 \\
\hline $\mathbf{8}$ & 0.018 & 0.006 & 0.008 & 0.010 \\
\hline $\mathbf{1 3}$ & 0.002 & 0.002 & 0.003 & 0.002 \\
\hline $\mathbf{1 8}$ & -0.002 & 0.006 & 0.003 & 0.003 \\
\hline $\mathbf{2 6}$ & 0.017 & 0.004 & 0.009 & 0.010 \\
\hline $\mathbf{3 9}$ & 0.009 & 0.005 & 0.002 & 0.005 \\
\hline $\mathbf{5 2}$ & 0.013 & 0.012 & 0.010 & 0.012 \\
\hline
\end{tabular}

\begin{tabular}{|c|c|c|c|c|}
\hline \multicolumn{5}{|c|}{ Sudbury Cylinders at $\mathbf{0 . 7 \%} \mathbf{~ N a}_{2} \mathbf{O}_{\mathbf{e}}$} \\
\hline Time (weeks) & $\mathbf{A}$ & $\mathbf{B}$ & $\mathbf{C}$ & Average \\
\hline $\mathbf{0}$ & 0.000 & 0.000 & 0.000 & 0.000 \\
\hline $\mathbf{1}$ & -0.002 & -0.009 & -0.008 & -0.006 \\
\hline $\mathbf{2}$ & 0.005 & 0.002 & 0.005 & 0.004 \\
\hline $\mathbf{4}$ & 0.011 & 0.005 & 0.009 & 0.008 \\
\hline $\mathbf{8}$ & 0.013 & 0.007 & 0.010 & 0.010 \\
\hline $\mathbf{1 3}$ & 0.004 & 0.000 & 0.002 & 0.002 \\
\hline $\mathbf{1 8}$ & 0.005 & 0.004 & 0.002 & 0.003 \\
\hline $\mathbf{2 6}$ & 0.007 & 0.002 & 0.010 & 0.006 \\
\hline $\mathbf{3 9}$ & 0.002 & 0.000 & 0.003 & 0.002 \\
\hline $\mathbf{5 2}$ & 0.017 & 0.018 & 0.010 & 0.015 \\
\hline
\end{tabular}

\begin{tabular}{|c|c|c|c|c|}
\hline \multicolumn{5}{|c|}{ Sudbury Cylinders at $\mathbf{0 . 8 \%} \mathbf{~ N a}_{\mathbf{2}} \mathbf{O}_{\mathbf{e}}$} \\
\hline Time (weeks) & $\mathbf{A}$ & $\mathbf{B}$ & $\mathbf{C}$ & Average \\
\hline $\mathbf{0}$ & 0.000 & 0.000 & 0.000 & 0.000 \\
\hline $\mathbf{1}$ & -0.010 & -0.008 & -0.008 & -0.009 \\
\hline $\mathbf{2}$ & -0.002 & 0.002 & -0.002 & 0.000 \\
\hline $\mathbf{4}$ & 0.003 & 0.005 & 0.002 & 0.003 \\
\hline $\mathbf{8}$ & 0.003 & 0.003 & 0.003 & 0.003 \\
\hline $\mathbf{1 3}$ & -0.003 & -0.006 & 0.005 & 0.004 \\
\hline $\mathbf{1 8}$ & 0.005 & 0.002 & 0.009 & 0.005 \\
\hline $\mathbf{2 6}$ & 0.010 & 0.011 & 0.007 & 0.009 \\
\hline $\mathbf{3 9}$ & 0.000 & -0.002 & 0.002 & 0.000 \\
\hline $\mathbf{5 1}$ & 0.005 & 0.007 & 0.014 & 0.009 \\
\hline $\mathbf{5 2}$ & 0.018 & 0.019 & 0.020 & 0.019 \\
\hline
\end{tabular}

\begin{tabular}{|c|c|c|c|c|}
\hline \multicolumn{5}{|c|}{ Sudbury Cylinders at $\mathbf{0 . 9 2 \%} \mathbf{~ N a}_{\mathbf{2}} \mathbf{O}_{\mathbf{e}}$} \\
\hline Time (weeks) & $\mathbf{A}$ & $\mathbf{B}$ & $\mathbf{C}$ & Average \\
\hline $\mathbf{0}$ & 0.000 & 0.000 & 0.000 & 0.000 \\
\hline $\mathbf{1}$ & -0.007 & -0.010 & 0.000 & -0.006 \\
\hline $\mathbf{2}$ & 0.001 & 0.002 & 0.006 & 0.003 \\
\hline $\mathbf{4}$ & 0.007 & 0.009 & 0.013 & 0.010 \\
\hline $\mathbf{8}$ & 0.004 & 0.007 & 0.013 & 0.008 \\
\hline $\mathbf{1 3}$ & 0.002 & 0.006 & 0.005 & 0.004 \\
\hline $\mathbf{1 8}$ & 0.001 & 0.008 & 0.011 & 0.007 \\
\hline $\mathbf{2 6}$ & 0.028 & 0.017 & 0.026 & 0.027 \\
\hline $\mathbf{3 9}$ & 0.035 & 0.038 & 0.044 & 0.039 \\
\hline $\mathbf{5 1}$ & 0.062 & 0.068 & 0.086 & 0.072 \\
\hline $\mathbf{5 2}$ & 0.078 & 0.098 & 0.109 & 0.095 \\
\hline
\end{tabular}




\begin{tabular}{|c|c|c|c|c|}
\hline \multicolumn{5}{|c|}{ Spratt Cylinders at 0.57\% $\mathbf{~ a a}_{2} \mathbf{O}_{\mathbf{e}}$} \\
\hline Time (weeks) & $\mathbf{A}$ & $\mathbf{B}$ & $\mathbf{C}$ & Average \\
\hline $\mathbf{0}$ & 0.000 & 0.000 & 0.000 & 0.000 \\
\hline $\mathbf{1}$ & -0.007 & -0.007 & -0.004 & -0.006 \\
\hline $\mathbf{2}$ & -0.002 & -0.002 & 0.000 & -0.001 \\
\hline $\mathbf{4}$ & 0.004 & 0.007 & 0.010 & 0.007 \\
\hline $\mathbf{8}$ & 0.009 & 0.011 & 0.015 & 0.012 \\
\hline $\mathbf{1 3}$ & 0.000 & 0.006 & -0.007 & 0.007 \\
\hline $\mathbf{1 8}$ & 0.006 & 0.008 & 0.007 & 0.007 \\
\hline $\mathbf{2 6}$ & 0.010 & 0.011 & 0.010 & 0.010 \\
\hline $\mathbf{3 9}$ & 0.003 & 0.011 & 0.009 & 0.008 \\
\hline $\mathbf{5 2}$ & 0.016 & 0.018 & 0.017 & 0.017 \\
\hline
\end{tabular}

\begin{tabular}{|c|c|c|c|c|}
\hline \multicolumn{5}{|c|}{ Spratt Cylinders at 0.7\% $\mathbf{N a}_{2} \mathbf{O}_{\mathbf{e}}$} \\
\hline Time (weeks) & $\mathbf{A}$ & $\mathbf{B}$ & $\mathbf{C}$ & Average \\
\hline $\mathbf{0}$ & 0.000 & 0.000 & 0.000 & 0.000 \\
\hline $\mathbf{1}$ & -0.005 & -0.007 & -0.006 & -0.006 \\
\hline $\mathbf{2}$ & 0.003 & 0.006 & 0.000 & 0.003 \\
\hline $\mathbf{4}$ & 0.008 & 0.010 & 0.006 & 0.008 \\
\hline $\mathbf{8}$ & 0.011 & 0.013 & 0.010 & 0.011 \\
\hline $\mathbf{1 3}$ & 0.026 & 0.019 & 0.021 & 0.022 \\
\hline $\mathbf{1 8}$ & 0.073 & 0.058 & 0.039 & 0.057 \\
\hline $\mathbf{2 6}$ & 0.146 & 0.125 & 0.063 & 0.111 \\
\hline $\mathbf{3 9}$ & 0.153 & 0.138 & 0.076 & 0.122 \\
\hline $\mathbf{5 2}$ & 0.178 & 0.167 & 0.102 & 0.149 \\
\hline
\end{tabular}

\begin{tabular}{|c|c|c|c|c|}
\hline \multicolumn{5}{|c|}{ Spratt Cylinders at $\mathbf{0 . 8 \%} \mathbf{~ N a}_{2} \mathbf{O}_{\mathbf{e}}$} \\
\hline Time (weeks) & $\mathbf{A}$ & $\mathbf{B}$ & $\mathbf{C}$ & Average \\
\hline $\mathbf{0}$ & 0.000 & 0.000 & 0.000 & 0.000 \\
\hline $\mathbf{1}$ & 0.001 & 0.007 & 0.000 & 0.003 \\
\hline $\mathbf{2}$ & 0.005 & 0.012 & 0.002 & 0.006 \\
\hline $\mathbf{4}$ & 0.013 & 0.017 & 0.007 & 0.012 \\
\hline $\mathbf{8}$ & 0.026 & 0.025 & 0.019 & 0.023 \\
\hline $\mathbf{1 3}$ & 0.053 & 0.041 & 0.041 & 0.045 \\
\hline $\mathbf{1 8}$ & 0.104 & 0.080 & 0.082 & 0.089 \\
\hline $\mathbf{2 6}$ & 0.166 & 0.143 & 0.146 & 0.152 \\
\hline $\mathbf{3 9}$ & 0.214 & 0.187 & 0.201 & 0.201 \\
\hline $\mathbf{6 3}$ & 0.220 & 0.216 & 0.218 & 0.217 \\
\hline
\end{tabular}

\begin{tabular}{|c|c|c|c|c|}
\hline \multicolumn{5}{|c|}{ Spratt Cylinders at $\mathbf{0 . 9 2 \%} \mathbf{~ N a}_{2} \mathbf{O}_{\mathbf{e}}$} \\
\hline Time (weeks) & $\mathbf{A}$ & $\mathbf{B}$ & $\mathbf{C}$ & Average \\
\hline $\mathbf{0}$ & 0.000 & 0.000 & 0.000 & 0.000 \\
\hline $\mathbf{1}$ & -0.002 & -0.002 & -0.005 & -0.003 \\
\hline $\mathbf{2}$ & -0.002 & 0.004 & -0.008 & -0.002 \\
\hline $\mathbf{4}$ & 0.010 & 0.002 & 0.008 & 0.007 \\
\hline $\mathbf{8}$ & 0.029 & 0.022 & 0.024 & 0.025 \\
\hline $\mathbf{1 3}$ & 0.093 & 0.095 & 0.106 & 0.098 \\
\hline $\mathbf{1 8}$ & 0.161 & 0.138 & 0.170 & 0.156 \\
\hline $\mathbf{2 6}$ & 0.205 & 0.186 & 0.216 & 0.202 \\
\hline $\mathbf{3 9}$ & 0.257 & 0.214 & 0.269 & 0.246 \\
\hline $\mathbf{5 2}$ & 0.274 & 0.246 & 0.301 & 0.274 \\
\hline
\end{tabular}




\begin{tabular}{|c|c|c|c|c|}
\hline \multicolumn{5}{|c|}{ Springhill Prisms at $\mathbf{0 . 5 7 \%} \mathbf{~ N a}_{2} \mathbf{O}_{\mathbf{e}}$} \\
\hline Time (weeks) & $\mathbf{A}$ & $\mathbf{B}$ & $\mathbf{C}$ & Average \\
\hline $\mathbf{0}$ & 0.000 & 0.000 & 0.000 & 0.000 \\
\hline $\mathbf{1}$ & 0.002 & 0.001 & -0.002 & 0.000 \\
\hline $\mathbf{2}$ & 0.012 & 0.010 & 0.007 & 0.010 \\
\hline $\mathbf{4}$ & 0.015 & 0.012 & 0.010 & 0.013 \\
\hline $\mathbf{8}$ & 0.014 & 0.010 & 0.011 & 0.011 \\
\hline $\mathbf{1 3}$ & 0.010 & 0.010 & 0.009 & 0.010 \\
\hline $\mathbf{1 8}$ & 0.012 & 0.011 & 0.010 & 0.011 \\
\hline $\mathbf{2 6}$ & 0.015 & 0.013 & 0.014 & 0.014 \\
\hline $\mathbf{3 9}$ & 0.006 & 0.000 & 0.006 & 0.004 \\
\hline $\mathbf{5 2}$ & 0.015 & 0.008 & 0.014 & 0.013 \\
\hline
\end{tabular}

\begin{tabular}{|c|c|c|c|c|}
\hline \multicolumn{5}{|c|}{ Springhill Prisms at $\mathbf{0 . 7 \%} \mathbf{~ N a}_{2} \mathbf{O}_{\mathbf{e}}$} \\
\hline Time (weeks) & $\mathbf{A}$ & $\mathbf{B}$ & $\mathbf{C}$ & Average \\
\hline $\mathbf{0}$ & 0.000 & 0.000 & 0.000 & 0.000 \\
\hline $\mathbf{1}$ & 0.008 & 0.002 & 0.010 & 0.007 \\
\hline $\mathbf{2}$ & 0.017 & 0.010 & 0.018 & 0.015 \\
\hline $\mathbf{4}$ & 0.022 & 0.013 & 0.022 & 0.019 \\
\hline $\mathbf{8}$ & 0.019 & 0.011 & 0.030 & 0.020 \\
\hline $\mathbf{1 3}$ & 0.011 & 0.009 & 0.014 & 0.011 \\
\hline $\mathbf{1 8}$ & 0.012 & 0.011 & 0.017 & 0.013 \\
\hline $\mathbf{2 6}$ & 0.023 & 0.014 & 0.024 & 0.020 \\
\hline $\mathbf{3 9}$ & 0.007 & 0.001 & 0.006 & 0.005 \\
\hline $\mathbf{5 2}$ & 0.014 & 0.011 & 0.012 & 0.013 \\
\hline
\end{tabular}

\begin{tabular}{|c|c|c|c|c|}
\hline \multicolumn{5}{|c|}{ Springhill Prisms at $\mathbf{0 . 8 \%} \mathbf{~ N a}_{2} \mathbf{O}_{\mathbf{e}}$} \\
\hline Time (weeks) & $\mathbf{A}$ & $\mathbf{B}$ & $\mathbf{C}$ & Average \\
\hline $\mathbf{0}$ & 0.000 & 0.000 & 0.000 & 0.000 \\
\hline $\mathbf{1}$ & -0.001 & 0.009 & -0.001 & 0.002 \\
\hline $\mathbf{2}$ & 0.011 & 0.015 & 0.011 & 0.013 \\
\hline $\mathbf{4}$ & 0.018 & 0.019 & 0.014 & 0.017 \\
\hline $\mathbf{8}$ & 0.015 & 0.018 & 0.011 & 0.015 \\
\hline $\mathbf{1 3}$ & 0.010 & 0.011 & 0.012 & 0.011 \\
\hline $\mathbf{1 8}$ & 0.011 & 0.014 & 0.016 & 0.014 \\
\hline $\mathbf{2 6}$ & 0.015 & 0.022 & 0.020 & 0.019 \\
\hline $\mathbf{3 9}$ & 0.010 & 0.008 & 0.004 & 0.007 \\
\hline $\mathbf{5 2}$ & 0.010 & 0.015 & 0.013 & 0.013 \\
\hline
\end{tabular}

\begin{tabular}{|c|c|c|c|c|}
\hline \multicolumn{5}{|c|}{ Springhill Prisms at $\mathbf{0 . 9 2 \%} \mathbf{~ N a}_{2} \mathbf{O}_{\mathbf{e}}$} \\
\hline Time (weeks) & $\mathbf{A}$ & $\mathbf{B}$ & $\mathbf{C}$ & Average \\
\hline $\mathbf{0}$ & 0.000 & 0.000 & 0.000 & 0.000 \\
\hline $\mathbf{1}$ & 0.001 & 0.003 & 0.002 & 0.002 \\
\hline $\mathbf{2}$ & 0.007 & 0.012 & 0.005 & 0.008 \\
\hline $\mathbf{4}$ & 0.010 & 0.014 & 0.010 & 0.011 \\
\hline $\mathbf{8}$ & 0.019 & 0.022 & 0.017 & 0.019 \\
\hline $\mathbf{1 3}$ & 0.018 & 0.018 & 0.015 & 0.017 \\
\hline $\mathbf{1 8}$ & 0.018 & 0.018 & 0.015 & 0.017 \\
\hline $\mathbf{2 6}$ & 0.021 & 0.023 & 0.020 & 0.021 \\
\hline $\mathbf{3 9}$ & 0.019 & 0.013 & 0.011 & 0.014 \\
\hline $\mathbf{5 2}$ & 0.023 & 0.020 & 0.016 & 0.020 \\
\hline
\end{tabular}




\begin{tabular}{|c|c|c|c|c|}
\hline \multicolumn{5}{|c|}{ Springhill Prisms at 1.25\% $\mathbf{~ a a}_{2} \mathbf{O}_{\mathbf{e}}$} \\
\hline Time (weeks) & $\mathbf{A}$ & $\mathbf{B}$ & $\mathbf{C}$ & Average \\
\hline $\mathbf{0}$ & 0.000 & 0.000 & 0.000 & 0.000 \\
\hline $\mathbf{1}$ & 0.006 & 0.006 & 0.004 & 0.006 \\
\hline $\mathbf{2}$ & 0.018 & 0.018 & 0.014 & 0.017 \\
\hline $\mathbf{4}$ & 0.025 & 0.025 & 0.019 & 0.023 \\
\hline $\mathbf{8}$ & 0.022 & 0.026 & 0.022 & 0.023 \\
\hline $\mathbf{1 3}$ & 0.037 & 0.038 & 0.034 & 0.036 \\
\hline $\mathbf{1 8}$ & 0.054 & 0.055 & 0.047 & 0.052 \\
\hline $\mathbf{2 6}$ & 0.068 & 0.069 & 0.061 & 0.066 \\
\hline $\mathbf{3 9}$ & 0.055 & 0.062 & 0.054 & 0.057 \\
\hline $\mathbf{5 2}$ & 0.066 & 0.071 & 0.063 & 0.067 \\
\hline
\end{tabular}




\section{References}

Alyamaç, K. E. and Ince, R. (2009) 'A preliminary concrete mix design for SCC with marble powders', Construction and Building Materials, 23(3), pp. 1201-1210. doi:

10.1016/j.conbuildmat.2008.08.012.

ASTM C1260 (2014) Standard Test Method for Potential Alkali Reactivity of Aggregates (Mortar-Bar. West Conshohocken, PA. doi: 10.1520/C1260-14.2.

ASTM C1293 (2018) Standard Test Method for Determination of Length Change of Concrete Due to Alkali- Silica Reaction. West Conshohocken, PA. doi: 10.1520/C1293-18.2.

ASTM C1437 (2015) Standard Test Method for Flow of Hydraulic Cement Mortar. West Conshohocken, PA. doi: 10.1520/C1437-15.2.

ASTM C1567 (2013) Standard Test Method for Determining the Potential Alkali-Silica Reactivity of Combinations of Cementitious Materials and Aggregate (Accelerated Mortar-Bar Method). West Conshohocken, PA.

ASTM C305 (2014) Standard Practice for Mechanical Mixing of Hydraulic Cement Pastes and Mortars. West Conshohocken, PA. doi: 10.1520/C0305-14.2.

Bérubé, M. A. et al. (2002) 'Laboratory assessment of alkali contribution by aggregates to concrete and application to concrete structures affected by alkali-silica reactivity', Cement and Concrete Research, 32(8), pp. 1215-1227. doi: 10.1016/S0008-8846(02)00766-4.

Bérubé, M. A. and Frenette, J. (1994) 'Testing Concrete for AAR in $\mathrm{NaOH}$ and $\mathrm{NaCl}$ solutions at $38^{\circ} \mathrm{C}$ and $80^{\circ} \mathrm{C}^{\prime}$, Cement and Concrete Composites, 16(3), pp. 189-198. doi: 10.1016/09589465(94)90016-7.

Bérubé, M., Fournier, B. and Côté, T. (2012) 'Testing concrete cores for residual expansion due to AAR- an attempt to minimize alkali leaching and consequent unrealistic expansion decrease', in 14th International Conference on Alkali Aggregate Reaction. Austin, Texas. 
Bleszynski, R. F. (2002) The performance and durability of concrete with ternary blends of silica fume and blast-furnace slag. University of Toronto. doi: 10.16953/deusbed.74839.

Bleszynski, R. F. and Thomas, M. D. A. (1998) 'Microstructural studies of alkali-silica reaction in fly ash concrete immersed in alkaline solutions', Advanced Cement Based Materials, 7(2), pp. 66-78. doi: 10.1016/S1065-7355(97)00030-8.

BS 812-123 (1999) Testing aggregates -Method for determinination of alkali-silica reactivity Concrete prism method. London, UK.

Chatterji, S. (1979) 'The role of $\mathrm{Ca}(\mathrm{OH}) 2$ in the breakdown of Portland cement concrete due to alkali-silica reaction', Cement and Concrete Research, 9(2), pp. 185-188.

Chatterji, S., Thaulow, N. and Jensen, A. D. (1987) 'Studies of alkali-silica reaction. Part 4. Effect of different alkali salt solutions on expansion', Cement and Concrete Research, 17(5), pp. 777-783.

Costa, U., Mangialardi, T. and Paolini, A. E. (2017) 'Minimizing alkali leaching in the concrete prism expansion test at $38^{\circ} \mathrm{C}$, Construction and Building Materials, 146. doi:

10.1016/j.conbuildmat.2017.04.116.

Craeye, B. et al. (2010) 'Effect of mineral filler type on autogenous shrinkage of self-compacting concrete', Cement and Concrete Research. Elsevier Ltd, 40(6), pp. 908-913. doi: 10.1016/j.cemconres.2010.01.014.

CSA A23.2-14A (2014) Potential expansivity of aggregate (procedure for length change due to alkali-aggregate reaction in concrete prisms at $38^{\circ} \mathrm{C}$ ). Toronto, Canada.

CSA A23.2-25A (2014) Test method for detection of alkali-silica reactive aggregate by accelerated expansion of mortar bars. Toronto, Canada.

CSA A23.2-27A (2014) Standard practice to identify degree of alkali-reactivity of aggregates and to identify measures to avoid deleterious expansion in concrete. Toronto, Canada.

CSA A23.2-28A (2014) Standard practice for laboratory testing to demonstrate the effectiveness 
of supplementary cementing materails and lithium-based admixtures to prevent alkali-silica reaction in concrete. Toronto, Canada.

Dhir, R. K., Dyer, T. D. and Tang, M. C. (2009) 'Alkali-silica reaction in concrete containing glass', Materials and Structures/Materiaux et Constructions, 42, pp. 1451-1462. doi: $10.1617 / \mathrm{s} 11527-008-9465-8$.

Douglas, R. W. and El-Shamy, T. M. (1967) 'Reaction of glasses with aqueous solutions', Journal of the American Ceramic Society, 50(1), pp. 1-8.

Drolet, C., Duchesne, J. and Fournier, B. (2017) 'Effect of alkali release by aggregates on alkalisilica reaction', Construction and Building Materials. Elsevier Ltd, 157, pp. 263-276. doi: 10.1016/j.conbuildmat.2017.09.085.

Elyamany, H. E., Abd Elmoaty, A. E. M. and Mohamed, B. (2014) 'Effect of filler types on physical, mechanical and microstructure of self compacting concrete and Flow-able concrete', Alexandria Engineering Journal. Faculty of Engineering, Alexandria University, 53(2), pp. 295307. doi: 10.1016/j.aej.2014.03.010.

FHWA (2008) 'Reactive Solutions - An FHWA Alkali-Silica Reactivity News Publication', pp. $1-4$.

FHWA (2009) 'Techbrief: Selecting candidate structures for lithium treatment: What to provide the petrographer along with concrete specimens, FHWA-HRT-06-069 - Pavements - FHWA', Fhwa-Hrt-06-069. Available at: http://www.fhwa.dot.gov/pavement/pccp/pubs/06069/.

FHWA (2012) Alkali-Aggregate Reactivity Workshops for Engineers and Practitioners.

Fournier, B. et al. (2008) 'Effect of environmental conditions on expansion in concrete due to alkali - silica reaction ( ASR )', Materials Characterization, 60(7), pp. 669-679. doi: 10.1016/j.matchar.2008.12.018.

Fournier, B. et al. (2018) 'Field and Laboratory investigations on the Use of Fly Ash and LiBased Admixtures to prevent ASR in Concrete', in 6th International Conference on Durability of Concrete Structures. Leeds, UK. 
Fournier, B. et al. (2019) 'The accelerated concrete prism test $\left(60^{\circ} \mathrm{C}\right)$ : variability of the test method and proposed expansion limits'.

Fournier, B., Nkinamubanzi, P. C. and Chevrier, R. (2004) 'Comparative Field and Laboratory Investigations on the use of Supplementary Cementing Materuals to Control Alkali-Silica Reaction in Concrete', in Proceedings of the 12th International Conference on Alkali-Aggregate Reaction (ICAAR). Beijing, China.

Gaboriaud, F. et al. (2002) 'Aggregation and Gel Formation in Basic Silico-Calco-Alkaline Solutions Studied: A SAXS, SANS, and ELS Study', The Journal of Physical Chemistry B, 103(28), pp. 5775-5781. doi: 10.1021/jp990151s.

Gabrovšek, R., Vuk, T. and Kaučič, V. (2006) 'Evaluation of the hydration of Portland cement containing various carbonates by means of thermal analysis', Acta Chimica Slovenica, 53(2), pp. 159-165.

Gautam, B. P. (2016) Multiaxially loaded concrete undergoing alkali-silica reaction (ASR) (PhD thesis). Univresity of Toronto.

Gautam, B. P. et al. (2017) 'Multiaxial expansion-stress relationship for alkali silica reactionaffected concrete', ACI Materials Journal, 114(1), pp. 171-184. doi: 10.14359/51689490.

Gilbert, C. M. (2007) The durability of concrete containing a high-level of fly ash or a ternary blend of supplementary cementing materials. The University of New Brunswick.

Gillott, J. E. (1975) ‘Alkali-aggregate reactions in concrete’, Engineering Geology, 9, pp. 303326.

Giorla, A. B. (2013) Modelling of Alkali-Silica Reaction under Multi-Axial Load. École Polytechnique Fédérale De Lausanne.

De Grosbois, M. and Fontaine, E. (2000) 'Evaluation of the potential alkali-reactivity of concrete aggregates: performance of testing methods and a producer's point of view', in 11th International Conference on AAR in Concrete. Quebec, Canada, pp. 267-276. 
Heisig, A. et al. (2016) 'Ingress of $\mathrm{NaCl}$ in concrete with alkali reactive aggregate: effect on silicon solubility', Materials and Structures. Springer Netherlands, 49(10), pp. 4291-4303. doi: 10.1617/s11527-015-0788-y.

HelmuthStark, R. and Diamond, S. (1993) Alkali-Silica Reactivity: An Overview of Research,SHRP-C-342, Strategic Highway Research Program. Washington, D.C.

Holcim (2014) Cement test report. Toronto, Canada.

Hunger, K. et al. (2012) 'Changes of pore solution composition under accelerated mortar bar and concrete prism test conditions', in 14th International Conference on Alkali Aggregate Reaction. Trondheim, p. 10.

Ideker, J. H. et al. (2008) 'The current state of the accelerated concrete prism test', in 13th International Conference on Alkali Aggregate Reaction. Trondheim. doi:

10.1016/j.cemconres.2009.08.030.

Ideker, J. H. et al. (2012) 'Importance of Outdoor Exposure Site Testing', in 14th International Conference on Alkali Aggregate Reaction. Austin, Texas.

Johnson, R. and Shehata, M. H. (2016) 'The efficacy of accelerated test methods to evaluate Alkali Silica Reactivity of Recycled Concrete Aggregates', Construction and Building Materials. Elsevier Ltd, 112, pp. 518-528. doi: 10.1016/j.conbuildmat.2016.02.155.

Kandasamy, S. and Shehata, M. H. (2014) 'The capacity of ternary blends containing slag and high-calcium fly ash to mitigate alkali silica reaction', Cement and Concrete Composites. Elsevier Ltd, 49, pp. 92-99. doi: 10.1016/j.cemconcomp.2013.12.008.

Khayat, K. H. (1999) 'Workability, testing, and performance of self- consolidating concrete Workability, Testing, and Performance of Self-Consolidating', ACI Materials Journal, 96(3), pp. 346-353.

Kim, T. and Olek, J. (2012) 'Effects of Sample Preparation and Interpretation of Thermogravimetric Curves on Calcium Hydroxide in Hydrated Pastes and Mortars', Transportation Research Record: Journal of the Transportation Research Board, 2290(1), pp. 
10-18. doi: 10.3141/2290-02.

Kjellsen, K. O. and Lagerblad, B. (1995) Influence of natural minerals in the filler fraction on hydration and properties of mortars, CBI report. Stockholm. Sweden.

Latifee, E. R. (2013) 'Influence of Pore Solution and Cement Alkalinity on', Journal of Civil Engineering Research, 3(5), pp. 143-147. doi: 10.5923/j.jce.20130305.01.

Leemann, A. and Lothenbach, B. (2008) 'The Na2O-equivalent of cement : a universal parameter to assess the potential alkali-aggregate reactivity of concrete?', in 13th International Conference on Alkali-Aggregate Reaction in Concrete. Trondheim.

Leemann, A. and Merz, C. (2012) 'An attempt to validate the concrete performance test with the degree of aar-induced damage observed in concrete structures', in 14th International Conference on Alkali Aggregate Reaction. Austin, Texas.

Lindgård, J. et al. (2012) 'Alkali-silica reactions (ASR): Literature review on parameters influencing laboratory performance testing', Cement and Concrete Research, 42(2), pp. 223243. doi: 10.1016/j.cemconres.2011.10.004.

Lindgård, J. et al. (2013) 'Alkali-silica reaction (ASR) - Performance testing: Influence of specimen pre-treatment, exposure conditions and prism size on alkali leaching and prism expansion', Cement and Concrete Research. doi: 10.1016/j.cemconres.2013.05.017.

Liu, K. and Mukhopadhyay, A. K. (2015) 'Testing and Evaluation Accelerated ConcreteCylinder Test for Alkali - Silica Reaction', 44(3). doi: 10.1520/JTE20140334.

Lu, D. et al. (2006) 'Evaluation of laboratory test method for determining the potential alkali contribution from aggregate and the ASR safety of the Three-Gorges dam concrete', Cement and Concrete Research, 36(6), pp. 1157-1165. doi: 10.1016/j.cemconres.2006.01.004.

Luke, K. and Glasser, F. P. (1988) 'Internal Chemical Evolution of the Constitution of Blended Cements', Cement and Concrete Research, 18, pp. 495-502.

MacDonald, C. A. et al. (2019) 'Use of the Damage Rating Index (DRI) to Evaluate Level of 
Deterioration due to Alkali-Silica Reaction in 30-35 Year Old Concrete from the Sudbury Area', in 1th Euroseminar on Microscopy Applied to Building Materials. Toronto, Canada.

Marsh, B. K. and Day, R. L. (1988) 'Pozzolanic and cementitious reactions of fly ash in blended cement pastes', Cement and Concrete Research, 18(2), pp. 301-310.

Merz, C. and Leemann, A. (2012) 'Assessment of the residual expansion potential of concrete from structures damaged by AAR', in 14th International Conference on Alkali Aggregate Reaction.

MTO LS-608 (2001) Method of test for determination of percent flat and elongated particles in coarse aggregate. Ontario, Canada.

Murthy, K. et al. (2012) 'N. Narasimha Rao, AV Ramanna Reddy IV and Vijaya Shekhar Reddy. M.; Mix Design Procedure for Self-Compacting Concrete', IOSR Journal of Engineering, 2(9), pp. 33-41.

Nixon, P. J. and Page, C. L. (1987) 'Pore solution chemistry and alkali aggregate reaction', in Katherine and Bryant Mather International Conference, pp. 1833-1862.

Nomura, M. et al. (2012) 'Evaluation of the residual expansivity of cores due to alkali-silica reaction in Hokuriku district, Japan', in 14th International Conference on Alkali Aggregate Reaction.

Pane, I. and Hansen, W. (2005) 'Investigation of blended cement hydration by isothermal calorimetry and thermal analysis', Cement and Concrete Research, 35(6), pp. 1155-1164. doi: 10.1016/j.cemconres.2004.10.027.

Pedersen, B. M. (2004) Alkali-reactive and inert Fillers in Concrete. Rheology of fresh Mixtures and expansive Reactions. Norwegian University of Science and Technology.

Piersanti, M. et al. (2015) 'Expansion of Concrete Containing Recycled Concrete Aggregate Suffering Different Levels of Alkali-Silica Reaction', in 4th International Engineering MEchanics and Materials Conference. Regina, SK, pp. 1-8. 
Piersanti, M. (2015) Testing Recycled Concrete Aggregate Suffering Different Levels of AlkaliSilica Reaction for Use in New Structures. Ryerson University.

Rajabipour, F. et al. (2015) 'Alkali-silica reaction: Current understanding of the reaction mechanisms and the knowledge gaps', Cement and Concrete Research, 76. doi: 10.1016/j.cemconres.2015.05.024.

Rajabipour, F., Maraghechi, H. and Fischer, G. (2010) 'Investigating the Alkali Silica Reaction of Recycled Glass Aggregates in Concrete Materials', Journal of Materials in Civil Engineering, 22(12). doi: 10.1061/(ASCE)MT.1943-5533.0000126.

RILEM AAR-2 (2000) 'Detection of potential alkali-reactivity - The ultra-accelerated mortar-bar method for aggregates', Materials \& Structures, 229(33), pp. 283-289.

RILEM AAR-3 (2000) 'Detection of potential alkali-reactivity $-38^{\circ} \mathrm{C}$ Method for aggregate combinations using concrete prisms', Materials \& Structures, 33(229), pp. 290-293.

Rivard, P. et al. (2007) 'Decrease of pore solution alkalinity in concrete tested for alkali-silica reaction', Materials and Structures/Materiaux et Constructions, pp. 909-921. doi: 10.1617/s11527-006-9191-z.

Rogers, C. A. and MacDonald, C. A. (2012) 'The geology, properties and field performance of alkali-aggregate reactive Spratt, Sudbury and Pittsburg aggregate distributed by the Ontario Ministry of Transportation', in 14th International Conference on Alkali Aggregate Reaction. Austin, Texas.

Serpa, D. et al. (2013) 'ASR of mortars containing glass', Construction and Building Materials. Elsevier Ltd, 47, pp. 489-495. doi: 10.1016/j.conbuildmat.2013.05.058.

Shehata, M. H. (2001) The effects of fly ash and silica fume on alkali silica reaction in concrete. University of Toronto. doi: 10.16953/deusbed.74839.

Shehata, M. H. et al. (2010) 'Reactivity of reclaimed concrete aggregate produced from concrete affected by alkali - silica reaction', Cement and Concrete Research. Elsevier Ltd, 40(4), pp. 575-582. doi: 10.1016/j.cemconres.2009.08.008. 
Shehata, M. H. and Thomas, M. D. A. (2000) 'Effect of fly ash composition on the expansion of concrete due to alkali-silica reaction', Cement and Concrete Research, 30(7), pp. 1063-1072. doi: 10.1016/S0008-8846(00)00283-0.

Shehata, M. H. and Thomas, M. D. A. (2006) 'Alkali release characteristics of blended cements', Cement and Concrete Research, 36(6), pp. 1166-1175. doi: 10.1016/j.cemconres.2006.02.015.

Shehata, M. H. and Thomas, M. D. A. (2010) 'The role of alkali content of Portland cement on the expansion of concrete prisms containing reactive aggregates and supplementary cementing materials', Cement and Concrete Research. doi: 10.1016/j.cemconres.2009.08.009.

Sibbick, R. G. and Page, C. L. (1992) 'Threshold alkali contents for expansion of concretes containing British aggregates', Cement and Concrete Research, 22(5), pp. 990-994. doi: 10.1016/0008-8846(92)90123-D.

Sika (2013) Alkali-silica-reaction resistant concrete. Available at: https://www.sika.com/content/corp/main/en/solutions_products/construction-markets/sikaconcrete-technology/concrete-handbook-2013/concrete-types/alkali-silica-reaction-resistantconcrete.html (Accessed: 22 April 2019).

Sinno, N. and Shehata, M. H. (2019) 'Effect of sample geometry and aggregate type on expansion due to alkali-silica reaction', Construction and Building Materials. Elsevier Ltd, 209, pp. 738-747. doi: 10.1016/j.conbuildmat.2019.03.103.

Smaoui, N. et al. (2004) 'Influence of specimen geometry, orientation of casting plane, and mode of concrete consolidation on expansion due to ASR', Cement, Concrete and Aggregates, 26(2), pp. 58-70. doi: 10.1520/CCA11927.

Smaoui, N. et al. (2005) 'Evaluation of the expansion attained to date by concrete affected by alkali - silica reaction . Part I : Experimental study’, 845(February), pp. 826-845. doi: 10.1139/L04-051.

Struble, L., Diamond, S. and Lafayette, W. (1981) 'Unstable swelling behavior of alkali silica gels', 11(4), pp. 611-617. 
Swamy, R. N. (1992) The Alkali-Silica Reaction in Concrete, New York. Abingdon, UK: Taylor \& Francis. doi: 10.4324/9780203332641.

Thomas, M. et al. (2006) 'Test methods for evaluating preventive measures for controlling expansion due to alkali-silica reaction in concrete', Cement and Concrete Research, 36(10), pp. 1842-1856. doi: 10.1016/j.cemconres.2006.01.014.

Thomas, M. (2011) 'Cement and Concrete Research The effect of supplementary cementing materials on alkali-silica reaction : A review', Cement and Concrete Research. Elsevier Ltd, 41(3), pp. 209-216. doi: 10.1016/j.cemconres.2010.11.003.

Touma, W. E. et al. (2001) 'Characterizing Alkali-Silica Reactivity of Aggregates Using ASTM C 1293, ASTM C 1260, and Their Modifications', Transportation Research Record: Journal of the Transportation Research Board, 1757(1), pp. 157-165. doi: 10.3141/1757-18.

Turkel, S. and Kandemir, A. (2010) 'Fresh and Hardened Properties of SCC Made with Different Aggregate and Mineral Admixtures', Journal of Materials in Civil Engineering, 22(10), pp. $1025-1032$.

Uysal, M. (2012) 'Self-compacting concrete incorporating filler additives: Performance at high temperatures', Construction and Building Materials. Elsevier Ltd, 26(1), pp. 701-706. doi: 10.1016/j.conbuildmat.2011.06.077.

Wang, Q. et al. (2012) 'The influence of high-temperature curing on the hydration characteristics of a cement-GGBS binder', Advances in Cement Research, 24(1), pp. 33-40. doi: 10.1680/adcr.2012.24.1.33.

Yujiang, W., Min, D. and Mingshu, T. (2008) 'Alkali release from aggregate and the effect on AAR expansion', Materials and Structures/Materiaux et Constructions, 41(1), pp. 159-171. doi: $10.1617 / \mathrm{s} 11527-007-9227-\mathrm{z}$. 